The Old World species of Boehmeria (Urticaceae, tribus Boehmerieae)

\title{
a taxonomic revision
}

Wilmot-Dear, Christine Melanie; Friis, lb

Published in:

Blumea

DOI:

$10.3767 / 000651913 \times 674116$

Publication date:

2013

Document version

Publisher's PDF, also known as Version of record

Document license:

CC BY-NC-ND

Citation for published version (APA):

Wilmot-Dear, C. M., \& Friis, I. (2013). The Old World species of Boehmeria (Urticaceae, tribus Boehmerieae): a taxonomic revision. Blumea, 58(2), 85-216. https://doi.org/10.3767/000651913X674116 


\title{
The Old World species of Boehmeria (Urticaceae, tribus Boehmerieae). A taxonomic revision
}

\author{
C.M. Wilmot-Dear ${ }^{1}$, I. Friis ${ }^{2}$
}

\section{Key words}

Boehmeria

conservation assessment

descriptions

distribution

ecology

keys

Old World

taxon richness

taxonomic revision

Urticaceae

\begin{abstract}
This is the second part of a world-wide revision of the genus Boehmeria, the previously-published part having dealt with the New World species. The Old World species are widely distributed in the tropics and subtropics from West Africa to islands in the Pacific Ocean and from Japan and China to Southern Africa, Madagascar and Australia, with the highest species richness in the Himalayas and their extension into China and Indochina. No indigenous species is common to both the Old and New World. The species represent taxonomic units of very different complexity: most species exhibit little infraspecific variation; in several others formal taxonomic infraspecific units can be recognised; however, in two, $B$. virgata and $B$. japonica, a highly complex variation is seen, fitting with difficulty into the normal hierarchy of taxonomic classification. With the conclusions reached here, 33 species, including 31 varieties, are recognised and over one hundred previously established names are placed in synonymy. Four new taxa are described: $B$. pilosiuscula var. suffruticosa, B. virgata subsp. macrophylla var. minuticymosa, $B$. virgata subsp. virgata var. velutina and $B$. virgata subsp. virgata var. maxima. The following new combinations are made: $B$. densiflora var. boninensis, B. heterophylla var. blumei, B. japonica var. silvestrii, B. japonica var. tenera, B. sieboldiana var. fuzhouensis, B. ternifolia var. kamley, B. virgata subsp. macrophylla, B. virgata subsp. macrophylla var. canescens, $B$. virgata subsp. macrophylla var. densiglomerata, $B$. virgata subsp. macrophylla var. longissima, B. virgata subsp. macrophylla var. macrostachya, $B$. virgata subsp. macrophylla var. molliuscula, $B$. virgata subsp. macrophylla var. rotundifolia, B. virgata subsp. macrophylla var. scabrella, B. virgata subsp. macrophylla var. strigosa, $B$. virgata subsp. macrophylla var. sumatrana, $B$. virgata subsp. macrophylla var. tomentosa and $B$. virgata subsp. virgata var. austroqueenslandica.
\end{abstract}

Published on 27 September 2013

\section{INTRODUCTION}

Friis (1993: 623-624) concluded that the two genera Boehmeria and Pouzolzia were in great need of revision and that the delimitation between them had to be clarified. In many herbaria large quantities of material of these two genera remained unidentified, the incorporated material was often misidentified and the nomenclature used was confusing. A revision of the New World species of Boehmeria and Pouzolzia (Wilmot-Dear \& Friis 1996) recognised 14 species of Boehmeria and 14 species of Pouzolzia, of which a considerable number of new taxa were described and named and a large number of new synonyms and transfers between genera were established. Subsequently, a number of shorter papers were published which established the taxonomic importance of anatomical characters in the fruiting perianth and the fruit wall in a range of species of Boehmeria and Pouzolzia (Kravtsova et al. 2000, 2003). A supplement to Boehmeria in the New World with additional discussion of the distinction between Boehmeria and Pouzolzia was published by Wilmot-Dear et al. (2003). Then followed a revision of Pouzolzia in the Old World (Wilmot-Dear \& Friis 2006), in which 24 species and 13 infraspecific taxa were recognised, 5 new taxa and names were proposed and Boehmeria australis Endl. was transferred to Pouzolzia. The distinction between Boehmeria and Pouzolzia was further elucidated in connection with a transfer of a species of Boehmeria, B. rugulosa Wedd., to Pouzolzia, as P. rugulosa (Wedd.) Acharya \& Kravtsova,

\footnotetext{
1 The Herbarium, Royal Botanic Gardens, Kew, Richmond, Surrey, England, UK; corresponding author e-mail: m.thomas@kew.org.

2 The Herbarium, Natural History Museum of Denmark, Sølvgade 83, Opgang S, DK-1307 Copenhagen K, Denmark; e-mail: ibf@snm.ku.dk.
}

analysing the anatomy of the fruiting perianth and the achene wall (Wilmot-Dear et al. 2009). New species of Boehmeria also appeared in Wilmot-Dear et al. (2010) and new species of Pouzolzia and new extensions of distributions of New World Boehmeria in Wilmot-Dear \& Friis (2011).

The present paper completes our world-wide revision of Boehmeria and Pouzolzia. It considers all published names and is based on an examination of the extensive herbarium collections of 38 major herbaria.

\section{MATERIALS AND METHODS}

The methods have been those of classical herbarium taxonomy, with special attention to small morphological details, as in previous parts of the project, particularly in the large revisions by Wilmot-Dear \& Friis $(1996,2006)$. Frequently, we have not chosen a lectotype from amongst a group of syntypes because where it was not necessary for taxonomic reasons we considered it desirable to retain useful information concerning material seen by the original author. Lectotypes have been selected only in cases where not to do so would cause confusion or loss of taxonomic precision, for example, where collections representing several taxa have been included among the syntypes, where there is rather wide morphological variation between syntypes/ isotypes or where there is doubt which material was seen by the author. As previously, it has been necessary to consult material from a large number of herbaria in order to be reasonably sure that the entire range of variation was seen and that rare taxa were reasonably covered. Unidentified material, especial from $\mathrm{G}, \mathrm{K}$ and $\mathrm{L}$, has been looked through for specimens not previously identified as Boehmeria, and in $\mathrm{K}$ and $\mathrm{L}$ we have looked 
through the other genera in the tribe Boehmerieae to extract misidentified material. Herbaria from which we have borrowed or studied material: A, AAU, ABD, B, BISH, BKF, BM, BO, BR, C, CAL, E, F, G, HK, IBSC, K, L, LE, M, MO, MSC, NAS, NEB, P, PE, PNH, S, TAI, TCD, TI, U, UC, UPS, US, W, WU, Z. A total of about 10000 specimens, representing c. 4000 collections have been seen for this revision. We have listed circa 3000 collections, leaving out some material of common and widespread taxa. Specimens without collection numbers or other unique data and therefore of which duplicates are unlikely to be identifiable with certainty have also been omitted from our listing in this paper. The collecting localities of a selection of the specimens which could be reasonably georeferenced were plotted in ArcView, v. 3.3. The map showing species and taxon richness was produced from the same dataset with the use of the 'Analysis/Point to Grid' function in Diva-GIS, v. 7.5. The parameters defined by IUCN (2001) 'extent of occurrence' (EOO) and 'area of occupancy' (AOO) have been calculated using ArcView and the CATS extension developed at the Royal Botanic Gardens, Kew (Moat 2007).

When referring to a geographical distribution, the following terminology is used. For New Guinea, any reference to 'New Guinea' or 'the island of New Guinea' includes both regions, Indonesian Papua and Papua New Guinea. 'China' without further detail refers only to mainland China and where a distribution includes the islands of Taiwan and/or Hong Kong this detail is added. Similarly, island groups belonging to countries with a large mainland territory (for example Japan, incl. Ryukyu Islands) are always specified.

\section{THE POSITION OF BOEHMERIA IN TRIBUS BOEHMERIEAE}

The definition of the tribus Boehmerieae used here is the one proposed by Friis (1993), with the modifications by Kravtsova (2009: 12-24, 342-345). Its two largest genera are Pouzolzia and Boehmeria. Species of Boehmeria are normally perennial herbs, shrubs or small trees with opposite or alternate leaves and petiolate or sessile lamina; the leaves of a pair in the opposite-leaved species or two leaves next to each other in the alternate-leaved species may be almost identical or dimorphic. The flowers are always unisexual and variously arranged in axillary clusters or in clusters along spike-like or paniculate flowering axes (modified stems). The male flowers have $3-5(-6)$ more or less free perianth-lobes, the same number of stamens and a pistillode. The female flowers consist of a perianth which completely encloses the ovary; the stigma is filiform and protrudes from the opening of the perianth. The female perianth persists during the ripening of the fruit, a moderately thin-walled and smooth, but dull rather than shiny achene, which remains completely enclosed in the perianth at maturity, only partially filling the fruiting perianth.

Species belonging to the genus Boehmeria are distinguished from species of most other genera in the tribe by their filiform rather than capitate stigma, but confusion may occur with the identification of Pouzolzia, Pipturus and Cypholophus, which also have a filiform stigma.

Pouzolzia often differs in its caducous stigma and strongly longitudinally ribbed perianth, but the only absolute distinction is its shiny rather than dull achene easily detachable from perianth at maturity and (usually) caducous stigma; the major differences between the two are in the anatomy of the fruiting perianth and outer layers of the achene (Kravtsova et al. 2000, 2003, Kravtsova 2001, 2009, Wilmot-Dear et al. 2009). Pipturus is distinguishable only by the pistillate perianth, which is succulent at maturity with a dark opening, a 'dark hole', at the apex after the early-caducous stigma has fallen. Cypholophus differs mainly in the minute tightly curled stigma and fleshy fruiting perianth. The morphological relationships between these three genera are dealt with in key form in Friis (1993: 618-619) and discussed in more detail in Wilmot-Dear (2009).

\section{THE HISTORY OF DISCOVERY OF THE GENUS BOEHMERIA IN THE OLD WORLD}

The earliest established taxa dealt with in this revision are Linnaean and were placed in the genus Urtica (Urtica nivea L., Urtica japonica L.f.). Subsequent early taxa were also placed in Urtica, e.g. by Blume (1825), but already Thunberg (1794a, b) began transferring taxa to the genus Boehmeria, which had been established by Jaquin (1760). The genus was named after Georg Rudolph Böhmer (1723-1803), German botanist and physician at the University of Wittenberg.

Monographic treatments of Boehmeria have been produced by Weddell $(1856,1869)$, who based his taxonomic conclusions on the collections held at $\mathrm{K}, \mathrm{P}$ and $\mathrm{G}$ and $\mathrm{G}-\mathrm{DC}$, while Blume (1857), basing his work mainly on the collections at L, published a considerable number of new Old World taxa in the genus. In the last revision by Weddell (1869) a total of 47 species and 48 varieties were recognised.

In the 19th century, when the largest number of Boehmeriaspecies was described, a certain number of different taxa were given identical specific epithets, thus creating a number of homonyms for several widespread and well-known taxa (e.g., several species were named $B$. caudata, $B$. macrophylla or $B$. platyphylla). This is partly due to the overall similarity of species in easily-observed characters of leaf- and inflorescencemorphology. This trend has continued by various authors almost to the present day, even by the present authors (Wilmot-Dear \& Friis 1996: 35; corrected Friis \& Wilmot-Dear 1999: 956), creating $B$. dolichostachys Friis \& Wilmot-Dear, a later homonym for the Chinese species $B$. dolichostachya W.T.Wang.

No world-wide revision of the genus has been attempted since those produced by Weddell, but many regional accounts have been published and many species and infraspecific taxa proposed on local material, thereby multiplying the number of taxa from that recognised in the last revision by Weddell (1869).

Together with our previous work (Wilmot-Dear \& Friis 1996) the current revision shows that many species of Boehmeria are widespread and variable, but no species of the genus is indigenous in both the New and Old Worlds.

\section{SPECIES DELIMITATION AND THE CATEGORIES OF SPECIES AND INFRASPECIFIC TAXA}

Nearly all taxonomic revisions of extensive tropical genera involve a number of species which defy traditional hierarchical classification. The family Urticaceae is particularly notorious for certain tropical species-groups being difficult to treat in a hierarchical taxonomy because of the morphological variation that defies traditional hierarchical taxonomy and nomenclature. Many of these problems were already noted by Weddell, in the following three quotations (in our translation from French) which we think are very important also for the users of this revision to consider.

Weddell (1856: 4) wrote in the introduction to his large monograph of the family: "... there is no plant family where the species are more variable, none, in other words, where it is more difficult to recognise the species and even the genera by a simple inspection of appearance ... there is hardly any part of the plant which is not subject to considerable variation. Therefore there is no group where it is more necessary to examine 
large quantities of material in order to form a correct idea of the limits between which a species varies".

In particular, the complex taxonomy of the genus Boehmeria was noted by Weddell (1856: 344): “... the extreme polymorphism of certain species, often combined with a wide geographical distribution, makes their study very difficult, and in attempting to correct the errors of my predecessors I do not claim to have avoided mistakes". Weddell (1856: 364-370) proposed an infraspecific classification of $B$. platyphylla (in the present revision treated as the major part of the even more complex and widespread species $B$. virgata) including 12 varieties and three subvarieties. About this complex Weddell commented: "... this species, one of the most polymorphic in the family, plays the same role in the Old World as do $B$. cylindrica and $B$. caudata in the New, but it tries the patience of the researcher even more, because there is no specimen which does not exhibit some notable feature. I regret that I have myself added to the multiplicity of species names referable to it. It is also worth pointing out that many of these forms so distinct in appearance do not have a particular geographical distribution, which makes me wonder about their true nature. For example, var. macrostachya, the most distinct form, which I first thought restricted to the Mascarenes, ... is also found in southern India. ... Whoever has available specimens representing only small parts of the variation will be eager to find fault with my interpretation, but whoever is able to study a large number of specimens will see that one passes from one form to another in almost imperceptible steps and that there is no part of the plant in particular on which one can rely for defining the forms".

Weddell's continued attempts at improving previous less satisfactory taxonomic concepts in Boehmeria are particularly well demonstrated when one compares his two monographic treatments of the genus (Weddell 1856, 1869). In his second revision (Weddell 1869: 203-216) the number of varieties that he recognised in $B$. platyphylla had increased from 12 to 21 .

After having worked with Urticaceae for more than 20 years and with the Old World species of the genus Boehmeria for more than ten years, the present authors fully subscribe to Weddell's words. We would add that the small size of the flowers and the need to have both male and female flowers add to the complications pointed out by him.

Several subsequent studies, including chromosome studies, experimental taxonomy and studies of apomixes in Boehmeria in Japan, have contributed to the understanding of the evolution of the genus (Okabe 1956, 1963, Yahara 1983a, 1984a, 1986, 1990). Kitamura \& Murata (1961) have attempted to explain the complex taxonomy of some species of Old World Boehmeria. In particular, cytological studies of the complexes associated with $B$. japonica and $B$. splitgerbera have revealed that many forms of Boehmeria in Japan are polyploids, reproducing mainly apomictically. Thus a formal classification is artificial and unsatisfactory, as is well-illustrated by the taxonomic history. Initially, Satake $(1936,1938 a, b, c)$ recognised c. 30 Japanese taxa, which he considered species, but his keys and descriptions "did not adequately identify many of the variants encountered" (Yahara 1983a: 218). Later, Ohwi $(1953,1965)$ and Kitamura \& Murata (1961) recognised c. 20 taxa but differed in their circumscription. Kitamura \& Murata (1961) proposed that the complicated morphological variation is partly due to occasional hybridisation between sexually reproducing and mainly apomictically reproducing races of Boehmeria. Subsequently the population studies and cytological investigation of Okabe and Yahara clarified some of the relationships. Okabe (1956) examined 21 Japanese taxa of Boehmeria and found that 14 were apomictic triploids, six were sexually reproducing diploids, and one included both ploidies and reproductive systems.
Yahara (1983a) tested the hypothesis of Kitamura \& Murata that hybridisation is involved. His work somewhat clarified the factors contributing to complicated morphological variation and in commenting on his results he stated (1984a) that it is very difficult to distinguish species from varieties in Japanese Boehmeria because of the presence of apomictic polyploid races which sometimes bear male flowers and then hybridise with neighbouring sexually reproducing diploid taxa.

Yahara (1983a) conducted three experiments. Firstly, he studied the relationship of a sympatric group of taxa, which he referred to as the $B$. longispica (= $B$. japonica) complex to a partly sympatric species, $B$. holosericea. He found that $B$. holosericea was diploid, reproducing sexually and was morphologically and ecologically distinct, while all members of his $B$. longispica complex were apparently mainly apomictic (well-developed fruits being found even though male flowers were rarely present) with both tetraploid and pentaploid races of morphologically identical material, suggesting occasional interbreeding (when male flowers were produced), giving rise to new races different in ploidy level. Initially, he found no evidence of hybridisation between his $B$. holosericea and his $B$. longispica complex, but later (Yahara 1984a: 141) he considered one of these entities to be a hybrid with $B$. holosericea.

Secondly, he studied the very distinctive species $B$. splitgerbera (cited by him as $B$. biloba) and several taxa claimed by various previous Japanese botanists to be related to it. He found that $B$. splitgerbera was diploid, sexually reproducing and distinct from the other six taxa in gross morphology and habitat, while the other six taxa were apomictic, each stable in its ploidy level, but the complex included triploid and tetraploid races, some of these entities having leaf characters otherwise unique to $B$. splitgerbera. He suggested that some of these taxa might have arisen by hybridisation between $B$. splitgerbera and other more distantly related species. These experiments are discussed more briefly in the systematic part of this paper under the relevant species.

Thirdly, to ascertain whether hybridisation produced new apomictic races, he cultivated material of two closely similar taxa showing partial altitudinal separation together with intermediate plants from intermediate altitudes. His cytological investigation strongly suggested the intermediates to be of hybrid origin between the higher-altitude sexually reproducing diploid taxon $B$. gracilis and the lower-altitude mainly apomictic triploid ' $B$. japonica' (these taxa both later (1984a) referred to as races of ' $B$. spicata'). This cultivation experiment is discussed in detail under B. japonica (see Note 6).

According to Cronk (1998), there are monotypic species (with no infraspecific taxa), polytypic species (which can often be meaningfully divided into subspecies), species which form a species group, and species that defy normal taxonomic treatment, the 'ochlospecies'. In this treatment two species, both including complexes that Weddell had already found difficult, might be characterised as 'ochlospecies': Boehmeria virgata (including Weddell's B. platyphylla) and B. japonica. As described above, the latter has partly been analysed with cytological methods, and some explanations for the notable variation have been found, but the taxonomic complexity of the very widespread $B$. virgata remains unexplained.

Nevertheless, we have tried to approach the structure and contents of a traditional hierarchical classification and traditional nomenclature even for these groups, utilising both the categories of subspecies and varieties. In this way it is possible to connect our findings with the tradition for classification in Boehmeria, where, since Weddell's two monographs, the concept of variety has had a prominent role. 
Within Girardinia (Urticaceae), Friis (1981) concluded that G. diversifolia (Link) Friis is highly polymorphic and infraspecific taxa could not readily be circumscribed. Consequently, he did not attempt to establish an infraspecific classification and nomenclature for the immense variation observed. However, since the revision was published, a number of new species have been described within the complex of $G$. diversifolia without any discussion of their status in relation to the complex as a whole. This situation seems unsatisfactory, and therefore, to avoid a similar situation within the much more widespread and variable genus Boehmeria, we have decided to follow the established tradition in the genus and to recognise infraspecific taxa where this has some correlation with geographical distribution. It will be easier and more practical for the users to relate to such a classification than to leave the complexes as broadly defined species without further formal subdivisions. In our experience, an infraspecific classification will contain an element of subjective judgement and the production and use of keys for the identification of the infraspecific taxa may sometimes be difficult. These are the reasons why it has been necessary to give such detailed descriptions and extensive discussions, as well as a lengthy key which takes account of the whole range of variation within species. The main key in this revision takes account of infraspecific variation but leads only to species level. Some polymorphic species key out at several places in the main key, while shorter keys, under the relevant species, identify the infraspecific taxa.

\section{TERMINOLOGY AND DIAGNOSTIC CHARACTERS FOR SPECIES AND INFRASPECIFIC TAXA}

Habit is occasionally diagnostic in the Old World species of Boehmeria (B. didymogyne is a slender herb), but most species are quite variable, some varying from being herbs to subshrubs, while others vary from being shrubs to trees. In the New World most species vary from being shrubs to trees.

Nature and density of indumentum on stems and leaves are useful diagnostically. In the New World taxa only leaf indumentum was found to be diagnostic (Wilmot-Dear \& Friis 1996: 1314).

Leaf form and arrangement are usually diagnostic. Leaves may be asymmetrical; opposite or adjacent alternate leaves may be dimorphic in size and/or shape. We have used the same terminology, of symmetry vs asymmetry and 'smaller' vs 'larger' leaves of dimorphic leaf-pairs, as in Wilmot-Dear \& Friis (1996: 12-14, f. 1). Notable difference in size of the 'larger' and 'smaller' leaves is seen in, e.g., B. densiflora, B. leptostachya, B. multiflora, B. subintegra (opposite leaves) and in, e.g., B. beyeri, B. heterophylla and $B$. manipurensis (alternate leaves).

The shape and proportions of the lamina and the number, proportions and shape of its marginal teeth are often diagnostic, as in Wilmot-Dear \& Friis (1996: 14). In this paper the term 'up-curved', referring to marginal teeth indicates that the distal margin of each tooth is somewhat concave such that their tips are directed towards the leaf apex; similarly, 'outward-pointing' indicates a \pm straight distal margin or, where specifically stated, a convex one.

Inflorescence architecture is at least as variable as in the New World taxa (Wilmot-Dear \& Friis 1996: 14-15) and can be summarised as follows: The basic inflorescence unit in Boehmeria is the flower-cluster which is a dense conglomeration of sessile or shortly-pedicellate flowers. These clusters are in this paper considered the inflorescences in the strict sense. In some species (e.g., B. didymogyne, B. helferi, B. heterophylla), these flower-clusters are borne only or predominantly in the axils of unmodified leaves which are spaced along stems otherwise undistinguishable from vegetative stems. In a few species (e.g., $B$. clidemioides) clusters are nearly always borne on distinctive, partly-leafless, axes with an apical tuft of normal leaves or returning to vegetative growth distally. In many species, clusters are borne on specialised, entirely leafless axes which may be terminal or axillary, paired or single, branched or unbranched. All of these character-states are useful diagnostically. The term used in this paper, 'inflorescence-bearing axis', refers to both of these two types of modified axes, partly or entirely leafless.

The arrangement of male and female flowers along modified inflorescence-bearing axes is also diagnostic. These axes may be entirely unisexual, may have male and female flower-clusters on different parts of the same axes or male clusters and female clusters both scattered throughout the axis, or varying proportions of male and female flowers may be present in the same cluster. In only one species (B. zollingeriana) the two sexes are differently arranged, female clusters being borne on highly modified leafless and branched axes, whereas male clusters are found in axils of normal leaves on the main stems. This is a much more varied set of character-states than is seen in the New World species.

The size and shape of the bract subtending each flower-cluster is sometimes diagnostic ( $B$. kurzii and $B$. siamensis have larger bracts than other taxa). Bracteoles subtending individual flowers vary in size relative to the flowers and are sometimes diagnostic, whereas in the New World species they are of limited size range and consistently inconspicuous; see Wilmot-Dear \& Friis (1996: 15).

The male flower is 4-merous in most species, 5-6-merous in $B$. zollingeriana and 3-merous in B. didymogyne. The female flowers are usually sessile or almost so, but consistently and distinctly pedicellate in $B$. virgata subsp. macrophylla var. minuticymosa, and occasionally distinctly pedicellate in $B$. virgata subsp. macrophylla var. canescens. The fruiting perianths may be completely filled by the fruit or markedly flattened dorsiventrally to form a marginal rim or wing on either side. This variation is similar to that of the New World taxa (Wilmot-Dear \& Friis 1996: 15)

\section{DISTRIBUTION PATTERNS AND HABITATS OF OLD WORLD BOEHMERIA}

A descriptive summary of the geographical range of each taxon, as well as a distribution map, is provided. Intermediate forms and their distribution are discussed informally under the heading 'Discussion'.

Only two species are widespread, $B$. virgata and B. depauperata. Boehmeria virgata is the most widespread of all, occurring from West Africa to the Marquesas and Society Islands in the Pacific, and from Sudan, Pakistan and China in the north to Zimbabwe, Madagascar and Australia in the south. It comprises two subspecies, one (subsp. macrophylla) occurring almost entirely to the west of Wallace's line, the other (subsp. virgata) almost entirely to the east of this line. Boehmeria depauperata is found from India (where it is especially common in the Himalayas) to Indonesian Papua and Papua New Guinea with no east-west division into infraspecific taxa.

One species (together with one variety of $B$. virgata) is restricted to Indochina and southern China; three others are also found in Indonesia and three others (together with one variety of $B$. virgata) are also found in Indonesia, southern India and Sri Lanka. Seven species (together with three varieties of $B$. virgata) are narrowly distributed in the Himalayas and the eastern extension of this mountain range into Indochina and China. Five species are found in the Philippines, two of which also occur in Indonesia and/or Papua New Guinea and one 


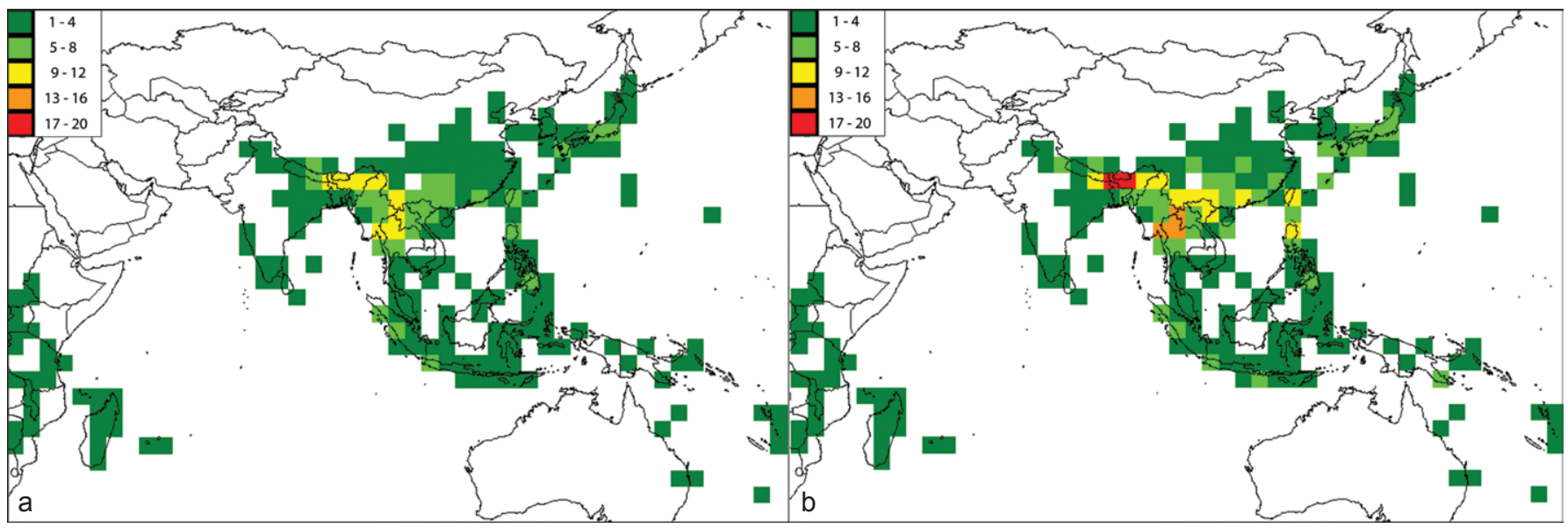

Map 1 Richness of species and infraspecific taxa in eastern Africa, Madagascar and Asia, recorded in 3 by 3 degree squares. a: richness of species; b: richness of infraspecific taxa, including unnamed but mapped intermediate forms. Numbers on colour-scale indicate numbers of taxa per square.

of which also occurs in Indonesia and Japan (Ryukyu Islands) and west to southern China. Four closely similar species are mainly restricted to Japan and adjacent islands, some of these also being found in China. Ten species are narrow endemics as follows: northern Madagascar (one); part of the Himalayas (three); Burma (one); Japan (Ryukyu Islands, two); Philippines (Luzon, one); Papua New Guinea (one); Hawaiian Islands (one). Boehmeria nivea has an uncertain natural distribution; the highest number of records is from China, Indochina and Japan, but the natural distribution of this cultivated and widely naturalised species may be even narrower.

The number of species and infraspecific taxa were mapped in grids of different sizes and it was decided that 3 by 3 degree squares gave the result that best conformed to our other findings. These results are illustrated in Map 1. Map 1a shows the species richness in 3 by 3 degree squares in the most species-rich part of the Old World (outside the area shown on the map only one or two species occur per square). Species richness is seen to be greatest in the eastern Himalayas and their extension into China and Indochina, with 11-12 species per square, which would seem to indicate the most prolific speciation in that area. Also squares in south-eastern China, Taiwan, northern Philippines, western Sumatera, western Jawa and Japan have five or more species. Map $1 \mathrm{~b}$ shows the richness of infraspecific taxa in 3 by 3 degree squares and includes varieties and unnamed but mapped intermediate forms; this map demonstrates basically the same pattern as the map of the species richness but it also shows that the infraspecific variation is very high (17-18 taxa) in squares in the eastern Himalayas and (15-16 taxa) in the border region of Burma and Thailand. Map $1 \mathrm{~b}$ also shows the high infraspecific variability in Japan (7-8 taxa), represented mainly by the variation in $B$. japonica and $B$. sieboldiana. This would seem to indicate that the speciation of which we now see the results has taken place mainly in the same regions where there is also high infraspecific variation.
An analysis similar to this one was not undertaken in our revision of the New World species (Wilmot-Dear \& Friis 1996), but it is clear from the data there presented that the highest number of species is found in the northern part of the Andean region.

Habitat preference seems to be rather similar in most species of Boehmeria. In both the Old and the New World almost all species occur in shaded places in secondary forest, in somewhat disturbed areas in primary forest, at forest edges and in primary or secondary evergreen bushland or grassland surrounding these habitats. On the main islands of Japan and the surrounding smaller islands there are several species and infraspecific taxa occurring in shady places near the sea. Boehmeria yaeyamensis is the species most strongly adapted to habitats near the sea, restricted to cliffs and rocks on the shores of the Ryukyu Islands. Most species occur at altitudes below 1600-1800 m, but some of those in the Himalayas and their extension into China and Indochina, or in the mountains of Japan, are found in montane forest and evergreen bushland at higher altitudes: one to $2000 \mathrm{~m}$; six to $2600-2700 \mathrm{~m}$ and one to $3500 \mathrm{~m}$.

\section{RELATIONSHIPS BETWEEN OLD AND NEW WORLD SPECIES OF BOEHMERIA}

In the New World 14 species have been recognised by us (Wilmot-Dear \& Friis 1996, Wilmot-Dear et al. 2003); this excludes $B$. nivea, which is only cultivated and naturalised in the New World. No indigenous species is common to both the Old and New World, but there are species showing a similar overall morphology. Such species have been tabulated in Table 1. Apart from these, there are several species with overall morphology distinctive for either the Old or the New World. In the Old World there are none analogous with the creeping herbaceous New World species $B$. repens. Conversely, there

Table 1 Species with analogous overall morphology in Old and New World.

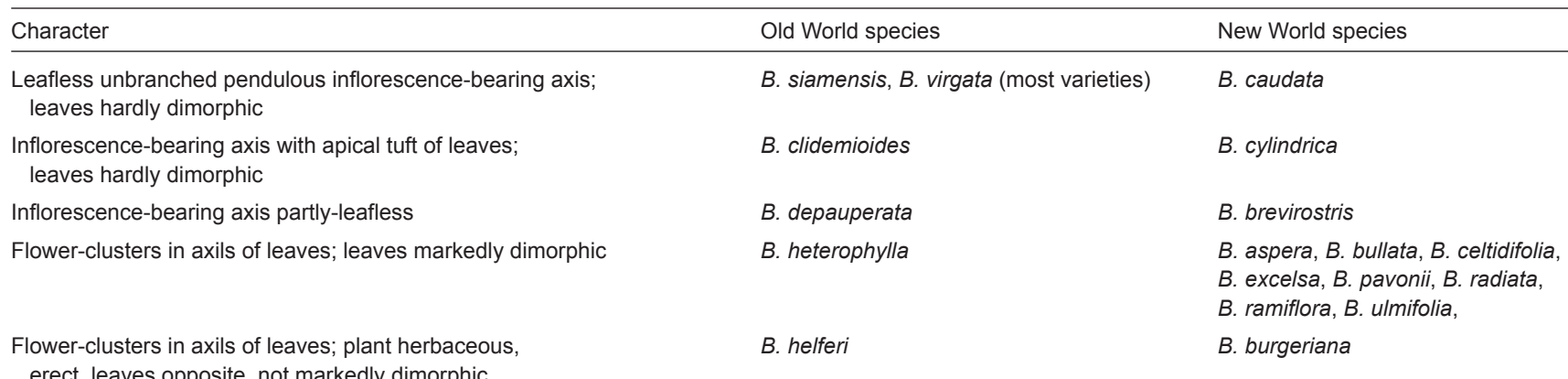


are no indigenous New World species exhibiting the branched leafless inflorescence-bearing axes seen in many Old World species. As is apparent from the discussion above of morphological terminology and diagnostic characters, interspecific morphological variation is much greater amongst the Old World taxa, and for the most part each overall morphological type is represented by more species in the Old World than in the New. However, as appears from Table 1, the type with flower-clusters axillary and leaves markedly dimorphic seems to have speciated in the New World proportionally much more than in the Old. These similar morphological patterns in the Old and New World suggest that some New World species may be more closely related to certain Old World taxa than to each other; however, a deeper analysis must wait for phylogenetic reconstruction of the genus Boehmeria world-wide.

\section{CONSERVATION STATUS FOR TAXA IN OLD WORLD BOEHMERIA}

Because of the complex taxonomic situation discussed above in the section on species delimitation and infraspecific taxa, we assess formal conservation status (IUCN 2001) only for species, subspecies, those varieties well-circumscribed morphologically and in geographical distribution, and those varieties where abundant material exists which is clearly referable to that variety (despite the presence also of intermediate material). In other cases, conservation status is discussed using informal criteria.

\section{Boehmeria}

Boehmeria Jacq. (1760) 9, 31. - Type: Boehmeria ramiflora Jacq.

Perennial herbs, shrubs or small trees; stems erect or sometimes scrambling. Stipules lateral or \pm intrapetiolar, free or partly so, mostly long-persistent. Leaves opposite or alternate, usually petiolate, often dimorphic (those of a dimorphic pair of opposite or adjacent alternate leaves are here referred to as 'smaller' and 'larger' leaves in the descriptions of the species); lamina 3-veined from base and with variable number of upper lateral veins, margin dentate, serrate or crenate, often asymmetrical with a wider half with many teeth and a narrower half with fewer teeth; indumentum variable (often characteristic for a species or infraspecific taxon); cystoliths punctiform. Plants monoecious or dioecious. Inflorescence-bearing axes terminal or axillary, branched or unbranched, sometimes modified by partial or complete reduction of leaves. Flowers grouped into inflorescences which are dense, rather small to medium-sized sessile bisexual or unisexual clusters of flowers, clusters single either in axils of normal leaves or arranged along modified axes and each subtended by a single bract and well-spaced to contiguous. Each flower subtended by a triangular chaffy often reddish bracteole. Male flowers (3-)4(-5-6)-merous; stamens of the same number as perianth, opposite perianthlobes; vestige of gynoecium present. Female flowers with perianth tubular, completely enclosing ovary, contracted and with several small teeth at apex; style linear, usually short; stigma linear, long, unilaterally papillose or long-papillose on all sides, nearly always long-persistent. Fruiting perianth persistent and firmly attached to achene, with which it is dispersed, sometimes markedly dorsiventrally flattened into 'shoulders' or prominent lateral wings. Achenes ovoid, surface dull.

A genus of 47 species, with 33 indigenous species in the Old World and 14 indigenous species in the New World (WilmotDear \& Friis 1996, Wilmot-Dear et al. 2003), pantropical and extending into warm temperate regions, but absent from Europe and with limited distribution in Australia.

\section{KEY TO THE SPECIES}

This key includes taxa from Cypholophus and Pouzolzia because they are frequently misidentified as Boehmeria.

1. Female and male flower-clusters both present on the same plant and males and females differently arranged: clusters of one sex all in leaf axils, of the other all dispersed along long leafless axes .................. 2

1. Flowers of only one sex present; or plant with clusters of both sexes present on same plant and then males and females similarly arranged: either both in leaf axils or both on long leafless axes

2. Male flower-clusters axillary, flowers $5(-6)$-merous with very long pedicels (4-8 $\mathrm{mm}$ long), these usually still present after flowers have fallen; female clusters on long, usually muchbranched, leafless axes; stigma straight. — Widespread .

9. B. zollingeriana

2. Male flower-clusters along long branched leafless axes, flowers 4-merous, subsessile; female clusters axillary, stigma minute, tightly-curved.

. [Cypholophus spp.]

3. Leaf apex bifurcated or consisting of 2-several almost equally long apical teeth such that apex appears as 2-3-lobed

3. Leaf apex rounded, acute or acuminate, marginal teeth all of uniform size or larger towards apex but not \pm equalling the terminal tooth.

4. At least some leaves alternate; flower-clusters borne on \pm leafless axes with a tuft of leaves at apex. - China. .

8. B. clidemioides

4. Leaves all opposite, inflorescence-bearing axes entirely leafless.

5. Leaf margin with teeth 30-40 either side, shallow outwardpointing of uniform size, indistinct or up to $6 \mathrm{~mm}$ long, leaf apex asymmetrically bilobed; indumentum of leaves and stems of two distinct kinds, long robust curved hairs mixed with short spreading hairs. - Pioneer on rocky cliffs; South Korea; Japan . . . . . . . . . . . . . 29. B. splitgerbera

5. Leaf margin with teeth 5-15 either side, up-curved and progressively markedly larger towards leaf apex, uppermost ones $\geq 10 \mathrm{~mm}$ long and forming 2-3 apical lobes; indumentum of leaves and stems \pm uniform, adpressed or spreading $\ldots \ldots \ldots \ldots \ldots \ldots \ldots \ldots \ldots \ldots \ldots \ldots \ldots \ldots \ldots$

6. Shrub up to $2.5 \mathrm{~m}$, with soft spreading indumentum on most parts. - Northern India; Nepal; Bhutan. . . 24. B. ternifolia

6. Herb or subshrub up to $1 \mathrm{~m}$, often unbranched, glabrous or adpressed-hairy or with coarser indumentum. - China; South Korea; Japan . . . . . . . . . . . . 28. B. japonica

7. Flower-clusters both in leaf axils and along axillary branches which are \pm leafless throughout most of length but with a tuft of small (otherwise unmodified) leaves at tip or returning to normal vegetative growth with typical foliage at apex; leaves often variously both alternate and opposite . . . . . . 8

7. Flower-clusters either in axils of normal stem leaves or in entirely leafless modified lateral and/or terminal axes; leaves either all opposite (at least on main stems) or alternate to subopposite . . . . . . . . . . . . . . 14

8. Female and male flowers very loosely arranged such that some flower-bases \pm visible even in flowering state; bracteoles conspicuous often as long as flowers; stigma caducous; fruiting perianth with several robust longitudinal ribs on each face but scarcely dorsiventrally flattened and without distinct marginal rim, perianth detaching from mature shiny achene; male flower buds conical-apiculate, with tepals lacking dorsal appendages; leaves alternate. — Widespread, excl. Philippines . . . . . . . . . [Pouzolzia sanguinea] 
8. Female and male flowers more crowded such that only apical part visible, bracteoles inconspicuous at most half the length of flower; stigma persistent; fruiting perianth with or without marginal wing or rim but without ribs on each face, perianth adnate to mature dull achene; male flower buds ovoid or globose with distinct appendages or, if appendages absent, then leaves always opposite . . . . . 9

9. Subshrub, shrub or tree with ultimate flowering stems leafless towards apex and bearing only flower-clusters but returning to vegetative growth with normal leaves above; male flower-clusters 2-10 $\mathrm{mm}$ diam; fruiting perianth usually asymmetrical; achene yellow-brown or deep redbrown

9. Herb or straggling subshrub with flower-clusters borne mainly on distinct side branches $3-15 \mathrm{~cm}$ long with only a small tuft of leaves at tip; male clusters $\leq 2 \mathrm{~mm}$ diam; fruiting perianth usually symmetrical; achene light yellowish brown or black

10. 'Smaller' leaves of markedly different shape to 'larger' ones; subshrub with ultimate stems slender, $\leq 1 \mathrm{~mm}$ diam near tip; leaves abundantly hairy on both sides; marginal teeth always distinct, often 2-3 mm long; male clusters with few-15(-20) loosely-arranged buds; female flowers with style eccentric; fruiting perianth distally inflated or markedly laterally flattened, proximal half of perianth scarcely laterally flattened and without a distinct wing surrounding the thickened achene-bearing part; achene yellow-brown, occupying proximal half of perianth. - Philippines; Indonesia - Sulawesi; Papua New Guinea 5. B. heterophylla

10. 'Smaller' leaves similar to 'larger' leaves or only slightly broader; tree or shrub with ultimate stems robust and woody, c. $2 \mathrm{~mm}$ diam near tip; leaves mostly glabrous above, marginal teeth often very indistinct, sometimes up to $1.5 \mathrm{~mm}$ long; male clusters with 20-more than 50 densely congested buds; style terminal; fruiting perianth obovoid-oblong, sometimes several-angled but not markedly flattened, never winged, achene deep red-brown \pm filling perianth

11. Lateral veins similar in number and arrangement on two sides of leaf; length of the 'larger' of the dimorphic leaves c. $2 \times$ width and $1.5-2.5 \times$ length of 'smaller' leaf. - Widespread . . . . . . . . . . . . . . 2. B. depauperata

11. Lateral veins markedly dissimilar in number and arrangement on two sides of leaf; length of the 'larger' of the dimorphic leaves $3-3.5 \times$ width and c. $3 \times$ length of 'smaller' leaf. - Papua New Guinea.

Undescribed taxon near 2. B. depauperata

(see under 2. B. depauperata, Note 5)

12. Length of 'larger' leaf of dimorphic pair 2-5x length of 'smaller' leaf, leaves alternate, opposite or variably arranged along stem, length (1.5-)2-4x width; fruiting perianth markedly laterally flattened with narrow marginal wing surrounding often centrally-located thickened achene-bearing part. - Widespread west of Wallace's line .

8. B. clidemioides

12. Length of 'larger' leaf of a dimorphic pair only $1-1.5 \times$ length of 'smaller' leaf; leaves always opposite, length usually only 1-1.4x width; fruiting perianth without distinct uniform marginal wing. - Japan; China; Indochina . . . . . . 13

13. Leaves and stems with spreading, often dense hairs; fruiting axis erect, clusters densely congested; leaves often thin-coriaceous. - Limestone at seashore; South Korea; Japan. . . . . . . . . . . . . . . 26. B. holosericea

13. Leaves and stems adpressed-hairy; fruiting axis pendulous, clusters not densely congested; leaves thin-chartaceous. - China; Indochina. 23. B. virgata
14. Leaves all opposite at least throughout most of length of

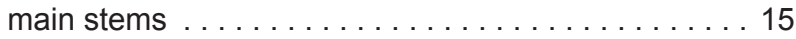

14. Leaves consistently alternate or at most some subopposite, none strictly opposite. . . . . . . . . . . . 106

15. Leaves apparently with entire margin, glabrous above, narrowly ovate, length c. $3.5 \times$ as long as wide; plants with flower-clusters borne along leafless flower-bearing axes

15. Leaves toothed, often hairy above, length often $\leq 3 \times$ width (plants with flower-clusters axillary or on leafless axes) 17

16. 'Larger' leaf of dimorphic pair at least $17 \mathrm{~cm}$ long, length up to $1.25 \times$ length of 'smaller' leaf; apex of 'smaller' leaf acute to acuminate, not mucronate; entire margin smooth; bracts subtending clusters almost as broad as long; fruiting perianth minute, up to $0.6 \mathrm{~mm}$ long, ovoid, unwinged. Burma ... . . . . . . . . . . . . . . . 15. B. kurzii

16. 'Larger' leaf of dimorphic pair up to $10 \mathrm{~cm}$ long, length usually > $1.5 \times$ length of 'smaller' leaf; apex of 'smaller' leaf usually conspicuously mucronate; distal part of margin not strictly entire, vestiges of teeth visible as slight thickenings; bracts subtending flower-clusters narrow, length $4 \times$ width; fruiting perianth large, $1-1.5 \mathrm{~mm}$ long, extremely flattened with conspicuous wing surrounding achene. - Papua New Guinea. .

22. B. subintegra

17. Flower-clusters in axils of normal stem leaves, no modified axes present . . . . . . . . . . . . . 18

17. Flower-clusters mainly along specialised leafless axes arising from leaf axils (with or without some clusters also in leaf axils) . . . . . . . . . . . . . . . . . . 21

18. Male flowers 5-6-merous on conspicuous pedicels 4-8 $\mathrm{mm}$ long; female flowers not occurring in axillary clusters. - China; southern India; Burma; Thailand; Indochina; Indonesia - Jawa; Philippines . . . . . . 9. B. zollingeriana

18. Male flowers 4-merous, subsessile; female flowers in axillary clusters . . . . . . . . . . . . . 19

19. Leaves asymmetrical, with distal lateral veins on either side markedly dissimilar in number and arrangement; stipules large and broad $10-20$ by $3-4.5 \mathrm{~mm}$; stigma minute $<0.5$ mm long. . . . . . . . . . . . . . [Cypholophus spp.]

19. Leaves \pm symmetrical, with venation similar on both sides; stipules $4-8$ by $1.5-2 \mathrm{~mm}$; stigma $1.5-2 \mathrm{~mm}$ long . . 20

20. Marginal teeth $3-4 \mathrm{~mm}$ long, width \pm equalling length, up to 25 either side. - North-eastern India; Burma.

7. B. helferi

20. Marginal teeth short and wide, $\leq 1 \mathrm{~mm}$ long, width $3-5 \times$ length, usually 30 or more either side. - Widespread .

2. B. depauperata

21. Marginal teeth progressively markedly wider and/or longer and increasingly up-curved in distal part of leaf, acute, relatively large, (2.5-)3-15 mm long; leaf apex acuminate consisting of a single long tooth . . . . . . . . 22

21. Marginal teeth \pm uniform in size and shape along most of margin but sometimes indistinct close to leaf base, (rounded or acute, numerous or not), or if progressively larger distally then teeth extremely short (<1 mm long) and margin completely entire in proximal part; leaf apex often toothed to tip

22. Leaves markedly dimorphic in size, length of 'larger' leaf $2-5 \times$ that of 'smaller' one. - Widespread, excl. Philippines and Pacific . . . . . . . . . . . 8. B. clidemioides

22. Leaves not or only moderately dimorphic, length of lamina of 'larger' leaf of dimorphic pair less than twice that of 'smaller' one .................. 23

23. Stem hairs closely-adpressed . . . . . . . . . . . . 24

23. Stem hairs spreading $\ldots \ldots \ldots \ldots \ldots \ldots$ 
24. Leaf margin with 15-40 teeth on either side, these usually outward-pointing, distal ones wider but only slightly longer than proximal ones; leaves mostly $10-40 \mathrm{~cm}$ long; terminal tooth comprising up to a quarter of total lamina length; leaves rhombic-ovate with length $2-4 \times$ width. - China (incl. Taiwan); Japan (incl. Ryukyu Islands).

27. B. sieboldiana

24. Leaf margin with 6-12 teeth on either side, and either all teeth markedly up-curved or length of distal ones (2-)3$10 \times$ length of proximal ones; leaves mostly $\leq 9 \mathrm{~cm}$ long but if up to $11 \mathrm{~cm}$ long, then with terminal tooth comprising $0.3-0.5 \times$ total lamina length; leaves often ovate, with length often only $1.5 \times$ width. - China; South Korea; Japan . . .

28. B. japonica

25. Much-branched shrub; length of distal marginal teeth up to $2(-3) \times$ length of proximal ones, acute, longer than wide; hairs on stem and leaves soft and all of similar length. Northern India; Nepal; Bhutan . . . . . . . . 24. B. ternifolia

25. Herb; either length of distal marginal teeth $\geq 4 \times$ length of proximal ones and hairs on adaxial leaf surface rough, or if distal teeth not markedly longer than proximal ones then hairs on leaves much longer than those on stem and marginal teeth wider than long, often rounded. - China; South Korea; Japan.

26

26. Distal marginal teeth only slightly larger than proximal ones, with distal ones up to $2 \times$ length of proximal ones, usually more than 19 in number; leaf with relatively long hairs (0.4-0.7 $\mathrm{mm}$ long); leaf surface sometimes bullate; female inflorescence-bearing axes erect. - South Korea; Japan . . . . . . . . . . . . . . . . . . . . 26. B. holosericea

26. Distal marginal teeth markedly larger than proximal ones, with the most distal ones $3-10 \times$ length of proximal ones, less than 17 in number; leaf-hairs often minute (0.1-0.2 $\mathrm{mm}$ long); leaf surface never bullate; female inflorescencebearing axes pendulous. - China; South Korea; Japan

28. B. japonica

27. Leaves, at least some, slightly misshapen with bifurcated midrib, always markedly asymmetrical, with width of one half of lamina up to $1.5 \times$ width of other half and basal veins usually extending almost to tip; lateral veins robust and reticulation often conspicuous; inflorescence-bearing axes single in each axil, unbranched. - Japan

29. B. splitgerbera and hybrids

27. Leaves with midrib never bifurcated; both sides of leaf often scarcely dissimilar; venation often slender and/or basal veins extending little into distal third of lamina; inflorescence-bearing axes often branched or several from each axil

28. Mature leaves with at least 50 marginal teeth on either side . . . . . . . . . . . . . . . . . . . . . 29

28. Mature leaves with less than 50 marginal teeth on either side

29. Leaves linear-ovate, length 5-7× width, rather thick-chartaceous or coriaceous; adaxial surface (excluding youngest leaves in distal node) glabrous or glabrescent; inflorescence-bearing axes unbranched or with 1-2 branches at base, with flower-clusters congested. - Northern and central India; Nepal; Bhutan; Burma; China; Thailand; Indochina; naturalised in Mascarenes ... . 17. B. penduliflora

29. Leaves ovate and relatively broader with length $\leq 3 x$ width (hairy or not) or if up to $4 \times$ width then with dense spreading hairs above; leaves often rather thin-textured, inflorescence-bearing axes often branched and/or with flower-clusters well-spaced . . . . . . . . . . 30

30. Leaves large, broadly ovate, $24-35 \mathrm{~cm}$ long, length $<2 x$ width, thin-textured, indumentum abundant but very incon- spicuous both sides, upper veins slender often inconspicuous and margin shallowly crenate. - Indonesian Papua; Papua New Guinea . . . . . . . . . . . . . . 23. B. virgata

30. Leaves smaller, up to $15 \mathrm{~cm}$ long and often much narrower with length at least $2.5 \times$ width, or if $>15 \mathrm{~cm}$ long with length $<2.5 \times$ width then margin serrate to dentate or leaf surface distinctly bullate (hairy or not, veins robust or not) . . 31

31. Veins markedly dissimilar on two sides of lamina, basal vein on narrower side reaching nearly to apex, on other side to slightly above middle, upper veins on narrow side either absent or 1-3 all arising near apex, on wide side 2-3 additional veins arising below lowermost on narrow side. 32

31. Veins on two sides of leaf less dissimilar: basal vein on one side extending at most slightly further into distal half of lamina than basal vein on other side, upper veins at most 1 more on one side than other

32. Petioles and leaves beneath both with mixed hairs of two types, abundant fine minute ( $<0.1 \mathrm{~mm}$ long) pubescence and sparse coarser and longer $(0.5-1 \mathrm{~mm})$ curved hairs; upper lateral veins on narrow side 3 ; both male and female clusters arranged along long (often bisexual) axes, stigma 1-2 mm long. - North-eastern India; Bhutan; Bangladesh; Burma . . . . . . . . . . . . . . . . . . . 33. B. listeri

32. Petioles and leaves beneath with hairs of uniform texture 0.2-0.5 mm long, never of two different types; upper lateral veins on narrow side $0-2$; female clusters absent (never on specialised axes); stigma minute $<0.5 \mathrm{~mm}$ long. - Papua New Guinea; Pacific, excl. Hawaiian Islands

[Cypholophus decipiens]

33. Leaves with upper veins (5-)6-9 either side, similarly arranged on both sides of leaf, impressed above, prominent beneath, arising in distal half but often hardly distinguishable from robust coarser tertiary veins arising lower on midrib; stipules large, boat-shaped (10-)25-65 by (3-)7-20 $\mathrm{mm}$. - Hawaiian Island; naturalised in Reunion

20. B. grandis

33. Leaves, at least on narrow side, with only $1-3(-4)$ distinct upper veins, these often arising nearer apex than on wide side, either inconspicuous or prominent but clearly distinct from tertiary veins, all arising near or above middle of lamina; stipules $7-10(-25)$ by $1-2 \mathrm{~mm}$

34. Indumentum on stem and leaves close-adpressed; stipules up to $12 \mathrm{~mm}$ long

34. Indumentum on stem and leaves \pm spreading; stipules various.

35. Leaves drying dark brown above, chestnut-brown and spreading-hairy beneath, usually thick-chartaceous; stem hairs half-adpressed; stipules mostly 12-24 mm long. - Philippines; Indonesia - Sumatera, Jawa, northern Sulawesi

31. B. rugosissima

35. Leaves drying either uniformly green both sides or dark green above and paler green beneath, often with fine adpressed hairs beneath (thin- or thick-chartaceous); stem hairs close-adpressed; stipules 7-10 mm long . . . . . 36

36. Tertiary veins prominent, conspicuous, coarser ones closespaced scalariform; lamina often thick-chartaceous; inflorescence-bearing axes branched throughout length and with 2nd-order branching. - North-eastern India; Nepal; Burma; China. . . . . . . . . . . . . . . 13. B. polystachya

36. Tertiary veins slender, inconspicuous; lamina thin-chartaceous; inflorescence-bearing axes unbranched or branched only near base and without 2nd-order branching. - Indian subcontinent; China.

23. B. virgata

37 . Leaf abundantly hairy on adaxial surface, length $3-4 \times$ width, marginal teeth blunt; stem and petiole hairs dense, 
uniform; inflorescence-bearing axes unbranched. - Philippines; Indonesia - Sulawesi ... . . . . . 19. B. multiflora

37. Leaf with adaxial surface glabrous or with single hair in centre of each areole (leaf relatively wider or not, marginal teeth acute or blunt); stem and petiole hairs often of two distinct kinds, coarse curved and minute spreading; inflorescence-bearing axes often branched

38

38. Lamina with length (2.5-)2.7-3x width, drying grey-green or blackish, marginal teeth always acute; stipules up to 11 by $25 \mathrm{~mm}$. - North-eastern India; Bhutan; Bangladesh; Burma ... . . . . . . . . . . . . . . . . . 33. B. listeri

38. Lamina with length $1.3-2.3 \times$ width, drying dark brown above, markedly paler chestnut-brown beneath; stipules mostly $12-25$ by $3-5 \mathrm{~mm}$ (marginal teeth acute or obtuse). - Philippines; Indonesia - Sumatera, Jawa, northern Sulawesi .

31. B. rugosissima

39. Female inflorescence-bearing axis with basal part long, naked, erect, robust and straight, upper (flower-bearing) part with many long and \pm drooping branches (male clusters present or not on plants with female inflorescences, but always sessile on main stem, never on the long, branched axes with female clusters). - China; Thailand; Indochina . . . . . . . . . . . . 9. B. zollingeriana

39. Female axis not as above, either unbranched, branched only at base or much-branched throughout; male clusters (if present) also on long axes . . . . . . . . . . 40

40. Length of lamina up to $1.5(-1.6) \times$ width

40. Length of lamina at least $1.7 \times$ width

41. Stem and leaves glabrous or with uniform straight very closely-adpressed hairs, those on abaxial surface of leaf all pointing in same direction or lying in an orderly pattern towards centre of areoles

42

41. Stem with spreading or half-adpressed hairs at least near apex, hairs uniform or of two distinct types; leaves (at least beneath) with \pm spreading short velvety or longer often curved hairs not lying in an orderly pattern when pressed and dried

42. Stipules large, boat-shaped (10-)25-65 by (3-)7-20 mm; upper lateral veins (5-)6-9 either side, \pm impressed above, prominent beneath, all in distal half of lamina but often hardly distinguishable from coarser tertiary veins arising lower on midrib. - Pacific - Hawaiian Islands; Reunion (naturalised).

20. B. grandis

42. Stipules $<8 \mathrm{~mm}$ long or $<2 \mathrm{~mm}$ broad or both; upper lateral veins slender, prominulous beneath, \pm inconspicuous above and/or only 1-3 either side, variously spaced but distinct from tertiary veins

43. Inflorescence-bearing axes (either sex) with short unbranched lateral branches throughout their length, these progressively and regularly markedly shorter towards apex giving conical appearance, main axis of this composite structure up to $8 \mathrm{~cm}$ long, \pm erect; leaf apex abruptly shortacuminate, base broadly rounded to cordate, rarely broadacuminate, margin crenate, crenations 20-30 either side, shallow, broad and rounded. — North-eastern India; Nepal; Bhutan; Burma; south-western China ... . . 14. B. conica

43. Inflorescence-bearing axes, especially female, unbranched or with irregular lateral branches in basal part, these mostly \pm equalling main axis of the composite structure or if with short branches throughout length then these not progressively shorter and marginal teeth acute, markedly upcurved (axes often very long, often pendulous; leaf apex often long-acute or obtuse, base cordate to cuneate) 44

44. Stems and inflorescence-bearing axes glabrous, often drying red-brown; leaf \pm glabrous above (rarely occasional single hair in centre of areole); margin usually broad-crenate, teeth usually up to 20 , with width c. $4 \times$ length; male clusters present or not on plants with female inflorescences, but always sessile on main stem, never on the long, branched inflorescence-bearing axes with female clusters. - China; southern India; Burma; Thailand; Indochina; Indonesia Jawa . . . . . . . . . . . . . . 9. B. zollingeriana

44. Stems (at least near apex) adpressed-hairy; leaf with inconspicuous fine hairs above, margin dentate; male clusters (if present) also on long axes

45. Leaf apex \pm acuminate but toothed almost to tip; marginal teeth not or only slightly up-curved. - Widespread, excl. Japan and Pacific . . . . . . . . . . . . 23. B. virgata

45. Leaf apex abruptly acuminate consisting of a single long tooth; marginal teeth markedly up-curved, increasingly so near leaf apex . . . . . . . . . . . . . 46

46. Leaf base truncate or cordate. - China, Indochina, Indonesia - Sumatera

23. B. virgata

46. Leaf base cuneate or rounded 47

47. Leaves rhombic or rhombic-ovate, with outward-pointing teeth; male tepals without dorsal appendage. - China; South Korea; Japan. 27. B. sieboldiana

47. Leaves ovate, teeth upward-pointing, male tepals with dorsal appendage

48. Distal marginal teeth of leaves longer than proximal ones. - Widespread, excl. Philippines and Pacific .

8. B. clidemioides

48. Marginal teeth all of similar length. - North-eastern India; Nepal; Bhutan

23. B. virgata

49. Stems with both spreading hairs c. $1 \mathrm{~mm}$ long and adpressed hairs $0.2-0.4 \mathrm{~mm}$ long, the spreading hairs concealing the adpressed ones at nodes and near apex but often lacking from lower internodes. - North-eastern India; Nepal; Bhutan; southern China ... . . . . . . . 23. B. virgata

49. Stems with spreading hairs which are \pm uniform or of two different types, minute fine ones, $<0.1 \mathrm{~mm}$ long, mixed with coarser curved ones, $0.2-0.4 \mathrm{~mm}$ long . . . . . . 50

50. Stem hairs all spreading but of two kinds (distinguishable with $\times 10$ hand lens), dense velvety fine minute ones $<0.1$ $\mathrm{mm}$ mixed with sparse coarser curved longer ones $0.2-0.4$ $\mathrm{mm}$ long. . . . . . . . . . . . . . 51

50. Stem hairs all of same nature: \pm uniform in texture and not widely varying in length

51. Leaf margin broadly crenate with only $7-12$ teeth, lamina $\leq 10 \mathrm{~cm}$ long, length $\leq 1.3 \times$ width; base \pm symmetrical, rounded to truncate or \pm cordate, female inflorescencebearing axes congested, male flowers occasional scattered in mainly female clusters, tepals without dorsal appendage. - Maritime; Japan - south-western Ryukyu Islands

30. B. yaeyamensis

51. Leaf margin dentate or crenate, with (15-)25-45 teeth; lamina $>10 \mathrm{~cm}$ long or not, base symmetrical or asymmetrical, male flowers on separate lower inflorescence-bearing axes or not, tepals with dorsal appendage or not . . . 52

52. Female inflorescence-bearing axes so congested that individual flower-clusters are indistinguishable. . . . . 53

52. Female inflorescence-bearing axes with clusters contiguous but distinct

53. Upper lateral veins similarly arranged, 1-2 on each half of lamina, arising above middle, lamina thin-chartaceous, length $\geq 1.6 \times$ width; male flowers in clusters on unisexual branched axes $\leq 6 \mathrm{~cm}$ long or in small clusters at apex of mainly female inflorescence-bearing axis; fruiting perianth $\leq 1.2 \mathrm{~mm}$ long and almost equally wide. - Evergreen forest; Burma; China (incl. Taiwan); northern Thailand

32. B. pilosiuscula 
53. Upper lateral veins on one side more numerous than on other, 2(-3) on one side, 4-5 on other, some arising below middle; lamina often thick-chartaceous or coriaceous, with prominent close reticulation, length often $<1.5 \times$ width; male and female inflorescence-bearing axes unbranched, male $\geq 10 \mathrm{~cm}$ long; fruiting perianth often $1.5 \mathrm{~mm}$ long, length usually $3 \times$ width. - Pioneer on maritime cliffs and roadsides; Japan

29. B. splitgerbera

54. Leaves \pm symmetrical, $10-25 \mathrm{~cm}$ long, marginal teeth (15-) 20-27 either side, these broad $3-10$ by $6-15 \mathrm{~mm}$. South Korea; Japan. . . . . . . . . . . 26. B. holosericea

54. Leaves with asymmetrical base, usually $\leq 10 \mathrm{~cm}$ long, marginal teeth (25-)35-45 either side, these $1-2$ by $2-4 \mathrm{~mm}$. — India; Sri Lanka; Philippines; Indonesia .

\section{B. pilosiuscula}

55. Leaf apex abruptly acuminate, consisting of a single tail-like \pm linear tooth only $1-2(-8) \mathrm{mm}$ broad, abruptly constricted at base, with length 5-20x width; stem hairs velvety, minute $\leq 0.3 \mathrm{~mm}$ long; leaf base broad often truncate, marginal teeth 12-25 either side; lamina length 1-1.25x width. Northern India; Nepal; Bhutan . . . . . . . . 24. B. ternifolia

55. Leaf apex variously rounded, attenuate or acuminate but not abruptly tail-like; lamina relatively narrow or not, teeth more numerous or not; stem indumentum long or short

56. Leaves large, broad-ovate, $24-35 \mathrm{~cm}$ long, length less than $2 \times$ width, thin-textured, indumentum abundant but very inconspicuous, adpressed above and spreading below, upper veins slender often inconspicuous, margin shallowly crenate, teeth many (40-50) either side, these up to $3 \mathrm{~mm}$ long, their width 4-6x length. - Indonesian Papua; Papua New Guinea. . . . . . . . . . . . . . . . . . . 23. B. virgata

56. Leaves $\leq 16 \mathrm{~cm}$ long or if up to $20 \mathrm{~cm}$ then either marginal teeth up to 30 either side, these often longer than wide and indumentum on both sides of leaf spreading, conspicuous; or leaves thick-textured and often bullate and/or with robust upper veins and major tertiary veins robust

57

57 . Lateral and often also tertiary veins robust, prominent beneath, often impressed above; stipules (11-)15-65 by $3-20$ $\mathrm{mm}$; leaves \pm symmetrical, with indumentum sparse above, restricted to veins beneath

58

57. Plant without this combination of characters: either upper lateral veins slender and tertiary veins very indistinct above or, if veins fairly robust, then leaves with abundant indumentum, sometimes also markedly asymmetrical; stipules often much shorter and narrower.

58. Upper lateral veins (5-)6-9 either side, all arising in distal half of lamina but often scarcely distinct from coarser tertiary veins arising lower on midrib: stipules large, boatshaped mostly $\geq 25-65$ by 7-20 $\mathrm{mm}$. - Pacific - Hawaiian Islands; Reunion (naturalised). . . . . . . . 20. B. grandis

58. Upper lateral veins on narrow side of lamina only $2-4$ and all arising in distal half, on wide side often 3-5 and arising slightly lower; stipules narrowly triangular, $\leq 25$ by $5 \mathrm{~mm}$. - Indonesia - Sumatera, Jawa; Philippines

31. B. rugosissima

59. Inflorescence-bearing axes erect, unbranched, mostly bisexual and congested, with a few pedicellate male flowers in mainly female clusters near apex, male flowers more numerous near apex; leaves \pm symmetrical, velvety, smooth, base truncate to cordate; indumentum $0.5-2 \mathrm{~mm}$ long, at least on stem, often dense giving golden-brown sheen to most parts of plant. - North-eastern India; Burma; southern China; Thailand

25. B. ourantha

59. Inflorescence-bearing axes pendulous or, if erect, then with several lateral branches, often not congested, always either unisexual or with male clusters on short lateral branches near base of mainly female axis; leaves often asymmetrical, or bullate or base cuneate; indumentum often pale, sparse or dense, sometimes very short and always much shorter than above.

60 . Indumentum dense and relatively long, $0.4-0.7 \mathrm{~mm}, \pm \mathrm{ob}-$ scuring surface of stem and leaves beneath (often also above), very pale giving silvery sheen to plant; leaves thick-chartaceous or coriaceous, marginal teeth 30-40 either side. - Afro-Malagasy region . . . . . 23. B. virgata

60. Indumentum sparse or if fairly dense then shorter, $\leq 0.3$ $\mathrm{mm}$, not obscuring surface and darker giving brownish sheen to plant, leaves mostly thinner-textured; teeth few or many

61. Abaxial leaf surface drying chestnut or blackish brown usually much paler than the dark brown adaxial surface, adaxial surface almost glabrous, with single hair or its bulbous base in centre of each areole, abaxial surface with hairs less sparse; leaves usually bullate and thick-textured; stipules 9-10 mm long; inflorescence-bearing axes unisexual, both sexes branched throughout length. - Indonesia

31. B. rugosissima

61. Without above combination of characters: leaves in dry state mostly similarly coloured both sides, greenish or greenish brown, smooth and thin-textured or if bullate and thick-textured then hairs on adaxial surface several per areole (leaf-size and margin various); stipules 4-7(-10) mm long; inflorescence-bearing axes mostly either unbranched or bisexual, with short male branches at base of mainly female inflorescence-bearing axis, only the entirely male axes (if present) sometimes much-branched throughout length.

62. Marginal teeth $35-45$ either side, $1.5-2$ by $2-3 \mathrm{~mm}$, their width usually $<1.5 \times$ length; leaves stiff-hairy above mostly $<10 \mathrm{~cm}$ long, base often oblique; stem hairs stiff and rough, half-adpressed, 0.3-0.4 mm long. - Himalayas; Burma; south-western China; Indonesia - Jawa, Borneo

23. B. virgata

62. Marginal teeth up to 15 either side or if up to 27 then longer and relatively broader, $3-10$ by (3-)5-15 $\mathrm{mm}$, their width 1.5-3x length; leaves soft-hairy both sides, $10-25 \mathrm{~cm}$ long, base \pm symmetrical truncate; stem hairs soft, minute spreading at right angles, 0.1-0.3 mm long, often dense and velvety. - Himalayas; South Korea; Japan . . . . 63

63. Indumentum on stem minute, $0.2(-0.3) \mathrm{mm}$ long, on leaves much longer, $0.5-0.7 \mathrm{~mm}$, curved and often half-adpressed; marginal teeth mostly more than 20 either side, outwardpointing and often rounded. — Limestone near seashore; Japan. . . . . . . . . . . . . . . . . . . 26. B. holosericea

63. Indumentum on leaves and stem similar, minute, $\leq 0.3$ $\mathrm{mm}$ long, spreading at right angles to stem; marginal teeth mostly more than 20 either side, up-curved acute. - Northern India; Nepal; Bhutan . . . . . . . . . 24. B. ternifolia

64. Stem and leaves above glabrous or with uniform closelyadpressed fine hairs . . . . . . . . . . . . 65

64. Stem with spreading or half-adpressed hairs at least near apex, hairs uniform or of two distinct types; leaves above often also spreading-hairy

96

65. Leaf margin entire in proximal quarter or half of lamina, indistinctly serrate towards apex, teeth only $0.1-1(-1.5)$ $\mathrm{mm}$ long but their width $5-20 \times$ depth . . . . . . 66 66

65. Leaf margin \pm uniformly toothed almost to base of lamina (teeth often longer and/or relatively narrower); if leaves obovate then their length $3-4 \times$ width and apex gradually attenuate; (inflorescence-bearing axes slender or robust) 
66. Leaves obovate to elliptic, with length $\leq 2.8 \times$ width, sparsely minute-hairy above; leaf apex broadly rounded terminated abruptly by short broad acumen; marginal teeth in distal part $0.3-1.5 \mathrm{~mm}$ long; petiole relatively long, half of lamina length; length of 'larger' leaves up to $1.5 x$ 'smaller'. Madagascar.............. 21. B. tsaratananensis

66. Leaves narrowly ovate to elliptic with length $3.5-4 \times$ width, glabrous and shiny above; leaf apex gradually attenuate; marginal teeth $\leq 0.2 \mathrm{~mm}$ long; petiole only $0.1-0.25 \times$ lamina length; length of 'larger' leaves often 2-4x 'smaller'. - Papua New Guinea.

22. B. subintegra

67. Leaves (except sometimes the very immature pair of leaves at the most distal node) \pm glabrous above or with only a single hair in centre of each areole . . . . . . . . 68

67. Leaves (at least fairly young leaves but not restricted to the distal node) clearly, even if finely and inconspicuously, hairy above

68. Upper lateral veins (5-)6-9 either side, robust, clearly visible, all in distal half of lamina but often scarcely distinct from robust coarser tertiary veins arising lower down: stipules large, boat-shaped, (10-)25-65 by (3-)7-20 mm. Pacific

68. Upper veins $1-3(-4)$ either side, usually slender, tertiary veins even more slender and less distinct than lateral veins; stipules $\leq 10 \mathrm{~mm}$ long

70

69. Margin of leaf serrate, leaf surface often bullate; inflorescence-bearing axes always branched. - Pacific - Hawaiian Islands; naturalised in Reunion ... . . . 20. B. grandis

69. Margin of leaf crenate, leaf surface always smooth; inflorescence-bearing axes often unbranched. - Pacific, excl. New Caledonia, Solomon Islands and Hawaii

23. B. virgata (Polynesian forms)

70. Length of leaf-blade $5-7 \times$ width; leaves thick-chartaceous or coriaceous, marginal teeth 35 or more either side, closespaced, shallow, $\leq 0.8$ by $2.5 \mathrm{~mm}$. - Northern and central India; Nepal; Bhutan; Burma; China; Thailand; Indochina; naturalised in Mascarenes .........17. B. penduliflora

70. Length of leaf-blade $\leq 4 \times$ width or if up to $6 \times$ width then leaves very thin-textured; marginal teeth often fewer and/ or broader

71. Leaf with margin so indistinctly and wide-spaced serrate as to appear entire, teeth only $10-15$ either side $2-5 \mathrm{~mm}$ apart, up to $0.2 \mathrm{~mm}$ long or only a slight callus; leaves markedly dimorphic in size and shape, their length/width ratio (1.5-)2-5: 1, 'larger' leaves linear-ovate-attenuate, up to $12 \mathrm{~cm}$ long, 'smaller' leaves much broader, obtuse to very short-acuminate, with distinct mucro 1-2 mm long; stem with dense fine hairs. - Papua New Guinea .

22. B. subintegra

71. Leaf without this combination of characters; either distinctly (even if shallowly) serrate to dentate or crenate, with teeth at least $0.5 \mathrm{~mm}$ long, or if indistinctly serrate and markedly dimorphic in shape then the 'larger' leaves longer, with 25 or more teeth, and 'smaller' leaves not mucronate (stem hairy or glabrous).

72. Stem glabrous; leaves beneath glabrous or with extremely sparse fine hairs on veins only

73

72. Stem hairy at least near apex (leaves beneath glabrous or hairy)

73. Leaves drying light or dark green, membranous or very thinchartaceous, length 3-6x width; upper veins $1-2(-3)$ in number, all arising in distal third, marginal teeth indistinct only $0.5-1 \mathrm{~mm}$ long but relatively broad, up to $2-5 \mathrm{~mm}$ wide; flower-clusters on axes 4-20 cm long, male and female inflorescence-bearing axes fine adpressed-hairy, these and stem drying greenish or dull brownish black. -
North-eastern India; Nepal; Bhutan; Bangladesh; Burma; south-western China; Thailand. . . . . 12. B. hamiltoniana

73. Leaves drying brownish black above, often thick-chartaceous and relatively broader or with upper veins $4-5$ in number spaced throughout lamina length; distal $2 / 3$ of margin with distinct teeth often $>1.5 \mathrm{~mm}$ long by $6-8 \mathrm{~mm}$ broad; female inflorescence-bearing axes (20-)30-40 cm long, glabrous, these and stem drying red-brown (male clusters absent, never on long axes). - Southern India; Burma; China; Thailand; Indochina; Indonesia - Jawa

9. B. zollingeriana

74. Leaf apex attenuate-acuminate formed by a single long tooth; leaf rhombic-ovate to narrowly ovate, \pm symmetrical, membranous to thin-chartaceous; abaxial surface usually glabrous, number of upper lateral veins $3-5 \ldots \ldots 75$

74. Leaf apex broad-acute or attenuate but toothed to tip; leaves elliptic, elliptic-ovate or obovate with often slightly oblique base, or obovate-oblong; abaxial surface usually hairy at least on veins, upper lateral veins usually fewer

75. At least some leaves with (13-)15 or more marginal teeth either side, most leaves $>10 \mathrm{~cm}$ long, with length mostly more than $2 \times$ width; flower-clusters often \pm contiguous along axes. - China; South Korea; Japan . . 27. B. sieboldiana

75. All leaves with up to 12 marginal teeth either side, most leaves $<10 \mathrm{~cm}$ long, with length more than $2 \times$ width; flowerclusters always well-spaced. - Northern and southern China; South Korea; Japan

28. B. japonica

76. Leaves widest above middle, narrowly obovate-oblong, with length 3-4x width and only the basal pair of veins clearly visible beneath, lamina symmetrical, thin-chartaceous; fruiting perianth very short and wide, $0.8-0.9$ by $0.7 \mathrm{~mm}$, subspherical. - China; Indochina; Malaysia

11. B. lanceolata

76. Leaves widest at or below middle, elliptic, rhombic-ovate or ovate, with at least one pair of upper veins visible or if lamina asymmetrical at least one upper vein present on wide side (proportions and texture various); fruiting perianth often longer and relatively narrower, elliptic-ovoid or obovoid

77. Lamina membranous to very thin-chartaceous, narrowly ovate-attenuate, with length $3-6 x$ width and 1-3 upper lateral veins usually all arising well into distal $2 / 3$ of leaf; male inflorescence-bearing often 1-2x dichotomous at extreme base. - North-eastern India; Nepal; Bhutan; Bangladesh; Burma; south-western China; Thailand

12. B. hamiltoniana

77. Lamina thin- or thick-chartaceous but never membranous, at least 1 upper lateral vein present on at least one side and arising in lower half; inflorescence-bearing axes not dichotomous, either unbranched or with lateral branches which are not restricted to base.

78

78. Leaf asymmetrical with number of upper veins on wide side $3-5$, on narrow side $0-2(-3)$, drying grey-brown, bullate; margin minutely close-serrate, teeth $<1 \mathrm{~mm}$ long, width of teeth equalling length

78. Leaf not markedly asymmetrical, number of upper veins on wide side usually $1-2$ and only 1 more than on narrow side; drying green or yellow-green, often smooth (margin various, but not as above) . . . . . . . . . 80

79. Narrow half of leaf with usually 3 upper veins; both female and male clusters arranged along long (often bisexual) inflorescence-bearing axes, stigma 1-2 $\mathrm{mm}$ long; indumentum on petioles and leaves beneath mixed, hairs of two distinct kinds, abundant fine minute $(<0.1 \mathrm{~mm}$ long) pubescence and sparse coarser longer $(0.5-1 \mathrm{~mm})$ curved hairs. - 
North-eastern India; Bhutan; Bangladesh; Burma

33. B. listeri

79. Narrow half of leaf with $0-2$ upper veins; female clusters absent (never on specialised inflorescence-bearing axes); stigma minute, $<0.5 \mathrm{~mm}$ long; petioles and leaves beneath with hairs uniform or all of similar texture and $0.2-0.5 \mathrm{~mm}$ long. - Papua New Guinea; Pacific - Solomon Islands; Vanuatu; New Caledonia.... . . [Cypholophus decipiens]

80. Abaxial leaf surface and petioles with \pm uniform short or long fine or coarse adpressed or spreading hairs; fruiting perianth with distinct wing, female inflorescence-bearing axes $20-70 \mathrm{~cm}$, axes usually branched throughout length; leaf margin with relatively wide-spaced teeth, their width 3-4x length. - Indonesia; Philippines; Pacific, excl. New Caledonia and Hawaii . . . . . . . . . . . 23. B. virgata

80. Abaxial leaf surface and petioles with two distinct kinds of hairs, abundant fine minute $(<0.1 \mathrm{~mm}$ long) pubescence and sparse coarser longer $(0.5-1 \mathrm{~mm})$ curved hairs; fruiting perianth obovoid or obovoid-truncate without wing; inflorescence-bearing axes $2-11 \mathrm{~cm}$, both sexes unbranched or branched very close to base; marginal teeth closer-spaced, their width usually 1-2x length. - North-eastern India; Bhutan; Bangladesh; Burma

33. B. listeri

81. Upper lateral veins robust, conspicuously impressed above and prominent beneath, 3 or more either side; tertiary veins distinctly scalariform, often close-spaced only 2-4 $\mathrm{mm}$ apart and \pm as conspicuous as secondary veins especially between basal vein and margin .

82

81. Upper lateral veins slender, fine-prominulous beneath, or if prominent then only 1-2 either side (tertiary veins much less conspicuous than lateral veins and often reticulate

82. Upper lateral veins (5-)6-9 either side, all in distal half of lamina but often scarcely distinct from coarser tertiary veins arising lower down: stipules large, boat-shaped (10-)2565 by (3-)7-20 mm. - Pacific - Hawaiian Islands; Reunion (naturalised).

20. B. grandis

82. Upper veins $3-4(-5)$ either side, all arising in distal half of lamina; stipules $\leq 10$ by $2 \mathrm{~mm}$.

83. Inflorescence-bearing axes 10-17 cm long, 1 from each axil, with short lateral branches throughout length, these secondarily branched; bracts subtending clusters inconspicuous, shorter than clusters, $1-1.5$ by $0.5-0.8 \mathrm{~mm}$; leaf apex short-attenuate, petiole c. $0.25 \times$ lamina length. — North-eastern India; Nepal; Burma; China

13. B. polystachya

83. Inflorescence-bearing axes 3-5(-10) $\mathrm{mm}$ long, paired or apparently many unbranched from each axil; bracts subtending clusters persistent, conspicuously longer than even fruiting clusters, $2-2.5$ by $1.5-2 \mathrm{~mm}$; leaf apex broadacute, sometimes with abrupt tiny acumen at extreme tip, petiole c. $0.05 \times$ lamina length. - Burma; south-western China; Thailand; Indochina . . . . . . . . 16. B. siamensis

84. Stem and inflorescence-bearing axes glabrous, drying redbrown; leaf margin usually crenate, teeth broad, often short, $0.5-2$ by $4-8 \mathrm{~mm}$, number often less than 20 either side; female clusters on long inflorescence-bearing axes, male clusters on long inflorescence-bearing axes or axillary on leafy shoots . . . . . . . . . . . . . . . . . 85

84. Stem (at least near apex) with fine or conspicuous hairs; leaf margin serrate or dentate, teeth longer and/or more numerous than above; both female and male clusters on long inflorescence-bearing axes

85. Leaves (at least most) elliptic, with both surfaces sparsely minute-hairy, basal veins at least on narrow side extending almost to tip, number of upper lateral veins 2(-3) all arising in distal half; flower-clusters female or bisexual, all on leafless inflorescence-bearing axes $10-50 \mathrm{~cm}$ long. - Southern China; Peninsular Thailand; Indonesia - Sumatera

\section{B. leptostachya}

85. Leaves ovate, adaxial surface with at most occasional single hair in centre of some areoles, basal veins extending less far, upper lateral veins spaced throughout lamina length, often 4-5 at least on wide side; male clusters absent or, if present, only axillary on main stem and never on long axes. - Southern India; Burma; China; Thailand; Indochina; Indonesia - Jawa . . . . . . 9. B. zollingeriana

86. Length of 'larger' lamina in dimorphic leaf-pair $>3.5 \times$ width

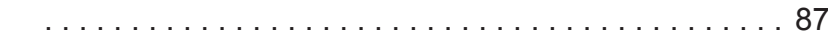

86. Length of 'larger' lamina in dimorphic leaf-pair $<3.5 \times$ width

87. Apex of leaf attenuate-acuminate formed by a single long tooth; hairs above few, scattered; marginal teeth 15-25 either side

27. B. sieboldiana

87. Apex of leaf attenuate but toothed almost to tip; hairs above abundant; marginal teeth often more than 35 either side

88. Leaves not markedly asymmetrical, veins similarly arranged on both sides or 1 more on one side . . . . . . . 89

88. Leaves markedly asymmetrical, veins dissimilar on two sides

89. Leaf fine-adpressed-hairy beneath, coarser tertiary veins reticulate; leaves $\leq 12(-16) \mathrm{cm}$ long; length (3.7-)4-7x width, marginal teeth up to 30 in number, shallow and wide, 0.3-0.7 mm long, width often $>6 \times$ length. - China south-western China, Taiwan, Hong Kong; Japan - Ryukyu Islands, Bonin Islands; Philippines - Luzon. . . .

18. B. densiflora

89. Leaf spreading-hairy beneath, coarser tertiary veins \pm scalariform; leaf often longer and relatively broader, marginal teeth often more numerous, longer and relatively narrower. - Widespread, excl. Japan . . . . . 23. B. virgata

90. Number of upper veins on wide side of leaf $3-5$, on narrow side 0-2; leaves drying grey-brown, bullate; female clusters absent (never on long inflorescence-bearing axes). - Papua New Guinea; Pacific - Solomon Islands, Vanuatu, New Caledonia . . . . . . . . . [Cypholophus decipiens]

90. Number of upper veins on wide side of leaf usually 1-2 and only 1 more than on narrow side; leaves often drying green, often smooth; female clusters (if present) also on long inflorescence-bearing axes. - Philippines; Indonesia; Papua New Guinea; Pacific excl. New Caledonia and Hawaii Islands.

23. B. virgata

91. Inflorescence-bearing axis branched throughout length and with 2nd-order branching, often bisexual. - North-eastern India; Nepal; Bhutan; Burma; China

13. B. polystachya

91. Inflorescence-bearing axis unbranched or with several long branches close to base, no 2nd-order branching, mostly unisexual

92. Lamina rhombic-ovate, with rounded base, \pm symmetrical, upper lateral veins 3-5 either side, apex consisting of a single long tooth; marginal teeth often $>4 \mathrm{~mm}$ long; leaves with only occasional scattered hairs; inflorescence-bearing axes unbranched. - Taiwan; Japan incl. Ryukyu Islands; China . . . . . . . . . . . . . . . . . . . . 27. B. sieboldiana

92. Lamina ovate or elliptic, rarely rhombic-elliptic but then with long-cuneate base; marginal teeth up to 2(-3.5) $\mathrm{mm}$ long; leaves either with inconspicuous but abundant hairs both sides or with only 1-2 veins either side and apex toothed \pm to tip, base often oblique; inflorescence-bearing axes often much-branched 
93. Leaves large and broad, ovate and subcordate, $24-35 \mathrm{~cm}$ long with length less than $2 \times$ width, thin-textured, upper veins inconspicuous, margin shallowly crenate. - Indonesian Papua; Papua New Guinea . . . . . . 23. B. virgata

93. Leaves usually smaller and often much narrower but if large and broad then either thick-textured and bullate with robust veins, or margin dentate

94. Lamina markedly asymmetrical, upper veins on wide side $3-5$, on narrow side $0-2$; leaf drying grey-brown, bullate, margin minutely close-serrate, teeth $<1 \mathrm{~mm}$ long, width \pm depth; female clusters absent or, if present, not on long inflorescence-bearing axes. - Papua New Guinea; Pacific - Solomon Islands, Vanuatu; New Caledonia

[Cypholophus decipiens]

94. Lamina not markedly asymmetrical, upper veins the same number on both sides or on one side only 1 more than on other; leaf often drying green, often smooth, marginal teeth much longer and/or relatively wider, with width 3-10x length; both male and female clusters on long inflorescence-bearing axes .

95. Male and female inflorescence-bearing axes with contiguous clusters, female erect, unbranched, < $12 \mathrm{~cm}$ long, clusters forming a dense congested mass; stem and leaves (on both sides) with abundant adpressed hairs; marginal teeth shallow but wide $\leq 0.7 \mathrm{~mm}$ long, with width $4-10 \times$ length. - China - south-western China, Taiwan, Hong Kong; Japan - Ryukyu Islands, Bonin Islands; Philippines . . .

18. B. densiflora

95. Male and female inflorescence-bearing axes with wellspaced clusters, usually pendulous, often $\geq 20 \mathrm{~cm}$, male axes often branched throughout length; stem and adaxial surface of leaves glabrescent or hairs spreading at least on leaves beneath; marginal teeth often much longer and relatively narrower than above, $\geq 1.5 \mathrm{~mm}$ long, with width 1.3-3x length. - Widespread, excl. New Caledonia and Hawaii

23. B. virgata

96. Upper lateral veins (5-)6-9 either side, robust and all arising in distal half but often hardly distinguishable from rather robust coarser tertiary veins arising lower on midrib, these and often fine reticulation prominent beneath and impressed above; leaves only sparsely adpressed-hairy above, hairs restricted to veins beneath; stipules large, boat-shaped (10-)25-65 by (3-)7-20 mm. - Pacific Hawaiian Islands; Reunion (naturalised). . 20. B. grandis

96. Upper lateral veins fewer and more easily distinguishable from slender tertiary venation (prominent or not), lowermost arising near middle of lamina; indumentum on leaves often denser and more widespread (stipules usually shorter) 97

97. Hairs on leaf underside, petiole and often also stem of 2 distinct kinds (visible with $\times 10$ lens): dense fine minute, $\leq 0.1 \mathrm{~mm}$ long, velvety, and sparse coarser and much longer, $0.5-1 \mathrm{~mm}$ long. . . . . . . . . . . . . . 98

97. Hairs on leaf underside, petiole and stem \pm uniform short or long

98. Fruiting perianth ovoid to obovoid, not markedly flattened, with or without slight marginal rim, apex not truncate nor with abrupt beak; inflorescence-bearing axes always unisexual and always 6-15 cm long, clusters well-spaced; stipules large, 10-25 mm long; leaves 13-25 cm long always glabrous above except for one hair in centre of each areole, marginal teeth 35 or more either side. - Philippines; Indonesia - Sumatera, Jawa, northern Sulawesi

98. Fruiting perianth obtriangular in outline, with truncate apex, with or without an abrupt minute beak, often laterally flattened or several-angled (inflorescence-bearing axes some- times shorter, with densely crowded clusters, stipules and leaves sometimes smaller, teeth sometimes fewer) . 99

99. Lamina length $\geq 2.3 \times$ width, marginal teeth mostly more than 45 either side, $\leq 1 \mathrm{~mm}$ long; leaves often markedly asymmetrical (outline of two sides of lamina dissimilar), with upper lateral veins often 2 more on one side than other and arising much nearer leaf base; inflorescencebearing axes $5-13 \mathrm{~cm}$, mostly with 1-2 long branches very close to base and therefore appearing as if several axes per axil, the bisexual ones with male clusters in lower part of axis or abundant along most of length; clusters well-spaced or contiguous but not congested; fruiting perianth scarcely laterally flattened. - North-eastern India; Bhutan; Bangladesh; Burma . . . . . . 33. B. listeri

99. Lamina length $1.75-2.25 \times$ width, marginal teeth mostly 20-40 either side often $2 \mathrm{~mm}$ long; outline and venation of two sides of lamina similar; inflorescence-bearing axes mostly $<6 \mathrm{~mm}$ long, the female and bisexual ones unbranched, the bisexual ones with male flowers either occasional in mainly female clusters or in small male clusters a few at apex; female clusters often a dense congested mass; fruiting perianth laterally flattened near apex. - India; Sri Lanka; Burma; southern China; Thailand; Philippines; Indonesia. .

32. B. pilosiuscula

100. Length of lamina (2.7-)3-4x width; indumentum on stems and leaves soft, on leaves sometimes sparse and inconspicuous

100. Length of lamina $\leq 2.5 \times$ width (indumentum soft or coarse)

101. Marginal teeth $2-4 \mathrm{~mm}$ long, $15-30(-35)$ either side; lamina not or scarcely bullate, basal veins reaching distal third of lamina. - Afro-Malagasy .... . 23. B. virgata

101. Marginal teeth $0.5-1 \mathrm{~mm}$ long, often more than 35 either side; lamina bullate or not, basal veins extending to middle of lamina or further

102. Inflorescence-bearing axes unbranched, male axes $\leq 11$ $\mathrm{cm}$, female axes $15-30 \mathrm{~cm}$; leaves usually bullate and thick-chartaceous, short and narrow, $<15 \mathrm{~cm}$ long, length $\geq 3 \times$ width; basal veins only reaching middle of lamina, upper veins 3-4 either side, reticulate tertiary venation prominent beneath; marginal teeth with width often only 1-2x length; petiole often short relative to lamina, $0.1-0.3 \times$ length. - Philippines; Indonesia - Sulawesi 19. B. multiflora

102. Inflorescence-bearing axes mostly longer, male axes 10$20 \mathrm{~cm}$, female axes $20-70 \mathrm{~cm}$, often branched; leaves mostly smooth thin-chartaceous and/or larger and relatively broader; basal veins extending to distal quarter of lamina or almost to tip, upper veins 1-2 (or up to 3 only on one side), slender, prominulous beneath; marginal teeth with width usually $\geq 4 \times$ length; petiole $>0.3 \times$ lamina length. - Indonesia; Philippines; Pacific, excl. New Caledonia and Hawaii.

23. B. virgata

103. Leaves \pm bullate and mostly thick-textured, glabrous above except for single hair in centre of each areole, spreadinghairy beneath; fruiting perianth $\leq 1.2 \mathrm{~mm}$ long, scarcely laterally flattened, with or without slight marginal rim, achene \pm filling perianth; stipules large and conspicuous, $10-25$ by (2-)3 $-5 \mathrm{~mm}$; male and female inflorescencebearing axes $\leq 15 \mathrm{~cm}$ long; leaf apex short and broad, attenuate-acuminate. - Philippines; Indonesia - Sumatera, Jawa, northern Sulawesi .... . 31. B. rugosissima

103. Leaves smooth thin-textured, hairs above fine and inconspicuous but fairly abundant, several per areole or if leaves \pm bullate and thick-textured then hairs above dense and spreading (hairs beneath sometimes adpressed; 
stipules mostly smaller, fruiting perianth often larger and winged, female inflorescence-bearing axes often $>30 \mathrm{~cm}$ long, leaf apex often gradually long-attenuate) . . . 104

104. Margin of leaf with 35 or more small shallow teeth either side, $0.2-1$ by $2-4.5 \mathrm{~mm}$ long, or if up to $3 \mathrm{~mm}$ long then 40-60 either side. - Widespread ... . 23. B. virgata

104. Margin of leaf with up to 27 large, broad teeth either side, $3-10$ by $6-15 \mathrm{~mm}$

105. Marginal teeth of leaves acute, up-curved, distal ones progressively more markedly so; leaf apex consisting of $1 \pm$ linear narrow tooth, (5-)15-20 by c. $2 \mathrm{~mm}$, with $1-2$ pairs of in-curved lateral teeth at its base. - North-eastern India; Nepal; Bhutan; Burma; south-western China . . .

23. B. virgata

105. Marginal teeth of leaves rounded or broad-acute, outwardpointing; leaf apex consisting of a short relatively much broader acumen. - Limestone, seashore; South Korea; Japan.

26. B. holosericea

106. Plants bisexual with sexes differently arranged, female clusters borne along long leafless inflorescence-bearing axes arising from leaf axils, male clusters in axils of stem leaves, male flowers with long (at least $5 \mathrm{~mm}$ ) pedicels usually still present after male flowers have fallen. - Burma; China; Thailand, Philippines; Indonesia - Jawa. .

9. B. zollingeriana

106. Plants without this combination of characters; if plant bisexual then male and female clusters similarly arranged either both along leafless inflorescence-bearing axes or both in axils of stem leaves; male pedicels $0-2 \mathrm{~mm}$ long (or male clusters absent).

107

107. Flower-clusters borne mainly along leafless inflorescencebearing axes (occasionally with tuft of small leaves at apex) and/or leaves markedly discolorous not or only slightly asymmetrical . . . . . . . . . . . . . 108

107. Flower-clusters sessile in axils of existing or fallen leaves; leaves never discolorous, often markedly asymmetrical and sideways-curved.

108. Leaves markedly discolorous, with either dense silvery adpressed hairs or white tomentum beneath . . . . 109

108. Leaves \pm concolorous, greenish or drying brownish beneath .

109. Lamina densely white-tomentose (or green, spreadinghairy) beneath, with tangled fine hairs but never with silvery sheen; broadly ovate or elliptic, mostly $\leq 1.5-2 x$ as long as wide; margin with 15-20 large, distinct teeth; inflorescence-bearing axes paniculate with 2nd-4thorder branching. - China; Japan; widely cultivated and naturalised. . . . . . . . . . . . . . . . . . . nivea

109. Lamina silvery-white beneath, with shiny-silky sheen due to dense adpressed long hairs in addition to short fine spreading hairs; narrowly elliptic or ovate, $2.5-3 \times$ as long as wide, margin with (20-) 30 indistinct shallow teeth; inflorescence-bearing axes unbranched. - Himalayas

[Pouzolzia spp.]

110. Inflorescence-bearing axes unbranched; male flowers absent or tepals without dorsal appendages. . . . . . 111

110. Inflorescence-bearing axes, at least upper ones, branched, often terminating leafy branches; male flowers, if present, with distinct dorsal appendage on each tepal

111. Stems and inflorescence-bearing axes glabrous drying reddish, inflorescence-bearing axes entirely female (male not present, not on long axes); stigma minute $\leq 1(-1.5)$ $\mathrm{mm}$; fruiting perianth markedly laterally flattened, with marginal rim or wing and $<1 \mathrm{~mm}$ long. - Southern India;
Burma; China; Indochina; Thailand; Philippines; Indonesia - Jawa . . . . . . . . . . . . . . . . 9. B. zollingeriana

111. Stem and inflorescence-bearing axes hairy, mostly bisexual; stigma usually $\geq 2 \mathrm{~mm}$ long; fruiting perianth not or slightly laterally flattened but with several prominent longitudinal ribs and usually $>1 \mathrm{~mm}$ long. - Widespread

[Pouzolzia sanguinea]

112. Female and male inflorescence-bearing axes 2 per axil, slender, pendulous, \pm paniculate, with up to 4 th-order branching, successive orders of branches shorter and ultimate branches usually $<1 \mathrm{~cm}$ long, with clusters often mostly along one side of axis; leaves with abundant spreading hairs beneath, clearly alternate throughout stem. - China; Indochina; Thailand; Japan . . .

1. B. nivea (concolorous form)

112. Female inflorescence-bearing axes 1 per axil and terminating leafy branches, sometimes pendulous with a few long lateral branches, sometimes robust and erect with pendent apex and 1st- or 2nd-order branching with ultimate branchlets not markedly shorter than main branches; clusters spirally arranged (male flowers not present, not on long axes); leaves with sparse adpressed hairs beneath, subopposite to opposite in lower part of stem. - China; southern India; Burma; Indochina; Thailand; Philippines; Indonesia - Jawa .9. B. zollingeriana

113. Leaves entire in basal half or third, distally with 5-15 broad conspicuous teeth, up to $1.5-2.5$ by $3-7 \mathrm{~mm}$, membranous, shiny and \pm glabrous above; slender herb to $0.5 \mathrm{~m}$, with few branches near apex; flowers with conspicuous hooked hairs, male flowers 3(?-4)-merous, female often with paired stigmas. - Burma .... 3. B. didymogyne

113. Leaves with margin either conspicuously toothed throughout or entire to indistinctly toothed, chartaceous or coriaceous (glabrous or conspicuously hairy); subshrub to tree, flowers variously hairy or glabrous, male flowers 4-merous, female with single stigma . . . . . . . . . 114

114. Male buds conical-apiculate without dorsal appendages; female and male flowers usually loosely arranged, flowerbases \pm visible, bracteoles conspicuous often equalling flowers; female perianth conical, not or only slightly laterally flattened, unwinged, detaching from mature achene; stigma usually $>2 \mathrm{~mm}$ long, persistent; leaves \pm symmetrical. - Widespread, excl. Philippines

[Pouzolzia sanguinea]

114. Male buds ovoid or globose, with distinct appendages; female (often also male) flowers tightly congested, only apical part visible, bracteoles usually inconspicuous at most half of flower length; female perianth usually laterally flattened and often winged, adnate to mature achene; stigma usually $<2 \mathrm{~mm}$ long; leaves asymmetrical or not

115. Leaves markedly dimorphic, alternately 'larger' and 'smaller' along stem, with length of 'larger' lamina (3-)5-12x that of 'smaller', conspicuously hairy above, often markedly asymmetrical

116

115. Leaves scarcely or moderately dimorphic, with length of 'larger' lamina only 1.5-2.5x that of 'smaller' (or, if $\geq 3 \times$, then leaves glabrous above), outline not or slightly asymmetrical, at most with oblique base . . . . . . . 118

116. Leaf-pairs dimorphic only in size, lamina \pm symmetrical; fruiting perianth narrowly or broadly ellipsoid to obovoid up to $0.4 \mathrm{~mm}$ broad, base often tapering and apex without distinct beak, markedly dorsiventrally flattened, with distinct marginal wing around relatively small swollen part of achene which is situated in distal part of perianth, \pm bilaterally symmetrical with central style. - Eastern Himalayas; Burma; China; Thailand; Indochina; Indonesia 
116. Leaf-pairs markedly dimorphic in both size and shape, lamina with two sides often markedly dissimilar; fruiting perianth broadly obovoid, up to $1 \mathrm{~mm}$ broad, only slightly laterally flattened, achene filling proximal part of perianth below the inflated or flattened apex and usually markedly asymmetrically swollen on one side with eccentric style on narrow side. - Philippines. . . . . 5. B. heterophylla

117. Leaf length $5 x$ width; female flowers tightly congested, more than 100 in number, stigma 2-3 mm long; fruiting perianth markedly laterally flattened, with broad thintextured marginal wing. - North-eastern India

\section{B. manipurensis}

117. Leaf length $2-4 \times$ width; female flowers loosely arranged, up to 60 in number; stigma 1-1.5 mm long; fruiting perianth only moderately laterally flattened, marginal wing thick-textured and often narrow. - Widespread, excl. Philippines and Pacific ........ 8. B. clidemioides

118. Adaxial leaf surface glabrous, smooth, leaves mostly fallen from axils bearing flower-clusters; most 'larger' laminas on plant $>12 \mathrm{~cm}$ long

118. Adaxial leaf surface hairy (leaves and axil various) 120

119. Lateral veins similar in number and arrangement on both sides of leaf; length of 'larger' leaf c. $2 \times$ width and $1.5-2.5 \times$ length of 'smaller' leaf; stipules short, broad, thick-textured, c. 4 by $1.5 \mathrm{~mm}$, length $<3 \times$ width. - Widespread

2. B. depauperata

119. Lateral veins markedly dissimilar in number and arrangement on either side of leaf; length of 'larger' leaf 3-3.5x width and c. $3 \times$ length of 'smaller' leaf; stipules longer (c. 8-2 mm) and thinner-textured. - Papua New Guinea

2'a'. B. sp. cf. depauperata

(see 2. B. depauperata, Note 5)

120. Fruiting perianth broadly ovate to obovate \pm asymmetrical, only c. $1 \mathrm{~mm}$ long, and almost as wide, often moderately laterally flattened and several-angled but never winged; achene \pm filling perianth, red-brown and slightly asymmetrical, with slightly eccentric stigma; hairs on stem and leaves beneath minute, $\leq 0.1 \mathrm{~mm}$ long; marginal teeth $\leq 1 \mathrm{~mm}$ long, their width $3-7 \times$ length

2. B. depauperata (Philippine form)

120. Fruiting perianth narrowly ovoid to ellipsoid, $1-2 \mathrm{~mm}$ long, length c. $2 \times$ width (distinctly winged or not); achene various but with centrally apical stigma; hairs on stem and leaves longer than above, often $0.5-1 \mathrm{~mm}$ long; marginal teeth longer than above and/or their width only $1.5-2 \times$ length.

121. Fruiting perianth up to $\mathrm{c} .1 \mathrm{~mm}$ long, ellipsoid, tapering into long narrow base and apex and laterally flattened to form \pm distinct thick-textured marginal wing around relatively small achene; leaves membranous or thin-chartaceous. — Widespread, excl. Philippines and Pacific

\section{B. clidemioides}

121. Fruiting perianth c. $2 \mathrm{~mm}$ long, narrowly ovoid, not markedly flattened nor winged; leaves thin-coriaceous. - Philippines - Luzon

4. B. beyeri

\section{ENUMERATION AND DESCRIPTION OF TAXA}

With the methodology utilised in this revision it seems not possible to draw formal conclusions about the closest affinities of each species. However, on the basis of gross morphology, most species fall into one of several informal groups, while a few are not closely similar to any other species. The following sequence best expresses these morphological relationships and these relationships are clarified in the discussions under the species.

\section{Boehmeria nivea (L.) Gaudich. - Fig. 1; Map 2, 3}

Boehmeria nivea (L.) Gaudich. (1830) 499. - Urtica nivea L. (1753) 985. Ramium niveum (L.) Kuntze (1891) 632. - Type: Unknown collector in Herb. Linn. 1111.19 (lecto LINN, selected by Ghafoor 1977: 18). - See Note 1

Urtica candicans Burm.f. (1768) 197. - Boehmeria candicans (Burm.f.) Hassk. (1844) 79. - Boehmeria nivea (L.) Gaudich. var. candicans (Burm.f.) Wedd. (1869) 207. - Type: Rumphius, Hortus Amboinensis 5: t. 79 (lectotype, selected here).

Urtica tenacissima Roxb. (1832) 590. - Boehmeria tenacissima (Roxb.) Blume (1857) 211, f. 56. - Boehmeria nivea (L.) Gaudich. var. tenacissima (Roxb.) Miq. (1859) 253. - Type: Roxburgh s.n. (holo BM; iso BR, G), cultivated in Calcutta Botanic Gardens. - See Note 2.

Boehmeria mollicoma Miq. in Zollinger (1854) 100, 104. - Type: Zollinger 1454 (holo BO, n.v.), Indonesia, Jawa [Java]. - See Note 3.

Boehmeria compacta Blume (1857) 210. - Type: Unknown collector (possibly Blume) s.n. (holo L), Indonesia, Jawa.

Boehmeria nivea (L.) Gaudich. var. reticulata Blume (1857) 211. - Syntypes: Blume \& Sieber s.n. (L, several collections, presumed syntypes), Japan. Boehmeria nivea (L.) Gaudich. var. concolor Makino (1909) 251. - Boehmeria frutescens (Thunb.) Thunb. var. concolor (Makino) Nakai (1927) 515. - Boehmeria nipononivea Koidz. var. concolor (Makino) Ohwi (1953) 441. - Boehmeria nivea (L.) Gaudich. forma concolor (Makino) Kitam. in Kitamura \& Murata (1962) 208. - Syntypes: T. Makino s.n. (not traced), Japan, Ryukyu Islands, Yamashiro Island, Takao; K. Ikeda s.n. (not traced), Harima Prov., Mt Masui, 1902.

Boehmeria nivea (L.) Gaudich. var. viridula Yamam. (1932) 50. - Boehmeria frutescens (Thunb.) Thunb. var. viridula (Yamam.) T.Suzuki (1936) 20. - Boehmeria nivea (L.) Gaudich. forma viridula (Yamam.) Hatus. (1971) 234. - Types: Yamamoto 542 (not traced), Taiwan, Kwarenko Pr., Beisan; Suzuki 1168 (not traced), Taiwan, between Doba and Taiheizan, 28 July 1928.

Boehmeria nipononivea Koidz. (1941) 223. - Boehmeria nivea (L.) Gaudich. subsp. nipononivea (Koidz.) Kitam. in Kitamura \& Murata (1962) 208. Boehmeria nivea (L.) Gaudich. forma nipononivea (Koidz.) Hatus. (1971) 234. - Boehmeria nivea (L.) Gaudich. var. nipononivea (Koidz.) W.T.Wang (1981a) 320. - Type: No material cited or traced.

Boehmeria thailandica Yahara (1981) 4. - Type: Tagewa et al. 11233 (holo KYO, seen as digital image), Thailand, Phiitsanulok.

Shrub or subshrub, rarely robust herb, 1-4(-7) m tall; ultimate branches robust, 3-4 $\mathrm{mm}$ diam, with abundant to dense hairs, these short fine adpressed, or variable $(0.1-\geq 0.5 \mathrm{~mm}$ long) fine or coarse spreading. Stipules linear-lanceolate, connate in proximal part or free to base, 5-12 by 1-2 $\mathrm{mm}$. Leaves alternate, not or scarcely dimorphic in size, broadly ovate to elliptic (rarely almost orbicular), very variable in size and proportions, 7-20 by $4-18 \mathrm{~cm}$, length (1-)1.52(-3)× width; margin very coarsely dentate, dentate-serrate or crenate, teeth 14-20(-25) either side, these larger on larger leaves (rather than more numerous) and therefore relatively few for size of lamina, \pm uniform in size, (2-)3-4 by $4-10 \mathrm{~mm}$, or proximal ones progressively shorter and less distinct; leaf apex usually with abruptly narrowing long acumen (rarely broadly acute); base sometimes cordate, usually truncate or broadly rounded but often abruptly narrowly cuneate at extreme base; basal veins extending into distal half or third of lamina, upper lateral veins (1-)2-3(-4) either side, well-spaced with lowermost arising from proximal quarter or near middle of lamina, inconspicuous on both sides of lamina or finely prominent abaxially; coarser tertiary venation more or less scalariform, most visible abaxially; texture membranous or fairly thin-chartaceous; adaxial surface either glabrous, with sparse coarse cystoliths giving rough feel, or also with sparse hairs, these fine, adpressed, $\pm 0.4 \mathrm{~mm}$ long; abaxial surface with or without shining white tomentum of long tangled hairs varying in density from thick and obscuring coarser reticulation to thinner and patchy with even fine reticulation visible; indumentum on veins and, where tomentum is entirely absent, also on rest of abaxial surface, consisting of sparse to abundant spreading fine hairs of varying lengths, usually longer on main veins, rarely even young leaves soon glabrescent; petiole relatively long, often half of lamina length, (3-)6-11 cm. Flower-clusters partly axillary but most arranged along specialised and very slender 


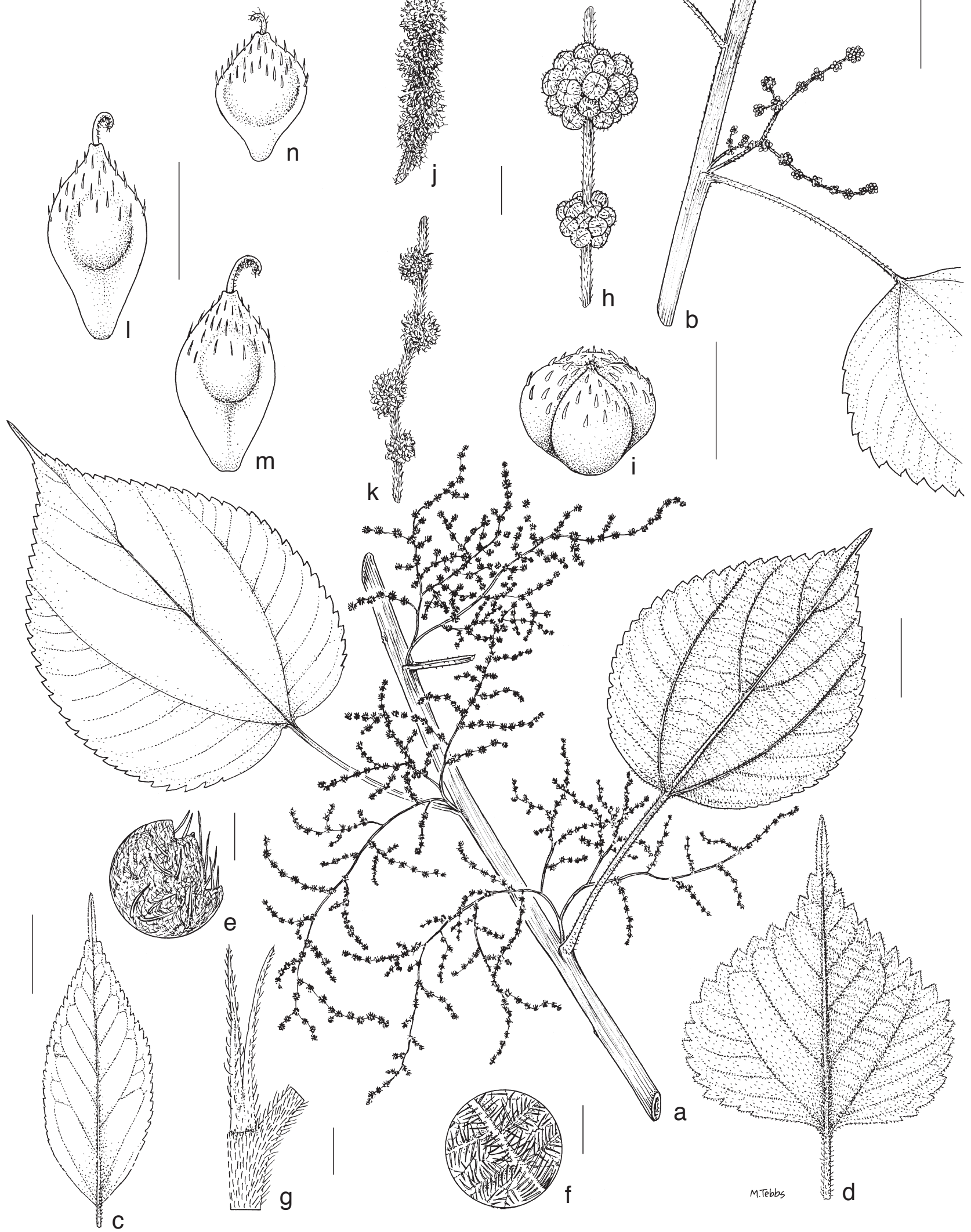

Fig. 1 Boehmeria nivea (L.) Gaudich. a. Female branch; b. male branch; c, d. leaves of varying form; e. discolorous leaf, detail of abaxial surface; f. concolorous leaf, detail of abaxial surface; g. stipule; h. detail of male inflorescence-bearing axis with two flower-clusters; i. male bud; j, k. details of female inflorescencebearing axes with (j) congested and (k) loosely arranged flower-clusters; I- $n$. fruiting perianths of different form (l and $m$ from same plant) (a, $\mathrm{f}, \mathrm{k}$ : Henry $12542, \mathrm{~K}$; b, g-i: Suddee 968, K; c, e, j, n: Balansa 2508, K; d: Teijsmann s.n., L; l, m: Hansen 12748, K). — Scale bars: a-d = 2 cm; e-h, j, k = 2 mm; i, l-n = 1 mm. 
axes 3-10 cm long, arising as a pair from each axil, mostly much-branched throughout length, often with 2 nd-4th-order branching, initial branches often partly dichotomous, successive orders of branching shorter and final branchlets very short $<1 \mathrm{~cm}$ long; flower-clusters mostly only on one side of axes; bracts minute, broadly triangular, $0.5-1$ by $0.3-0.5 \mathrm{~mm}$; plants unisexual or with female inflorescence-bearing axes towards stem apex, male towards base, some axes with both male and female clusters, male towards base; clusters small, 2-4 mm diam, flowers in male clusters recorded as tinged pink, up to 10 , in female clusters greenish yellow, 10-30 densely crowded; bracteoles inconspicuous, only up to $0.3 \mathrm{~mm}$ long. Male flowers 4-merous, sessile, large, mature buds depressed-globose, 1.5 $\mathrm{mm}$ diam, tepals without dorsal appendages, sparsely hairy (hairs spreading). Female flowers narrowly ovoid, $0.5-0.8$ by $0.3 \mathrm{~mm}$, with abundant coarse often hooked hairs; stigma often minute, $0.3-1 \mathrm{~mm}$. Fruiting perianth $1-1.5$ by c. $0.6 \mathrm{~mm}$, ovoid or ellipsoid without beak, \pm flattened, with marginal ridge and often tapering to pedicel region up to $0.3 \mathrm{~mm}$ long; surface with conspicuous long spreading hairs.

Distribution - Presumed native to China, Indochina and Japan, but natural distribution difficult to ascertain. The species has been in cultivation for over 3000 years in China (see Note 7 ) and is now widely naturalised in the Old World as well as being widely cultivated for fibre.

Habitat \& Ecology - Evergreen forests especially along streams; widely naturalised at forest margins, in ravines and thickets, along roadsides and in other disturbed areas, often on limestone; 70-1700 m altitude.

Conservation status - Least Concern (LC). It is impossible now to establish the natural distribution of this common, widely cultivated and naturalised species.

Notes -1 . The authority of $B$. nivea is normally cited as "(L.) Gaud." even though Gaudichaud cites Linnaeus's U. nivea with only a quotation mark. Despite this expression of doubt we have accepted that Gaudichaud in effect made a new combination.

2. The combination $B$. tenacissima, based on $U$. tenacissima, was apparently first made by Blume (1857) but he wrongly attributed it to Gaudichaud (1830: 500) where neither the combination nor the epithet appear. Miquel (1859: 243) repeated the error.

3. The name $B$. mollicoma is tentatively placed in synonymy here since its description conforms to this taxon: "young parts golden-hairy, leaves alternate with long petiole, acuminate, fine-serrate, coriaceous, adult leaves glaucous grey tomen- tose, rough-hairy adaxially. Female inflorescence-bearing axes axillary dichotomously branched, with interrupted glomerules, fruiting perianth ovoid white-hairy".

4. "Boehmeria utilis Blume (1853) 483" - This name is cited by both Blume (1857: 211) and Miquel (1859: 253) in synonymy (under $B$. tenacissima and $B$. nivea var. tenacissima, respectively). The reference given is "Indisch Bij. (1853): 483 n. 4", but we have not been able to trace such a reference, nor have we been able to find the name in any other of Blume's known works which might have been cited incorrectly.

5. Boehmeria nivea is easily recognisable by its combination of consistently alternate leaves which are often discolorous (indumentum tomentose, with hairs shining, white) and often broader than long and its very slender much-branched peduncles which are usually partly dichotomous, some branches usually with 3 rd or 4th-order branching giving a clearly paniculate appearance to the inflorescence architecture. Boehmeria zollingeriana has branched (female) axes and sometimes some leaf-pairs alternate leaves but is so dissimilar in stems glabrescent reddish, leaves with adaxial surface glabrescent, shiny smooth, drying dark brownish black rather than green, abaxial surface with inconspicuous adpressed hairs and male clusters axillary with long-pedicellate flowers, that the two would not be confused.

6. Boehmeria nivea is very variable in density of indumentum on abaxial leaf surface, leaf-size, shape and proportions and in length of marginal teeth although teeth are always relatively few even on large leaves; stigma is very short but variable in length (in Japan and China mostly only $0.3-0.5 \mathrm{~mm}$ long; in Indochina, Thailand, Indonesia usually $0.5-1 \mathrm{~mm}$ long). Variants have often been recognised formally at the level of species, variety or form, distinguished on characters such as size of leaves, shape of leaf base, length of acuminate apex, density or presence or absence of white tomentum on abaxial leaf surface and stipules connate or free, but a range of intergrading forms exists with all characters varying independently such that formal distinction is artificial.

Walker (1976: 413) stated that it was not possible to define limits between the varieties which had been formally described as present on Ryukyu Islands and Weddell (1856: 391), in discussing the variation, had earlier come to a similar conclusion. However, Yahara (1981: 4), while noting the widely varying density of indumentum, formally distinguished those forms which entirely lack white tomentum as $B$. thailandica. He stated that they are distinctive also in unbranched habit, very thin-textured leaves

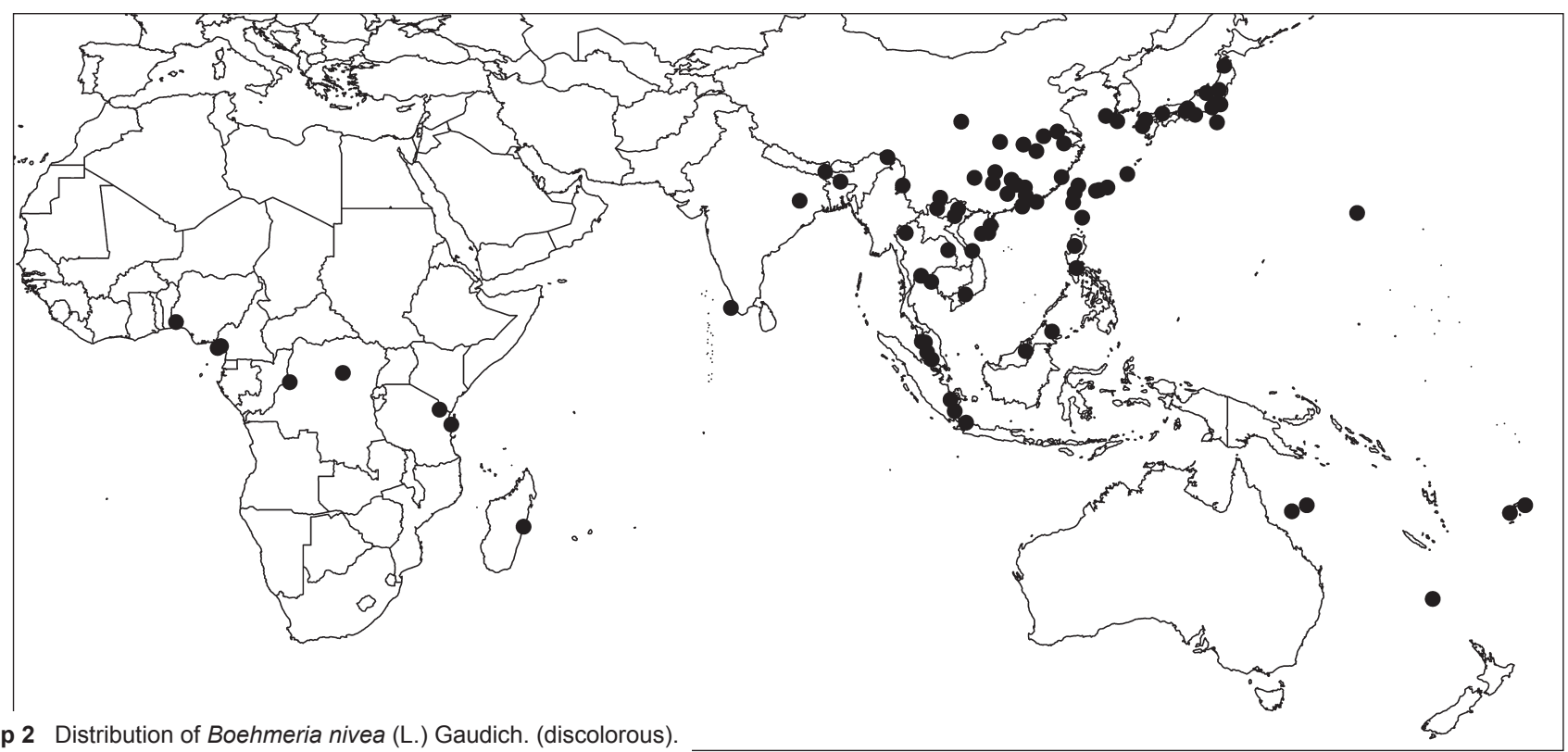




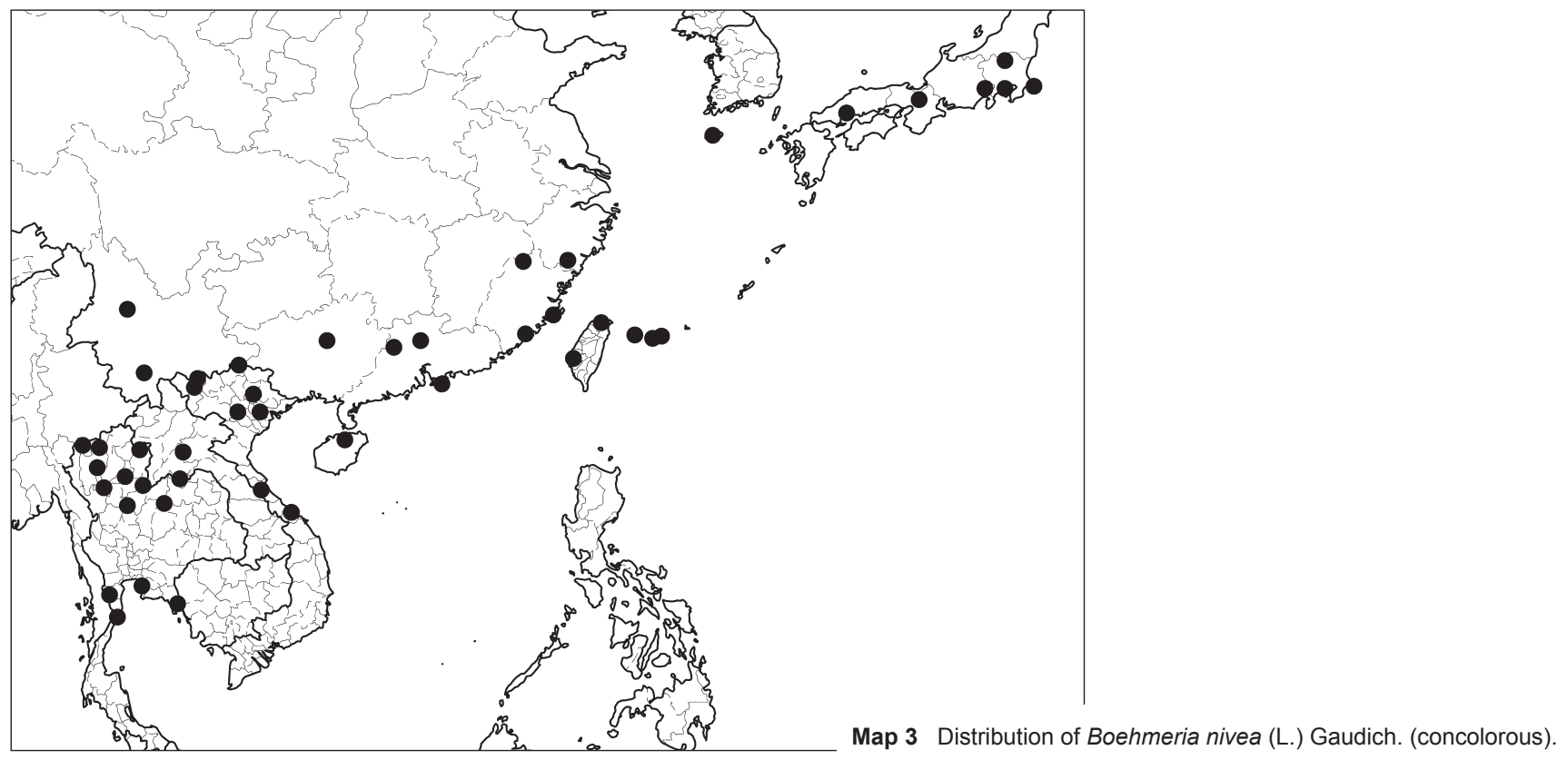

and more extensively branched inflorescence-bearing axes often longer (rather than shorter) than petiole of subtending leaf, and restricted to tropical dry evergreen forest, whereas discolorous forms occur in disturbed vegetation and dry soil. We have seen similar thin-leaved concolorous material in China, Vietnam and Japan (Ryukyu Islands), often with particularly narrow leaves (length up to $3 \times$ width), much narrower than any seen in the white form, but the distinctions mentioned by Yahara do no hold up because we have observed sparsely white-tomentose forms also having thin-textured leaves and extensively branched inflorescence-bearing axes and occurring in undisturbed habitat, and similar concolorous material sometimes occurring in disturbed or degraded forest. Therefore a formal distinction between strictly concolorous and sparsely discolorous forms cannot be maintained on grounds of either habitat or morphology.

7. Chen et al. (2003: 167) states that it is now widely cultivated in eastern Asia, especially China, where the history of cultivation can be traced back at least 3000 years. The species was introduced to Europe and the Americas in the 18th century. They suggest that $B$. nivea originated in eastern Asia and that forms with white tomentum absent or very sparse may be the original wild form. Our observation that entirely concolorous forms seem to be restricted to eastern Asia and are mostly found in relatively undisturbed vegetation together with forms with erratic patches of thin sparse tomentum, whereas forms with dense white or grey tomentum are mostly found in disturbed areas, supports this suggestion. However, since these sparsely tomentose forms have a wider distribution and wider habitat-range and also grade into the clearly discolorous entity via a continuous series of intermediate forms, it is not possible to define and recognise formally this supposed naturally-occurring variety. As discussed above, separation of merely those forms with leaves entirely lacking white tomentum from similar and apparently also naturally-occurring but sparsely tomentose forms would be artificial and misleading. We therefore here treat the variation as one polymorphic taxon at the rank of species. Nevertheless, a separate map of the completely concolorous variants has been provided (Map 3), since, even without being able to include the full range of the putative original wild form, it shows clearly the restriction of these variants to eastern Asia.

8. Concolorous forms are sometimes mistaken for two consistently opposite-leaved taxa. Boehmeria polystachya (Himalayas, China) is distinguished by tertiary leaf-veins more robust, inflorescence-axis with only 2 nd-order branching and a winged fruiting perianth. When inflorescence-bearing axes are only small and little-branched, concolorous forms can be confused with the widespread $B$. virgata subsp. macrophylla var. macrostachya which differs in inflorescence-axis only branched near base and with only 1st-order branching.

9. Discolorous forms would not be mistaken for other species of Boehmeria, but, when sterile, are frequently confused with discolorous-leaved species in other genera of the tribe, especially Oreocnide frutescens (eastern and south-eastern Asia), Debregeasia australis (Australia) and various species within Leucosyke once separated as Maoutia (Asia and the Pacific). Fertile material is easy to distinguish since all three genera have a capitate stigma and inflorescence-bearing axes strictly dichotomously branched, with all clusters at the apex of branches rather than mostly laterally branched with clusters lateral as well as terminal on branches. Additionally, Oreocnide also has a conspicuous fleshy receptacle surrounding each fruiting perianth, and the leaves of $O$. frutescens are always relatively narrow, sometimes obovate. Debregeasia australis has much more conspicuous leaf venation than $B$. nivea because the white tomentum is almost absent from veins, and the apex of its fruiting perianth opens with a 'mouth-like' slit rather than being tightly constricted as normally seen in Boehmeria. Leucosyke has a very short perianth not reaching the base of the stigma, often also thick-textured bullate leaves. However, sterile material of L. puya and related Pacific taxa can be impossible to distinguish with certainty, although their leaves have less clearly scalariform tertiary venation than $B$. nivea. Pipturus argenteus, also discolorous-leaved, is distinguished by stigmas long, straight and caducous, inflorescence-bearing axes solitary in axil and tomentum less bright white, consisting of extremely short hairs, this tomentum also present on male and female flowers.

\section{Boehmeria depauperata Wedd. - Fig. 2; Map 4}

Boehmeria depauperata Wedd. (1854) 202. - Boehmeria malabarica Wedd. (1856) 355 , nom. illeg. superfl., Weddell cites $B$. depauperata in synonymy. - Boehmeria malabarica Wedd. var. depauperata (Wedd.) Wedd. (1856) 356. - Type: Zollinger 977 (holo G; iso BM, K, U, Z), Indonesia, Jawa [Java]. - See Note 1.

Boehmeria glomerulifera Miq. in Zollinger (June 1854) 101, 104. - Type: Zollinger 977 (holo Z; iso BM, G, K, U), Indonesia, Jawa [Java], humid woods near Tjikoya. - See Note 1.

Boehmeria subperforata Wedd. (1856) 383. - Type: Gaudichaud s.n. in herb. Wallich s.n. (holo P; iso G, L), India. 
Boehmeria neglecta Blume (1857) 200. - Boehmeria comosa Wedd. var. neglecta (Blume) Wedd. (1869) 206. - Type: Blume s.n. (holo L; iso U), Indonesia, western Jawa [Java].

Boehmeria monticola Blume (1857) 227. - Type: Korthals s.n. (holo L; iso $\mathrm{U})$, Indonesia, Sumatera [Sumatra], Myrapa.

Boehmeria travancorica Bedd. (1873) 225. - Syntypes: Beddome s.n. (K), India, Travancore Mts, southern Canara Ghats (male specimen); Beddome s.n. (not traced), Brumagherry Hills, Wynaad.

Boehmeria ramiflora Bedd. (1873) t. 27, f. 2. - Name in error on figure of B. travancorica, not Boehmeria ramiflora Jacq.

Pipturus mindanaensis Elmer (1910) 898. - Type: Elmer 10520 (iso K, LE), Philippines, Mindanao, Todaya.

Boehmeria cypholophoides Merr. (1913) 368. - Type: Wenzel 35 (iso A, BM, F, G, L), Philippines, Leyte, Dagami, 20 May 1913.

Boehmeria klossii Ridl. (1920) 117. - Type: Boden-Kloss 6903 (not traced), Thailand, Tasan, near boundary between Ranong and Chumporn.

Boehmeria glomerulifera Miq. var. leioclada W.T.Wang (1981a) 318. - Boehmeria malabarica Wedd. var. leioclada (W.T.Wang) W.T.Wang in Wang \& Chen (1995) 326. - Type: Exp. compl. Yunnan 7817 (holo PE), China, Yunnan, Puwen, 17 Apr. 1957.

Boehmeria leiophylla W.T.Wang (1981a) 318. - Type: Exped. Luchun 275 (holo PE), China, Yunnan, Luchun.

Boehmeria oblongifolia W.T.Wang (1981a) 319. - Type: H.Y. Liang 66619 (holo IBK), China, Guangxi, Lungzhou, 30 Apr. 1974.

Subshrub to small tree, evergreen, erect or \pm scrambling, (0.5-) 1-8 $\mathrm{m}$ tall; ultimate stems fairly robust and often slightly zigzagged between nodes, (1-)1.5-1.8 mm diam, indumentum very variable, some hairs dense or sparse, quite long (up to $0.2 \mathrm{~mm}$ ), curved, half-adpressed or spreading, minute fine hairs (less than $0.1 \mathrm{~mm}$ long), spreading often also present, but stem often soon glabrescent. Stipules variably short and thick-textured to long, with broad hyaline margin, $4-7$ by $1.5-2$ $\mathrm{mm}$, hairy outside. Leaves opposite, subopposite or alternate, slightly dimorphic with 'larger' leaves 1.5-2.5(-3)× length of 'smaller', usually \pm symmetrical (or sometimes outline of two sides slightly dissimilar), elliptic or elliptic-ovate, or sometimes obovate, with wide size range but usually fairly large, (7-)12-20 by $(2.5-) 7-10 \mathrm{~cm}$, length $2-2.5(-3) \times$ width; 'smaller' leaves of similar shape; margin shallowly and broadly crenate-serrate, teeth (15-)30-40 either side, short, broad, up to $1(-1.5)$ by $4.5 \mathrm{~mm}$, width (3-)4-5x length (but sometimes progressively less distinct or absent towards base or margin only indistinctly irregularly undulate throughout length); leaf apex gradually attenuate-acuminate or with abrupt acumen, this long, \pm untoothed, base broadly rounded to slightly cuneate; basal veins extending to middle of lamina or on one side slightly further, upper veins $2-3(-4)$ either side, similarly arranged or on one side one more (arising lower down) than on other side, lowermost arising near middle of lamina, inconspicuous adaxially, finely prominent abaxially; tertiary venation very finely prominent abaxially; texture thin- or thick-chartaceous and leaves some- times slightly bullate; adaxial surface grey-green or glossy dark green in living state, glabrous (rarely occasional scattered hairs or (Philippines, Thailand) hairs more numerous, bulbous-based) and with abundant but minute cystoliths and with hydathodes often conspicuous; abaxial surface paler and with red-tinged veins in living state, with hairs sparse, extremely short, fine, spreading, restricted to veins or abundant on whole surface; petiole variable but often rather long, (0.1-)0.25-0.5x lamina length, up to $10 \mathrm{~cm}$ long. Flower-clusters partly in leaf axils on upper part of stems but also along partly-leafless lower, often woody part of stems and subtended only by a single bract, each branch usually entirely unisexual, less often both male and female flowers occurring in same cluster; male clusters (3-)4-6(-10) mm diam, with 20-50 crowded flowers, mature buds usually so densely congested as to appear a solid mass; female clusters $2-5(-8) \mathrm{mm}$ diam, with (1-)10-30(-50) flowers; bracteoles often conspicuous and almost as long as flowers, broadly ovate, $(0.5-) 1 \mathrm{~mm}$ long. Male flowers 4-merous, subsessile or on pedicels $0.5(-1) \mathrm{mm}$ long, mature buds \pm globular or sometimes ovoid, $1-1.5 \mathrm{~mm}$ diam, tepals with long flap-like dorsal appendages, densely adpressed-hairy. Female flowers $\mathrm{c} .1$ by $0.3 \mathrm{~mm}, \pm$ obovoid with short beak; stigma very variable in length, (1-)1.3-3(-4) $\mathrm{mm}$ long. Fruiting perianth $0.8-1.2$ by $0.6-1.2 \mathrm{~mm}$, often as wide as long, broadly ovoid or obovoid, often \pm asymmetrical, several-angled and/or moderately laterally flattened, always abruptly narrowed at apex, often only with minute apical teeth and without distinct beak, but sometimes with abrupt asymmetrical or symmetrical beak up to $0.5 \mathrm{~mm}$ long, sparsely hairy or glabrous. Achene $0.8 \mathrm{~mm}$ long and wide, \pm filling fruiting perianth, red-brown, slightly asymmetrical with slightly eccentric style.

Distribution - Widespread from the Indian subcontinent (Pakistan, India, Bangladesh), Bhutan and Sri Lanka, eastwards to Burma, south-western China and in Indochina (Thailand, Vietnam), Malaysia, Indonesia (Sumatera, Jawa, Borneo, Papua), Philippines and Papua New Guinea.

Habitat \& Ecology - Shade in the understory of moist evergreen or mixed primary or secondary forest or forest edges, often riverine, often calcareous rock, on banks of rivers and streams; scrubland limestone at cliff base; $100-1700 \mathrm{~m}$ altitude.

Conservation status - Least Concern (LC). The species is known from several hundred collections, and occurs in innumerable locations and in a wide range of habitats, with an EOO of $1656800 \mathrm{~km}^{2}$.

Notes - 1. Boehmeria depauperata was independently described in the same year as $B$. glomerulifera and based on a different duplicate of the same collection. The exact month of publication (and therefore priority) cannot be ascertained for

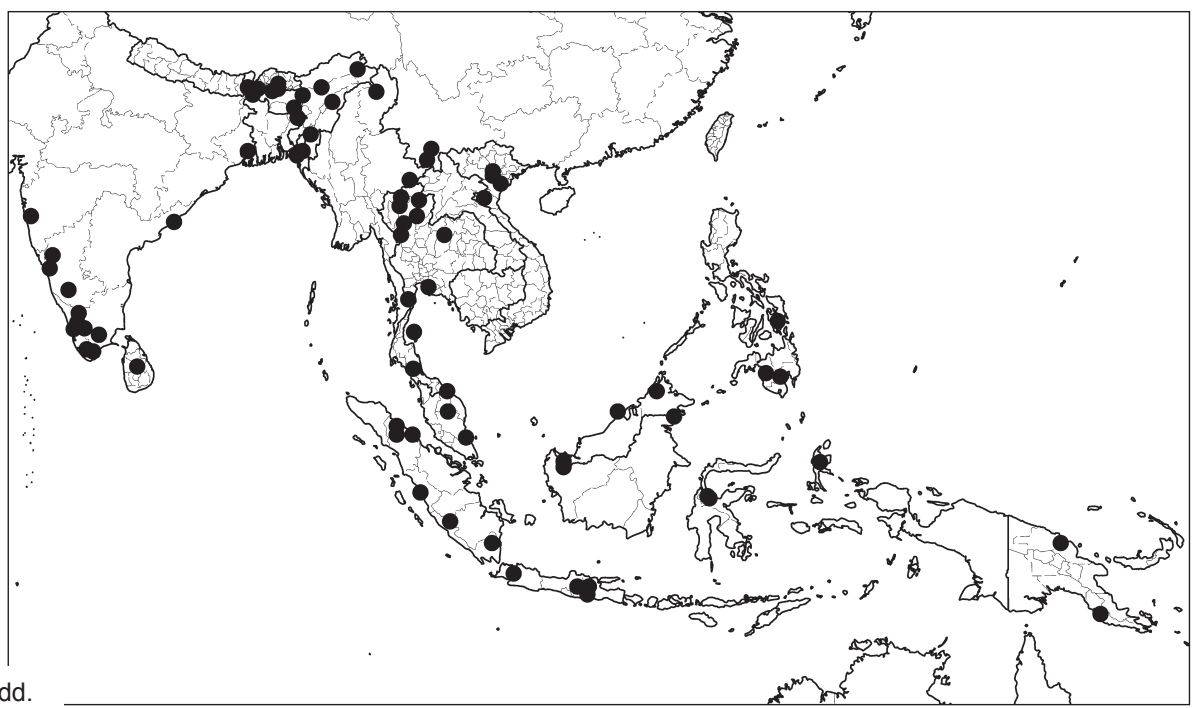




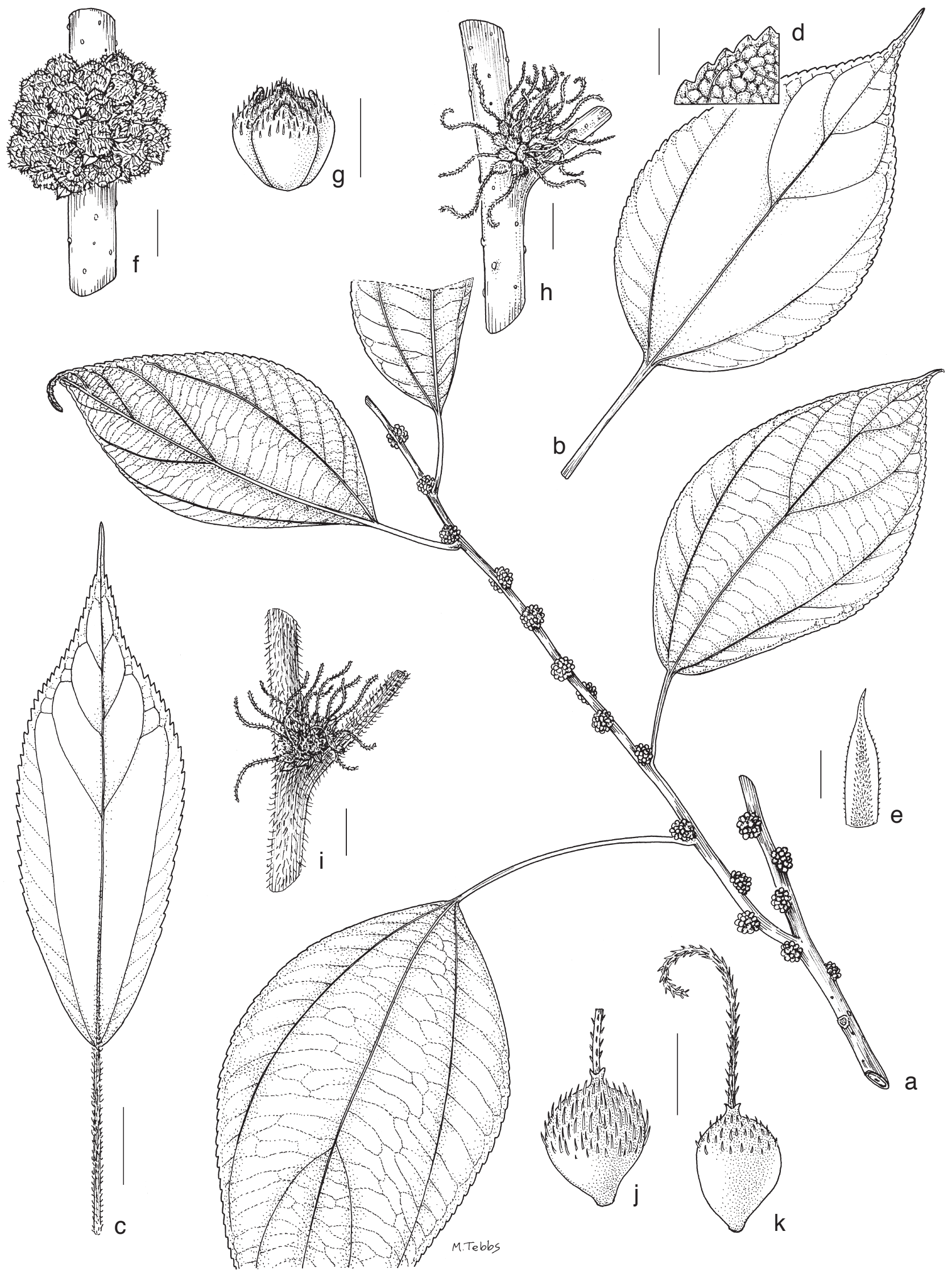

Fig. 2 Boehmeria depauperata Wedd. a. Branch with axillary male flower-clusters (inflorescences); b, c. leaves; d. leaf, detail of adaxial surface and margin; e. stipule; f. part of stem with male flower-clusters (inflorescences); g. male bud; $h$, i. detail of glabrous (h) and densely hairy (i) stem and female flower-clusters (inflorescences); j, k. fruiting perianths of different form (from different plants) (a, f, g: Haines 1066, K; b-d: Tadong 250, BO; c, i, j: Eyma 2535, K; e, k: Balansa 2514, K; h: Hooker \& Thompson s.n., K). - Scale bars: a-c $=2 \mathrm{~cm}$; d-f, h, i = 2 mm; g, j, k = 1 mm. 
either name, but $B$. depauperata is maintained here to maintain consistency with our decision on exactly the same situation within $B$. zollingeriana (see Note 1 under that species).

2. This species does not closely resemble any of the other species with variably alternate to opposite leaves, axillary flowerclusters and eccentric style. It is distinctive within the genus in its thick, soon-woody stems often zigzag between nodes and with leaves often fallen from most flowering axils except near stem apex, its leaves often elliptic or slightly obovate rather than ovate, drying very greyish green mostly glabrescent, its large male clusters closely-adpressed to stem with densely congested flowers and its fruiting perianth broad, many-angled, very smooth glabrescent with achene dark red-brown.

3. Boehmeria depauperata shows a wide variation in size, shape and indumentum of leaves, with some regional variation. Subshrubs less than $1.5 \mathrm{~m}$ tall (rather than shrubs or trees) with leaves oblong or oblong-ovate, greyish hairy abaxially, marginal teeth relatively large and a distinct fruiting perianthbeak were stated (Yahara 1981) to occur only in Malaysia, Indonesia (Jawa) and Thailand and in low altitude secondary rather than primary forest or at forest margins. Yahara regarded these (which he considered to be $B$. glomerulifera (= B. depauperata s.str.) as distinct from the remaining variation, shrubs or trees 2-4 m tall with leaves ovate or elliptic often sparsely long-hairy abaxially with less distinct teeth, fruiting perianth without beak, occurring in dense primary forest (which he recognised as B. malabarica), an entity more widespread both in Thailand and Indonesia and extending to Himalaya. However, collections seen especially from Thailand and Himalayas did not show such clear correlation between greyish indumentum, tooth size and habitat, and many Himalayan (primary forest) collections had leaves without greyish indumentum abaxially but large marginal teeth as in secondary forest material. The collections were therefore not separable into two distinct groups without intermediate material. Some of this variation may also be habitat-induced.

Collections with leaves conspicuously hairy adaxially have only been seen from Thailand and Philippines, but Yahara (1981) does not mention this aspect of the variation.

4. Boehmeria depauperata was hitherto not recorded from the Philippines and material was described under two other names, firstly as Pipturus mindanaensis with leaves hairy adaxially, and secondly as $B$. cypholophoides, a depauperate specimen with very small leaves but otherwise conforming to this taxon. The latter epithet highlights the similarity of this taxon to the genus Cypholophus in its clusters closely-adpressed to the stem with densely congested flowers, and style eccentric and often short. Cypholophus is distinguished on its consistently opposite leaves, tightly recurved style and fleshy fruiting perianth.

5. Boehmeria depauperata was not hitherto recorded from Indonesian Papua or Papua New Guinea and only two collections of certain identity have so far been seen (Indonesia, Papua, Ramu Flusse, Jan. 1902, Schlechter 13868 (G); Papua New Guinea, Central Dist., Sogeri plateau, 1 Oct. 1962, Schodde 3137 (G). Another collection of uncertain identity has also been seen (Papua New Guinea, Bourawarri, Sayers in herb von Mueller s.n. (L)). It appears to be either a regional variant of $B$. depauperata or a distinct but morphologically similar species, differing in leaf proportions, venation and appearance of male flower-clusters but the material is inadequate for a formal description, lacking female flowers and with most of the 'larger' leaves being incomplete. It differs from B. depauperata as follows: Stem hairs only c. $0.1 \mathrm{~mm}$ long, leaves markedly dimorphic, length of 'larger' leaves $3-3.5 \times$ width and $3 \times$ that of 'smaller' leaves; veins on two sides of leaf very dissimilar, on one side all arising near apex, on the other with an additional 2 arising lower down; petiole relatively short, c. $0.1-0.2 \times$ lamina length. Male clusters only c. $4 \mathrm{~mm}$ diam, not densely congested. Female flowers not seen.

\section{Boehmeria didymogyne Wedd. - Fig. 3; Map 5}

Boehmeria didymogyne Wedd. (1869) 204. - Type: Parish s.n. (holo K; iso NY), Burma, Moulmein, 1862.

Slender herb, up to $0.5 \mathrm{~m}$ tall; main stem leafless in lower part with few branches near apex, ultimate branches c. $0.8 \mathrm{~mm}$ diam, glabrous or with indumentum of scattered fine soft long hairs, soon becoming thick (possibly fleshy) and glabrous. Stipules narrowly triangular, thin-chartaceous, $4-5$ by $1.2 \mathrm{~mm}$, glabrous or with hairs abaxially like the stem. Leaves alternate, markedly dimorphic in size and somewhat in shape, with length of 'larger' leaves c. $3 x$ that of 'smaller'; 'larger' leaves ovate but often slightly asymmetrical (outline of one half ovate, of other half elliptic), medium-sized, $7-10$ by $4-5 \mathrm{~cm}$, length c. $2 \times$ width; margin entire in proximal third or half, crenate-dentate distally with (5-)10-15 teeth either side, these broad, conspicuous, $1.5-2.5$ by $3-7 \mathrm{~mm}$; leaf apex abruptly acuminate with single long tooth; base asymmetrically cuneate; basal veins running into margin beyond middle of lamina (on one side slightly further than other), upper lateral veins 1-2, arising near apex but hardly distinguishable from coarser reticulation, visible adaxially, fine-prominulous abaxially; texture membranous; surface smooth and glabrous adaxially or with occasional

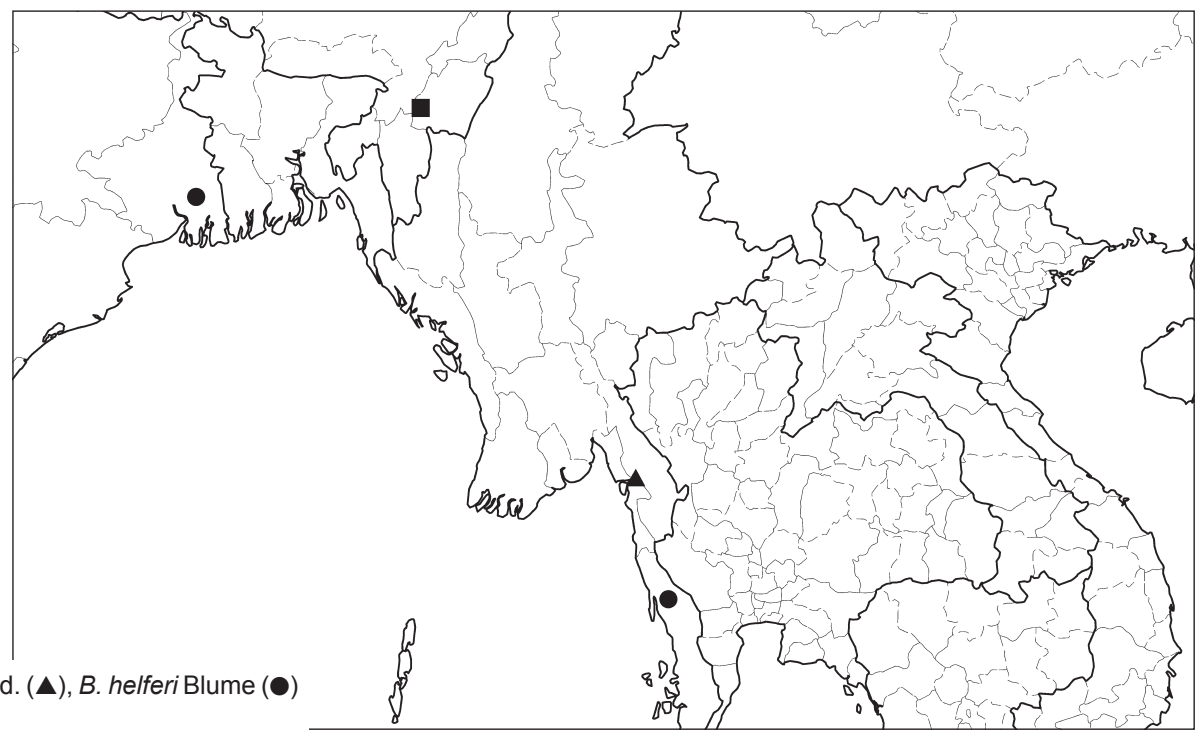




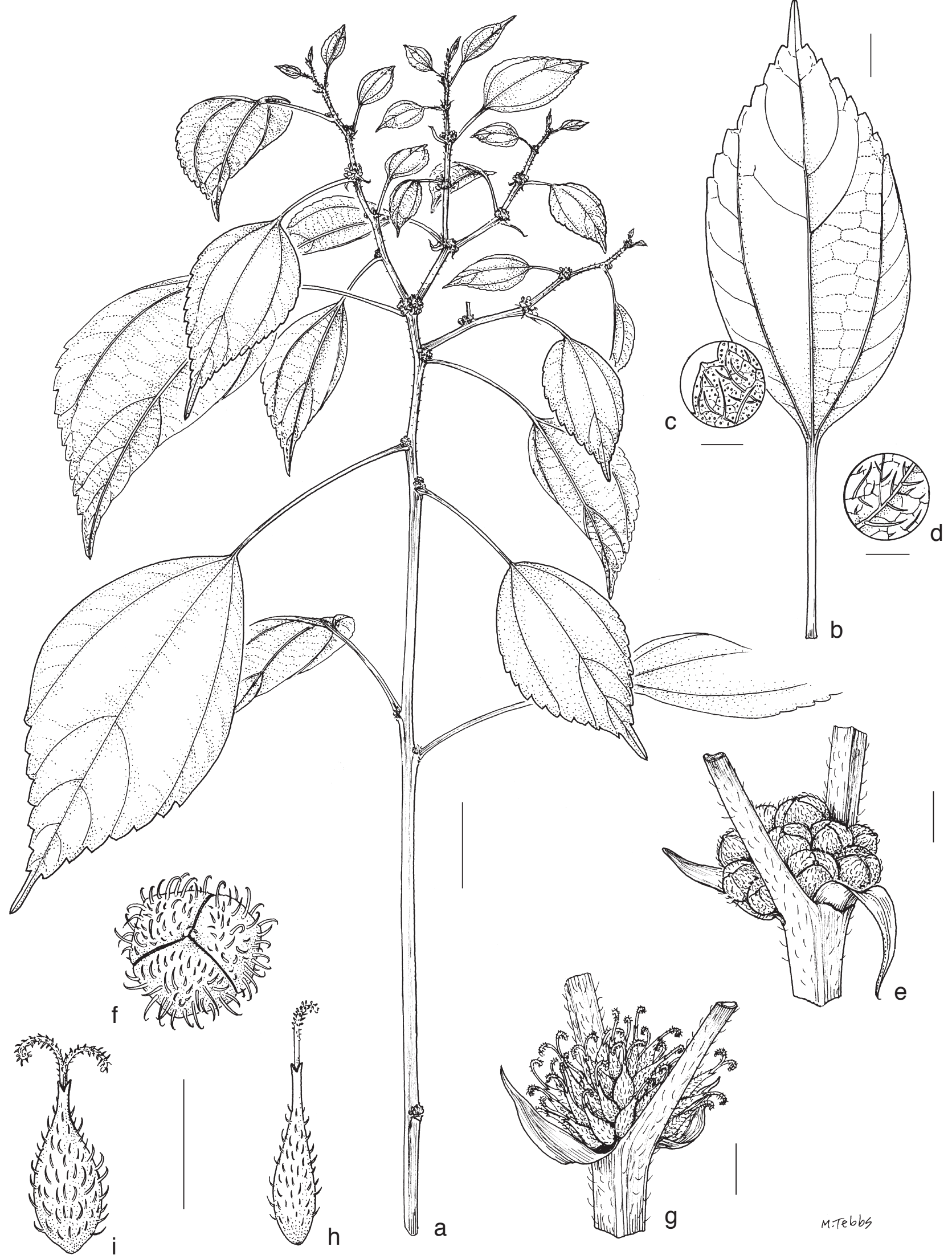

Fig. 3 Boehmeria didymogyne Wedd. a. Habit; b. large leaf; c. leaf, detail of adaxial surface and margin; d. detail of abaxial surface; e. axillary male flowercluster (inflorescence); f. male flower; g. axillary female inflorescence; h. female perianth and single stigma; i. female perianth and paired stigmas (all: Parish 400; K). - Scale bars: $a=2 \mathrm{~cm} ; b=1 \mathrm{~cm} ; \mathrm{c}, \mathrm{d}=5 \mathrm{~mm} ; \mathrm{e}-\mathrm{i}=1 \mathrm{~mm}$. 
long fine hairs, similar hairs present and less sparse abaxially, mostly restricted to veins; petiole very variable short or up to half of lamina length, $1.5-5 \mathrm{~cm}$, glabrous or sparsely hairy like the leaf; 'smaller' leaves relatively broader, often acute at apex, often toothed nearer to base and usually with very short petiole. Flower-clusters axillary, lower ones male or bisexual, 2-4 mm diam, with c. 15-30 crowded flowers, upper ones female, of similar size or smaller with fewer flowers; bracteoles inconspicuous, up to $0.3 \mathrm{~mm}$ long, linear, oblong to obovate. Male flowers 3- (or 4-, according to Weddell)merous, subsessile, mature buds depressed-globose, c. $1 \mathrm{~mm}$ diam, tepals with prominent dorsal appendages and abundant conspicuous hooked hairs. Female perianth rather long, narrowly ovoid to ellipsoid, $1-1.2$ by c. $0.6 \mathrm{~mm}$, narrowing gradually or abruptly into markedly long beak up to $0.4 \mathrm{~mm}$ and up to $\mathrm{c}$. half of flower length, apparently much-flattened (possibly feature of drying and/or pressing) with hairs abundant, fine, long, spreading; stigmas 1-2 (or stigma possibly bilobed), only $0.4-0.6 \mathrm{~mm}$ long. Mature achenes not seen.

Distribution - Burma.

Habitat \& Ecology - Unknown, as there is no information on the specimens and the exact locality is not known with sufficient precision to obtain modern information. Since the known collections are from near-coastal localities and the habit is slender with membranous leaves, it is presumed that the species occurs in coastal rainforest or other shaded habitats.

Conservation status - Data Deficient (DD). Known from only one locality (Moulmein) and two old collections (the type and 18 Oct. 1875, Kuntze 6274 (NY)). However, the area has undergone considerable conversion from natural habitats to farmland and the species is probably at risk.

Note - This species appears to be unique in the Old World species of Boehmeria in its tendency to paired stigmas (suggesting paired fused fruiting perianths as seen otherwise only in the Central American endemic B. burgeriana (Wilmot-Dear et al. 2003) and apparently 3-merous male flowers. It is also distinctive in its axillary flower-clusters, slender habit and leaves which are alternate, membranous, glabrous or sparsely hairy adaxially, with conspicuous teeth only in distal part. It does not closely resemble any other species of Boehmeria.

\section{Boehmeria beyeri C.B.Rob. - Fig. 4a-d; Map 6}

Boehmeria beyeri C.B.Rob. (1911) 309. - Type: Beyer BS 13540 (iso K, NY), Philippines, Luzon, Ifugao, Bila.

Shrub (habit and height not clear from the scarce material); ultimate stems 1.5-2 mm diam, with sparse or abundant short adpressed and distinctly longer $(0.5-1 \mathrm{~mm})$ spreading hairs. Stipules narrowly ovate, $7-8$ by $1.5-2 \mathrm{~mm}$, \pm membranous, pubescent outside. Leaves alternate, markedly dimorphic only in petiole, 'larger' leaves with lamina length only up to $2.5 \times$ that of 'smaller' but with petiole up to $10 \times$ as long, 'larger' leaves not markedly asymmetrical, narrowly ovate to narrowly elliptic, medium, c. 9 by $3 \mathrm{~cm}$; margin serrate with 30-40 large teeth either side, up-curved (their upper margin slightly or markedly concave), $1 \mathrm{~mm}$ long, 1.5-2 $\mathrm{mm}$ broad with width 1.5-2x length; leaf apex short-acuminate only slightly sideways-curved; base asymmetrically cuneate to rounded; basal veins extending into distal third or half of lamina, upper lateral veins $2-3(-4)$ but hardly distinct from coarser tertiary veins, all arising in distal half or distal third of lamina, finely impressed adaxially, finely prominent abaxially; finer reticulation inconspicuous; texture thinly coriaceous and leaves distinctly shallow-bullate, both surfaces with abundant hairs, these long and spreading like on the stem; petiole very short relative to lamina, up to $1.2 \mathrm{~cm}$ long, c. $0.1 \times$ length of lamina; 'smaller' leaves relatively broader, subsessile. Flower-clusters axillary, male clusters large, 6-7 $\mathrm{mm}$ diam, with over 30 flowers, these fairly loosely arranged, female clusters small, 2-3 mm diam, with less than 10 flowers; bracteoles very conspicuous often almost enveloping flower buds, 1-1.5 mm long, with long hairs like on the stem. Male flowers 4-merous, subsessile, mature buds globose, 1-1.5 mm diam, lobes with slight dorsal thickening and fine adpressed pubescence. Female flowers 1-1.5 mm long; stigma c. $1.5 \mathrm{~mm}$ long. Fruiting perianth relatively large, 2 by $0.8 \mathrm{~mm}$, narrowly ellipsoid tapering gradually into beak and with abundant long hairs. Achene appears to be symmetrical, but more material is needed to ascertain this.

Distribution - Philippines (restricted to Luzon).

Habitat \& Ecology - Roadside banks; no natural habitats indicated, probably forest edges or scrub. Altitudinal range not known.

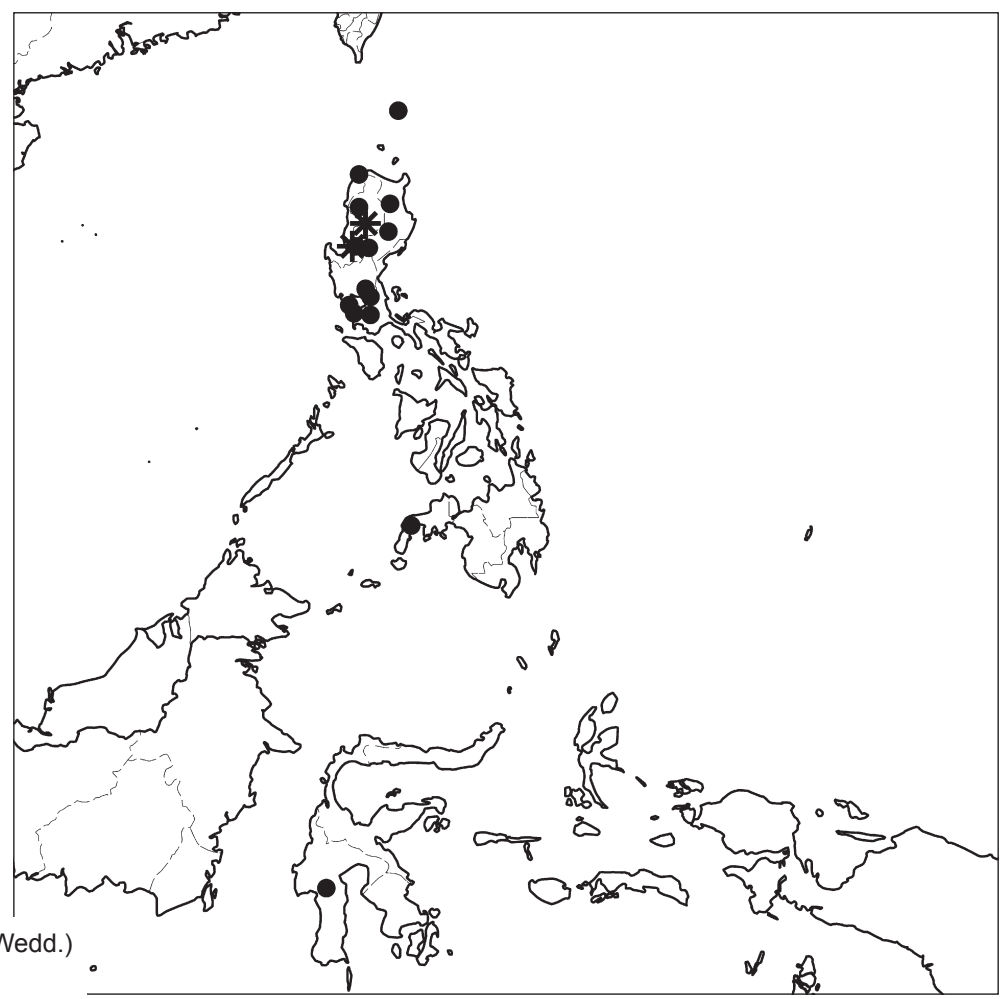




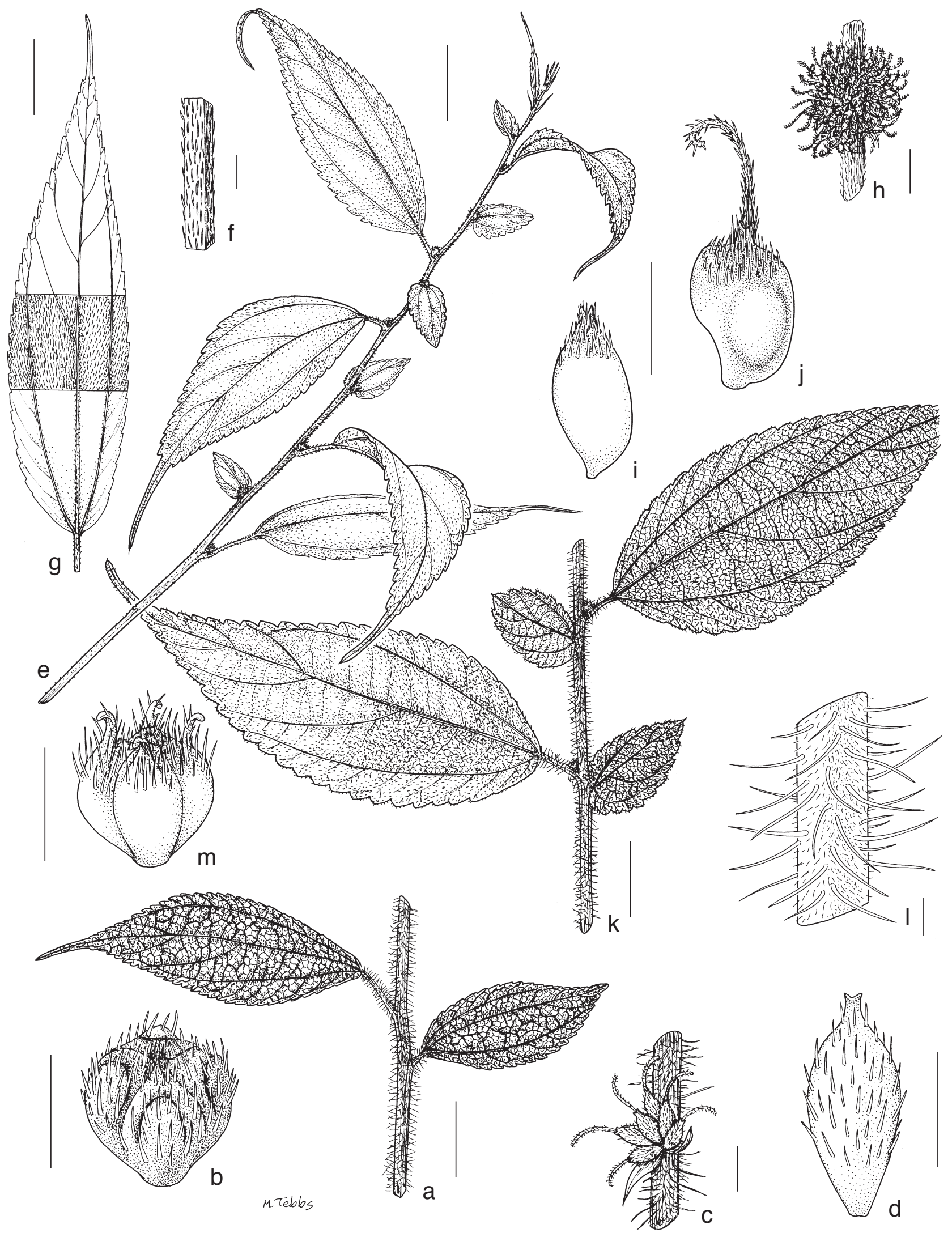

Fig. 4 a-d: Boehmeria beyeri C.B.Rob. a. Part of stem showing leaves dimorphic in petiole length; b male flower; c. axillary female flower-cluster (inflorescence); d. female perianth. - e-j: Boehmeria heterophylla Wedd. var. heterophylla. e. Stem with alternate dimorphic leaves and axillary flower-clusters (inflorescences); f. detail of stem with fine adpressed indumentum; g. leaf with adpressed indumentum on adaxial surface; h. axillary female flower-cluster (inflorescence); i, j. fruiting perianths of different form (from same plant). - k-m: Boehmeria heterophylla var. blumei (Wedd.) Friis \& Wilmot-Dear. k. Stem with subopposite dimorphic leaves; I. detail of stem with coarse and fine spreading indumentum; $\mathrm{m}$. male flower in bud (a-d: Beyer 13540; e: Cuming 1561; f, h: Borbon 8866; g: Elmer 15627; i, j: Edano 19876; k, l: Cuming 731; m: PPI 11815; all K). - Scale bars: a, e, g, k = 2 cm; c, h = 2 mm; b, d, f, i, j, l, m = 1 mm. 
Conservation status - Critically Endangered (CR). Only known from 4 collections from two localities in northwest Luzon (Benguet, Bangue). Since the natural vegetation throughout Luzon is seriously degraded, and indeed the entire Philippine Islands have lost more than $2 / 3$ of their old-growth rainforest since the early $1900 \mathrm{~s}$, much of this in the last 20 years, and since the AOO is calculated as only $8 \mathrm{~km}^{2}$ we propose the IUCN category CR B2ab (severely fragmented species in a region suffering severe and continuing habitat decline).

Note - This species is very similar to $B$. heterophylla var. blumei in bullate leaves and indumentum, and might have been considered merely a variant of $B$. heterophylla with unusually symmetrical leaves but for the female clusters which are only few-flowered and the markedly different ellipsoid fruiting perianth which tapers gradually into a beak rather than being either apically inflated or flattened with an abrupt beak. Although only 4 collections have been seen, we consider that these three correlated characters make it worthy of recognition at specific level. From the appearance of the fruiting perianth the achene is probably also symmetrical with a central rather than eccentric style, which would be a significant difference.

\section{Boehmeria heterophylla Wedd. - Fig. 4e-I; Map 6, 7}

Boehmeria heterophylla Wedd. (1856) 351, non Boehmeria heterophylla (Wedd.) Blume (1857), nom. illeg. (see Note 1 under var. blumei). - Type: Cuming 1561 (iso BM, G, K, M, P), Philippines, Luzon, Manila.

Small subshrub or shrub, 0.5-2(-4) m tall, rather juicy; ultimate branches slender, up to $1 \mathrm{~mm}$ diam, with abundant hairs, these either \pm adpressed, fine, uniform, straight and up to $0.2 \mathrm{~mm}$ long or a mixture of two kinds, usually spreading, some very short (0.2 $\mathrm{mm}$ long), others much longer (0.4 mm long), stems sometimes later glabrescent. Stipules lanceolate, longacuminate, membranous, ((in specimens from Mindanao only) 3-)6-9 by (1-)1.5-2 mm. Leaves alternate or subopposite, dimorphic in size and relative width, often also in shape with the 'larger' ones (at least those on main stems) $3-10 \times$ as large as the 'smaller'; larger leaves (slightly or) usually markedly asymmetrical (outline of one side ovate, of other elliptic) and sometimes slightly sideways-curved at apex, narrowly ovate or linear-lanceolate (rarely \pm obovate), medium or large, (6-) $8-16$ by $1.4-4 \mathrm{~cm}$, length $2.5-5(-6) \times$ width; margin with (15-)25-40 teeth either side, these broad, relatively shallow, acute or rounded, 1-3(-4) $\mathrm{mm}$ long, 2-5(-7) mm broad; leaf apex short-acuminate or attenuate-long acuminate; base asym- metrically rounded or slightly cuneate; basal veins extending to middle of lamina or less (narrow side) or distal third (wide side) of lamina, number of upper lateral veins 3-4 on wide side, 1-2 on narrow side, all arising in distal $1 / 2$ or $2 / 3$ of lamina, finely impressed adaxially, thinly prominent abaxially; tertiary venation finely prominent abaxially; texture very thin-chartaceous or slightly thicker and leaves somewhat bullate, adaxial surface with hairs abundant, adpressed or spreading (longer than on stem); abaxial surface with hairs sparse or abundant, longer, more or less spreading; petiole short but variable relative to size of lamina, 0.1-0.3x lamina length, pubescent like stem, sometimes also with longer spreading hairs; 'smaller' leaves relatively broader, rounded to broadly acute (rarely narrowly acute) and often subsessile with cordate base. Flower-clusters axillary, male clusters 2-4 $\mathrm{mm}$ diam, with flowers few or up to $15(-20)$, not very densely congested, female clusters up to $5(-8) \mathrm{mm}$ diam, with flowers $50-70(-$ more than 100$)$ in number, densely crowded; some clusters with both sexes; bracteoles in male clusters conspicuous, up to $0.8(-2)$ by $1 \mathrm{~mm}$, ovate or obovate, rounded or acute at apex, pubescent like stem, bracteoles in female clusters mostly inconspicuous linear-elliptic, $<0.5 \mathrm{~mm}$ long. Male flowers 4-merous, subsessile or on pedicel up to $0.5 \mathrm{~mm}$ long, mature buds globose up to $1.3 \mathrm{~mm}$ diam, tepals with prominent dorsal appendage, pubescent like the leaves. Female flowers mostly subsessile but in larger clusters sometimes grouped into highly reduced cymes with peduncle and pedicels lengthening in fruit, overall length of peduncle becoming up to $2 \mathrm{~mm}$ long; perianth narrowly ovoid, 1 by $0.3-0.4 \mathrm{~mm}$, often flattened towards apex; stigma $1-3 \mathrm{~mm}$ long, extremely slender. Fruiting perianth $1-1.8$ by $0.6-1 \mathrm{~mm}$, broad or narrow, very variable in shape often even in one cluster, \pm oblong in outline or ovoid, (slightly or) markedly asymmetrical, achene occupying only basal half, base \pm narrowly rounded, distal part either inflated to markedly dorsiventrally flattened giving winged or shouldered appearance, \pm without beak (2-toothed) or else narrowed into abrupt long beak up to $0.3 \times$ total length. Achene $0.7-1$ by c. $0.4-1 \mathrm{~mm}$, obovoid slightly laterally flattened but usually markedly asymmetrical, swollen on one side in apical part and with style slightly asymmetrically inserted, yellowish, with sometimes tuberculate surface.

Distribution - Indonesia (restricted to Sulawesi), Philippines (Luzon, Mindanao, Mindoro, Panay), Papua New Guinea (West Sepik, Milne Bay).

Habitat \& Ecology - Secondary forest, evergreen forest margins; 200-1100 m altitude.

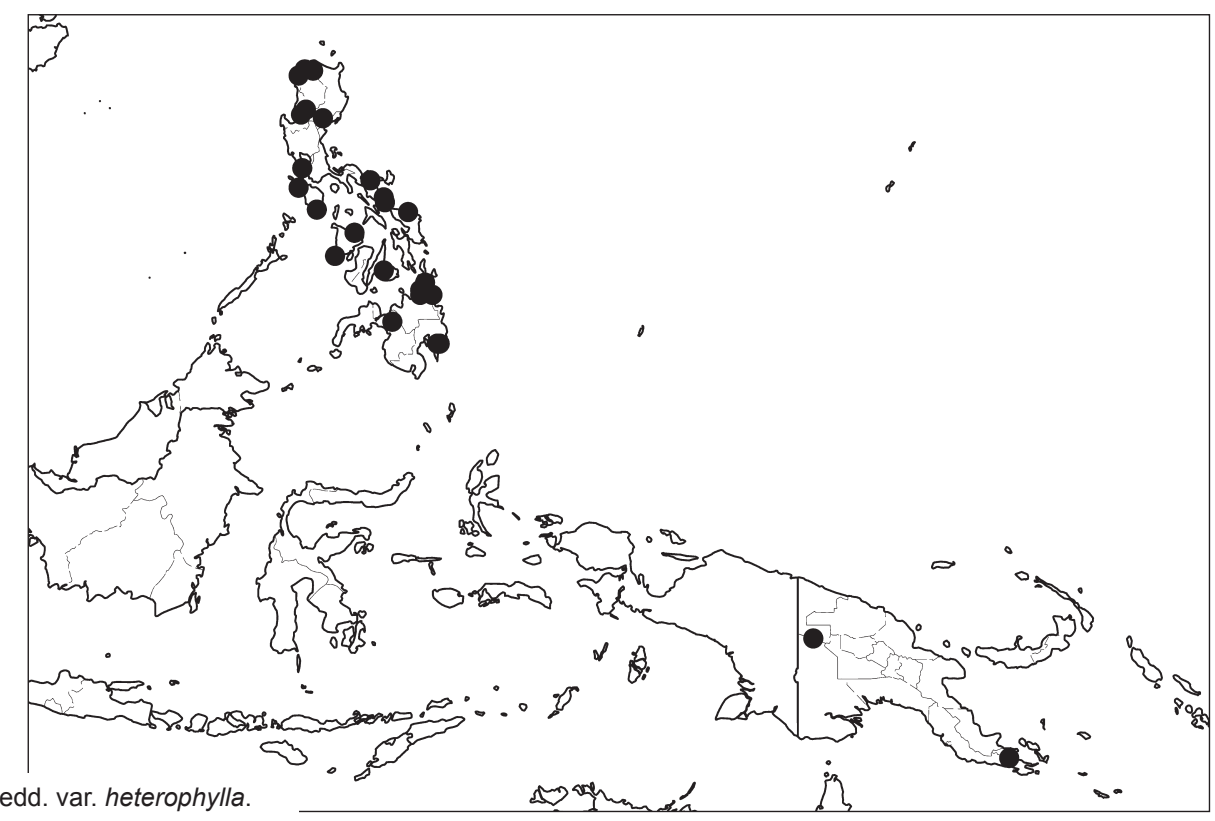


Conservation status - Near Threatened (NT). The species is known from c. a hundred collections, but most of them are more than 50 years old and as discussed under $B$. beyeri, the Philippines have been subject to severe and continuing degradation of their natural habitats. The three widely scattered records from outside the Philippines make the figure for EOO (355 $398 \mathrm{~km}^{2}$ ) rather misleading. The AOO is calculated as less than $500 \mathrm{~km}^{2}$. Although it appears to occur in too many localities to qualify formally for Endangered status it is probably under threat. Of the two varieties, var. blumei, almost entirely restricted to Luzon, is probably the more endangered.

Notes - 1. Boehmeria heterophylla was hitherto thought to be a Philippine endemic and the few records from Indonesia (one from Sulawesi, two from the island of New Guinea) suggest that it is under-collected.

2. This and $B$. beyeri form a distinct small group mainly or entirely found in the Philippines, unique among the Old World taxa in having a combination of consistently alternate to subopposite (rather than variable or consistently opposite) arrangement of leaves and simple axillary flower-clusters. Boehmeria heterophylla is distinguished from $B$. beyeri by its markedly asymmetrical and dimorphic leaves, female clusters many-flowered and fruiting perianth apically inflated or with abrupt beak rather than gradually tapering to beak.

3. It can be confused with the widespread Pouzolzia sanguinea (sympatric in Indonesia) which sometimes has flowerclusters large and densely congested and appears superficially rather similar. Leaves in $P$. sanguinea are not markedly asymmetrical but the only consistent gross morphological distinctions are the male tepals without dorsal appendage and the conical, only slightly laterally flattened, bilaterally symmetrical fruiting perianth with several longitudinal ribs. Boehmeria heterophylla can also be confused with $B$. clidemioides which differs in leaves dimorphic only in size and not markedly asymmetrical, and fruiting perianth markedly laterally flattened with a distinct wing, often symmetrical.

4. The two varieties here recognised were hitherto considered as separate species, and at the extremes of the variation (as represented by the respective type collections) they do look very different, var. blumei having two markedly different lengths of indumentum on the stem, relatively broader thicker bullate leaves, marginal teeth longer and mostly relatively broader with convex rather than concave upper margin; stipules also seem to be often longer-persistent. However, there is overlap with var. heterophylla in leaf proportions and in tooth size and shape and considerable variation in leaf texture; many collections are difficult to assign to either entity, being somewhat intermediate in indumentum with the two sizes of hair only moderately different (longer indumentum only $0.2 \mathrm{~mm}$ long) or with most characters as in var. heterophylla but leaves subopposite. There also appears to be little difference in flower and fruiting perianth, except the tendency to larger female clusters and sometimes tuberculate achene surface in var. blumei. It therefore seems better to recognise these two entities only as varieties. They are only partly sympatric, var. blumei being apparently less widespread in the Philippines and absent from the island of New Guinea but also recorded from Sulawesi (see above). It is unfortunate that there is very little habitat information for var. blumei, to ascertain whether the variation may be correlated with habitat differences.

5. Type material of the following name is intermediate between the two varieties.

Boehmeria villosa C.B.Rob. (1911) 3. - Type: Fenix BS 3754

(holo PNH n.v.; iso BO, NY), Philippines, Batan Islands,

Santo Domingo de Basco.

One collection from Luzon (Ramos BS 13580, BM. K, L) has narrowly obovate (rather than ovate) cuneate leaves only sparsely hairy adaxially and minute pubescence abaxially, and stigma with unusually long hairs giving a 'bottle brush' appearance. In other respects it conforms to $B$. heterophylla s.lat. and is therefore included here.

\section{Key to varieties}

1. Hairs on stem short (up to $0.2 \mathrm{~mm}$ ), fine, adpressed, uniform; leaves clearly alternate, thin-chartaceous, relatively narrow (length (3-)4-7× width), marginal teeth with concave upper margin . . . . . . . . . . . . var. heterophylla

1. Hairs on stem of two distinct kinds, minute, $<0.1 \mathrm{~mm}$ long, spreading and longer (c. $0.5 \mathrm{~mm}$ long), curved; leaves often subopposite, often thicker-textured and/or bullate or relatively broader (length $2.5-4.5 \times$ width), marginal teeth with convex upper margin . . . . . . . . . . b. var. blumei

\section{a. var. heterophylla - Fig. 4e-j; Map 7}

Boehmeria cumingiana Blume (1857) 199. - Type: Cuming 1561 (holo L; iso $\mathrm{G}, \mathrm{M}, \mathrm{P})$, Philippines. - See Note 1.

Ultimate stems slender, up to $1 \mathrm{~mm}$ diam, with abundant hairs, these fine, adpressed or half-adpressed, straight, up to $0.2 \mathrm{~mm}$ long, sometimes later glabrescent. Leaves alternate, the 'larger' ones 3-10x length of 'smaller' ones; 'larger' leaves slightly or markedly asymmetrical, narrowly ovate or linear-lanceolate, (6-)8-16 by $1.4-4 \mathrm{~cm}$, length (3-)4-5(-6)× width; margin with up to 35 teeth either side, these acute, broad, shallow, $1-2(-3)$ by $2-3(-6) \mathrm{mm}$, with their upper margin concave, base asymmetrically rounded or slightly cuneate; texture very thin-chartaceous, adaxial surface with hairs abundant, more or less adpressed, longer than on stem, abaxial surface with hairs sparse or abundant longer, more or less spreading; petiole short but variable relative to size of lamina, $0.1-0.3 x$ lamina length, pubescent like stem, sometimes also with longer spreading hairs. Female flower-clusters up to $5 \mathrm{~mm}$ diam, with $50-70(-100)$ densely crowded flowers; bracteoles up to $0.8 \mathrm{~mm}$ long, rounded. Male flowers sessile. Stigma 1-1.4 mm long, extremely slender. Fruiting perianth $1-1.2$ by c. $0.6 \mathrm{~mm}$. Achene $0.7-1$ by c. $0.4-0.6 \mathrm{~mm}$, (excluding apical stylar projection).

Distribution - Philippines (Luzon, Mindanao, Mindoro, Panay), Indonesia (Papua), Papua New Guinea.

Habitat \& Ecology - Margins of evergreen forest adjoining riverine forest; secondary forest; $200-500 \mathrm{~m}$ altitude.

Notes -1 . The holotype of $B$. cumingiana belongs to the same collection as $B$. heterophylla but represents a different duplicate.

2. This variety is very variable in leaf shape. See under the species for discussion of differences from var. blumei.

3. There is some regional variation. In Mindanao, as well as more 'typical' material, small-leaved collections have been seen with stipules short and relatively broad, acute rather than acuminate (length only $3 \times$ rather than $4 \times$ width). In Mindoro, the only 3 collections seen differ in young fruiting perianth having apparently a long and narrow achene nearly as long as the fruiting perianth, and a broad marginal winged region as well as an apical winged region. However, the fruiting perianths of these specimens are too immature to determine its adult form, and as the material vegetatively falls within the above range of variation and is therefore included here.

b. var. blumei (Wedd.) Friis \& Wilmot-Dear, comb. \& stat. nov. — Fig. 4k, l; Map 6

Basionym: Boehmeria blumei Wedd. in A. de Candolle (ed), Prodromus systematis naturalis regni vegetabilis, vol. 16, 1 (1869) 204. - Margarocarpus heterophyllus Wedd. (1854) 204. - Boehmeria heterophylla (Wedd.) Blume (1857) 204, nom. illeg., non Wedd. (1856). - Type: Cuming 731 (holo L; iso BM, G, K), Philippines. 
Ultimate stems 1.5-2 mm diam, with mixed indumentum, some hairs sparse or abundant, short (<0.1 mm long) spreading or half-adpressed, others distinctly longer (c. $0.5 \mathrm{~mm}$ long), spreading, usually sparser. Leaves alternate or subopposite, 'larger' leaves 5-9x length of 'smaller' but on some lateral shoots of similar size; 'larger' leaves asymmetrical, narrowly ovate, $8-13$ by $2.5-5 \mathrm{~cm}$, length $2.5-4(-4.5) \times$ width; margin with up to 40 teeth either side, these rounded or acute, slightly broader than long (1-)2-3(-4) by $2-5(-7) \mathrm{mm}$, with their upper margin convex; base \pm cuneate; texture fairly thin-chartaceous but leaves often somewhat bullate, with abundant spreading hairs like the stem or longer both sides or hairs half-adpressed adaxially; petiole very short c. $0.1 \times$ lamina length. Female flower-clusters sometimes (especially on main stem) very large, up to $8 \mathrm{~mm}$ diam, with more than 100 flowers; bracteoles up to $2 \mathrm{~mm}$ long, usually acute. Male flowers often clearly pedicellate. Stigma $1-3 \mathrm{~mm}$ long. Fruiting perianth $1-1.8$ by $0.5-1 \mathrm{~mm}$. Achene $0.8-1$ by $0.4-1 \mathrm{~mm}$, often with tuberculate surface.
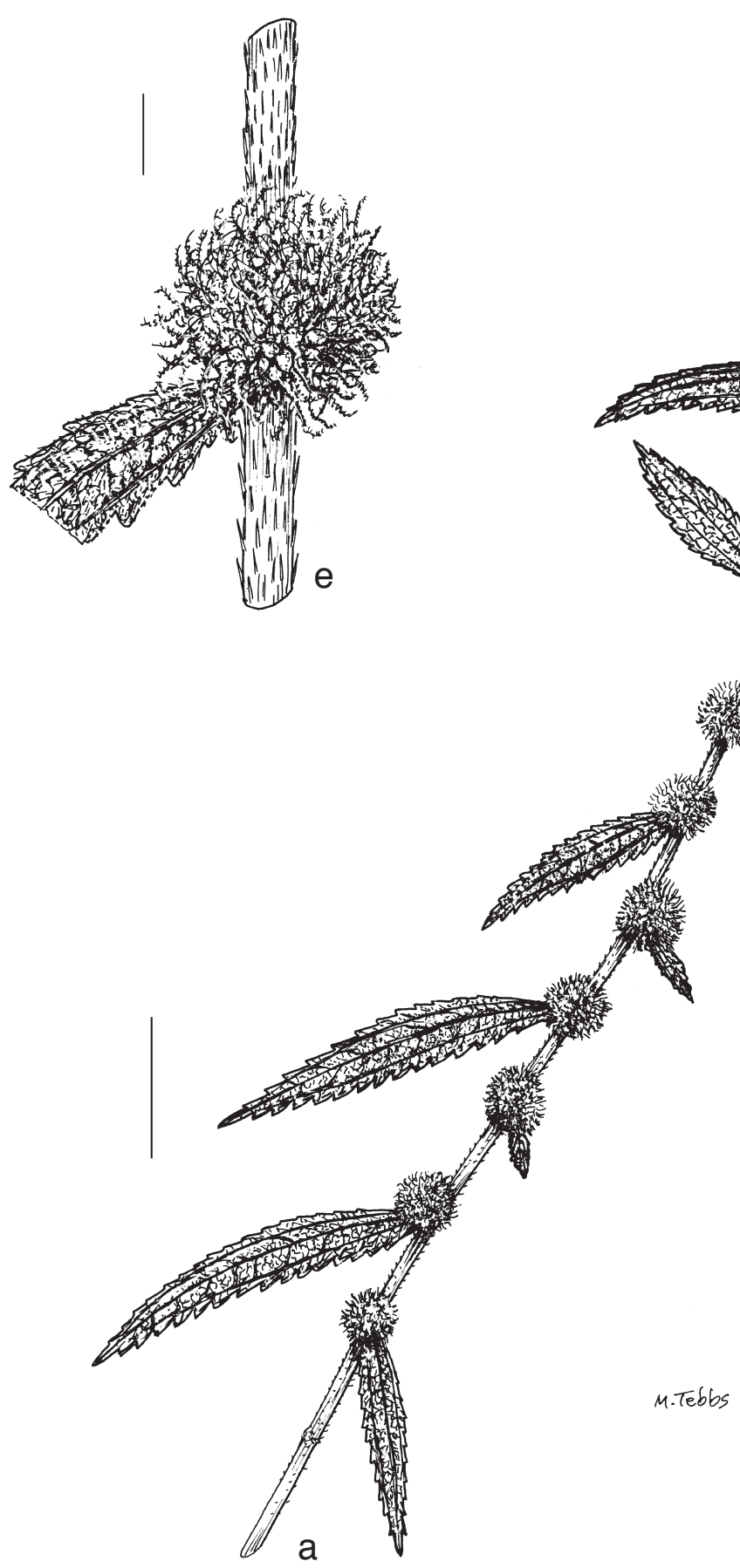

Fig. 5 Boehmeria manipurensis Friis \& Wilmot-Dear. a. Upper part of stem of fruiting female plant with axillary flower-clusters (inflorescences); b. leaf; c. leaf, detail of adaxial surface; d. detail of abaxial surface; e. axillary female flower-cluster (inflorescence); $f-h$. fruiting perianths of different form ( $f, g$ from same plant); i. fruit with perianth removed $(\mathrm{a}-\mathrm{g}$, i: Meebold 6253; h: McClelland s.n.; all K). - Scale bars: a $=2 \mathrm{~cm}$; $\mathrm{b}=5 \mathrm{~mm} ; \mathrm{c}, \mathrm{d}, \mathrm{f}-\mathrm{h}=1 \mathrm{~mm} ; \mathrm{e}=2 \mathrm{~mm} ; \mathrm{i}=0.5 \mathrm{~mm}$.
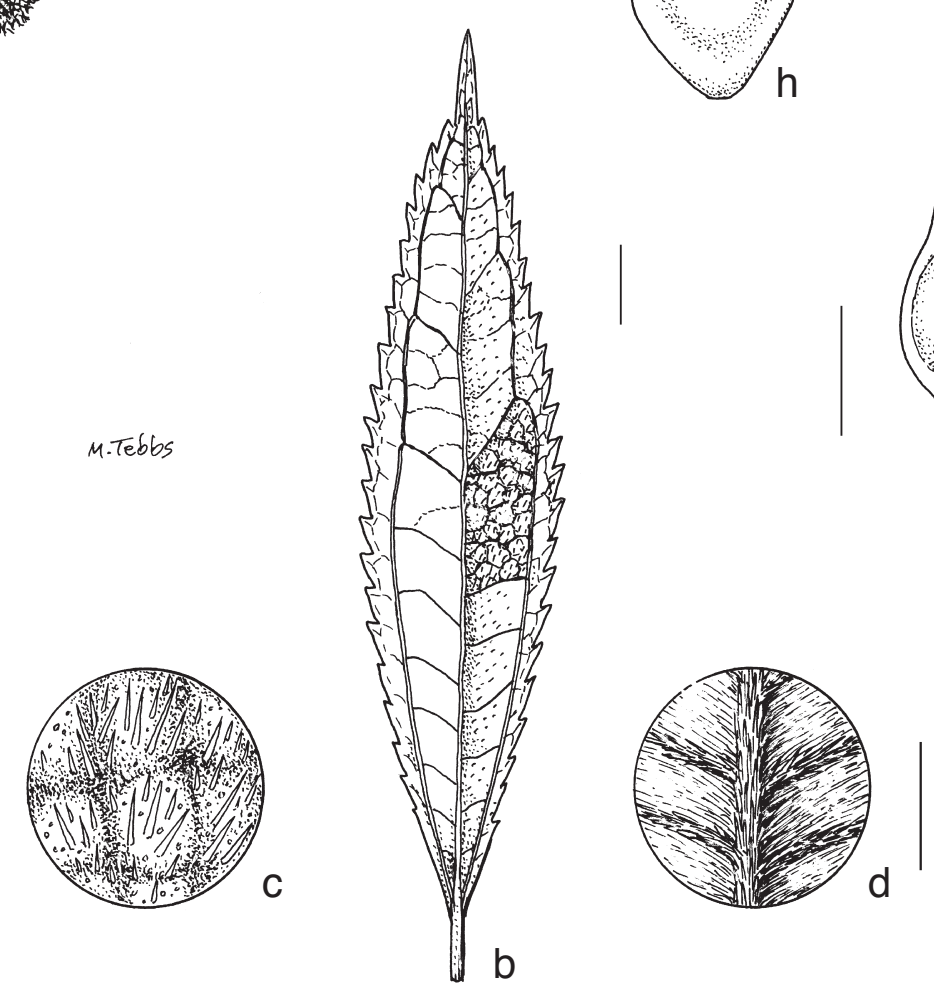
Distribution — Indonesia (Sulawesi), Philippines (Luzon, Mindanao).

Habitat \& Ecology — Secondary forest; 250-1100 m altitude.

Notes - 1. Weddell (1856: 352 ) refers to the type collection of this entity in a footnote under his new species $B$. heterophylla, regarding it as "a variety of $B$. heterophylla" but not formally transferring it from Margarocarpus to Boehmeria. Therefore his new name $B$. heterophylla (1856) (for a different entity with a different type collection), is valid, even though his Margarocarpus heterophyllus, also validly published, antedates it. Blume (1857) formally transfered the epithet of Margarocarpus heterophyllus to Boehmeria, creating an illegitimate later homonym which is corrected by Weddell (1869) with a new epithet. The facts that both type specimens of these closely-related entities have the same collector and that at some point they have each been given the same species epithet, create many possibilities for confusion.

2. For differences from var. heterophylla and discussion of its distribution see under the species.

3. This variety is more similar than var. heterophylla to $B$. beyeri in leaf texture and indumentum.

\section{Boehmeria manipurensis Friis \& Wilmot-Dear — Fig. 5 Map 5}

Boehmeria manipurensis Friis \& Wilmot-Dear in Wilmot-Dear et al. (2010) 438. - Type: Meebold 6253 (holo K), India, Manipur, Irang River, Nov. 1907.

Subshrub (habit and height not clear from scarce material); ultimate branches slender, c. $0.7 \mathrm{~mm}$ diam, with hairs abundant, short, fine, adpressed. Stipules not seen. Leaves alternate, markedly dimorphic in size and moderately so in shape with 'larger' leaves (2-)5-10x length of 'smaller' ones, linear-elliptic and slightly sideways-curved, relatively small c. $5 \times 1 \mathrm{~cm}$, length c. 5x width; margin sharply serrate with 15-20 teeth either side, these up-curved, c. 1 by $3 \mathrm{~mm}$; leaf apex gradually attenuate; base narrowly cuneate; basal veins extending into distal half of lamina and arching and joining upper lateral veins, upper lateral veins slightly dissimilarly arranged on either side, $2-3$ either side but scarcely distinct from coarser tertiary veins especially on one half, lowest arising near middle of lamina, lateral veins and coarser reticulation deeply impressed adaxially, fine but prominent abaxially; texture thin-coriaceous and leaves slightly bullate, adaxial surface with sparse or abundant hairs, a mixture of coarse adpressed and sparser, longer, finer, spreading; abaxial surface with hairs dense, adpressed or half-adpressed, \pm obscuring surface; 'smaller' leaves very variable in size relative to adjacent 'larger' leaves, sometimes resembling 'larger' ones but relatively broader, or sometimes reduced almost to being bractiform, only 2-3 $\mathrm{mm}$ long; all leaves subsessile. Flower-clusters axillary, only female clusters seen, large, 5-8 mm diam, with well over 100 flowers, these very densely congested forming almost a solid mass; flowers pedicellate and often borne on 2-3-branched peduncles; bracteoles inconspicuous less than half of flower length. Stigma relatively long, $2-3 \mathrm{~mm}$. Fruiting perianth small and narrow, $1-1.2$ by $0.3-0.5 \mathrm{~mm}$, spindle-shaped or obovoid to ovoid (varying even on one plant) with short (c. $0.1 \mathrm{~mm}$ long) apical beak, always greatly laterally flattened with central part thickened only in distal half or third and surrounded by a marginal wing, this broad, thin-textured; at base long tapering flattened and winged running into the winged pedicel; sparsely hairy near apex, hairs adpressed. Achene narrowly obovoid, $0.5-0.7$ by $0.3-0.4 \mathrm{~mm}$, yellow-brown. pur).

Distribution - India (only known from south-western Mani-

Habitat \& Ecology - No details certain. Presumably montane forest habitats.
Conservation status - Data Deficient (DD). The conservation status was discussed by Wilmot-Dear et al. (2010). The species is only known from one single collection made in 1907 , and it is presumed to be rare and local, but no conclusions can be drawn as to habitat or conservation status from the minimal label data. The region from which the species has been recorded is remote and under-collected and has still large areas of undisturbed vegetation.

Notes -1 . This species, which is only known from its type, is distinctive in its combination of alternate small narrow thicktextured markedly dimorphic leaves and very large axillary female clusters with tightly congested pedicellate (often also pedunculate) flowers and long stigmas. Most Old World taxa have opposite leaves and flowers on long leafless axes, and flower-clusters are rarely so large or tightly packed. The material was hitherto misidentified as Pouzolzia sanguinea var. fulgens, probably due to the distinctive leaf characters mentioned above, which are similar to those of that taxon.

2. In habit it is reminiscent of the Philippine $B$. heterophylla which also has dense sessile clusters and alternate markedly dimorphic sometimes thick-textured leaves (differing in being markedly asymmetrical with hairs spreading rather than adpressed abaxially, not sufficiently dense as to obscure the surface); however, $B$. heterophylla has a very dissimilar fruiting perianth, sessile, round-based, inflated to dorsiventrally flattened in the distal part giving a 'shouldered' appearance (rather than having a distinct marginal wing surrounding a central thickened part) and often entirely without a beak; the achene occupies only the basal half of the fruiting perianth and is markedly asymmetrical, apically swollen on one side with the style asymmetrically inserted.

3. Boehmeria manipurensis could be confused with depauperate material of the often alternate-leaved $B$. clidemioides (sympatric but widespread) where the diagnostic partly-leafless short lateral inflorescence-bearing axes of the latter are missing; $B$. clidemioides has a similar fruiting perianth but with a narrower thicker-textured wing and usually sessile; vegetatively it is very variable but its leaves are never coriaceous and are also usually relatively broader and less markedly dimorphic with at least some of the 'larger' leaves on a stem petiolate.

\section{Boehmeria helferi Blume - Fig. 6; Map 5}

Boehmeria helferi Blume (1857) 201. - Type: Helfer 4585 (holo W; iso CAL, K), Burma, Tenasserim, 13 May 1838.

Subshrub (height not clear from the scarce material); ultimate branches 1-1.5 $\mathrm{mm}$ diam, with sparse inconspicuous adpressed hairs, soon robust and glabrous. Stipules broadly or narrowly triangular, $4-8$ by $1.5-2 \mathrm{~mm}$, thin-chartaceous with scattered hairs outside. Leaves opposite, dimorphic in petiole length ('larger' petiole at least $2 x$ length of 'smaller') and sometimes slightly in lamina size, all leaves broadly ovate, symmetrical, $5-10$ by $3.5-6 \mathrm{~cm}$, length (1.4-) $1.8 \times$ width, margin deeply serrate with 15-25 teeth, these acute, up-curved, 3-4 by $3-4 \mathrm{~mm}$; leaf apex abruptly acuminate consisting of one long tooth with 1-2 lateral teeth at base; base rounded and slightly cordate; basal veins extending slightly into distal half or to distal third, upper lateral veins c. 2 each side, similarly arranged but hardly distinct from coarser tertiary venation, lowermost arising near or below middle of lamina, inconspicuous adaxially, finely prominulous abaxially; texture very thin-chartaceous, adaxial surface with sparse fine inconspicuous adpressed hairs; abaxial surface with longer hairs and also minute and often spreading hairs; petiole long compared to lamina length, on 'larger' leaf often almost equalling lamina, 3-8 cm long. Flower-clusters axillary, large, $4-5 \mathrm{~mm}$ diam, with more than 50 flowers, these densely crowded, all flowers female or clusters with a few male ones; bracteoles narrowly elliptic to obovate, \pm acute, $\leq 0.3 \mathrm{~mm}$. 


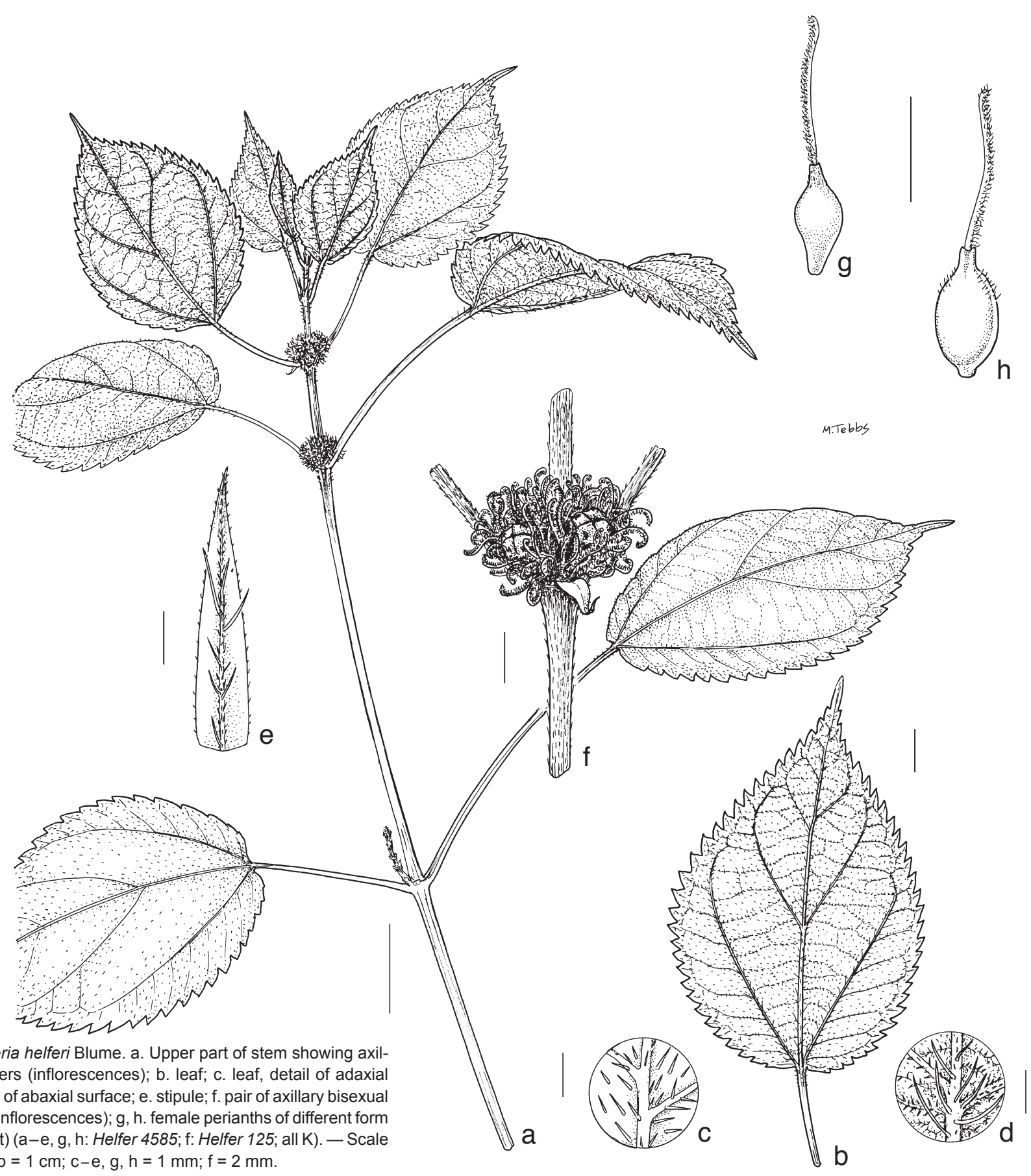

Fig. 6 Boehmeria helferi Blume. a. Upper part of stem showing axillary flower-clusters (inflorescences); b. leaf; c. leaf, detail of adaxial surface; $d$. detail of abaxial surface; e. stipule; $f$. pair of axillary bisexual flower-clusters (inflorescences); $\mathrm{g}$, h. female perianths of different form (from same plant) (a-e, g, h: Helfer 4585; f: Helfer 125; all K). - Scale bars: $a=2 \mathrm{~cm} ; b=1 \mathrm{~cm} ; c-e, g, h=1 \mathrm{~mm} ; f=2 \mathrm{~mm}$.

Male flowers 4-merous, depressed-globose, mature buds large, c. $1.8 \mathrm{~mm}$ diam, with slight dorsal thickening and sparse adpressed hairs. Female flowers ellipsoid to or ovoid with short beak, $0.8-1$ by c. $0.5 \mathrm{~mm}$, slightly laterally flattened; stigma long, 1.5-2 mm. Fruiting perianth very small, c. 1 by $0.5 \mathrm{~mm}$, ovoid to ellipsoid, moderately flattened and with slight marginal wing and broad beak. Achene \pm filling fruiting perianth, fawn.

Distribution - India (West Bengal), Burma (Tenasserim).

Habitat \& Ecology - No details in original description, presumably coastal rainforest.

Conservation status - Critically Endangered (CR). The species is known from only two collections, both from the 1830s, the type (from Tenasserim in Burma) and a collection from India, West Bengal, Kolkota [Calcutta], 1836-1838, Helfer 125 (K). Since these two collections are from localities far apart, both regions where major habitat loss has occurred (one being within the urban expansion of Kolkota), and the AOO is only $8 \mathrm{~km}^{2}$, we propose the IUCN category Critically Endangered CR 2Bab(iii).
Note - A species of very restricted distribution unique among the Old World taxa in its combination of opposite leaves and axillary flower-clusters. Its leaves which are large, broad and deeply-up-curved-toothed are rather similar to smaller forms of $B$. japonica (which differs in marginal teeth progressively markedly larger towards leaf apex) and also similar to some forms of $B$. clidemioides. Both these taxa differ from it in inflorescence architecture, flower-clusters being borne in $B$. japonica on specialised leafless axes and in $B$. clidemioides mostly on short lateral axes which are partly-leafless.

\section{Boehmeria clidemioides Miq. — Fig. 7; Map 8, 9}

Boehmeria clidemioides Miq. (1851) 34. - Boehmeria platyphylla D.Don var. clidemioides (Miq.) Wedd. (1856) 366. - Type: Junghuhn s.n. (holo $\mathrm{L}$; iso A, CAL), Indonesia, Jawa [Java], Mt Merapi.

Boehmeria platyphylla D.Don var. cinerascens Hook.f. (1888) 579. - Syntypes: Booth s.n. (K), India, Arunachal Pradesh, Duphla Hills; Wallich 4591 (K-WALL), Nepal, 1821. - See Note 6. 


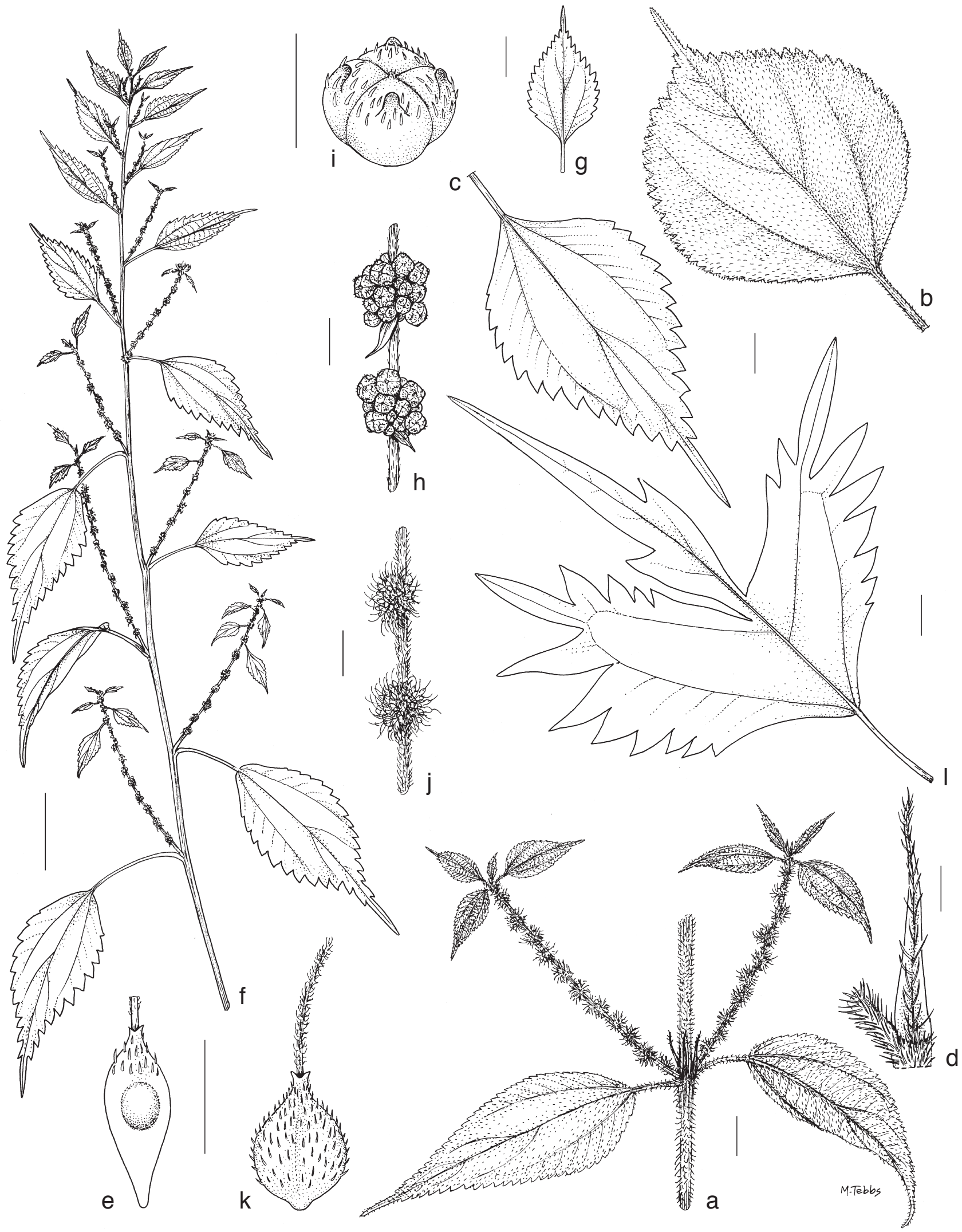

Fig. 7 a-e: Boehmeria clidemioides Miq. var. clidemioides. a. Part of stem showing pair of partly-leafless inflorescence-bearing axes with flower-clusters (inflorescences); b, c. leaves; d. stipule; e. flattened winged fruiting perianth. - f-k: Boehmeria clidemioides var. diffusa (Wedd.) Handel-Mazzetti. f. Habit of stem showing axillary, partly-leafless inflorescence-bearing axes with flower-clusters (inflorescences); g. leaf; h. part of male inflorescence-bearing axis with two flower-clusters (inflorescences); i. male flower; j. part of female inflorescence-bearing axis with two flower-clusters (inflorescences); k. unwinged fruiting perianth. - I: Boehmeria clidemioides var. umbrosa Hand.-Mazz. Leaf (a: Henry 12795; b, d: Hancock 375; c: Faber 431; e, h, i: Ferguson s.n; g, k: Henry 2924; j: Forrest 15885; h: Wilson 5157; all K). — Scale bars: a-c, g, I = $1 \mathrm{~cm} ; \mathrm{d}, \mathrm{h}, \mathrm{j}=2 \mathrm{~mm}$; e, i, k = $1 \mathrm{~mm} ; \mathrm{f}=2 \mathrm{~cm}$. 
Herb to shrub; woody-based, erect and few-branched or prostrate and ascending, laxly branched, 0.4-3 m tall; ultimate branches fairly slender, up to $1 \mathrm{~mm}$ diam, with fine hairs, these sparse short (c. $0.2 \mathrm{~mm}$ long) and adpressed or conspicuous long (up to $1 \mathrm{~mm}$ ) and spreading. Stipules narrowly triangular, acuminate, $3-5$ by $1 \mathrm{~mm}$, pubescent outside on midrib. Leaves opposite, subopposite or alternate, (mostly alternate in var. diffusa), usually markedly dimorphic (opposite leaves sometimes isomorphic) with both lamina and petiole of 'larger' leaf 2-5x length of 'smaller' lamina and relatively narrower but otherwise of similar shape, \pm symmetrical, narrowly linear-ovate, ovate, ovate-elliptic or rhombic-ovate, rarely broadly ovate to almost orbicular, very variable in size and proportions (3-)4-16(-19) by $(1.5-) 3-7(-12) \mathrm{cm}$, length (1.1-)2-4x width; margin upcurved-serrate or dentate, size and number of teeth very variable, mostly $15-30(-35)$ either side, \pm uniform in size, $(1-) 4(-7)$ by $3-5(-7) \mathrm{mm}$, but in broader-leaved variants sometimes few (5-15) and markedly larger and increasingly up-curved towards apex, up to $15 \mathrm{~mm}$ long; leaf apex ranging from abruptly acuminate or caudate, with a single long tooth and 1-2 smaller lateral teeth to deeply laciniate with several long teeth giving irregularly bilobed or trilobed appearance; base symmetrical or slightly oblique, narrowly rounded or short-cuneate; basal veins extending to middle of lamina, upper lateral veins 1-3 either side, lowermost arising at or below middle of lamina, finely impressed adaxially, finely prominent abaxially; tertiary venation often visible both sides; texture membranous to thin- or (some small-leaved forms) thickchartaceous, leaves sometimes slightly bullate; both surfaces with sparse or abundant hairs, these adpressed or spreading, fine, very long ( $\geq 0.5 \mathrm{~mm}$ ), cystoliths prominent adaxially; petiole very variable in length compared to lamina, $0.1-0.3(-0.5) \times$ lamina length. Flower-clusters partly axillary on main stems and partly well-spaced or almost contiguous along modified lateral branches which are short or fairly long, 5-15 cm long, partly or almost entirely leafless, mostly erect, unbranched or laterally branched and with a tuft of crowded very small leaves at apex (rarely most of these modified axes lacking any apical leaves), or sometimes the axis returning to vegetative growth with wellspaced normal sized leaves; axes often with both unisexual and bisexual clusters; male clusters 1.5-2 $\mathrm{mm}$ diam, with 20-30 (-40) crowded flowers, female clusters 2.5-6 mm diam, with flowers 20-more than 50 in number, loosely arranged; in larger clusters flowers sometimes borne in groups of 2-3 along minute flattened peduncles up to $1 \mathrm{~mm}$ long and/or individual flowers on pedicels up to $1 \mathrm{~mm}$ long; bracteoles inconspicuous, half of mature flower length. Male flowers 4-merous, sessile, mature buds globose, 0.6-1.2 $\mathrm{mm}$ diam, each lobe with fairly distinct dorsal thickening, adpressed or spreading-hairy. Female flowers with stigma rather variable in length, 1-1.5(-2) mm long, sometimes hooked. Fruiting perianth $0.8-1.5$ by $0.3-0.5$ $\mathrm{mm}$, rather variable in shape, ellipsoid-ovoid gradually tapering to apex, often also to base, without distinct beak (rarely with short abrupt beak), with short pale hairs especially near apex, markedly dorsiventrally flattened along margins or in distal half, the flattening giving rise to an indistinct marginal rim or a fairly distinct thick wide marginal and sometimes apical wing. Achenes tuberculate or smooth.

Distribution - Widespread from eastern Himalayas (northeastern India, Nepal, Bhutan) to Burma, Thailand, Laos, Vietnam, China, and south to Malaysia and Indonesia mostly west of Wallace's line (Sumatera, Jawa, Nusa Tenggara [Lesser Sunda Islands]).

Habitat \& Ecology - Very varied; dry or moist primary evergreen forest, moist slopes and ravines, margins, deciduous forest with bamboo, secondary forest and forest edges and paths, scrubland, exposed cliff tops; 200-2600 m altitude.
Conservation status - Least Concern (LC). The species is known from at least 400 collections, many of which are recent, and occurs in innumerable locations, and in a wide range of habitats, with an EOO of $8165970 \mathrm{~km}^{2}$.

Notes -1 . This species is distinctive in the presence of lateral flowering branches which are almost leafless, often short, with a small tuft of leaves at their apex, occasional specimens having been seen with most flowering axes lacking apical leaves. (Boehmeria holosericea occasionally has an apical tuft of leaves on its male axes, but does not otherwise resemble $B$. clidemioides, having large broad \pm cordate leaves with teeth outward-pointing often rounded and male axes branched.) In this character $B$. clidemioides is reminiscent of the New World species $B$. cylindrica, the only other species where tufts of leaves at the end of the flowering axes are usual. Boehmeria clidemioides can also often be recognised by leaves being subopposite or variably \pm opposite and distinctly alternate on a single stem (this character is especially useful when apical leaf-tufts are lacking).

2. Boehmeria clidemioides is extremely variable in texture, size and shape of the lamina and in size and proportions of its marginal teeth, also in density of the inflorescence architecture and shape of fruiting perianth, especially the relative width of the marginal wing. There is some correlation between characters and geographical distribution.

Pedunculate and pedicellate female flowers, correlated with fruiting perianth markedly pale near base and markedly dark in middle region, have only been seen in a few collections from the eastern Himalayas.

In China flower-clusters are rarely contiguous and leaves at the apex of flowering axes are usually well-developed; in China and Himalayas leaves are rarely thick-textured; in Indochina, Thailand and Indonesia most leaves are narrow, length 3-4x width. In China three taxa can be recognised, with most collections falling within one or other of two distinct and apparently common entities with only a few intermediate individuals impossible to assign to either. Var. clidemioides is an erect shrub with (few or many) lateral branches mostly much shorter than main stem with flower-clusters mainly in lower part which is often entirely leafless, leaves medium-sized often relatively broad, almost all opposite. It appears to be restricted to southern China. Var. diffusa is a herb or shrub, much-branched often straggling (prostrate and ascending), with lateral branches of similar length to main stem bearing flower-clusters and scattered leaves along most of their length, leaves being mainly alternate (sometimes some lower ones opposite), often small and usually narrow; it is more widespread, occurring also further north in China.

Outside China this distinction becomes obscured; some collections in the eastern Himalayas and Burma conform to each of these two entities and a few collections in Indochina and Thailand conform to the typical variety but most material outside China consists of a range of intermediates in which the character-states vary independently. Yahara (1981: 11) observed habitat differences between the two entities in Thailand and recognised them as species, with $B$. clidemioides s.str. restricted to more moist habitat especially along streams, $B$. diffusa abundant in the dry inland region at the edges of dry evergreen forest and in somewhat disturbed areas, which may account for its wider distribution in China.

In China the typical form also grades via a range of intermediates into var. umbrosa, a form which at the extreme of its variation is very distinctive in leaf characters. Its leaf is broader, often almost orbicular apart from its long apical tooth, irregularly deeply cleft at apex or truncate with several long teeth; marginal teeth are fewer, and gradually markedly larger towards leaf apex, the largest at least $10 \mathrm{~mm}$ long. This range of variation 
parallels that seen in some forms of $B$. japonica such that specimens of var. umbrosa where inflorescence-bearing axes mostly lack conspicuous apical tufts of leaves can be confused with $B$. japonica.

3. Opposite-leaved specimens \pm conforming to var. clidemioides with apical leaves lacking from most inflorescencebearing axes can be confused with thin-leaved forms of either $B$. japonica or B. virgata subsp. macrophylla (especially var. scabrella which has short inflorescence-axes), or, where flower-clusters are particularly crowded, with B. pilosiuscula. These taxa are distinguished from $B$. clidemioides as follows: Boehmeria japonica usually has leaves much less dimorphic in size, length of 'larger' less than $2 x$ that of 'smaller.' Leaf apex in $B$. virgata subsp. macrophylla rarely consists only of a single long tooth and is never laciniate and the broader-leaved forms of $B$. clidemioides which would be confused with it tend to have leaves with marginal teeth increasingly long and up-curved towards leaf apex rather than uniform (see further discussion under B. virgata subsp. macrophylla var. scabrella). Boehmeria pilosiuscula differs from $B$. clidemioides in its spreading stem indumentum of two distinct kinds, leaves often markedly asymmetrical and in its fruiting perianth obconical-truncate, flattened near apex but without a true wing.

4. Alternate-leaved specimens of $B$. clidemioides can be difficult to distinguish from $B$. heterophylla, which differs in leaves markedly dimorphic in shape as well as size and markedly asymmetrical, fruiting perianth not markedly flattened with stigma often slightly eccentric and the achene \pm filling the lower part of the perianth (rather than surrounded by a distinct wing) and with stigma eccentrically located.

5. Alternate-leaved specimens can be difficult to distinguish from Pouzolzia sanguinea var. sanguinea, which is distinguishable as follows: male flowers larger, mature buds conical, c. $1 \mathrm{~mm}$ diam, tepals without dorsal appendage, stigma usually longer (usually at least $2 \mathrm{~mm}$ long, rather than usually up to 1.5 $\mathrm{mm}$ ), flowers less tightly congested, most clusters bisexual; its fruiting perianth detaches easily from the shiny mature achene; leaves are thicker with coarser tertiary venation more robust \pm scalariform (rather than all venation reticulate) and their hairs are more conspicuous and adpressed.

6. Material intermediate between var. clidemioides and var. diffusa includes the type of $B$. platyphylla var. cinerascens. This is cited above under the species.

\section{Key to varieties}

1. Leaf apex deeply 2-3-lobed-laciniate; marginal teeth progressively markedly larger, increasingly up-curved and relatively narrower towards apex, distal ones $3-5 \times$ length of proximal ones. - China ... . . . . . . . c. var. umbrosa

1. Leaf apex long-acuminate; teeth not or only slightly larger towards apex. - Widespread . . . . . . . . . . 2

2. Leaves opposite, main stems erect, often woody; lateral flowerbearing branches mostly much shorter than main stem, almost or entirely leafless in lower part a. var. clidemioides

2. Leaves alternate, plant \pm herbaceous, laxly branched often prostrate and ascending; lateral flower-bearing branches of similar length to main stem, often with scattered leaves throughout length. . . . . . . . . . . b. var. diffusa

\section{a. var. clidemioides - Fig. 7a-e; Map 8}

Boehmeria sidaefolia Wedd. (1854) 203. - Type: Not traced.

Boehmeria clidemioides Miq. var. platyphylloides Yahara (1981) 11, syn. nov. - Type: Shimizu et al. 20469 (holo KYO; photo K), northern Thailand, Chiang Mai, Doi Chang. - See Note 2.

Herb or robust shrub, woody-based erect (few-)many-branched, 0.4-3 m tall; lateral branches much shorter than main stems, $5-10(-15) \mathrm{cm}$, mostly unbranched with few or no leaves in lower part subtending the well-spaced or crowded flowerclusters. Leaves opposite or subopposite, rarely alternate near branch apex, ovate to elliptic-ovate or rhombic-ovate, medium, (4.5-)6-16(-19) by (2-)2.5-7(-12) cm, proportions very variable, length $(1.3-) 2-2.5(-4) \times$ width; marginal teeth (10-)15-30(-35) either side, uniform or slightly larger and increasingly up-curved near leaf apex, $4(-7)$ by $5(-7) \mathrm{mm}$, width (1-)1.5-2(-3)× length; leaf apex acuminate to caudate; base narrowly rounded to short-cuneate. Stigma often short, 1-1.5 $\mathrm{mm}$ long. Fruiting perianth up to $1.5 \mathrm{~mm}$ long, length often $3 \times$ width, wing distinct. Achene smooth.

Distribution - Widespread from eastern Himalayas (northeastern India, Nepal) to Burma, Thailand, Vietnam.

Habitat \& Ecology — Forest, mostly moist places and near streams; 1000-2500 m altitude.

Notes -1 . See general discussion of variation under the species. Leaves are rarely over $8 \mathrm{~cm}$ and often less than $6 \mathrm{~cm}$ long, often relatively broader than in var. diffusa or with marginal teeth more numerous; lateral branches mostly short and con-

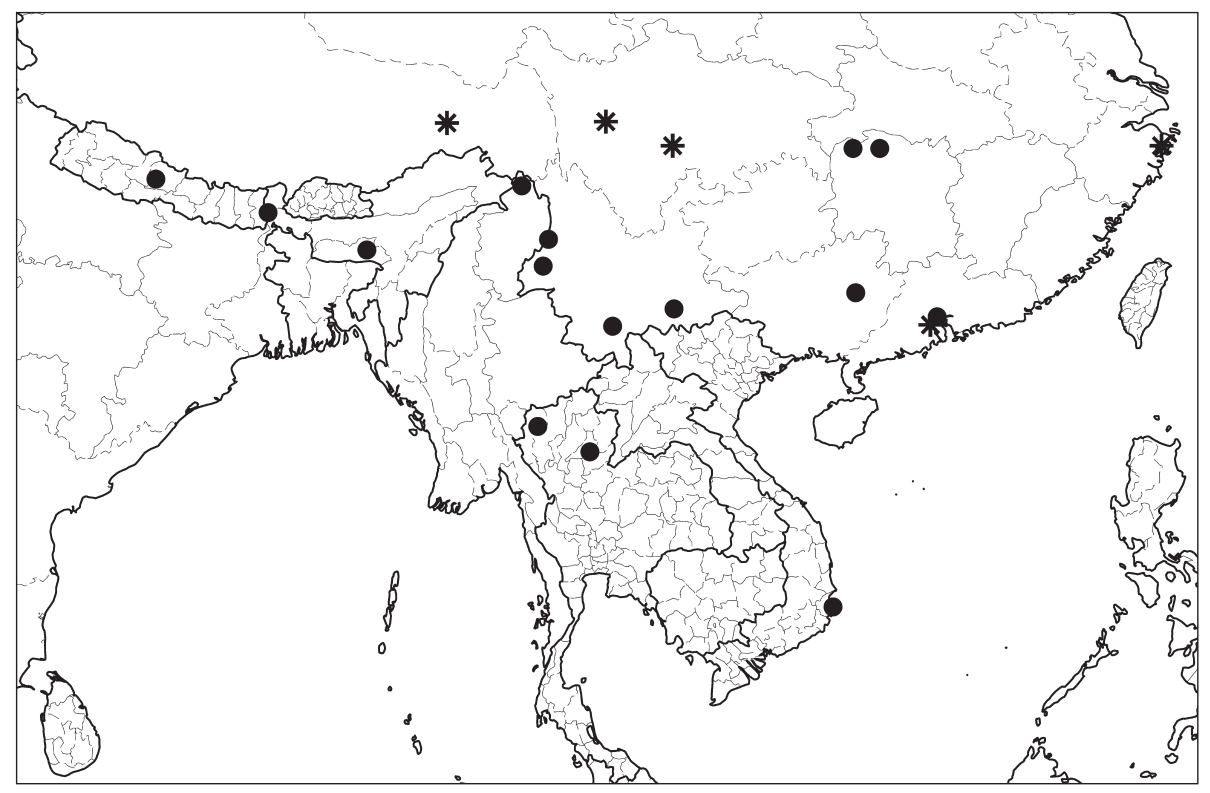

Map 8 Distribution of Boehmeria clidemioides Miq. var. clidemioides $(\bullet)$ and B. clidemioides Miq. var. umbrosa Hand.-Mazz. (*). 
spicuously leafless in lower part. Said to be edible, according to Poilane 4259.

2. Var. platyphylloides, distinguished on branched stems, larger leaves, longer acumen and smaller teeth, is here reduced to synonymy since there is a continuous range of intermediates with the typical variety. Yahara himself noted the existence of intermediate forms.

\section{b. var. diffusa (Wedd.) Hand.-Mazz. - Fig. 7f-k; Map 9}

Boehmeria clidemioides Miq. var. diffusa (Wedd.) Hand.-Mazz. (1929) 152. Boehmeria diffusa Wedd. (1856) 356. - Boehmeria comosa Wedd. (1869) 205, nom. superfl. illeg., based on Boehmeria diffusa Wedd. - Type: J.D. Hooker s.n. in Herb. Hooker \& Thomson (lecto K, selected here), eastern Nepal, Jambing River, $3000 \mathrm{ft}$ - See Note 1.

Boehmeria maugereti H.Lév. \& Vaniot in Léveillé (1907) 144. — Syntypes: Bodinier 1715 (E), China, Guizhou, Mont du Collège, July 1897; L. Martin 1715 (P, n.v.), China, Gan-pin, 20 Aug. 1897.

Boehmeria thorelii Gagnep. (1928) 127. - Type: Thorel 2379 (holo P), Laos.

Herb, laxly branched, often prostrate and ascending up to $1.5 \mathrm{~m}$, rooting at nodes; lateral branches often branched, $5-15 \mathrm{~cm}$ long with clusters, especially female, often so crowded as to be almost contiguous, some subtended by leaves. Leaves mostly alternate (sometimes some lower ones opposite), ovate to elliptic-ovate, (3-)4-8(-16) by (1.5-)2-3(-6.5) cm, length (1.75-) $2-3.5(-4) \times$ width; marginal teeth $7-20(-30)$ either side, relatively narrow, $1-4$ by $1.5-4 \mathrm{~mm}$, width $0.75-1.5(-3) \times$ length; leaf apex as in typical variety; base usually short-cuneate. Stigma 1.5-2 mm long, extremely slender. Fruiting perianth up to c. $1 \mathrm{~mm}$ long, with length usually c. $2 \times$ width, often scarcely flattened and with marginal rim rather than wing. Achene usually tuberculate.

Distribution - Widespread from eastern Himalayas (northeastern India, Nepal) to Burma, Thailand, China.

Habitat \& Ecology - Forest margins, thickets, open sunny slopes and dry disturbed areas; 200-2400 m altitude.

Conservation status - See under the species.

Notes - 1. When Weddell (1856) created his three varieties under B. diffusa (var. hirta Wedd. 1856: 356, var. strigosa Wedd. 1856: 357 and var. canescens Wedd. 1856: 357), he also created the autonym var. diffusa, which was transferred to $B$. clidemioides by Handel-Mazzetti (1929). We are not sure which of the preserved material of $B$. diffusa Weddell considered to represent the typical variety, and we have seen no material annotated by Weddell with varietal names; we have therefore decided to list the varietal names other than var. diffusa under names of uncertain identity, rather than sinking them into synonymy of var. diffusa. We have seen six collections which we believe are syntypes of B. diffusa: J.D. Hooker S.n. (K), India, Khasia; J.D. Hooker S.n. (K), Sikkim; J.D. Hooker s.n. (K), Nepal; Griffith s.n. (K), Mishmi; MacClelland s.n. (K), Pegu and Rangoon; J.D. Hooker s.n. in Herb. Hooker \& Thomson (K), eastern Nepal, Jambing River, $3000 \mathrm{ft}$. For taxonomic precision we have chosen the latter collection as lectotype.

2. Variation is discussed fully under the species as a whole; leaves are mostly alternate and generally smaller and narrower than in typical variety, often less than $6 \mathrm{~cm}$, rarely over $8 \mathrm{~cm}$ long, with teeth fairly large and relatively narrow; lateral branches longer and more lax with scattered leaves; stigma 1.5-2 $\mathrm{mm}$ long, mostly longer than in typical variety.

\section{c. var. umbrosa Hand.-Mazz. - Fig. 7I; Map 8}

Boehmeria clidemioides Miq. var. umbrosa Hand.-Mazz. (1929) 152. Boehmeria umbrosa (Hand.-Mazz.) W.T.Wang (1981a) 324. - Syntypes: Handel-Mazzetti 9340 (not traced), China, north-western Yunnan, Taran, 5 July 1916; Maire s.n. (W), China, Dschenfung-schan; Wilson in Veich Exped. $5157(\mathrm{~K})$, China, Mt Omei.

Boehmeria bicuspis C.J.Chen in W.T.Wang \& C.J.Chen (1979) 109. - Type: T.S. Ying \& D. Y. Hong 575 (holo PE), China, Tibet, I-Kung, 15 July 1965. Boehmeria pseudotricuspis W.T.Wang (1981a) 324. - Type: C.W. Wang 85419 (holo KH, not traced; iso PE), China, Yunnan, Xichou, 7 Dec. 1939.

Perennial herb, unbranched or few-branched, up to c. $1 \mathrm{~m}$ tall. Leaves all or mostly alternate, often almost orbicular apart from long terminal tooth, medium, (5-)7-15 cm long, length 1.1-1.5x width; marginal teeth few, 5-10(-15), relatively narrow, near leaf base 3-5 $\mathrm{mm}$ long and wide, gradually markedly longer towards leaf apex, those near apex 10-25 mm long, length 1.5-5x width; either apex irregularly deeply bilobed, deeply trilobed or deeply laciniate with a long apical tooth terminating one lobe or inserted between two lobes, or apex truncate, with several almost equal long apical teeth $0.3-1.5 \times$ lamina length; base short-cuneate. Inflorescence-bearing axes usually unbranched, clusters well-spaced. Stigma 1.5-2 mm long. Fruiting perianth up to c. $1 \mathrm{~mm}$ long, with length usually c. $2 \times$ width.

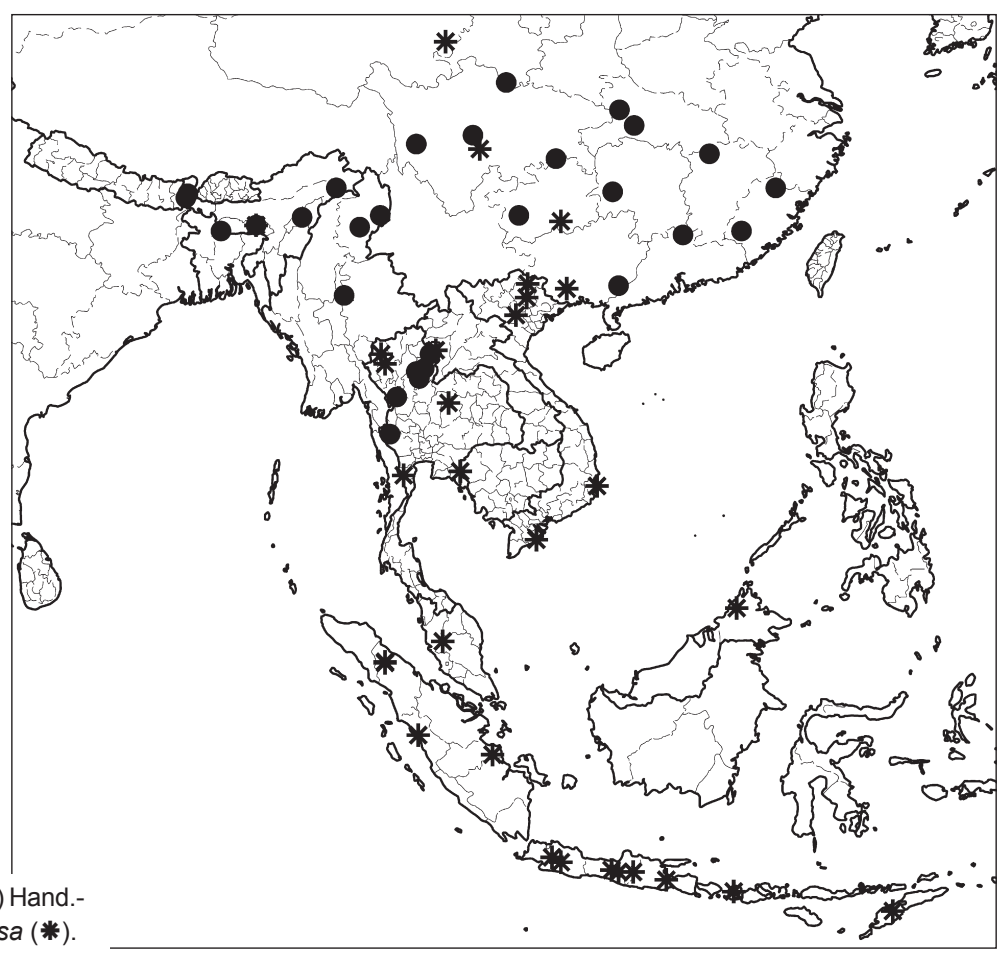




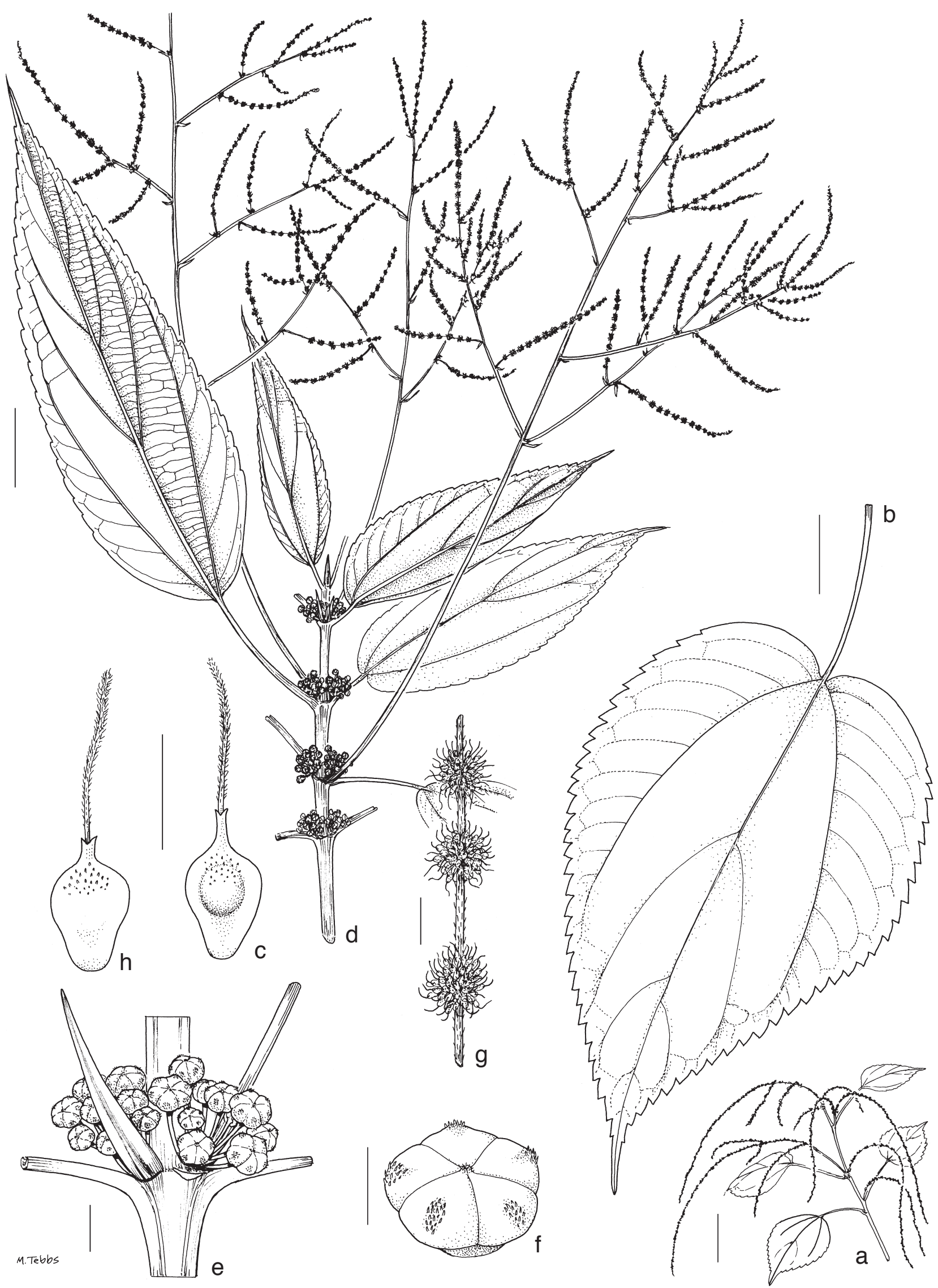

Fig. 8 a-c: Boehmeria zollingeriana Wedd. var. zollingeriana. a. Habit of plant with female inflorescence-bearing axes; b. leaf; c. winged fruiting perianth. $\mathrm{d}-\mathrm{h}$ : Boehmeria zollingeriana var. podocarpa (W.T.Wang) W.T.Wang \& C.J.Chen. d. Habit of plant with axillary male flower-clusters (inflorescences) on main stem and branched inflorescence-bearing axes with female clusters (inflorescences); e. detail of stem with stipule and pair of male flower-clusters (inflorescences), flowers pedicellate; f. male bud; g. detail of female axis with three flower-clusters (inflorescences); h. unwinged fruiting perianth (a: Winit 1422; b, c: Henry 12541A; d-f: Ford 33; g, h: Collett 922; all K). - Scale bars: a $=5 \mathrm{~cm} ; \mathrm{b}, \mathrm{d}=2 \mathrm{~cm} ; \mathrm{c}, \mathrm{f}, \mathrm{h}=1 \mathrm{~mm} ; \mathrm{e}, \mathrm{g}=2 \mathrm{~mm}$. 
Distribution - Scattered distribution in southern China.

Habitat \& Ecology — Forest, mostly shady moist places and near streams; $1100-2600 \mathrm{~m}$ altitude.

Note - This variety can be confused with $B$. japonica (see discussion under the species as a whole). A range of intermediates with the typical variety exists (discussed above under the species), sometimes with leaves of various forms on one plant.

\section{Boehmeria zollingeriana Wedd. - Fig. 8; Map 10, 11}

Boehmeria zollingeriana Wedd. (1854) 201. - Type: Zollinger 2765 (holo P; iso BO, G, U), Indonesia, Jawa [Java], Bandowosso Prov., Warmagen. Boehmeria diversiflora Miq. in Zollinger (1854 June) 101, 104 - Type: Zollinger 2765 (iso BO, G, U), Indonesia, Jawa [Java], Bandowosso Prov., “ad rupes prope Warringin". - See Note 1.

Shrub, sometimes scrambling, 3(-4) m tall; ultimate branches slender, up to $0.5 \mathrm{~mm}$ diam, glabrous or sometimes hairy, hairs sparse fine weak \pm spreading; drying often red-brown. Stipules lanceolate, $7-11(-15)$ by $1-1.5(-3) \mathrm{mm}$, fairly thick-textured. Leaves opposite (but often subopposite or alternate close to apex, especially those just below terminal inflorescence-bearing axes), not or moderately dimorphic with length of 'larger' leaves up to $2 x$ that of 'smaller' and 'larger' leaves often also relatively wider, symmetrical or with apex slightly sideways-curved, ovate to narrowly ovate (to deltate), small to large $7-19$ by $2-14 \mathrm{~cm}$, length 1.3-4x width; margin crenate or bluntly, rarely (China) sharply, serrate, teeth relatively few ether side, 8-20(-30), distinct, $0.5-2(-4)$ by $4-11 \mathrm{~mm}$, becoming indistinct or absent in proximal quarter of lamina; leaf apex gradually long-attenuate to indistinctly long-acuminate or abruptly short-acuminate; base rounded to slightly cuneate, truncate or slightly cordate, usually slightly asymmetrical; basal veins extending to middle of lamina or on adaxial side sometimes into distal third, upper lateral veins $2-4(-5)$ either side, on abaxial side usually arising slightly lower, lowermost often arising in proximal third of lamina, these and coarser \pm scalariform tertiary venation (especially veins arising between basal vein and margin) often fine-prominent abaxially; texture very thin-chartaceous, rarely thicker and leaves slightly bullate, drying dark brownish black, lighter brown below, adaxial surface usually glabrous and \pm shiny, rarely (Thailand) with an occasional minute adpressed single hair in centre of some areoles, abaxial surface with extremely sparse adpressed hairs only on veins; petiole of 'larger' leaf variable with respect to leaf-size but relatively short 0.1-0.25x lamina length, relatively even shorter on 'smaller', glabrous or sparsely hairy like the stem. Male flower-clusters simple axillary, up to $15 \mathrm{~mm}$ diam, sessile with 5-30 flowers, these loosely arranged, long-pedicellate; female clusters borne along \pm leafless axes (occasionally with 1-2 pairs of leaves in lower half, these much smaller and narrower than main-stem leaves and often alternate), axes terminal and 1 per axil in upper axils, glabrous or very sparsely spreading-hairy, drying redbrown, $20-40 \mathrm{~cm}$ long, sometimes pendulous and unbranched, more often erect and robust (sometimes pendulous towards apex) with basal third or half of main axis often naked (i.e., no flower-clusters or leaves present), much-branched in upper half with lateral branches often equalling main axis and often 1-branched again, these ultimate branches also long; bracts minute, inconspicuous, < $1 \mathrm{~mm}$ long; clusters well-spaced, 2-more than $10 \mathrm{~mm}$ apart, in flowering state small, up to 3 mm diam, with 10-30 flowers, densely congested; bracteoles narrowly linear-oblong, sometimes conspicuous, $0.5-1 \mathrm{~mm}$ long. Male flowers 5-6-merous with a conspicuous pedicel 5-8 mm long, mature buds depressed-globose, c. $2 \mathrm{~mm}$ diam, with conspicuous dorsal thickening on each lobe, glabrescent or with very sparse hairs near apex, these very fine. Female flowers up to $0.5 \mathrm{~mm}$ long, stigma variable in length but often minute, curved, 0.5-1(-1.5) mm. Fruiting perianth only $0.5-1$ by $0.4-0.8 \mathrm{~mm}$, broadly obovoid or ellipsoid with minute beak, markedly dorsiventrally flattened with marginal rim or distinct thick-textured marginal wing, with inconspicuous hairs, these very sparse, short, fine; achene filling most of fruiting perianth.

Distribution - South-eastern India and from Burma to southwestern China (including Taiwan), Thailand, Laos, Vietnam, Indonesia (Jawa) and Philippines (Luzon).

Habitat \& Ecology - Evergreen and deciduous forest, maritime forest and open shrubby areas; sea level-1400 m altitude.

Conservation status - Least Concern (LC). The species is known from at least 200 collections, many of which are recent, and it occurs in many widely scattered location, and in a wide range of habitats, with an EOO of $6683520 \mathrm{~km}^{2}$.

Notes - 1. Boehmeria zollingeriana was independently described in the same year as $B$. diversiflora and based on a different duplicate of the same collection; the exact month of publi-

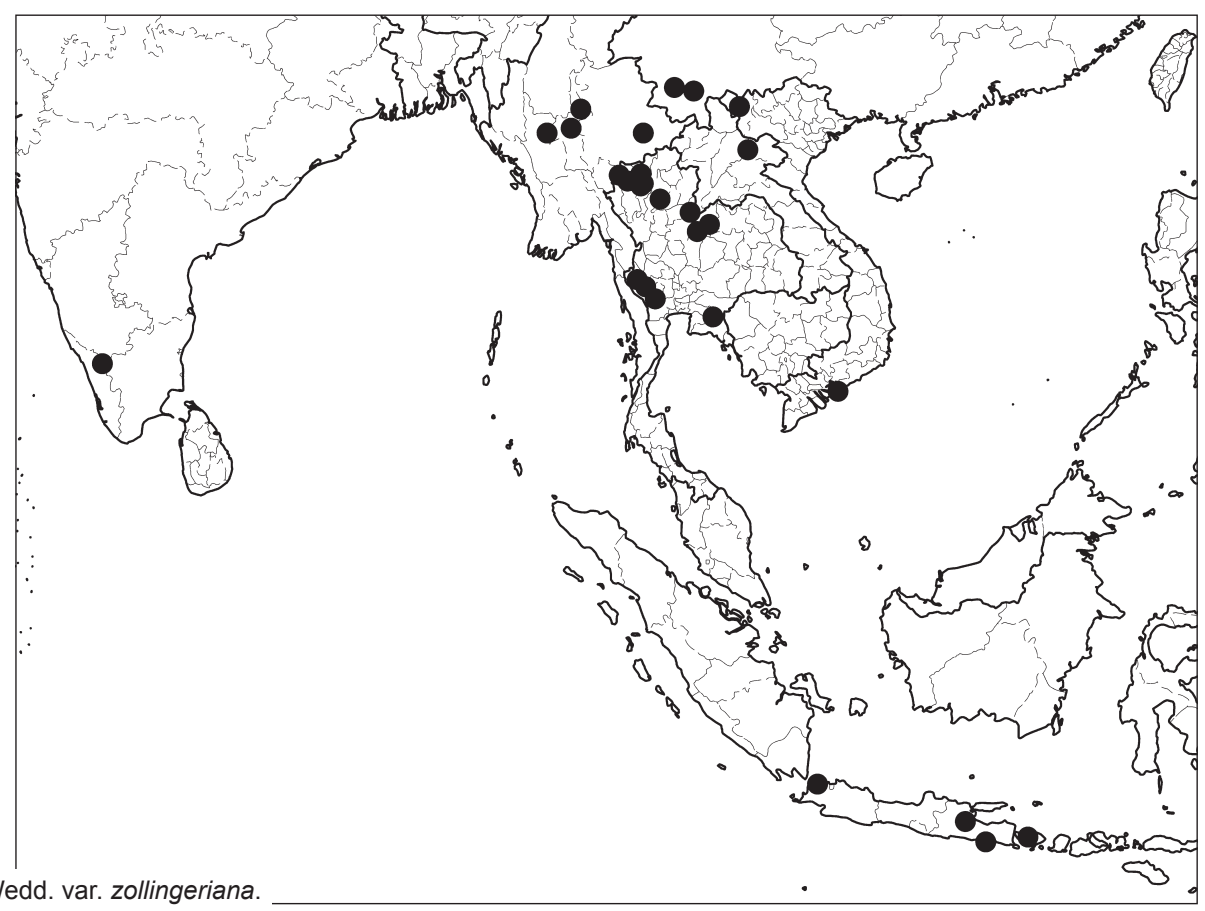


cation (and therefore priority) of both names cannot be ascertained but $B$. zollingeriana is maintained here as it is the name in current use.

2. This species is normally easily recognisable. It is unique in the genus in having male and female clusters very differently arranged, female on specialised leafless axes, male ones simple axillary; male flowers are also unique in the Old World in being 5-6-merous (rather than 4-merous) and in pedicels being many times longer than in any other species. Axillary clusters of pedicels usually remain long after male flowers have fallen and are good distinguishing character from all other species even in fruiting specimens. Its glabrous appearance in most parts, stems and inflorescence-axes drying red-brown, inflorescence-bearing axes long but robust, erect, \pm branched, the fruiting perianth often very small and broad and leaves \pm glabrous, shiny, usually with rounded base, are also useful distinguishing characters.

3. Boehmeria leptostachya which was hitherto confused with this species, has similarly red-tinged stems, petioles and axes but differs markedly in its male flowers \pm sessile and borne along the slender leafless bisexual axes and in its leaves \pm elliptic, abundantly minute-hairy adaxially with basal veins extending nearer to lamina apex and lowermost lateral veins arising nearer apex.

4. Specimens consisting only of the apical part of a branch and therefore lacking the distinctive axillary male clusters can be mistaken for $B$. virgata subsp. virgata var. virgata (sympatric only in Jawa) whose wide range of variation in leaf shape, -texture and indumentum overlaps. However, B. virgata never has alternate leaves even in the upper part of stems.

5. Two varieties are recognised, partly sympatric (Burma, China, Thailand and Indonesia (Jawa)). Var. zollingeriana is also known from southern India (from only one collection, suggesting that it is under-collected) and occurs in both forest and more open habitat. It has leaves broadly ovate to deltate with relatively long, rounded teeth, female axis with clusters throughout length, often unbranched and very long (up to $40 \mathrm{~cm}$ ), \pm pendulous. Var. podocarpa is also known from Taiwan and the Philippines and appears to be restricted to forest; it has leaves narrowly ovate, with shallow, sometimes acute teeth,

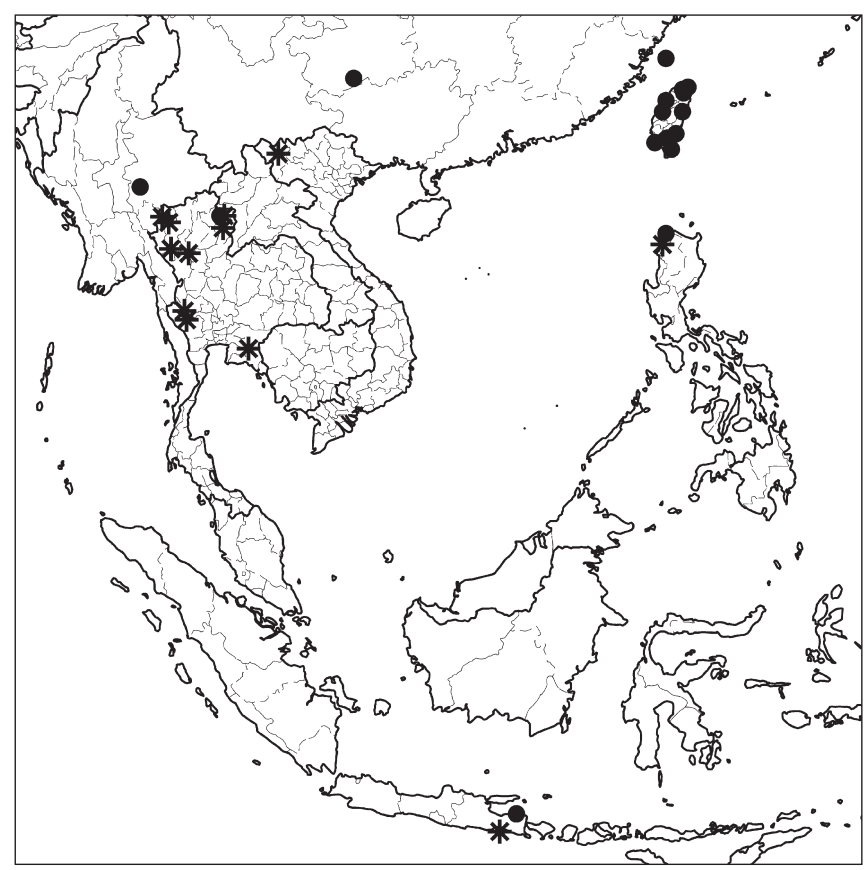

Map 11 Distribution of Boehmeria zollingeriana Wedd. var. podocarpa (W.T.Wang) W.T.Wang \& C.J.Chen $(\mathbf{O})$ and intermediates between var. zollingeriana and var. podocarpa (*). female axes generally shorter (up to $25 \mathrm{~cm}$ ), much-branched and erect (except for pendulous tip) with clusters often absent from lower quarter or half of axis. At the extremes of their range of variation the two varieties look very different, but forms impossible to assign to either variety, with leaves shallowly crenate as in var. podocarpa but of intermediate length and proportion have been seen from Indochina, Philippines and Jawa. Yahara (1981: 13) noted this variation in leaf proportions and margin in Thai material. In Taiwan var. podocarpa sometimes has fine weak hairs on young stems and petioles; the glabrous more widespread forms were recognised by Chen et al. (2003) as var. blinii (H.Lév.) C.J.Chen, but indumentum in Taiwan ranges from (rarely) abundant to sparse to \pm absent and no formal distinction is possible.

6. Leaves of var. podocarpa are rather like those of the partly sympatric $B$. hamiltoniana in shape but drying dark brownish black rather than green, usually shinier, never membranous and sometimes thick-chartaceous and upper veins are more numerous spaced throughout length rather than only in distal half.

7. Var. podocarpa is easily distinguishable from most other species of Boehmeria (even when the diagnostic male clusters are absent) by leaves narrow, attenuate, \pm glabrous, rather shiny with relatively numerous lateral veins throughout length and female axes much-branched erect with a long naked lower portion. Var. zollingeriana is less distinctive with its broader, acuminate leaves with lateral veins fewer, often all in distal half of lamina, and female inflorescence-bearing axes often pendulous, unbranched or few-branched, and has been confused with broader cordate forms of the widespread $B$. virgata subsp. macrophylla, which, however, has leaves dentate rather than crenate always with inconspicuous hairs adaxially (rather than shiny \pm glabrous or with occasional scattered hairs), and the stem is hairy at least near its apex.

8. Var. podocarpa is also often vegetatively somewhat similar to Pouzolzia sanguinea var. sanguinea, and can be misidentified when flowers and fruiting perianths are absent. Pouzolzia sanguinea differs in flower-clusters all similarly arranged, mostly axillary and often bisexual; male flowers are subsessile and female flowers are large $(0.8-1.3 \mathrm{~mm}$ diam) with stigma often very long $(1.5-5 \mathrm{~mm})$; the fruiting perianth is large $(1.5-2 \mathrm{~mm}$ diam), ribbed but not flattened or winged.

\section{Key to varieties}

1. At least lower leaves broadly ovate or deltate-truncate with length only up to $1.4 \times$ width and apex abruptly short-acuminate; female inflorescence-bearing axes often pendulous, (20-)30-40 cm long, with clusters throughout most of length, few-branched or sometimes entirely unbranched

a. var. zollingeriana

1. All leaves narrowly ovate with length more than $2 \times$ width, apex gradually long-attenuate; female inflorescence-bearing axes much branched and erect, $20-25 \mathrm{~cm}$, with clusters often absent from lower quarter or half of axis. . .

\section{b. var. podocarpa}

\section{a. var. zollingeriana - Fig. $8 a-c$; Map 10}

Boehmeria heteroidea Blume (1857) 216. - Type: Helfer s.n. (holo L; iso W), Himalaya.

Boehmeria heteroidea Blume var. Iatifolia Gagnep. (1929) 844. - Boehmeria zollingeriana Wedd. var. latifolia (Gagnep.) T.H.Nguyên (2003) 210. — Syntypes: Pierre 4808 (P; isosyn NY), Vietnam, [Cochinchina], Monts Dinh, Baria; Kerr s.n. (n.v.), Thailand, Doi Sutep.

Stem and petioles glabrous. Leaves broadly ovate or deltate, medium or large, $14-19$ by $9.5-14 \mathrm{~cm}$, length $1.3-1.4 \times$ width; margin always crenate, teeth c. 2 by $8 \mathrm{~mm}$; leaf apex with abrupt short acumen; base rounded to truncate or cordate; 
upper lateral veins usually only $2-3$, lowermost often arising near middle of lamina, coarser scalariform tertiary veins often conspicuous \pm prominent abaxially. Male clusters often with only 5-10 flowers. Female inflorescence-axes often pendulous, without robust naked basal region, (20-)30-40 cm, often unbranched or few-branched.

Distribution - Throughout the range of the species excluding Taiwan and the Philippines.

Habitat \& Ecology - Deciduous or evergreen forest or open areas with shrubs and stunted trees, including beach forest, often on limestone; sea level-1100 m altitude.

Note - See under the species as a whole.

\section{b. var. podocarpa (W.T.Wang) W.T.Wang \& C.J.Chen - Fig.} 8d-h; Map 11

Boehmeria zollingeriana Wedd. var. podocarpa (W.T.Wang) W.T.Wang \& C.J.Chen in Chen et al. (2003) 168. - Boehmeria blinii H.Lév. var. podocarpa W.T.Wang (1981a) 323. - Type: Masamune 827 (not traced), Taiwan, Xindien, 19 June 1930

Boehmeria blinii H.Lév. (1913) 551. - Boehmeria wattersii (Hance) B.L.Shih \& Yuen P.Yang var. blinii (H.Lév.) B.L.Shih \& Yuen P.Yang (1998) 151. - Boehmeria zollingeriana Wedd. var. blinii (H.Lév.) C.J.Chen in Chen et al. (2003) 168. - Type: Esquirol 940 (holo P, not traced), China, Guizhou, Potchang, Aug. 1908.

Boehmeria wattersii (Hance) B.L.Shih \& Yuen P.Yang (1998) 150. — Pilea wattersii Hance (1885) 327. - Type: Watters in herb Hance 22296 (holo BM, photo K), Taiwan, Tam Sui, Apr. 1882.

Stem and petioles sometimes hairy, hairs sparse (to abundant), fine, weak. Leaves narrowly ovate, small to medium, 7-15 by $2-4.5 \mathrm{~cm}$, length $2.2-4 \times$ width; margin crenate or bluntly (China rarely sharply) serrate, teeth $0.5-1$ by c. $4 \mathrm{~mm}$; leaf apex gradually long-attenuate to indistinctly long-acuminate; base rounded to slightly cuneate or slightly cordate; upper lateral veins often prominent, mostly $4-5$ at least on abaxial side, lowermost always arising in lower quarter to third so that lateral veins are spaced \pm throughout leaf, coarser scalariform tertiary veins not markedly prominent. Male flower-clusters with 20-30 flowers; female inflorescence-bearing axes erect and often robust in basal part, pendulous only near apex, 20-25 $\mathrm{cm}$ long, much-branched, lateral branches often once-branched again, but main axis with a long basal region (up to $0.5 \times$ total axis length) which is unbranched and naked (i.e., without nodes bearing clusters)

Distribution - Burma, southern China (including Taiwan), northern Thailand, Indonesia (Jawa), Philippines (Luzon).

Habitat \& Ecology - Forest, especially dense montane forest, sometimes on exposed rocky outcrops within forest; (100-)300-1400 m altitude.

Note - See under the species as a whole.

\section{Boehmeria leptostachya Friis \& Wilmot-Dear - Fig. 9; Map 12}

Boehmeria leptostachya Friis \& Wilmot-Dear in Wilmot-Dear et al. (2010) 441. - Type: Geesink et al. 7428 (holo K; iso AAU, BKF, L, S), Thailand, Peninsula, Ranong, Khao Pawta Luang Keow, 22 June 1974.

Boehmeria erythropoda sensu Yahara (1981) 15, non Miq. - See Note 1.

Shrub, 2-4 m tall; ultimate branches 1-15 mm diam, glabrous drying red-brown. Stipules lanceolate $4-7$ by $1-1.5 \mathrm{~mm}$, rather thick-textured. Leaves opposite, very variably slightly or moderately dimorphic in size, with length of 'larger' leaves 1.3-1.7(-2.7)× 'smaller', \pm symmetrical or with abaxial side slightly broader than adaxial, most leaves on most branches elliptic, often a few elliptic-ovate, medium to large, 'larger' $13-18$ by $5-7 \mathrm{~cm}$, length $2.1-2.8 \times$ width; margin shallowly and broadly crenate to bluntly serrate, with 30-35 teeth either visible throughout length or progressively shallower towards base and only discernible in distal $2 / 3$ of margin, up to 0.7 by 5-8 $\mathrm{mm}$; leaf apex short-attenuate to indistinctly or abruptly short-acuminate; base slightly asymmetrically short-cuneate; basal veins extending to distal third of lamina or on adaxial side almost to tip, upper lateral veins 2(-3), lowermost on adaxial side arising near middle of lamina, on adaxial side in distal third, slender inconspicuous adaxially, fine-prominent abaxially, coarser tertiary venation \pm scalariform fine-prominent abaxially; texture membranous or very thin-chartaceous, both surfaces green when living but drying consistently dark brownish black adaxially and lighter brown abaxially with especially veins redtinged, adaxial surface \pm shiny (said to be sticky when live: Yahara 1981) with sparse hairs, these minute (<0.2 mm long), adpressed; abaxial surface with sparse hairs even smaller, finer, often \pm spreading; petiole hairy as lamina, drying red-tinged, in 'larger' leaves relatively long, 0.3-0.5x lamina length, in 'smaller' leaves much shorter (often only $0.1 \times$ lamina length). Flower-clusters borne along leafless axes, these \pm pendulous very slender, $10-50 \mathrm{~cm}$ long, unbranched; bracts minute, inconspicuous, $1-1.5$ by $1-1.5 \mathrm{~mm}$; clusters well-spaced, $2-$ more than $5 \mathrm{~mm}$ apart, most clusters with both sexes, clusters small, 1.5-2 mm diam, with up to $10(-15)$ flowers; bracteoles minute inconspicuous. Male flowers 4-merous; pedicels up to $0.5 \mathrm{~mm}$ long, mature buds depressed-globose, 1.2-1.5 mm diam, with conspicuous dorsal thickening on each lobe and sparse fine hairs like leaves. Female flowers up to $0.5 \mathrm{~mm}$ long, stigma often minute, down curved, $0.3-1.5 \mathrm{~mm}$ long. Fruiting perianth only $0.7-0.9$ by $0.5-0.7 \mathrm{~mm}$, very broadly ovoid or ellipsoid with minute beak, markedly dorsiventrally flattened with marginal ridge or narrow thick-textured wing, sparsely hairy, hairs short, \pm spreading. Achene filling most of fruiting perianth.

Distribution - Southern China, southern Thailand, Indonesia (Sumatera).

Habitat \& Ecology - Evergreen forest on clay or shale, often in damp places along stream banks; 500-900 m altitude.

Conservation status - Vulnerable (VU). The conservation status was assessed by Wilmot-Dear et al. (2010: 443). It has been collected so seldom that it is believed to be uncommon and vulnerable to extinction if habitat conversion continues.

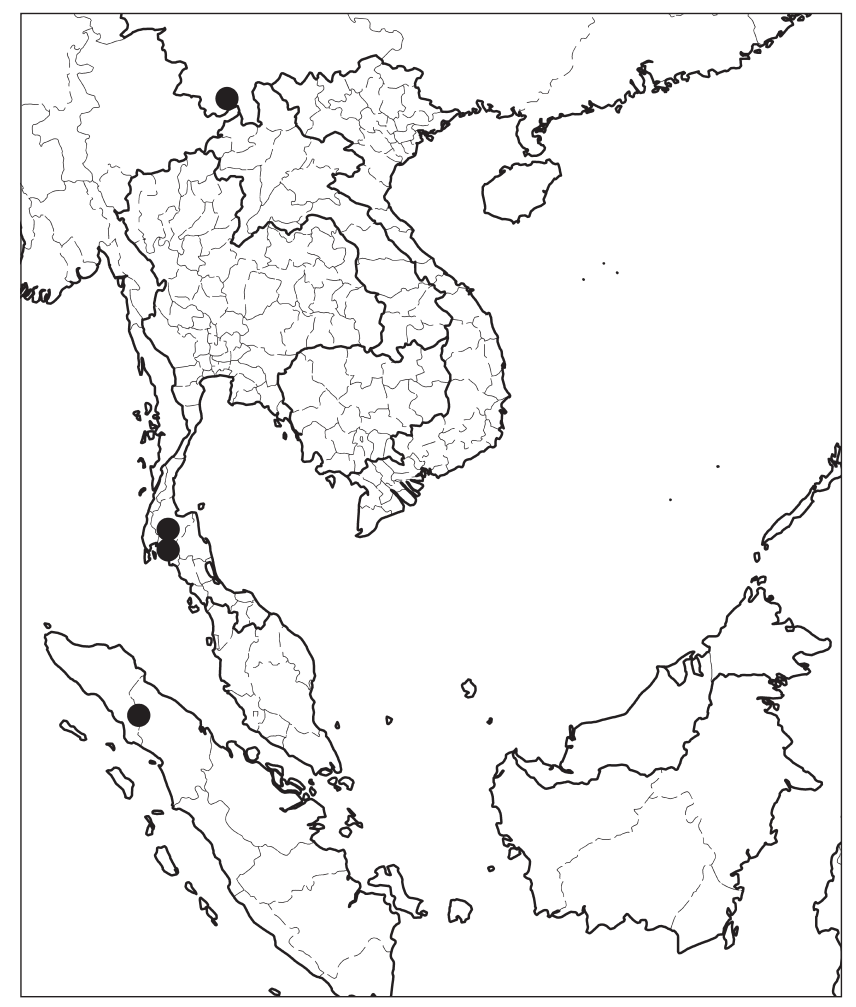

Map 12 Distribution of Boehmeria leptostachya Friis \& Wilmot-Dear. 

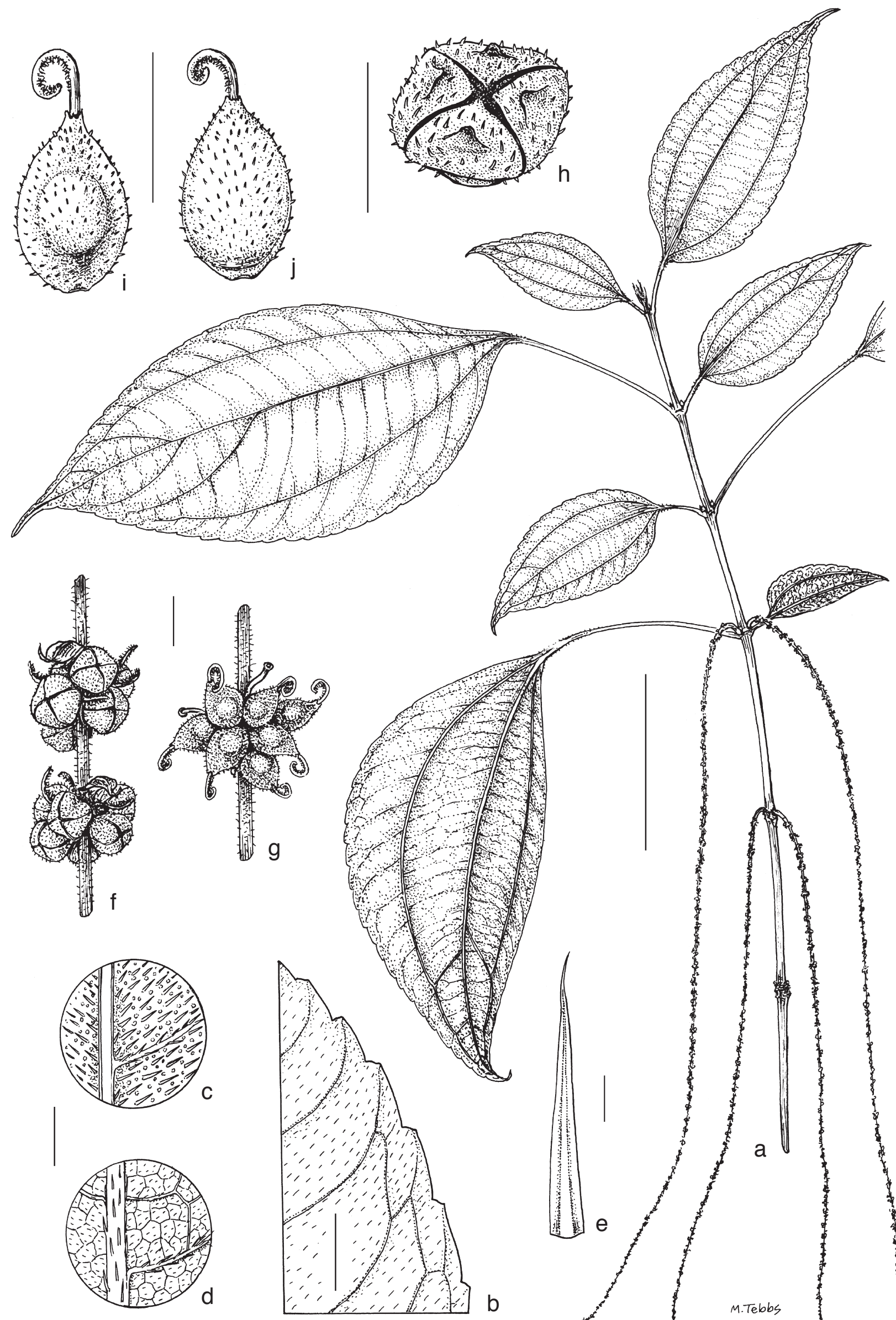
Notes - 1. Yahara (1981: 15) recognised and mentioned the distinctive appearance of this taxon but did not describe it as new, apparently believing that the name $B$. erythropoda applied to this taxon. He had probably not seen the type of $B$. erythropoda (from Jawa) which is a different entity referable to the Southeast Asian taxon $B$ virgata subsp. virgata var. virgata. Thin-leaved forms of $B$. virgata var. virgata are often similar in leaf shape and teeth, but differ in stems hairy, fruiting perianth with a wide wing and plants drying green rather than brown, flower-clusters often crowded along axis, male flowers in unisexual clusters on separate axes or separate branches.

2. This species appears to be rare and with a strangely disjunct distribution, but it is possibly overlooked, and might be expected to occur also in Indochina. Material seen is as follows: China, Yunnan, Xishuangbanna Dist., Jing Hong city, 21 v 1958 , Class of 1958 no. 2437 (PE); Thailand (Pen.), Ranong, Khao Pawta Luang Keow, 30 i 1929, Kerr 16899 (K) \& 22 vi 1974, Geesink et al. 7428 (AAU, BKF, K, L, S); Indonesia, Sumatera Utara [North Sumatra], Karo, Laubaleng, 4 ix 1974, S. Yoshida 1975 (L).

3. It is very distinctive in its leaves extremely thin-textured, relatively large, shiny, elliptic, with hairs abundant and minute, marginal teeth indistinct, its veins, petioles and inflorescencebearing axes distinctly red-tinged, and its slender inflorescencebearing axes with clusters few-flowered and bisexual. However, some duplicates of these four collections were previously identified as either $B$. zollingeriana or $B$. hamiltoniana.

Boehmeria zollingeriana (sympatric but common and widespread) is rather similar in habit, fruit-form, leaf shape and -texture and in its red-tinged petioles, stems and inflorescencebearing axes. Fertile specimens of $B$. zollingeriana are easily distinguished by their male clusters sessile, axillary with longpedicellate 5-6-merous male flowers and their inflorescencebearing axes entirely female, robust with large flower-clusters; leaves of $B$. zollingeriana are also ovate, \pm glabrous adaxially or with hairs longer $(0.3-0.4 \mathrm{~mm})$ but extremely sparse, basal veins extending little into distal half and some lateral veins arising nearer leaf base than in $B$. leptostachya.

Boehmeria hamiltoniana (sympatric but slightly more widespread) is somewhat similar to $B$. leptostachya in leaf shape and -texture and in the shape of its fruiting perianth, differing in leaves entirely glabrous adaxially, relatively narrower with acumen markedly long and marginal teeth mostly closerspaced, female flower-clusters usually crowded along the axes and often many-flowered; in the dry state the two are easily distinguished, the leaves of $B$. hamiltoniana drying consistently distinctly greenish.

\section{Boehmeria lanceolata Ridl. - Fig. 10a-j; Map 13}

Boehmeria lanceolata Ridl. (1911, nec 1910) 94. - Type: Ridley 14645 (holo $\mathrm{K}$; iso BM), Malaysia, Perak State, Tenmangoh, July 1909.

Boehmeria tonkinensis Gagnep. (1928) 127. - Syntypes: Petelot 723 (P), Vietnam, Tonkin, Pia-ouac; Poilane 10474 (P; isosyn A), Vietnam, Annam, Mai Lanh, pres de Quang Tri, 21 May 1924; Poilane 12172 (P), Laos, Tchepone; McClure $9146(\mathrm{P})$, China, Hainan. - See Note 1.

Boehmeria lohuiensis S.S.Chien in Chun et al. (1963) 355, syn. nov. - Type: Z.S. Chung 534 (holo HC), China, Hainan, Lohui Dist., 15 Sept. 1953. See Note 2

Shrub or subshrub, 1-2 m tall; ultimate branches quadrangular, up to $1.2 \mathrm{~mm}$ diam, hairy, hairs abundant but inconspicuous, adpressed. Stipules linear, fairly long, c. 9 by $1.2 \mathrm{~mm}$, glabrous very soon caducous. Leaves opposite, not or slightly dimorphic in size with 'larger' up to $1.5 \times$ length of 'smaller' and sometimes relatively narrower, \pm symmetrical, linear-oblong-obovate (i.e., margins almost parallel for most of length, but widest above the middle), small or medium-sized, $6-11(-14)$ by $3(-5.5) \mathrm{cm}$, length $3.5-$ more than $4 \times$ width; margin dentate with $20-30$ teeth (number increasing with leaf-size), $0.5-1$ by $3 \mathrm{~mm}$, rather rounded in outline but each with an abruptly apiculate tip; leaf apex broad-acute or with short indistinct broad acumen; base gradually attenuate to short-cuneate or narrowly rounded, outline of base and apex often similar; basal veins extending into distal third or nearly to tip, upper lateral veins 1-2(-3) either side but very indistinct, with lowermost arising in distal quarter or third, inconspicuous adaxially, basal veins finely prominent abaxially; coarser tertiary venation somewhat scalariform often visible abaxially; texture thin-chartaceous; glabrous adaxially (or with occasional single hair in centre of areoles, these always present in very young leaves at stem apex), adaxial surface with numerous cystoliths; abaxial surface hairy on veins only, hairs very sparse, inconspicuous, adpressed; petiole $0.5-2.5$ $\mathrm{cm}$ long, only $0.1-0.2 \times$ lamina length. Flower-clusters borne on leafless axes, these straight erect, up to $11 \mathrm{~cm}$ long, 1 per axil, but often with 1-2 branches close to base and thus appearing as if several axes from axil; clusters spaced only 1-3 $\mathrm{mm}$ apart and thus almost contiguous when mature, $2-3 \mathrm{~mm}$ diam, male clusters in distal part of axis with up to 10 flowers, female clusters proximal with up to c. 15 flowers; bracteoles broadly triangular but minute, inconspicuous, $<0.3 \mathrm{~mm}$ long. Male flowers 4-merous, sessile or subsessile, mature buds c. $1 \mathrm{~mm}$ diam, tepals with very distinct dorsal appendages up to $0.2 \mathrm{~mm}$ long, sparsely hairy. Female flowers with stigma only $0.8-1.2 \mathrm{~mm}$ long. Fruiting perianth very short and broad, 0.80.9 by $0.7 \mathrm{~mm}$, subspherical-obovoid (to ovoid) with broadly rounded base, variable either scarcely laterally flattened and with no marginal rim or distinctly laterally flattened with marginal wing-like rim to 3-4-angled; glabrous or short-spreading-hairy. Achene filling fruiting perianth.

Distribution - Southern China (including Hainan), northern Vietnam, Laos, Thailand, Malaysia (Perak).

Habitat \& Ecology - Primary season or mixed evergreen and deciduous forest, secondary forest, thickets, moist open areas, rocky areas in ravines; 180-700 m altitude.

Conservation status - Near Threatened (NT). The species is known from only 20 collections, some of which are recent, from fairly scattered locations, with some considerable gaps in the range. The EOO of $1153440 \mathrm{~km}^{2}$ is therefore probably exaggerated. The AOO gives a figure of less than $500 \mathrm{~km}^{2}$. It occurs in a moderate range of habitats, mainly forests, and although the habitats are not currently threatened by serious degradation, and it therefore does not meet the criteria for a formal status of Vulnerable (VU), it may become so in the future with increasing agriculture in the region.

Notes - 1. Boehmeria tonkinensis was reduced to synonymy by Chen et al. (2003, 2005), since its distinctive characters fall within the range of variation of $B$. lanceolata (Ridley was mistaken in describing the male flowers of $B$. lanceolata as 5-merous). Hainan and Tonkin have a very similar flora with many species in common, these often localised around the Beibu [Tonkin] Gulf.

2. Boehmeria lohuiensis is here reduced to synonymy. Although the type has not been seen, its identity is clear from its description and diagnosis. The leaves are larger than otherwise seen (up to $14 \mathrm{~cm}$ rather than $11 \mathrm{~cm}$ long) and marginal teeth are stated to be 'larger' (size not stated) but other stated differences (leaf base cuneate, inflorescence-bearing axis up to $10 \mathrm{~cm}$ long, branched dichotomously at base and with scattered clusters) in fact fall within the range of variation of $B$. lanceolata. In addition, many of the particularly distinctive features of $B$. lanceolata (leaves thin-textured \pm glabrous, marginal teeth sharply apiculate, flowers minute and fruiting perianth very small ovoid), are clearly depicted in the ample description.

3. Boehmeria lanceolata is apparently rare (only a few populations so far known), but probably also under-collected, 


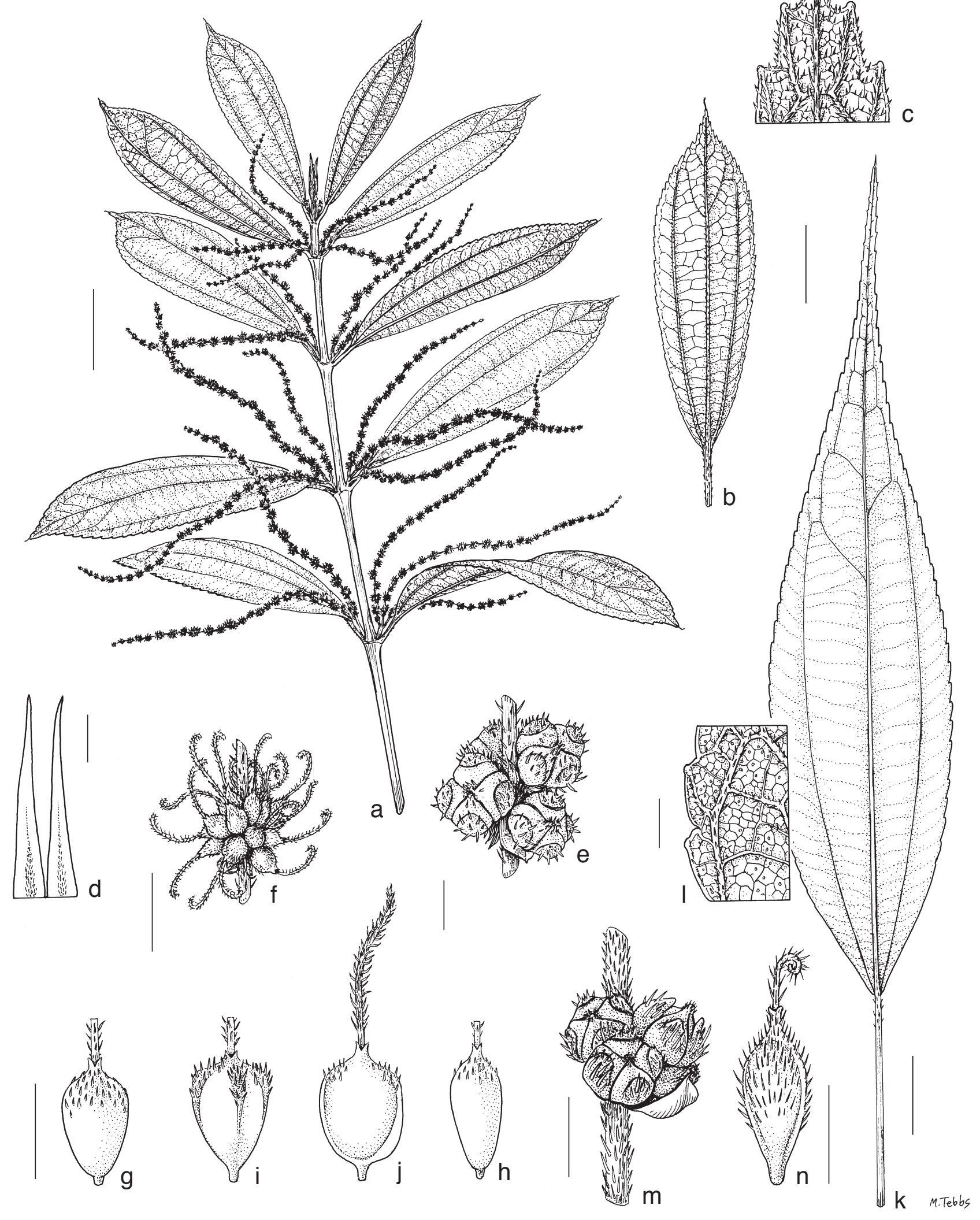

Fig. 10 a-j: Boehmeria lanceolata Ridl. a. Habit, upper part of stem with inflorescence-bearing axes; b. leaf; c. detail of leaf apex; d. stipule; e. detail of male inflorescence-bearing axis showing one cluster (inflorescence); f. detail of female inflorescence-bearing axis showing one cluster (inflorescence); $\mathrm{g}-\mathrm{j}$. fruiting perianths of different form (from same plant: $\mathrm{g}$, h. unribbed; i. four-angled; j. fruiting perianth with marginal rim). $-\mathrm{k}-\mathrm{n}$ : Boehmeria hamiltoniana Wedd. k. Leaf; I. detail of leaf margin; $m$. detail of male inflorescence-bearing axis showing one cluster (inflorescence); $n$. fruiting perianth (a-f: Hiep 130; g-j: Tsang 30455; k, l: Gamble 7291; m, n: Clarke 27246; all K). — Scale bars: a, b, k = 2 cm; c, e-j, m, n = 1 mm; d, I = 2 mm. 
only one collection so far seen from each of Laos, Thailand and Malaysia. It is easily distinguished from all other species of Boehmeria by its leaves linear-oblong-obovate (i.e., margins almost parallel for most of length, but widest above the middle) with base and apex similar in outline or with base more tapering than apex and its fruiting perianth small almost spherical with a broadly rounded base.

4. It can also be distinguished from most taxa by its leaves being thin-textured, \pm glabrous adaxially, with long basal veins and few upper veins, and its inflorescence-bearing axes short, slender, erect, dichotomously branched close to base. The partly sympatric $B$. hamiltoniana is somewhat similar but leaves are membranous often relatively narrower, stems glabrescent and female inflorescence-bearing axes \pm pendulous, often longer. The partly sympatric $B$. densiflora is also similar in general appearance, but has inflorescence-bearing axes unbranched, solitary and leaves often thicker-textured.

\section{Boehmeria hamiltoniana Wedd. - Fig. $10 \mathrm{k}-\mathrm{n}$; Map 13}

Boehmeria hamiltoniana Wedd. (1856) 371. - Boehmeria platyphylla D.Don var. hamiltoniana (Wedd.) Wedd. (1869) 213. - Type: Wallich 4590 (holo K-WALL), Nepal, 1821.

Boehmeria ingjiangensis W.T.Wang (1981b) 414, syn. nov. - Type: G.D. Tao 13627 (holo KUN), China, Yunnan, Ingjiang, 4 Oct. 1974.

Shrub, up to $5 \mathrm{~m}$ tall; ultimate branches fairly slender, 0.8-1.2 $\mathrm{mm}$ diam, glabrous or with sparse fine hairs near apex, soon glabrescent. Stipules very narrowly triangular, 7 by $1.5 \mathrm{~mm}$, robust, glabrescent, soon deciduous. Leaves opposite, slightly dimorphic in size and shape with 'larger' leaves c. $1.5 \times$ length of 'smaller' leaves; asymmetrical or not, narrowly ovate-attenuate, fairly long, $(6-) 12-20$ by $(1.5-) 2-4.5 \mathrm{~cm}$, length $3-6 \times$ width; margin irregularly and often indistinctly serrate (rarely largest leaves crenate), teeth $20-30(-40)$ either side, shallow, $0.5-1$ by (1.5-)2-5 $\mathrm{mm}$, their upper margin convex; leaf apex gradually tapering long-attenuate and sometimes slightly sideways-curved; base short-cuneate; basal veins usually extending almost to tip, upper lateral veins rather indistinct, unequally arranged 1-2 on one side with both arising near tip and $2(-3)$ on other side with lowermost arising in distal third or rarely near middle of lamina; venation inconspicuous adaxially, basal veins finely prominent abaxially, coarser tertiary venation somewhat scalariform often visible abaxially; texture membranous or very thin-chartaceous, drying light or deep dark green; adaxial surface glabrous and almost shiny with many prominent cystoliths; abaxial surface glabrous or with hairs on veins, these very sparse, adpressed; petiole $5-6 \mathrm{~cm}$ long, very variable, relative to lamina, often more than half of lamina length. Flower-clusters borne on leafless axes, these 1-several from each axil and each axis often forked once or twice near base, male inflorescence-bearing axes 4-9 cm long in lower axils, female ones \pm pendulous, (7-)10-20 cm long in upper axils, some axes with both sexes; clusters very crowded almost contiguous or spaced, up to $5 \mathrm{~mm}$ apart, male clusters $2-4(-5)$ $\mathrm{mm}$ diam, with c. 3-10 crowded flowers; female clusters 1.5-3 $\mathrm{mm}$ diam, with 15-30(-more than 50) flowers; bracts broadly triangular but minute, $0.5-0.8 \mathrm{~mm}$ long. Male flowers 4-merous, sessile, mature buds globose and slightly depressed, relatively large, $1.5 \mathrm{~mm}$ diam, tepals with prominent dorsal appendage, glabrous or very sparsely adpressed-hairy. Female flowers up to $0.8 \mathrm{~mm}$ long, sparsely fine-hairy; stigma only $0.7-0.8(-1)$ $\mathrm{mm}(-1.2 \mathrm{~mm}$ in Thailand). Fruiting perianth only $0.6-1$ by 0.3-0.4 mm, ellipsoid or obovoid, somewhat laterally flattened with marginal rim becoming \pm wing-like in distal part, (sparsely-) abundantly hairy, hairs spreading, usually very short. Achene filling most of fruiting perianth.

Distribution - Eastern Himalayas: north-eastern India (Sikkim, Meghalaya, Arunachal Pradesh, Nagaland), Nepal, Bangladesh, Bhutan, Burma, southern China, northern Thailand. The single record from Indonesia (Jawa) is presumed introduced, see discussion in Note 1.

Habitat \& Ecology - Steep valleys in subtropical forest, gallery forest, open limestone outcrops in mixed forest; $800-$ $2000 \mathrm{~m}$ altitude.

Conservation status - Near Threatened (NT). The species is known from c. 50 collections, some of which are recent, with an estimated EOO of $962172 \mathrm{~km}^{2}$, but an AOO of less than $500 \mathrm{~km}^{2}$. It occurs in many scattered locations and in fairly restricted forest habitat. Although the habitats in many of its localities are not currently threatened by serious degradation, and it therefore does not meet the criteria for a formal status of Vulnerable (VU), it may become so in the future with increasing agriculture in these regions.

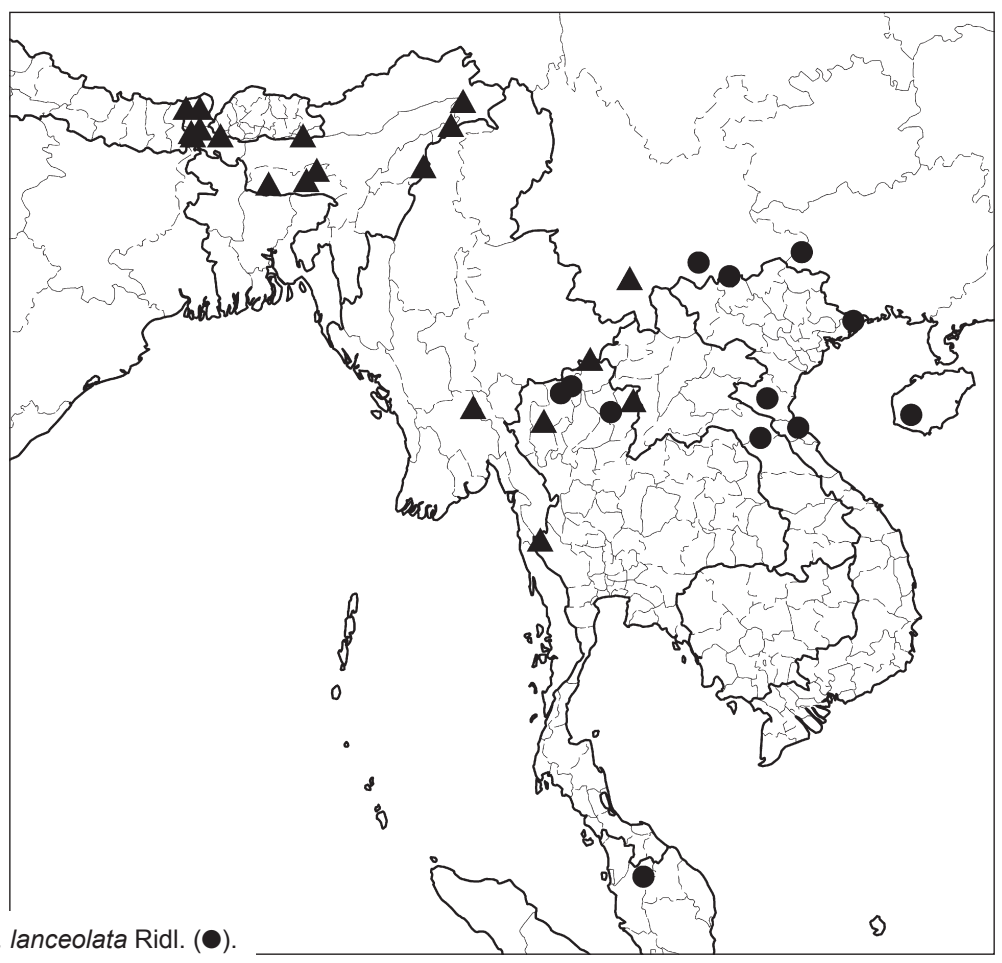




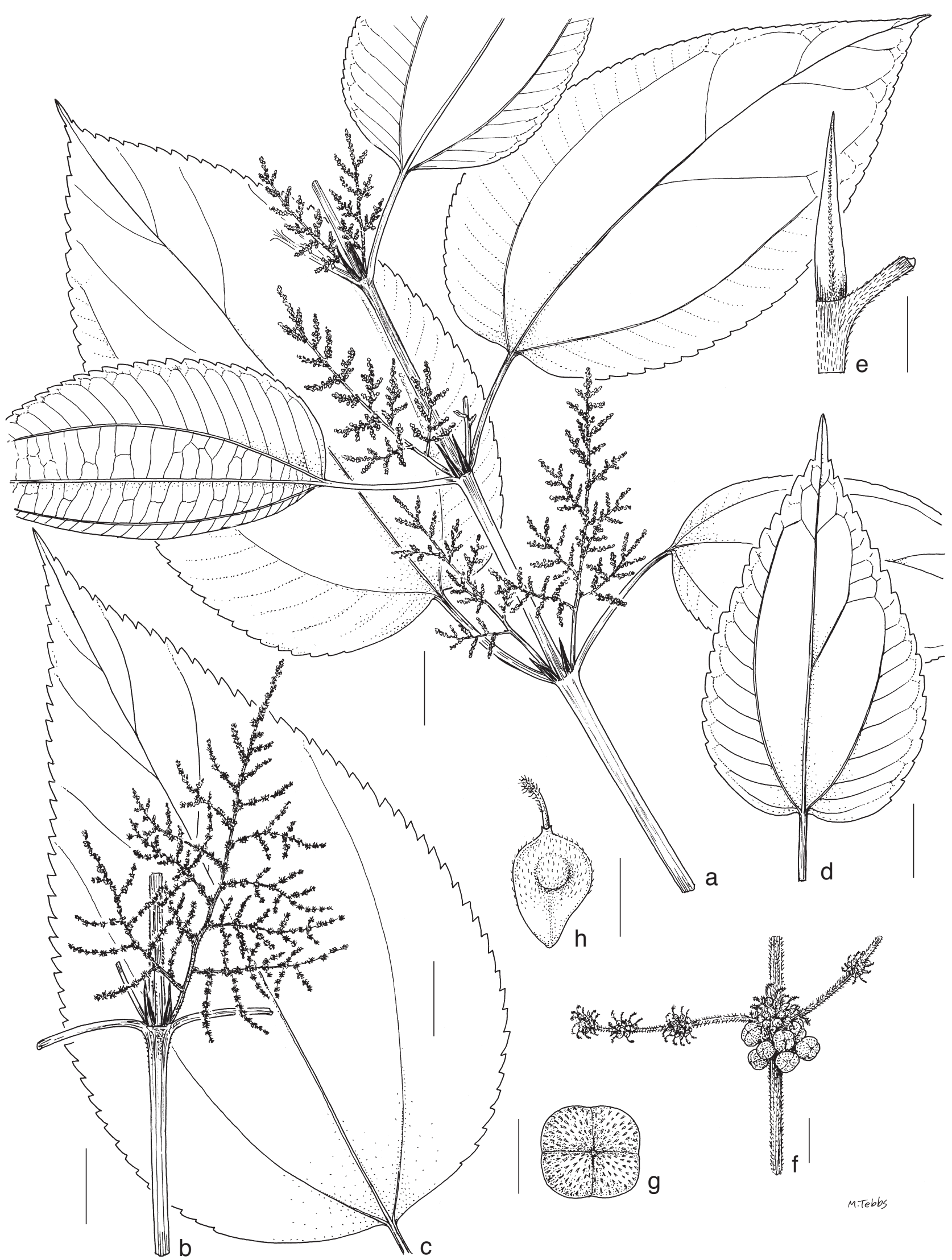

Fig. 11 Boehmeria polystachya Wedd. a. Habit with branched, immature inflorescence-bearing axes; b. part of stem with branched, mature inflorescencebearing axes; $c$, d. leaves of different form (from different plants); e. detail of stem indumentum and stipule; $f$. detail of inflorescence-bearing axes with female and bisexual clusters (inflorescences); g. male bud; h. fruiting perianth (a: Gamble 906A; b: Gamble 7103; c, e: KEKE 897; d: Hooker \& Thomson s.n.; f, g: Clarke 26736B; h: Clarke 26467C; all K). - Scale bars: a-d, f = $2 \mathrm{~mm}$; e $=5 \mathrm{~mm} ; \mathrm{g}, \mathrm{h}=1 \mathrm{~mm}$. 
Notes -1 . The record from Jawa is probably an accidental introduction, since the collection (Van Harreveld 6665 (L)) states "Experimental station of the Javanese sugar industry". It has therefore not been mapped or included in the assessment of conservation status.

2. Distinctive in its leaves membranous, long-attenuate, drying consistently light or dark green, often glabrous and/or only indistinctly toothed, with basal veins long and upper veins few, inconspicuous, its inflorescence-bearing axes often dichotomously forked at the extreme base, the males axes short and slender with few-flowered clusters, and its fruiting perianth small, relatively broad with width often almost equalling length. It is otherwise rather similar to the partly sympatric (China) $B$. densiflora which differs in leaves mostly thicker-textured with fine adpressed hairs adaxially and tepals of male flowers without dorsal appendages.

3 . The sympatric but rare $B$. leptostachya has been misidentified as this species, having leaves thin-textured with inconspicuous veins but differing in its leaves shorter, wider, broadertoothed, shiny and distinctly minute-hairy adaxially, drying consistently brownish black with veins, petioles and inflorescencebearing axes all distinctly red-tinged, and its flower-clusters well-spaced with few flowers.

4. The partly sympatric $B$. lanceolata also has similar venation but leaves obovate, thicker-textured, relatively wider, stem fine-hairy and female inflorescence-bearing axes erect.

5. Boehmeria zollingeriana var. blinii has somewhat similar leaves but drying markedly brownish black with upper veins more numerous and conspicuous; fertile material is easy to distinguish, with male flowers long-pedicellate and in simple axillary clusters and female inflorescence-bearing axes often branched.

\section{Boehmeria polystachya Wedd. - Fig. 11; Map 14}

Boehmeria polystachya Wedd. (1856) 370. - Type: Wallich 4584 (holo KWALL; iso G, K), Nepal.

Boehmeria tibetica C.J.Chen in Wang \& Chen (1979) 109. - Type: ChinghaiTibet exped. 2775 (holo PE), China, Tibet, Tsona, 4 Oct. 1974.

Urtica venosa Wall. (1831) 164, nom. nud. - See Note 1.

Robust herb or subshrub, up to $1.5 \mathrm{~m}$ tall; ultimate branches at extreme apex 1-1.5(-2) $\mathrm{mm}$ diam, but soon becoming very robust, hairy, hairs sparse or dense fine short adpressed, soon glabrescent. Stipules linear-lanceolate rather thin-textured \pm membranous, 7-10 by 1-2 mm. Leaves opposite, not or very slightly dimorphic in size only, ovate, medium or large, (8-)11-23 by (4-)6-12 cm, little-varying in relative proportions with length usually c. $2 \times$ width; margin sometimes crenate, usually serrate or dentate, teeth acute or obtuse, often slightly up-curved, 30-55 either side, varying in number and size depending on lamina size, $1-1.5$ by $2-4.5 \mathrm{~mm}$; leaf apex short-attenuate; base slightly asymmetrically rounded to slightly cuneate or cordate; basal veins extending into distal half of leaf, upper lateral veins 3-5 subopposite, lowermost usually arising in distal half, finely impressed adaxially, robust and prominent abaxially; coarser tertiary veins close-spaced scalariform $(0.3-0.5 \mathrm{~cm}$ apart, up to $1 \mathrm{~cm}$ apart in largest leaves) and very prominent abaxially, especially those arising from outer side of basal veins, giving a very ridged appearance to young leaves; fine reticulation often also relatively prominent; texture thin- or thick-chartaceous; adaxial surface drying markedly dark, hairy, hairs sparse (rarely abundant), very fine, adpressed, cystoliths abundant but minute; abaxial surface rather paler green in both living and dry state, hairs often restricted to veins, sparse (rarely abundant), extremely fine, adpressed; petiole usually c. $0.25 \times$ lamina length. Flowerclusters borne on leafless axes, these fairly long, pendulous or drooping, 10-17 cm long, arising one from each axil with many much shorter lateral branches throughout length which are also branched (i.e., inflorescence-bearing axes with 2 ndorder branching), axes unisexual or bisexual (female clusters in apical part; entirely female axes also generally towards branch apex); bracts short, ovate-triangular, thick-textured, $1-1.5$ by 0.5-0.8 mm; flower-clusters spaced 2-4 mm apart, recorded as dark crimson, small, $2-3 \mathrm{~mm}$ diam, flowers in male clusters $5-10$, in female clusters 20-30(-40), densely crowded; bracteoles oblong, inconspicuous, $0.2-0.3 \mathrm{~mm}$ long. Male flowers 4-merous, sessile, mature buds depressed-globose, 0.8-1 mm diam, without appendage or with slight dorsal thickening, hairy, hairs abundant, minute, spreading or adpressed. Female flowers narrowly oblong, c. 0.8 by $0.2 \mathrm{~mm}$; stigma minute, $0.3-0.6$ $\mathrm{mm}$ long, hooked. Fruiting perianth $1-1.5$ by $0.5-0.8 \mathrm{~mm}$, ellipsoid without distinct beak, markedly flattened either side of achene into distinct wing either side comprising $0.25(-0.3) \times$ whole width; hairs minute, spreading. Achene in central part of fruiting perianth, occupying less than half of it.

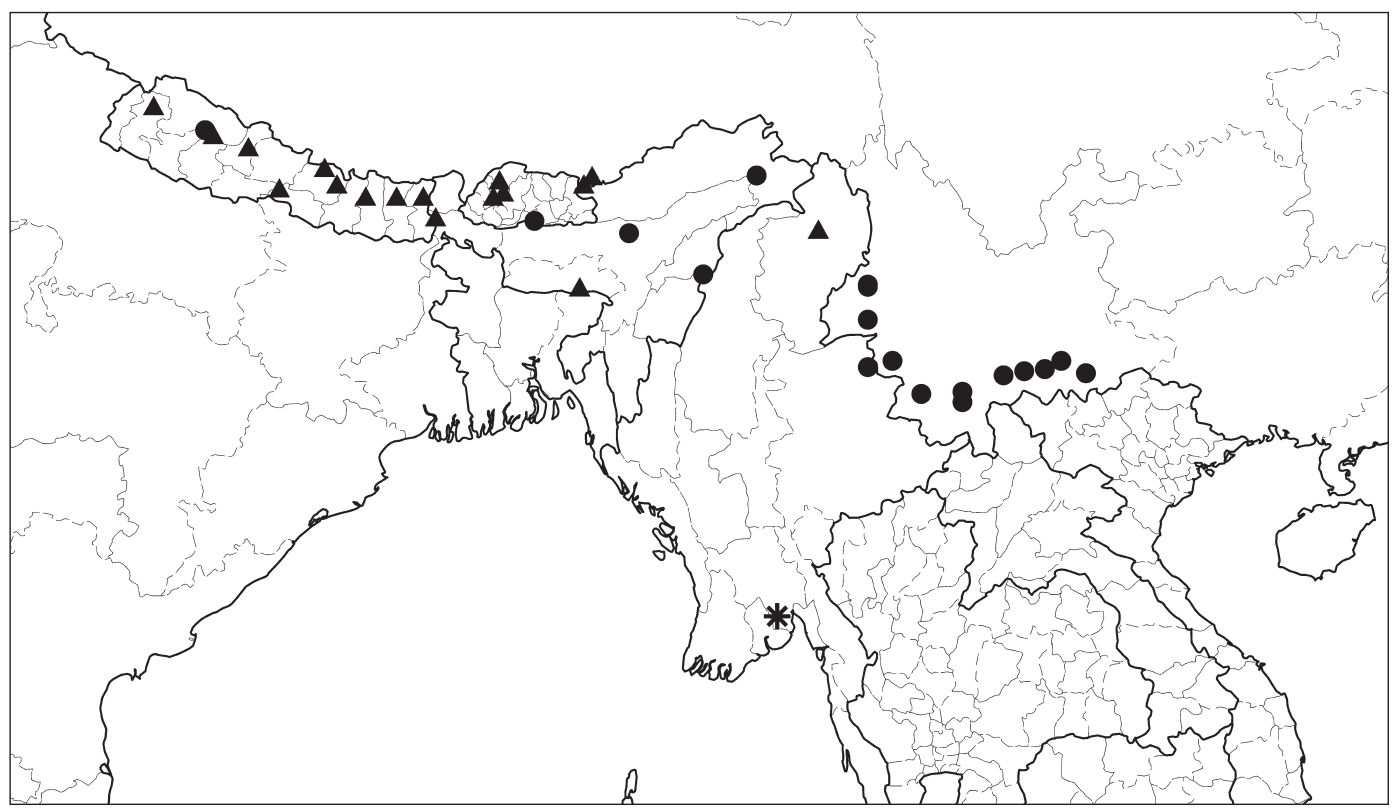

Map 14 Distribution of Boehmeria conica C.J.Chen, Wilmot-Dear \& Friis $(\bullet)$, B. polystachya Wedd. (A) and B. kurzii Hook.f. (*). 
Distribution - Eastern Himalayas: north-eastern India (Sikkim, Assam, Meghalaya, Uttarakhand), Nepal, Bhutan, Burma, China (Tibet border region with India).

Habitat \& Ecology — Mixed broad-leaved deciduous forest, forest margins, scrub, open slopes, walls and banks in disturbed ground; 1300-3300 m altitude.

Conservation status - Least Concern (LC). The species is known from at c. 50 collections, some of which are recent. It occurs in many scattered locations and in fairly restricted forest habitat. The EOO is $284285 \mathrm{~km}^{2}$. Although the AOO gives a figure of less than $500 \mathrm{~km}^{2}$, its localities in the Himalayas are not currently threatened by serious habitat degradation, and it therefore does not meet the criteria for a formal status of Vulnerable (VU).

Notes -1 . The nomen nudum $U$. venosa, cited by Weddell (1856: 378 ) as a synonym under $B$. rugulosa, is referable to this species.

2. Distinctive in its leaves relatively large broadly-toothed with hairs very inconspicuous adpressed and tertiary veins scalariform closely-spaced prominent (giving a ridged appear-

Fig. 12 Boehmeria conica C.J. Chen, Wilmot-Dear \& Friis. a. Habit of stem with inflorescence-bearing axes; b. male bud; c. male flower; d. fruiting perianth; e. fruit with perianth removed (a: Sino-Russian Expedition 1358; b, c: Tsiang 13400; d, e: Henry 12070; all PE). - Scale bars: a $=2 \mathrm{~cm}$; $\mathrm{b}-\mathrm{e}=1 \mathrm{~mm}$.

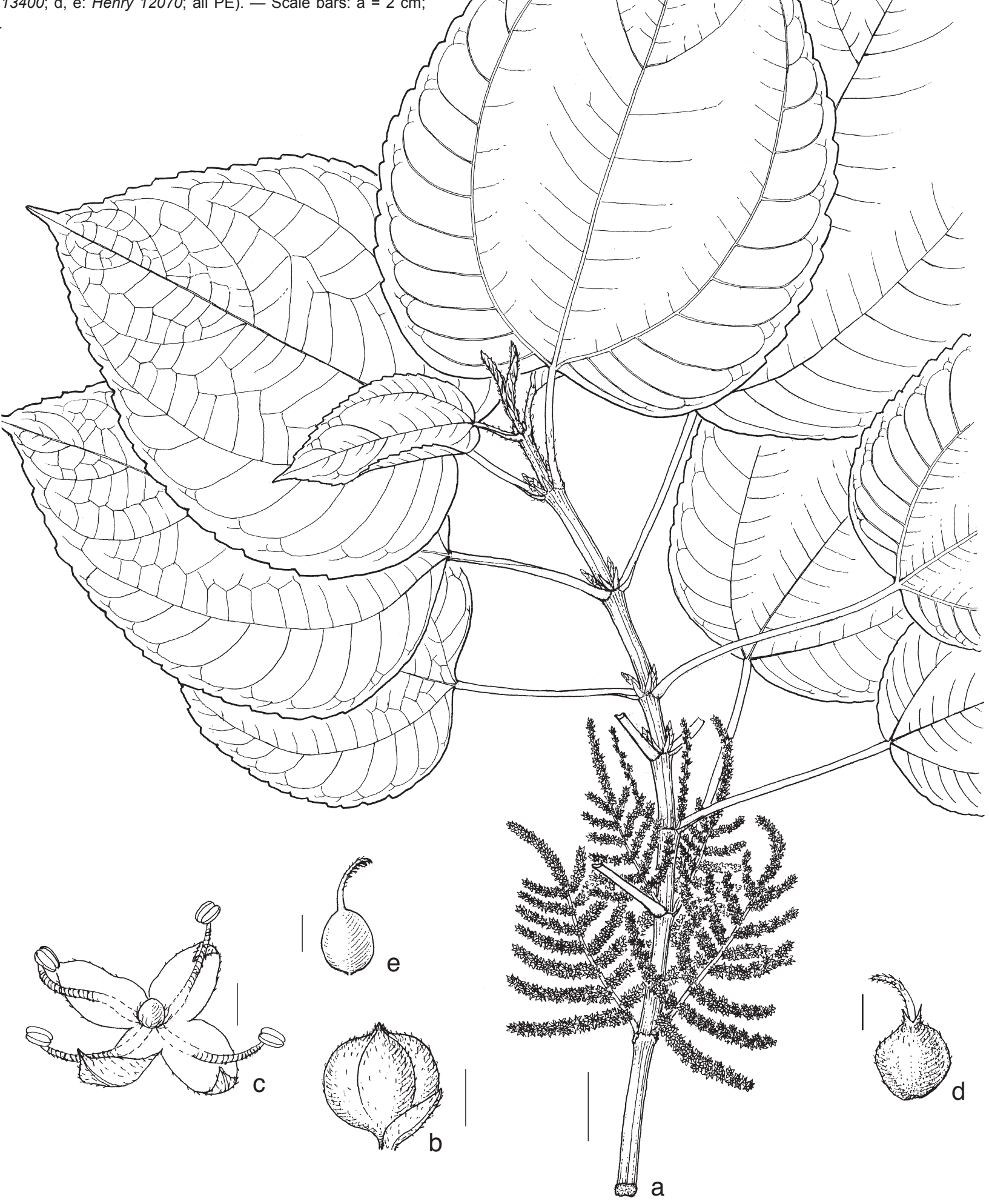


ance to young leaves), its inflorescence-bearing axes with short branches throughout length and with 2nd-order branching, tiny stigma and fruiting perianth broadly-winged.

3. The sympatric $B$. conica has been confused with this species but differs in its inflorescence-bearing axes small, neat and rather conical, its leaves thin-textured often truncate with slender veins and its fruiting perianth short and broad.

4. The partly sympatric $B$. siamensis with its very similar scalariform venation prominent close-spaced can also be confused with $B$. polystachya but differs in leaves often relatively narrower, petioles extremely short relative to lamina and bracts at the flower-clusters always conspicuous, longer than mature clusters and often almost as wide as long, inflorescence-bearing axes paired and unbranched.

5 . Several sympatric varieties of $B$. virgata subsp. macrophylla have similar leaf shape to $B$. polystachya and branched inflorescence-bearing axes, especially var. scabrella and var. rotundifolia which have male axes much-branched throughout length (although always without 2nd-order branching) but venation is always finer and not conspicuously scalariform. Var. scabrella can also be distinguished by its hairs on stem and adaxial leaf surface conspicuous, coarse, rough and var. rotundifolia also by its leaves thinner-textured with a distinct abrupt acumen consisting of a single tooth and by its marginal teeth markedly up-curved especially near the leaf apex.

\section{Boehmeria conica C.J. Chen, Wilmot-Dear \& Friis - Fig.} 12; Map 14

Boehmeria conica C.J.Chen, Wilmot-Dear \& Friis in Chen et al. (2003) 173; (2005) 449. - Type: A. Henry 12070 (holo K), China, Yunnan, Szemao.

Large subshrub or shrub, up to $4 \mathrm{~m}$ tall, often dioecious, sometimes monoecious; ultimate branches 4-angled, 2-2.5 mm diam, sparsely hairy, hairs fine, minute adpressed, soon glabrescent. Stipules narrowly triangular, $3-4$ by $1.5 \mathrm{~mm}$, connate at base. Leaves opposite, not or slightly dimorphic in size, ovate-orbicular to suborbicular or broadly ovate, $8-13(-17)$ by $6.5-12.5(-15) \mathrm{cm}$, length $1.2-1.5 \times$ width, margin crenate, teeth 20-30 either side, shallow but very broad, $1-1.5(-2)$ by $3-6$ $(-10) \mathrm{mm}$, with width $3-5 \times$ length; leaf apex consisting of a single long tooth, cuspidate to short-acuminate, rarely long-acuminate; base broadly cordate, rounded-truncate or rarely broadly cuneate, sometimes oblique; basal veins distinctly curved, extending into apical fifth of lamina (almost to apex in very broad leaves), upper lateral veins $2(-3)$ either side, lowermost arising just in distal half of lamina (on one side veins often fewer and nearer apex), finely prominent abaxially; coarser scalariform tertiary veins and reticulation visible abaxially; texture \pm membranous; adaxial surface dark green when dried, hairy like the stem, soon glabrescent; abaxial surface light green, subglabrous; petiole very variable relative to lamina size, $4-11 \mathrm{~cm}$, usually over half of lamina length, sometimes longer than lamina, indumentum like that of the stem. Flower-clusters borne on leafless axes, these \pm erect axillary, 4-8 cm long, each with lateral branchlets throughout its length, these short (< half of length of main axis), spreading, unbranched and progressively and regularly shorter towards apex of main axis, some axes arising from upper leaf axils unbranched; some axes bisexual with female and bisexual clusters in apical part; bracts broadly triangular, conspicuous, $0.7-1$ by $0.7-0.8 \mathrm{~mm}$; clusters spaced 1-2 $\mathrm{mm}$ apart, male clusters $1.5-2 \mathrm{~mm}$ diam, with 1-c. 5(-c. 10) flowers, female clusters similar or rarely up to $3.5 \mathrm{~mm}$, with up to 25 flowers; bracteoles inconspicuous, c. $0.4-0.5 \mathrm{~mm}$ long. Male flowers 4-merous, sessile; mature buds \pm globose or depressed-globose, usually apiculate, c. $1 \mathrm{~mm}$ diam, tepals without dorsal appendages, sparsely hairy like stem. Female flowers with very slender stigma only $0.8-1.2 \mathrm{~mm}$ long. Fruiting perianth broadly ovoid, only $0.8-1.2$ by $0.6-1 \mathrm{~mm}$, markedly dorsiventrally compressed either side of the achene to form an indistinct marginal wing, base \pm rounded, apex with very short beak; sparsely hairy like stem especially towards apex. Achene ovoid, slightly dorsiventrally compressed, occupying $0.7 \times$ length of fruiting perianth, fawn.

Distribution - North-eastern India, Nepal, Bhutan, Burma (not georeferenced and not shown on map), south-western China.

Habitat \& Ecology - Forest, often dense, shady wet places in ravines; (700-)1200-2600 m altitude.

Conservation status - Least Concern (LC). The species is known from c. 30 collections, many of which are recent. It occurs in locations along the Himalayas and their extension into southern China, and in fairly restricted forest habitat. The $\mathrm{EOO}$ is $505840 \mathrm{~km}^{2}$. Although the AOO gives a figure of less than $500 \mathrm{~km}^{2}$; its localities in the Himalayas are not currently threatened by serious habitat degradation, and it therefore does not meet the criteria for a formal status of Vulnerable (VU).

Notes - 1. This species is distinctive in its inflorescencebearing axes of both sexes small, branched and having lateral branchlets progressively shorter towards the apex of the main axis, producing a markedly neat conical appearance, its leaves broad, thin-textured, crenate and often truncate and fruiting perianth small, relatively broad.

2. Boehmeria conica has been confused with B. polystachya (sympatric but not extending so far east) which differs in its inflorescence-bearing axes large, crowded, much more irregular, secondarily branched with large clusters bearing 40-50 flowers and its leaves narrower, thicker-textured, serrate, gradually acuminate, cuneate at the base, with secondary veins prominent close-spaced scalariform. Boehmeria polystachya also has larger bracts subtending its flower-clusters, stigma even shorter (0.3-0.6 mm long) and fruiting perianth relatively narrow with length c. $2 \times$ (rather than at most $1.3 \times$ ) width, tapering rather than rounded at the base.

3. The sympatric but more widespread $B$. virgata subsp. macrophylla can sometimes be confused with $B$. conica, since some variants have male axes of similar architecture, but differ in leaves relatively narrower usually thicker-textured with marginal teeth relatively much narrower usually acute and female inflorescence-bearing axes usually unbranched.

\section{Boehmeria kurzii Hook.f. - Fig. 13; Map 14}

Boehmeria kurzii Hook.f. (1888) 577. - Type: Kurz 3115 (holo K; iso CAL), Burma, Pegu.

Habit unknown; ultimate stems up to $1.3 \mathrm{~mm}$ diam, glabrescent or hairy, hairs very fine, short adpressed. Stipules very early deciduous, not seen. Leaves opposite, scarcely dimorphic with 'larger' up to $1.25 \times$ length of 'smaller', narrowly ovate, 13.5-19 by $5-5.5 \mathrm{~cm}$, length $3.5 \times$ width; margin entire; leaf apex attenuate to indistinctly acuminate; base broadly cuneate; basal veins extending almost to apex, upper veins $0-1(-2)$, arising very near apex but scarcely distinguishable from coarser tertiary venation, coarser tertiary venation conspicuously scalariform, close-spaced, 2-4 mm apart, finer tertiary venation reticulate, all veins finely prominent abaxially; texture membranous; glabrous both sides or hairy on main veins, hairs very sparse adpressed; adaxial surface with abundant cystoliths giving slightly rough feel; petiole c. $2.5 \mathrm{~cm}$ long, $0.13 \times$ lamina length. Flower-clusters borne on leafless inflorescence-bearing axes, these apparently always bisexual, unbranched, up to $20 \mathrm{~cm}$ long, 1 per axil; male clusters in lower part of axil, female above, a few clusters with both sexes; bracts very conspicuous, broadly triangular-cordate, c. 1.4 by $1.6 \mathrm{~mm}$, with broad apex sharply acute at extreme tip; clusters spaced 2-3 mm apart, 2-4 mm diam, male clusters with (1-)5-10 relatively densely crowded 


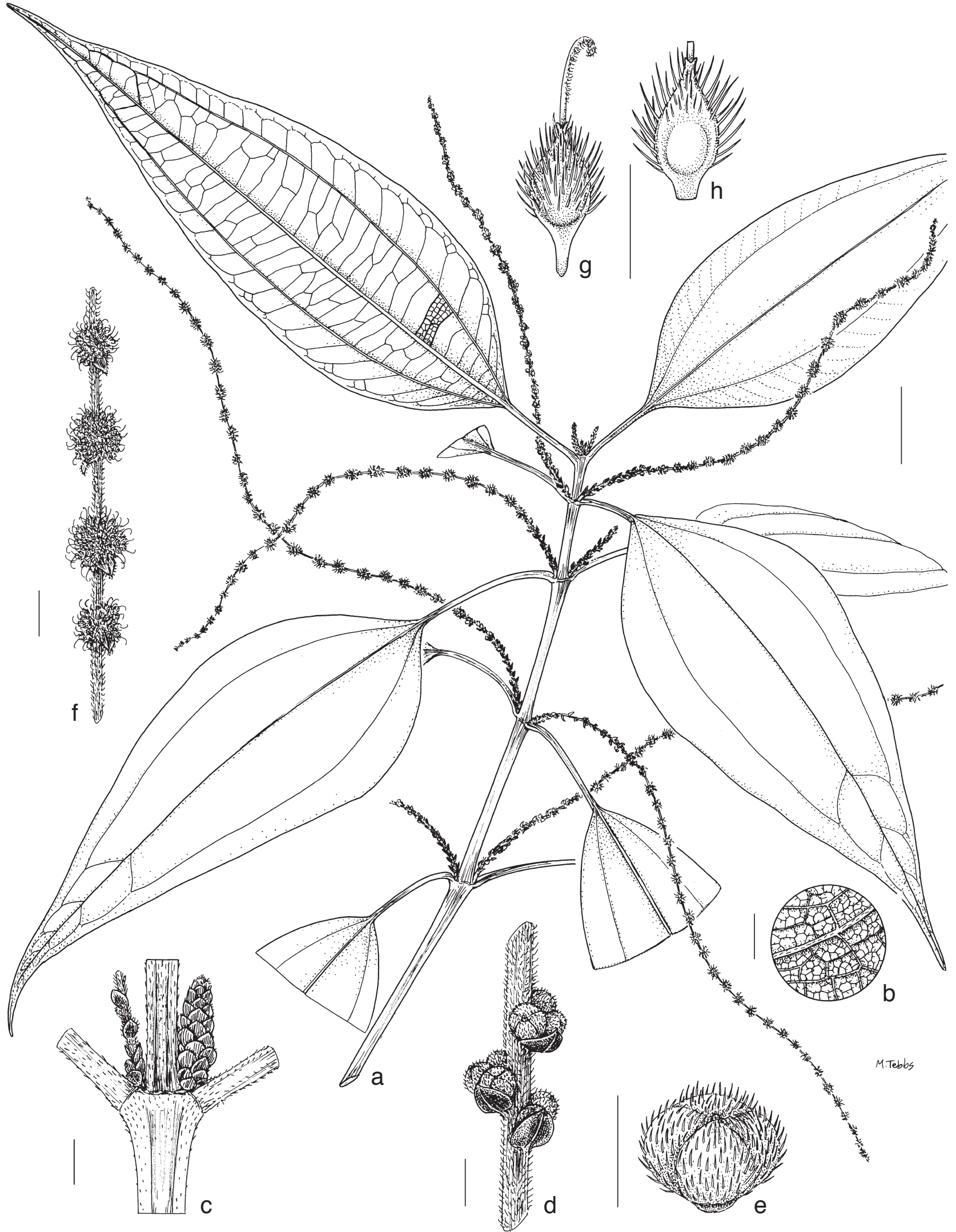

Fig. 13 Boehmeria kurzii Hook.f. a. Upper part of stem with inflorescence-bearing axes; b. leaf, detail of abaxial surface; c. detail of one node with young flower-clusters (inflorescences); d. detail of male part of inflorescence-bearing axis with flower-clusters (inflorescences); e. male bud; f. detail of female part of inflorescence-bearing axis with flower-clusters (inflorescences); g. female perianth in flower; h. fruiting perianth (all: Kurz $3115, \mathrm{~K}$ ). $-\mathrm{Scale}$ bars: a $=2 \mathrm{~cm}$; $b-d, f=2 \mathrm{~mm} ; \mathrm{e}, \mathrm{g}, \mathrm{h}=1 \mathrm{~mm}$. 
flowers, female clusters with 25-35 flowers; bracteoles inconspicuous. Male flowers 4-merous, subsessile, mature buds depressed-globose, c. $1.2 \mathrm{~mm}$ diam, tepals without dorsal appendage, hairy, hairs abundant, long, spreading. Stigma $0.8-1$ $\mathrm{mm}$ long, hooked. Fruiting perianth ovoid, minute c. 0.6 by 0.3 $\mathrm{mm}$, not markedly laterally flattened but with \pm distinct marginal rim. Achene more or less filling fruiting perianth.

Distribution - Burma (Pegu).

Habitat \& Ecology - No certain data available. Probably collected in coastal rainforest or further inland in drier \pm forested habitats.

Conservation status - Critically Endangered (CR). The species is known from only one old collection from the 1800 s from Pegu in Burma. No EOO or AOO can be calculated, but the locality is within areas of urban development; we therefore suggest that the species is Critically Endangered with the criteria CR 2Bab(iii).

Note - This species is easily distinguished from all others in the genus in its entire leaves (the only Old World species known with truly entire leaves with no trace of marginal teeth); however, only one collection is known. The scalariform coarser tertiary venation and conspicuous inflorescence-bracts are distinctive, being similar only to those of $B$. siamensis, but $B$. siamensis differs markedly in venation robust rather than slender, leaves serrate, not membranous nor glabrous, often also relatively broader and flower-clusters much more crowded.

\section{Boehmeria siamensis Craib - Fig. 14; Map 15}

Boehmeria siamensis Craib (1916) 269. - Syntypes: Kerr 538 (K; isosyn TCD), northern Thailand, Chiang Mai, Doi Sutep; Hosseus 455 (K), Thailand, Chiang Mai [Chengmai].

Boehmeria spirei Gagnep. (1950) 35. - Type: Spire 1546 (holo P), Laos, Xieng-Kung.

Boehmeria chiangmaiensis Yahara (1981) 18, syn. nov. - Type: Nimanong et al. 1726 (holo BKF), northern Thailand, Chiang Mai, Hod. - See Note 2.

Large or small shrub, up to $3.5 \mathrm{~m}$, often sparsely-branched, rarely small tree; ultimate branches robust, $2-2.5 \mathrm{~mm}$ diam, hairy, hairs sparse or abundant, fine, short, adpressed soon glabrescent. Stipules narrowly triangular, c. 6 by $2 \mathrm{~mm}$, thicktextured. Leaves opposite (sometimes some subopposite on lateral stems), scarcely dimorphic with 'larger' leaves up to $1.2 \times$ length of 'smaller' ones, narrowly elliptic or ovate, usually medium or large, $(4-) 12-24(-28)$ by $(1.5-) 4.5-12(-15) \mathrm{cm}$, length 2-3x width; margin shallowly serrate (rarely more deeply crenate-serrate, teeth $25-40$ either side, $1(-3)$ by $1.5-5(-7)$ $\mathrm{mm}$; leaf apex broadly acute sometimes with abrupt tiny acumen at extreme tip; base broadly or narrowly cuneate to more or less rounded, sometimes slightly asymmetrical; basal veins hardly curved, extending into distal third or quarter of lamina; upper lateral veins similarly arranged on both sides of midrib, $3(-4)$, often hardly distinct from coarser tertiary venation, all arising in distal third of lamina, inconspicuous adaxially, prominent abaxially; coarser tertiary venation conspicuously scalariform, close-spaced, 2-4 mm apart, finer tertiary venation reticulate, all venation visible adaxially, rather reddish, prominent abaxially; texture coriaceous (rarely thin-chartaceous in dense forest); adaxial surface pubescent, hairs abundant, fine, \pm adpressed, giving rather rough feel; abaxial surface with hairs on veins only, these very sparse, otherwise glabrous, rather yellowish and slightly gleaming in dry state; petiole very short relative to lamina, c. $0.05 \times$ length, $0.7-1 \mathrm{~cm}$. Flower-clusters borne on leafless axes, these pendulous, unbranched, a pair (rarely only one) arising from each axil or sometimes apparently many in a congested mass but these in fact arising from axils of short axillary leafy shoots; male and female inflorescence-bearing axes often on same plant with male ones in upper axils; male axes relatively short, $3-5 \mathrm{~cm}$ long, female axes up to $15 \mathrm{~cm}$ long, some axes bearing both male and female clusters; bracts exceeding mature clusters and therefore conspicuous (recorded as pink in bud), often visible even in fruiting clusters, broadly ovate-triangular, $2-2.5$ by $1.5-2.5 \mathrm{~mm}$, width often equalling length, apex often broadly rounded, blunt; clusters crowded, usually more or less contiguous, male clusters 3-4 mm diam, with c. 10 flowers, female clusters $4-5 \mathrm{~mm}$ diam, with over 30 densely crowded flowers. Male flowers 4-merous, sessile, mature buds globose sometimes slightly flattened, (1.2-)1.5-2 $\mathrm{mm}$ diam, dorsal thickening inconspicuous, pubescence dense, short, spreading. Female flowers recorded as white tinged purple, $1-2$ by $0.3-0.6 \mathrm{~mm}$, spindle-shaped tapering into indistinct pedicel, hairy like male; stigma $0.6-1 \mathrm{~mm}$. Fruiting perianth yellow-brown, spindle-shaped or elliptic in outline, markedly laterally flattened into distinct marginal wing up to quarter of total fruiting perianth width either side, also with very short broad beak and two distinct apical teeth. Achene spindle-shaped, large, c. 2.3 by $0.8-1 \mathrm{~mm}$, filling fruiting perianth.

Distribution - Nepal, Burma, southern China, northern and western Thailand, Laos.

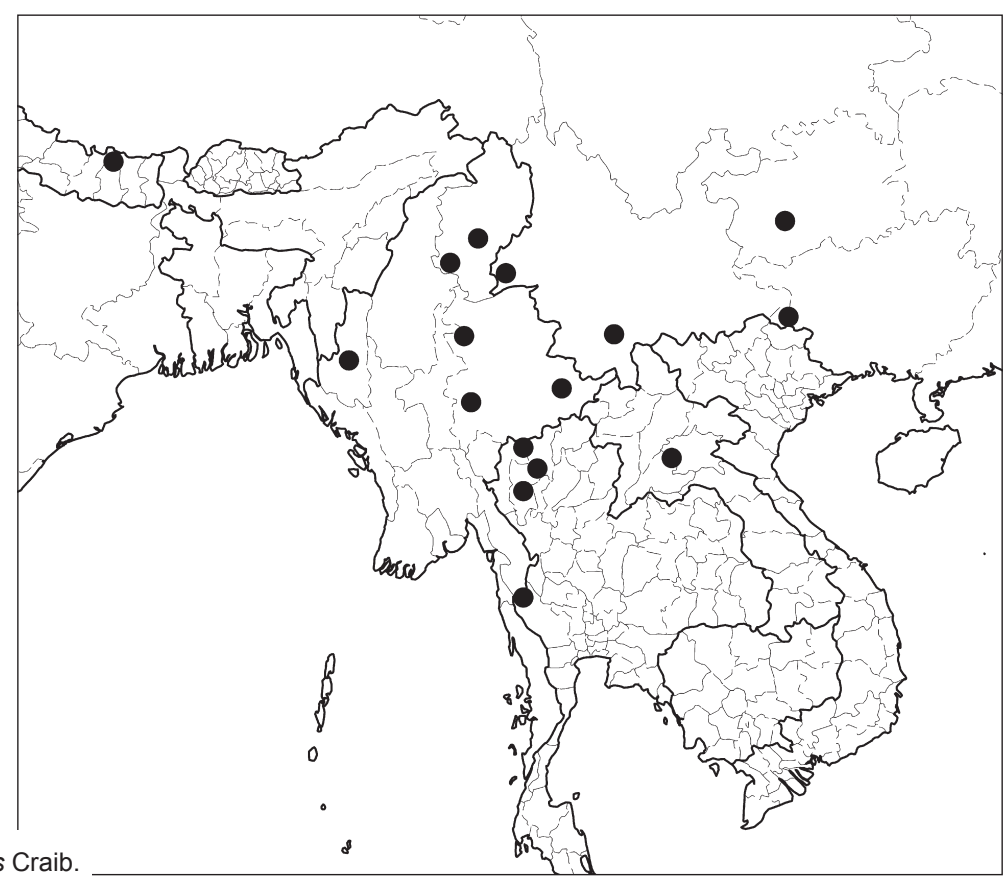




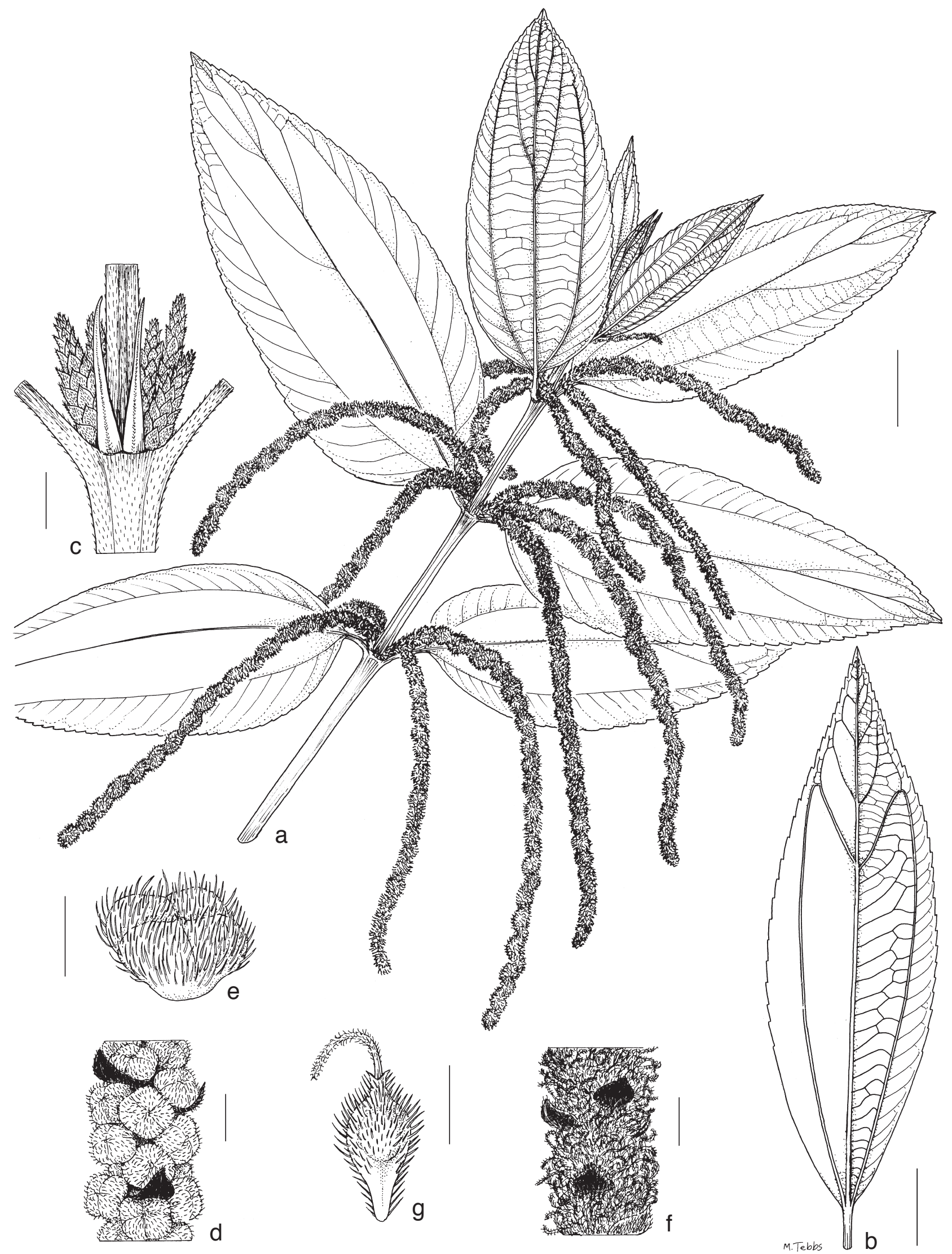

Fig. 14 Boehmeria siamensis Craib. a. Habit of stem with inflorescence-bearing axes; b. leaf, abaxial surface; c. detail of one node with young inflorescencebearing axes; $d$. detail of male inflorescence-bearing axis with congested flower-clusters (inflorescences) and bracts; e. male bud; f. detail of female axis with congested flower-clusters (inflorescences) and bracts; g. fruiting perianth (a, g: Harder et al. 4928; b: Kerr 538; c: Geesink 8042; d, e: Nooteboom 791; f: Hosseus 455; all K). - Scale bars: $a, b=2 \mathrm{~cm} ; c=5 \mathrm{~mm} ; \mathrm{d}, \mathrm{f}=2 \mathrm{~mm} ; \mathrm{e}, \mathrm{g}=1 \mathrm{~mm}$. 
Habitat \& Ecology - Evergreen forest, and disturbed areas in forest remnants, secondary grassland on granite, open hillsides; (300-)500-2750 m altitude.

Conservation status - Near Threatened (NT). The species is known from c. 30 collections, some of which are recent, and it occurs in fairly scattered locations, with some considerable gaps in the range. The EOO of $1401620 \mathrm{~km}^{2}$ is therefore probably exaggerated, and the AOO gives a figure of less than 500 $\mathrm{km}^{2}$. It occurs in a moderate range of habitats, mainly forests. Although these are not currently threatened by serious degradation, and it therefore does not meet the criteria for a formal status of Vulnerable (VU), it may become so in the future with increasing agriculture in the region.

Notes -1 . This species is not easily confused with any other taxa. It is distinctive in its leaves with tertiary veins scalariform, prominent, reddish, giving a reached appearance to leaves, and close-spaced, apex broad-acute, teeth numerous, abaxial surface drying markedly paler (yellow-brown or chestnut-brown) and almost glabrous, leaves usually also thick-textured (only some very low altitude collections thin-textured), in its inflorescence-bearing axes at least 2 from each axil, with subtending bracts conspicuous, broad, longer than the flower-clusters and in its fruiting perianth and achene spindle-shaped.

The species which it most closely resembles is $B$. kurzii which differs in leaves entire, membranous and flower-clusters wellspaced. The ridge-like close scalariform venation is also very like that of $B$. polystachya which differs in branching inflorescence-bearing axes with inconspicuous bracts.

2. Yahara (1981) discussed in detail the similarities and differences amongst Thai species of Boehmeria, but was apparently unaware of the publication of the name $B$. siamensis, to which the description of his new species $B$. chiangmaiensis clearly conforms.

\section{Boehmeria penduliflora Wedd. exD.G.Long - Fig. 15a-g;} Map 16

Boehmeria penduliflora Wedd. ex D.G.Long (1982) 130. - Boehmeria densiflora Hook. \& Arn. var. penduliflora (Wedd. ex D.G.Long) Acharya \& Yonek. in Acharya et al. (2002) 8. - Type: Buchanan-Hamilton s.n. (lecto BM, selected by Long 1982: 130), Nepal, Narainhetty, 5 Sept. 1802.

Boehmeria macrophylla D.Don (1825) 60, nom. illeg., non B. macrophylla Hornem. (1815). - Syntypes: Wallich 4595A (K-WALL; isosyn G, K, M), Nepal; Buchanan-Hamilton s.n. (BM), Nepal, Narainhetty. - See Note 1. Boehmeria densiflora Hook. \& Arn. var. intermedia Acharya \& Yonek. in Acharya et al. (2002) 8. - Type: Dobremez 673 (holo BM), Nepal, Gandaki Zone, Gorkha Dist., syn. nov. - See Note 2.
Subshrub or dense often arching shrub, 1-4(-7) m; ultimate stems 1-1.2 mm diam, hairy, hairs abundant, adpressed or half-adpressed, pale, fine, uniform; soon glabrous. Stipules conspicuous, triangular, $10-17$ by $2-3 \mathrm{~mm}$, membranous. Leaves opposite, not or slightly dimorphic, with 'larger' leaves up to $1.4 \times$ length of 'smaller' ones and relatively narrower, narrowly ovate-lanceolate to linear-ovate, straight or slightly sideways-curved, widely ranging in length (6-)10-32 by (1.2-) $2-5 \mathrm{~cm}$, length (4-)5-7× width; margin finely denticulate, teeth (35-)50-85 either side, $0.4-0.8$ by $1.5-2(-3) \mathrm{mm}$, distinct and acute throughout most of leaf length, with width $2-4 \times$ length, but often becoming indistinct close to leaf base; leaf apex gradually acuminate; base rounded (rarely slightly cuneate), slightly asymmetrical; basal veins extending almost to apex, upper lateral veins 1-3 arising in distal third or quarter but often indistinguishable from coarser tertiary venation, inconspicuously slightly impressed adaxially, finely prominent abaxially; texture fairly thickly chartaceous or coriaceous, leaves often markedly bullate; adaxial surface very dark green in live state, with fine adpressed hairs often present in youngest 1-2 pairs of very immature leaves at uppermost nodes but always very soon \pm glabrous, with large often prominent cystoliths; abaxial surface fine-pubescent, hairs long curved or very short spreading, dense in young leaves, later sparse or absent, also longer fine hairs on main veins, these sparse adpressed; petiole very short for length of leaf, up to $2.5 \mathrm{~cm}$, hairy like the stem. Flowerclusters borne along leafless inflorescence-bearing axes, these pendulous, usually unbranched, 1 per axil (rarely several or branched very close to base so as to appear several), male clusters 5-15(-20) cm, female clusters (6-)10-25(-more than 30 ) cm long; inflorescence-bearing axes usually unisexual but often both sexes on same plant, female axes in upper axils, male ones below; axes hairy, hairs sparse or abundant, spreading, often minute; bracts triangular, short, up to $1.5 \mathrm{~mm}$ long; clusters often so crowded as to be contiguous along axis, male clusters c. $2 \mathrm{~mm}$ diam, with less than 10 flowers, female clusters 3-4 mm diam, with more than 50 densely crowded flowers; bracteoles obovate, in male up to $0.6 \mathrm{~mm}$ long, in female inconspicuous. Male flowers 4-merous sessile, mature buds c. $1 \mathrm{~mm}$ diam, depressed-globose, with very slight dorsal thickening and sparse hairs, these conspicuous, long, spreading. Female flowers narrowly obovoid, beaked, c. 0.6 by 0.2 $\mathrm{mm}$, with abundant hairs, these conspicuous, spreading, pale; stigma $1-1.5 \mathrm{~mm}$ long. Fruiting perianth $1.5-2.5$ by $0.5-0.8$ $\mathrm{mm}$, markedly flattened but very variable in shape, ranging from narrowly obovoid, with truncate apex and long tapering base,

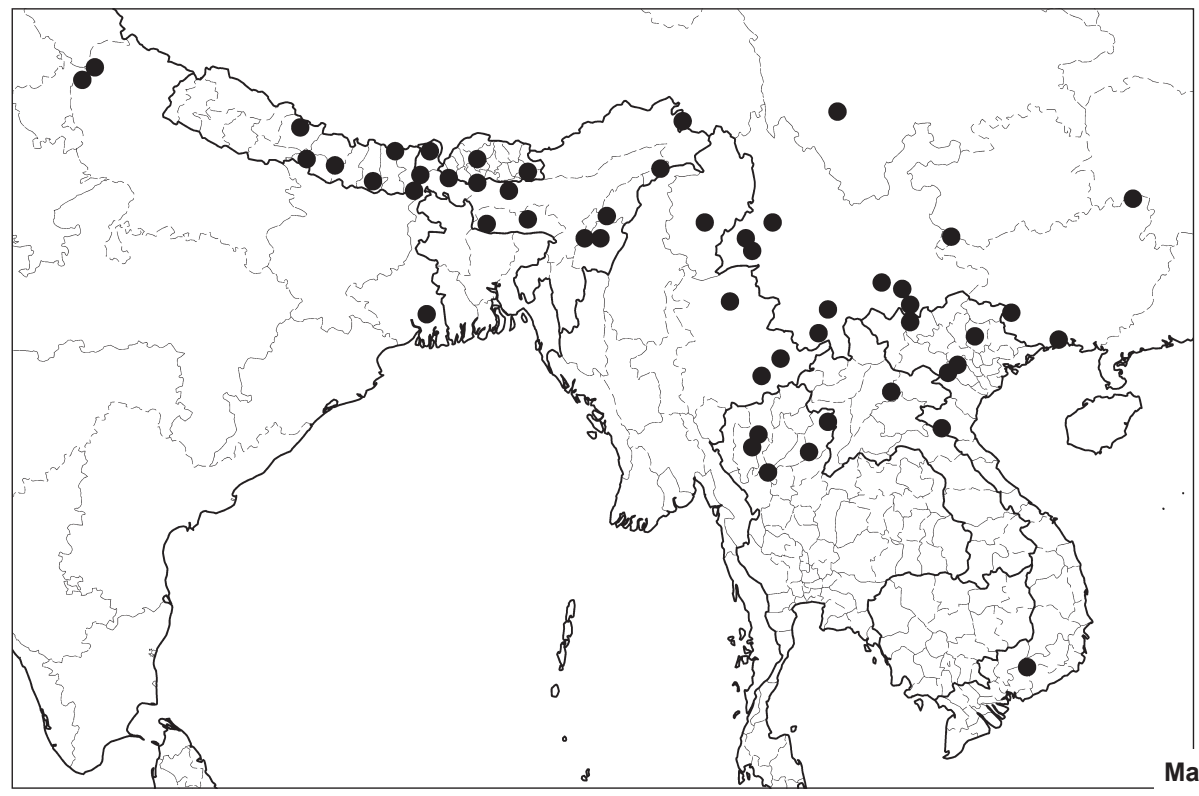




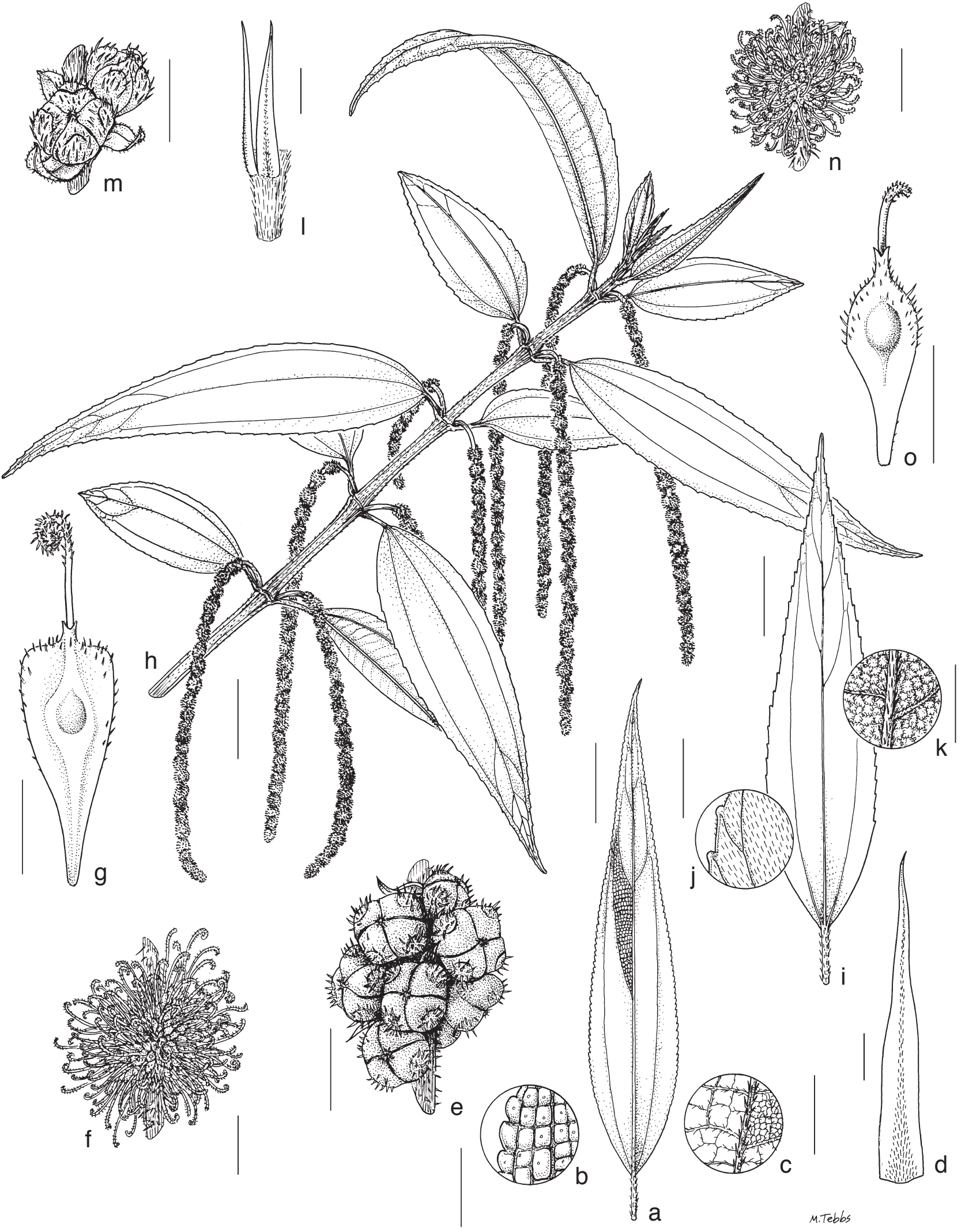

Fig. 15 a-g: Boehmeria penduliflora D.G.Long. a. Leaf; b. leaf, detail of margin and adaxial surface; c. detail of abaxial surface; d. stipule; e. detail of inflorescence-bearing axis with male flower-cluster (inflorescence); f. detail of inflorescence-bearing axis with female flower-cluster (inflorescence); $g$. fruiting perianth. - h-o: Boehmeria densiflora Hook. \& Arn. var. densiflora. h. Habit of stem with inflorescence-bearing axes; i. leaf; j. detail of leaf margin and adaxial surface; $k$. detail of abaxial surface; I. stipules; $m$. detail of inflorescence-bearing axis with male flower-cluster (inflorescence); $n$. detail of inflorescence-bearing axis with female flower-cluster (inflorescence); o. fruiting perianth (a-d: Strachey \& Winterbottom 7; e-g: Boyce 842; h-l: Furuse 4743; m, n: Furuse 5404; o: Woo 13744; all K). - Scale bars: $a, h, i=2 \mathrm{~cm} ; \mathrm{b}, \mathrm{c}, \mathrm{j}, \mathrm{k}=5 \mathrm{~mm} ; \mathrm{d}, \mathrm{I}=2 \mathrm{~mm} ; \mathrm{e}-\mathrm{g}, \mathrm{m}-\mathrm{o}=1 \mathrm{~mm}$. 
to ovoid-spindle-shaped, with long apical beak, but always with distinct marginal rim and fairly broad wing surrounding small thickened middle or basal part and with sparse coarse hairs near apex. Achene minute for size of fruiting perianth, c. 0.3 $\mathrm{mm}$ diam.

Distribution - Northern India, Nepal, Bhutan, Burma, northern Thailand, Laos, Vietnam, south-western China; naturalised in Mascarenes (Reunion).

Habitat \& Ecology - Ravines in monsoon forest; evergreen forest; dry open Fagaceae forest; scrub and disturbed land; often near water; 550-2000 m altitude.

Conservation status - Least Concern (LC). The species is known from c. 300 collections from many locations in the Himalayas and their eastern extension with an EOO of 14999300 $\mathrm{km}^{2}$. It occurs in a range of moist forest habitats, which in many of its localities are not currently seriously threatened.

Notes - 1. Boehmeria penduliflora was published as a new name for Boehmeria macrophylla D.Don, non Hornem., taking up the nomen nudum Boehmeria penduliflora Wedd. (1854) 199.

2. Wang (in Wang \& Chen 1995) regarded B. penduliflora and $B$. densiflora as varieties of the same species. Acharya (in Acharya et al. 2002) followed this, observing that the youngest leaves of $B$. penduliflora initially have similar indumentum to that of $B$. densiflora. He pointed out that differences in fruiting perianth given in earlier literature are not consistent and described a new variety, $B$. densiflora var. intermedia, for collections with leaves like $B$. penduliflora and a fruiting perianth which he considered to conform to that of $B$. densiflora (tapering, without beak, hairy throughout rather than rounded, with distinct beak). However, we have observed that both fruiting perianth shape and presence of a beak vary widely (and independently) amongst otherwise identical collections (as has been observed in several other Old World Boehmeria taxa) whereas two entities, conforming to the types of the two names $B$. penduliflora and $B$. densiflora, can be separated on a consistent set of vegetative characters discussed below (see Note 4) to which these authors did not attach significance. We observed that this distinction correlates with two distinct geographical distributions; the two taxa as thus separated are sympatric only in south-eastern China, $B$. densiflora var. densiflora otherwise restricted to the adjacent island groups, often occurring at lower altitude and always in dry habitats. We have therefore here maintained $B$. penduliflora and $B$. densiflora as distinct species easy to recognise vegetatively, with no intermediate forms, but both with fruiting perianth form unreliable for identification. The type and other collections seen of Acharya's new variety $B$. densiflora var. intermedia all conform to $B$. penduliflora as here conceived.

3. This species shares with $B$. densiflora and $B$. multiflora several rather distinctive characters; leaves are minutely-toothed, narrow (length always over $3 \times$ width), often thick; inflorescence-bearing axes are long, often very congested, usually unbranched; the achene is tiny in a large \pm winged fruiting perianth. Boehmeria penduliflora is distinguished from both in leaves somewhat bullate, very soon glabrous adaxially, usually extremely long \pm linear and marginal teeth particularly numerous. It is more widespread than the other two species, although its presence in the Indian Ocean Island of Reunion is presumed to be the result of introduction by early settlers.

4. The typical variety of $B$. densiflora (partly sympatric; Guangdong) is the most closely similar taxon and the two are easily confused. Although leaves in B. penduliflora are often much longer than in $B$. densiflora, the only consistent difference from var. densiflora is in leaf indumentum and marginal teeth. Mature leaves of $B$. densiflora differ in leaves adaxially, consistently hairy, hairs abundant, adpressed, inconspicuous but giving a rough texture (rather than even young leaves soon glabrescent), abaxial leaf surface with only adpressed hairs. The marginal teeth, although tiny in both taxa, differ in proportions and often number, giving the leaf margin always a rather different appearance even to the naked eye, as follows: teeth in $B$. densiflora are sometimes reduced to a tiny mucro but where of similar depth to those of $B$ penduliflora they are much wider relative to depth (width 7-more than 10x length (rather than 2-4x)) and therefore much less numerous, mostly only 20-30 either side, occasionally up to 40 in larger leaves. (Only one, unusually small-leaved, collection of $B$. penduliflora has been seen with teeth as few as 35 either side, although still close-spaced and of narrow proportions; all other material seen had 50-85 teeth either side). Leaves of $B$. densiflora are never very long (only up to $16 \mathrm{~cm}$ ) and also often relatively broader, (length $3-5(-7) \times$ width rather than almost always $5-7 \times$ width) and often not bullate; stipules are shorter and relatively broader and the female inflorescence-bearing axes are rarely as long, mostly $\leq 10 \mathrm{~cm}$ rather than mostly $10-30 \mathrm{~cm}$ long.

5. Boehmeria multiflora (allopatric, Philippines \& Indonesia (Sulawesi: Bouton)) is less easily confused with $B$. penduliflora. It differs in leaves relatively broader (length up to $3.5 \times$ width), spreading-hairy both sides (rather than glabrescent) with marginal teeth blunt, usually fewer and often up to $1 \mathrm{~mm}$ long.

6 . The partly sympatric (eastern Himalaya) B. listeri can also be misidentified as $B$. penduliflora, being similar in leaves with numerous marginal teeth and mixed indumentum on the abaxial leaf surface. It differs in having mixed indumentum also on stem, petiole and inflorescence-bearing axis, relatively much broader leaves (length up to $3 \times$ width) and its fruiting perianth lacks a marginal wing.

\section{Boehmeria densiflora Hook. \& Arn. - Fig. 15h-0, 16;} Map 17, 18

Boehmeria densiflora Hook. \& Arn. (1838) 271. - Type: Voyage of Capt. Beechey, Lay \& Collie in herb. Arnott s.n. (holo E, n.v.), Japan, Ryukyu Islands [Lou-tchou Islands]

Shrub, 0.3-2(-7) $\mathrm{m}$ tall but often low and spreading, stem up to $1.5(-5) \mathrm{cm}$ diam; ultimate branches c. $1.2 \mathrm{~mm}$ diam, adpressed-hairy, hairs dense, fine, giving rather greyish appearance, later glabrescent. Stipules $5-10$ by $1.5-2 \mathrm{~mm}$, relatively thick-textured. Leaves opposite (rarely a few alternate), (slightly to) markedly dimorphic with lamina of 'larger' leaves (1.1-)1.5-2.5x length of 'smaller' ones and usually relatively narrower, with more tapering apex; 'larger' leaves usually slightly asymmetrical, ovate to linear-ovate (rarely elliptic or obovate), small or medium 6-14(-20) by (1-)1.5-6(-9) cm, length $2-5(-7) \times$ width, margin finely-serrate, teeth $20-30(-40$ on longest leaves) either side, sharply acute and shallow but markedly wide-spaced, 0.3-0.7(-1) $\mathrm{mm}$ long (sometimes reduced to hard mucro), tooth-apices 3-6 mm apart; leaf apex gradually tapering attenuate or very indistinctly acuminate and often sideways-curved, or acute but extreme tip abruptly long-mucronate; base shortly cuneate or narrowly rounded, often slightly asymmetrical; 'smaller' leaves relatively slightly broader and less tapering, narrowly to broadly acute; basal veins extending into distal third of lamina or almost to tip, upper lateral veins (1-)2-3, all arising in distal half or in distal third of lamina, indistinct adaxially, distinct and finely prominent abaxially; tertiary venation reticulate, distinct or not; texture thin- or thick-chartaceous, leaves smooth or slightly bullate, adaxial surface abundantly hairy, hairs very fine, inconspicuous, adpressed, giving a slightly rough feel, cystoliths large, prominent; abaxial surface with similar hairs on main veins and finer hairs on tertiary venation, these so fine that surface appears almost glabrous; petiole short relative to lamina, $0.13-0.2 \times$ length, 1-2 $\mathrm{cm}$ long. Flower-clusters borne along leafless inflorescence- 

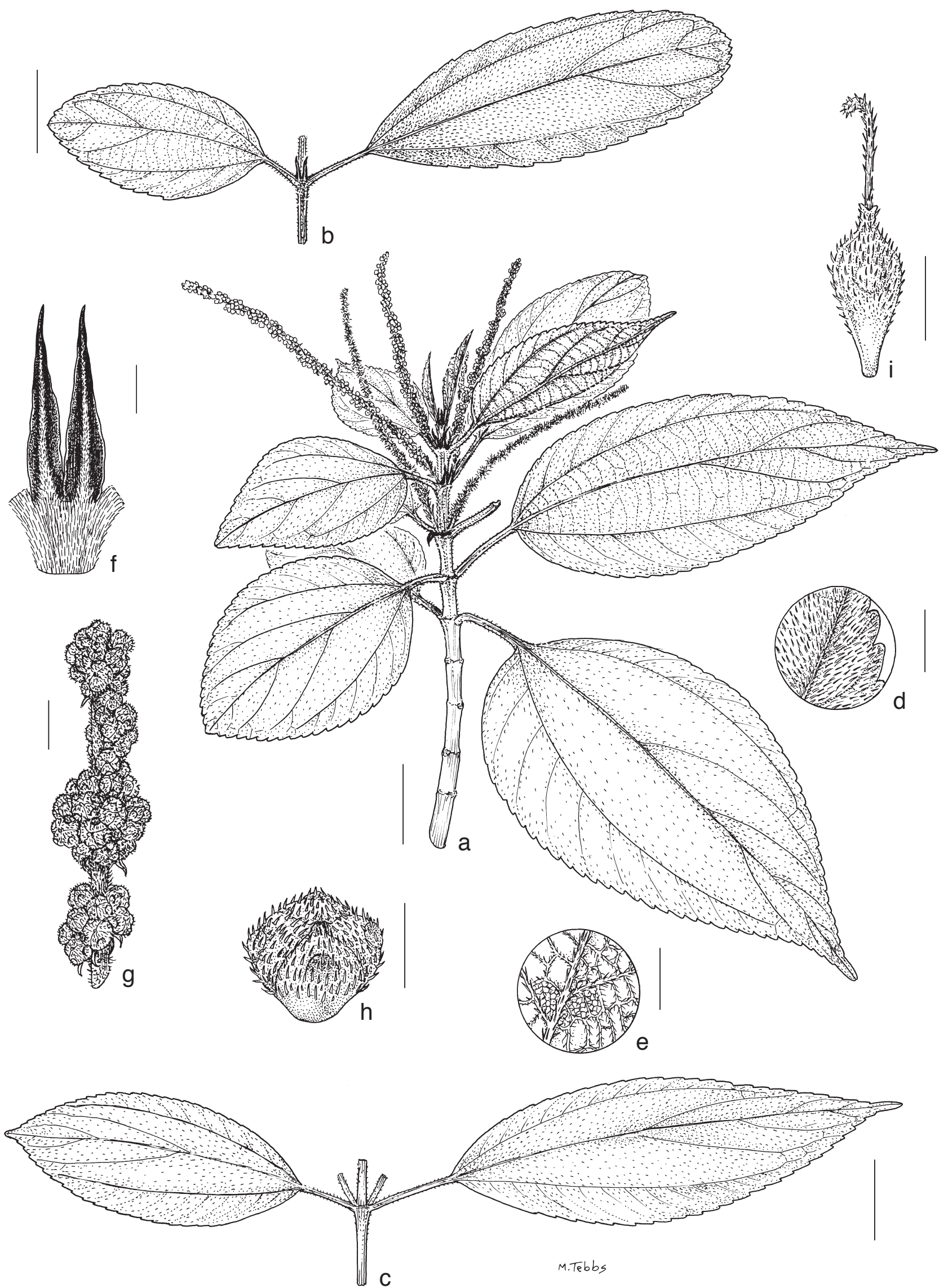

Fig. 16 Boehmeria densiflora var. boninensis (Nakai) Friis \& Wilmot-Dear. a. Habit of stem with inflorescence-bearing axes; b, c. detail of stems with dimorphic leaf-pairs of varying form (from different plants); d. leaf, detail of margin and adaxial surface; e. detail of abaxial surface; $f$. stipules; g. detail of male inflorescence-bearing axis with crowded flower-clusters; h. male bud; i. fruiting perianth (a, d-h: Yoshida \& Tannowa s.n., K; b, i: Yasui s.n., Tl; c: Tsuiyama s.n., TI). - Scale bars: a-c $=2 \mathrm{~cm} ; \mathrm{d}, \mathrm{e}=5 \mathrm{~mm} ; \mathrm{f}, \mathrm{g}=2 \mathrm{~mm} ; \mathrm{h}, \mathrm{i}=1 \mathrm{~mm}$. 
bearing axes, these unbranched, unisexual or bisexual, 1 per axil, up to $12 \mathrm{~cm}$ long, male axes \pm pendulous $5-10 \mathrm{~cm}$ long often arising mainly from lower axils, female axes erect but pendulous near tip (1.5-)5-10(-18) cm; axes with abundant adpressed or \pm spreading hairs; bracts broadly triangular, 2 by $1 \mathrm{~mm}$, acute or acuminate; male clusters usually \pm contiguous, 2-3 mm diam with less than 10 flowers, female clusters densely congested into thick continuous mass along axis, each cluster 3-4 mm diam, with more than 50 densely crowded flowers (light pink in live state); bracteoles inconspicuous less than half of flower length, oblong to broadly triangular, with rounded or acute apex. Male flowers 4-merous, sessile, mature buds depressedglobose, c. $1.5 \mathrm{~mm}$ diam, dorsal appendage of tepals indistinct or broad flap-like, pubescence abundant, fine, adpressed. Stigma $0.5-1 \mathrm{~mm}$ long. Fruiting perianth narrowly ellipsoid or obovoid, very variable in length, (1-)1.5-2(-2.5) mm long, but consistently narrow, c. $0.5 \mathrm{~mm}$ wide, much-flattened except for central thickened part, occupying only distal third or quarter of fruiting perianth; leaf apex \pm truncate, without beak or abruptly slightly constricted at apex into minute or conspicuous beak; base gradually long tapering; indumentum spreading, abundant but minute and inconspicuous.

Distribution - Southern China (including Hong Kong and Taiwan), Japan (only Ryukyu and Bonin Islands), Philippines (Luzon).

Habitat \& Ecology - Dry broad-leaved primary forest, secondary forest; forest margins and thickets, rocky riverbanks, roadsides, cliffs often amongst Selaginella; walls; coral limestone rock; 20-1650 m altitude.

Conservation status - Formal assessment for each variety is considered meaningful in this case, where geographical range and identity can be established with certainty. We consider the typical variety as Near Threatened (NT). It is known from c. 150 collections but most of these are over 50 years old. Its main distribution is on Luzon in the Philippines, Taiwan and adjacent parts of south-eastern China with a few widely scattered records, one from Yunnan and a few from the Ryukyu Islands. For this reason, and because of the many old records, the EOO of $2260570 \mathrm{~km}^{2}$ is misleadingly optimistic. It occurs in a range of fairly dry habitats. As discussed under $B$. beyeri and $B$. heterophylla, natural habitats in the Philippines are subject to severe and continuing degradation; there is similar, but less serious, pressure on the natural habitats in Taiwan. Although it does not meet the criteria for a formal status of Vulnerable (VU), it appears to be at risk.
For var. boninensis, we consider it meaningful to give a formal threat rating of Endangered (EN) since it is restricted to two island habitats (Bonin and Ryukyu Islands) which have suffered major habitat destruction from factors such as the introduction of goats. We base this on the criteria EN B2ab(iii).

Notes -1 . The two regional variants of this species are here recognised as partly sympatric varieties, var. densiflora occurring from Ryukyu Islands to Taiwan, Hong Kong and Luzon, var. boninensis restricted to two island groups, Ryukyu and the Bonin Islands further west. The two varieties are usually easily distinguished, leaves in var. boninensis being relatively broad, (length 2-2.5x width) mostly broad-acute or obtuse, in var. densiflora usually much narrower (length $\geq 4 \times$ width), mostly narrow-acute to attenuate. However, a few collections of var. densiflora from Taiwan have leaves approaching the proportions of var. boninensis (length only $3.2-3.5 \times$ width) and the range of variation in leaf apex partly overlaps; they are therefore recognised only at varietal rank.

2. Var. densiflora is distinguishable from other Boehmeria taxa in its leaves long, narrow, hairs fine, adpressed, marginal teeth minute but wide-spaced, sharp-acute, stipules rather short broad. Broad-leaved forms with length $<5 \times$ width are not easily confused with other taxa, but leaf proportions are rather variable and narrower-leaved forms can be confused with the partly sympatric (China, Guangdong) B. penduliflora which is distinguished by leaves (except the youngest pair at the extreme stem apex) glabrous adaxially and spreading-hairy abaxially, with marginal teeth closer-spaced usually much more numerous, giving the margin a very different appearance clearly visible to the naked eye, also often markedly bullate and stipules longer and narrower. As discussed in detail in Note 2 under B. penduliflora, Wang (in Wang \& Chen 1995) and Acharya et al. (2002) regarded $B$. penduliflora and $B$. densiflora (var. densiflora) as varieties of the same taxon (these authors did not refer to var. boninensis).

3. Both varieties of $B$. densiflora are rather similar to the Philippine endemic $B$. multiflora which differs in leaves with spreading hairs both sides and mostly relatively broader, length $3(-4)$ rather than (3.7-)4-7× width, inflorescence-bearing axis often much longer and stipules longer, narrower.

4. Var. densiflora is sometimes confused with $B$. hamiltoniana (partly sympatric but found in south-western rather than southeastern China) which has leaves of somewhat similar shape but glabrous adaxially and always thin-textured, its inflorescence-

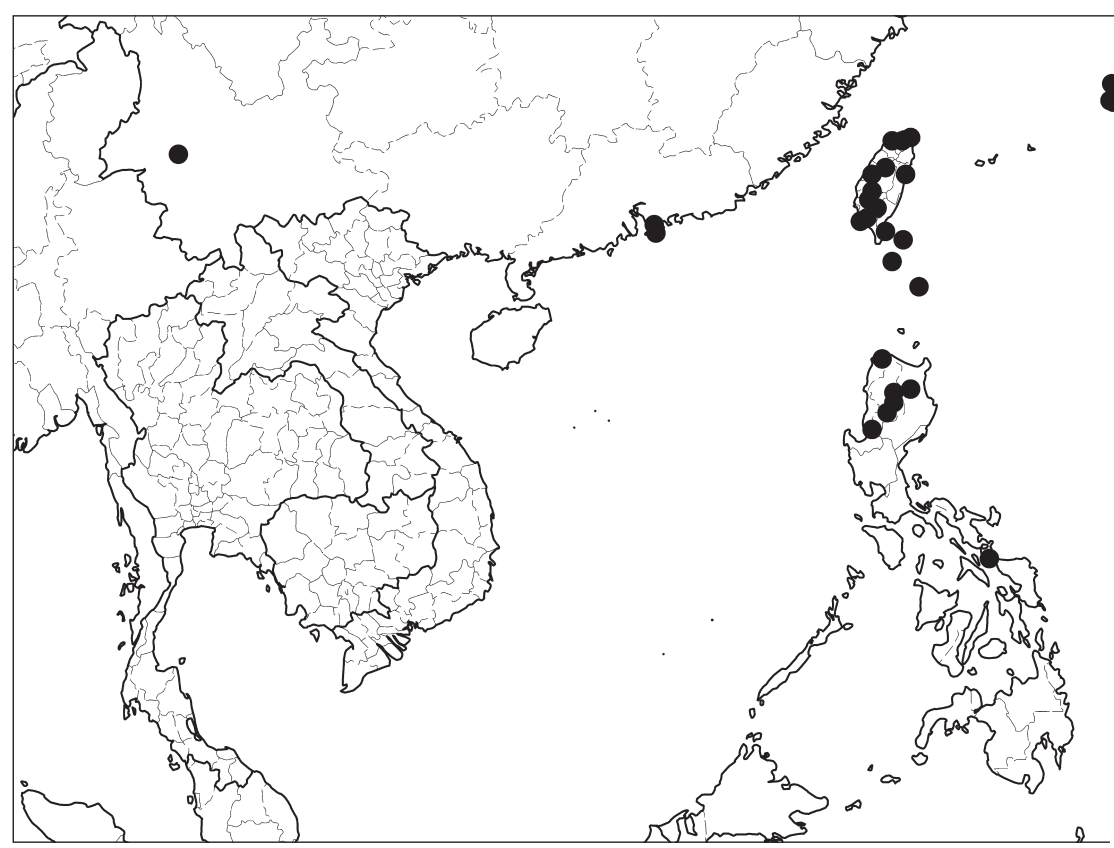

Map 17 Distribution of Boehmeria densiflora Hook. \& Arn. var. densiflora. 
Table 2 Distinction of the varieties of Boehmeria densiflora from B. virgata var. virgata.

\begin{tabular}{|c|c|c|c|}
\hline & B. densiflora var. densiflora & B. densiflora var. boninensis & B. virgata var. virgata \\
\hline Hairs on young stems & Dense adpressed & Dense adpressed & $\begin{array}{l}\text { Spreading or sparse } \\
\text { adpressed or none }\end{array}$ \\
\hline $\begin{array}{l}\text { Indumentum on leaf surfaces } \\
\text { ('ad' = adaxial; 'ab' = abaxial) }\end{array}$ & $\begin{array}{l}\text { Abundant adpressed hairs on } \\
\text { both sides }\end{array}$ & $\begin{array}{l}\text { Abundant adpressed hairs on } \\
\text { both sides }\end{array}$ & $\begin{array}{l}\text { 'Ad' glabrescent ('ab' various) or } \\
\text { 'ad' adpressed and 'ab' spreading }\end{array}$ \\
\hline Apex and proportions of marginal teeth & Acute, $0.3-0.7(-1)$ by $3-6 \mathrm{~mm}$ & Acute or obtuse, $0.5-1$ by $3.5-4.5 \mathrm{~mm}$ & Acute or obtuse, $(0.2-) 0.5-1$ by $2-4.5 \mathrm{~mm}$ \\
\hline Ratio leaf width : length & $1: 4-5(-7)$ & $1: 2-3$ & $1: 1.8-3.5$ \\
\hline $\begin{array}{l}\text { Apex and dimorphism of 'larger' and } \\
\text { 'smaller' leaf }\end{array}$ & $\begin{array}{l}\text { Always 'larger' attenuate, 'smaller' } \\
\text { acute or obtuse }\end{array}$ & $\begin{array}{l}\text { Both 'larger' and 'smaller' obtuse or } \\
\text { 'larger' attenuate, 'smaller' always } \\
\text { obtuse }\end{array}$ & $\begin{array}{l}\text { 'Larger' attenuate, 'smaller' acute or } \\
\text { both attenuate }\end{array}$ \\
\hline
\end{tabular}

bearing axis dichotomous at the base and a higher, only partly overlapping, altitudinal range.

5. The leaves of $B$. zollingeriana var. podocarpa (long, narrow, tapering, occasionally sparsely hairy) can also be confused with var. densiflora when the diagnostic axillary male clusters and long apically branched female axes are lacking; they differ in teeth usually much finer and blunt, at least one lateral vein arising somewhat lower, and petiole often longer relative to lamina.

6. Boehmeria densiflora has also been confused with some variants of the very variable and widespread $B$. virgata subsp. virgata var. virgata (sympatric in the Philippines). Boehmeria virgata var. virgata is easily distinguishable in flower and fruit from both varieties of $B$. densiflora, having inflorescencebearing axes \pm pendulous, slender with well-spaced clusters, the females long $(20-70 \mathrm{~cm})$ and sometimes branched, male axes also often $>15 \mathrm{~cm}$ long, usually branched throughout length, but it is almost identical to $B$. densiflora in stipules and range of leaf texture and is rather variable vegetatively.

Table 2 gives the characters for distinguishing sterile material of $B$. virgata var. virgata from $B$. densiflora. It is distinguishable from both varieties by its indumentum, and additionally from var. densiflora on leaf proportions, sometimes also on marginal tooth shape and proportions, and from var. boninensis additionally on shape and/or dimorphism of apex of larger and smaller leaves.

\section{Key to varieties}

1. Leaf length (3.2-)4-7× width. - China (incl. Taiwan); Japan (Ryukyu Islands); Philippines (Luzon) . . . a. var. densiflora

1. Leaf length 2-2.5(-3)× width. - Ryukyu and Bonin Islands ................. bar. boninensis

\section{a. var. densiflora - Fig. 15h-0; Map 17}

Boehmeria platyphylla D.Don var. loochooensis Wedd. (1869) 213. - Boehmeria penduliflora Wedd. var. loochooensis (Wedd.) W.T.Wang in Wang \& Chen (1995) 355. - Type: Wright 303 (holo K), Japan, Ryukyu Islands [Loo Choo Islands].

Boehmeria weddelliana S.Vidal (1886) 256. - Type: Vidal 1784 (iso A, K, L, PNH), Philippines, northern Luzon, Bontoc.

Stipules only 5-6 mm long. Leaves narrowly ovate to linearovate, small or medium $6-12(-16)$ by $(1-) 1.5-4 \mathrm{~cm}$, length $4-5(-7) \times$ width (sometimes only $3.2-3.5 \times$ width in Taiwan), marginal teeth acute, only $0.3-0.7 \mathrm{~mm}$ long and wide-spaced, 3-6 mm apart, with width 7-more than 10x length (or sometimes reduced to minute hard mucro); leaf apex of 'larger' leaves gradually tapering attenuate or very indistinctly acuminate and often sideways-curved, or acute but extreme tip abruptly long-mucronate; 'smaller' leaves relatively slightly broader and less tapering, narrowly to broadly acute; basal veins extending almost to tip, upper lateral veins $2-3$, all arising in distal half or in distal third of lamina; tertiary venation mostly indistinct; texture thin- or thick-chartaceous (if thick then leaves often slightly bullate). Inflorescence-bearing axes unbranched, male axes often arising mainly from lower axils, female axes (1.5-) $5-10(-18) \mathrm{cm}$. Fruiting perianth with apex \pm truncate, without beak or abruptly slightly constricted at apex into minute beak, $0.1-0.2 \mathrm{~mm}$ long (apical teeth clearly visible), base gradually long tapering; indumentum spreading, abundant but minute and inconspicuous.

Distribution - Throughout the range of the species except Bonin Islands.

Habitat \& Ecology - As for the species as a whole.

Conservation status - See under the species as a whole.

Notes - See under the species as a whole.

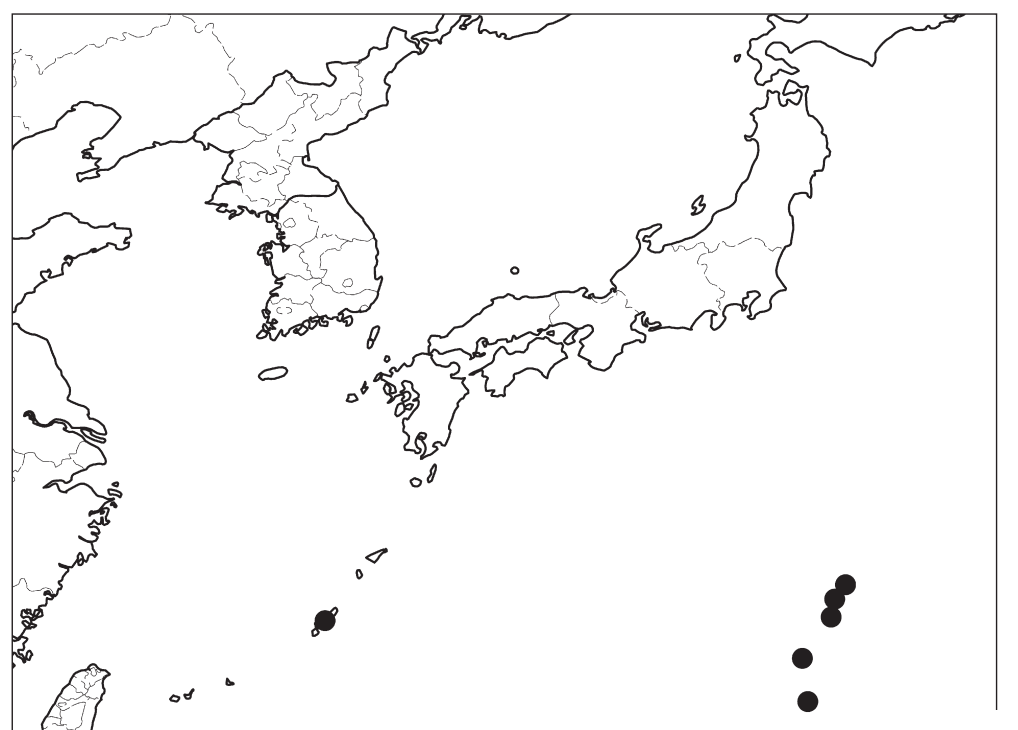

Map 18 Distribution of Boehmeria densiflora Hook. \& Arn. var. boninensis (Nakai) Friis \& Wilmot-Dear. 
b. var. boninensis (Nakai) Friis \& Wilmot-Dear, comb. \& stat. nov. - Fig. 16; Map 18

Basionym: Boehmeria boninensis Nakai (1918) 217; Makino (1925) 1062; Makino \& Nemoto (1931) 222. - Type: Maximowicz 37 (holo TI), Japan, Bonin Islands, July-Aug. 1905.

Stipules up to $10 \mathrm{~mm}$ long. Leaves ovate, elliptical or obovate, \pm symmetrical, slightly or moderately dimorphic in size and either all leaves of similar shape with broadly acute to obtuse apex, or leaves markedly dimorphic with the 'larger' leaves differing in being distinctly attenuate-acuminate; 'larger' leaves $10-14(-20)$ by $4-6(-9) \mathrm{cm}$, length $2-2.5(-3) \times$ width, marginal teeth rounded or acute, $0.5-1$ by (usually) $3.5-4.5 \mathrm{~mm}$; leaves always smooth (never bullate), texture varying from thin-chartaceous with secondary and coarser tertiary veins prominulous abaxially, to coriaceous with even fine reticulation prominent, lateral veins similar on both sides of lamina, basal veins extending just into distal half of lamina, upper veins 1-3 either side arising in distal half. Male inflorescence-bearing axes few-branched near base or unbranched, female unbranched, $<10 \mathrm{~cm}$ long. Fruiting perianth narrow-ellipsoid or sometimes obovoid, beak conspicuous or very short.

Distribution - Endemic to Japan (Ryukyu and Bonin Islands).

Habitat \& Ecology - Thickets and sunny rocky clearings, roadsides; $150-910 \mathrm{~m}$ altitude.

Conservation status - See under the species as a whole.

Notes - See under the species as a whole.

\section{Boehmeria multiflora C.B.Rob. - Fig. 17; Map 19}

Boehmeria multiflora C.B.Rob. (1908) 179. - Type: R.S. Williams 1088 (iso NY), Philippines, Luzon, Benguet, Baguio, 6 June 1904.

Shrub or small tree, 2-5 m tall; ultimate branches 1-2 $\mathrm{mm}$ diam, indumentum dense, velvety, hairs short (c. 0.3-0.4 mm long), robust, \pm spreading, white. Stipules linear-ovate, longacuminate, $8-13$ by $2-2.5 \mathrm{~mm}$, thick-textured, hairy, hairs on midrib dense, \pm adpressed, longer than on stem, elsewhere sparse very short and fine. Leaves opposite, not or moderately dimorphic with 'larger' leaves 1.2-2x length of 'smaller' ones and relatively narrower with more distinctly acuminate apex; slightly asymmetrical, narrowly ovate, small to medium-sized, $9-14$ by $3-5 \mathrm{~cm}$, relative proportions little-varying, length $3(-4) \times$ width; margin finely serrulate, teeth (30-)35-45(-55) either side, up-curved, blunt, c. 1 by (1-)1.5-2(-4) mm; leaf apex long-acute to long-attenuate and often slightly sideways-curved; base asymmetrically rounded or slightly cuneate; basal veins extending just into distal half of lamina, upper lateral veins 3-4 but often indistinguishable from coarser tertiary veins, usually all arising in distal half of lamina, these and fine reticulation robust and prominent abaxially; texture fairly thick-chartaceous and leaves usually slightly bullate; adaxial surface with abundant hairs like the stem but softer, pale or brownish; hairs on abaxial surface denser, greyish; petiole very variable relative to lamina, (0.1-)0.2-0.3× length, 1-4 cm long. Flower-clusters borne along leafless inflorescence-bearing axes, these unbranched (or rarely male branched), pendulous or apically drooping, 1 per axil, plants mostly bisexual, with male axes up to $11 \mathrm{~cm}$ long borne in upper axils, female axes $15-30 \mathrm{~cm}$ long borne in lower leaf axils, some intermediate axes with bisexual clusters; bracts c. $1.5 \mathrm{~mm}$ long, narrowly triangular long-acuminate; flower-clusters closely-spaced or (especially female) contiguous along axis, male clusters c. $3 \mathrm{~mm}$ diam with less than 10 loosely arranged flowers, female clusters 5-6 mm diam, with 30 -more than 50 densely crowded flowers; bracteoles in male clusters narrowly triangular or obovate up to $0.4 \mathrm{~mm}$ long, in female clusters narrower, linear-ovate, up to $0.7 \mathrm{~mm}$ long, c. half length of fruiting perianth. Male flowers 4-merous, sessile, mature buds depressed-globose, c. $1.5 \mathrm{~mm}$ diam, tepals with apiculus and without dorsal appendages or sometimes with distinct dorsal thickening, with dense indumentum like the stem. Female flowers ovoid to obovoid, up to 0.7 by $3 \mathrm{~mm}$, beaked; stigma small, $0.8-1 \mathrm{~mm}$ long, hooked. Fruiting perianth obovoid to spindle-shaped (tapering to base and to distinct apical beak), up to 1.5 by $0.7 \mathrm{~mm}$, much-flattened with indistinct or distinct marginal wing, hairs sparse or abundant, short, fine, spreading. Achene ellipsoid, c. $0.6 \mathrm{~mm}$ long.

Distribution - Philippines (Luzon, Bohol, Mindanao), Indonesia (Bouton [also Buton or Butung, island adjacent to Sulawesi]).

Habitat \& Ecology - Margins of pine and oak or oak-ericaceous forest; disturbed roadsides in forest; 750-2600 m altitude.

Conservation status - Vulnerable (VU). The species is known from c. 30 collections, most of them more than 50 years old. Its main distribution is on Luzon in the Philippines; as

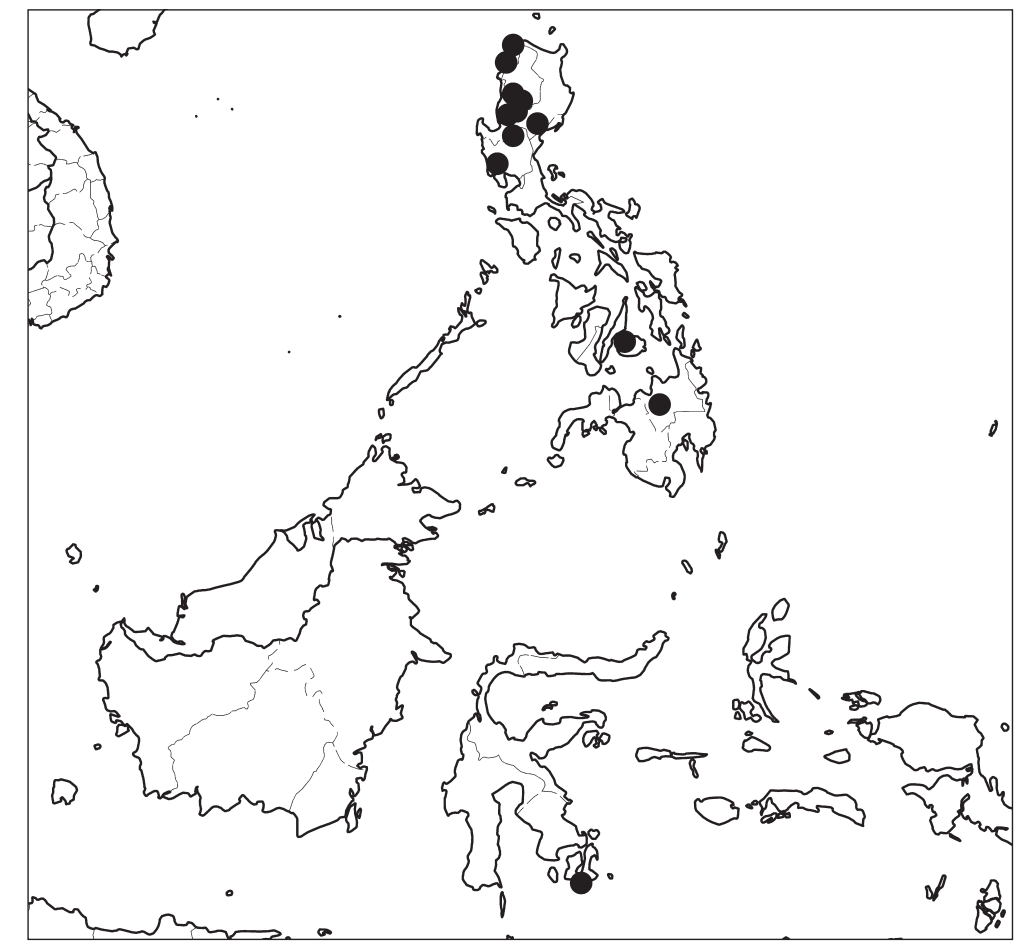




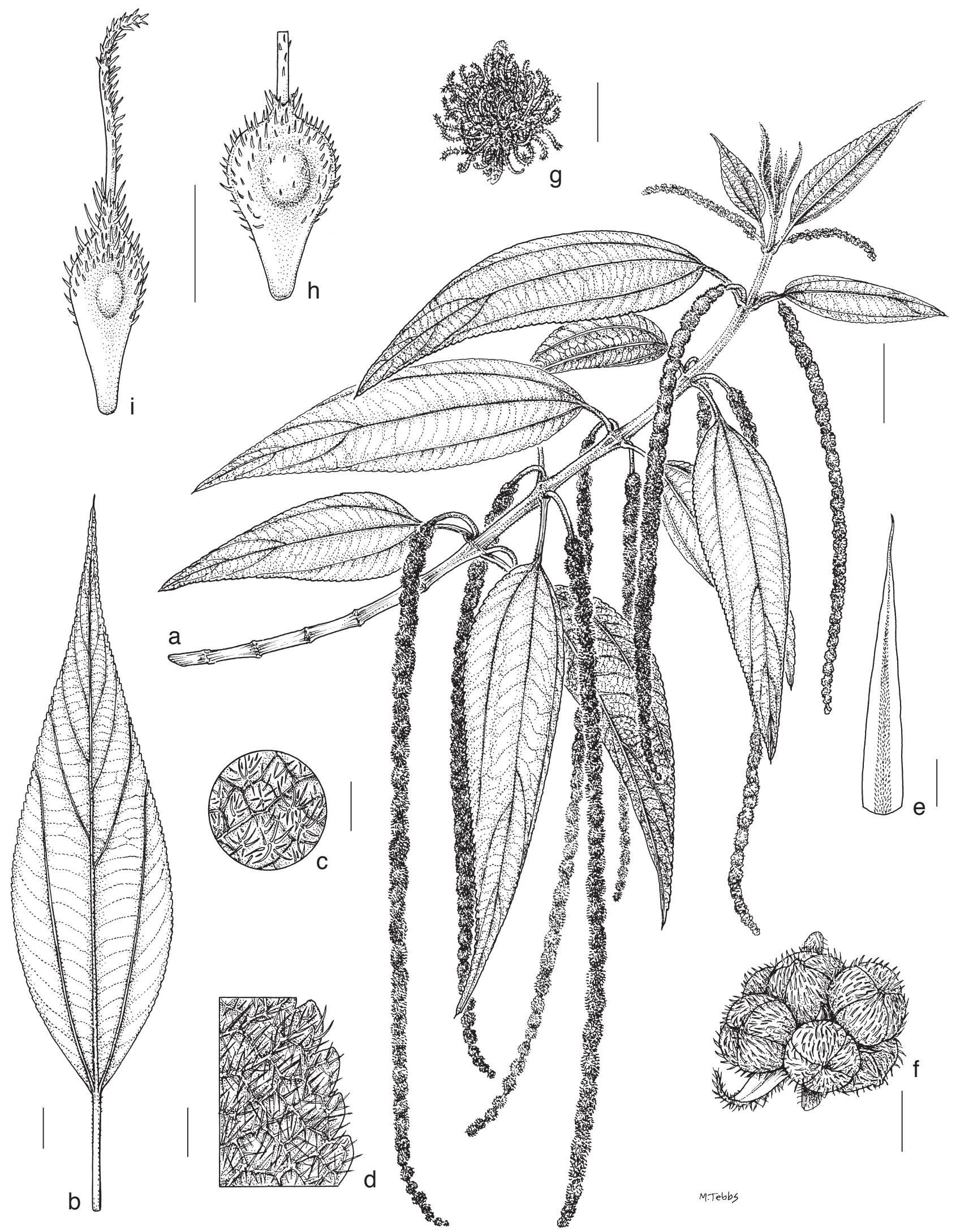

Fig. 17 Boehmeria multiflora C.B.Rob. a. Habit of stem with inflorescence-bearing axes; b. leaf; c. leaf, detail of adaxial surface; d. detail of leaf margin and abaxial surface; e. stipule; f. detail of male inflorescence-bearing axis showing one flower-cluster (inflorescence) and bract; g. detail of female inflorescencebearing axis showing one flower-cluster (inflorescence); h, i. fruiting perianths of different form (from different plants) (a, i: Elmer 21976, K; b-e, h: Gaerlan 26686, L; f: Elmer 14275, K; g: Williams 1088, K). - Scale bars: $a=2 \mathrm{~cm} ; \mathrm{b}=1 \mathrm{~cm} ; \mathrm{c}, \mathrm{d}, \mathrm{f}-\mathrm{i}=1 \mathrm{~mm}$; $\mathrm{e}=2 \mathrm{~mm}$. 
discussed under $B$. beyeri and $B$. heterophylla, the Philippines are subject to severe and continuing habitat degradation. The EOO of $601968 \mathrm{~km}^{2}$ is misleading because of the many old records and the single (old) record that documents the extension to Sulawesi, the AOO is calculated as less than $500 \mathrm{~km}^{2}$ and it is recorded from only c. 30 collections. For these reasons we will propose the criterion VU B2ab(iii).

Notes -1 . This species is distinctive in leaves relatively narrow, with spreading indumentum on both sides (velvety abaxially), often slightly bullate with prominent reticulation. It is similar in general appearance to two other narrow-leaved taxa, the partly sympatric but more widespread $B$. densiflora var. densiflora which differs in leaves mostly narrower (length $4-10 \times$ width, rather than $3(-4) \times$ width) with adpressed hairs adaxially and marginal teeth shallow, acute, mostly more widely spaced, and the allopatric (Indian subcontinent to China and Indochina) $B$. penduliflora which differs in much narrower glabrescent leaves with more than 50 acute teeth.

2. Boehmeria multiflora can be confused with certain densely-pubescent forms of $B$. virgata var. virgata which differ in inflorescence-bearing axes usually branched and generally longer (male 10-20 $\mathrm{cm}$ rather than $\leq 10 \mathrm{~cm}$, female up to 70 rather than $\leq 30 \mathrm{~cm}$ ), leaves not bullate, often longer and relatively broader, marginal teeth relatively broader, upper veins only $1-2(-3)$, basal veins reaching nearly to tip. However, these densely hairy forms of $B$. virgata are found mostly in the island of New Guinea whereas its forms found in the Philippines are mostly much more easily distinguished, being sparsely adpressed-hairy and broader-leaved.

3. Boehmeria multiflora can also be confused with narrowerleaved forms of the sympatric $B$. rugosissima which differs in leaves relatively broader with length at most $2.5 \times$ width, only sparsely hairy adaxially, and inflorescence-bearing axes branched.

4. Boehmeria multiflora is possibly under-collected and might be expected to occur also in the intermediate islands of the Central Philippines.

\section{Boehmeria grandis (Hook. \& Arn.) A.Heller - Fig. 18; Map 20}

Boehmeria grandis (Hook. \& Arn.) A.Heller (1897) 812. - Urtica grandis Hook. \& Arn. (1837) 95. - Type: Beechey s.n. (holo BM; iso K), Hawaiian Islands, Oahu.

Boehmeria stipularis Wedd. (1854) 200. - Syntypes: du Petit-Thouars s.n. (not traced), Mascarene Islands; Gaudichaud s.n. (not traced), Reunion; Commerson $(\mathrm{P})$, Mauritius.

Boehmeria amplissima Blume (1857) 219 - Type: Richard 690 (iso P), Réunion.

Boehmeria grandis (Hook. \& Arn.) A.Heller var. kauaiensis Skottsb. (1926) 220. - Type: Skottsberg 951 (holo GB, n.v.), Hawaiian Islands, Kauai, Waimea.

Boehmeria grandis (Hook. \& Arn.) A. Heller var. cuneata Skottsb. (1944) 350. - Type: Cranwell 3392 (holo GB), Hawaiian Islands, Molokai, 20 Sept. 1938.

Shrub, to $7 \mathrm{~m}$ tall; ultimate stems relatively robust, (1.5-)2.5-3 $\mathrm{mm}$ diam, hairs sparse or abundant, adpressed or spreading, $\leq 0.4(-0.5) \mathrm{mm}$ long. Stipules connate to apex, large, boatshaped, (10-)25-65 by (3-)7-20 mm, pubescent outside in a broad band and with prominent parallel venation, very soon deciduous. Leaves opposite, not or slightly dimorphic in size and shape ('smaller' leaves slightly relatively broader), elliptic or elliptic-ovate, often very large and broad, (9-)12-21 by (4-)7-12.5 cm, length (1.2-)1.5-2(-3)× width; margin up-curved-serrate, teeth (20-)25-50 either side, medium or large, well-spaced, $1-2$ by $2-6 \mathrm{~mm}$; leaf apex short broad attenuate-acuminate; base narrowly rounded or slightly cordate (in the Mascarenes distinctly cordate, with auricles overlapping or wrapped around the petiole); basal veins extending into distal third of lamina, upper lateral veins numerous (5-)6-9, subopposite, all arising in distal half of lamina but often hard to distinguish from robust coarser tertiary veins in proximal half, veins visible or somewhat impressed adaxially and finely prominent abaxially, coarser tertiary veins scalariform, conspicuous or sometimes inconspicuous; texture chartaceous, leaves thin or thick and bullate; adaxial surface glabrous or with sparse adpressed hairs except on veins; hairs on abaxial surface usually on veins only, sparse, adpressed or abundant, longer, spreading; petiole relatively long, $0.3-0.5(-0.8) \times$ lamina length. Flower-clusters borne on \pm erect leafless inflorescence-bearing axes, these arising one from each axil, mostly unisexual, branched throughout length; male axes $20-30 \mathrm{~cm}$ long with robust main axis and long lateral branches with 2nd-order branching, female more slender, $7-13 \mathrm{~cm}$ with lateral branches shorter and unbranched; bracts triangular, 2 by $1 \mathrm{~mm}$; male clusters spaced 2-10 mm, tiny with 1-few flowers, female clusters generally more crowded, spaced $1-3 \mathrm{~mm}$, clusters 1.5-2 mm diam, with few-20 (-more than 40) fairly crowded flowers; bracteoles obovoid or oblong-spathulate, $0.3-0.5 \mathrm{~mm}$ long, only conspicuous once flowers have fallen. Male flowers 4-merous, sessile, mature buds depressed-globose, 1.2-1.4 $\mathrm{mm}$, segments divided almost to base, dorsal appendage of tepals thick, prominent, hairs abundant, fine, spreading. Female flowers broadly ovoid, flattened, 0.5 by $0.3 \mathrm{~mm}$ with abundant coarse hairs; stigma 1-1.5 mm long. Fruiting perianth 1-1.2 by $0.5-1 \mathrm{~mm}$, ovoid or with rhombic outline, markedly laterally flattened into narrow or wide wings up to $0.3 \times$ total fruiting perianth width. Achene elongate and occupying middle third of fruiting perianth.

Distribution - Hawaiian Islands (incl. Hawaii, Mauai, Lauai, Molokai, Oahu, Kauai); presumed naturalised in Reunion and Mauritius.

Habitat \& Ecology - Ravines and clearings in rainforest, exposed slopes and ridges, often forming dense thickets; 130$1100 \mathrm{~m}$ altitude.

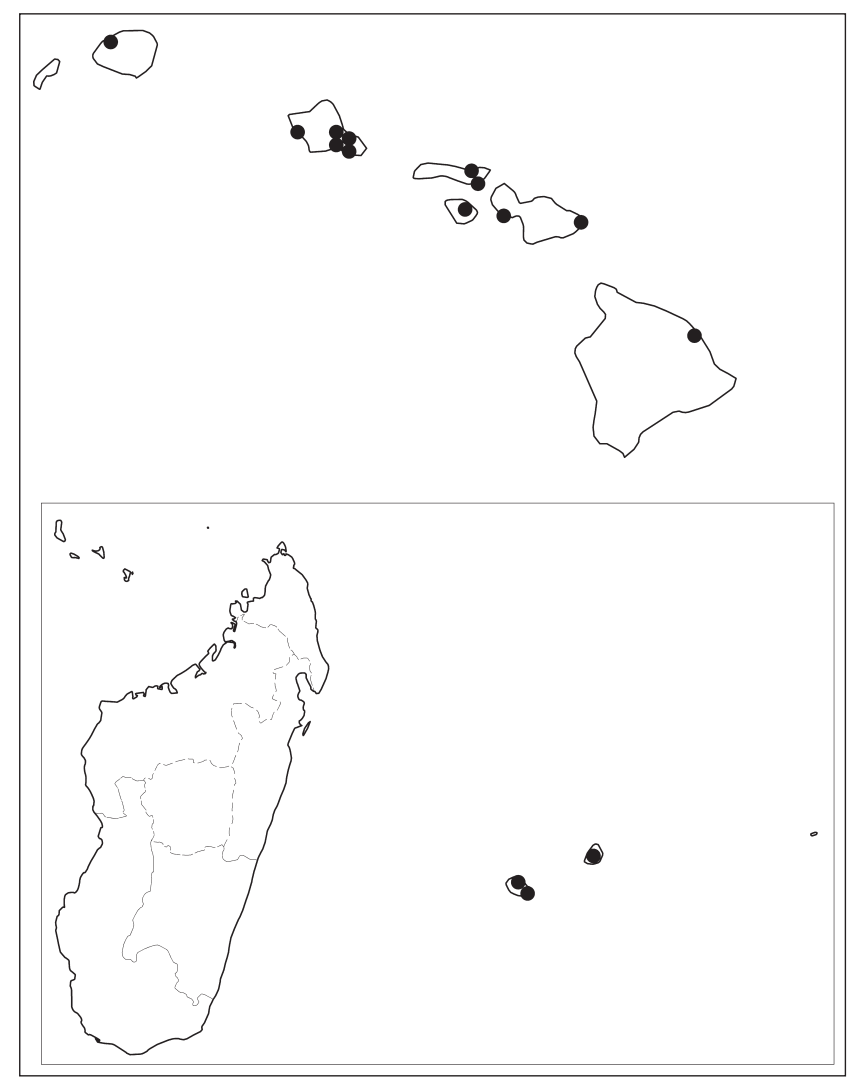

Map 20 Distribution Boehmeria grandis (Hook. \& Arn.) A.Heller; indigenous on the Hawaiian Islands (above) and naturalised distribution on the Mascarenes (below). 


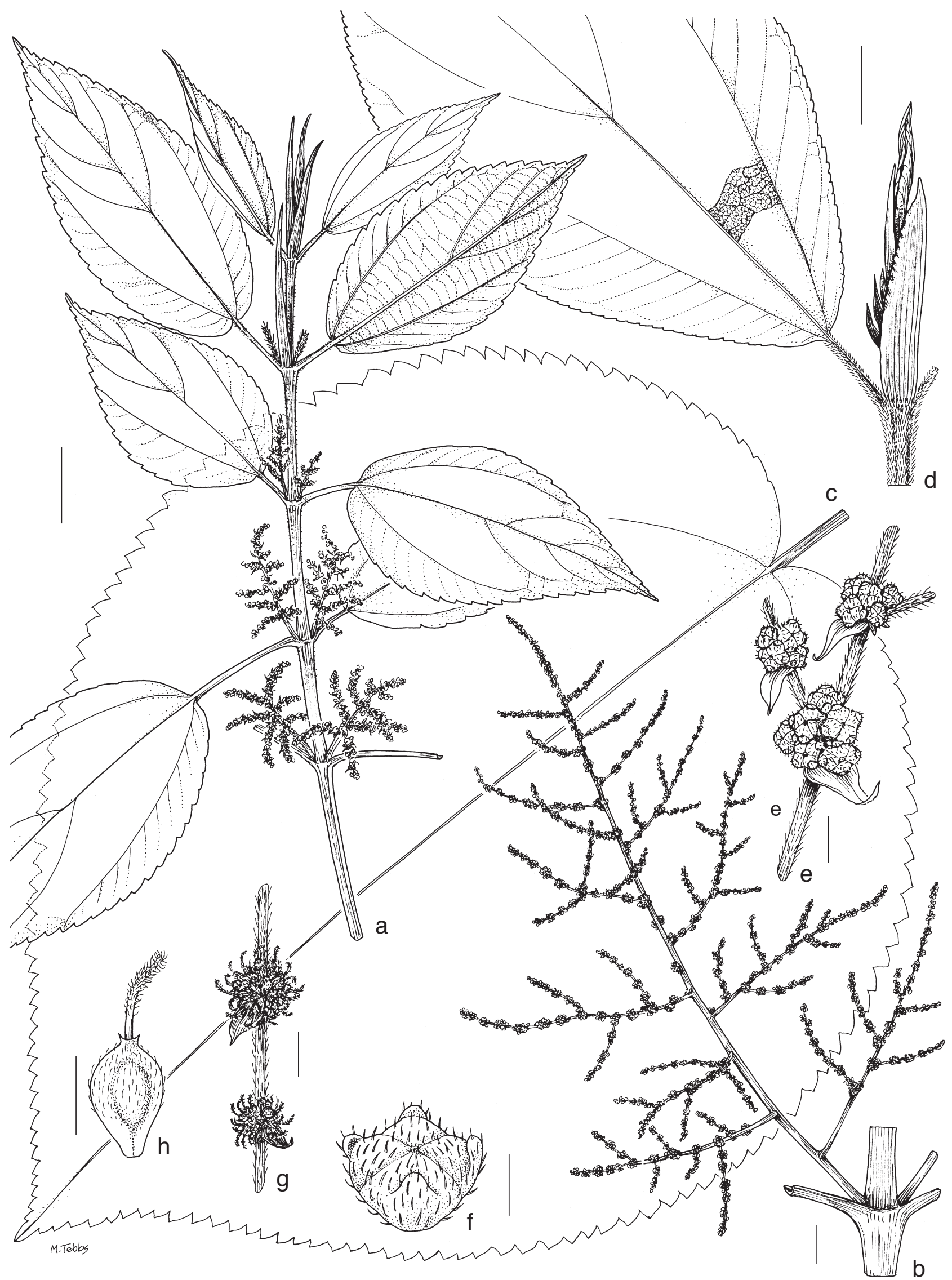

Fig. 18 Boehmeria grandis (Hook. \& Arn.) A.A.Heller. a. Habit of stem with inflorescence-bearing axes; b. detail of one node with branched inflorescencebearing axes; $c$. leaf; $d$. detail of stem apex with leaf and stipule; e. detail of male inflorescence-bearing axis with branch, flower-clusters (inflorescences) and bracts; f. male bud; g. detail of female inflorescence-bearing axis with flower-clusters (inflorescences) and bracts; h. fruiting perianth (a: Selling $3098 ; \mathrm{b}$, e, f: Cowan 679; c: Boyer 3; d: Christofferson 3702; g: Degener 8696; h: Bosser 20880; all K). - Scale bars: a, c, d = $2 \mathrm{~cm} ; \mathrm{b}=1 \mathrm{~cm} ; \mathrm{e}, \mathrm{g}=2 \mathrm{~mm} ; \mathrm{f}, \mathrm{h}=1 \mathrm{~mm}$. 
Conservation status - Vulnerable (VU). The species is known from c. 300 collections, although most of them are more than 50 years old. There is habitat destruction on all the Hawaiian Islands, but also conservation efforts and the existence of forest reserves where many of the collections come from. The EOO in its presumed native distribution is $16760 \mathrm{~km}^{2}$, which meets the criteria for Vulnerable, as does the AOO of less than $500 \mathrm{~km}^{2}$. This would justify the conservation status VU 2Bab(iii).

However, if one includes the records from the Mascarene Islands where the habitat destruction is as severe as in the Hawaiian Islands, the EOO becomes meaninglessly large, and criteria based on EOO can no longer be used. But the AOO remains less than $500 \mathrm{~km}^{2}$, and would still justify a status of Vulnerable. However, with two far removed populations it seems unlikely that the species would become extinct.

Notes - 1. This is the only species of Boehmeria known from Hawaii. It is distinctive in stipules extremely large, connate and boat-shaped, (10-)20-60 mm long, and leaves large, only sparsely hairy, relatively broad, often bullate and ridged, drying brownish, with many upper veins and almost equally robust tertiary veins spaced throughout lamina. Its strongly-veined leaves and branched female inflorescence-bearing axes are reminiscent of those of the Himalayan $B$. polystachya.

2. Marginal teeth in $B$. grandis are very varied in number and width relative to leaf-size and some forms can be confused with some Southeast Polynesian forms of the very variable $B$. virgata var. virgata which also have large thick leaves and stipules unusually large for $B$. virgata. However, $B$. virgata differs in male axis without 2 nd-order branching, female axes unbranched or with short male branches at base; larger-toothed forms often also have margin crenate (teeth rounded) rather than serrate, leaf texture smooth rather than bullate and secondary veins distinct from tertiary. Some collections of $B$. virgata appear somewhat intermediate with $B$. grandis (discussed in Note 5 under $B$. virgata var. virgata).

3. Forms with the smallest stipules are rather similar to the largest forms of $B$. rugosissima (Jawa, Philippines) which differs in lateral veins fewer but more distinct all clearly arising in distal half, and fruiting perianth less markedly flattened with indistinct wing and relatively large achenes.

4. The material found in Mascarenes (B. stipularis) is indistinguishable from that found in Hawaii. The differences suggested in literature (e.g., Hillebrand 1888: 412) between these two taxa are non-existent; $B$. stipularis appears to differ from $B$. grandis only in leaves strongly cordate, often with marked auricles overlapping each other or wrapped round the petiole, lamina often abundantly velvety hairy abaxially, stigma $1.5 \mathrm{~mm}$. Wagner et al. (1999: 1300) note that Heller (1897) recognised the Hawaiian taxon as distinct "without any comment other than, when considered conspecific with $B$. stipularis, it had an odd distribution". It is presumed to be an early introduction to the Mascarenes from Hawaii (just as is the presence there of the East Asian B. penduliflora). The species was cultivated by the early Hawaiians for fibre (Degener 1947: Fam. 97, Urticaceae, Boehmeria).

5. There is some regional variation within the Hawaiian Islands which appears to be genetic rather than environmentallyinduced. Throughout the Hawaiian Islands occur typical forms with stems robust, stipules very large, leaves broad, prominently reticulate-veined and often very large, but a variant which has been recognised as var. kauaiensis occurs only in Kauai, with ultimate stems slender, c. $1.5 \mathrm{~mm}$ diam (rather than c. $3 \mathrm{~mm}$ ), stipules only 10-35 (rather than 25-65) $\mathrm{mm}$, leaves only up to $12 \mathrm{~cm}$ long, length $2-3 \times$ (rather than $1.2-2.2 \times$ ) width, margins with only up to c. 30 teeth, veins less prominent and tertiary reticulation inconspicuous. The two forms are fairly distinct in Kauai but elsewhere (especially in Molokai) the distinction com- pletely breaks down and it is therefore not formally recognised here.

6. Two forms occur on Reunion (Boyer, pers. comm.) almost identical in leaves and flowers but very different in habit. $A$ large shrub, 2-4 $\mathrm{m}$ tall, is widespread on the island, with many weak arching branches which send up vertical leafy shoots to 7-10 m, with fibrous aerial roots at shoot junctions, stipules persistent and flowering once a year. However, in only one locality the species occurs as trees up to $8 \mathrm{~m}, 13-20 \mathrm{~cm}$ diam, with a single unbranched trunk or with one or two strong branches in upper half of plant, without arching branches or aerial roots, stipules deciduous even from near stem apex, flowering twice a year, in July and October. Boyer has suggested that this variation is a result of environmental damage from which the widespread form is regenerating whereas the very localised tree form grows in a locality which has somehow escaped damage.

\section{Boehmeria tsaratananensis Leandri - Fig. 19; Map 21}

Boehmeria tsaratananensis Leandri (1950) 59. - Syntypes: Humbert 18285 (syn P, n.v.), Madagascar, Centre Tsaratanana and Sambirano, Andavaka; Perrier de la Bâthie 15501 (P) \& 9972 (P), Madagascar, Tsaratanana; Perrier de la Bâthie $17678(\mathrm{P})$, Madagascar, Ambre.

Boehmeria platyphylla D.Don var. masoalensis Leandri (1950) 59. - Type: Perrier de la Bâthie 9973 (holo P), Madagascar, Masoala. - See Note 2.

Shrub, \pm scrambling, 1-3 m tall, branches rather fleshy; ultimate branches slender, c. $1 \mathrm{~mm}$ diam, hairs dense, minute (up to $0.1 \mathrm{~mm}$ long), fine, closely-adpressed, eventually glabrescent. Stipules broad- or narrow-triangular (shortest in high altitude specimens), $3.5-10$ by $1-1.5 \mathrm{~mm}$, fused for $0.3-0.5 \times$ length, usually cordate in basal part, sparsely hairy outside as stem. Leaves opposite and slightly or moderately dimorphic with length of 'larger' leaves up to $1.5 x$ 'smaller' ones, elliptic or elliptic-obovate, sometimes asymmetrical with one half slightly wider, small or medium, $5-16$ by $2.5-7 \mathrm{~cm}$, length $1.7-2.2$ $(-2.8) \times$ width; margin entire in basal quarter or half, distal part indistinctly serrate, teeth $10-15(-20)$ either side, these very

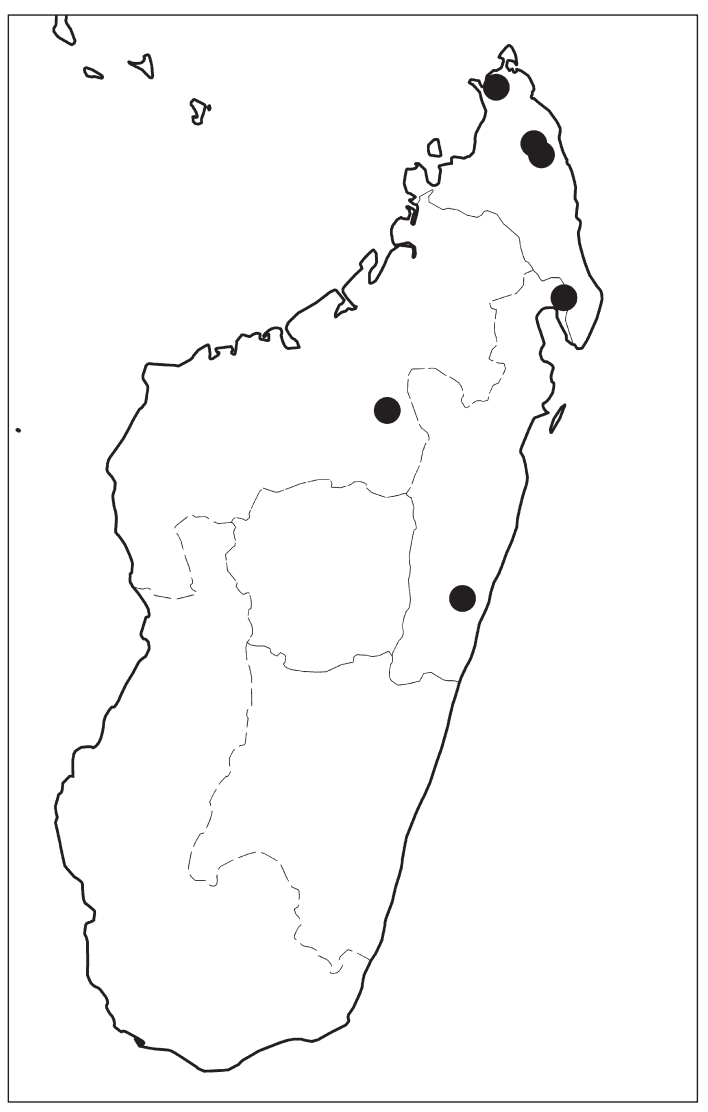

Map 21 Distribution of Boehmeria tsaratananensis Leandri. 
shallow but broad, $0.3-1(-1.5)$ by $3-8 \mathrm{~mm}$, length usually $5-10 \times$ width, the longest near apex; leaf apex broadly rounded terminated abruptly by short acumen tapering to fine point; base broadly rounded to broadly cuneate, often slightly oblique; basal veins extending to distal quarter of lamina, upper lateral veins (1-)2 on wide side, 1(-2) on narrow side, all arising in distal third or near apex, inconspicuous or (in thick leaves) deeply impressed adaxially, prominent abaxially, recorded as purple when live, coarser tertiary venation \pm scalariform, prominent abaxially; texture thin- or thick-chartaceous to \pm coriaceous (leaves sometimes slightly bullate), adaxial surface hairy, hairs like the stem but sparse, extremely inconspicuous and often lying in a rather regular pattern pointing towards the centre of areoles; abaxial surface with similar hairs on veins and reticulation but denser and even smaller; petiole long with respect to lamina, half of to almost equalling lamina length, pubescent

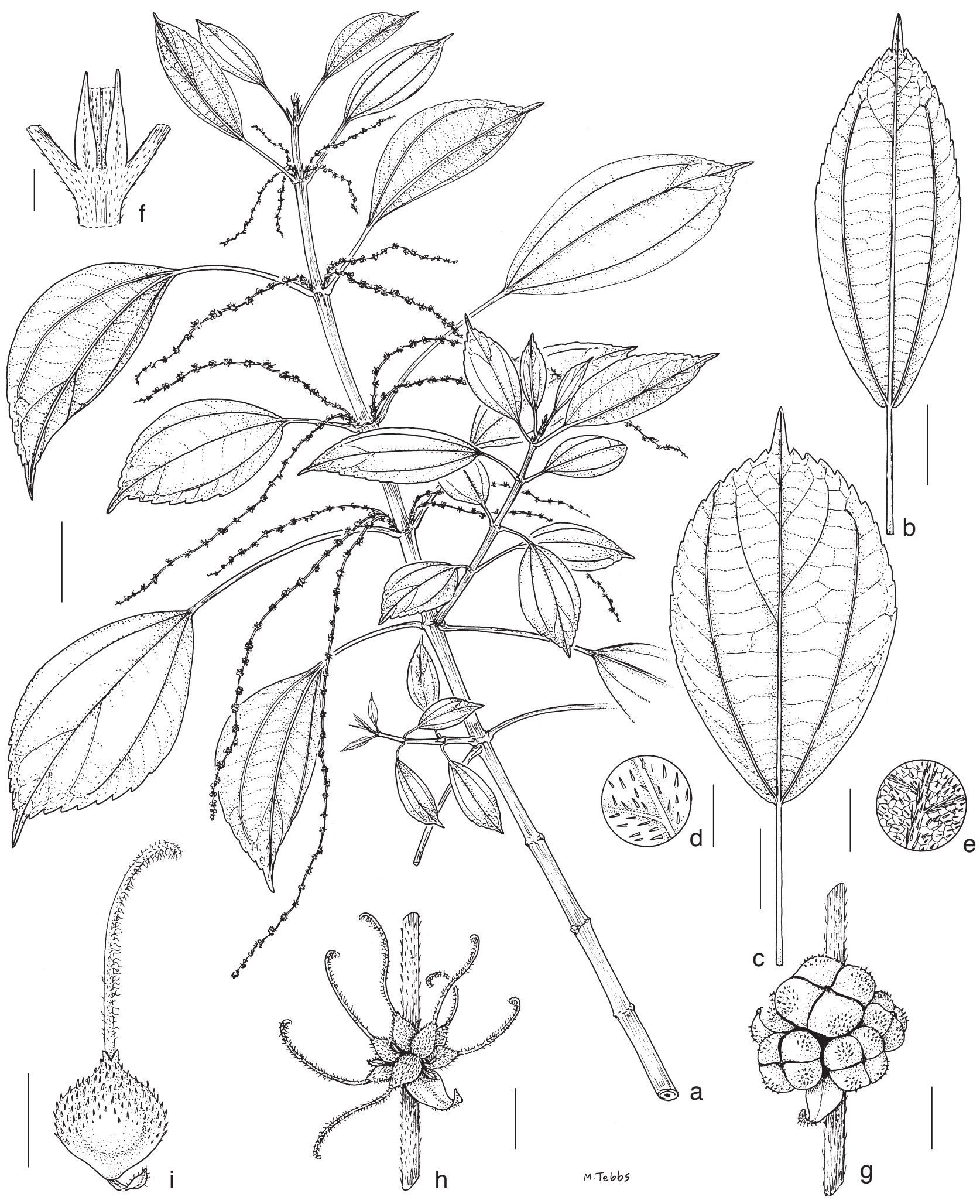

Fig. 19 Boehmeria tsaratananensis Leandri. a. Habit of stem with inflorescence-bearing axes; b, c. leaves of different form (from different plants); d. leaf, detail of adaxial surface; e. detail of abaxial surface; f. detail of stem and stipules; g. detail of male inflorescence-bearing axis with flower-clusters (inflorescences) and bract; $\mathrm{h}$. detail of female inflorescence-bearing axis with flower-clusters (inflorescences) and bract; i. fruiting perianth (a, f: Schatz 2402, K; b, g: Andrianantoanina 343, K; c-e, h: Lowry 4084, K; i: Bathie 9972, P). - Scale bars: a-c = $2 \mathrm{~cm}$; d, e = $5 \mathrm{~mm} ; \mathrm{f}-\mathrm{i}=1 \mathrm{~mm}$. 
like stem. Flower-clusters borne along leafless inflorescencebearing axes, these extremely slender, $(0.2-0.5 \mathrm{~mm}$ diam when dry), (red in live state) 1-several arising from thicker basal part which is extremely short $2-5 \mathrm{~mm}$ long; axes rarely bisexual, more often unisexual but both sexes sometimes on same plant with male axes in upper axils; male axes $3-10 \mathrm{~cm}$, erect, female ones (10-)15-40 cm, pendulous; flower-clusters often rather wide-spaced, 2-20 $\mathrm{mm}$ apart, up to $2.5 \mathrm{~mm}$ diam, with only $1-5(-10)$ flowers; bracts broadly ovate, acuminate 1.5 by $1 \mathrm{~mm}$; bracteoles very conspicuous, triangular or elliptic, acute, 0.5-0.8 mm long. Male flowers 4-merous, subsessile, male buds globular, large c. $1.5 \mathrm{~mm}$ diam, with slight dorsal thickening and sparse hairs as stem. Female perianth small, c. $0.5 \mathrm{~mm}$ long, ovoid without distinct beak; stigma 1-1.5(-2) mm. Fruiting perianth ellipsoid short and broad $1-1.2$ by $0.6-0.7 \mathrm{~mm}$, slightly laterally flattened with marginal rim and short beak, hairs sparse, minute, spreading. Achene \pm filling fruiting perianth.

Distribution - Madagascar (northern and eastern part).

Habitat \& Ecology - Cloud forest, moss forest, wet hollows in dense undisturbed primary forest, on siliceous soil; 400$1000 \mathrm{~m}$ altitude.

Conservation status - Endangered (EN). The species is known from c. 10 collections from five localities. The material is both old and relatively recent, the latest from 2005 . There is habitat destruction on Madagascar, but also conservation efforts, and forest reserves exist. The EOO is $96172 \mathrm{~km}^{2}$, which would give it a conservation status as Near Threatened (NT) but, the AOO is only $24 \mathrm{~km}^{2}$. Taking into account the few, small and scattered populations in restricted habitats it can be given a status of Endangered with the criteria EN 2Bab(iii).

Notes - 1. This species is endemic to Madagascar (one of only three taxa native to the region, the other being two varieties of $B$. virgata subsp. macrophylla) and does not closely resemble any other taxon. It is distinctive in its leaves obovate to elliptic-obovate with teeth sharply-up-curved but very shallow and wide-spaced, these progressively shallower proximally and finally absent in basal part of leaf margin, upper veins only 1-2, arising close to apex, its petiole very long relative to lamina; its inflorescence-bearing axes extremely slender with large male flowers and its short broad fruiting perianth.

The character of partly-entire leaf margin is also seen only in two allopatric and otherwise very dissimilar species. The extremely rare Burmese endemic $B$. didymogyne is a slender herb with leaves membranous and flower-clusters axillary. The Papua New Guinean endemic $B$. subintegra has leaves much narrower (length 3.5-4x width), glabrous and shiny above with apex gradually attenuate, marginal teeth only up to 0.2 $\mathrm{mm}$ long, petiole relatively much shorter $(0.1-0.25 \times$ lamina length), leaves often markedly more dimorphic with length of 'larger' leaves up to $4 x$ 'smaller' ones.

2. Leandri (1950), at the same time as describing $B$. tsaratananensis, also described material of it as B. platyphylla var. masoalensis. Subsequently (Leandri 1965), he remarked on the long petiole and shallow teeth, but had presumably not seen a sufficiently wide range of variation of $B$. tsaratananensis to define its other distinguishing characters of leaf shape, venation and progressive change in form of marginal teeth.

\section{Boehmeria subintegra Friis \& Wilmot-Dear - Fig. 20; Map 22}

Boehmeria subintegra Friis \& Wilmot-Dear in Wilmot-Dear et al. (2010) 444. - Type: Brass 23704 (holo K; iso A), Papua New Guinea, Milne Bay, Gwariu River, Biniguni camp, 30 July 1953

Shrub or small tree, 2-4 m tall, with erect branches; ultimate stems slender (but soon becoming thick and woody), c. $1 \mathrm{~mm}$ diam, hairs dense, short fine, closely-adpressed, white; later glabrescent. Stipules narrowly triangular-attenuate, \pm free to base, fairly long and conspicuous, $7-8$ by c. $1 \mathrm{~mm}$, but very soon caducous. Leaves opposite, dimorphic in size and shape, usually markedly so, with 'larger' leaves, (1.5-)2-4x length of 'smaller' ones and relatively narrower, slightly sideways-curved, linear-ovate to narrowly elliptic-ovate, fairly small, (3.5-)5-12 by (1-)1.5-3 cm, length $3.5-4 \times$ width; margin often \pm entire and slightly undulate throughout most of its length but towards leaf apex indistinctly serrate, teeth 10-12(-15) either side, indistinct shallow, sometimes up to $0.2 \mathrm{~mm}$ long but often reduced to slight thickening or tiny mucro, very widely spaced, 2-5 $\mathrm{mm}$ apart; leaf apex gradually attenuate to \pm long-acuminate, sometimes mucronate at extreme tip; base narrowly cuneate; basal veins extending into distal third or nearly to tip, upper lateral veins similarly arranged on both sides of leaf, 2-4 either side but scarcely distinct from coarser tertiary veins, lowermost arising just in distal half of lamina; inconspicuous (rarely impressed) adaxially, finely prominulous abaxially; texture fairly thin-chartaceous to (dry habitat) very thin-coriaceous, adaxial surface glabrous and shiny (dark green when live); abaxial surface paler, hairy on veins, hairs sparse or dense, adpressed; petiole short relative to lamina, $0.1-0.25 \times$ lamina length. 'Smaller' leaves relatively broader, broadly elliptic or ovate with apex obtuse, broadly acute or rarely short-acuminate, extreme tip usually also distinctly mucronate, mucro 1-2 mm long, base broadly cuneate. Flower-clusters borne on leafless inflorescence-bearing axes, these pendent, unbranched, unisexual, 1 per axil, male axes up to $10 \mathrm{~cm}$ long, female ones very variable in length, $10-35 \mathrm{~cm}$ long; bracts narrowly triangular, c. 2 by $0.5 \mathrm{~mm}$, soon caducous; flower-clusters spaced 2-5 $\mathrm{mm}$ apart, male clusters up to $2 \mathrm{~mm}$ diam, with 1-5 flowers, female clusters c. $2.5 \mathrm{~mm}$ diam, with 10-30 flowers; bracteoles inconspicuous, linear-elliptic, $0.3-0.5 \mathrm{~mm}$ long. Male flowers 4-merous, pedicels $0.5-1 \mathrm{~mm}$ long, mature buds c. $1 \mathrm{~mm}$ diam, dorsal appendages of tepals small, hairs sparse coarse stiff \pm spreading hairs. Female flowers c. 0.6 by $0.3 \mathrm{~mm}$, ellipsoid, hairy like male; stigma $1-1.5(-2) \mathrm{mm}$ long. Fruiting perianth

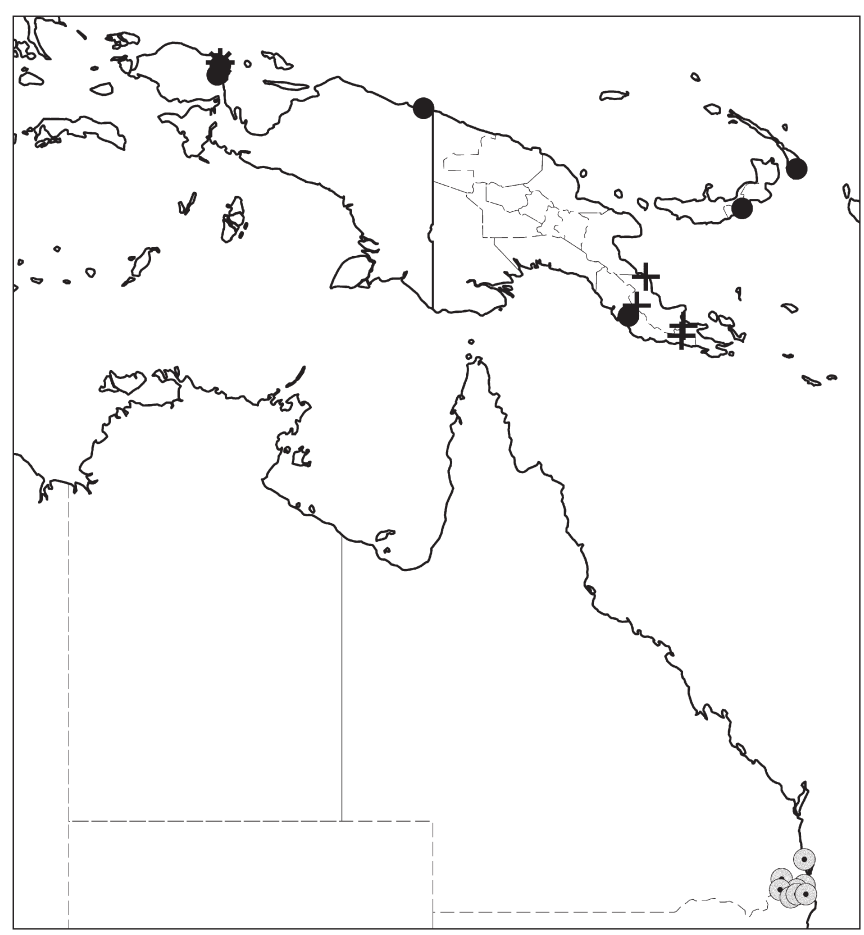

Map 22 Distribution of Boehmeria subintegra Friis \& Wilmot-Dear (+), B. virgata (G.Forst.) Guillem. subsp. virgata var. velutina Friis \& Wilmot-Dear (0), $B$. virgata (G.Forst.) Guillem. subsp. virgata var. maxima Friis \& Wilmot-Dear (*) and B. virgata (G.Forst.) Guillem. subsp. virgata var. austroqueenslandica (Domin) Friis \& Wilmot-Dear $(\odot)$ 
obovate in outline and extremely laterally flattened, with distinct marginal wing surrounding the part filled by the achene, $1-1.5$ by c. $0.8 \mathrm{~mm}$. Achene located in middle or distal part of fruiting perianth.

Distribution - Papua New Guinea.

Habitat \& Ecology - Ridge forest, secondary forest, brushy seral growth on ravines and steep riverbanks, regrowth vegetation on steep slope, grassy slopes (Arundinella); 200-1760 m altitude.
Conservation status - Vulnerable (VU). The conservation status was established by Wilmot-Dear et al. (2010: 448). The species is known from five localities and 11 collections, mainly made between 1935 and 1953 in remote areas of Papua New Guinea, and the EOO is $16604 \mathrm{~km}^{2}$, while the AOO is $16 \mathrm{~km}^{2}$, according to which it is endangered. However, the remoteness of the region in which the species occurs would seem to indicate that it is not currently threatened.
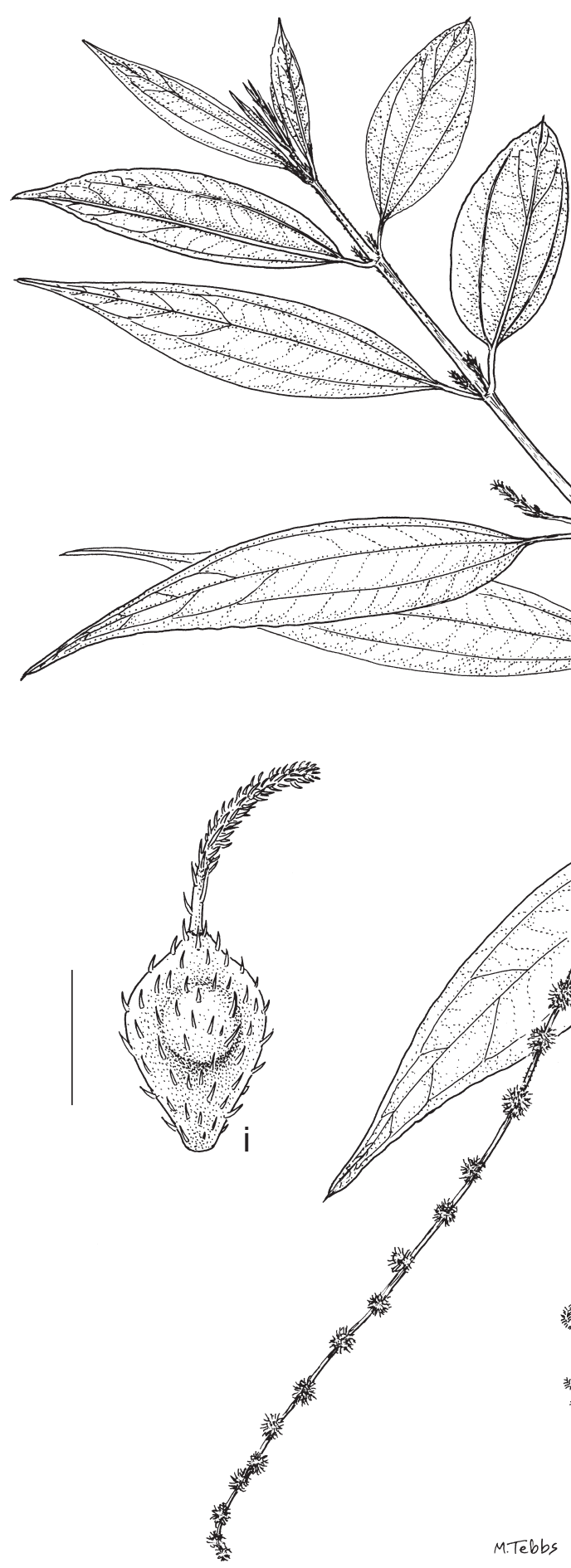

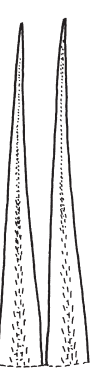

e
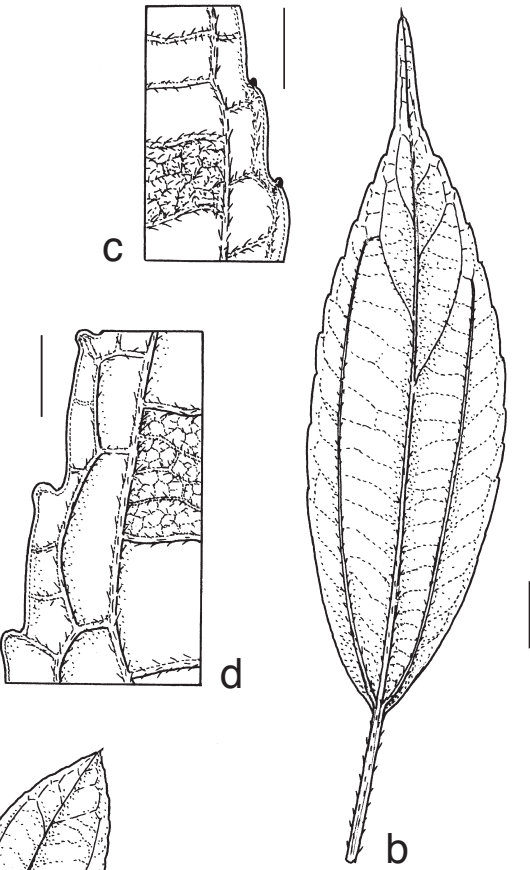

a
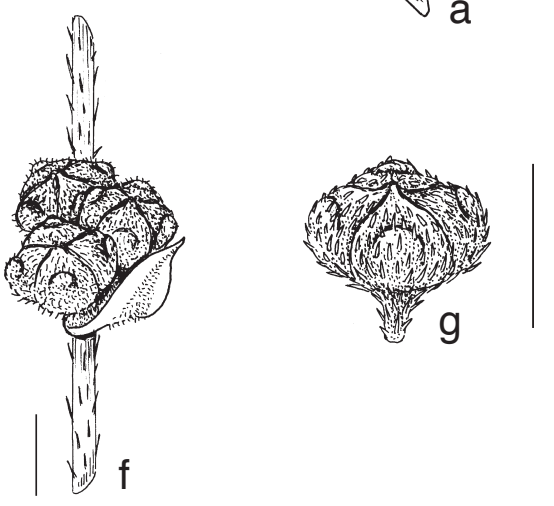

$\mathrm{h}$

Fig. 20 Boehmeria subintegra Friis \& Wilmot-Dear. a. Habit of stem with inflorescence-bearing axes; b. leaf; c, d. detail of leaf margin and abaxial surface (different plants); e. pair of stipules; f. detail of male inflorescence-bearing axis with flower-cluster (inflorescence) and bract; g. male bud; h. detail of female inflorescence-bearing axis with flower-cluster (inflorescence); i. fruiting perianth (a, e, i: Brass 23704; b, c, f, g: Hoogland 3988; d: Stevens 58169; h: Carr 15315; all K). - Scale bars: $a=2 \mathrm{~cm} ; \mathrm{b}=1 \mathrm{~cm} ; \mathrm{c}-\mathrm{e}=2 \mathrm{~mm} ; \mathrm{f}-\mathrm{i}=1 \mathrm{~mm}$. 
Notes - 1. An endemic of restricted distribution and one of only four species known from the island of New Guinea, the others being $B$. virgata (three varieties), $B$. depauperata and $B$. heterophylla, none of which would be confused with it. It is very distinctive in the whole genus in its relatively small leaves which are so indistinctly toothed as to appear almost entire, and in its 'smaller' leaves usually conspicuously long-mucronate. The Burmese endemic B. kurzii is the only other Old World species with entire (but truly entire) leaves and is otherwise very dissimilar.

2. The long pendulous unbranched crowded inflorescencebearing axes with broadly-winged fruiting perianths are like those of $B$. penduliflora, B. multiflora and B. densiflora (this last also has well-spaced teeth and somewhat similar leaf shape), but leaves in all three are easily distinguished by being uniformly and distinctly toothed throughout.

\section{Boehmeria virgata (G.Forst.) Guill. - Fig. 21-29; Map 23-30}

Boehmeria virgata (G.Forst.) Guill. (1837) 182. — Urtica virgata G.Forst. (1786) 66, no. 345. - Boehmeria taitensis Wedd. (1854) 200, nom. illeg. superfl., based on Urtica virgata G.Forst. (1786). - Boehmeria platyphylla D.Don var. virgata (G.Forst.) Wedd. (1856) 366. - Type: G. Forster s.n. (iso K), the locality indicated is "Society Islands" in the protologue, but the $\mathrm{K}$ isotype material indicates two localities on the label: "Tongo Tabo, Taheetee" [Tonga Tapu, main islands in the Tonga Islands, and Tahiti, main island in the Society Islands].

Erect or scandent subshrub, shrub or tree (rarely woody-based herb), 0.5-8 $\mathrm{m}$ tall; ultimate stems fairly robust, $1.5-2 \mathrm{~mm}$ diam, soon becoming thicker and woody, with widely varying indumentum, hairs sparse, inconspicuous, adpressed short, stiff or fine, or dense, spreading longer and soft. Stipules narrowly triangular mostly rather small and inconspicuous, \pm free to base, $4-6(-11)$ by $1(-2.3) \mathrm{mm}$, thin- or thick-chartaceous, hairy outside or sometimes glabrescent. Leaves mainly opposite (sometimes some on ultimate lateral branchlets alternate), with laminas not or only slightly dimorphic in size and shape but petioles often more markedly dissimilar; lamina ovate to rhombic-ovate or elliptic, with wide range of size and relative proportions, (5-)10-24 by 3-16 mm, length (1.2-)1.5-3.5x width; almost symmetrical or slightly asymmetrical especially at base and apex; margin regularly toothed throughout length, teeth widely varying in number, size and shape, minute and indistinct or large and conspicuous, rounded or narrow-acute, 10-60 either side, (0.2-)1-4(-7) mm long; leaf apex attenuate or distinctly acuminate, toothed to tip or consisting mainly of a single long terminal tooth; base slightly or markedly asymmetrical, cuneate to narrowly or broadly rounded, rarely \pm truncate or slightly cordate; basal veins extending into distal half or well into distal third of lamina, upper lateral veins 1-3(-[very rarely] 7) either side, similar or dissimilarly arranged on the two sides of the lamina, usually inconspicuous adaxially, these and coarser often inconspicuously scalariform tertiary reticulation visible abaxially; texture thin- or thick-chartaceous, leaves rarely slightly bullate or rugulose, both surfaces with indumentum usually similar to that of stem, often sparser below or sometimes adaxial surface glabrous; petiole (0.1-)0.25-0.7(-1.3) x lamina length. Flowerclusters borne on leafless inflorescence-bearing axes, these short and \pm erect to apically pendent or more often medium to long and pendulous, arising one from each axil, (5-)10-40 cm long, axes unbranched or sometimes male or both sexes with a few long lateral branches near base or throughout length but without 2nd-order branching; both sexes often on same plant with male axes usually in lower axils or forming short lateral branches at base of mainly female inflorescence-bearing axis; clusters well-spaced or crowded; male clusters with up to c. 15 flowers, female clusters with (less than 10-)20-more than 50 crowded or rather loosely-arranged flowers; bracts triangular, up to $2 \mathrm{~mm}$ long; bracteoles up to $0.3(-0.5) \mathrm{mm}$ long. Male flowers 4-merous, sessile, mature buds depressed-globose, c. $1 \mathrm{~mm}$ diam, dorsal appendages of tepals usually prominent, hairs sparse (rarely dense), adpressed or spreading. Female flowers fairly narrowly ovoid, up to $0.5 \mathrm{~mm}$ long; stigma rather variable, $0.6-2 \mathrm{~mm}$ long. Fruiting perianth $0.7-2$ by $0.3-0.5(-1)$ $\mathrm{mm}$, always with minute or longer beak, otherwise extremely varied in form, ovoid-conical or ellipsoid to obovoid \pm inflated in distal part, or obtriangular in outline with truncate apex, and either scarcely laterally flattened with achene \pm filling fruiting perianth, or more markedly laterally flattened with or without distinct marginal rim or narrow to broad wing and achene not filling fruiting perianth, glabrescent or more often hairy, hairs sparse to abundant, minute or coarse.

Distribution - Tropical Africa, from Sierra Leone and Senegal to Ethiopia, south to Angola, Zimbabwe and Mozambique, Comoro Islands, Madagascar, Mascarene Islands, Pakistan, India, Sri Lanka, Bangladesh, Nepal, Bhutan, Burma, Thailand, Laos, Vietnam, southern and south-western China (including Hong Kong), Malaysia (Selangor), Indonesia (Sumatera, Kalimantan, Jawa, Nusa Tenggara [Lesser Sunda Islands], Sulawesi, Moluccas, Papua), Philippines, Papua New Guinea, Australia (Queensland, New South Wales), Solomon Islands, Vanuatu, Fiji, Tonga Islands, Samoan Islands, Society Islands, Marquesas Islands, Austral Islands.

Habitat \& Ecology - See under infraspecific taxa.

Conservation status - See under each subspecies.

Notes -1 . This species is much more widely-distributed geographically than any other species of Boehmeria and exhibits a wide range of variation, especially in leaf shape. However, as discussed below, it is not possible to divide this taxon into species by applying the same criteria as elsewhere in this revision. See comments by Weddell (1856: 369) extensively quoted in the introduction to this paper. We have found it necessary to widen the concept of this species even more than Weddell. Well over 30 basionyms have been proposed for the taxa which we here refer to this very variable species, for which we have tried to establish a reasonably satisfactory infraspecific classification.

\section{Summary of the infraspecific classification within B. virgata}

Fourteen varieties with varying degree of distinctiveness are recognised in this treatment, most of which fall clearly within one of two subspecies with centres of distribution either side of Wallace's line, subsp. virgata to the east (Indonesia, Australia and the Pacific) and scarcely crossing the line (c. 20 collections out of several hundred seen), subsp. macrophylla entirely to the west of it (Afro-Malagasy region, Indian subcontinent, Indochina, China, Sumatera and Jawa). The distinctions between subsp. virgata and subsp. macrophylla are summarised in Table 3.

For two reasons these two entities cannot satisfactorily be recognised as separate species. Firstly, two regional variants are intermediate in leaf morphology between the two subspecies and are here considered as best placed within subsp. virgata only because of their distribution (see following paragraph). Secondly, in the northern and western part of its distribution the most variable and frequently collected variety (subsp. virgata var. virgata) appears to approach subsp. macrophylla var. macrostachya via a range of forms progressively less distinct from var. macrostachya. This variation is discussed in detail below (Note 3).

Subsp. virgata comprises the widespread and variable var. virgata and three narrowly distributed regional variants; two are sympatric with var. virgata and endemic to the island of 
Table 3 Characters of the subspecies of Boehmeria virgata summarised.

\begin{tabular}{lll}
\hline & B. virgata subsp. virgata & B. virgata subsp. macrophylla \\
\hline Habit & Tree / shrub / scandent & Shrub / subshrub / woody-based herb \\
Leaf shape & Elliptic / elliptic-ovate, thick, narrow & Ovate / rhombic-ovate / (elliptic), thin, broader \\
Leaf apex & Attenuate / indistinct acumen, toothed to tip & Distinct acumen(-attenuate), often tip made up of single tooth \\
Marginal teeth & Dentation shallow, teeth 0.2-1.5(-2) mm long rounded / & Dentation deep, teeth (1-)1.5-6 mm long, acute, up-curved; \\
& out-pointing; number more than 25 & number sometimes less than 25 \\
Basal veins & Extend almost to apex & Scarcely into distal half \\
Lateral venation & Robust, arise in distal half & Slender, lowest arise at or below middle \\
Tertiary venation & \pm Scalariform, close-spaced & \pm Reticulate, wider-spaced \\
Adaxial leaf indumentum & Glabrous / adpressed / spreading & (glabrescent-) / adpressed / (-spreading) \\
Stipule length & $7-10$ mm & $\leq 7$ mm \\
Fruiting perianth & Strongly laterally flattened, winged & Flattened or not, with marginal rim (or sometimes wing)
\end{tabular}

New Guinea, one closely similar to it; the other, var. maxima, is intermediate in certain leaf characters with subsp. macrophylla var. macrostachya, as is the third variety, var. austroqueenslandica (eastern Australia, allopatric to the rest of the species).

Subsp. macrophylla comprises ten varieties. The variation here recognised at varietal rank is correlated with geographical distribution and some of these entities are strikingly different from one another; however, the existence of a range of intermediate forms where their distributions overlap, especially in the Himalayas, makes it impossible to recognise them at anything other than varietal rank. Molecular and classical cytological work would be very helpful in clarifying the relationships between all these entities and better interpreting this confusing variation, in the same way that cytological work on $B$. japonica and its allies (discussed elsewhere) has led to understanding of that hitherto equally confusing matrix of intergrading entities. The entities here formally recognised are discussed in detail in what follows. The wide range of variation still included within the two most variable varieties subsp. virgata var. virgata and subsp. macrophylla var. macrostachya also shows some correlation with geographical distribution but further regional variants cannot be formally recognised for the reasons discussed below. The pattern of variation within and between the two subspecies and their varieties is as follows.

\section{The range of variation within subsp. virgata var. vir- gata and its approach to that of subsp. macrophylla var. macrostachya}

As summarised in Table 3 the two subspecies differ in the range of variation in leaf proportions, shape and texture and characters of the marginal teeth. Subsp. macrophylla var. macrostachya is further distinguished from subsp. virgata var. virgata by its leaves always thin-textured, relatively broad (length $\leq 2(-2.25) \times$ width), marginal teeth acute, at least $1.5 \mathrm{~mm}$ long, although both varieties show a wide range in number of teeth. Var. virgata is often further distinguishable from var. macrostachya by leaves often much more distinctly asymmetrical in outline and venation and sometimes with hairs on stem and upper leaf surface spreading (rather than adpressed). However, var. virgata becomes progressively less distinct in the northern and western part of its distribution (Vanuatu, Indonesia and the Philippines), as follows.

In the Pacific var. virgata shows considerable variation between (sometimes also within) the various island groups but is mostly very distinct from var. macrostachya.

i. In Southeast Polynesia (Marquesas, Austral and Society Islands) plants are often scandent; there is an especially wide range of variation in leaf-size, texture, relative proportions, indumentum density and marginal tooth length. Most variants are distinguished from var. macrostachya by leaves relatively narrow, marginal teeth short and often blunt and adaxial (or both) surfaces often glabrous. However, certain variants (Rapa and Tahiti) have teeth up to $2 \mathrm{~mm}$ long and leaves broad, adpressed-hairy; these are distinguished from var. macrostachya by being always thick-textured with veins robust, upper veins rather numerous and stipules unusually large, up to $20 \mathrm{~mm}$ long. Plants at the extremes of this range of variation (for example leaves small narrow thin-textured and shallowly crenate as compared to large broad thick-textured and dentate) appear very different from one another, but the continuous matrix of variation (most characters varying independently of one another) makes any further formal distinction impossible.

ii. In Fiji leaves vary in size and texture but less in marginal teeth and indumentum and are distinguished from those of var. macrostachya in being shallowly-toothed (mostly crenate), mostly narrow, often asymmetrical, often glabrous; the apex of the 'smaller' leaves (sometimes also the 'larger' leaves) is unusual in being often broad-acute rather than attenuate.

iii. In the Samoan Islands leaves are even less variable, mostly small (<10 cm long), thin-textured, veins slender, teeth rather few (20-25 either side); these forms are clearly distinct from var. macrostachya in being narrow, shallowly crenate, mostly elliptic and glabrous, often markedly asymmetrical. (Only one collection has been seen with large broad leaves, 17 by $9 \mathrm{~mm}$.)

iv. In Melanesia (Vanuatu) leaves are relatively large, thintextured, veins rather indistinct, teeth only 25-30 either side; these forms still \pm conform to var. virgata in being glabrous adaxially, crenate and often asymmetrical, but are less distinct from var. macrostachya since marginal teeth are often larger, some $>1 \mathrm{~mm}$ long.

v. From the island of New Guinea little material has been seen; marginal teeth are mostly relatively large (as in var. macrostachya) but otherwise leaves conform to subsp. virgata, being thick-textured with robust veins and mostly narrow, closely similar to or intermediate with the sympatric var. velutina (see below).

vi. From Sulawesi and Moluccas (i.e., towards the western limits of the distribution of var. virgata) material is abundant with widely varying leaf-size and -texture. The majority of collections are easily distinguished from var. macrostachya, having leaves relatively narrowly elliptic-ovate, attenuate, shallowly crenate, many-toothed, \pm glabrous adaxially and often thick-textured with venation \pm distinct, scalariform. However, some material is less distinct, having leaves thin-textured, teeth acute, $>1 \mathrm{~mm}$ long, and adaxial surface abundantly adpressed-hairy.

vii. At the northern and western limits of its range, crossing Wallace's line (Malaysia, Sumatera, Jawa, Bali) and in the Philippines, var. virgata appears to be uncommon. Most 
material is somewhat intermediate with var. macrostachya in leaf texture and/or shape and size of marginal teeth. In the Philippines some material is impossible to assign to either taxon.

In summary, forms of var. virgata seen in most of the Pacific are clearly distinct from var. macrostachya, becoming less so from east to west. In Indonesia east of Wallace's line some material is less distinct than in the Pacific, but distinction is the least clear in some of the few collections of var. virgata which cross Wallace's line, where much material seen has most characters of var. virgata but indumentum and teeth conforming to var. macrostachya.

\section{Distribution and variation in regional variants of subsp. virgata}

Two regional variants are sympatric with var. virgata in the island of New Guinea.

i. Var. velutina is distinctive in its indumentum long and dense, leaves thick-textured, often distinctly subcordate, marginal teeth longer and its inflorescence-bearing axes always much-branched. It is formally recognised only at varietal level because it grades into var. virgata via a range of intermediate forms with leaves cuneate and/or more sparsely pubescent and thinner-textured.

ii. Var. maxima is distinctive in its extremely large leaves, the largest seen in this species, their size overlapping only with the largest forms of var. macrostachya. It is somewhat intermediate between the two subspecies; its marginal teeth of leaf rounded, much broader than long, and fruiting perianth with a broad thin wing surrounding a relatively small achene conform to subsp. virgata, but its thin leaves with large long teeth are closer to subsp. macrophylla. As discussed above (Note 2), it is included under subsp. virgata because of its distribution, being allopatric to subsp. macrophylla and within a small part of the distribution of subsp. virgata var. virgata.

It is distinguished from var. virgata on leaves thin-textured, both very large and relatively broad (at least some $\geq 24 \mathrm{~cm}$ long, longer than any seen in var. virgata) with length mostly $<1.8 \times$ width; (in any collections of var. virgata where leaves are fairly long $15-22 \mathrm{~cm}$ they will also be relatively much narrower and/or thick-textured); the number of marginal teeth is mostly more than 45 either side (mostly less than 45 in var. virgata).

iii. Var. austroqueenslandica, allopatric to the rest of the species (eastern Australia), is distinctive in narrow attenuate leaves with marginal teeth relatively few, large, and hairs on adaxial surface and stem close-adpressed, abundant but extremely fine and inconspicuous, male inflorescencebearing axes long, unbranched, female axes with flowerclusters often densely crowded and fruiting perianth not greatly flattened. It is somewhat intermediate in leaf characters between the two subspecies, having marginal teeth $1-2 \mathrm{~mm}$ long (rather than mostly $<1.5 \mathrm{~mm}$ in subsp. virgata, mostly $>1.5 \mathrm{~mm}$ in subsp. macrophylla). It is similar firstly to certain narrow-leaved Indonesian forms of var. virgata (these forms differing in teeth smaller and shorter, male axes branched), and secondly to narrow-leaved forms of the African subsp. macrophylla var. molliuscula with fruiting perianths only moderately laterally flattened (these forms differing in leaves often glabrous adaxially, teeth larger, leaf apex mostly a single long tooth and stem hairs spreading). Because of the distribution of the two subspecies with respect to Wallace's line, this intermediate variety is also here included under subsp. virgata.

\section{Distribution and variation within and between regional variants of subsp. macrophylla}

i. Subsp. macrophylla var. molliuscula (Afro-Malagasy) and var. macrostachya (Indian subcontinent), both frequently collected and rather variable, were hitherto considered as one taxon. Var. molliuscula is distinguishable from var. macrostachya as summarised in Table 4.

Although var. molliuscula is generally rather unlike var. macrostachya in overall appearance, those collections with the broadest leaves and the smallest teeth overlap in variation with narrow-leaved large-toothed forms of var. macrostachya, being clearly distinct only in their spreading stem indumentum. (Notably, most material from Réunion has leaves rather broad and stem hairs half-adpressed; a few collections from Bioko and Cameroon also have stem hairs half-adpressed.) However, from Tanzania most material (e.g., Harris 5095, Renvoize 1509) has more closelyadpressed stem hairs; these variants somewhat obscure the main distinction from var. macrostachya. Nevertheless, we consider the Afro-Malagasy entity worthy of formal recognition in view of its geographical separation and the fact that these variants conform to Afro-Malagasy material (rather than to var. macrostachya) in other characters.

The density of indumentum on stem and leaves of var. molliuscula varies greatly and seems to be correlated with habitat, with almost glabrous forms in dense rainforest and much more hairy ones in open or riverine forest.

ii. These latter forms of var. molliuscula intergrade via a continuous range of intermediates with var. tomentosa which is found only in open forest and appears to be relatively uncommon and is presumed to be the dry habitat variant, occurring sporadically throughout the range of var. molliuscula. It is distinguished from var. molliuscula by indumentum on most parts of plant dense, long, pale, spreading and leaves thick-textured with robust main veins all arising in the distal half of the lamina, often rhombic-ovate and

Table 4 Characters of Boehmeria virgata subsp. macrophylla: distinction between var. molliuscula and var. macrostachya.

\begin{tabular}{|c|c|c|}
\hline & B. virgata subsp. macrophylla var. molliuscula & B. virgata subsp. macrophylla var. macrostachya \\
\hline Stem hairs & Spreading / half-adpressed, mostly curved, brown & Closely-adpressed, straight, pale \\
\hline Leaf texture & Smooth & Often bullate \\
\hline Leaf adaxial surface & Often almost glabrous & With sparse or abundant hairs \\
\hline Leaf shape & Length $1.5-3.5 \times$ width, often elliptic & Length $1.5-2(-2.25) \times$ width, ovate, rarely elliptic-ovate \\
\hline Leaf base & Often narrowly subcordate & Mostly cuneate to rounded \\
\hline Marginal teeth & $15-35$, slightly up-curved, $>2 \mathrm{~mm}$ long & $(22-) 25-50(-60)$, often markedly up-curved, $1.5-2 \mathrm{~mm}$ long \\
\hline Male inflorescence-bearing axes & Unbranched, pendulous & Often branched, basal part often \pm erect \\
\hline Female axes & Unbranched & Often with $1-2$ branches near base \\
\hline Female clusters & With $10-40(-$ more than 50$)$ flowers, loosely arranged & Mostly with $30-$ more than 50 flowers, often densely congested \\
\hline Fruiting perianths & $\begin{array}{l}\text { Only moderately laterally flattened with marginal rim } \\
\text { or indistinct wing, ellipsoid or ovoid without distinct beak }\end{array}$ & $\begin{array}{l}\text { Mostly much-flattened with distinct marginal wing and apical beak, } \\
\text { sometimes obovoid or } \pm \text { spindle-shaped }\end{array}$ \\
\hline
\end{tabular}


short-petioled. The material of var. tomentosa seen from Nigeria and Tanzania is the most distinctive with narrow thick leaves densely hairy adaxially. Many collections intermediate between the two varieties have been seen from Zaire, Cameroon and Angola (a few also from Nigeria, Uganda and Zambia), mostly from more moist habitat, with markedly thick-textured narrow leaves but indumentum (especially on leaves) much sparser.

iii. Var. macrostachya is widespread and apparently common in the northern and central part of the Indian subcontinent, with a few collections also seen from the southern part of peninsular India and Sri Lanka. (According to Chen et al. (2003) it also occurs in China, but all collections seen hitherto identified as this entity were intermediate with var. rotundifolia, var. scabrella or var. strigosa. It is characterised by stem hairs closely-adpressed and a combination of other characters as listed in Table 4, but leaf shape and indumentum of abaxial leaf surface are extremely variable. Most collections from the eastern and western Himalayas and all from central India have relatively wide leaves (length $1.25-1.5(-1.75) \times$ width), with marginal teeth numerous, (30-)40-50(-60) and often small, $1.5-2$ by $4-5 \mathrm{~mm}$. In the eastern Himalayas some material has relatively narrower elliptic-ovate leaves with fewer larger teeth more similar to var. molliuscula.

iv. Many collections of subsp. macrophylla have been seen from the Indian subcontinent; many of these, especially from the Himalayas (including the type of B. massuriensis) exhibit a range of intergrading forms intermediate between the various entities whose different distributions overlap in that region (var. canescens, var. macrostachya, var. minuticymosa, var. rotundifolia and var. scabrella). Most of these have some leaf characters of var. scabrella (marginal teeth numerous and relatively narrow, leaves often asymmetrical in outline, often thick-textured with hairs conspicuous rather stiff, or asymmetrically cordate with sparse hairs; see Note $x$ below) but inflorescence-bearing axes pendulous as in var. macrostachya. Some of these forms also have minute peduncles in the flower-clusters as in var. minuticymosa. From mainland China and Vietnam relatively few collections of the subspecies as a whole have been seen; five varieties are known (see Notes viii-x, xii, xiii below) and some material is intermediate between them.

v. Three varieties are sympatric to var. macrostachya but restricted to small parts of its distribution, two others partly sympatric but more widespread and four others allopatric.

vi. Var. longissima (Tamil Nadu and Sri Lanka) is restricted to high altitude evergreen rainforest; it is more similar in its narrow leaves with relatively few teeth to the Afro-Malagasy var. molliuscula (also restricted to moist forest) than to the Indian var. macrostachya which occurs in a wide range of habitats. It is distinctive in its spreading but minute straight stem hairs, its fruiting perianth densely minutelyred-pubescent, broad, scarcely flattened and its leaves often rhombic-ovate. Although it is restricted to a small part of the range of var. macrostachya and no collections intermediate in stem indumentum or fruit form have been seen, the distinctive characters are so slight that we see no reason to raise it to higher rank.

vii. Var. canescens (eastern Himalayas, sympatric within part of the distribution of var. macrostachya, var. minuticymosa and var. scabrella), is similar to var. minuticymosa (see Note ix), in its marginal teeth numerous, relatively narrow and flower-clusters elongate rather than \pm globose with female flowers pedicellate often pedunculate. However, it differs markedly from that and all other varieties in its inflorescence-bearing axes extremely slender (only half of the diameter of other varieties) with clusters sparse, widely spaced and very few-flowered, its female perianth extremely small in both flower and fruit and its stem indumentum of two kinds, dense fine closely-adpressed hairs which at the stem apex and at upper nodes are completely concealed by dense coarser spreading much longer hairs. Hairs on the abaxial leaf surface are soft and of varying lengths, usually much more abundant than in other varieties of subsp. macrophylla, often giving the distinctive whitish cast to the leaf indicated by its name. Some material from the eastern Himalayas of var. minuticymosa and var. rotundifolia (see Notes viii, ix) with a few long spreading hairs near the stem apex in addition to their shorter adpressed hairs tends somewhat towards this taxon.

viii. Var. rotundifolia (eastern Himalayas, south-western China) also has marginal teeth relatively narrow, but fewer than in var. canescens and is distinctive in its terminal tooth of the leaf apex abrupt, very narrow, long and \pm tail-like and its marginal teeth strongly up-curved, distal ones markedly more in-curved than proximal ones. Stem indumentum is abundant, short and adpressed, but longer hairs which are sparse, coarser and spreading (as in var. canescens but much more sparse) are sometimes also present; collections have also been seen \pm intermediate in leaf-shape with var. canescens with leaf-acumen abrupt but short and inflorescence-bearing axes rather slender. Forms somewhat intermediate with var. macrostachya or var. scabrella have been seen from the eastern Himalayas and southern China with leaves much narrower and less abruptly acuminate but with distal teeth markedly up-curved. From Sikkim and Burma other forms of more obscure identity have been seen less abruptly acuminate and with hairs on leaves on stems conspicuous, coarse and spreading but with leaves broad and sometimes two kinds of hair near the stem apex. From Vietnam similar intermediate forms, but with soft rather than coarse spreading hairs, have been seen.

ix. Var. minuticymosa is the only variety seen from Thailand and extends eastwards to Indochina and South China and westward to the Himalayas where it is sympatric to var. macrostachya. It is especially distinctive in its often elongate female clusters with many minute flattened peduncles bearing several pedicellate flowers (otherwise seen only in var. canescens); it is also characterised by leaves medium-sized with base cuneate to rounded, thin-textured and often slightly bullate like those of var. macrostachya but more uniform in size and narrower with marginal teeth numerous (40-45 either side) and rather small as in var. canescens, while hairs on adaxial surface are conspicuous, usually coarse and rough and female inflorescence-bearing axes rather short $($ c. $13 \mathrm{~cm}$ ) and often erect with clusters often crowded as in var. scabrella; fruiting perianths are distinctive, broadly ovoid with rounded base, pale yellowish brown (rather than darker reddish brown), glabrous except at apex. Yahara (1981: 21) included this taxon within 'B. platyphylla' (= var. macrostachya) but noted that its leaves were more uniform than in material from elsewhere and its inflorescence-bearing axes often bisexual (males on short branches near the base of the axis).

In the Himalayas and further south in C. India a range of variants intermediate between var. minuticymosa and var. macrostachya also occurs, with female flowers clearly pedunculate and/or pedicellate but fruiting perianths narrow, tapering, sometimes much more hairy and leaves broader or cordate. A few collections from the Himalayas are somewhat intermediate with var. canescens in stem indumentum, leaf shape and inflorescence architecture. 
x. Var. scabrella is sympatric to var. macrostachya in the Indian subcontinent but more widespread, occurring from the Himalayas (most material seen being from there) to south-western and southern China (incl. Hong Kong), and in Indonesia west of Wallace's line in Jawa, Bali and southeastern Borneo. It is often very similar to var. rotundifolia in marginal teeth numerous, markedly up-curved and inflorescence-bearing axes short, erect, much-branched, the male axes often with short branches throughout length, but is distinctive within subsp. macrophylla in its leaves rough-hairy (abaxial hairs spreading), relatively small, broad, mostly asymmetrical, often thick-textured and bullate; marginal teeth small; leaf apex with short, broad, rather gradual acumen toothed in its basal third and inflorescencebearing axes with clusters often congested. It has a slightly lower altitudinal range than var. rotundifolia and occurs in forest and thickets. Var. scabrella is sympatric with subsp. virgata var. virgata where the latter crosses Wallace's line in Jawa and Bali but the two entities are morphologically very distinct with no intermediate forms nor possibility of confusion, since subsp. virgata has inflorescence-bearing axes long, pendulous and usually also leaves narrow, smooth shallowly crenate, adpressed-hairy abaxially. Forms of ssp. virgata with leaves slightly less dissimilar vegetatively (spreading-hairy abaxially, teeth comparatively long) have been seen (restricted to the island of New Guinea), but have a very different overall appearance, leaves symmetrically broadly subcordate to truncate with marginal teeth relatively much broader (usually $\geq 4 \mathrm{~mm}$ wide). From various parts of the Indian subcontinent abundant material has been seen intermediate between var. scabrella and var. macrostachya, and from the Himalayas material intermediate with var. rotundifolia in leaf shape. In Jawa some collections approach the allopatric but neighbouring var. sumatrana in leaf-size and shape but var. scabrella differs from that variety in hairs on abaxial surface spreading, on stem and adaxial surface often half-adpressed, indumentum often dense, rather than all indumentum close-adpressed and very sparse.

xi. Var. sumatrana and the remaining two varieties, var. densiglomerata and var. strigosa, form a distinctive small group with leaves \pm symmetrical broad \pm membranous, base truncate to cordate, marginal teeth few and hairs fine and adpressed. Var. sumatrana is allopatric to the rest of the subspecies (Sumatera) and is distinguished from both var. strigosa and var. densiglomerata by inflorescencebearing axis rather short, erect, bisexual, often branched and leaves extremely sparsely hairy, distal marginal teeth markedly more up-curved than proximal ones; distinct additionally from var. densiglomerata by female clusters not densely congested and from var. strigosa by leaves small and stipules rather long. No intermediate forms have been seen. In addition to the characters of leaf shape and marginal teeth, var. sumatrana is easily distinguished from var. macrostachya by its petiole long relative to lamina length and its inflorescence-bearing axes short and erect. In general appearance it is somewhat similar to certain fairly symmetrical-leaved thin-leaved forms of var. scabrella (allopatric but neighbouring), but these differ in leaf indumentum coarse and spreading.

xii. Var. densiglomerata, known only from rather scanty material from southern and central China, has small leaves like those of var. sumatrana but usually less sparsely hairy and inflorescence-bearing axes unisexual, the females very different from both var. sumatrana and var. strigosa, very short (less than $5 \mathrm{~cm}$ ), unbranched and flower-clusters so tightly congested that individual flower-clusters are indistinguishable; male and bisexual axes are similar to the branched (bisexual) axes of var. sumatrana and leaves differ from it only in indumentum less sparse and marginal teeth mostly fewer (10-13), less up-curved.

xiii. Var. strigosa, sympatric to var. densiglomerata in southern China but extending to Vietnam, is distinguished from both var. sumatrana and var. densiglomerata in its indumentum of leaf underside conspicuously dense and shining silky, leaves mostly larger, marginal teeth more numerous and usually smaller and narrower, female inflorescence-bearing axes long, pendulous, unbranched (as in var. macrostachya). It differs additionally from var. sumatrana in axes never bisexual and from var. densiglomerata in female clusters well-spaced. A few collections seen from Vietnam are somewhat intermediate with var. densiglomerata (not recorded from Vietnam) in having small leaves and fewer (only 16) teeth although the silky hairs are fairly dense. A few collections have been seen somewhat intermediate with var. macrostachya, with leaves broad \pm cordate membranous but indumentum on abaxial surface soft and spreading.

xiv. Several varieties can be confused with other species. This is discussed under the subspecies as a whole.

\section{Key to subspecies and varieties of $B$. virgata}

1. Leaves symmetrical, truncate to cordate, lamina broad (length only 1-1.2(-1.8)× width, thin-textured with hairs both sides, these fine, closely-adpressed, sometimes dense and silky abaxially, marginal teeth only $13-25(-30)$ either side; petiole usually $\geq 0.6 \times$ lamina length; stem hairs straight, closelyadpressed. - Indochina; southern and central China; Indonesia - Sumatera . . . . . . . . . . . . . . . . 2

1. Leaves without above combination of characters: either narrowly rounded to cuneate at base and relatively narrower, or if broad and truncate to cordate then hairs, at least abaxially, coarse, spreading, rough and/or texture thick and/or lamina markedly asymmetrical; marginal teeth usually 35-60 either side; petiole usually less than half lamina length (stem hairs adpressed or spreading)

2. Hairs on abaxial surface of leaf dense, \pm obscuring surface and lying in a regular pattern giving conspicuously shinysilky appearance, marginal teeth (16-)20-30 either side; female inflorescence-bearing axes pendulous, 10-40 cm long. - Southern China; Vietnam .

o. subsp. macrophylla var. strigosa

2. Hairs on both sides of leaf sparse, leaves not shiny-silky abaxially, marginal teeth 10-17 either side; female inflorescence-bearing axes erect, $1.5-12 \mathrm{~cm}$ long . . . . . . . 3

3. Inflorescence-bearing axes mostly unisexual, the female ones only $1.5-4.5 \mathrm{~cm}$ long, unbranched, densely congested with individual clusters usually indistinguishable; male and bisexual axes mostly $<5 \mathrm{~cm}$; fruiting perianth broadly obconical, inflated at apex; leaves with up to 13 teeth either side. - Southern China

n. subsp. macrophylla var. densiglomerata

3. Inflorescence-bearing axes mostly bisexual and branched but if female, and also unbranched, then 8-12 cm long; individual female clusters contiguous or not, but distinguishable; fruiting perianth conical or obovoid, somewhat laterally flattened; leaves with more than 13 teeth either side. - Indonesia - Sumatera. . m. subsp. macrophylla var. sumatrana

4. Leaf apex abruptly acuminate, a single tooth, (5-)15-20 $\mathrm{mm}$ long, very narrow and \pm linear 'tail-like', c. $2 \mathrm{~mm}$ wide for most of its length, with 1-2 pairs of often markedly in-curved lateral teeth at its base; marginal teeth acute and markedly up-curved, distal ones increasingly in-curved, 2-5 mm long and relatively narrow with width rarely $>1.25 \times$ length; leaves sparsely hairy adaxially; stem with adpressed hairs (rarely 
also long spreading hairs near apex). — Eastern Himalayas; south-western China

j. subsp. macrophylla var. rotundifolia

4. Leaf apex gradually attenuate or if an abrupt acumen then not linear tail-like and basal third of acumen toothed; (marginal teeth often shorter and broader, often only slightly up-curved, leaf sparsely or densely hairy; stem hairs adpressed or spreading or both) . . . . . . . . 5

5. Female flowers with minute flattened pedicels, often in small groups on minute branched peduncles . . . . . 6

5. Female flowers sessile $\ldots \ldots \ldots \ldots \ldots \ldots \ldots$

6. Stem with both spreading and adpressed indumentum 7

6. Stem with only adpressed indumentum, hairs all of similar nature and mostly \pm same length . . . . . . . 8

7. Stem with abundant short hairs $(0.2-0.4 \mathrm{~mm}$ long), which are fine, closely-adpressed and clearly visible lower on stem but at apex and upper nodes concealed by much longer hairs (c. $1 \mathrm{~mm}$ ) which are coarser, dense and spreading; leaves abaxially with sparse hairs of varying length, soft, fine and often giving a whitish cast; inflorescence-bearing axes very slender, $\leq 0.2 \mathrm{~mm}$ diam, pendulous with small well-spaced clusters; fruiting perianth small and narrow, $\leq 0.5$ by $0.3 \mathrm{~mm}$, apex \pm beak-like. - Eastern Himalayas . . . . . . . . i. subsp. macrophylla var. canescens

7. Stem with all hairs of similar texture and length, c. 0.5-0.7 $\mathrm{mm}$ long, the abundant adpressed hairs not concealed by the sparse spreading hairs present at apex; leaves not whitish abaxially; inflorescence-bearing axes robust (0.4-)0.6-1 mm diam, \pm erect, with crowded clusters; fruiting perianth broadly ovoid, $0.7-1.2$ by $0.5-0.8 \mathrm{~mm}$, without beak. - Himalayas to Indochina

k. subsp. macrophylla var. minuticymosa

8. Leaves cuneate, thin-textured; fruiting perianth broadly ovoid without beak. - Himalayas to Indochina.

k. subsp. macrophylla var. minuticymosa

8. Leaves cordate at base, often thick-textured; fruiting perianth often narrowly spindle-shaped.

subsp. macrophylla intermediate between var. macrostachya and var. minuticymosa

9. Stem with two distinct kinds of indumentum, long spreading hairs (c. $1 \mathrm{~mm}$ ) which are dense at stem apex and nodes where they conceal abundant shorter (0.2-0.4 $\mathrm{mm}$ ) closely-adpressed hairs clearly visible lower on stem; inflorescence-bearing axes very slender, $\leq 0.2 \mathrm{~mm}$ diam, pendulous with small well-spaced clusters; fruiting perianth small and narrow, $\leq 0.5$ by $0.3 \mathrm{~mm}$; leaves abaxially with rather sparse soft fine hairs of varying lengths often giving whitish cast, adaxially with long soft curved hairs. - Eastern Himalayas ... i. subsp. macrophylla var. canescens

9. Stem with either spreading or adpressed indumentum, hairs all of similar nature and mostly \pm same length; inflorescence-bearing axes robust, (0.4-) 0.6-1 mm diam; fruiting perianth usually $>0.7$ by $0.5 \mathrm{~mm}$; (axes sometimes erect, clusters sometimes contiguous; leaves densely or sparsely hairy, if whitish abaxially then hairs \pm uniform, mostly $>0.5 \mathrm{~mm}$ long) .

10. Leaves (both sides) and stems with hairs spreading, dense, \pm obscuring surface; leaves thick-textured . . . . . . 11

10. Leaves and stems with hairs either closely-adpressed (dense or sparse) or spreading but sparse (leaves thin or thick-textured) . . . . . . . . . . . . . 12

11. Inflorescence-bearing axes unbranched or (male) fewbranched near base, pendulous; fruiting perianth with marginal rim, achene \pm filling fruiting perianth; hairs on stem and leaves beneath $0.5-1 \mathrm{~mm}$ long, often pale giving whitish sheen to whole plant especially leaves abaxially; leaf base broadly cuneate to rounded or narrowly subcordate; low subshrub, $\leq 1.5 \mathrm{~m}$ tall. - Afro-Malagasy

f. subsp. macrophylla var. tomentosa

11. Inflorescence-bearing axes much-branched, male axes sometimes \pm erect; fruiting perianth with distinct relatively broad marginal wing either side comprising $0.5-0.7 \times$ total fruiting perianth width; hairs on stem and leaves beneath shorter and velvety, $\leq 0.2 \mathrm{~mm}$, brownish; leaf base broadly subcordate to truncate; large shrub or tree, 1.5-2.5 $\mathrm{m}$ tall. - Indonesian Papua; Papua New Guinea

b. subsp. virgata var. velutina

12. Leaves very large and broad, at least some on plant $24-35$ by (11-)15-20 cm, thin-textured, length only up to $1.75(-2) \times$ width; marginal teeth 40-60 either side, large (1.5-3 mm long); hairs both sides fine and inconspicuous, adpressed adaxially, spreading abaxially; stem hairs halfadpressed . . . . . . . . . . . . . . . . . 13

12. Leaves much shorter or if up to $20(-22) \mathrm{cm}$ long then much narrower and/or number of marginal teeth up to 35 either side (leaves thin or thick-textured, hairs on leaves and stem adpressed or spreading, marginal teeth long or short)

13. Marginal teeth broad-acute, $1.5-2$ by $(2-) 4-7 \mathrm{~mm}$, width (1.3-)2.5-3.5x length. - Indian subcontinent .

g. subsp. macrophylla var. macrostachya

13. Marginal teeth rounded, $1.5-3$ by $(5-) 8-12 \mathrm{~mm}$, width 4-5x length. - Indonesian Papua

c. subsp. virgata var. maxima

14. Marginal teeth of leaves indistinct or up to $1 \mathrm{~mm}$ long (or if $\geq 1 \mathrm{~mm}$ long then rounded) and with width usually $\geq 4 \times$ length; leaf length $\geq 1.8 \times$ width; leaves glabrescent or with inconspicuous adpressed hairs adaxially, basal veins extending well into distal half and on one side often almost to tip, upper lateral veins all arising in distal half. - Indonesia; Pacific . . . . . . . . . a. subsp. virgata var. virgata

14. Marginal teeth of leaves acute, mostly $\geq 1.5 \mathrm{~mm}$ long and relatively narrower; leaves often much broader and/or with spreading hairs (basal veins extending less far or not, lowermost upper vein often arising below middle of lamina)

15. Inflorescence-bearing axes erect, only $5-10 \mathrm{~cm}$ long, male axes with lateral branches throughout length; leaves at least slightly asymmetrical with outline of two sides of lamina often dissimilar and base often oblique, often \pm bullate and coarsely rough-hairy adaxially, usually $<10(-13) \mathrm{cm}$ long. - Eastern Himalayas to southern China; Indonesia - Jawa, Borneo ... . I. subsp. macrophylla var. scabrella

15. Inflorescence-bearing axes pendulous, 10-40 cm long, branched at base or unbranched; leaves not or scarcely asymmetrical, $\geq 10 \mathrm{~cm}$ long (bullate or not, hairs often fine, soft and inconspicuous).

16. Stem hairs spreading, marginal teeth $2-5 \mathrm{~mm}$ long, only 15-35 either side, lamina length (1.5-)2-3.5x width; inflorescence-bearing axes always unbranched, clusters spaced 2-10 mm apart . . . . . . . . . . . . . . . . 17

16. Stem hairs closely-adpressed; marginal teeth $1.5-2 \mathrm{~mm}$ long (teeth often more than 35 either side; lamina length often less than $2 \times$ width; male inflorescence-bearing axes sometimes with several long branches near base, clusters sometimes contiguous)

17. Fruiting perianth with broad distinct wing either side comprising $0.5-0.7 \times$ total fruiting perianth width; stipules $15-$ $20 \mathrm{~mm}$ long . . . . . . . a. subsp. virgata var. virgata (Southeast Polynesian form, see under var. virgata, Note 5)

17. Fruiting perianth with only a marginal rim or at most a narrow indistinct wing; stipules $\leq 10 \mathrm{~mm}$ 
18. Stem hairs fine and straight but very short, $0.1-0.2(-0.3)$ $\mathrm{mm}$ long; fruiting perianth densely-pubescent throughout with minute reddish hairs $(<0.1 \mathrm{~mm}$ long) and broadly ovoid, $\leq 1.5 \mathrm{~mm}$ long with distinct beak up to $0.3 \times$ whole length, not or scarcely laterally flattened with slight marginal rim; seed \pm filling perianth. - South India; Sri Lanka . . .

h. subsp. macrophylla var. longissima

18. Stem hairs, at least some, $>0.4 \mathrm{~mm}$ long, often curved; fruiting perianth without distinct beak, often obovoid, distinctly laterally flattened and often \pm winged with hairs usually longer, often pale and restricted to apex. - Afro-Malagasy . . . . . . . . . . e. subsp. macrophylla var. molliuscula

19. Leaves thick-textured, often glabrescent adaxially with robust veins and large stipules 15-20 mm long; fruiting perianth with broad thin-textured wing comprising $0.5-0.7 \times$ total fruiting perianth width; stipules $15-20 \mathrm{~mm}$ long . . . . . . $\ldots \ldots \ldots \ldots$ a. subsp. virgata var. virgata (Southeast Polynesian form, see under var. virgata, Note 5)

19. Leaves thin-textured with fine adpressed hairs adaxially and slender veins; stipules $\leq 10 \mathrm{~mm}$ long (fruiting perianth with or without wing) . . . . . . . . . . . 20

20. Marginal teeth (22-)35-60 in number, lamina relatively broad with length $1.5-2(-2.25) \times$ width; fruiting perianth often much-flattened and distinctly winged. - Indian subcontinent .... g. subsp. macrophylla var. macrostachya 20. Marginal teeth 20-30 in number; lamina length (2.5-)3$3.5 \times$ width; fruiting perianth only slightly laterally flattened with marginal rim. - Eastern Australia . . . . . . . . . . d. subsp. virgata var. austroqueenslandica

\section{i. subsp. virgata - Fig. 21-23a-c; Map 22, 23}

Scandent or erect shrub or slender tree; ultimate stems glabrous or with fine adpressed or coarser spreading hairs. Stipules 7-10 by 1-2 (rarely up to 25 by 4 ) $\mathrm{mm}$, rather thick-textured. Leaves slightly dimorphic in size with 'larger' lamina up to $2 \times$ length of 'smaller' ones and relatively narrower, elliptic or elliptic-ovate, very variable in size and relative proportions, $5-22(-30)$ by $3-12(-20) \mathrm{cm}$; margin indistinctly or sharply fine-serrate to bluntly crenate-serrate or large-crenate (sometimes irregularly double-toothed), teeth (20-)25-45 either side, shallow but often relatively broad for size of lamina, $(0.2-) 0.5-1$ by $2-4.5$ (rarely up to 2 by 7 ) $\mathrm{mm}$; leaf apex attenuate to indistinctly short-acuminate and usually toothed \pm to apex; base not or slightly asymmetrical, broadly cuneate to rounded, truncate or subcordate becoming abruptly cuneate at extreme base; basal and upper lateral veins very variable, similar or dissimilar on the two sides of lamina, upper lateral veins on one side $1-5(-7)$ but often hardly distinct from coarser tertiary veins, on other side usually one fewer, often inconspicuous adaxially; texture thin- or thick-chartaceous, both surfaces hairy or adaxial surface glabrous; petiole variable but usually long relative to lamina (0.15-)0.3-0.5(-0.75)× lamina length, hairy like lower leaf surface. 'Smaller' leaves of similar form or with apex broadacute. Inflorescence-bearing axes glabrous or with hairs sparse, fine, spreading or adpressed; male axes pendulous or the shorter ones erect or with drooping apex, (5-)10-20 cm long (unbranched or) with short lateral branches usually throughout length; female (or mainly female) inflorescence-bearing axes pendulous, very long, (6-)20-70 cm, variably unbranched to branched, or with short male branches near base; bracts robust, 1-2 mm long; flower-clusters usually well-spaced along axis (rarely almost contiguous), male clusters 3-4 mm diam, flowers up to c. 15, very crowded; female clusters $1.5-3 \mathrm{~mm}$ diam, flowers up to c. 30 (-more than 50) densely crowded; bracteoles ovate or rhombic, in male clusters very inconspicuous, in female ones up to $0.4 \mathrm{~mm}$ long. Male flowers with dorsal appendages of tepals usually broad flap-like, sometimes reduced to wartlike thickening, almost glabrous or with coarse hairs. Female flowers up to 0.8 by $0.2 \mathrm{~mm}$, stigma variable often even on one plant ranging from short and hooked, 0.4-0.6 mm long, to longer, straight and 1.5-2 mm long. Fruiting perianth 1.5-2 by $0.6 \mathrm{~mm}$, quite variable in shape, ranging from obtriangulartruncate in outline, and slightly constricted into minute beak at extreme apex, to spindle-shaped or ellipsoid-ovoid with distinct beak; always markedly flattened into usually broad wing around relatively small achene, glabrous or with hairs fine often minute, straight, spreading. Achene minute, up to 0.6 by $0.3 \mathrm{~mm}$, elongate or almost spherical.

Distribution - Malaysia (Selangor), Philippines (Luzon, Bohol, Mindanao), Indonesia (a few records to the west of Wallace's line: Sumatera, Jawa and Bali; east of this line Nusa Tenggara [Lesser Sunda Islands], Sulawesi, Maluku [Moluccas], Papua), Papua New Guinea, Australia, Pacific incl. Solomon Islands, Vanuatu, Fiji, Tonga Islands, Samoan Islands, Society Islands, Marquesas Islands, Austral Islands).

Habitat \& Ecology - Very varied: dense or open primary or secondary often wet montane forest and forest edges, clearings, dry rocky forest, cliffs and rocky riversides; (30-)300-1400 m altitude.

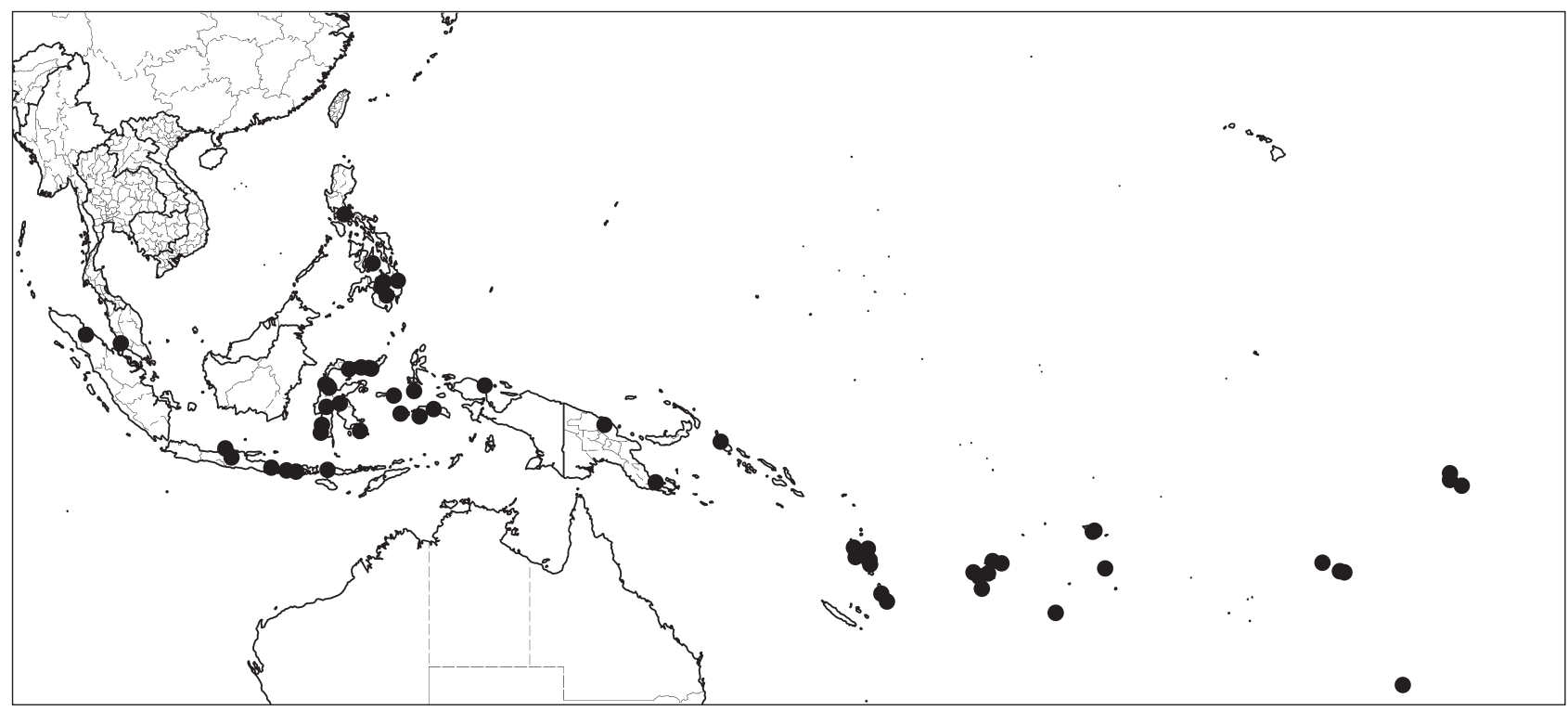

Map 23 Distribution of Boehmeria virgata (G.Forst.) Guillem. subsp. virgata var. virgata. 

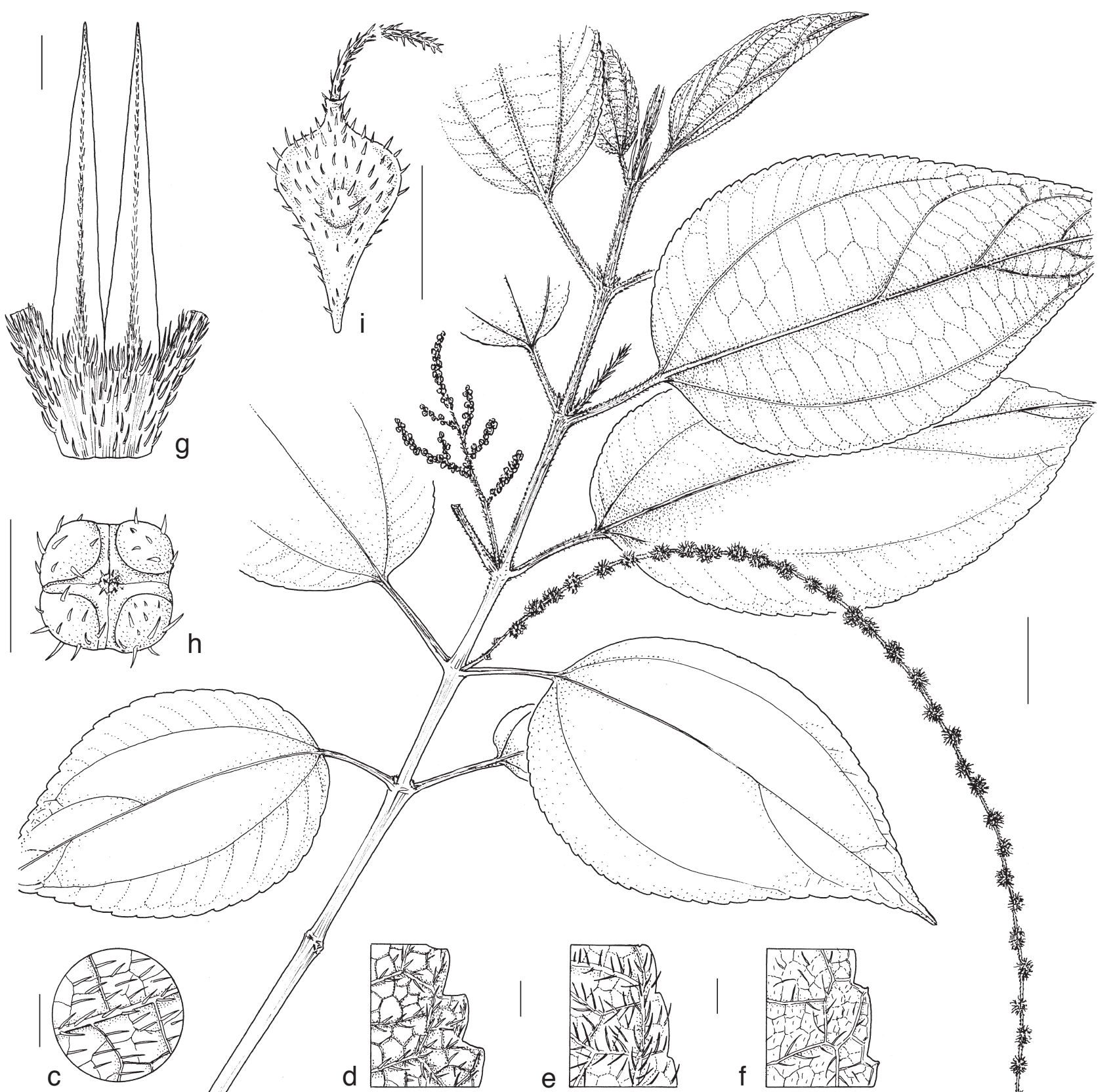

\section{,}

(

a
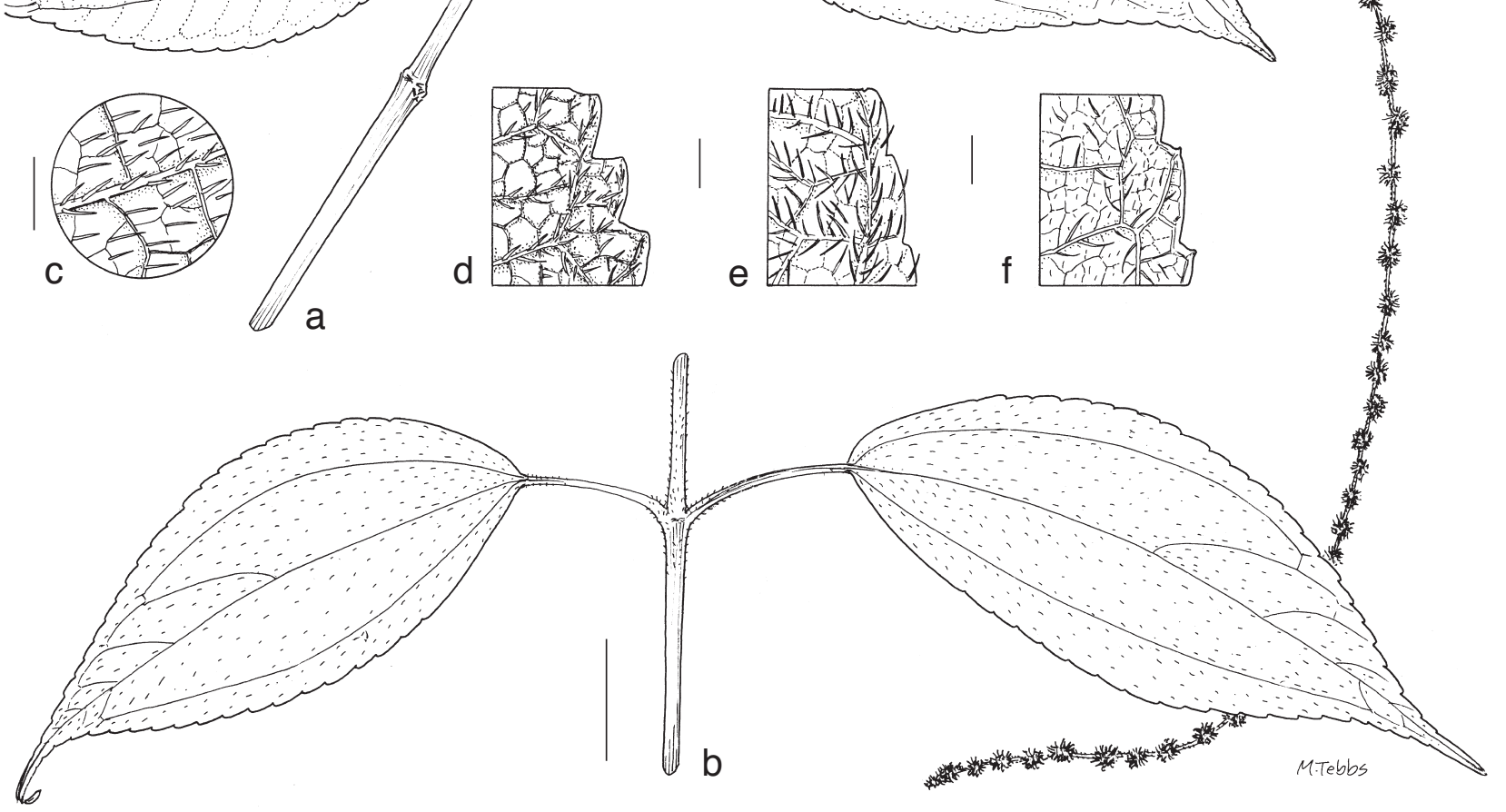

Fig. 21 Boehmeria virgata (G.Forst.) Guillem. subsp. virgata var. virgata. a. Habit of stem with inflorescence-bearing axes; b. detail of one node showing dimorphic leaf-pair; c. leaf, detail of adaxial surface; $d-f$. leaf, detail of margin and abaxial surface (from different plants); g. detail of stem and stipules; h. male bud; i. fruiting perianth (a, g, h: Smith 8761; b: Christofferson 3070; c, d, i: Kostermans 6362a; e: Degener 15008; f: Johanis 5248; all K). - Scale bars: $a, b=2 \mathrm{~cm} ; \mathrm{c}-\mathrm{g}=2 \mathrm{~mm} ; \mathrm{h}, \mathrm{i}=1 \mathrm{~mm}$. 
Conservation status - Least Concern (LC). Widespread, in a wide range of habitats and presumed often abundant. Over 400 collections, many recent, seen from much of its distribution. Formal assessment is given separately only for the abundant var. virgata and the well-circumscribed var. austroqueenslandica.

Note - One widespread and three regional varieties are recognised, two sympatric with the typical (widespread) variety. For a discussion of their relationship see Notes 2 and 4 under the species as a whole and for comparisons with other species see further under each variety.

\section{a. var. virgata - Fig. 21; Map 23}

Urtica celebica Blume (1825) 492. - Boehmeria celebica (Blume) Blume (1857) 217. - Boehmeria platyphylla D.Don var. celebica (Blume) Wedd. (1869) 211. - Boehmeria caudata (Burm.f.) J.J.Sm. var. celebica (Blume) J.J.Sm. (1910) 709. - Type: Blume s.n. (holo L), Indonesia, Sulawesi.

Boehmeria erythropoda Miq. in Zollinger (1854) 101, 104. - Type: Zollinger 534 (holo U), Indonesia, Jawa [Java], shady woods near Lamadjang, Tenga. Boehmeria microcarpa Wedd. (1854) 201. - Boehmeria platyphylla D.Don var. microcarpa (Wedd.) Wedd. (1856) 366, 369. - Type: Labillardiere s.n. (lecto $\mathrm{G}$, selected here; isolecto $\mathrm{P}$ ), Indonesia, Sulawesi, Bouton Island. - See Note 1.

Boehmeria platyphylla D.Don var. marquesensis F.Br. (1935) 49. - Type: Brown 986 (holo BISH), Marquesas Islands, Uapou, 25 Febr. 1922. - See Note 2.

Scandent or erect shrub or slender tree, 1-8 $\mathrm{m}$ tall, with trunk up to $30 \mathrm{~cm}$ diam, often with drooping branches; stems glabrous or with pale or brownish sparse adpressed closely-adpressed fine hairs or hairs dense, coarser, half-adpressed to spreading. Stipules up to 10 by $2 \mathrm{~mm}$ (up to 25 by $4 \mathrm{~mm}$ in Southeast Polynesia), glabrous or adpressed-hairy abaxially on midrib or (New Guinea) whole surface. Leaves almost symmetrical or two sides dissimilar; 'larger' leaves (5-)10-22 by $3-12 \mathrm{~cm}$, length 1.8-3.5x width; marginal teeth (20-)25-45 either side, rounded or acute but not or scarcely up-curved, indistinct or distinct, $(0.2-) 0.5-1$ by $2-4.5 \mathrm{~mm}$ ( -2 by $7 \mathrm{~mm}$ in Southeast Polynesia and New Guinea); leaf apex gradually short-attenuate with fine tip; base broad-cuneate to narrowly rounded; upper lateral veins on one side 1-3 (up to c. 7 in Southeast Polynesia), often only basal vein visible (impressed) adaxially, lateral veins and coarser often \pm scalariform tertiary veins finely prominent abaxially; texture thin- or thick-chartaceous, adaxial surface often somewhat shiny with prominent minute cystoliths, glabrous or with very sparse (Indonesia, abundant) hairs, short, fine, straight, closely-adpressed, usually lying in pattern pointing towards centre of areoles, or (New Guinea, forms somewhat intermediate with var. velutina) sparse longer half-adpressed soft wavy hairs giving rough feel to leaf; abaxial surface with hairs on veins only or whole surface, sparse closeadpressed or \pm spreading; petiole usually $0.3-0.5 \times$ lamina length. Male inflorescence-bearing axes $10-20 \mathrm{~cm}$ with short lateral branches usually throughout length; female (or mainly female) inflorescence-bearing axes $20-70 \mathrm{~cm}$, and of varying form, in the Pacific usually unbranched or with a few short lateral entirely male branches near base, in New Guinea these lateral branches entirely female, more numerous, longer and sometimes with 2nd-order branching, in Maluku and Sulawesi with 1st-order branching throughout length; clusters crowded or well-spaced. Male flowers almost glabrous or (Indonesia) with sparse coarse hairs. Fruiting perianth with a wide range of shape, ovoid-conical or ellipsoid to obovoid or obtriangular in outline but always with a distinct often broad wing.

Distribution - Malaysia (Selangor), Philippines (Luzon, Bohol, Mindanao), Indonesia (a few records to the west of Wallace's line: Sumatera, Jawa and Bali, east of this line as for the species), Papua New Guinea, Pacific (incl. Solomon Islands,
Vanuatu, Fiji, Tonga Islands, Samoan Islands, Society Islands, Marquesas Islands, Austral Islands).

Habitat \& Ecology - As for the subspecies as a whole.

Conservation status - Least Concern (LC). Widespread in a wide range of habitats and presumed often abundant. Over 400 collections, many recent, have been seen clearly referable to this widespread variety.

Notes - 1. No type collection was cited for B. microcarpa Wedd. in 1854 (only "Ins. Molucc.") but Weddell (1856: 369) cites for var. microcarpa and var. moluccana several collections including this one: " $\eta$ \& $\theta$ Labillardiere, Blume, D'Urville, Milne" and the Labillardiere sheet at $\mathrm{G}$ has the epithet microcarpa in Weddell's hand.

2. The variation within this variety and its relationship with the rest of the species are discussed fully under the species as a whole (Notes 2-4).

3 . This variety is one of only two Boehmeria taxa native to the Pacific (the other being the Hawaiian B. grandis with which it sometimes appears \pm intermediate as discussed below (Note 5 ). It is extremely variable in leaf-size, relative proportions and texture, sometimes also in stipule length (Southeast Polynesia), specimens at the extremes of variation looking very different; this variation is partly correlated with geographical distribution but in each region a range of intermediates with more 'typical' material also occurs. For this reason variants from Southeast Polynesia (Marquesas Islands and Tahiti) with unusually small leaves and only moderately flattened indistinctly winged fruiting perianth, which were described as var. marquesensis, are not formally distinguished here.

4. Boehmeria virgata var. virgata is so variable that it has often been confused with four other species of Boehmeria. It can be rather similar vegetatively to one or other variety of $B$. densiflora the allopatric var. boninensis (Bonin and Ryukyu Islands) and the partly sympatric var. densiflora (China, Japan and sympatric in the Philippines). In flower or fruiting perianth both varieties are easily distinguished from $B$. virgata var. virgata by female inflorescence-bearing axes erect, densely congested, often short and male axes unbranched with usually contiguous clusters. Forms of var. virgata from Fiji with thick-textured leaves and acute rather than acuminate leaf apex are vegetatively rather similar to $B$. densiflora var. boninensis. Var. virgata is usually easily distinguished from var. densiflora in having leaves larger, relatively broader \pm glabrous adaxially; however, without flowers certain Indonesian variants with leaves small, narrow, thin-textured, abundantly adpressed-hairy adaxially, can only be distinguished from $B$. densiflora var. densiflora by spreading rather than adpressed hairs abaxially and tertiary venation clearly scalariform and fairly conspicuous. (See further discussion under $B$. densiflora as a whole.)

5. Certain other, very different, variants found in Southeast Polynesia (Tahiti and Rapa) with large stipules (> $10 \mathrm{~mm}$ long) and leaves large, broad, thick-textured with 4-7 upper veins are strikingly similar to forms of the allopatric but 'neighbouring' $B$. grandis (Hawaii) with large sparsely hairy leaves. Smallleaved variants of the two taxa are fairly easily distinguished (in $B$. grandis they have marginal teeth $1-2 \mathrm{~mm}$ long, in $B$. virgata var. virgata much shorter) but in large leaves the size range of teeth overlaps. However, leaves of these particular variants of $B$. virgata are mostly crenate and smooth with inconspicuous fine reticulation, whereas leaves of $B$. grandis are always serrate and large ones usually bullate due to close-spaced adpressed robust reticulate veins which are impressed adaxially, prominent abaxially. Boehmeria grandis is easier to distinguish in flower and fruit, differing in inflorescence-bearing axes always branched, the male ones secondarily branched. A few collections (e.g., Tahiti, Florence 3854, P and Rapa, St. John 15359, A) appear entirely intermediate and it is possible that 


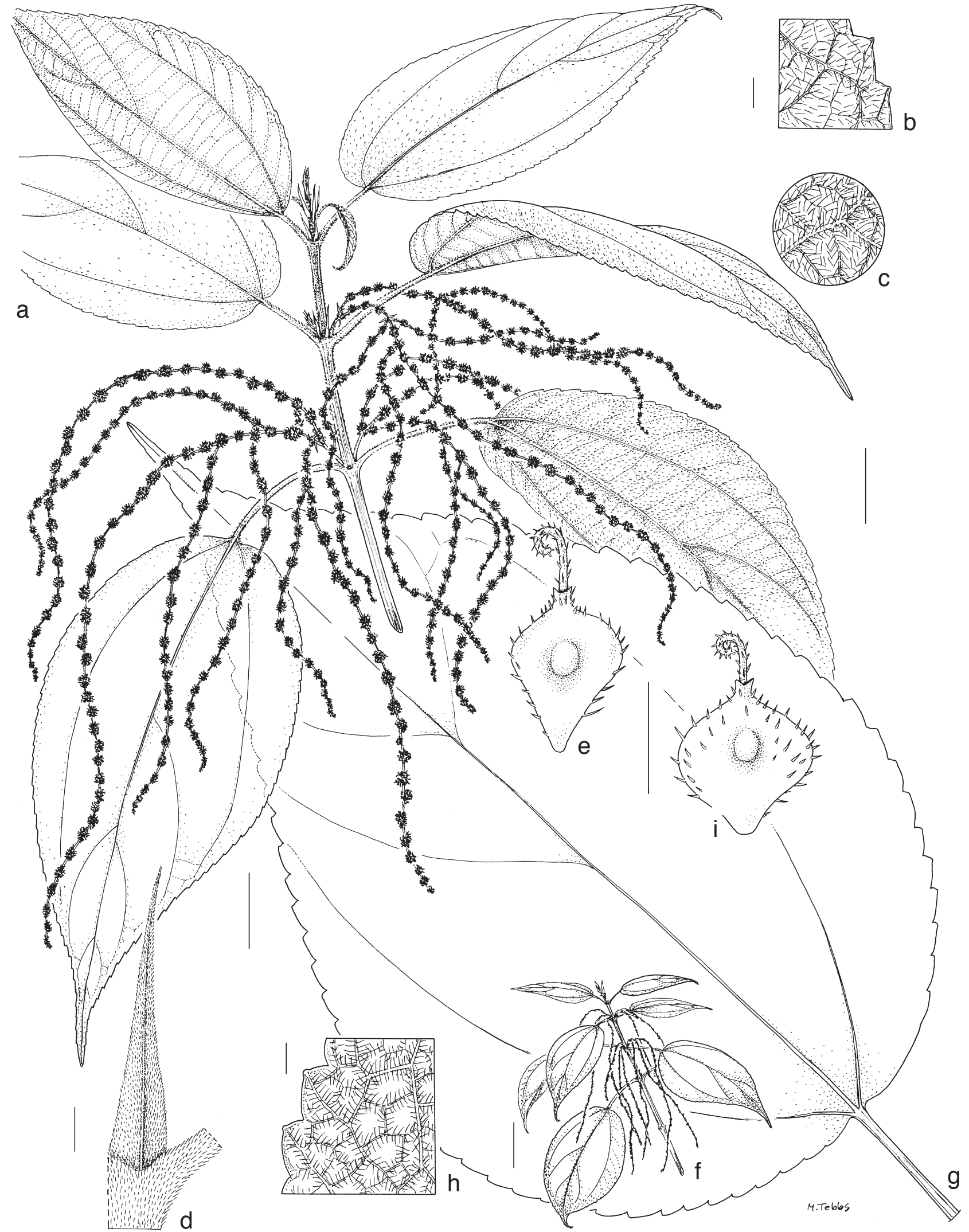

Fig. 22 a-e: Boehmeria virgata subsp. virgata var. velutina Friis \& Wilmot-Dear. a. Habit of stem with inflorescence-bearing axes; b. leaf, detail of margin and adaxial surface; c. leaf, detail of abaxial surface; $d$. detail of stem and stipule; e. fruiting perianth. $-\mathrm{f}-\mathrm{i}$ : Boehmeria virgata subsp. virgata var. maxima Friis \& Wilmot-Dear. f. Habit of stem with inflorescence-bearing axes; g. leaf; h. leaf, detail of adaxial surface; i. fruiting perianth (a-e: Davis 596; f, h, i; Mahyar 436; g: Van Royen 7542; all K). - Scale bars: a, $\mathrm{g}=2 \mathrm{~cm}$; b-d, h = $2 \mathrm{~mm}$; e, i $=1 \mathrm{~mm} ; \mathrm{f}=10 \mathrm{~cm}$. 
these variants of $B$. virgata, from the eastern extreme of its distribution and closest to the distribution of $B$. grandis) may represent an intermediate between the two taxa.

6. Certain variants from Indonesia and Philippines with leaves broad and large-toothed, relatively hairy abaxially can be confused with less bullate forms of the partly sympatric but less widespread B. rugosissima (Indonesia mostly west of Wallace's line and Philippines). Boehmeria rugosissima differs from these variants in stipules almost always larger, inflorescence-bearing axes $\leq 15 \mathrm{~cm}$ long, achene almost filling fruiting perianth and leaf apex more distinctly acuminate, but two collections impossible to place in either taxon have been seen from Mindanao (discussed under B. rugosissima).

7. Most forms of var. virgata are easily distinguished from B. multiflora (Philippines and Sulawesi) by leaves larger and relatively broader, adaxially glabrous or adpressed-hairy, but variants from Indonesia with leaves relatively narrow and spreading-hairy can be confused with it. Boehmeria multiflora is distinguishable by inflorescence-bearing axes unbranched mostly shorter and leaves narrower usually bullate with length $\geq 3 \times$ width (rather than, in this form at least, only up to $2.5 \times$ width), basal veins scarcely extending to the distal half of lamina and marginal teeth often relatively narrower.

8. Forms with leaves \pm glabrous, thin-textured and crenate can be confused with the widespread $B$. zollingeriana where the diagnostic male flowers are lacking.

9. Var. virgata often has leaves long, narrow and asymmetrical in outline, which leads to confusion with the genus Cypholophus and especially with $C$. decipiens which has female clusters simple, axillary, stigma minute, curved and fruiting perianth succulent (see discussion in Wilmot-Dear \& Friis 1998: 920-921). The distribution of C. decipiens overlaps in Papua New Guinea (where it is not easily confused with the relatively broad-leaved long-toothed regional variants of var. virgata found there) and Melanesia (Bougainville and Vanuatu), where $B$. virgata is narrower-leaved and less easily distinguished. Vegetative differences are not absolute but C. decipiens always has leaves narrow, closely-finely-serrate (tooth width often equalling length) drying dull greyish brown or blackish brown (rather than usually greenish or yellow-brown), often markedly asymmetrical and sideways-curved at the apex and with the upper lateral veins on the two halves usually very dissimilar, 3-5 and 0-2, respectively, (rather than usually 1-2 and $0-2$ ). (The many-veined variants of var. virgata found in Southeast Polynesia would not be confused with C. decipiens as their leaves are relatively broader, \pm symmetrical and veins similarly arranged on both halves of the lamina.)

\section{b. var. velutina Friis \& Wilmot-Dear, var. nov. - Fig. 22a-e; Map 22}

A var. virgata indumento densisimo patenti longiore usque $0.5 \mathrm{~mm}$ longo (nec in foliis sparso neque saupe adpresso), foliis ad basin subcordatis (nec cuneatis neque rotundatis) et ad marginem dentibus maioribus 1.5-2 $\mathrm{mm}$ (nec plerumque $0.5-1 \mathrm{~mm}$ ) longis ornatis atque axe inflorescentiarum multo ramosa differt. - Type: Streimann \& Kairo 30765 (holo K; iso A, BISH, BO, BRI, CANB, E, L, PNH, SING, SYD, US), Papua New Guinea, Central Distr., Sogeri.

Large shrub or small tree, $1.5-2.5 \mathrm{~m}$ tall. Stem with hairs abundant, up to $0.5 \mathrm{~mm}$ long, coarse, spreading or only half-adpressed, dark brown. Stipules 8-10 mm long, with hairs dense, adpressed, finer than on stem. Leaves ovate, mostly symmetrical, medium or large with rather variable proportions (9-)15-20 by $3.5-8 \mathrm{~cm}$, length $1.6-3 \times$ width; marginal teeth $30-40$ either side, medium-sized, usually acute, not or slightly up-curved, c. $1.5(-2)$ by $2.5-5 \mathrm{~mm}$; leaf apex attenuate-acuminate, base broadly subcordate or sometimes \pm truncate; upper lateral veins on at least one side $1-3$, lateral and coarser tertiary venation robust and conspicuous abaxially; thick-textured, leaves often bullate, often drying grey-green, with spreading hairs both sides, abundant, giving a \pm velvety appearance; petiole relatively short usually $0.25-0.35 \times$ lamina length. Inflorescence-bearing axes of both sexes much-branched, 7-20 cm long. Male flowers densely hairy. Fruiting perianth broadly ellipsoid to obovoid, 0.8-1.2 by $0.5-0.8 \mathrm{~mm}$, markedly laterally flattened into a broad thintextured marginal wing around thickened ovoid middle portion comprising $0.3-0.5 \times$ total fruiting perianth size.

Distribution - Endemic to New Guinea (Indonesian Irian Jaya, Papua New Guinea).

Habitat \& Ecology — Lowland rainforest, sandy riverbanks, grassy roadside; $150-580 \mathrm{~m}$ altitude.

Notes -1 . This variety, sympatric with var. virgata in New Guinea, is distinctive in its indumentum and several leaf characters; it grades into var. virgata via a range of intermediate forms, as discussed under the species (Note 4-i) and formal conservation status assessment is therefore not meaningful. Although less than ten collections have been seen clearly referable to this variety, habitats in these areas appear not to be suffering deterioration and we do not consider it currently at risk.

2. Leaf shape, texture and indumentum are rather reminiscent of the allopatric $B$. multiflora which can be distinguished by inflorescence-bearing axes unbranched and leaves always small often relatively narrower.

c. var. maxima Friis \& Wilmot-Dear, var. nov. - Fig. 22f-i; Map 22

A var. virgata foliis maioribus relative latioribus $24-35 \times 15-20 \mathrm{~cm}$ (nec 5-22 × 3-12 cm) distinguenda. - Type: Mahyar 436 (holo K; iso A, BISH, BO, L, MAN, NSW), Indonesia, Indonesian Papua [Irian Jaya], Arfak Mts, Mupi Valley System.

Shrub, to c. $2 \mathrm{~m}$. Stem, at least when young with dense but fine rather inconspicuous half-adpressed to close-adpressed pale straight hairs up to $0.5 \mathrm{~mm}$ long. Stipules $11-15$ by $3 \mathrm{~mm}$, with hairs dense, adpressed, finer than on stem. Leaves broadly ovate to elliptic, $24-35$ by (11-)15-20 cm with length $1.5-$ $1.75(-2) \times$ width; marginal teeth 40-60 either side, shallow but very broad, usually rounded, $1.5-3$ by (5-)8-12 $\mathrm{mm}$; leaf apex attenuate-acuminate; base narrowly rounded or subcordate; upper lateral veins on at least one side (3-)4-5, lateral and tertiary venation fine and rather inconspicuous; texture thin-chartaceous but sometimes slightly bullate; both surfaces with hairs fine, inconspicuous, pale, much shorter than on stem ( $\leq 0.2 \mathrm{~mm}$ long), abundant and adpressed adaxially, sparse and spreading below; petiole long relative to lamina $0.4-0.6 \times$ lamina length. Inflorescence-bearing axes unbranched, 12-20 $\mathrm{cm}$. Male flowers sparsely hairy. Fruiting perianth broadly ovoid to obovoid, $1-1.5$ by $0.5-1.3 \mathrm{~mm}$, much-flattened laterally into broad thin-textured wing, central thickened portion sometimes spherical and minute.

Distribution - Endemic to Indonesia (Papua).

Habitat \& Ecology - Disturbed forest or amongst shrubs along riverbanks; 550-650 m altitude.

Note - This variety, sympatric with var. virgata in New Guinea, is distinctive in its leaves extremely large, thin-textured with numerous large long marginal teeth. A formal conservation status assessment is not meaningful. Only three collections have been seen, all from the same region (Bird's Head Peninsula) but habitats in this region appear not to be undergoing serious deterioration and we do not consider it currently at risk. See detailed discussion in Note 4-ii under the species. 


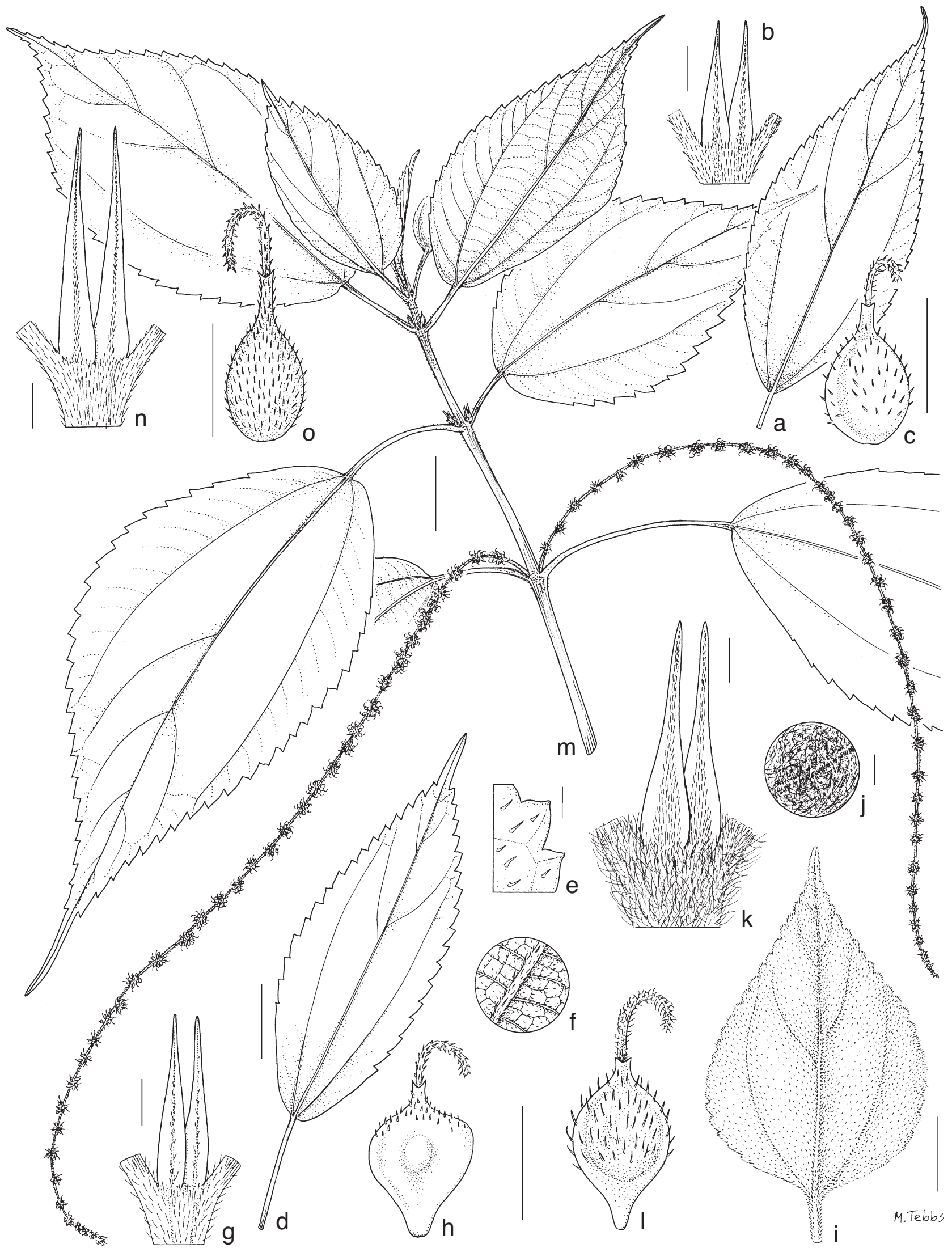

Fig. 23 a-c: Boehmeria virgata subsp. virgata var. austroqueenslandica (Domin) Friis \& Wilmot-Dear. a. Leaf; b. detail of stem and stipules; c. fruiting perianth. - d-h: Boehmeria virgata subsp. macrophylla var. molliuscula (Blume) Friis \& Wilmot-Dear. d. Leaf; e. leaf, detail of adaxial surface; f. leaf, detail of abaxial surface; g. detail of stem and stipules; h. fruiting perianth. - i-l: Boehmeria virgata subsp. macrophylla var. tomentosa (Wedd.) Friis \& Wilmot-Dear. i. Leaf; j. leaf, detail of abaxial surface; k. detail of stem and stipules; I. fruiting perianth. $-\mathrm{m}-\mathrm{o}$ : Boehmeria virgata subsp. macrophylla var. longissima (Hook.f.) Friis \& Wilmot-Dear. $\mathrm{m}$. Habit of stem with inflorescence-bearing axes; $\mathrm{n}$. detail of stem and stipules; o. fruiting perianth (a-c: Melville \& Hunt 3628; d-h: Manning 2007; i, j: McClintock 147; k, l: Daramola 67450; m, o: Gamble 1260B; n: Bourne s.n.; all K). — Scale bars: a, d, i, m = 2 cm; b, e-g, j, k, n= 2 mm; c, h, l, o = 1 mm. 


\section{d. var. austroqueenslandica (Domin) Friis \& Wilmot-Dear,} comb. nov. - Fig. 23a-c; Map 22

Basionym: Boehmeria platyphylla D.Don var. austroqueenslandica Domin in Bibliotheca Botanica 22, Heft 89 (1921) 576. - Type: Domin s.n. (holo PRC or PR, n.v.), Australia, Queensland, Tamborine and Beech Mts [Beechmont], March 1910. - See Note 1.

Shrub, 1-2 m tall. Stem with hairs (sparse-)abundant or dense, adpressed, stiff, straight. Stipules 6-8 mm long, hairy like stem on outside. Leaves moderately dimorphic in size with length of 'larger' lamina up to $2 \times$ length of 'smaller', narrowly ellipticovate, (6-)11-22 by (2.5-)4-7 cm, length $2.5-3.5 \times$ width, marginal teeth distinct $1-1.5$ by $2.5-5 \mathrm{~mm}$, not or slightly up-curved; leaf apex gradually attenuate to indistinctly short-acuminate, mostly toothed to tip but sometimes terminated by a single tooth slightly longer than the width of marginal teeth; base slightly asymmetrical, narrowly rounded to narrow-cuneate; basal veins often extending almost to apex, slender; adaxial surface with abundant hairs like the stem but very fine and inconspicuous, abaxial surface with shorter hairs, sparser mostly restricted to veins or sometimes almost absent; petiole very variable with respect to leaf-size, $0.2-0.5(-0.75) \times$ lamina length Inflorescence-bearing axes unisexual or sometimes bisexual with male clusters near base, pendulous, unbranched, 8-25 $\mathrm{cm}$ long, flower-clusters often contiguous, sometimes spaced 2-3 mm apart; female clusters 2-3 mm diam, with c. 20more than 30 flowers. Fruiting perianth ellipsoid to ovoid, 1-1.5 by $0.5-0.7 \mathrm{~mm}$, scarcely laterally flattened or more so with marginal rim or indistinct wing and abundant hairs, these fine, minute and hooked.

Distribution - Australia (south-eastern Queensland, northeastern New South Wales).

Habitat \& Ecology - Montane rainforest understory and forest margins and clearings, often on steep-sided river valleys; 300-800 m altitude.

Conservation status — Least Concern (LC). This well-circumscribed variety has a restricted distribution and is known from only c. 40 collections from a relatively small area with an EOO of $7429 \mathrm{~km}^{2}$. However, its habitat (rainforest) in eastern Australia is now well-protected and not greatly subject to disturbance. Several recent collections of this plant exist and it is reasonable to assume that its populations remain fairly stable.

Notes - 1. The type of $B$. platyphylla var. austroqueenslandica was not traced by either us or Chew (1989: 85), but there is no doubt about its identity and, apart from cultivated and escaped populations of $B$. nivea, this is the only Boehmeria which has been collected in Australia.

2. Distinguished on indumentum, leaf shape, number and proportions of marginal teeth, male and female inflorescencebearing axes long, unbranched and fruiting perianth littleflattened. See detailed discussion under the species as a whole (Note 4-iii). It is allopatric to the rest of the species and very localised, restricted to low altitude rainforest in north-eastern New South Wales and south-eastern Queensland and often noted as 'rare' or 'occasional' by collectors.

\section{ii. subsp. macrophylla (Hornem.) Friis \& Wilmot-Dear, comb.} \& stat. nov. - Fig. 23d-0, 24-29; Map 24-30

Basionym: Boehmeria macrophylla Hornem., Hortus Regius Botanicus Hafniensis, Vol. 2 (1815) 809, non B. macrophylla D.Don (1825), nec B. macrophylla (Thunb.) Siebold \& Zucc. (1846). - Type: Hornemann s.n. (holo C; photo $\mathrm{E}, \mathrm{K})$, cultivated in Copenhagen Botanic Garden.

Non B. macrophylla D.Don (1825) nec B. macrophylla (Thunb.) Siebold \& Zucc. (1846)

Erect shrub, subshrub or woody-based herb, 0.5-2 m tall; ultimate stems with widely varying indumentum, hairs sparse, stiff or fine, inconspicuous, adpressed and short or dense, soft, spread- ing and longer. Stipules mostly rather small and inconspicuous, $4-6(-11)$ by $1(-2.3) \mathrm{mm}$, chartaceous. Leaves not or slightly dimorphic with length of 'larger' lamina up to 1.5(-2)× 'smaller' and relatively narrower but petioles of 'larger' leaves often up to $5 \times$ length of 'smaller' ones, ovate to rhombic-ovate or elliptic, with wide range of size and relative proportions, (5-)10-24 by (3-)7-16 mm, length (1.2-)1.5-2(-3.5, Africa only)× width; margin regularly dentate throughout length, teeth $10-60$ either side, (1-)1.5-3(-5) mm long, these acute \pm mucronate at apex and usually slightly (to markedly) up-curved; leaf apex attenuate or more often narrowed into distinct acumen sometimes markedly sideways-curved and often consisting mainly of a single long terminal tooth; base slightly or markedly asymmetrical, cuneate to narrowly or broadly rounded, rarely \pm truncate or slightly cordate; basal veins extending into distal half or well into distal third of lamina, upper lateral veins 1-2(-3) either side, not markedly dissimilar on two sides of lamina, lowermost arising at or below middle of lamina (var. tomentosa in distal half), usually inconspicuous adaxially, these and coarser tertiary reticulation visible abaxially; texture usually relatively thin-chartaceous, rarely thicker and leaves bullate or rugose; adaxial surface rarely glabrescent, usually with abundant indumentum similar to that of stem, hairs inconspicuous, adpressed often stiff, or conspicuous soft and spreading; abaxial surface with adpressed or spreading indumentum often restricted to veins; petiole very variable between or within varieties (0.1-)0.25-0.7(-1.3)× lamina length. Inflorescence-bearing axes erect short or pendulous, medium to long, (5-)10-40 cm long, usually unbranched, sometimes, especially male ones, with a few long lateral branches near base (in var. scabrella male axes may be branched throughout length); axes mostly unisexual; flower-clusters well-spaced or crowded; male clusters up to $2 \mathrm{~mm}$ diam, with few-10(-15) flowers, female clusters (1-)2-4 mm diam, with (10-)20-more than 50 crowded or rather loosely-arranged flowers; bracteoles inconspicuous, linear-oblong or spathulate, 0.3(-0.5) mm long. Male flowers: tepals with dorsal appendages usually prominent, knob-like, sparsely to densely adpressed- or spreading-hairy. Female flowers fairly narrowly ovoid tapering to indistinct beak, small, up to 0.5 by $0.2 \mathrm{~mm}$; stigma usually fairly short, $0.6-1.5(-2)$ $\mathrm{mm}$ long. Fruiting perianth $0.7-1.5(-2)$ by $0.3-0.5(-1) \mathrm{mm}$, extremely varied in form and indumentum, sometimes ovoidconical, scarcely laterally flattened with narrow marginal rim and achene \pm filling fruiting perianth, densely minute-pubescent throughout; sometimes ellipsoid to obovoid \pm inflated in distal part, scarcely laterally flattened and with sparse coarse pale hairs near apex, sometimes ovoid to obovoid or spindle-shaped markedly laterally flattened with a narrow thick-textured wing and achene not filling fruiting perianth, glabrescent or with coarse or fine pale hairs at apex or throughout.

Distribution - As for the species west of Wallace's line.

Habitat \& Ecology — Lowland rainforest, riverine forest, montane evergreen or seasonal forest, secondary scrub, open areas; 100-3500 m altitude.

Conservation status - Least Concern (LC). Widespread, in a wide range of habitats and presumed often abundant. Well over 1000 collections, many recent, have been seen from the subspecies as whole. Formal assessment is given separately for the widespread varieties var. macrostachya, var. minuticymosa, var. molliuscula and the well-circumscribed varieties var. longissima and var. sumatrana.

Notes - 1. The name 'subsp. macrophylla' was created as an autonym by Panigrahi \& Murti (1999) who were the first to publish a subspecies (subsp. canescens) under B. macrophylla Hornem. Since these two subspecies are united here, the autonym takes priority according to the Vienna Code (art. 11.6) and the authority is to be cited according to Art. 26.3 and Ex. 6. 
2. Relationships within subsp. macrophylla and between it and subsp. virgata are discussed under the species as a whole (Notes 2, 3, 5). Various varieties of subsp. macrophylla are also frequently confused with other species, as follows.

3. Boehmeria pilosiuscula (partly sympatric but more widespread) has often been confused with var. scabrella due to the similar leaf shape and short erect inflorescence-bearing axes with crowded clusters but can always be distinguished by its stem indumentum of mixed minute and long hairs, its distinctive inflorescence-bearing axes with male flowers mostly in small clusters near the apex of an unbranched mainly female inflorescence-bearing axes and its female flowers obconical-truncate and extremely densely congested in the cluster. Boehmeria pilosiuscula var. suffruticosa is the easier of its two varieties to distinguish, with its leaves soft-hairy, thin-textured, markedly asymmetrical, and its female and bisexual axes extremely short ( $<2 \mathrm{~cm}$ long) and densely congested. The material of var. scabrella vegetatively most similar to $B$. pilosiuscula (leaves thin-textured and markedly asymmetrical) occurs in Assam and Bihar, from which $B$. pilosiuscula is absent. See under B. pilosiuscula (Note 8) for detailed discussion of differences.

4. Broad-leaved opposite-leaved forms of the widespread and highly variable $B$. clidemioides are often similar in leaf shape, texture and fruiting perianth shape to some variants of var. macrostachya, var. rotundifolia and var. scabrella and incomplete specimens lacking the diagnostic apical leaf-tufts on inflorescence-bearing axes can be misidentified as these varieties. (Var. scabrella also rarely has an apical tuft of leaves on occasional axes, causing further confusion.) Boehmeria clidemioides can usually be distinguished by leaf base \pm symmetrical, female axes often with many lax branches and male and female clusters often mixed throughout the same axis; the above-mentioned particularly similar forms of $B$. clidemioides can usually also be distinguished by relatively narrower leaves with relatively narrower marginal teeth which are increasingly long and increasingly up-curved towards leaf apex and some leaves alternate.

5. Thai collections of $B$. zollingeriana var. zollingeriana with long unbranched female inflorescence-bearing axes and scattered hairs on the adaxial leaf surface have often been misidentified as 'B. platyphylla' (= subsp. macrophylla) but are distinguished (besides the diagnostic male flowers in axillary clusters and long-pedicellate) by stems entirely glabrous, leaf margin very shallowly crenate rather than dentate (teeth $<1 \mathrm{~mm}$ long) and adaxial surface \pm shiny often glabrous, lowermost upper veins also sometimes arising in basal third of leaf.

6. Boehmeria ternifolia can sometimes be confused with var. strigosa (allopatric, China), var. macrostachya, and often with var. rotundifolia whose leaves with terminal tooth long and tail-like and distal marginal teeth markedly in-curved are often almost identical in form to $B$. ternifolia var. ternifolia. However, $B$. ternifolia is distinguishable by its hairs on stem and often also on leaves spreading, dense, minute $(\leq 0.3 \mathrm{~mm}$ long) and velvety, marginal teeth often fewer and from var. rotundifolia additionally on its shrubby habit, its inflorescence-bearing axes never branched throughout length and its habitat, forest (rather than more open areas) and at low altitude.

7. In India and China thinner-leaved forms of $B$. polystachya may be confused with var. rotundifolia or var. scabrella but $B$. polystachya is distinguished by its scalariform venation distinctive, prominent, its inflorescence-bearing axes (often bisexual) branched throughout its length and with 2nd-order branching; male axes of var. scabrella and var. rotundifolia may also be branched throughout length but without 2nd-order branching. Var. scabrella also differs from B. polystachya in hairs on stem and leaf coarse conspicuous (rather than fine inconspicuous).
8. Var. minuticymosa has sometimes been mistaken for $B$. ourantha (sympatric in the Himalayas) which has similar erect female inflorescence-bearing axes with congested clusters but which differs in indumentum long, soft usually dense, leaves often truncate and marginal teeth usually rounded and especially in its inflorescence architecture with male clusters located at the apex (rather than base) of mainly female axes.

9. Boehmeria conica, a species of very restricted distribution (south-western China, north-east Himalaya) has been confused with broad- and thin-leaved forms of var. macrostachya with branched male axes; $B$. conica can be distinguished by \pm glabrous leaves and a distinctive 'conical' branched inflorescence architecture.

10. Chinese material of var. macrostachya with large leaves has been confused with the allopatric $B$. holosericea (Japan, South Korea) which differs in leaves with marginal teeth larger and broader and hairs conspicuous, long, curved, stem with hairs spreading, dense, short (up to $0.2 \mathrm{~mm}$ long) (rather than stem and leaves both with hairs inconspicuous short, adpressed), also in female inflorescence-bearing axes robust erect thick with large contiguous clusters, 4-7 mm diam. Var. strigosa can have similar leaf shape to $B$. holosericea but differs in adpressed silky indumentum.

11. Var. macrostachya and sometimes also var. strigosa and var. densiglomerata can be confused with some variants of the partly sympatric and rather variable species $B$. japonica (China, South Korea, Japan), which is distinguished from all three varieties by its marginal teeth progressively markedly larger towards leaf apex, those close to the leaf apex up to 15 $\mathrm{mm}$ long (rather than $<5 \mathrm{~mm}$ ), with length (2-)5-10x that of lower ones or so large as to form a broad 3-5-toothed apex; $B$. japonica can be distinguished additionally from the latter two varieties by its leaf base often cuneate and never cordate, from var. densiglomerata on female clusters never tightly congested along axis, and from var. macrostachya by its marginal teeth relatively few, only up to 25 even on large leaves, rather than usually over 25 , often $30-50$ on large leaves.

12. Unidentifiable collections from Taiwan (from which subsp. macrophylla has not been recorded), Taipei; Hsie s.n. (UC) and Hsie s.n. 15 Aug. 1988 (NY), conform to B. sieboldiana in leaves glabrous very thin textured and absence of dorsal appendages on male tepals, but to $B$. virgata subsp. macrophylla in its ovate rather than rhombic-ovate leaves.

13. Var. macrostachya is strongly reminiscent of the New World species $B$. caudata Sw. in general appearance, with its leaves often large, close-serrate with \pm uniform teeth and its inflorescence-bearing axes long, pendulous, although $B$. caudata is often densely spreading-hairy and has fruiting perianths more than twice as large, c. 2.5 by $1.5 \mathrm{~mm}$, wide stipules and longer stigma.

14. Material of subsp. macrophylla of uncertain identity intermediate between var. macrostachya and other varieties (discussed in Note 5-iv under the species) includes the following types:

Boehmeria massuriensis Blume (1857) 216. - Type: Hugel 49 (holo L; iso W), Himalaya, Massuri [Mussoori], etc. - Intermediate with var. scabrella.

Boehmeria huegeliana Blume (1857) 218. - Type: Hugel 1935 (holo L; iso W), eastern India. - Intermediate with var. scabrella.

Boehmeria cuspidata Blume (1857) 216, non Wedd. (1856) 345 , nec Boehmeria platyphylla var. cuspidata Wedd. (1856) 365. - Type: Unknown collector in Herb. Blume s.n. (holo L), Nepal. - Intermediate with var. rotundifolia. 
e. var. molliuscula (Blume) Friis \& Wilmot-Dear, comb. nov. Fig. 23d-h; Map 24

Basionym: Boehmeria mauritiana Wedd. var. molliuscula Blume, Museum Botanicum Lugduno Batavum, Vol. 2 (fasc. 13-16) (1857) 216. - Syntypes: Sieber, Fl. Maurit. II, n. 375 (L; isosyn P), Mauritius; ex Herb. Mus. Paris 689 (L, not traced), Reunion. - See Note 1.

Urtica caudata Poir. (1798) 640, nom. illeg., non. Burm.f. (1768) 197, nec Blume (1825) 492. - Boehmeria mauritiana Wedd. (1854) 200, nom. nov. for Urtica caudata Poir. (1798) 640. - Type: Sonnerat in Herb. Poiret s.n. (holo P), Mauritius.

Boehmeria elliptica Wedd. (1854) 200. - Boehmeria platyphylla D.Don var. macrostachya (Wight) Wedd. subvar. elliptica (Wedd.) Wedd. (1856) 367. - Type: M. Richard 291 (lecto P, selected here because label has the annotation in Weddell's handwriting 'subvar. elliptica'), Madagascar, Ile Mohilla. Boehmeria platyphylla D.Don var. macrostachya (Wight) Wedd. subvar. phyllostachya Wedd. (1856) 367. - Type: Bory de St. Vincent s.n. (lecto $\mathrm{P}$, selected here as the only identifiable part of the original material possible to trace for this account), Reunion [Bourbon].

Boehmeria mauritiana Wedd. var. luxurians Blume (1857) 216. - Type: Richard 696 (holo L), Reunion.

Boehmeria platyphylla D.Don var. angolensis Rendle (1917) 201. — Syntypes: Gossweiler 4656 (BM) \& 4851 (BM), Angola.

Understorey shrub, subshrub (sometimes scrambling) or small fleshy robust herb, up to 2-3 m tall. Stems with hairs sparse to abundant, spreading (rarely half-adpressed), fine, soft, weak often curved and often of varying lengths but at least some 0.4-0.5 mm long. Stipules 6-9 mm long, glabrous or sparsely hairy abaxially. Leaves slightly or moderately dimorphic in size with length of 'larger' lamina up to $2 \times$ length of 'smaller', elliptic, ovate or rhombic-ovate to narrowly ovate, $4-25$ by $2.5-15 \mathrm{~cm}$, length 1.5-3.5x width, marginal teeth relatively few, 15-35 either side, $2-5$ by $4-7 \mathrm{~mm}$, distal ones sometimes slightly up-curved; leaf apex attenuate to indistinctly long-acuminate mostly consisting of a single long tooth; base narrow, cuneate or narrowly rounded but often subcordate; texture very thin- to thick-chartaceous, leaves smooth or sometimes slightly bullate; both surfaces glabrescent or with hairs abundant, fairly soft, curved, sometimes giving adaxial surface a rough texture; veins slender or robust; petiole very variable with respect to lamina 0.25 -more than $0.5 \times$ lamina length (in moist habitats sometimes longer than lamina). Inflorescence-bearing axes unisexual or sometimes bisexual, pendulous, unbranched, 5-50 cm long, flower-clusters spaced 2-6 mm apart, female clusters 2-5 mm diam, flowers c. 10-40(-more than 50), usually loosely arranged. Fruiting perianth ovoid to obovoid without distinct beak, up to 2 by $1 \mathrm{~mm}$, moderately or markedly laterally flattened with distinct marginal rim or indistinct thick-textured wing, glabrescent to abundantly hairy at apex or throughout, hairs sometimes minute, usually fairly long and conspicuous.
Distribution - Tropical Africa (from Sierra Leone and Senegal to Ethiopia, south to Angola, Zimbabwe, Mozambique), Comoro Islands, Madagascar, Mauritius, Reunion.

Habitat \& Ecology - Lowland rainforest, often in riverine forest undergrowth or among rocks in moist woodland, often near streams; 800-2100 m altitude.

Conservation status - Least Concern (LC). Widespread, in a wide range of habitats and often common. Several hundred collections have been seen.

Notes -1 . The origin of the type specimen of $B$. macrophylla Hornem. (cited under $B$. virgata subsp. macrophylla) is not known, as the plant was grown from seeds of unknown origin, but the specimen agrees with material from Mauritius and Reunion, and we suggest it referred to var. molliuscula. Therefore, var. molliuscula is the typical variety of subsp. macrophylla, but the varietal epithet $B$. mauritiana Wedd. var. molliuscula Blume (1857) was published earlier than B. macrophylla Hornem. var. macrophylla (created as an autonym by Long (1982), when he made three other new combinations at the level of variety under B. macrophylla Hornem.: var. canescens (Wedd.) Long, var. tomentosa (Wedd.) Long and var. scabrella (Roxb.) Long). Subsp. macrophylla is not the typical subspecies of $B$. virgata, and the epithet var. molliuscula has priority and has to be used at this rank.

2. As discussed in detail under the species (Note 5-i, Table 4 ), this variety is distinguished from the allopatric var. macrostachya in its stem indumentum spreading, its leaf shape and proportions, and characters of the marginal teeth and inflorescence-bearing axes.

3. Forms in moist habitats (such as rainforest) often have almost glabrous stem and leaves while those in drier habitats have much denser indumentum, with a range of forms (including the type of $B$. platyphylla var. nigeriana) intermediate with the dryhabitat var. tomentosa. This intermediate material includes the type collections of var. nigeriana, and var. ugandensis, as follows: Boehmeria platyphylla D.Don var. nigeriana Wedd. (1869) 213. - Type: Barter s.n. (holo K; iso P), Nigeria, Aboh.

Boehmeria platyphylla D.Don var. ugandensis Rendle (1917) 201. - Syntypes: E. Brown 2040 (BM; isosyn K), Uganda, Mawokota; Dawe 423 (K) \& Scott Elliott 7531 (BM; isosyn K), both Uganda, Ankole; Bagshawe 799 (BM), Uganda, Mengo, Entebbe; Dummer 89 (BM; isosyn K), Uganda, Kirerema; Schweinfurth 3203 (K; not found), Sudan/Zaire, Monbuttu, Kussumbo River.

Map 24 Distribution of Boehmeria virgata (G.Forst.) Guillem. subsp. macrophylla (Hornem.) Friis \& Wilmot-Dear var. molliuscula Blume) Friis \& WilmotDear $(\odot)$ and B. virgata (G.Forst.) Guillem. subsp. macrophylla (Hornem.) Friis \& Wilmot-Dear var. tomentosa (Wedd.) Friis \& Wilmot-Dear $(\bullet)$.

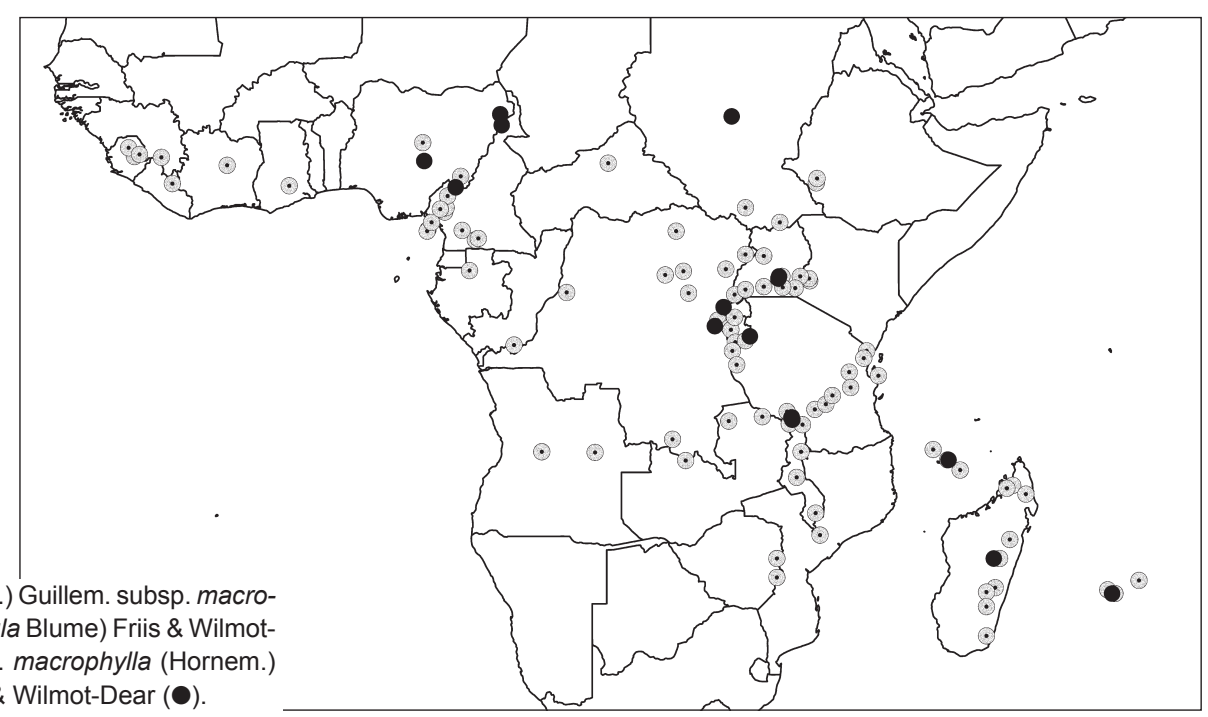


f. var. tomentosa (Wedd.) Friis \& Wilmot-Dear, comb. nov. Fig. 23i-l; Map 24

Basionym: Boehmeria tomentosa Wedd. in Annales des Sciences Naturelle, Sér. 4, Botanique, Vol. 1 (1854) 200. - Boehmeria platyphylla D.Don var. tomentosa (Wedd.) Wedd. (1856) 367. - Boehmeria macrophylla Hornem. var. tomentosa (Wedd.) D.G.Long (1982) 130. - Type: Chapelier s.n. (lecto $\mathrm{P}$, selected here as part of the original material best conforming to the original description), Madagascar.

Non Boehmeria tomentosa sensu auct., which is B. ourantha. - See Note 2.

Low subshrub branching from base, up to $1.5 \mathrm{~m}$ tall; ultimate stems very robust, $2-3 \mathrm{~mm}$ diam, with hairs dense, spreading, stiff, straight, pale or brownish, $0.4-0.7(-1) \mathrm{mm}$ long, often so dense as to completely obscure surface, persistent on older branches. Stipules $8-11$ by $2-2.5(-3) \mathrm{mm}$, fairly thick-textured, hairy abaxially. Leaves scarcely or markedly dimorphic in size with length of 'larger' lamina 1.1-2x length of 'smaller', rhombicovate (Nigeria) to broadly ovate (Cameroon, Madagascar), medium, $8-12(-16)$ by $3.5-6(-10) \mathrm{cm}$, length $(1.6-) 1.75-2 \times$ width; margin dentate, teeth 30-40 either side, shallow, distal ones sometimes slightly up-curved, (1-) $1.5-3$ by $1.5-3.5(-6)$ $\mathrm{mm}$; leaf apex attenuate-acuminate or abruptly short-acuminate consisting mostly of a single tooth c. $1 \mathrm{~mm}$ long; base broadly cuneate to rounded, sometimes narrowly subcordate; texture thick-chartaceous to thin-coriaceous; both surfaces velvety with dense spreading indumentum like the stem, or (Cameroon, Madagascar) hairs half-adpressed and sparser adaxially; veins robust; petiole variable but often very short relative to lamina, $0.1-0.3(-0.4) \times$ lamina length. Inflorescence-bearing axes pendulous, sometimes bisexual, $15-30 \mathrm{~cm}$ long, female unbranched, male and bisexual branched or not; clusters mostly unisexual, almost contiguous to well-spaced, male clusters very variable in size, $2.5-4 \mathrm{~mm}$ diam, with less than $10-$ more than 40 flowers; female clusters $2-3.5 \mathrm{~mm}$ diam $(3-4 \mathrm{~mm}$ in fruit), with 30-more than 50 flowers. Male and female flowers densely hairy. Fruiting perianth relatively large and broad, ovoid to ellipsoid, c. 1.5 by $1 \mathrm{~mm}$, with tapering or broadly rounded base and acute apex without beak, moderately laterally flattened in fruiting part and with either winged 'shoulders' or narrow marginal rim around achene, with dense short spreading dark brown pubescence. Achene \pm filling fruiting perianth.

Distribution - Africa (Nigeria, Cameroon, Congo Republic, Uganda, Tanzania, Zambia), Madagascar, Comoro Islands, Reunion.

Habitat \& Ecology - Open dry rocky hillsides, savannah, disturbed land (millet cultivation terraces); 1250-3500 m altitude.

Notes - 1. Formal conservation assessment is not given for this variety which intergrades with the typical one. Only c. 30 collections have been seen clearly referable to this variety but it is widespread and not considered at risk.

It appears to be a dry-habitat variant of var. molliuscula, distinctive in indumentum and leaf texture and uncommon compared to var. molliuscula. As discussed under the species as a whole (Note 5-ii) the two taxa intergrade, with many intermediate collections seen mostly from more moist habitat.

2. According to our circumscription and lectotypification the epithet tomentosa has been persistently misapplied to a very different Southeast Asian entity for which the name $B$. ourantha Miq. (1851: 33) already existed. Weddell (1856: 367) appears to have assumed the South-east Asian material to be conspecific with his earlier-described Malagasy species B. tomentosa (Weddell 1854: 200). Hochreutiner (1925), in making the combination $B$. platyphylla var. ourantha, noted the Asian material as distinct from the Malagasy entity bearing the epithet 'tomentosa' but the misapplication of the epithet 'tomentosa' to material of $B$. ourantha continued in much subsequent literature (e.g., Chen et al. 2003: 170). Most confusingly, the combination B. macrophylla Hornem. var. tomentosa (Wedd.) D.G.Long (1982: 130) was made in the Flora of Bhutan due to this misapplication (see discussion under $B$. ourantha, Notes 3 and 4 ). This validly published new combination as a variety under $B$. platyphylla (= B. virgata var. macrostachya in our sense) was applied to Bhutanese material of $B$. ourantha. This Southeast Asian species, $B$. ourantha, is easily recognised by its distinctive inflorescence architecture with male flowers pedicellate and scattered along unbranched mainly female inflorescence-bearing axes or in a few clusters at their apex (rather than on short lateral side branches near the base); female and bisexual inflorescence-bearing axes are also short mostly $\leq 10 \mathrm{~cm}$ (rather than $\geq 15 \mathrm{~cm}$ ) with clusters larger and more densely crowded. Boehmeria ourantha is also distinctive in its indumentum golden-brown, often very long (up to $2 \mathrm{~mm}$ ), giving a distinct golden-brown rather than pale sheen to plant, leaves broader, often crenate, not distinctly acuminate, base often truncate and marginal teeth fewer and often larger.

\section{g. var. macrostachya (Wight) Friis \& Wilmot-Dear, comb. nov. — Fig. 24a-i; Map 25}

Basionym: Splitgerbera macrostachya Wight, Icones Plantarum Indiae Orientalis, vol. 6 (1853) 10, pl. 1977. - Boehmeria platyphylla D.Don var. macrostachya (Wight) Wedd. (1856) 367. - Boehmeria wightiana Blume (1857) 217, nom. superfl. illeg. - Boehmeria macrostachya (Wight) F.M.Bailey (1888) 55. - Type: Wight s.n. (not found), India. - See Note 1.

Boehmeria platyphylla D.Don (1825) 60. - Type: Hamilton s.n. (holo BM), Nepal, Narainhetty, 3 Sept. 1802.

Boehmeria macrophylla Hornem. var. dongtouensis W.T.Wang (1996) 248. - Type: ZH Chen 910339 (holo PE), China, Zhejiang, Dongtou Island, 27 July 1991.

Woody-based herb, subshrub or shrub, up to $2 \mathrm{~m}$ tall. Stems with fine inconspicuous straight closely-adpressed short hairs 0.2-0.4 mm long. Stipules 4-9(-11) mm long. Leaves widely varying in shape, proportions and number of teeth, ovate to rhombic-ovate or elliptic, medium or large, (4-)10-20(-26) by $(2.5-) 7-16(-24) \mathrm{cm}$, usually relatively broad, length $1.5-2$ $(-2.25) \times$ width; marginal teeth (22-)25-50(-60) either side, slightly or distinctly up-curved (especially towards apex or in larger leaves), fairly short and wide, $1.5-2$ by (2-) $4-7 \mathrm{~mm}$, width (1.3-)2.5-3.5x length, on individual specimens usually greater in width rather than in number on larger leaves; leaf apex with acumen either short and broad with many-toothed margin or made up mainly of a single long terminal tooth to $0.7 \times$ total acumen length; base only slightly asymmetrical, narrowly or broadly cuneate or rounded; texture relatively thin-chartaceous, but leaves often slightly bullate; hairs on adaxial surface like those on the stem, sparse or abundant soft (rarely stiff) often rather inconspicuous, on abaxial surface either similar or \pm spreading usually restricted to veins; petiole widely varying relative to lamina, $0.25-0.5(-0.7) \times$ lamina length. Inflorescencebearing axes (5-)10-50 cm long, pendulous, unbranched or with a few long branches close to base or sometimes male with lateral branches throughout length and \pm erect with pendent apex; axes unisexual or sometimes mostly female with a few short lateral male branches near base, clusters usually relatively well-spaced, 2-5 $\mathrm{mm}$ apart, sometimes almost contiguous along parts of axis; female clusters $2-5 \mathrm{~mm}$ diam, with c. 20more than 50 often densely crowded flowers. Fruiting perianth $0.7-1(-1.5)$ by $0.3-0.5(-1) \mathrm{mm}$, widely varying in shape but mostly markedly laterally flattened with distinct marginal rim or wing, broadly or narrowly ovoid or obovoid sometimes with an indistinct beak (in Indian subcontinent sometimes \pm spindleshaped, \pm pedicellate), length $1.5-3 \times$ width, less often broadly obovoid, with width equalling length and slightly inflated at apex, moderately laterally flattened but without distinct marginal rim 


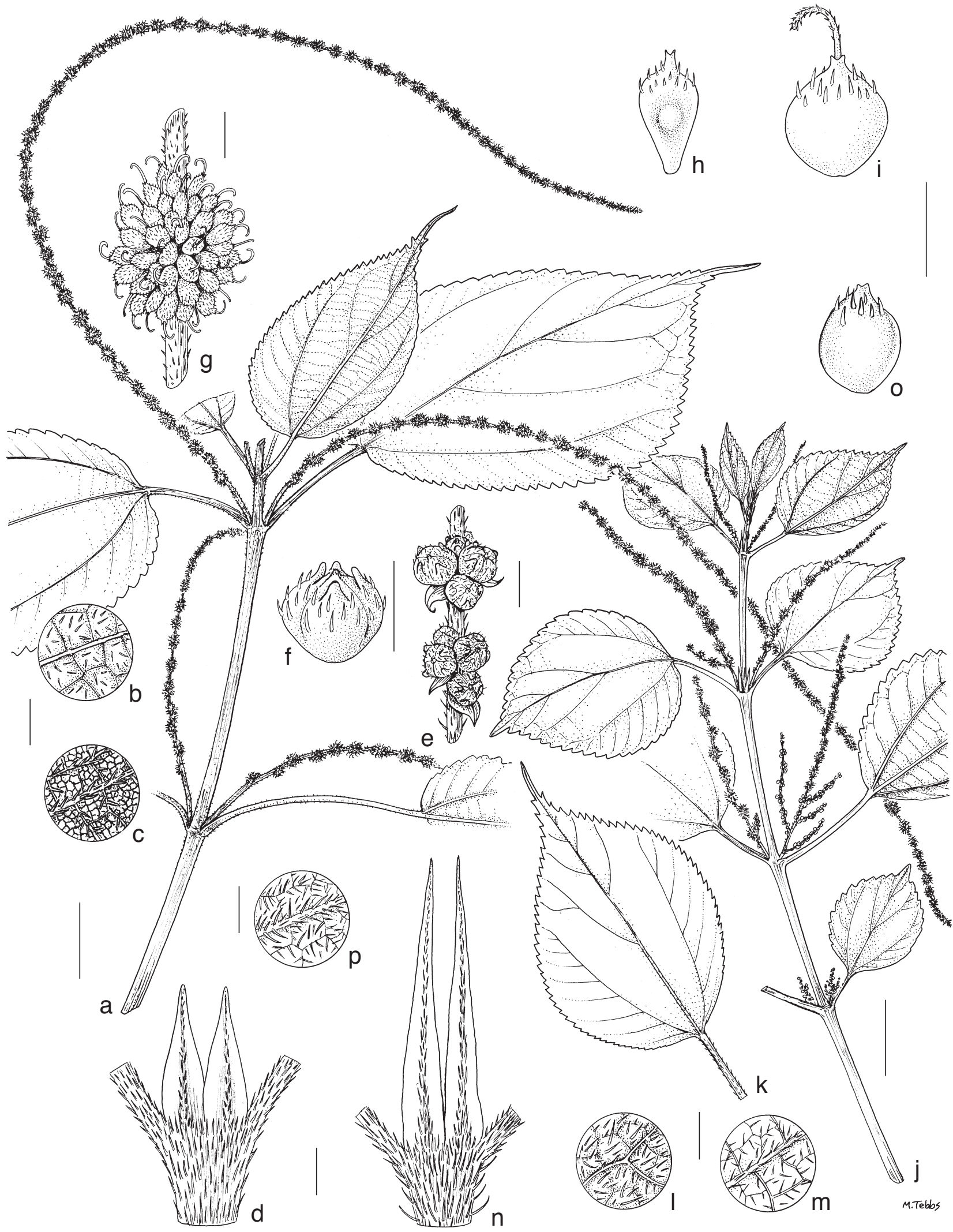

Fig. 24 a-i: Boehmeria virgata subsp. macrophylla var. macrostachya (Wight) Friis \& Wilmot-Dear. a. Habit of stem with inflorescence-bearing axes; b. leaf, detail of adaxial surface; c. leaf, detail of abaxial surface; $d$. detail of stem and stipules; e. detail of male inflorescence-bearing axis and flower-clusters (inflorescences); f. male bud; g. detail of female inflorescence-bearing axis and flower-cluster (inflorescence); $h$, i. fruiting perianths of different form (from different plants). - j-o: Boehmeria virgata subsp. macrophylla var. scabrella (Roxb.) Friis \& Wilmot-Dear. j. Habit of stem with branched inflorescence-bearing axes; k. leaf; I. leaf, detail of adaxial surface; $m$. leaf, detail of abaxial surface; $n$. detail of stem and stipules; o. fruiting perianth. - p: Boehmeria virgata subsp. macrophylla var. canescens (Wedd.) Friis \& Wilmot-Dear. Leaf, detail of adaxial surface (a-c, h: Gamble 9034; d, i: Haines 5068; e, f: Haines 2309; g: Clarke 34129; j: Schiffner 1900; k, n: Hooker \& Thompson s.n.; I, m, o: Ford 173; p: Wallich 4582; all K). - Scale bars: $a, j, k=2$ cm; b-d, l-n = 2 mm; e-h, i, o = 1 mm. 
or wing and with relatively large achene; indumentum widely varying from sparse long conspicuous white hairs throughout or restricted to apex, or hairs shorter and more inconspicuous or fruiting perianth glabrescent.

Distribution — India, Nepal, Bhutan, Sri Lanka.

Habitat \& Ecology - Very varied: forests and forest margins, streams, scrub, roadsides and open stony areas; 100-2600 m altitude.

Conservation status - Least Concern (LC). Over a hundred collections have been seen clearly referable to this variety and it is widespread in a wide range of habitats.

Notes - 1. Wight (1843: 10) cites the localities "Coimbatore, Nilgiris, Courtallum, etc" for his species Splitgerbera macrostachya. The taxonomical identity of the name can be established with certainty from the plate in the Icones (Wight 1843: pl. 1977). We do not propose a formal lectotypification, in case an original specimen is later found. Wight does not mention the manuscript name $U$. macrostachya Wall. for this taxon, but he states that his species belongs to the same genus as $U$. scabrella Roxb. Weddell (1854: 199) cites B. macrostachya as a nomen nudum, referring to the specimen Wallich $4582 B$. The first to take up the combination $B$. macrostachya is therefore Bailey (1888: 55), and this combination is not illegitimate as was suggested by Chew (1989: 85).

2. This variety appears to be common in the northern part of the Indian subcontinent (many collections seen) but rare in peninsular India and Sri Lanka. It exhibits a wide range of partly geographically-correlated variations, intergrading in parts of its geographical range with other varieties (Map 29) and is frequently confused with other species. Its relationship to other varieties within the species is discussed above under the species as a whole (Notes 2, 3, 5), and its confusion with B. clidemioides, B. conica, B. holosericea, B. japonica, B. ternifolia and $B$. zollingeriana is discussed above under the subspecies (Notes 4-6, 9-11).

\section{h. var. Iongissima (Hook.f.) Friis \& Wilmot-Dear, comb. nov.} — Fig. 23m-o; Map 25

Basionym: Boehmeria platyphylla D.Don var. longissima Hook.f., Flora of British India, vol. 5, part 15 (1888) 574. - Boehmeria macrophylla Hornem. var. longissima (Hook.f.) V.S.Ramach. \& V.J.Nair (1988) 436. - Syntypes: Wight 2707 (K), southern India, Pulney Mts; Gardner s.n. (K), southern India, Nilgiris; Walker s.n. (K), Sri Lanka.

Shrub or subshrub, to $4 \mathrm{~m}$. Stems with hairs sparse to abundant, minute $(0.1-0.2(-0.3) \mathrm{mm}$ long $), \pm$ spreading, fine and soft but straight. Stipules $7-10 \mathrm{~mm}$ long. Leaves ovate to rhombicovate, medium-sized and relatively narrow, $9-20$ by $4.5-9$ $\mathrm{cm}$, length (1.5-)2-2.4x width, marginal teeth few, 25-30 either side, large, acute, only slightly up-curved, $2-4$ by $4-7$ $\mathrm{mm}$; leaf apex attenuate to indistinctly long-acuminate, often terminated by a single tooth up to $5 \mathrm{~mm}$ long or sometimes toothed almost to tip; base almost symmetrical, cuneate to narrowly rounded, sometimes subcordate; texture thin- (sometimes thick-)chartaceous, leaves usually smooth, both surfaces glabrescent or hairs very sparse, short, fine, adpressed both sides or spreading abaxially; petiole $0.25-0.5 \times$ lamina length. Inflorescence-bearing axes unisexual or sometimes bisexual, $15-40 \mathrm{~cm}$, pendulous, clusters spaced $2-10 \mathrm{~cm}$ apart; female clusters $2-3 \mathrm{~mm}$ diam, with c. $10-$ more than 30 flowers. Fruiting perianth $1.2-1.5$ by c. $0.7 \mathrm{~mm}$, broadly ovoid tapering gradually or abruptly into distinct beak up to $0.3 \times$ entire fruiting perianth length and scarcely laterally flattened but with a distinct marginal rim. Achene \pm filling fruiting perianth, indumentum abundant minute ( $<0.1 \mathrm{~mm}$ long) spreading red-brown.

Distribution — Southern India (Kerala, Tamil Nadu), Sri Lanka.

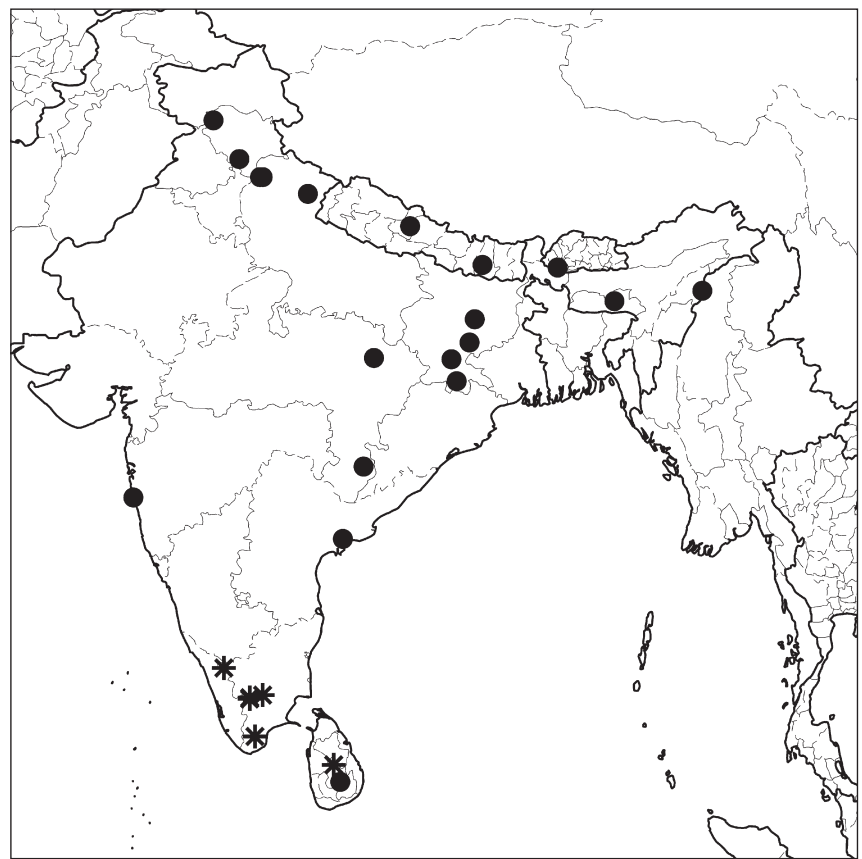

Map 25 Distribution of Boehmeria virgata (G.Forst.) Guillem. subsp. macrophylla (Hornem.) Friis \& Wilmot-Dear var. macrostachya (Wight) Friis \& Wilmot-Dear (๑) and B. virgata (G.Forst.) Guillem. subsp. macrophylla (Hornem.) Friis \& Wilmot-Dear var. longissima (Hook.f.) Friis \& Wilmot-Dear (*).

Habitat \& Ecology — In and along edges of high altitude evergreen forest (in southern India called Shola forest) characteristic of Western Ghats (Karnataka, Kerala, Tamil Nadu); 2000-2300 m altitude.

Conservation status - Vulnerable (VU). This well-circumscribed variety is known from c. 15 collections in six localities in Tamil Nadu and Sri Lanka. The EOO of $48346 \mathrm{~km}^{2}$ suggests a status of Near Threatened, but its narrow distribution with an $\mathrm{AOO}$ of under $500 \mathrm{~km}^{2}$ and the increasing pressure on and fragmentation of its Shola forest habitat suggests that it is Vulnerable (VU) with the criteria of VU 2Bab(iii).

Note - As discussed in detail under the species as a whole (Note 5-vi), this variety is more similar to var. molliuscula (also restricted to moist forest) than to var. macrostachya. It is distinctive in its fruiting perianth morphology, minute indumentum and often rhombic-ovate leaves. No collections intermediate with other varieties have been seen.

i. var. canescens (Wedd.) Friis \& Wilmot-Dear, comb. nov. Fig. 24p, 25; Map 26

Basionym: Boehmeria platyphylla D.Don var. cuspidata Wedd. subvar. canescens Wedd., Archiv. Mus. Hist. Nat. Paris 9 (1856) 365. - Boehmeria canescens Wedd. (1854) 200, nom nud. - Boehmeria canescens (Wedd.) Blume (1857) 224. - Boehmeria platyphylla D.Don var. canescens (Wedd.) Wedd. (1869) 213. - Boehmeria macrophylla Hornem. var. canescens (Wedd.) D.G.Long (1982) 129. - Boehmeria macrophylla Hornem. subsp. canescens (Wedd.) Panigrahi \& Murti (1999) 558. - Type: Wallich 4582D (lecto K; isolecto BM, G, K [non K-WALL]; lectotype selected here), Nepal. - See Note 3.

Subshrub, to $2 \mathrm{~m}$. Stems with two kinds of indumentum, abundant fine hairs $0.2-0.4 \mathrm{~mm}$ long, close-adpressed, inconspicuous, and coarser longer (c. $1 \mathrm{~mm}$ ) hairs spreading, curved hairs, the latter sparse or absent in lower part of stem but dense at upper nodes and stem apex and concealing the adpressed hairs. Stipules 6-9 mm long, with adpressed hairs on abaxial surface and long hairs only on midrib. Leaves ovate-elliptic, with a wide size range $4.5-16$ by $3-12 \mathrm{~cm}$, length $1.3-1.8 \times$ width, rather variable in proportions and in number of marginal teeth, marginal teeth (22-)25-45(-50) either side, small 


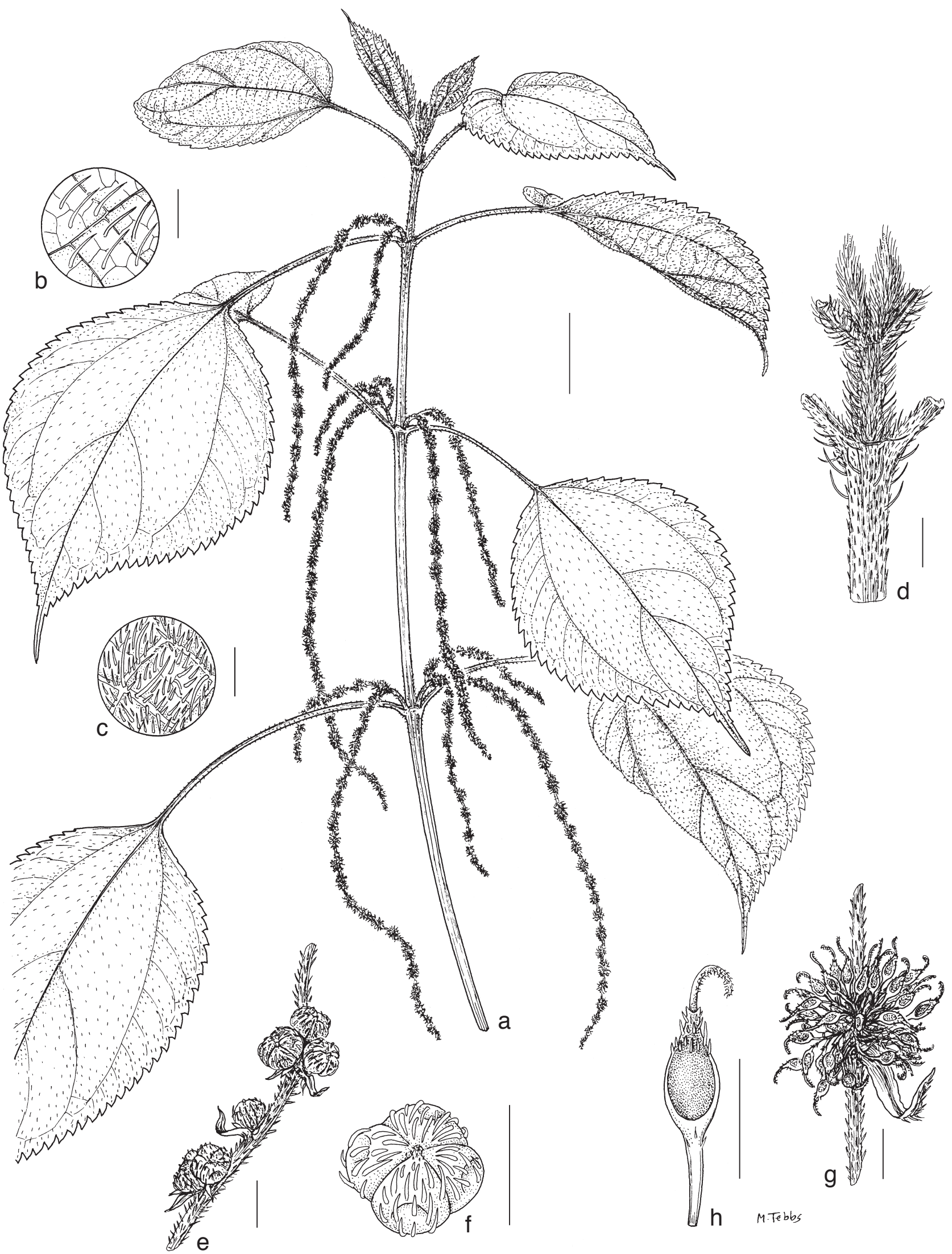

Fig. 25 Boehmeria virgata subsp. macrophylla var. canescens (Wedd.) Friis \& Wilmot-Dear. a. Habit of stem with inflorescence-bearing axes; b. leaf, detail of adaxial surface; $c$. leaf, detail of abaxial surface; d. detail of stem and stipules; e. detail of male inflorescence-bearing axis with flower-clusters (inflorescences) and bracts; $f$. male bud; g. detail of female inflorescence-bearing axis with flower-cluster and bract; h. pedicellate fruiting perianth (a, d, g, h: Kanai 6307148 , BM; b, c: Wallich 4582, K; e, f: Wallich 4582D, K). - Scale bars: $a=2 \mathrm{~cm} ; \mathrm{b}-\mathrm{d}=2 \mathrm{~mm}$; $\mathrm{e}-\mathrm{h}=1 \mathrm{~mm}$. 


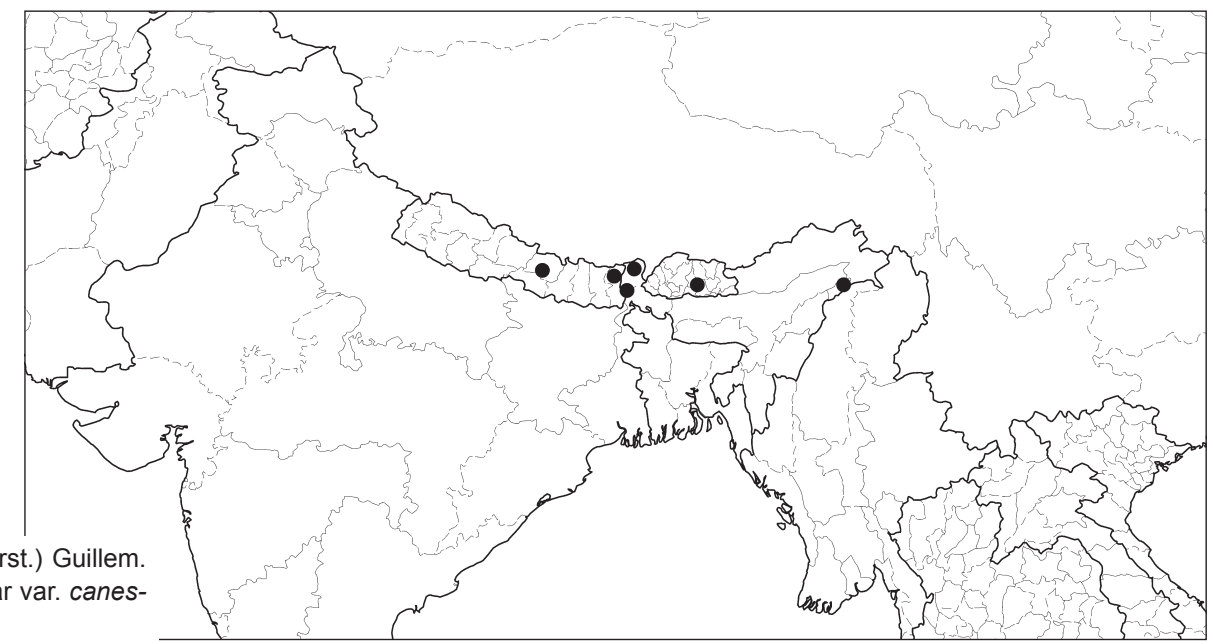

subsp. macrophylla (Hornem.) Friis \& Wilmot-Dear var. canescens (Wedd.) Friis \& Wilmot-Dear.

narrow-acute up-curved, $2-3$ by $2-3.5(-5.5) \mathrm{mm}$, with width $1-1.25(-1.75) \times$ length; leaf apex short-attenuate or with indistinct short acumen 2-5 mm long, toothed nearly to tip; base slightly asymmetrical, cuneate or narrowly(-broadly) rounded; texture thin-chartaceous, adaxial surface with long curved hairs like those on the stem, sparse or abundant, abaxial surface with spreading hairs of varying lengths, these usually abundant giving whitish cast to leaf; petiole rather variable (0.25-)0.3$0.6 \times$ lamina length, hairy like the stem. Inflorescence-bearing axes $10-20 \mathrm{~cm}$, pendulous with a few long branches near base, or sometimes male ones $\leq 5 \mathrm{~cm}$ and \pm erect with drooping branches, always very slender, only $0.2-0.4 \mathrm{~mm}$ diam (in dry state); both sexes on same plant, male in lower axils; flowerclusters rarely \pm contiguous, mostly spaced $0.5-1(-2) \mathrm{mm}$ apart, c. $1.5-1.75 \mathrm{~mm}$ diam, male clusters with few \pm sessile flowers, female clusters with less than 30 flowers often with pedicel to c. $0.5 \mathrm{~mm}$ long and flowers often borne a few together on minute peduncles (up to c. $1 \mathrm{~mm}$ long) which are flattened, strap-shaped; clusters rather elongate (due to the region of insertion of the peduncles onto the stem being unusually long and narrow). Fruiting perianth small c. 0.5 by $0.25-0.3 \mathrm{~mm}$, narrowly ellipsoid with base rounded or tapering and running into pedicel, with fine hairs near apex or throughout. Achene almost filling fruiting perianth.

Distribution - Eastern Himalayas: India (Sikkim, Arunachal Pradesh), Nepal, Bhutan.

Habitat \& Ecology - Mixed forest, 1800 m altitude.

Notes - 1. As discussed in detail under the species as a whole (Note 5-vii), it is distinctive in its extremely slender inflorescence-bearing axes, its minute female perianth, two kinds of indumentum abundant on the stem and the white cast to the abaxial leaf surface (where present). Pedicellate and pedunculate female flowers are otherwise seen only in var. minuticymosa.

2. Even the few collections seen (only 11 clearly referable to var. canescens) are rather variable and probably do not represent its full range of variation. A few collections have been seen intermediate with var. rotundifolia and var. minuticymosa, and formal conservation status assessment is not meaningful. The variety is thought to be rare as it is so far only known from a few locations along the Himalayas, and in fairly restricted forest habitat, but is probably not currently at risk since these localities in the Himalayas are not currently threatened by serious habitat degradation.

3. The specimens at $\mathrm{K}$ and K-WALL labelled Wallich 4582D both have inflorescence-bearing axes slender, pendulous and marginal teeth many, rather narrow, but appear to represent different collections since they differ markedly in stem indumen- tum. The indumentum on the $\mathrm{K}$ specimen is of two kinds, long spreading hairs sufficiently dense in the upper part of stem as to conceal an under-layer of also dense but much shorter and finer adpressed hairs, while that of K-WALL lacks the spreading indumentum. Only the $\mathrm{K}$ specimen has leaves with sufficiently dense indumentum to conform well to Weddell's description "leaves ... canescent" and it is therefore here selected as the lectotype. (By contrast, another specimen, Nepal, 1831, Wallich $4582(\mathrm{~K})$, without the letter ' $\mathrm{D}$ ' as suffix to the number, very closely resembles the lectotype and may be an isolectotype). The numbering of the K-WALL specimen is somewhat doubtful since it is annotated by C.B. Clarke merely "Napalia, 4582"; the ' $D$ ' and the epithet canescens were inserted by Hooker who also states there and in Hooker (1888) 579, that "Herb Madras" in Herb. Wallich is probably an error. This specimen and a possible duplicate of it at E also labelled Wallich 4582D with a few spreading hairs at stem apex, are best considered as somewhat intermediate, possibly with var. minuticymosa. (A further specimen in K-WALL, "4582?D" is a mixture of leaves and inflorescence from different taxa, one leaf probably of $B$. nivea; none of its material conforms to the $\mathrm{K}$ specimen.)

\section{j. var. rotundifolia (D.Don) Friis \& Wilmot-Dear, comb. nov. -} Fig. 26; Map 27

Basionym: Boehmeria rotundifolia D.Don, Prodromus Florae Nepalensis (1825) 60. - Boehmeria macrophylla Hornem. var. rotundifolia (D.Don) W.T.Wang in Wang \& Chen (1995) 337. - Type: Hamilton s.n. (lecto BM; left-hand specimen only, lectotype selected here), Nepal, Upper Nepal, Suembu. - See Note 2.

Woody-based herb, 1-2 $\mathrm{m}$ tall. Stems with abundant fine hairs 0.2-0.4 mm long, close-adpressed, inconspicuous, and sometimes also sparse longer (c. $1 \mathrm{~mm}$ long) hairs, spreading, curved, coarser. Stipules $7-10 \mathrm{~mm}$, with long hairs on midrib and short adpressed hairs elsewhere like those on the stem. Leaves broadly elliptic to almost orbicular, small or fairly large, $5-20$ by $3.5-16 \mathrm{~cm}$, length $1-1.25(-1.4) \times$ width; marginal teeth (20-)25-30 either side, (2-)2.5-5 by $2.5-7 \mathrm{~mm}$, longer and relatively broader on larger leaves and with width $1-1.25(-2) \times$ length, markedly up-curved and usually increasingly so towards leaf apex; leaf apex with abrupt distinct narrow acumen (5-)15-20 mm long, mostly only c. $2 \mathrm{~mm}$ wide but sometimes widening to $3-5 \mathrm{~mm}$ close to its base, consisting mostly of a single long tooth but with $1(-2)$ pairs of teeth close to base; base broadly cuneate to broadly rounded (rarely \pm truncate); texture thin-chartaceous, adaxial surface with sparse adpressed (rarely curved) hairs like those on the stem, abaxial surface with sparse fine hairs mostly restricted to veins, these half-adpressed, straight, those on main veins the longest, 


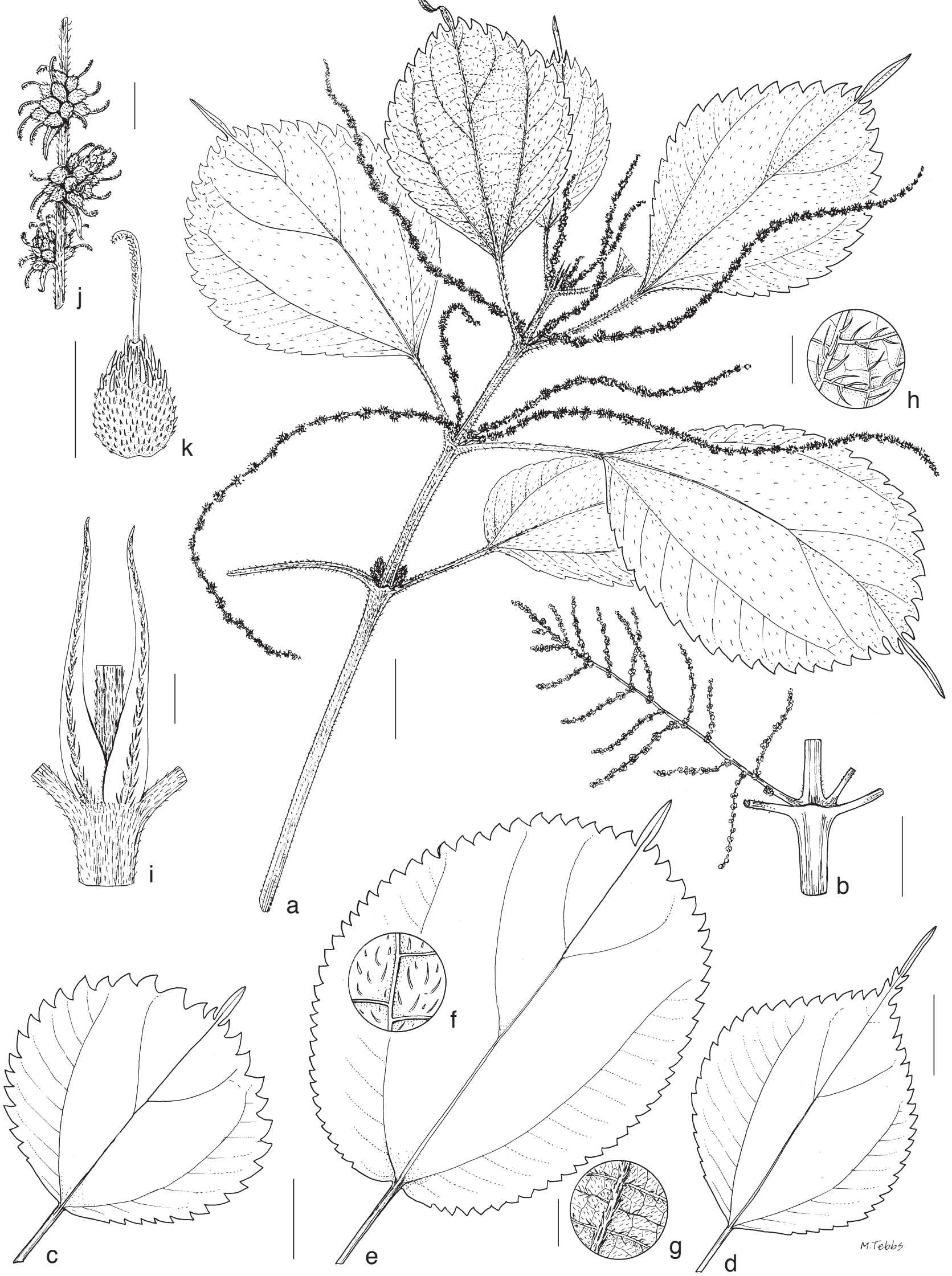

Fig. 26 Boehmeria virgata subsp. macrophylla var. rotundifolia (D.Don) Friis \& Wilmot-Dear. a. Habit of stem with inflorescence-bearing axes; b. detail of stem with branched male inflorescence-bearing axes; c-e. leaves from different plants; f. leaf, detail of adaxial surface; g, h. leaf, detail of abaxial surface; i. detail of stem and stipules; j. detail of female inflorescence-bearing axis with flower-clusters (inflorescences) and bracts; k. fruiting perianth (a, h: Hooker s.n., K; b, e-g, i: Stainton 1622, BM; c, j, k: Kanai 6307118, BM; d: Nicholson 2359, BM). - Scale bars: a-e = $2 \mathrm{~cm} ; \mathrm{f}-\mathrm{j}=2 \mathrm{~mm} ; \mathrm{k}=1 \mathrm{~mm}$. 


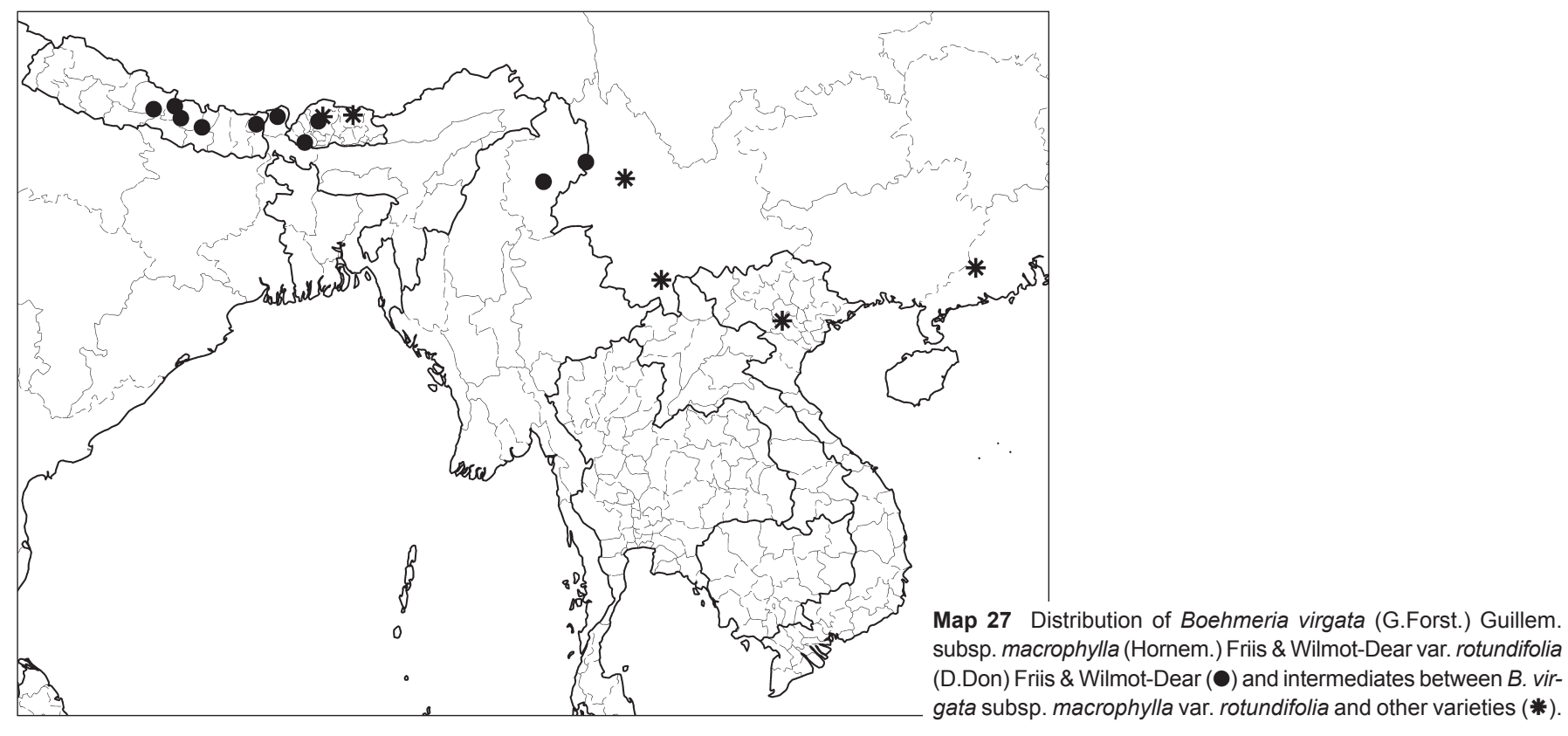

rarely with shorter finer less sparse hairs on whole surface; petiole variable but often relatively long $0.4-0.8(-1) \times$ lamina length, hairy like the stem. Inflorescence-bearing axes \pm erect or drooping, male axes $5-13 \mathrm{~cm}$ long, female ones $8-14 \mathrm{~cm}$ long, sometimes unbranched or with a few long branches near base or male ones mostly (female rarely) with short $(2-3 \mathrm{~cm})$ branches throughout most of length, sexes sometimes on same axes with male clusters on lateral branches; clusters spaced (2-)3-5 mm apart or sometimes, especially female clusters, \pm contiguous in parts of the axis, male clusters with up to c. 10 flowers, female with usually 30-40 flowers. Fruiting perianth rather small $\leq 0.8$ by $0.4-0.5 \mathrm{~mm}$, broadly ellipsoid with rounded base and without distinct beak, with abundant fine spreading hairs throughout. Achene \pm filling fruiting perianth.

Distribution - Eastern Himalayas: India (Sikkim), Nepal, Bhutan, Burma; south-western China.

Habitat \& Ecology — Open grassy areas and secondary vegetation around field-edges or amongst dense herbaceous vegetation, usually in moist places, rarely as successional regrowth in fire-damaged evergreen broad-leaved forest; (1600-)2000$3000 \mathrm{~m}$ altitude.

Notes - 1. As discussed in detail under the species as a whole (see Note 5-viii), var. rotundifolia is distinctive in its leaves with terminal tooth long and tail-like and distal marginal teeth markedly in-curved; it is often rather similar to var. scabrella which has a slightly lower altitudinal range and occurs in forest and thickets. Only ten collections clearly referable to this variety have been seen, together with other material intermediate with var. macrostachya or var. scabrella; therefore formal conservation status assessment is not meaningful. It occurs in locations along the Himalayas and the extension of this mountain range into southern China. It is not clear whether the open and often somewhat disturbed habitats in which it is often found are currently threatened by serious degradation.

2. As discussed under the species, most material of var. rotundifolia has only adpressed hairs on the stem; only the type from Nepal and the single collection seen from Bhutan have both kinds of stem-hairs like those found in var. canescens (but much sparser). The type specimen is 'atypical' in various characters, appearing to represent one extreme of the range of variation, with both kinds of hairs on the stem and is also the only material seen with rather slender inflorescence-bearing axes approaching those of var. canescens. This material consists of two detached stems, the left-hand one with the distinctive long terminal tooth $(15 \mathrm{~mm})$ but the right hand one less distinctive, with an acumen only c. $5 \mathrm{~mm}$ long; these are sufficiently dissimilar that they may have come from separate plants and we therefore select the left-hand specimen as lectotype.

3. As discussed under the subspecies as a whole (Notes 4, $6,7)$, var. rotundifolia can be confused with $B$. ternifolia and narrow-leaved forms also with the sympatric but more widespread $B$. clidemioides and $B$. polystachya.

k. var. minuticymosa Acharya, Friis \& Wilmot-Dear, var. nov. — Fig. 27; Map 28

$\mathrm{Ab}$ omnibus ceteris varietatibus var. canescenti excepta glomerulis secus axem aliquantum elongatis (nec globosis) flores pedicellatos atque saepe in cymis minutis bracteolatis dispositos ferentibus differt; a var. canescenti axe florifero robusto $0.4-1 \mathrm{~mm}$ diametro (nec gracillimo usque $0.2 \mathrm{~mm}$ tantum diametro), perianthio fructifero longiore atque multo latiore $0.7-1.2$ $\times 0.5-0.8 \mathrm{~mm}$ (nec usque $0.5 \times 0.3 \mathrm{~mm}$ tantum) subglabro luteo-brunneo (nec badio-brunneo) et caule ad apicem adpresse piloso vel sparsissime (nec densissime) patente piloso differt. - Typus: J.F. Maxwell 89-1370 (holo E; iso L), northern Thailand, Chiang Mai, Chiang Dao, Doi Chiang Dao, north-eastern side of Sop Huay Pa Dang Huay Na Lao Forest Station, alt. 550 m, 5 Nov. 1989.

Herb or subshrub, 0.5-1.5 m tall, branched (from horizontal stems rooting at the nodes) or unbranched. Stems with hairs short, closely-adpressed, rarely also (eastern Himalayas) with sparse spreading hairs near apex. Stipules $0.5-1.2 \mathrm{~cm}$ long, hairy abaxially. Leaves slightly or moderately dimorphic in size and shape, length of 'larger' leaves 1.1-1.5x that of 'smaller' ones; 'larger' leaves fairly narrowly ovate or elliptic-ovate, 5-20 by $3-10 \mathrm{~cm}$, length $1.7-2.3 \times$ width, marginal teeth $40-45$ either side, acute fairly narrow up-curved, $1.25-3$ by $2-5 \mathrm{~mm}$, with width 1.5-1.7× length; leaf apex with long or short acumen, up to $1.7 \mathrm{~cm}$ long; base not or slightly (rarely markedly) asymmetrical, short-cuneate or sometimes rounded; texture thin-chartaceous, but leaves often slightly bullate; adaxial surface with abundant \pm spreading coarse stiff hairs; abaxial surface with hairs denser and finer; petioles (0.2-) $0.25-0.5 x$ lamina length, hairy like the stem; 'smaller' leaves relatively broader with petiole shorter relative to lamina. Inflorescencebearing axes with both sexes usually on same plant; male axes in lower axils, erect, often branched at base, 5-7 cm long, clusters well-spaced with few flowers; female axes in upper axils, \pm erect but often pendent at apex, 5-20 cm long, unbranched or with short (up to $1 \mathrm{~cm}$ ) lateral sometimes male branches near base, clusters usually densely congested along 


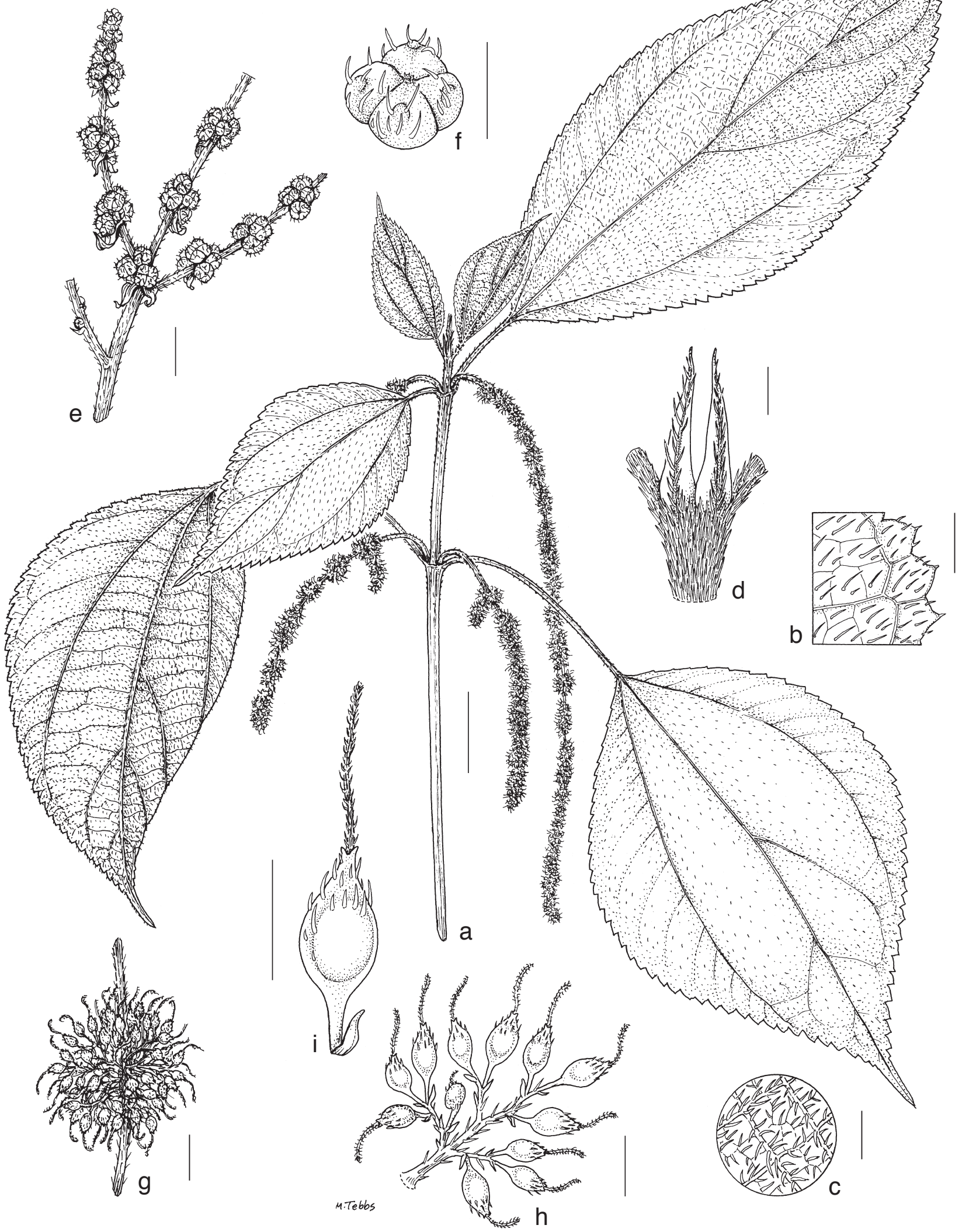

Fig. 27 Boehmeria virgata subsp. macrophylla var. minuticymosa (Acharya \& Yonek.) Friis \& Wilmot-Dear. a. Habit of stem with female inflorescence-bearing axes; b. leaf, detail of adaxial surface; c. leaf, detail of abaxial surface; d. detail of stem and stipules; e. detail of branched male inflorescence-bearing axes with flower-clusters (inflorescences); f. male bud; g. detail of female inflorescence-bearing axis with one flower-cluster (inflorescence), flowers pedicellate; h. detail of part of fruiting cluster, showing fruiting perianths arising from common peduncle; i. fruiting perianth (a-d, g-i: Chantaranothai et al. 90/452; e, f: Chantaranothai et al. 90/68; all K). - Scale bars: $a=2 \mathrm{~cm} ; \mathrm{b}=5 \mathrm{~mm} ; \mathrm{c}-\mathrm{e}, \mathrm{g}=2 \mathrm{~mm} ; \mathrm{f}, \mathrm{h}, \mathrm{i}=1 \mathrm{~mm}$. 


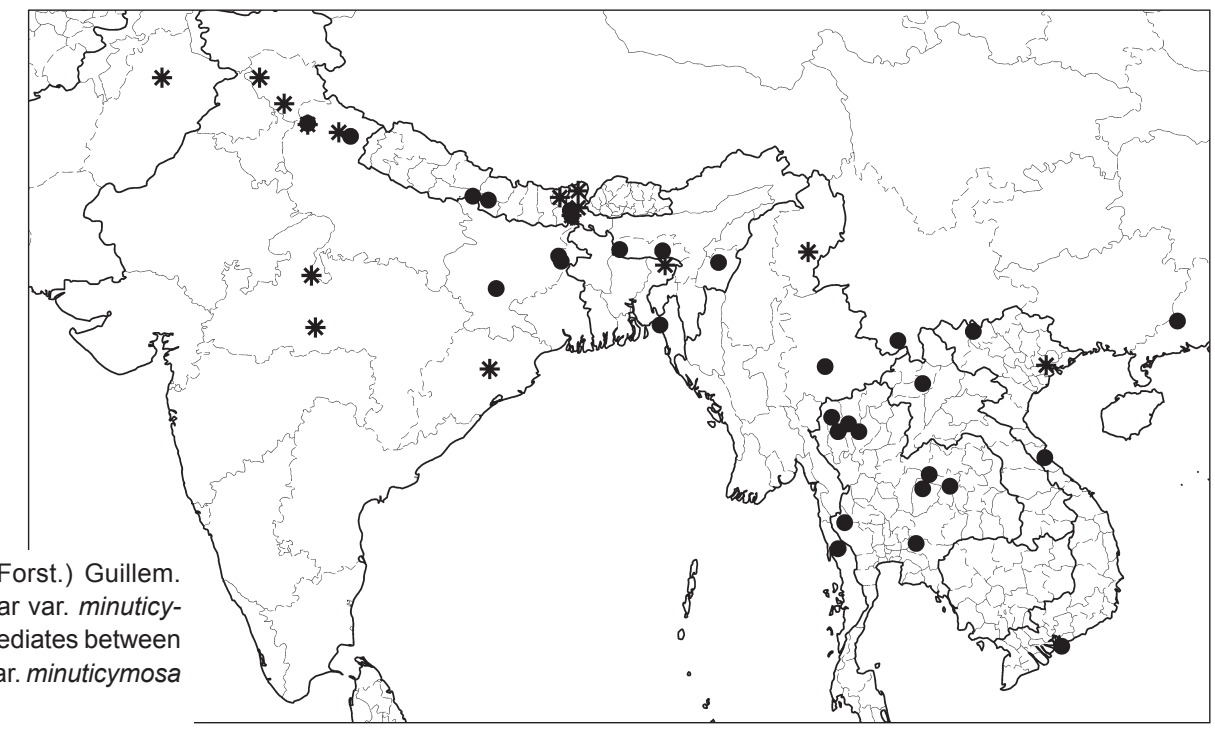

Map 28 Distribution of Boehmeria virgata (G.Forst.) Guillem subsp. macrophylla (Hornem.) Friis \& Wilmot-Dear var. minuticymosa Acharya, Friis \& Wilmot-Dear $(\bullet)$ and intermediates between $B$. virgata (G.Forst.) Guillem. subsp. macrophylla var. minuticymosa and other varieties (*).

axis, sometimes spaced 1-2(-3) $\mathrm{mm}$ apart; bracts $5-6 \mathrm{~mm}$ long; female clusters $2-4 \mathrm{~mm}$ diam in flower $(4-6 \mathrm{~mm}$ in fruit) but mostly somewhat elongate, with many peduncles up to $1.5 \mathrm{~mm}$ long, these flattened, strap-shaped, often once or twice branched, each with conspicuous scattered straight hairs and bearing several flattened-pedicellate flowers; bracteoles subtending peduncles reddish, narrowly ovate or obovate up to c. $0.4 \mathrm{~mm}$ long, smaller bracteoles often also present along peduncles. Male flowers spreading-hairy. Female flowers up to c. $1 \mathrm{~mm}$ long excluding pedicel; stigma $0.5-1 \mathrm{~mm}$ long. Fruiting perianth broadly ovoid or subspherical $0.7-1.2$ by $0.5-0.8 \mathrm{~mm}$, moderately laterally flattened with indistinct or distinct marginal rim, without apical beak, rounded or slightly tapering at base, light yellowish brown (in dry state) and glabrous except for a few conspicuous hairs, like those on the pedicels, near apex. Achene filling fruiting perianth.

Distribution - Northern India, Nepal, Burma, Thailand, Laos, Vietnam, South China.

Habitat \& Ecology — Primary or secondary evergreen or mixed seasonal forest or forest margins, often along tracks or in disturbed areas; dry or wet places and beside streams; 160-1300 m altitude.

Conservation status - Least Concern (LC). Nearly 200 collections, many recent, clearly referable to this variety have been seen. It occurs in a wide range of habitat and does not appear to be currently at risk, but in future may become so with increasing pressure on habitats in Indochina.

Notes -1 . Var. minuticymosa is the only variety known from Thailand. It is distinctive in its female flowers pedunculate, its short \pm erect congested female axes and its yellowish almost glabrous broad round-based fruiting perianths and relatively narrow, thin-textured, leaves, short-cuneate with many teeth. Forms intermediate with var. macrostachya and var. canescens exist (see detailed discussion Note 5-ix under the species as a whole).

2. Although pedicellate female flowers on minute flattened peduncles are unusual, certain other species exhibit these sporadically (for example B. heterophylla and B. clidemioides, where they are not correlated with geographical distribution and are seen on material otherwise indistinguishable from that with sessile flowers); this character is therefore here considered to be of taxonomic significance only when correlated with other morphological characters and/or distribution.

3. As discussed under the subspecies (Note 8), this variety has sometimes been mistaken for $B$. ourantha.

4. The joint publication of this new taxon was accepted by $\mathrm{N}$. Acharya and is partly based on his earlier unpublished findings.
I. var. scabrella (Roxb.) Friis \& Wilmot-Dear, comb. nov. Fig. 24j-0; Map 29

Basionym: Urtica scabrella Roxb., Flora Indica, vol. 3 (1832) 581. - Boehmeria macrophylla Hornem. var. scabrella (Roxb.) D.G.Long (1982) 129. Boehmeria platyphylla D.Don var. scabrella (Roxb.) Wedd. (1856) 365. Syntypes: Wallich 4581A (K-WALL), India, Assam, Goalpara; Wallich 4581B (K-WALL; isosyn G, M), Bangladesh, Silhet; Wallich 4581C (K-WALL), Nepal; Wallich 4581D (K-WALL), cultivated in Hort. Bot. Calcutta. - See Note 1. Urtica caudata Burm.f. (1768) 197, non Poir. (1798) 640, nec Blume (1825) 492. - Boehmeria caudata (Burm.f.) J.J.Sm. (1910) 706, nom. illeg., non Sw. (1788) 34. - Type: Unknown collector (not traced), Indonesia, Jawa [Java]. - See Note 2.

Urtica caudata Blume (1825) 492, nom. illeg., non Burm.f. (1768) 197, nec Poir. (1798) 640. - Type: Unknown collector (not traced), Indonesia, Jawa [Java], Tjanjor. - See Note 2.

Woody-based herb, to $1 \mathrm{~m}$ tall. Stem with very sparse to dense hairs only $0.3-0.4 \mathrm{~mm}$ long, these fine or coarse, \pm uniform, usually stiff and straight, closely-adpressed or half-adpressed, sometimes (only where long and dense) slightly curved. Stipules often conspicuous, up to $11 \mathrm{~mm}$ long. Leaves ovate and often markedly asymmetrical with outline of two sides and length of basal veins dissimilar; usually small or medium, $5-10(-13)$ by $3-7(-10) \mathrm{cm}$, relatively broad, length $1.2-1.5(-1.8) \times$ width; acumen short and broad consisting mainly of a single tooth (with 1-2 teeth in its lower third or half); base broad-cuneate, broadly rounded, to markedly obliquely truncate or subcordate; marginal teeth numerous, (30-)35-45 either side, small close-spaced distinctly up-curved, $1.5-2$ by $2(-3) \mathrm{mm}$, relatively narrow with width 1-1.3(-1.5) × length; texture (thin-) or thick-chartaceous, leaves often rugose, adaxial surface with adpressed or halfadpressed hairs like those on stem (but usually longer, up to $0.7 \mathrm{~mm}$ ), stiff giving rough texture; abaxial surface with hairs stiff but shorter \pm spreading; petiole usually relatively short relative to lamina, $0.25-0.4(-0.7) \times$ length. Inflorescence-bearing axes short only $2-8(-12) \mathrm{cm}$ long, \pm erect (female sometimes pendent at tip), male axes with lateral branches throughout length which are shorter than or equalling its main axis, female axes unbranched or with short side branches 1-3 cm long near base bearing male clusters, also very occasionally its main axis with a tuft of leaves at tip; female clusters crowded sometimes \pm contiguous along parts of axis, especially on shorter axes. Fruiting perianth not widely varying, mostly ovoid to ellipsoid with minute abrupt beak, moderately laterally flattened with or without distinct marginal rim.

Distribution - Eastern and western Himalaya: northern India, Nepal; southern China, Indonesia (west of Wallace's line: Jawa, Bali, Borneo). 
Map 29 Distribution of Boehmeria virgata (G.Forst.) Guillem. subsp. macrophylla (Hornem.) Friis \& Wilmot-Dear var. scaberrima (Roxb.) Friis \& WilmotDear (@), B. virgata (G.Forst.) Guillem. subsp. macrophylla (Hornem.) Friis \& Wilmot-Dear var. sumatrana (Miq.) Friis \& Wilmot-Dear $(\boldsymbol{A})$ and intermediates . between $B$. virgata subsp. macrophylla var. scaberrima and $B$. virgata subsp. macrophylla var. macrostachya (*).

Habitat \& Ecology - Shaded places in forest, scrub and disturbed old cultivations; 200-2400 m altitude.

Conservation status - Least Concern (LC). Approximately 100 collections clearly referable to this variety have been seen. Its locations in forest along the Himalayas and the extension of these mountains into southern China, are probably not currently at risk, although it is not clear whether the open and often somewhat disturbed habitats elsewhere in which it is also found are currently threatened.

Notes - 1. In 1832 Roxburgh refers to his Urtica scabrella as "native of Chittagong" [Bangladesh] without citing any collections; his Catalogue (1814: 67) lists living material from Chittagong (donated by a "Mr J. R.") and Wallich 4581D may represent this plant although it bears no further information and all four specimens under K-WALL 4581 bear Roxburgh's name. Weddell (who cites Wallich 4581 without qualification) does not mention Sylhet but only 'Assam and ?Nepal' so had perhaps not seen $4581 B$.

2. Var. scabrella is the only taxon within B. macrophylla Hornem. s.lat. known from Jawa. In spite of missing type material of Urtica caudata Burm.f. the taxon is placed here based on later material from Jawa, as was implied by Friis \& Marais (1982: 163). Urtica caudata Blume, nom. illeg., is also placed here on the authority of Weddell (1856: 365) who referred it to B. platyphylla D.Don var. scabrella (Roxb.) Wedd.

3. As discussed (see Note 5-x under the species as a whole), var. scabrella is distinctive its combination of short \pm erect inflorescence-bearing axes, the male ones much-branched, the female axes with congested clusters, and small or medium leaves, usually rough-hairy with numerous close- spaced teeth, often thick-textured and/or asymmetrical. It is partly sympatric to var. macrostachya (which occurs in much of the Indian subcontinent), and a range of material exists intermediate in leaf and/or inflorescence-morphology with either var. macrostachya or var. rotundifolia. In Jawa occur also forms with leaf shape (but not indumentum) approaching var. sumatrana.

4. Var. scabrella is one of only two varieties of subsp. macrophylla partly sympatric with subsp. virgata (var. virgata west of Wallace's line in Jawa and Bali) but, as discussed in detail under the species, the two entities are morphologically very distinct with no intermediate forms nor possibility of confusion.

5. Var. scabrella has been confused frequently with the sympatric but more widespread $B$. pilosiuscula and sometimes also with $B$. polystachya and $B$. clidemioides (see detailed discussed (Notes 3, 4, 7) under the subspecies). m. var. sumatrana (Miq.) Friis \& Wilmot-Dear, comb. nov. Fig. 28a-e; Map 29

Basionym: Boehmeria sumatrana Miq., Plantae Junghuhnianae, Pars 1 (1851) 32. - Boehmeria platyphylla D.Don var. virgata (G.Forst.) Wedd. subvar. sumatrana (Miq.) Wedd. (1856) 367. - Boehmeria platyphylla D.Don var. sumatrana (Miq.) Wedd. (1869) 211. - Type: Junghuhn s.n. (holo U; iso BO, L), Indonesia, Sumatera, Tapanuli, Sipirok plain, Warseh, Battarum Dist.

Subshrub or possibly shrub (height unknown). Stem with hairs 0.2-0.4 mm long, sparse to abundant, closely-adpressed, fine, straight. Stipules usually relatively long, 7-10 mm. Leaves broadly ovate (deltate-ovate), small or medium, $5.5-10$ by $4-8.5$ $\mathrm{cm}$, length only $1.1-1.3(-1.4) \times$ width; margin dentate, teeth only $13-17$, relatively short and broad, $2-3$ by $5-6 \mathrm{~mm}$, with width (1.5-)2-3x length, of \pm uniform size but proximal ones progressively less up-curved, those near apex with their upper margin distinctly concave, those near base often \pm rounded and outward-pointing (both margins convex); leaf apex with short abrupt acumen, (5-)10-15 mm long, consisting mostly of single tooth; base truncate or \pm cordate, rarely broadly rounded; texture very thin-chartaceous; both surfaces with rather sparse fine adpressed hairs like the stem; petiole variable but extremely long relative to lamina, $0.6-1.2 \times$ lamina length. Inflorescence-bearing axes \pm erect and mostly bisexual, sometimes unbranched and relatively long, $8-12 \mathrm{~cm}$, sometimes with lateral branches throughout lower half and then often shorter, 5-8 cm, distal clusters female, proximal ones and those on lateral branches often bisexual, some lower lateral branches and some axes in lower leaf axils entirely male; clusters contiguous (but distinguishable) or spaced up to 1(-2) $\mathrm{mm}$ apart, only 1-2 $\mathrm{mm}$ diam, with few-10(-20) flowers. Fruiting perianth ovoid to obovoid flattened or inflated in distal part but without distinct marginal rim, c. $0.8 \mathrm{~mm}$ long, almost without beak, hairy like stem.

Distribution - Indonesia (western Sumatera).

Habitat \& Ecology - No label data but the localities are within the ridge of mountains in western Sumatera, so it is assumed to inhabit forest at fairly high altitude.

Conservation status - Near Threatened (NT). The lack of habitat data for this well-circumscribed variety makes formal assessment tentative. It is known from only six collections from the early 1900s from three localities, with an EOO of only 2343 $\mathrm{km}^{2}$ and $\mathrm{AOO}$ of only $12 \mathrm{~km}^{2}$. Habitat in this region is apparently not currently seriously degraded and Kerinci [Kerinchi] has protected status but with so few collections it is probably at risk.

Notes -1 . This variety is apparently allopatric to the rest of the subspecies (and species). As discussed (Note 5-xi-xiii 


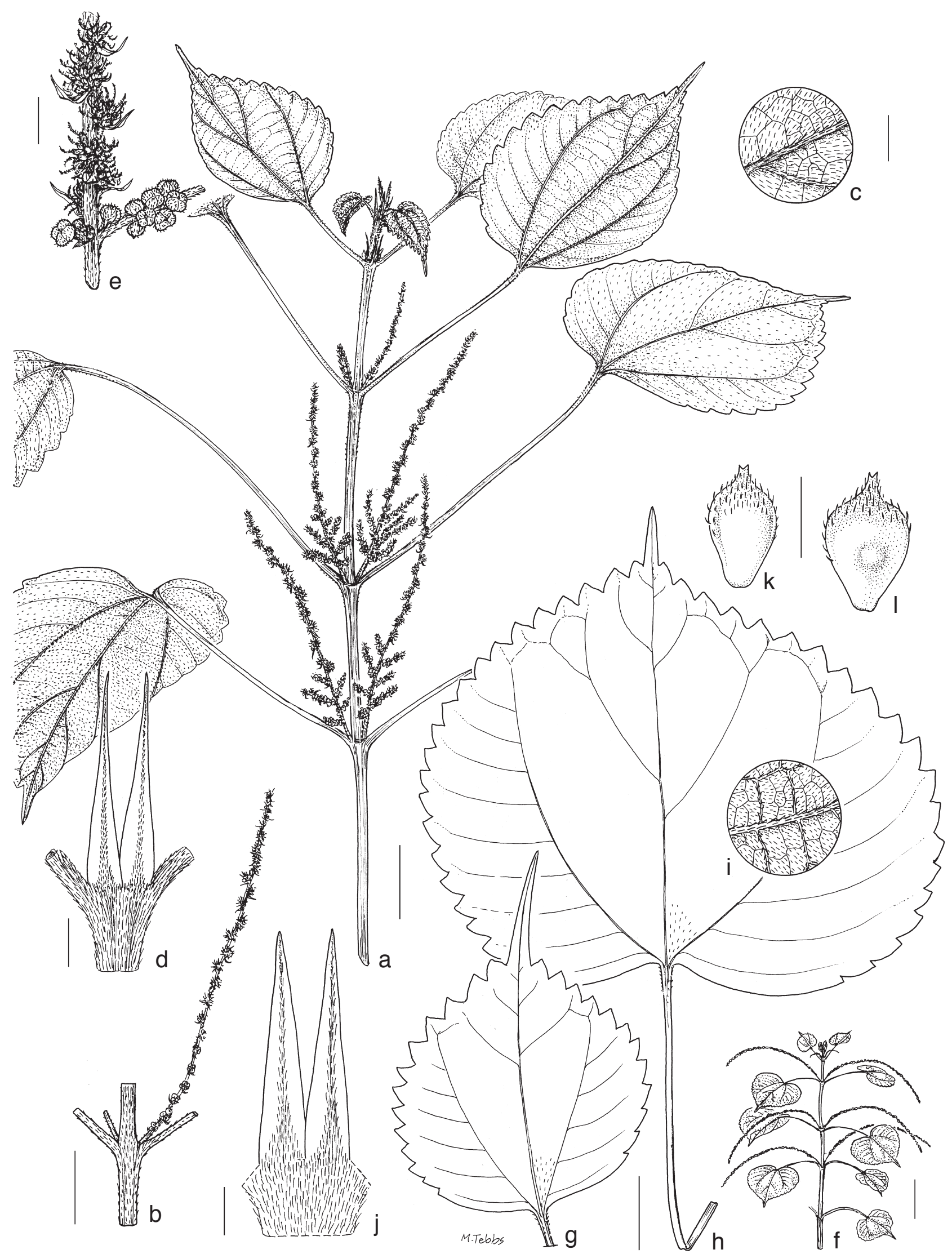

Fig. 28 a-e: Boehmeria virgata subsp. macrophylla var. sumatrana (Miq.) Friis \& Wilmot-Dear. a. Habit of stem with branched bisexual inflorescence-bearing axes with flower-clusters (inflorescences); b. detail of stem with unbranched female inflorescence-bearing axis; c. leaf, detail of abaxial surface; $d$. detail of stem and stipules; e. detail of lower part of branched bisexual inflorescence-bearing axes. - $f-l$ : Boehmeria virgata subsp. macrophylla var. strigosa (W.T.Wang) Friis \& Wilmot-Dear. f. Habit of stem with branched bisexual inflorescence-bearing axes with flower-clusters (inflorescences); g, h. leaves from different plants; i. leaf, detail of abaxial surface; j. detail of stem and stipules; k, l. fruiting perianths (from different plants) (a, c-e: Praet s.n., L; b: Bunnemeijer 4828, L; f, j, k: Chow \& Wai 79126, E; g, I: Balansa 595, K; h, i: Cuong 150, L). — Scale bars: a, b, g, h = 2 cm; c-e, i, j = 2 mm; f = $10 \mathrm{~cm} ; \mathrm{k}, \mathrm{l}=1 \mathrm{~mm}$. 
under the species as a whole), this and the following two varieties, var. densiglomerata and var. strigosa, are distinctive in leaf shape, texture and indumentum; var. sumatrana is distinguished from the other two on morphology of the inflorescence-bearing axes and marginal teeth, and sparse indumentum.

2. Little material has been seen, possibly not reflecting the full range of variation. One less distinctive collection has been seen with obtuse marginal teeth and lacking the distinctive cordate base but otherwise conforming to this variety: Sumatera, Kerinchi, Robinson \& Kloss Apr. 1914 (BM). The material represents a small herb to $60 \mathrm{~cm}$ with leaves $4-9$ by $2.5-6 \mathrm{~cm}$, length c. $1.5 \times$ width, margin crenate-dentate (i.e., teeth obtuse although still up-curved with their upper margin concave), base broadly rounded to broadly cuneate and inflorescence-bearing axes $12 \mathrm{~cm}$, unbranched, mainly female, with scattered male flowers throughout length.

n. var. densiglomerata (W.T.Wang) Friis \& Wilmot-Dear, comb. \& stat. nov. - Fig. 29; Map 30

Basionym: Boehmeria densiglomerata W.T.Wang, Acta Bot. Yunnanica 3, 4 (1981b) 408. - Type: S.S. Sin 844 (holo IBSC), China, Guangxi, Dayaoshan, 24 June 1928.

Perennial herb, $0.3-0.5 \mathrm{~m}$, branched or not; ultimate stems 1-1.5 mm diam, hairs sparse, adpressed, short, fine, soon glabrous. Stipules 5-9 mm long. Leaves broadly ovate-cordate to ovate-truncate, not or slightly asymmetrical, relatively small (3.5-)5-10 by (3-)5-7.5 cm, length only $1.1-1.25 \times$ width; margin dentate, teeth few, $10-13$ either side, large $2-4$ by $4-5$ $\mathrm{mm}$, acute or mucronate, usually outward-pointing (their upper margin straight); leaf apex with abrupt acumen, this relatively short $(\leq 1 \mathrm{~cm})$, narrow and consisting entirely or mostly of a single tooth; base cordate or truncate, not or slightly asymmetrical; texture membranous or very thin-chartaceous; adaxial surface rather shiny with scattered adpressed hairs like stem, abaxial surface recorded as purple when live, with less sparse hairs; petiole often very long for leaf-size, $0.7-1 \times$ lamina length. Inflorescence-bearing axes 1 per axil, mostly unisexual, male and bisexual axes $2-5.5(-7) \mathrm{cm}$ long often with several short branches at base, female axes unbranched, $1.5-4(-4.5) \mathrm{cm}$ long with clusters usually so densely congested along the axis that individual clusters are indistinguishable (axis thus rather thick, c. $3 \mathrm{~mm}$ diam in fruit); each cluster with less than 10 densely crowded flowers; bracts inconspicuous. Fruiting perianth broadly obconical, small, c. 1 by $0.5 \mathrm{~mm}, \pm 3$-angled or slightly laterally flattened, distal part \pm inflated into collar and hairy like stem with abrupt minute beak, lower part rugulose.

Distribution - Southern and south-western China.

Habitat \& Ecology - Forests, thickets, often in marshy places and along streams; 200-700(-1200) m altitude.

Notes - 1. As discussed (Note 5-xi-xiii under the species as a whole), the leaves of var. densiglomerata are closely similar only to those of var. sumatrana and var. strigosa. It is distinctive in its congested female axes and fewer marginal teeth. Only 13 collections clearly referable to this variety have been seen; material intermediate between this and var. strigosa has been seen from Vietnam (outside the known distribution of var. densiglomerata), making formal conservation status assessment not meaningful. The variety is probably at risk from the increasing pressure on natural habitats in these parts of China.

2. As discussed under the subspecies (see Note 11), var. densiglomerata can be confused with small forms of the partly sympatric (China, Japan) B. japonica.

o. var. strigosa (W.T.Wang) Friis \& Wilmot-Dear, comb. nov. Fig. 28f-I; Map 30

Basionym: Boehmeria holosericea Blume var. strigosa W.T.Wang, Acta Bot. Yunnanica 3, 4 (1981b) 404. - Type: Guangxi Exped. 3818 (holo PE), China, Guangxi, 27 Sept. 1953.

Boehmeria dolichostachya W.T.Wang (1981b) 405. - Type: P.X. Tan 2715 (holo IBSC), China, Guangxi, Lungzhou, 1 Dec. 1957.

Boehmeria strigosifolia W.T.Wang (1983) 77. - Type: W.T. Tsang 28128 (holo IBSC), China, Guangxi, Guilin, 26-31 Aug. 1937.

Herb, subshrub or shrub, $0.5-1(-3) \mathrm{m}$ tall. Stipules usually relatively short, $5-6(-8) \mathrm{mm}$ long. Stem with hairs sparse to abundant, closely-adpressed, fine, straight, 0.3-0.4 mm long. Leaves broadly ovate (deltate-ovate) or almost orbicular, medium or large $6.5-19$ by $6-17.5 \mathrm{~cm}$, length $1-1.2(-1.8) \times$ width, margin dentate, teeth few, usually only (16-)20-25 either side,

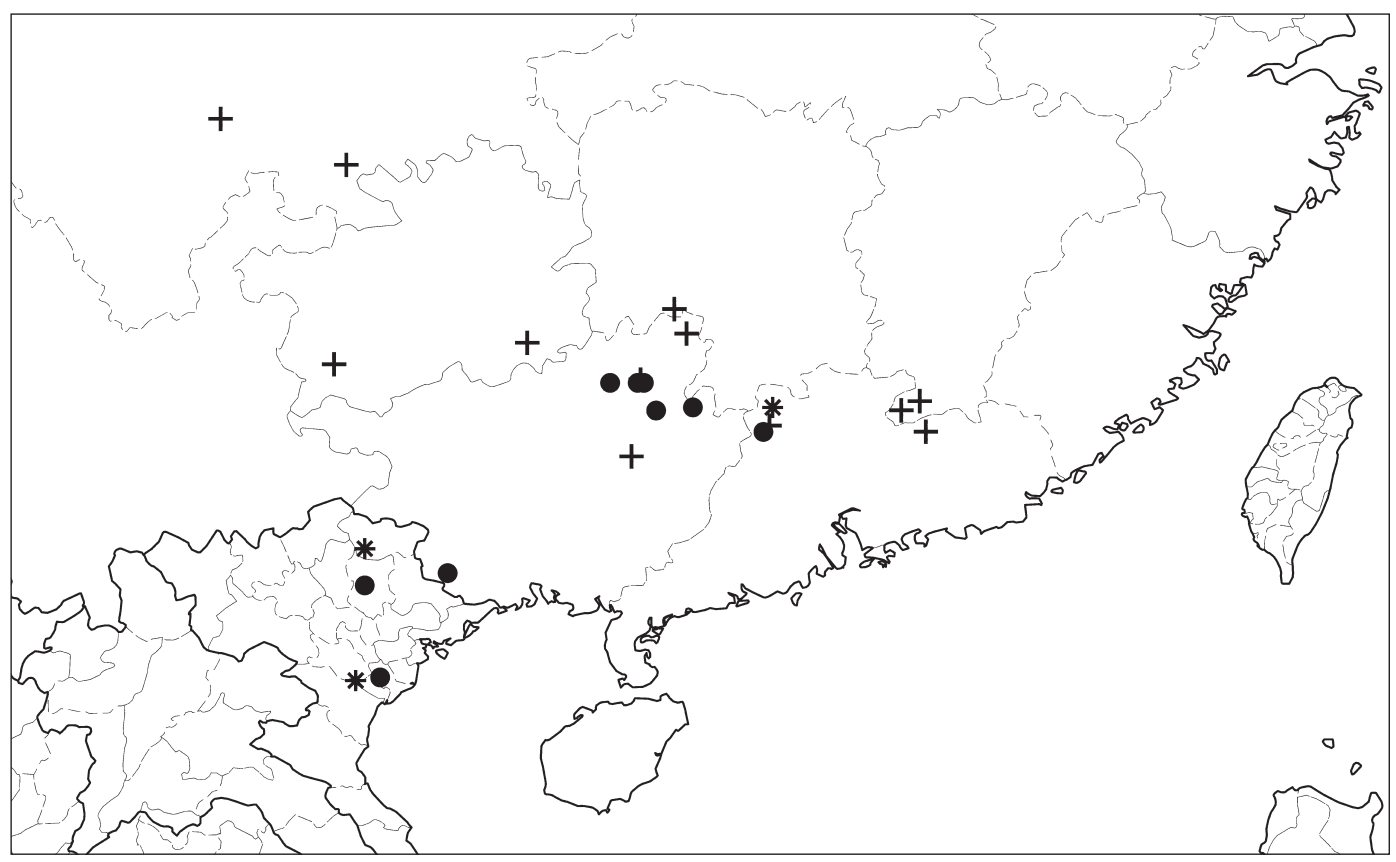

Map 30 Distribution of Boehmeria virgata (G.Forst.) Guillem. subsp. macrophylla (Hornem.) Friis \& Wilmot-Dear var. densiglomerata (W.T.Wang) Friis \& Wilmot-Dear (+), B. virgata (G.Forst.) Guillem. subsp. macrophylla (Hornem.) Friis \& Wilmot-Dear var. strigosa (W.T.Wang) Friis \& Wilmot-Dear (๑), intermediates between $B$. virgata subsp. macrophylla var. densiglomerata and $B$. virgata subsp. macrophylla var. strigosa (*) and intermediates between $B$. virgata subsp. macrophylla var. strigosa and other varieties (* under $\bullet$ representing var. strigosa). 


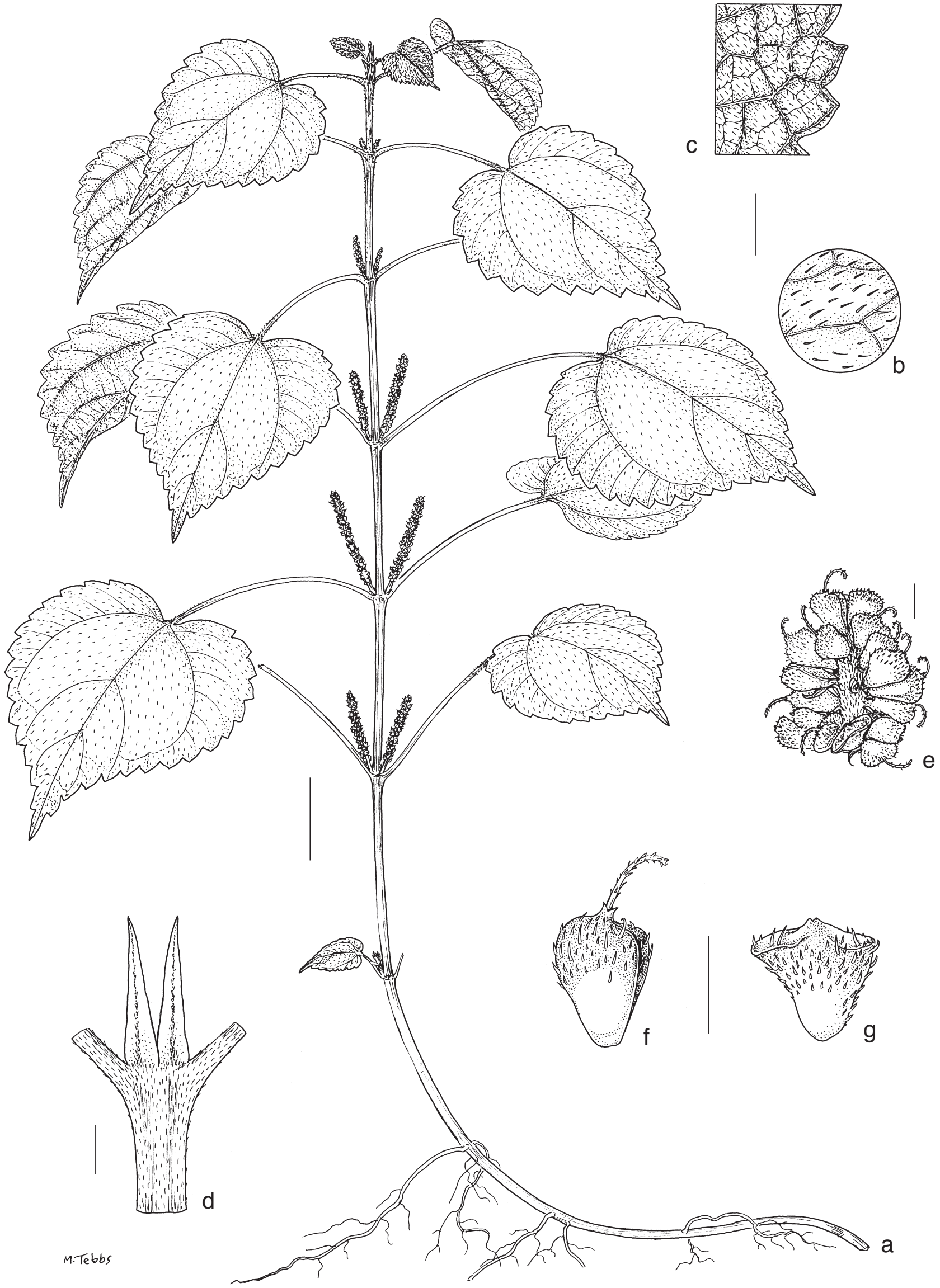

Fig. 29 Boehmeria virgata subsp. macrophylla var. densiglomerata (W.T.Wang) Friis \& Wilmot-Dear. a. Habit of stem with inflorescence-bearing axes; b. leaf, detail of adaxial surface; c. leaf, detail of abaxial surface; $d$. detail of stem and stipules; e. portion of female inflorescence-bearing axis showing extremely congested flower-clusters (inflorescences); f, g. fruiting perianths of different form (from same plant) (all: Luo 0132, K). $-\mathrm{Scale}$ bars: $\mathrm{a}=2 \mathrm{~cm} ; \mathrm{b}, \mathrm{c}=$ $5 \mathrm{~mm} ; \mathrm{d}=2 \mathrm{~mm} ; \mathrm{e}-\mathrm{g}=1 \mathrm{~mm}$. 
usually $3-5$ by $3-10 \mathrm{~mm}$ (sometimes only 2 by $2 \mathrm{~mm}$ and up to 30 in number), with width 1-2x length, proximal ones mostly more outward-pointing (their upper margin convex), sometimes most teeth \pm outward-pointing); leaf apex broadly rounded and with abrupt short acumen which is sometimes \pm linear and taillike; base distinctly truncate or \pm broad-cordate; texture very thin-chartaceous; adaxial surface with hairs like the stem, rather sparse but conspicuous, fine, adpressed; abaxial surface with similar but finer hairs, dense and lying in a regular pattern giving a conspicuously shiny-silky appearance; petiole variable but often extremely long relative to lamina, $0.4-1 \times$ lamina length. Inflorescence-bearing axes unisexual, leafless throughout most of length but sometimes returning to vegetative growth at apex; male axes 5-10 cm long, erect, often branched at base, female axes (10-)15-40 cm long, pendulous, unbranched; clusters sometimes contiguous but more often spaced 1-2 cm apart, female clusters c. $2 \mathrm{~mm}$ diam, with c. 10-20 flowers. Fruiting perianth variable, broadly ovoid to obovoid, slightly laterally flattened with distinct marginal rim or more markedly flattened \pm winged, c. 0.8 by $0.6 \mathrm{~mm}$, without beak, hairy like stem, always slightly rugulose.

Distribution - Southern China, Vietnam.

Habitat \& Ecology - Thickets in hills, moist or disturbed places; 100-1300 $\mathrm{m}$ altitude.

Notes - 1. As discussed (see Note 5-xi-xiii under the species as a whole), the distinctive leaves of var. strigosa are similar only to var. sumatrana (allopatric) and var. densiglomerata (sympatric) but larger with more numerous teeth and dense shiny-silky hairs abaxially, and it differs also from both in inflorescence-morphology. (The difference in habit stated by Chen et al. (2003) is not consistent since var. strigosa can be a herb as well as a shrub).

2. Only 21 collections clearly referable to this variety have been seen, with a few others from Vietnam somewhat intermediate with var. densiglomerata (not recorded from Vietnam). Formal conservation status assessment is therefore not meaningful for this variety. It is probably at risk from the increasing pressure on natural habitats in these regions of China and Indochina.

3. As discussed under the subspecies as a whole (see Notes $6,11)$, this variety has sometimes been mistaken for $B$. japonica and $B$. ternifolia.

4. As discussed under the species as a whole (see Note 5 -xiii), a range of somewhat intermediate material has been seen with only half-adpressed or \pm spreading indumentum on stem, petioles and leaves abaxially; this includes the following type and names based on it:

Boehmeria strigosifolia W.T.Wang var. mollis W.T.Wang (1983)

78. - Boehmeria dolichostachya W.T.Wang var. mollis

(W.T.Wang) W.T.Wang \& J.C.Chen in Chen et al. (2003) 171.

- Type: Z. T. Li 661100 (holo PE), China, Guangxi, Nandan,

1 Aug. 1958.

\section{Boehmeria ternifolia D.Don - Fig. 30; Map 31}

Boehmeria ternifolia D.Don (1825) 59. - Type: Hamilton s.n. (holo BM), Nepal.

Subshrub, shrub or small tree, $0.5-4.5 \mathrm{~m}$. Stems with hairs abundant to very dense, minute ( $\leq 0.3 \mathrm{~mm}$ long), fine, soft, spreading, brown. Stipules long and narrow, $8-9$ by $1-2 \mathrm{~mm}$, densely hairy outside like the stem. Leaves scarcely or markedly dimorphic in size with length of 'larger' 1-1.5(-2)× 'smaller' ones, very broadly elliptic or deltate, rarely obovate-obdeltate or rhombicovate to ovate-truncate, slightly or moderately asymmetrical, widely varying in size $(4-) 7-14(-20)$ by $(3-) 7-13.5(-16) \mathrm{cm}$ excluding apical tooth (see below), length $0.8-1.25 \times$ width; margin dentate or sometimes \pm crenate with 7-20(-25) teeth either side, these up-curved with a wide size range on different plants, small to large, $(1.5-) 2-6$ by $4-11 \mathrm{~mm}$, length $1.25-4 \times$ width, all \pm uniform or distal ones progressively larger, also usually increasingly up-curved with the pair of teeth either side of the apex often markedly in-curved; leaf apex either with $2-3$ lobes of \pm equal length giving truncate outline to apex, or abruptly terminated by a terminal tooth which is long, narrow \pm linear and tail-like; base often \pm oblique, very broadly cuneate or \pm truncate with cordate extreme base, sometimes broadly rounded to \pm cordate; texture thin-chartaceous or (mostly in Nepal) membranous; leaves recorded as greenish purple in live state; adaxial surface with hairs sparse or fairly abundant, fine, half-adpressed or spreading, soft, bulbous-based; abaxial surface velvety with hairs \pm spreading denser and finer (not bulbous-based), rarely on veins only, often whole surface densely hairy. Flower-clusters on leafless inflorescence-bearing axes, these pendulous slender, unisexual but often on same stem with male axes in lower leaf axils; male axes $4-15 \mathrm{~cm}$, unbranched or more often with several branches at or close to base; female axes $10-20(-30) \mathrm{cm}$, rarely branched; clusters on both male and female axes spaced 1-2 $\mathrm{mm}$ apart or contiguous, female clusters 3-4 $\mathrm{mm}$ diam in fruit, with bracts often conspicuous up to $1 \mathrm{~mm}$ long but soon caducous from female clusters. Male flowers 4-merous, \pm sessile, mature buds c. $1.5 \mathrm{~mm}$ diam, globose, tepals with dorsal appendage. Fruiting perianth ellipsoid or obovoid, without or with very slight beak, with distinct marginal rim or occasionally \pm winged, \pm rounded, rarely slightly tapering at base, $1-1.5(-2)$ by $0.6-0.8 \mathrm{~mm}$, densely minute-hairy.

Distribution - Eastern and western Himalayas: northern India, Nepal, Bhutan.

Habitat \& Ecology - Dense montane forest, forest clearings and margins, often in damp shady ravines or by waterfalls; 1000-2300 m altitude.

Conservation status - Least Concern (LC). It is known from over 50 collections from many locations along the Himalayas. It occurs in fairly restricted forest habitat, but is probably not at risk since these localities in the Himalayas are not threatened by serious habitat degradation. Separate formal assessments are not considered meaningful for the two intergrading varieties.

Notes -1 . This species is a small shrub distinctive in the appearance of its marginal teeth and in its abundant minute spreading brown stem indumentum (often also dense on most parts of plant) and in its leaf shape and marginal teeth which distinguish the two varieties from one another. It is restricted to the southern foothills of the Himalayas from Garhwal and Kumaon to Bhutan (and possibly extending into Burma).

2. The typical variety is distinctive in its leaves with an abrupt long single terminal tooth which may be long-triangular but is often very narrow \pm linear 'tail-like' and constricted at its base and is usually much longer than marginal teeth (a character otherwise seen only in $B$. virgata subsp. macrophylla var. rotundifolia, which differs as discussed below, see Note 5). The marginal teeth of var. ternifolia are sometimes \pm uniform along most of margin but usually distinctive in distal ones being progressively wider (but scarcely longer) than proximal ones, often markedly so, also usually progressively more up-curved (even if proximal ones are out-pointing and rounded) and the uppermost pair often markedly in-curved towards the terminal tooth, giving a distinctive claw-like appearance to the leaf apex.

3 . In the eastern part of its range var. ternifolia merges gradually via a range of intermediate forms into var. kamley whose leaves are often less densely hairy and have fewer marginal teeth, distal ones progressively markedly larger (both longer and wider) and leaf apex with 2-3 large broad apical teeth or lobes rather than a single tail-like tooth. The two variants of $B$. ternifolia are recognised only at varietal level because of the range of intermediates. Leaf form in the species changes 


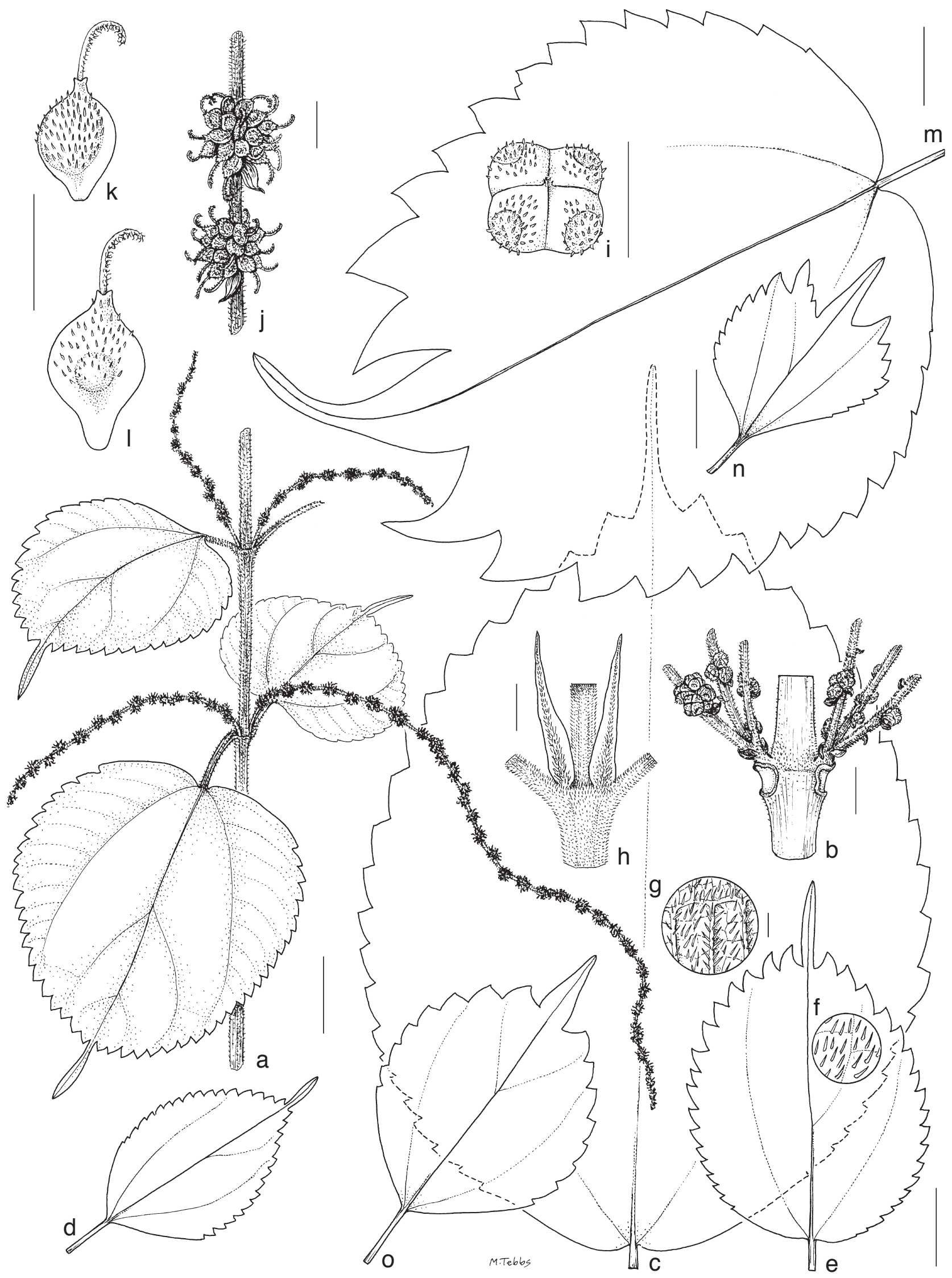

Fig. 30 a-I: Boehmeria ternifolia D.Don var. ternifolia. a. Habit of stem with inflorescence-bearing axes; $b$. detail of stem showing basal branching of male inflorescence-bearing axes; c-e. leaves from different plants; f. leaf, detail of adaxial surface; g. leaf, detail of abaxial surface; h. detail of stem and stipules; i. male bud; j. detail of female inflorescence-bearing axis with two flower-clusters (inflorescences); $\mathrm{k}$, l. fruiting perianths from different plants. - m, n: Boehmeria ternifolia var. kamley (Acharya \& Yonek.) Friis \& Wilmot-Dear. Leaves from different plants. - o: Intermediate between var. ternifolia and var. kamley. Leaf (a: Duthie 24955; b: Thomson 701; c, l: Gamble 7006; d: Gamble 26635; e-i: Wallich 1262; j, k: Grey-Wilson 271; m: Clarke 13029; n: Grierson 4161; o: Bourne s.n.; all K). - Scale bars: a, c-e, $m-0=2 \mathrm{~cm} ; \mathrm{b}, \mathrm{h}, \mathrm{j}=2 \mathrm{~mm} ; \mathrm{f}, \mathrm{g}, \mathrm{i}, \mathrm{k}, \mathrm{l}=1 \mathrm{~mm}$. 
from west to east with some material from Nepal and Sikkim being impossible to assign to either variety, while further west all conforms to var. ternifolia and almost all from Bhutan and some from Sikkim conforms to var. kamley.

4. The allopatric $B$. japonica is also characterised by change in form of marginal teeth towards leaf apex, its distal teeth markedly longer as well as wider. It would not easily be confused with var. ternifolia (which has distal teeth scarcely longer), but broad-leaved apically 3 -toothed variants of $B$. japonica var. japonica are almost identical in leaf shape to var. kamley. Boehmeria japonica is distinguished by unbranched herbaceous (rather than branched shrubby) habit, adaxial leaf-hairs coarse and stiff (rather than fine and soft) and male tepals without a dorsal appendage. The cytological work of Acharya (in Acharya et al. 2003) shows var. kamley to be diploid and sexually reproducing whereas Okabe (1956) and Yahara (1983a, 1984a) demonstrated (as discussed in the introduction) that $B$. japonica comprises a polyploid complex of partly apomictic and partly hybridising entities. This indicates that hybridisation between these two neighbouring but allopatric taxa has not occurred despite the remarkably intermediate appearance of var. kamley and its occurrence where the distribution of $B$. ternifolia is least far from that of $B$. japonica. This is a good example of the way cytological information can clarify relationships where taxa are similar in gross morphology.

5. Boehmeria ternifolia var. ternifolia can be confused with certain Himalayan varieties of the very variable $B$. virgata subsp. macrophylla. Var. rotundifolia is the most similar with a tail-like terminal tooth and increasingly up-curved marginal teeth but is distinguished by its stem hairs closely-adpressed rather than spreading (sometimes longer (c. $1 \mathrm{~mm}$ long) curved hairs also present), its marginal teeth often more numerous and its inflorescence-bearing axes (especially the male ones) erect and often branched throughout length; it is also a herb rather than a shrub, occurring in more open habitat at higher altitude. Himalayan forms of the very variable subsp. macrophylla var. macrostachya can also be somewhat similar to $B$. ternifolia but never have a distinctive basal constriction to the terminal tooth nor distal marginal teeth progressively wider nor uppermost teeth in-curved, and these particular Himalayan forms are also distinguished by smaller more numerous teeth. Subsp. macrophylla var. strigosa (allopatric, China and Indochina) can also have an abrupt tail-like leaf apex but would not be confused with $B$. ternifolia, differing markedly in closely-adpressed \pm silky indumentum on stem and leaves.
6. Forms of var. ternifolia with fairly uniform teeth and dense indumentum are easily confused with the sympatric but more widespread $B$. ourantha which also has dense soft indumentum. The clearest distinguishing character of $B$. ourantha is its unusual inflorescence architecture, with male flowers differently arranged, being mostly in a few clusters at the apex of a mainly female axis or scattered flowers in mainly female clusters; female and bisexual axes are always unbranched and mostly much more congested, and the apical tooth of leaves is never tail-like nor basally constricted; marginal teeth are mostly more numerous (more than 25) and distal ones not in-curved; indumentum is also longer, (0.5-)1-2 mm long, (rather than $\leq 0.3 \mathrm{~mm}$ ) and always dense on the abaxial surface of leaves.

7. Leaves of var. ternifolia with fairly uniform marginal teeth are also somewhat similar to those of $B$. holosericea but this species is allopatric (eastern Asia) and less likely to be confused with it, being a herb with marginal teeth wider than long (rather than length exceeding width) and with its leaf indumentum much longer than its stem indumentum (rather than both leaf and stem indumentum similar, very short).

\section{Key to varieties}

1. Leaf apex consisting of a single terminal tooth, long, linear tail-like; marginal teeth 12-25 in number, uniform or distal ones progressively wider but scarcely longer. - Eastern and western Himalayas . . . . . . . . . a. var. ternifolia

1. Leaf apex with $2-3 \pm$ equally large teeth or lobes; marginal teeth up to $10(-13)$ in number, distal ones much larger. — Eastern Himalayas ............. b. var. kamley

\section{a. var. ternifolia - Fig. 30a-l; Map 31}

Boehmeria platyphylla D.Don var. cuspidata Wedd. (1856) 365, non B. cuspidata Blume (1857) 216. - Boehmeria caudigera Wedd. (1854) 199, nom nud. - Type: Wallich 4585, specimen marked "U. blanda" [= Urtica blanda] (lecto K-WALL; isolecto BR, G; lectotype selected here), Nepal, Nag-arjuhn, 1821. - See Note 1.

Leaf length 1-1.25x width; marginal teeth 12-20(-25) either side, these all of similar size or progressively wider but not or scarcely longer towards apex, uppermost distal ones at most $2 \times$ length of proximal ones; leaf apex obtuse or broadly rounded in outline excluding terminal tooth, this sometimes only \pm twice as long as wide and twice as long as distal marginal teeth, constricted at its base, but usually extremely narrow and

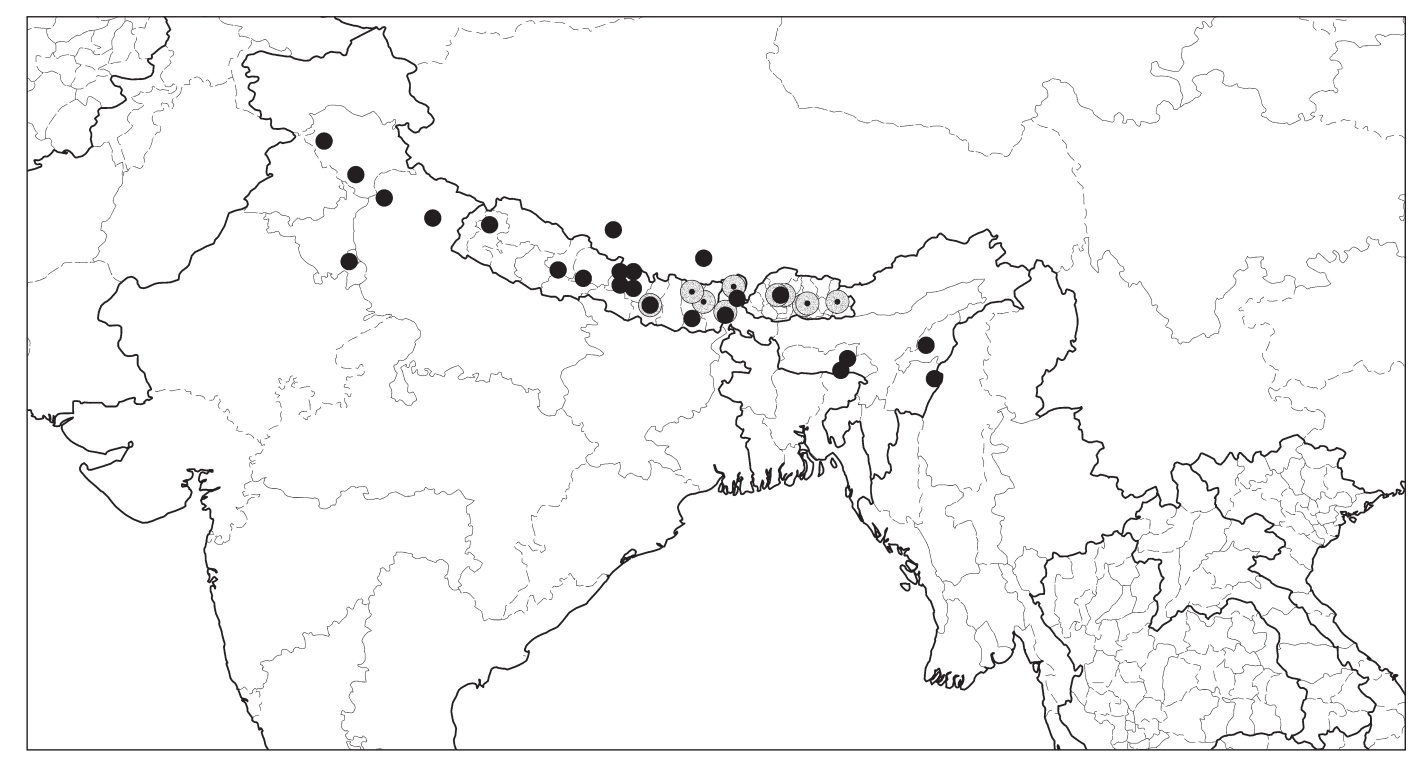


tail-like, $10-30$ by $1.5-2(-35) \mathrm{mm}$, length (4-)5-20x width and $(0.1-) 0.2(-0.4) \times$ length of rest of lamina. Hairs on fruiting perianth usually $\leq 0.1 \mathrm{~mm}$ long.

Distribution - As for the species as a whole.

Habitat \& Ecology - As for the species as a whole.

Notes -1 . Weddell cites " $U$. caudigera \& $U$. blanda, Wallich 4585" which represents two different collections. The one selected here has the number " 4585 " inserted only in pencil on Wallich's original label and is not listed in Wallich's Catalogue, but was selected rather than the one listed in the Catalogue, which is " $U$. caudigera Wall., Mont ad Bumpady, 17 Dec 1821". The latter is less helpful as a type, being of unclear identity somewhat intermediate with $B$. virgata var. macrostachya.

2. For further taxonomic discussion see under the species as a whole. Over 40 collections clearly referable to this variety have been seen.

b. var. kamley (Acharya \& Yonek.) Friis \& Wilmot-Dear, comb. \& stat. nov. - Fig. 30m-0; Map 31

Basionym: Boehmeria kamley Acharya \& Yonek. in Acharya et al., Acta Phytotax. Geobot. 53, 1 (2002) 4. - Type: Stainton 6995 (holo E), Nepal, Koshi Zone, Inkhuwa Khola, 5 July 1974

Leaf length $0.5-1.25 \times$ width; margin with 7-13 teeth either side, distal ones both longer and wider than proximal; leaf apex 2-lobed or with relatively broad terminal tooth and 2 subapical teeth almost equalling terminal tooth, giving a 3-lobed appearance, subapical teeth or lobes often secondarily toothed. Hairs on fruiting perianth usually $\geq 0.1 \mathrm{~mm}$.

Distribution - Eastern Himalayas: India, Nepal, Bhutan.

Habitat \& Ecology - Forests and forest margins; 1700$2000 \mathrm{~m}$ altitude.

Notes - See under the species as a whole.

\section{Boehmeria ourantha Miq. - Fig. 31; Map 32}

Boehmeria ourantha Miq. (1851) 33. - Boehmeria caudata (Burm.f.) J.J.Sm. var. ourantha (Miq.) J.J.Sm. (1910) 714. - Boehmeria platyphylla D.Don var. ourantha (Miq.) Hochr. (1925) 344. - Type: Junghuhn s.n. (holo U), Indonesia, Jawa [Java], Bantam Dist. - See Note 1.

Boehmeria pseudotomentosa Yahara (1981) 16, syn. nov. - Type: Shimizu et al. 22457 (holo KYO, n.v.), north-eastern Thailand, Phu Kradung. - See Note 2.

Boehmeria tomentosa sensu auct., incl. Wedd. (p.p.), non B. tomentosa Wedd. s.str.; B. macrophylla Hornem. var. tomentosa (Wedd.) D.G.Long, sensu D.G.Long, non var. tomentosa (Wedd.) D.G.Long, s.str. - See Note 3 and 5.

Robust erect subshrub or shrub, 0.1-2(-4) m tall; ultimate stems robust, 2-3 $\mathrm{mm}$ diam, hairs dense, spreading, soft goldenbrown, (0.5-)1-2 mm long; eventually glabrescent. Stipules conspicuous, narrowly triangular, tapering to apex, (5-)6-11 by 2-3 mm, length $3 \times$ width, thin(-thick)-textured, densely hairy outside on midrib. Leaves opposite, not or moderately dimorphic in size only, 'larger' leaf with length of lamina 1-1.5x, but petiole $1-2(-2.5) \times$, length of 'smaller' ones; broadly ovate or deltate, at least some usually medium or large, (7-)10-20 by (5.5-)7-15 $\mathrm{cm}$, length (0.8-)1.3-1.5(-1.8) $\times$ width; margin dentate, most or all leaves with (20-)25-30(-33) medium-sized teeth either side, teeth $2-3$ by $4-6.5(-8) \mathrm{mm}$ (wider rather than more numerous on largest leaves but some of the smallest leaves with only c. 17 teeth, these 1.5 by $3 \mathrm{~mm}$ ), their width $2-3 \times$ length, acute or obtuse but mucronate, slightly up-curved (their upper margin convex or ' $S$ '-shaped), \pm uniform size but leaf margin entire near base; leaf apex acute, short-attenuate or indistinctly acuminate, acumen consisting mainly of one short broad apical tooth only $1.5-3 \times$ length of marginal teeth and length often only $2 \times$ width, usually rounded at tip; base symmetrical or almost so, \pm truncate or broadly shallowly cordate (rarely broad-cuneate or broadly rounded); basal veins extending into distal half of lamina, upper lateral veins 1-2 either side, similarly arranged in both sides or sometimes 3 veins on one side, lowermost arising near middle of lamina or all arising in distal half, basal veins thinly prominent abaxially, upper veins and reticulation rather indistinct; texture thin- or thick-chartaceous; both surfaces velvety with spreading hairs like stem, so dense as to give golden sheen to leaf, or sometimes shorter and sparser adaxially (rarely both sides); petiole quite variable relative to lamina, $0.15-0.25(-0.3) \times$ lamina length. Flower-clusters borne on leafless inflorescence-bearing axes, these \pm erect, unbranched, 1 per axil, (4-)6-10(-15) cm long; entirely male axes sometimes present in lower part of plant, upper axes either entirely female or bisexual with mainly female flowers, male flowers being either restricted to a few male clusters at extreme apex or as scattered flowers in mainly female clusters, more numerous towards axis apex and with uppermost clusters sometimes entirely male; flower-clusters \pm contiguous or male ones often (female rarely) spaced up to $2 \mathrm{~mm}$ apart, entirely male clusters only 2-3 mm diam, with few-15 flowers; entirely female clusters (2-)5-6(-8) mm diam, with c. 40-more than 100 flowers; bracts $2-3$ by $1-1.5 \mathrm{~mm}$, narrowly or broadly triangular with narrowly acute tip, sometimes conspicuous in male clusters; bracteoles variable in shape and size, obovate or spathulatelanceolate, 0.5(-1) $\mathrm{mm}$ long but inconspicuous in the densely congested clusters. Male flowers 4-merous, subsessile or on pedicels up to $1 \mathrm{~mm}$, mature buds globose, c. $1.5 \mathrm{~mm}$ diam, tepals with prominent dorsal appendage; hairs dense, short, spreading. Female flowers flattened-ovoid, c. 1 by $0.3-0.5$ $\mathrm{mm}$, tapering to apex, densely hairy; stigma 1-1.5(-2) mm. Fruiting perianth quite variable in shape and proportions, ovoid to ellipsoid or obovoid and often 3-angled, $1.5-2$ by (0.5-)1-1.5 $\mathrm{mm}$ with apex acute, rounded or truncate, rarely with indistinct beak, moderately laterally flattened, sometimes more flattened around the achene forming a \pm distinct rim or narrow indistinct wing, with dense spreading hairs in distal half. Achene occupying most of fruiting perianth, ovoid.

Distribution - North-eastern India, Burma, Thailand, southwestern China, Indonesia (Jawa).

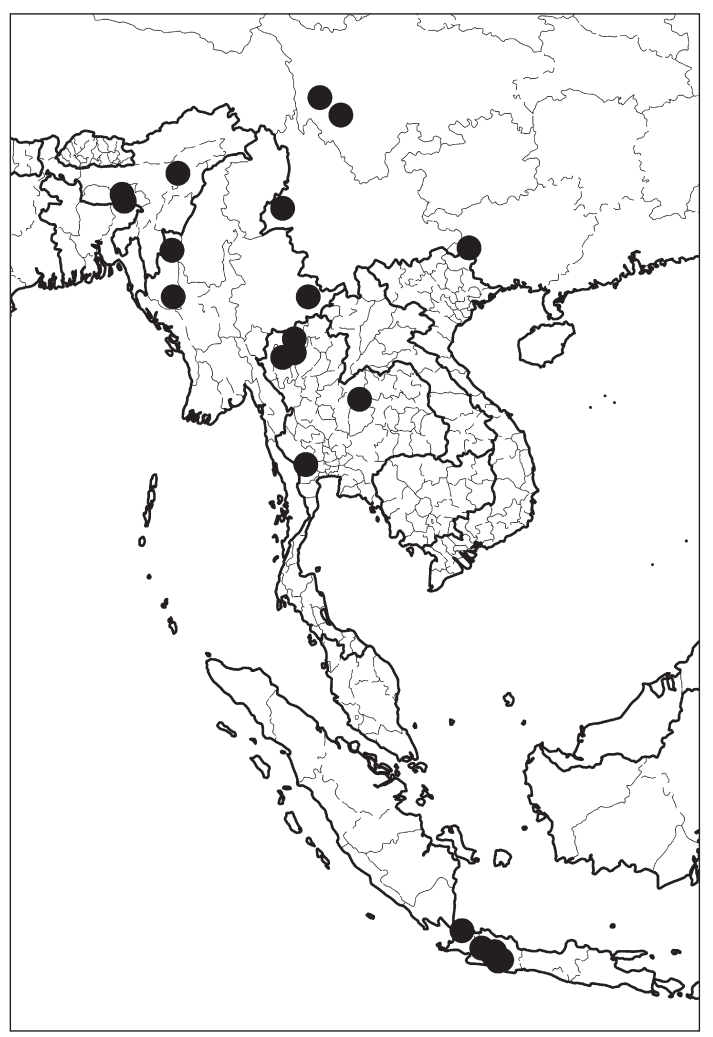

Map 32 Distribution of Boehmeria ourantha Miq. 
Fig. 31 Boehmeria ourantha Miq. a. Habit of stem with bisexual inflorescence-bearing axes; b. leaf, detail of adaxial surface; c. leaf, detail of abaxial surface; d. detail of stem and stipules; e. detail of inflorescence-bearing axis showing bisexual clusters; f. male bud; g, h. fruiting perianths from different plants (a-d: Clarke 19262, K; e: Van Beusekom 1316, BKF; f: Hooker \& Thomson s.n., K; g: Griffith s.n., K; h: Handel-Mazzetti 5619, US). - Scale bars: $a=2 \mathrm{~cm}$; b-e = $2 \mathrm{~mm} ; \mathrm{f}-\mathrm{h}=1 \mathrm{~mm}$.
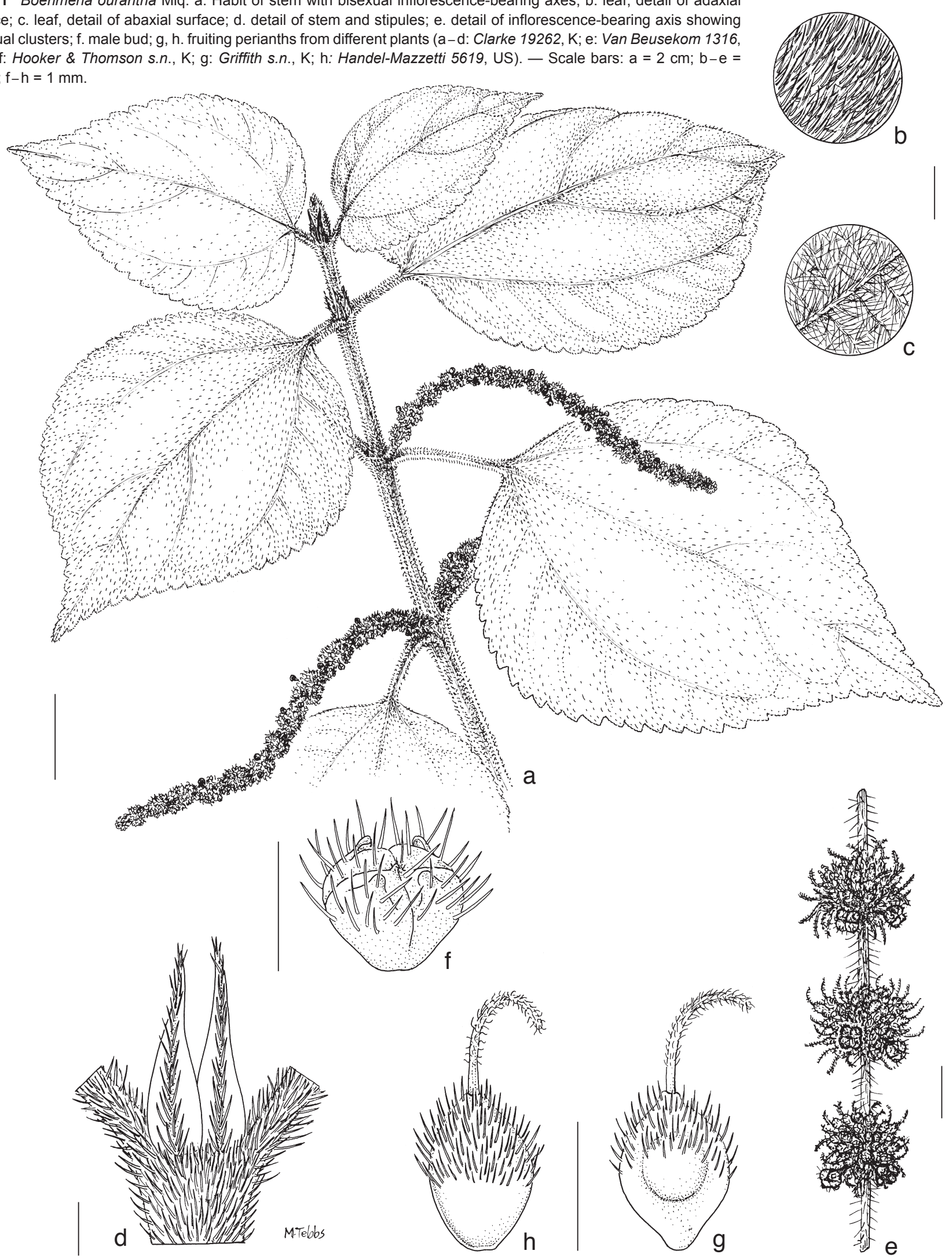

Habitat \& Ecology - Dense evergreen forest, open scrub, grassland, disturbed land (old cultivations), roadside banks (under Cinchona); 1000-2300 m altitude.

Conservation status - Near Threatened (NT). The species is known from c. 50 collections, some of which are recent. The EOO of $3372270 \mathrm{~km}^{2}$ is misleading due to the distance between Jawa and its known localities in Indochina, but its AOO of less than $500 \mathrm{~km}^{2}$ suggests that it is at risk. It occurs in 15 rather scattered locations, and in fairly restricted forest habitat.
Although the habitats in many of its localities are not currently threatened by serious degradation, and it therefore does not meet the criteria for a formal status of Vulnerable (VU), it may become so in the future with increasing agriculture in these regions.

Notes - 1. Blume (1857: 221) cites the name of this species as " $B$. urantha" but refers it to Miquel, so it is considered an orthographic error, not a new name. 


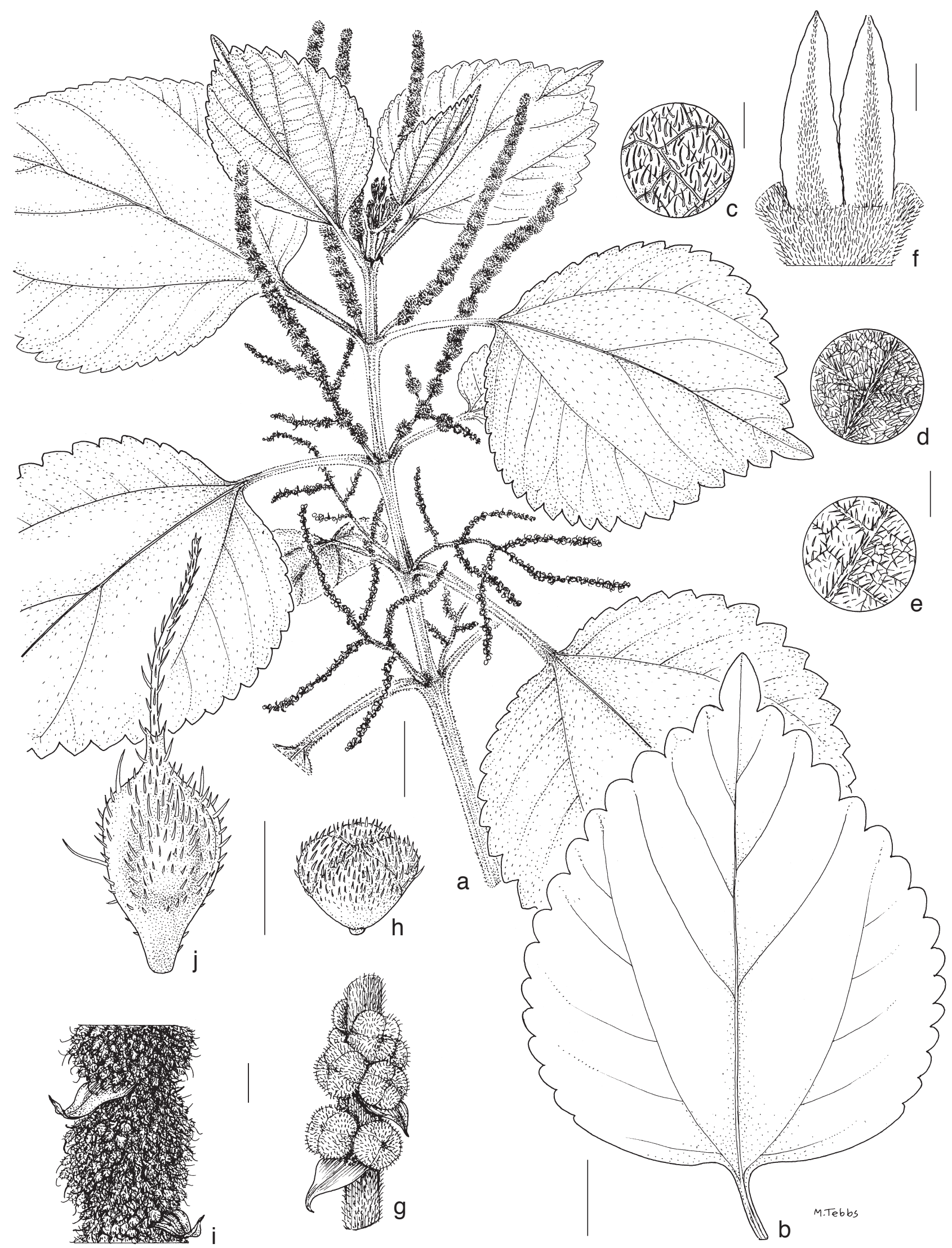

Fig. 32 Boehmeria holosericea Blume. a. Habit of stem with inflorescence-bearing axes, lowermost entirely male, branched axes, uppermost bisexual branched, bisexual axes and unbranched female axes; b. leaf; c. leaf, detail of adaxial surface; $d$, e. leaves, detail of abaxial surface (different plants); $f$. detail of stem and stipules; g. detail of male inflorescence-bearing axis with flower-clusters (inflorescences) and bracts; $h$. male bud; i. detail of female inflorescence-bearing axis with congested flower-clusters (inflorescences) and bracts; j. fruiting perianth (a, c, d, g, i: Iwatsuki et al. 399, L; b, f: Furuse 42899, Tl; e, j: Sieber s.n., L; h: Burger s.n. [L 908.185-1665], L). - Scale bars: $a, b=2 \mathrm{~cm} ; \mathrm{c}-\mathrm{f}=2 \mathrm{~mm} ; \mathrm{g}-\mathrm{j}=1 \mathrm{~mm}$. 
2. The holotype of $B$. pseudotomentosa has not been seen but most other collections cited in the original description have been studied. Yahara (1981) in describing B. pseudotomentosa noted its general resemblance to $B$. ternifolia (see Note 7) and the similar inflorescence architecture to that of $B$. yaeyamensis (see Note 4); he also noted the earlier misapplication of the epithet tomentosa (see Note 3) to his 'new' species but was apparently unaware that the earlier name $B$. ourantha applied to this entity.

3. See under B. virgata subsp. macrophylla var. tomentosa for discussion of this confusing situation of valid publication of a new combination based on application of epithet to a different taxon.

4. Boehmeria ourantha is distinctive in its male flowers arranged at the apex rather than base of mainly female inflorescence-bearing axes, its long spreading golden indumentum (often at least $2 \times$ the length of hairs seen in most other taxa) which is often so dense on most parts as to give a distinctive golden sheen to the plant and its broad truncate to cordate velvety leaves. It was reduced to a variety of the very variable entity $B$. virgata subsp. macrophylla (as B. caudata (Burm.f.) J.J.Sm. var. ourantha) by Smith (1910) who is stated by Hochreutiner (1925) to have seen collections originally identified by Miquel, but it is here considered worthy of recognition as a species because of this unusual arrangement of male flowers. In most species of Boehmeria including $B$. virgata, male flowers, if found on a mainly female axis, are located in the basal part, often on short entirely male branches; in $B$. virgata male flowers also differ in being subsessile rather than pedicellate. Only B. pilosiuscula (sympatric) and B. yaeyamensis (allopatric, Ryukyu Islands) have the same unusual arrangement of male flowers; these two taxa also resemble it in their densely congested female clusters giving a distinctively cylindrical appearance to the fruiting axis but differ in their stem indumentum of mixed minute and long hairs not giving a golden sheen. Boehmeria pilosiuscula also differs in smaller leaves with a distinctly oblique base and $B$. yaeyamensis in broadly crenate leaves.

5. Hochreutiner (1925), in making the new combination $B$. platyphylla var. ourantha, noted the apical male clusters on unbranched bisexual axes and the long indumentum as distinctive, suggesting that var. ourantha might be worthy of recognition as a species but not wishing to over-ride existing taxonomy. He also noted it as distinct from the Malagasy entity bearing the epithet "tomentosa" (here placed as B. virgata subsp. macrophylla var. tomentosa (Wedd.) Friis \& Wilmot-Dear).

Nevertheless, the misapplication of the epithet "tomentosa" to material of $B$. ourantha has continued in much subsequent literature (e.g., Chen et al. 2003: 170). Most confusingly, the combination B. macrophylla Hornem. var. tomentosa (Wedd.) Long, based on the Afro-Malagasy B. tomentosa Wedd., was misapplied for Asian material in the Flora of Bhutan (Grierson \& Long 1983: 126). Boehmeria virgata subsp. macrophylla var. tomentosa (Wedd.) Friis \& Wilmot-Dear is an Afro-Malagasy taxon and in addition to the different arrangement of male flowers is also rather dissimilar in its overall appearance with velvety but whitish indumentum giving a grey rather than golden cast to the plant, leaves narrower and not truncate with teeth smaller, more numerous (35-40) and inflorescence-bearing axes long, slender with well-spaced clusters.

6. Hochreutiner (1925) also remarked that $B$. ourantha somewhat resembled $B$. rotundifolia (= the Himalayan $B$. virgata subsp. macrophylla var. rotundifolia); the partly sympatric subsp. macrophylla vars. macrostachya and scabrella are also sometimes similar to $B$. ourantha in general appearance; the first two varieties are easily distinguished by hairs on the stem and adaxial (often also abaxial) leaf surface inconspicuous adpressed, var. scabrella by its short usually adpressed stem indumentum, leaves often smaller with teeth smaller relatively narrower and hairs stiffer giving a rough texture to the surface; both var. rotundifolia and var. scabrella are also distinguished by the entirely male inflorescence-bearing axes being branched, and var. rotundifolia by its leaf apex abruptly narrowly longacuminate.

7. Forms of the sympatric but less widespread B. ternifolia var. ternifolia with densely-pubescent stems and leaves are very easily confused with $B$. ourantha but differ in the leaf apex abruptly acuminate consisting of an apical tooth which is usually long and tail-like and/or constricted at its base; inflorescencebearing axes are also usually less congested, never bisexual and the male ones are often branched; the indumentum is also usually shorter ( $\leq 0.3 \mathrm{~mm}$ ) and sparser and thus does not give a distinctive golden sheen to the plant; the leaf margin usually bears less than 25 teeth either side and the distal teeth are often progressively markedly wider than the lower ones.

8. The more densely hairy forms of $B$. holosericea (Japan, South Korea), allopatric but rather similar in its leaf shape and its erect often thick female inflorescence-bearing axes with large crowded clusters, are distinguished by male flowers (sessile) on separate pendulous axes, minute stem hairs, rounded and outward-pointing marginal teeth of their often thinner-textured leaves.

\section{Boehmeria holosericea Blume - Fig. 32; Map 33}

Boehmeria holosericea Blume (1857) 221. - Boehmeria platyphylla D.Don var. holosericea (Blume) Wedd. (1869) 212. - Type: Burger s.n. [L 908.1851666] (lecto L, selected here), Japan. - See Note 1.

Boehmeria hispidula Blume (1857) 223, syn. nov. - Type: Burger s.n. [L 908. 185-1665] (lecto L, selected here), Japan. - See Note 2.

Boehmeria gigantea Satake (1936) 513, syn. nov. - Type: Nakai \& Maekawa s.n. (holo TI), Japan, Honsyu, Suo, 22 July 1935.

Boehmeria quelpaertensis Satake (1936) 514 \& Nakai (1936) 152, syn. nov. - Type: Nakai 4999 (holo TI), South Korea, Quelpaert Island [Quelpart], 3 Nov. 1917. - See Note 6.

Boehmeria grandissima Nakai (1927) 18 [Japanese description only]; Nakai in Satake (1936) 514 [latin description]. - Type: Nakai s.n. (holo TI, n.v., but photograph of type specimen in Satake 1936), Japan, Sikoku, Iyo, 9 June 1927.

Boehmeria grandissima Nakai var. serrulata Satake (1938c) 512. - Type: Hatusima 25 (holo TI), Japan, Kyusyu, Tikuzen, Sikanosima Island [Peninsula], 1937

Boehmeria tosaensis Miyazaki \& H.Ohba (2003) 63, syn. nov. - Type: Miyazaki s.n. (holo TI, photo K), Japan, Shikoku, Kochi Pref., Tosa, 10 Aug. 1992. - See Note 4.

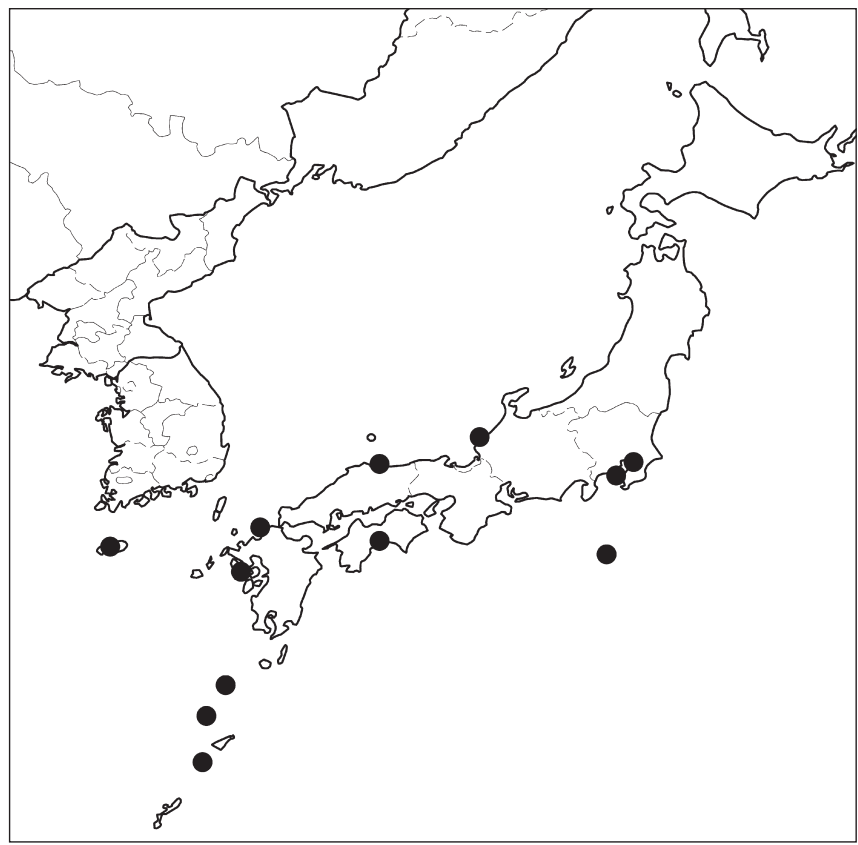

Map 33 Distribution of Boehmeria holosericea Blume. 
Robust erect woody-based herb, up to $1.5 \mathrm{~m}$ tall; ultimate stems robust, $1.5-2 \mathrm{~mm}$; hairs dense, curved \pm spreading, pale, soft minute $(<0.2 \mathrm{~mm}$ ) or rarely half-adpressed, sparser, slightly longer (up to $0.3 \mathrm{~mm}$ ); later glabrescent. Stipules relatively broad, not markedly tapering to apex, $4-7$ by $1.5-4 \mathrm{~mm}$, thintextured. Leaves opposite, not or slightly dimorphic in size only, 'larger' leaf with length of lamina up to $1.2 \times$, but petiole up to $2 \times$ length of 'smaller'; very broadly ovate or deltate, usually medium or large, $10-25$ by $7-21 \mathrm{~cm}$, length equalling or up to $1.4(-1.7) \times$ width; margin dentate or crenate, teeth (15-)20-27 either side, outward-pointing broadly rounded or broadly acute, large $3-10$ by $5-15 \mathrm{~mm}$, width $1.5-3 \times$ length, distal ones progressively slightly longer and wider (length of distal teeth up to $2 \times$ proximal ones) towards leaf apex or of \pm uniform size along most of margin, but always short and indistinct near base; leaf apex with short abrupt acumen of single tooth up to $10(-20) \mathrm{mm}$, up to twice as long as distal teeth and rounded or mucronate at tip, sometimes some leaves also distinctly or indistinctly laciniate with a cleft either side near apex giving \pm trilobed appearance; base broadly rounded, truncate or \pm cordate (rarely slightly cuneate); basal veins extending into distal half of lamina, upper lateral veins similarly arranged on both sides, 1-2 either side, arising in distal half, basal veins thinly prominent abaxially, upper veins and reticulation rather indistinct; texture chartaceous, often rather thin (rarely thicker and leaves slightly bullate); adaxial surface with hairs sparse to abundant, soft, curved, half-adpressed or spreading, often much longer than on stem (0.5-0.7 mm long); abaxial surface with hairs shorter (0.4-0.6 mm long), curved, (sparse-)abundant, often dense and velvety and concealing epidermis, abaxial surface paler than adaxial in dry state; petiole very variable $0.25-0.6 x$ lamina length, hairy as lamina. Flower-clusters borne on leafless axes, 1 per axil, mostly unisexual but often on same plant; male axes pendulous, $7-12(-15) \mathrm{cm}$ long, (unbranched or) often with many short or long lateral branches throughout length, very occasionally main axis with tuft of leaves at tip, flower-clusters very crowded or well-spaced, 3-5 $\mathrm{mm}$ diam, with few $(-20)$ flowers; female (or mainly female) axes erect, (7-)15-20 cm long, mostly entirely female and unbranched but sometimes bisexual with a few very short male lateral branches near base, flower-clusters \pm contiguous but distinguishable, 4-7 cm diam, with over 50 densely congested flowers; bracteoles tiny and inconspicuous in densely congested clusters. Male flowers 4-merous, sessile, mature buds depressed-globose, c. $1 \mathrm{~mm}$ diam, tepals without dorsal appendage or with slight dorsal thickening, hairy like stem. Female flowers ellipsoid to obovoid, relatively broad, c. 1 by $0.3 \mathrm{~mm}$, distinctly beaked, densely hairy; stigma 1.5-2 mm long. Fruiting perianth slightly asymmetrically ellipsoid to obovoid-truncate, c. 2 by $1 \mathrm{~mm}$, scarcely beaked, slightly laterally flattened with distinctly inflated winged shoulders, pubescent. Achene ellipsoid to ovoid, $0.4-0.5$ by $0.8-1.2 \mathrm{~mm}$, partly filling fruiting perianth.

Distribution - South Korea (Jeju 'Quelpart' Island), Japan (Honshu, Shikoku, Kyusyu, Ryukyu Islands).

Habitat \& Ecology - Rocky areas near seashore; sunny or semi-shaded mesic plains along forest margins; at or near sea level (most collections lack habitat data).

Conservation status - Data deficient (DD). We are not able to give a formal assessment of $B$. holosericea as either Least Concern (LC) or Near Threatened (NT), since its particular habitats are not currently threatened, but it is known from less than 20 collections, only a few of which are recent and it occurs in only 15 rather scattered locations.

Notes -1 . No material is cited in the protologue of $B$. holosericea by Blume (1857), but Weddell (1869) cited only material collected by Burger. At $L$ there are two sheets annotated by Blume with this name. One is only marked ' $\mathrm{B}$ ', the other is marked 'Burger'. We therefore select the specimen Burger s.n. as the lectotype of $B$. holosericea.

2. According to Blume (1857) his B. hispidula comes from "Sumatra, Palembang." However, Koidzumi (1926: 346) has recorded two specimens as types: Burger s.n. [L 908.1851665] Japan, and Siebold [L 908.185-1680], without locality, and stated that Blume had apparently mistaken the locality for this plant. We have seen both specimens and select the one with the epithet in Blume's original handwriting as lectotype.

3. This and the following two species, B. sieboldiana and $B$. japonica, are closely similar and appear to constitute a complex of partly intergrading taxa. Boehmeria japonica is extremely variable. Boehmeria holosericea and $B$. sieboldiana (partly sympatric with one another and both sympatric within part of the distribution of $B$. japonica and extending to the Ryukyu Islands) show much less morphological variation but exhibit intermediates with one another and with $B$. japonica. The extensive synonymy relating to $B$. japonica reflects the complexity of the inter-relationships between and within the taxa here recognised; partial apomixis within $B$. japonica further complicates the relationships.

4. Boehmeria holosericea is endemic to Japan and South Korea. Its spreading indumentum varies widely from dense and conspicuous to rather sparse, such that individuals at the extremes of the range of variation appear rather different but cannot be separated as distinct taxa because they are linked by a continuous range of intermediates. For this reason $B$. tosaensis, described in the protologue as "differing from $B$. gigantea on its sparse indumentum" is here reduced to synonymy.

5. Boehmeria holosericea is distinctive in its very broad leaves with large often rounded marginal teeth, some leaves being indistinctly trilobed at the apex and its thick crowded erect \pm unbranched female inflorescence-bearing axes with clusters 4-7 mm diam.

6. The sympatric but more widespread B. japonica var. japonica has similar spreading indumentum, leaves often large and broad leaves with apex often trilobed. Boehmeria japonica differs from $B$. holosericea in marginal teeth acute and up-curved with distal ones progressively markedly larger than proximal ones (teeth usually also fewer) and apical tooth distinct, relatively longer and narrower; leaf-hairs are often minute, the leaf is never bullate and inflorescence-bearing axes are mostly pendulous with clusters often smaller and wider-spaced along the axis. As discussed in our introduction, Yahara (1983a) showed ecological, cytological and reproductive separation, $B$. holosericea being diploid and sexual, B. japonica var. japonica (cited as $B$. longifolia) an apomictic complex of many polyploid races with occasional fertile male flowers. He did not find any evidence of hybridisation between the two species, although subsequently (Yahara 1984a: 141) he suggested one of these entities, $B$. quelpartensis, to be a hybrid between $B$. holosericea and $B$. japonica. However, the type of $B$. quelpartensis is extremely similar to that of $B$. holosericea and the two are here considered conspecific.

7. However, material intermediate between $B$. holosericea and $B$. japonica var. japonica has also been seen (teeth many, slightly up-curved and/or larger upwards, apex sometimes \pm trilobed). This intermediate (possibly hybrid) material includes the types of the following names (including B. nakashimae, one of the entities studied by Yahara):

Boehmeria villigera Satake (1936) 516. - Type: Satake 3541 (holo TI), Japan, Honsyu, Izu, 8 Sept. 1935.

Boehmeria praestabilis Satake (1936) 519. - Type: Satake 3544 (holo TI; iso TI), Japan, Honsyu, Izu, 5 Sept. 1935.

Boehmeria nakashimae Yahara (1983b) 88. - Type: K. Nakashima 15 (holo TI), Japan, Kyushu, Fukuoka City, 19 Sept. 1937. 
Probably also the following type material:

Boehmeria quelpaertensis Satake forma glabra Satake (1936)

516. - Type: Nakai s.n. (not traced), South Korea, Quelpart Island, 3 Nov. 1917.

8. A range of entities of obscure identity with the same geographical range as $B$. holosericea also exists, having some characters of the often coastal sympatric species $B$. splitgerbera (2 kinds of hairs; leaves sometimes misshapen or slightly bilobed at apex; reticulation prominent) but marginal teeth fewer, larger, like those of $B$. holosericea. As discussed in our introduction Yahara (1983a: 242) suggested that these entities originated through hybridisation of $B$. splitgerbera with other taxa, the thinner-leaved forms possibly with the $B$. japonica complex. However, some of this thin-leaved material is so similar in leaf shape to $B$. holosericea that this is as likely a parent as $B$. japonica. The types of nine names, some of which were mentioned by Yahara, fall within this range of variation and are cited in Note 5 under B. splitgerbera.

9. Some other material without the distinctive bilobed leaf apex and lacking male flowers (therefore possibly apomictic) is impossible to assign with certainty to either $B$. holosericea or the above-mentioned probable hybrid populations.

10. Material intermediate (?hybrid) with the sympatric but more widespread $B$. sieboldiana has also been seen, discussed under that species (see Note 3). Boehmeria sieboldiana differs in much narrower gradually attenuate \pm glabrous usually thintextured leaves often with more numerous upper veins, male and female inflorescence-bearing axes with small usually wellspaced clusters.

11. Boehmeria ourantha (China, Himalayas, Indonesia) is rather similar in leaf shape and marginal teeth to $B$. holosericea, but differs in extremely long stem indumentum, thicker-textured leaves with up-curved teeth and the unusual arrangement of its male flowers at the extreme apex of mainly female axes or a few male flowers scattered along the axis.

12. Marginal teeth are reminiscent of some forms of the variable $B$. virgata subsp. macrophylla s.lat. (allopatric) although larger, and two varieties of $B$. virgata subsp. macrophylla, var. macrostachya and var. strigosa, can have very similar leaf shape but stem hairs are inconspicuous and closely-adpressed, female inflorescence-bearing axes long, pendulous and slender with well-spaced clusters and male axes often short, erect and with several branches; var. strigosa also differs in shiny-silky indumentum on the abaxial leaf surface.

\section{Boehmeria sieboldiana Blume - Fig. 33; Map 34}

Boehmeria sieboldiana Blume (1857) 220. - Boehmeria platyphylla D.Don var. sieboldiana (Blume) Wedd. (1869) 213. - Syntypes: Herb Siebold s.n. [L 908.185-1370] (L), Japan; Siebold s.n. [L 908.185-1446] (L), Japan; Burger s.n. [L 908.185-1420] (L; isosyn P), Japan.

Perennial herb, up to $1.3 \mathrm{~m}$, often robust and thick-stemmed (up to $8 \mathrm{~mm}$ diam), ultimate stems (1-)1.5-2 mm diam; hairs very sparse to abundant, fine, adpressed. Stipules long and narrow, $4-9$ by $1-1.5 \mathrm{~mm}$, with long-acuminate apex. Leaves opposite, not or slightly dimorphic, with length of 'larger' leaves up to $1.4 x$ 'smaller' ones and relatively narrower, and narrowly ovate or ovate-attenuate to rhombic-ovate, rarely very narrowly elliptic-ovate, most leaves medium or large, (8-)10-20 by $3.5-10 \mathrm{~cm}$, length $2-3(-4.5) \times$ width (leaves near base of stem often longer and relatively broader, up to 24 by $15 \mathrm{~cm}$, length only $1.5 \times$ width); marginal teeth (13-)15-30(-40) either side, large, acute, often relatively narrow, mostly outward-pointing (upper margin straight or slightly convex), usually fairly uniform in size $(0.5-) 2-5(-10)$ by $(3-) 5-9(-15) \mathrm{mm}$ (rarely distal ones larger, up to $1.5 \times$ broader but not markedly longer than proximal ones and with their upper margin slightly concave); leaf apex attenuate-acuminate with a single fairly long tooth up to $0.2(-0.25) \times$ total lamina length; base broadly rounded or slightly cordate or rounded with abruptly short-cuneate extreme base; basal veins reaching distal third of leaf, upper lateral veins 3-5 either side but scarcely distinguishable from coarser tertiary venation, lowermost arising near middle of lamina, these and the somewhat scalariform coarser tertiary venation visible but not prominent abaxially; texture membranous or thin-chartaceous, rarely thicker and leaves slightly bullate (but see Note 3); surface glabrous or sometimes (especially very young leaves) with hairs both sides, these very sparse, long; abundant minute cystoliths visible adaxially in dry state; petiole 0.25-0.5x lamina length. Flower-clusters borne on leafless inflorescence-bearing axes, these unbranched, \pm erect, 8-more than $20 \mathrm{~cm}$ long, uni- or bisexual with female clusters in upper part; clusters usually fairly well spaced $1-4 \mathrm{~mm}$ apart giving slender appearance, rarely almost contiguous; male clusters small, 1-2 mm diam, with few-10 flowers, female clusters $1.5-3 \mathrm{~mm}$ diam (up to $4(-5) \mathrm{mm}$ in fruit), with $10-50$ loosely arranged flowers; bracteoles obovate, inconspicuous, c. $0.3 \mathrm{~mm}$ long. Male flowers 4-merous, sessile, lobes divided more or less to base, mature buds depressed-globose, c. $1.5 \mathrm{~mm}$ diam, tepals without dorsal appendages, hairs sparse, adpressed. Female flowers broad-ovoid, often relatively flattened, c. 0.7 by $0.3 \mathrm{~mm}$; stigma of varying length, $0.3-2 \mathrm{~mm}$ long. Fruiting perianth either broadly ovoid to obovoid sometimes tapering to indistinct pedicel, only moderately laterally flattened but with distinct marginal rim or \pm winged, or rhombic to subglobose with broadly rounded base, not or scarcely laterally flattened and without marginal rim; $1-2.5$ by $0.7-1.5 \mathrm{~mm}$, length usually less than $1.5 \times$ width; glabrous or very sparsely adpressed-hairy.

Distribution - South Korea (Jeju 'Quelpart' Island), Japan (Honshu, Shikoku, Kyushu, Ryukyu Islands), southern and southeastern China.

Habitat \& Ecology - Dense forest on Eocene limestone, littoral forest, secondary forest, thickets, margins of cultivation, often in partial sun in moist soil by streams or on coral; 10$1400 \mathrm{~m}$ altitude.

Conservation status - Least Concern (LC). It is known from more than 200 collections from many locations in a wide range of habitats, and some of these collections are recent. Separate formal assessments are not given for the two, intergrading, varieties.

Notes -1 . This species is distinctive in its leaves rhombic or rhombic-ovate, fairly narrow ('nettle-like') \pm glabrous and usually thin-textured, marginal teeth fairly uniform, large but relatively narrow, flower-clusters relatively small and well-spaced.

2. Two varieties of $B$. sieboldiana are recognised. Var. fuzhouensis is considered worthy of recognition in its possession of several correlated characters and its apparent restriction to part of the species range, but recognised only at varietal level due to the existence of several intermediate collections from part of the same region (Zhejiang).

3. Forms of $B$. sieboldiana var. sieboldiana with marginal teeth slightly larger towards the leaf apex are difficult to distinguish from some forms of $B$. japonica, which is partly sympatric with $B$. sieboldiana, extending to Northern China and Northern Japan (Hokkaido) but absent from Ryukyu Islands. Boehmeria japonica differs from $B$. sieboldiana mainly in its leaves ovate (rather than mostly rhombic-ovate) with cuneate to truncate base, also mostly relatively broader (length rarely up to $2 \times$ width); leaves differ in one or usually two of the following characters of the marginal teeth: distal ones progressively markedly larger than proximal; or all teeth markedly up-curved; or teeth very few (only up to 12 either side) and very long such that leaf appears laciniate, leaves then also often being smaller than in $B$. sieboldiana with their terminal tooth often comprising up to half of lamina length. Some forms of $B$. japonica have 


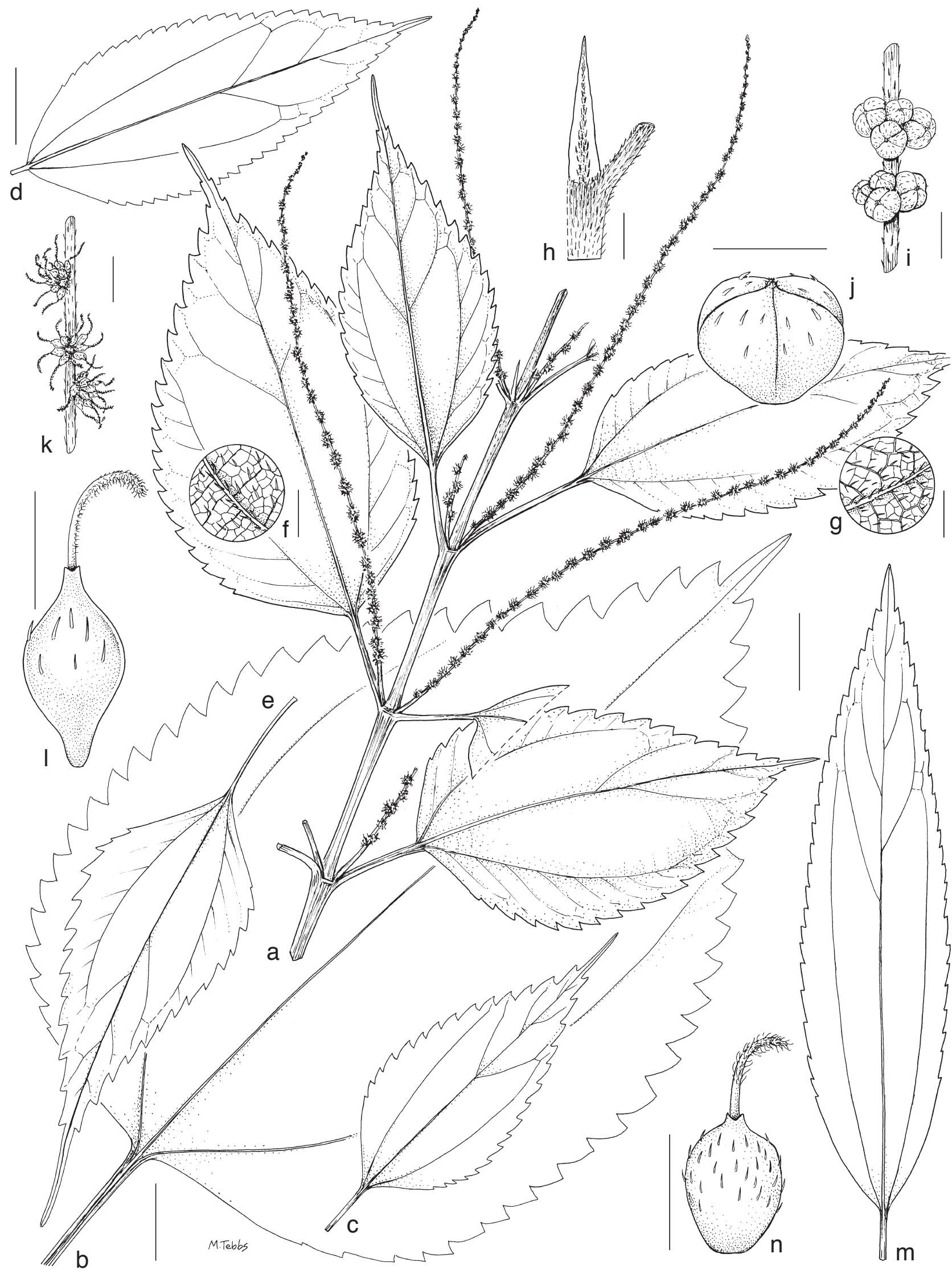

Fig. 33 a-l: Boehmeria sieboldiana Blume var. sieboldiana. a. Habit of stem with inflorescence-bearing axes; b. large leaf from basal part of stem; c. small leaf from upper part of stem (same plant); d, e. leaves from different plants; f. leaf, detail of adaxial surface; g. leaf, detail of abaxial surface; h. detail of stem and stipule; i. detail of male inflorescence-bearing axis with two flower-clusters (inflorescences); j. male bud; k. detail of female inflorescence-bearing axis with three flower-clusters (inflorescences); I. fruiting perianth. $-\mathrm{m}, \mathrm{n}$ : Boehmeria sieboldiana var. fuzhouensis (W.T.Wang) Friis \& Wilmot-Dear. $\mathrm{m}$. Leaf; n. fruiting perianth (a-c, f-h: Furuse 45347; d: Wilford 547; e: Mizushima 939; i-k: Furuse 3790; l: Fosberg 37912; m, n: Chung 2798; all K). — Scale bars: $a-e, m=2 \mathrm{~cm} ; f-i, k=2 \mathrm{~mm} ; j, \mathrm{l}, \mathrm{n}=1 \mathrm{~mm}$. 
spreading hairs, the inflorescence-bearing axes are sometimes branched, and its fruiting perianth is often broadly-winged. Differences are discussed in detail under $B$. japonica (see Note 12). Material somewhat intermediate (possibly hybrid) between the two species includes the type collections of $B$. kiusiana and $B$. sieboldiana var. ovata, which are cited under B. japonica var. japonica (see Note 7).

4. Material intermediate in appearance with $B$. holosericea (sympatric but less widespread: Japan, South Korea) occurs in Japan. Boehmeria holosericea differs from B. sieboldiana in leaves thicker, broader, sometimes somewhat bullate with short distinct acumen, fewer veins, female axes with large contiguous clusters and most parts of plant usually with spreading indumentum. In the intermediate material leaves are relatively broader and mostly more thick-textured than in $B$. sieboldiana, female axes have flower-clusters large and contiguous and fruiting perianth sometimes broader-winged and tapering. This entity, described as $B$. egregia Satake, was considered by Kitamura \& Murata (1961) as intermediate, possibly a hybrid with $B$. splitgerbera, Ohba (2006: 108) similarly suggested it to be a hybrid between $B$. sieboldiana and $B$. splitgerbera, but Yahara (1983a) thought hybridisation unlikely because it lacks any of the distinctive characters of $B$. splitgerbera (two kinds of hairs, bilobed leaves, bifurcated main veins). He suggested the possibility of parallel evolution, but it could equally be considered, and is here considered, as intermediate (possibly a hybrid) with $B$. holosericea. This intermediate material includes the type of $B$. egregia, which is therefore cited below.

5. Walker (1976: 413) noted similarly thicker- and broaderleaved variants (also with longer stigma and fruiting perianth) in Ryukyu Islands (which he referred to as $B$. sieboldiana, referring to the thin-leaved ones as $B$. formosana even though the types of both names have thin narrow leaves), but suggested that the two entities were probably variants of a single species.

The following type and the name based on it represents material intermediate with $B$. holosericea:

Boehmeria egregia Satake (1936) 487. - Type: Satake 3522

(holo TI; iso TI), Japan, Honsyu, Izu Province, Izu Osima Is., 9 Sept. 1935.

\section{Key to varieties}

1. Leaves narrowly ovate or rhombic-ovate, length $2-3 \times$ width, marginal teeth 2-4 $\mathrm{mm}$ long, often more than 25 either side; fruiting perianth tapering to base, ovoid or obovoid, moderately laterally flattened with distinct marginal rim or wing. - Japan; South Korea; southern and south-eastern China . . . . . . . . . . . . . . a. var. sieboldiana

1. Leaves very narrowly elliptic-ovate, length $4-4.5 \times$ width, most marginal teeth only $0.5-1 \mathrm{~mm}$ long, up to 25 either side; fruiting perianth rounded at base, rhomboid or subspherical, not or scarcely laterally flattened and without rim. - Southeastern China . . . . . . . . . . . b. var. fuzhouensis

\section{a. var. sieboldiana - Fig. 33a-I; Map 34}

Boehmeria platyphylla D.Don var. stricta C.H.Wright (1899) 487. - Boehmeria formosana Hayata var. stricta (C.H.Wright) C.J.Chen in Chen et al. (2003) 171. - Syntypes: Oldham 521 (K), Taiwan; Wilford 547 (K), Taiwan; Henry 187 (K; isosyn NY) \& 1293 (K), China; Ford 107 (K), China, Guangdong.

Boehmeria formosana Hayata (1911) 281. - Syntypes: Kawakami \& Kobayashi 1472b (TI), Taiwan, Taito, May 1906; Nakahara 68 (not traced), no loc., June 1905.

Boehmeria taquetii Nakai (1914) 267. - Type: Taquet 5965 (holo TI), South Korea, Quelpart Island, Aug. 1911.

Boehmeria pseudo-sieboldiana Honda (1931) 469. - Type: K. Mayebara 318 (holo TI), Japan, Kiusiu, Higo Prov., Omura, 12 Aug. 1929.

Boehmeria nakaiana Satake (1936) 491; Satake in Nakai (1936) 145. — Type: Nakai 6156 (holo TI), South Korea, Quelpart Island, 31 Oct. 1917.

Boehmeria hirtella Satake (1936) 493; Satake in Nakai (1936) 145. - Type: Taquet 4433 (holo TI), South Korea, Quelpart Island, 16 Aug. 1910.

Boehmeria stenostachya Satake (1938a) 202. - Type: Hatusima s.n. (holo TI), Japan, Kyusyu, Hizen Prov., Mt Kurokamiyama, 6 Sept. 1936.

Boehmeria sieboldiana Blume var. sikokiana Satake (1938b) 263, syn. nov. - Type: Koidzumi s.n. (holo TI), Japan, Sikoku, lyo, 6 July 1915. - See Note 4.

Leaves narrowly ovate, ovate-attenuate or rhombic-ovate, (8-) $10-20$ by $3.5-10 \mathrm{~cm}$, length $2-3 \times$ width, margin with $15-30$ $(-40)$ large teeth either side, $2-5(-10)$ by $5-9(-15) \mathrm{mm}$. Fruiting perianth broadly ovoid to obovoid tapering to base, sometimes with indistinct pedicel, $1.2-2.5$ by $0.7-1.5 \mathrm{~mm}$, length $1.3-1.5(-1.8) \times$ width, only moderately laterally flattened but with distinct marginal rim or \pm winged, glabrous or sparsely adpressed-hairy.

Distribution - Throughout the range of the species.

Habitat \& Ecology - Dense forest on Eocene limestone, littoral forest, secondary forest, thickets, margins of cultivation, often in partial sun in moist soil by streams or on coral; $10-$ 1400 m altitude.

Notes -1 . Distinguished from var. fuzhouensis by its leaves always clearly ovate with length usually only up to $3 \times$ width,

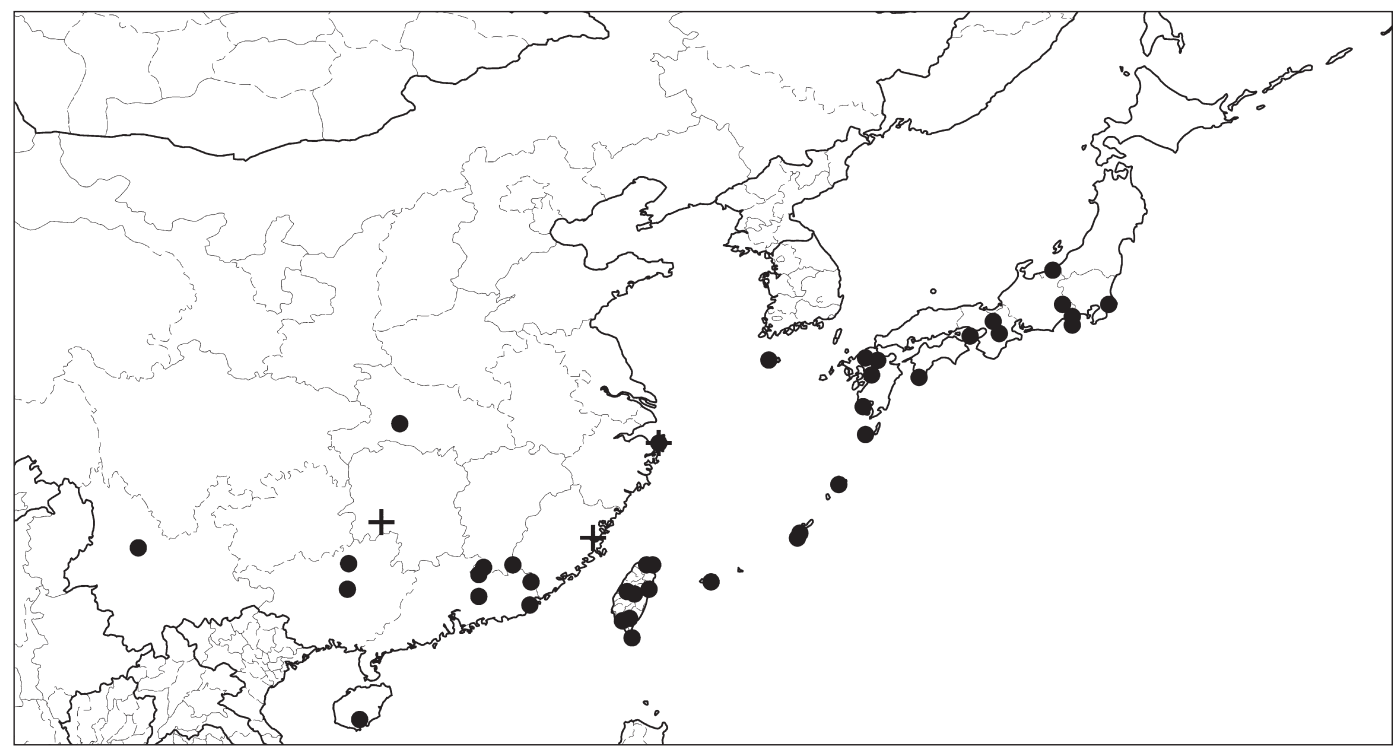

Map 34 Distribution of Boehmeria sieboldiana Blume var. sieboldiana $(\bullet)$ and B. sieboldiana Blume var. fuzhouensis (W.T.Wang) Friis \& Wilmot-Dear (+). 
marginal teeth usually longer, fruiting perianth always somewhat flattened with tapering base.

2. One collection of uncertain identity from the Philippines (Luzon, Apayao, May 1917, Fenix BS28030, BO) is possibly referable to this taxon which has not been recorded so far to the south-east, but might possibly occur there.

3. Ying (1988) contains a photograph (no. 561) labelled as $B$. formosana but clearly not of $B$. sieboldiana (almost certainly of $B$. pilosiuscula); however, the figure on p. 465 labelled $B$. formosana is indeed $B$. sieboldiana. Yang et al. (1996: photo no. 78,80 on p. 785 ) illustrate both these taxa.

4. The material described as var. sikokiana has small but unusually wide leaves but is not otherwise distinct, and the name is therefore reduced to synonymy here.

5 . For discussion of similarity to $B$. japonica and $B$. holosericea, and possible hybrid material, see Notes 3-5 under the species as a whole.

\section{b. var. fuzhouensis (W.T.Wang) Friis \& Wilmot-Dear, comb.} nov. - Fig. 33m, n; Map 34

Basionym: Boehmeria formosana Hayata var. fuzhouensis W.T.Wang (1981b) 403. - Type: H.H. Chung 2798 (holo F; iso K, UC), China, Fujian, Fuzhou, 28 July 1935.

Boehmeria platyphylla D.Don var. stricta sensu Chen et al. (2003) 171, non Wright. - See Note 2.

Leaves narrowly elliptic to narrowly ovate, $7-18$ by $1.8-4 \mathrm{~cm}$, length 4-4.5x width, margin with 15-25 shallow teeth, $0.5-2$ by 3-6 $\mathrm{mm}$. Fruiting perianth, broadly rhomboid to subspherical, $1-1.5$ by $1-1.2 \mathrm{~mm}$, not or scarcely laterally flattened and without marginal rim, base broadly rounded.

Distribution - South-eastern China.

Habitat \& Ecology - Shaded and disturbed places, e.g., by roadsides, recorded from limestone; $350 \mathrm{~m}$ altitude.

Notes -1 . This variety is distinctive in its leaves very narrowly elliptic-ovate with teeth relatively few broad and short and its fruiting perianth without a marginal rim and with a broadly rounded base. It is restricted to part of the range of the typical variety and apparently rare, only four collections seen. Four additional collections seen from Zhejiang were somewhat intermediate with leaves ovate-attenuate rather than linearelliptic-ovate, and fruiting perianth slightly flattened with slight marginal rim.

2. Var. fuzhouensis was recognised by Chen et al. (2003: 171) under the name $B$. formosana var. stricta, with the later published epithet fuzhouensis in synonymy. However, although the description in Chen et al. (2003) conforms to var. fuzhouensis all the syntypes of var. stricta (described as B. platyphylla D.Don var. stricta C.H.Wright by Wright (1899: 487)) conform to the typical variety and var. fuzhouensis is therefore the earliest name for this taxon.

\section{Boehmeria japonica (L.f.) Miq. - Fig. 34, 35; Map 35-37}

Boehmeria japonica (L.f.) Miq. (1867) 131. — Urtica japonica L.f. (1781) 418. - Boehmeria platyphylla D.Don var. japonica (L.f.) Wedd. (1869) 213, nom. illeg., non Boehmeria platyphylla D.Don var. japonica Wedd. (1856) 365. - Type: Thunberg s.n. (lecto in Smith herbarium [Linnaean Society of London], IDC microfiche LINN. no. 1456-5, lectotype selected by Yahara 1984a: 133), Japan. - See Note 1.

Urtica spicata Thunb. (1784) 69. - Boehmeria spicata (Thunb.) Thunb. (1794b) 330, nom. illeg. superfl. - Type: Thunberg 22116 (lecto UPSTHUNB, left-hand plant, lectotype selected by Yahara 1984a: 130). - See Note 1.

Subshrub or woody-based herb, often robust and thick-stemmed, 1.5-5 m tall; ultimate stems (1-)1.5-2 mm diam; hairs very sparse to abundant, fine, adpressed and short or \pm spreading and often of various lengths. Stipules long and narrow, 4-9 by
1-2 mm, with long-acuminate apex, with dense pubescence on outside often restricted to midrib. Leaves opposite, not or slightly dimorphic with length of 'larger' leaves $1-1.5(-2) \times$ that of 'smaller' leaves, ovate to broadly rhombic-ovate or ovatetruncate, rarely obovate, rather variable in size and proportions, small to very large, $2-20$ by $1-17 \mathrm{~cm}$, length equalling or up to $2 \times$ width; margin large-dentate, teeth $6-15(-25)$ large, broad, slightly up-curved, acute, 1-15 by 1-15 $\mathrm{mm}$, distal ones progressively markedly larger, length of those near apex at least twice, usually $3-10 \times$ length of those in proximal third of lamina; leaf apex varying from acuminate with single long tooth (several times longer than most marginal teeth and often constricted at base), to rounded-truncate in outline but 3-5-toothed, with 1-2 long subapical teeth either side of terminal tooth, leaf appearing either deeply laciniate (terminal and subapical teeth narrow, in-curved) or \pm 3 -lobed (terminal and subapical teeth broad, outward-pointing, often secondarily toothed); base broadly cuneate to \pm truncate (rarely slightly cordate), basal veins reaching distal third of leaf, upper lateral veins $3-5$ but scarcely distinguishable from coarser tertiary venation, lowermost arising near middle of lamina, these and somewhat scalariform coarser tertiary venation visible but not prominent abaxially; texture usually thin- or thick-chartaceous, sometimes \pm membranous; hairs on adaxial surface abundant but often minute inconspicuous, adpressed or \pm spreading, cystoliths fairly abundant but not conspicuous; hairs on abaxial surface denser but finer mostly restricted to main veins and fine reticulation; petiole very variable with respect to leaf-size, 0.25-0.5x lamina length. Flower-clusters borne on leafless axes, these unisexual, erect or \pm pendulous, (5-)10-25 cm long, 1 (-several) per axil, unbranched or with few long branches near base (rarely throughout most of length); plants unisexual or bisexual but male axes often rare (see discussion in Note 3); flower-clusters rather close-spaced almost contiguous or up to $2 \mathrm{~mm}$ apart, male clusters small with few-c.10 flowers, female very variable in number of flowers and size, $1.5-2(-3) \mathrm{mm}$ diam in flower (up to 4-5 mm in fruit), with (10-)30-50 or more densely crowded flowers; bracts conspicuous or inconspicuous, in male clusters short, broadly triangular, up to $1.5 \mathrm{~mm}$ long, in female clusters up to $5 \mathrm{~mm}$ long, linear-oblong or narrowly triangular. Male flowers 4-merous, sessile, lobes divided more or less to base, mature buds depressed-globose, c. $1.5 \mathrm{~mm}$ diam, tepals without or with only slight dorsal appendages (male flowers often absent or infertile as discussed below), hairs sparse, spreading. Female flowers narrowly ellipsoid or ovoid, slightly flattened, c. 1 by $0.2-0.4 \mathrm{~mm}$, hairs abundant, short, stiff; stigma very variable, (0.5-)1-2.5 mm long. Fruiting perianth rather variable in size and shape, narrowly ellipsoid to broadly obovoid, rarely ovoid, abruptly or gradually tapering to base and without or with very short abrupt apical beak, slightly laterally flattened in middle portion and with distinct marginal rim or (especially Japanese material) markedly flattened into wing around achene, $1-2.5$ by $0.5-1.5$ with length scarcely exceeding or up to $2.5 \times$ width; with indumentum of sparse or abundant adpressed or long to short velvety spreading hairs especially in distal half. Achene occupying middle third of fruiting perianth (broadly-winged forms) or almost filling fruiting perianth.

Distribution - China (including Taiwan), South Korea, Japan (Hokkaido, Honshu, Shikoku, Kyushu).

Habitat \& Ecology - Very varied; swamps in sandy soil; streams and moist slopes in deciduous forest, forest margins; open or shady damp ravines; thin evergreen forest; scrub in valleys; barren dry hillsides; grassland; walls and roadsides; 70-2600 m altitude.

Conservation status - Least Concern (LC). It is known from more than 200 collections from many locations in a wide range of habitats. Formal assessments are not given for the three, intergrading, varieties. 
Notes -1 . The first name to be published on material of this taxon brought back from Japan by Thunberg was Urtica japonica L.f. (1781), based on an unnumbered Thunberg specimen in the Linnaean herbarium, followed by Urtica spicata Thunb. (Thunberg 1784), based on 2 collections (comprising 3 specimens) in the Thunberg herbarium. Thunberg later (1794b) transferred his Urtica spicata to Boehmeria and cited Urtica japonica as a synonym; his new combination $B$. spicata (Thunb.) Thunb. is therefore illegitimate, since Linnaeus's epithet japonica (1781), is earlier and should have been adopted. Subsequently, Yahara (1984a: 135) stated that the type of $U$. japonica, (a single specimen) although considered a duplicate of Thunberg 22115 \& 22116, is similar only to the left half of 22116; he considered that the other two specimens of Thunberg's type material belonged to a distinct taxon, for which he maintained Thunberg's illegitimate name $B$. spicata. This distinct taxon is recognised here as $B$. japonica var. tenera taking up the earliest available name at varietal rank.

2. Boehmeria japonica s.lat., as here circumscribed, occurs throughout most of Japan (Hokkaido, Honshu, Kyushu, Shikoku), in South Korea and most of China including Taiwan. It is a herb or subshrub characterised by ovate leaves with marginal teeth markedly up-curved, the distal ones progressively regularly longer and wider than proximal, relatively few even on large leaves, often also a tendency to leaf apex 3-5-lobed and leaf base often truncate.

3. Boehmeria japonica exhibits a matrix of variation with respect to a range of leaf characters some of which vary independently of one another: leaf-size and proportions, number of marginal teeth, leaf apex (caudate, acuminate or truncatelaciniate with 1-2 almost equally long marginal teeth or even lobes either side of terminal tooth), indumentum of stems, petioles and inflorescence-bearing axis (spreading or adpressed). As discussed in detail in our introduction section on species delimitation, Okabe (1956) and Yahara (1983a, 1984a) demonstrated apomixis and polyploidy in some parts of this group of taxonomic entities in Japan, complicated by the occasional production of fertile male flowers and subsequent hybridisation within the group or with other Japanese taxa, resulting in "complicated morphological variation and obscure species boundaries" such that "Boehmeria in Japan is an example of an apomictic complex" (Yahara 1983a: 218). Thus a formal classification is artificial and unsatisfactory, as is well-illustrated by the complicated taxonomic history of this group discussed in the introduction. Yahara's work also strongly suggested hybridisation with taxa outside the group, $B$. splitgerbera (previously referred to as $B$. biloba) (Yahara 1983a: 243, 1984a: 141) and B. holosericea (Yahara 1984a: 141).

Interpreting the range of variation seen in herbarium material in the light of the morphological and cytological findings of Okabe and Yahara, this group of entities seems best considered as comprising three partly intergrading varieties, differing in a combination of indumentum and leaf morphology with incompletely overlapping distributions, the morphological distinctions slightly obscured by intermediates between them and by a group of hybrids, some of uncertain parentage.

4. Boehmeria japonica var. japonica is characterised by its spreading pubescence on young stems, inflorescence-bearing axes, petioles and abaxial leaf surface, and its medium or large often thick-textured leaves. Inflorescence-bearing axes vary widely in length and in spacing of clusters. Its leaf shape varies greatly from narrowly rhombic-ovate and acuminate to very wide with apex laciniate-3-toothed or leaf \pm 3 -lobed, base truncate or broadly rounded, and marginal teeth few and large. It occurs further south and less far north in China than the other two varieties and is absent from northern Japan (Hokkaido). The forms with broad-laciniate leaves appear to extend to higher altitude and more moist habitats than the ovate acuminate forms.

This variety broadly corresponds to Yahara's $B$. longispica (1983a) which he subsequently (1984a) altered to " $B$. Iongispica complex" in which he recognised two intergrading varieties, $B$. japonica var. japonica and var. apiculata, the former with apex long-caudate and distal lateral teeth narrow and long-caudate, the latter more variable with distal lateral teeth broader and apex acute to deeply 3-toothed. However, our concept of var. japonica is broader in including material conforming to the type of $B$. japonica var. tricuspis (Hance) Maxim. (leaves deeply laciniate, \pm 3 -lobed to nearly half of lamina length, width of lamina usually exceeding length). The epithet tricuspis is not mentioned by Yahara, but some of his line-drawings of leaves of his $B$. longispica complex represent almost this extreme variant. Although the type of var. tricuspis represents one extreme of the range of variation, neither this nor Yahara's concept of var. japonica and var. apiculata are maintained here because abundant herbarium material provides a continuous series of intergrading intermediates exhibiting various character states with respect to leaf proportions, apex and marginal teeth; therefore any separation into two entities would be arbitrary and unworkable. This contrasts with the situation between var. silvestrii and var. tenera discussed below (see Notes 5, 6 ), where there is a similar difference in leaf apex but where most entities can be referred to one or the other taxon with comparatively few intermediate collections.

Yahara (1983a) demonstrated various polyploid apomictic races and the occasional production of fertile male flowers within his ' $B$. longispica'. Further cytological investigation and population studies including these extreme ('var. tricuspis') entities would be helpful to clarify the situation with respect to apomixis and possible hybridisation with the following variety, var. silvestrii.

5. Boehmeria japonica var. silvestrii has leaves deeply laciniate and few-toothed as in the apically broad-laciniate forms of var. japonica, but thinner-textured, often smaller and the plant is glabrous or sparsely adpressed-hairy. It is the only variety recorded as far north as Hokkaido, and in China it extends further to the north, and less far south and east, than var. japonica. The cytological work of Okabe (1956) showed it to be diploid and sexually reproducing, supporting recognition of it as a distinct entity. Yahara (1983a: 232) discussed a range of polyploid entities intermediate between var. silvestrii and his ' $B$. longispica' (= var. japonica as circumscribed here) with leaves laciniate or \pm 3 -lobed, very large and thick-textured but glabrescent. These entities included material conforming to the type of B. platanifolia. Subsequently, Yahara (1984a: 141) assumed this material to be a hybrid between his ' $B$. japonica' (= var. japonica here) and ' $B$. silvestrii' (= var. silvestrii). We follow his suggestion here and consider these variants as intermediates between the two varieties here recognised; they are cited under var. japonica, Note 6. The above-mentioned extreme variants of var. japonica with deeply laciniate but spreadinghairy (rather than adpressed-hairy) leaves, to which the epithet 'tricuspis' applies, may also be of hybrid origin.

6. Boehmeria japonica var. tenera is almost sympatric with var. silvestrii (no material seen from Hokkaido but extending further south to most of southern China, incl. Taiwan). It has inflorescence-bearing axes short and erect and is glabrous or glabrescent with thin-textured leaves, as in var. silvestrii but leaves are always fairly small and narrow, ovate or rhombicovate with apex long-acuminate. Leaves are of similar shape to the narrow acuminate forms of var. japonica but mostly much smaller and relatively narrower with fewer marginal teeth, these longer relative to leaf-size, giving a distinctly long-toothed appearance, and the two varieties can be distinguished on a combination of characters as follows. Leaves of var. tenera always 
have a relatively long terminal tooth and any within the size range of var. japonica (i.e., $6-12 \mathrm{~cm}$ long) have an extremely long terminal tooth comprising $0.3-0.5 \times$ total lamina length whereas any narrow and acuminate leaves of var. japonica which are similarly small (only $6-12 \mathrm{~cm}$ ) have a terminal tooth only $0.17-0.25 \times$ lamina length.

Var. tenera broadly corresponds to Yahara's two entities first referred to (1983a) as B. gracilis and (confusingly) ' $B$. japonica' and later (1984a) as respectively a diploid sexually reproducing race and a triploid apomictic race of ' $B$. spicata'. Yahara (1983a) demonstrated that these two entities showed partial altitudinal separation and a range of forms intermediate in morphology and distribution which his cytological investigation strongly suggested to be of hybrid origin. An apomictic polyploid was found at low to medium altitude (300-650 m), a much-branched woody perennial (lacking male flowers) with small leaves with relatively few very in-curved marginal teeth. The sexually reproducing diploid (his $B$. gracilis) was found at medium to high altitude (600 $\mathrm{m}$ and above), a woody-based or annual herb with more numerous less in-curved marginal teeth, shorter terminal tooth and shorter denser hairs on inflorescence-bearing axis. Intermediate plants were found at altitudes of 350-800 m. These usually had a few developed male flowers, were very variable morphologically and were found to include a triploid and a tetraploid race (both races apparently including several apomictic clones), suggesting that this complex taxonomic situation had originated through partial introgression between the supposed parental species.

These two entities, apomictic and sexually reproducing, are here treated as two races of the same variety, because the presence of a continuous series of intermediates makes distinction, as Yahara himself admits, "difficult" (and from herbarium material in practice often impossible). The epithet tenera, the earliest available name at varietal rank, is included in the synonymy of $B$. spicata by Yahara (1984a: 130; note that on page 132 he quotes it as "indistinguishable from typical $B$. japonica", but from the context this must be a slip of the pen for " $B$. spicata").

7. Most collections of $B$. japonica with thin leaves glabrescent abaxially can satisfactorily be identified to either var. silvestrii (apex truncate-laciniate, leaves medium) or var. tenera (apex acuminate, leaves small or medium), but a few individuals with intermediate leaf-shapes have also been seen. Material also exist with leaf apex widely varying on the same plant, from longacuminate near stem apex to truncate-laciniate in lower parts, further illustrating the unsatisfactory nature of formal taxonomy within this partly apomictic group as a whole. Interestingly, var. silvestrii appears to be much less common since more than twice as many collections have been seen conforming to var. tenera.

8. There is fairly clear distinction (based on indumentum, leaf-size, -texture and relative proportions, relative length of terminal tooth and number of teeth) between var. tenera and the acuminate-leaved forms of var. japonica. Only a few intermediate collections (with small sparsely hairy leaves) have been seen compared to the large amount of clearly distinct material of the two taxa. However, between var. japonica and var. silvestrii (which differ in indumentum and leaf texture) there exists a greater range of intermediate entities, as mentioned above (see Note 5); we follow Yahara's interpretation of such entities (1984a: 141 referred to as $B$. platanifolia) as hybrids. Such material is illustrated in Fig 34j, k.

9. Although not all types of names published for eastern Asian entities within this complex have been seen, the discussions and figures of Yahara (1983a, 1984a) make their identities clear.

10. The presence or absence of dorsal appendages on male tepals, usually consistent within a taxon, is variable in $B$. japo- nica, being usually \pm absent but in var. japonica and var. tenera sometimes prominent. The variability in this character also suggests a complex situation of hybridisation.

11. The allopatric (East Himalayan) B. ternifolia var. kamley has leaf shape almost identical to the broad-laciniate variant of $B$. japonica var. japonica, but Acharya et al. (2002, 2003), found no evidence of polyploidy and apomixis within $B$. ternifolia, demonstrating that $B$. ternifolia and $B$. japonica are cytologically distinct as well as allopatric, with no evidence of hybridisation (see further discussion under B. ternifolia, Note 4).

12. Boehmeria sieboldiana (sympatric but absent from northern China and extending to the Ryukyu Islands) is often confused with $B$. japonica (var. japonica and var. tenera), distinguished by leaves rhombic-ovate rather than ovate, with base rounded rather than usually cuneate to truncate, \pm glabrous, with distal marginal teeth not or scarcely larger than proximal ones and out-pointing with \pm straight upper margin and inflorescence-bearing axis never branched. It is distinguished additionally from var. japonica by leaves always thin-textured, never spreading-hairy, always narrow (length of at least upper leaves $2-4 \times$ width) and from var. tenera by its more numerous relatively short marginal teeth (15-40 either side rather than up to 12); the teeth of var. tenera are often so long relative to leaf-size that the leaf appears almost laciniate, and its leaves are also mostly smaller (mostly less than $10 \mathrm{~cm}$ long (rather than mostly over $10 \mathrm{~cm}$ ) and relatively broader, while any leaves within the size range of $B$. sieboldiana have a terminal tooth $0.3-0.5 \times$ (rather than up to $0.25 x$ ) total lamina length. Flowers in $B$. japonica are also narrower and fruiting perianth is more variable, often much more flattened and tapered.

However, forms of $B$. japonica intermediate between the various varieties (hairs adpressed, leaves relatively large and narrow, marginal teeth only moderately up-curved) are hard to distinguish from $B$. sieboldiana var. sieboldiana and several collections somewhat intermediate between the two species have been seen, mostly from Japan; these may be hybrids since (as discussed in the introduction) hybridisation has been demonstrated between B. japonica and other taxa (Yahara 1983a, 1984a). This intermediate material includes the type collections of $B$. kiusiana and $B$. sieboldiana var. ovata which are cited below under var. japonica (see Note 7).

13. Boehmeria holosericea, which is sympatric but less widespread, absent from China and extending to the Ryukyu Islands, has large broad leaves and spreading indumentum which can be confused with those of $B$. japonica var. japonica, differing in marginal teeth more numerous and not up-curved, not or scarcely larger towards leaf apex and often rounded; its apical tooth is often broad and indistinct rather than markedly larger than the marginal teeth; hairs on leaves are soft but coarser, usually longer and its female clusters are often larger and always densely crowded along the axis. However, forms exist with leaf margin characters intermediate between $B$. holosericea and $B$. japonica s.lat. These may be hybrids between the two; see further discussion on hybridisation below and under B. holosericea (see Notes 6, 7).

14. Material exists which is intermediate between $B$. japonica s.lat. and $B$. splitgerbera. The population studies of Yahara (1983a: 218) strongly suggested hybridisation between the two; his further reflections (1984a: 141) on these studies also suggested hybridisation between $B$. japonica and $B$. holosericea, as mentioned above.

15. Two varieties of the widespread $B$. virgata subsp. macrophylla, the partly sympatric var. strigosa (China, Indochina) and var. rotundifolia (eastern Himalaya, China), have marginal teeth mostly increasingly up-curved near leaf apex and can therefore be confused with $B$. japonica, differing in marginal teeth never also markedly larger near leaf apex. Var. tenera can be confused with the small-leaved variety $B$. virgata subsp. 
macrophylla var. densiglomerata which differs in leaf base often cordate, never cuneate, marginal teeth \pm uniform and outwardpointing and inflorescence-bearing axes never over $6 \mathrm{~cm}$ long. Acharya et al. (2002, 2003), found no evidence of polyploidy or apomixis within Himalayan material of ' $B$. macrophylla' (= B. virgata subsp. macrophylla), and thus found no evidence of any hybridisation with the Japanese and Chinese partly polyploid and apomictic and partly hybridising entities which are here all included within $B$. japonica s.lat. He suggested that the Himalayan diploid sexually reproducing taxa, which are restricted to warm humid habitats, may be ancestral to the Japanese and Chinese taxa whose polyploidy has enabled them to be tolerant of a wider range of environmental conditions. Further cytological and molecular work, also extending to Indonesian material, would be helpful in clarifying relationships.

\section{Key to varieties}

1. Young stems, petioles, inflorescence-bearing axis with spreading pubescence, leaves often similarly hairy on major and minor venation abaxially (adpressed or spreading adaxially); leaves (6-)8-20 cm long, mostly thick-textured and/or with more than 12 teeth either side; male flowers densely hairy. China incl. Taiwan; South Korea; Japan (excl. Hokkaido) .

a. var. japonica

1. Young stems, petioles, leaves and often inflorescence-bearing axis entirely glabrous or with sparse short fine adpressed hairs; leaves membranous or very thin-chartaceous, often $<6 \mathrm{~cm}$ long, teeth up to 12 either side; male flowers only sparsely spreading-hairy . . . . . . . . . . . . 2

2. Leaf apex very broadly rounded to truncate in outline, with $1(-2)$ very long teeth either side of terminal tooth giving 3(-5)toothed-laciniate appearance; leaves very broad, length only 1-1.5x width. - Northern \& central China (excl. Taiwan); South Korea; Japan (incl. Hokkaido) . . . . . b. var. silvestrii

2. Leaf apex acute or acuminate in outline with long terminal tooth; leaves relatively narrower, length $1.5-2.7 \times$ width. North, central \& south-western China; South Korea; Japan $\ldots \ldots \ldots \ldots \ldots \ldots \ldots \ldots$. var. tenera

\section{a. var. japonica - Fig. 34a-f; Map 35}

Urtica macrophylla Thunb. (1784) 69. - Boehmeria macrophylla (Thunb.) Siebold \& Zucc. (1846) 215, nom. illeg., non Hornem. (1815) 890. — Boehmeria platyphylla D.Don var. japonica Wedd. (1856) 365. - Boehmeria grandifolia Wedd. (1854) 199, nom. illeg., based on Urtica macrophylla Thunb. (1784). - Boehmeria platyphylla D.Don var. macrophylla (Thunb.) Wedd. (1869) 213, nom illeg. superfl., based on Boehmeria platyphylla
D.Don var. japonica Wedd. (1856) 365. - Boehmeria miqueliana Tanaka (1925) 198, 208, nom. illeg. superfl., based on Urtica macrophylla Thunb. Type: Thunberg 22160 (holo UPS-THUNB, seen on microfiche), Japan. Boehmeria longispica Steud. (1850) 260. - Boehmeria japonica (L.f.) Miq. var. longispica (Steud.) Yahara (1984b) 320. - Type: Fortune "A85" (lecto P, selected by Yahara 1984a: 135; isolecto K), China, Ning Po. - See Note 1.

Boehmeria longispica Steud. var. appendiculata Blume (1857) 221. - Boehmeria japonica (L.f.) Miq. var. appendiculata (Blume) Yahara (1984a) 134, f. 3 right hand. - Type: Blume s.n. [L 908.185-1662] (lecto L, selected by Yahara 1984a: 134), Japan. - See Note 1.

Boehmeria longispica Steud. var. heterodonta Blume (1857) 221. - Type: Unknown collector s.n. (lecto L 908.185-1675, selected here), Japan.

Boehmeria platyphylla D.Don var. tricuspis Hance (1874) 261. - Boehmeria japonica (L.f.) Miq. var. tricuspis (Hance) Maxim. (1876) 642; (1877) 252. - Boehmeria longispica Steud. var. tricuspis (Hance) Franch. \& Sav. (1878) 497. - Boehmeria tricuspis (Hance) Makino (1912) 387. - Boehmeria platanifolia Franch. \& Sav. var. tricuspis (Hance) Matsum. (1912) 42. Type: Otto van Moellendorff s.n. (holo BM), China, Zhejiang, Kiukiang, 2-3 Aug. 1873.

Boehmeria spicata (Thunb.) Thunb. var. duploserrata C.H.Wright (1899) 488. - Type: Hicken s.n. (holo K), China, Zhejiang (rec. 11-1896).

Boehmeria tricuspis (Hance) Makino forma viridipes Satake (1936) 481. Type: Satake s.n. (type not traced; identity clear from description), Japan, Honshu, Awa Prov., Mt Kiyozumi, 5 Nov. 1935.

Boehmeria minor Satake (1936) 506. - Type: K. Hisauchi s.n. (holo TI), Japan, Honsyu, Sagami, 24 Sept. 1928. - See Note 2.

Boehmeria tiliifolia Satake (1936) 507. - Type: Satake 3533 (holo TI), Japan, Honsyu, Izu, 5 Sept. 1935.

Boehmeria tikusiensis Satake (1936) 510. - Type: Nakasimia 6 (holo TI), Japan, Kyusyu, Tikuzen, Minamihata-mura, 26 Sept. 1937. - See Note 3. Boehmeria pachystachya Satake (1936) 524. — Type: Satake \& Jotani 3577 (holo TI), Japan, Honsyu, Awa, 5 Nov. 1935.

Boehmeria taiwaniana Nakai \& Satake in Satake (1936) 526. - Type: Matsuda 14 (holo TI), Taiwan, Nanto, 11 Aug. 1919.

Boehmeria robusta Nakai \& Satake in Satake (1936) 528. - Type: Hisauchi s.n. (holo TI), Japan, Honsyu, Sagami, 4 Oct. 1931.

Boehmeria hatusimae Satake (1938a) 203. - Type: Hatusima s.n. (holo TI), Japan, Kyusyu, Tikuzen, 8 Nov. 1936.

Boehmeria pilushanensis Y.C.Liu \& F.Y.Lu in Lu (1978) 102 \& photo 5. Boehmeria taiwaniana Nakai \& Satake var. pilushanensis (Y.C.Liu \& F.Y.Lu) S.S.Ying (1988) 466. - Type: Lu \& Ou 3552 (holo TCF, seen as digital image), Taiwan, Taichung, Pilushan.

Boehmeria allophylla W.T.Wang (1981b) 412, syn. nov. - Type: L.Q. Chen 92643 (holo IBK, seen as digital image), China, Guangxi, Liang yun, 17 Aug. 1928.

Boehmeria chingshuishaniana S.S.Ying (1988) 468. - Type: Ying s.n. (holo NTUF), Taiwan, Hualien Co., 26 June 1988.

Herb or subshrub, up to $2(-5) \mathrm{m}$ tall. Stem hairs abundant, \pm spreading. Length of 'larger' leaves 1-1.4(-2)× 'smaller' ones, shape very variable ranging from broadly ovate-rhombic or ovate with truncate base to very broadly elliptic or deltate (rarely obovate-obdeltate), $6-21$ by $5.5-18 \mathrm{~cm}$, length $0.9-1.7(-2) \times$ width; marginal teeth either 5-10 either side (broad-laciniate

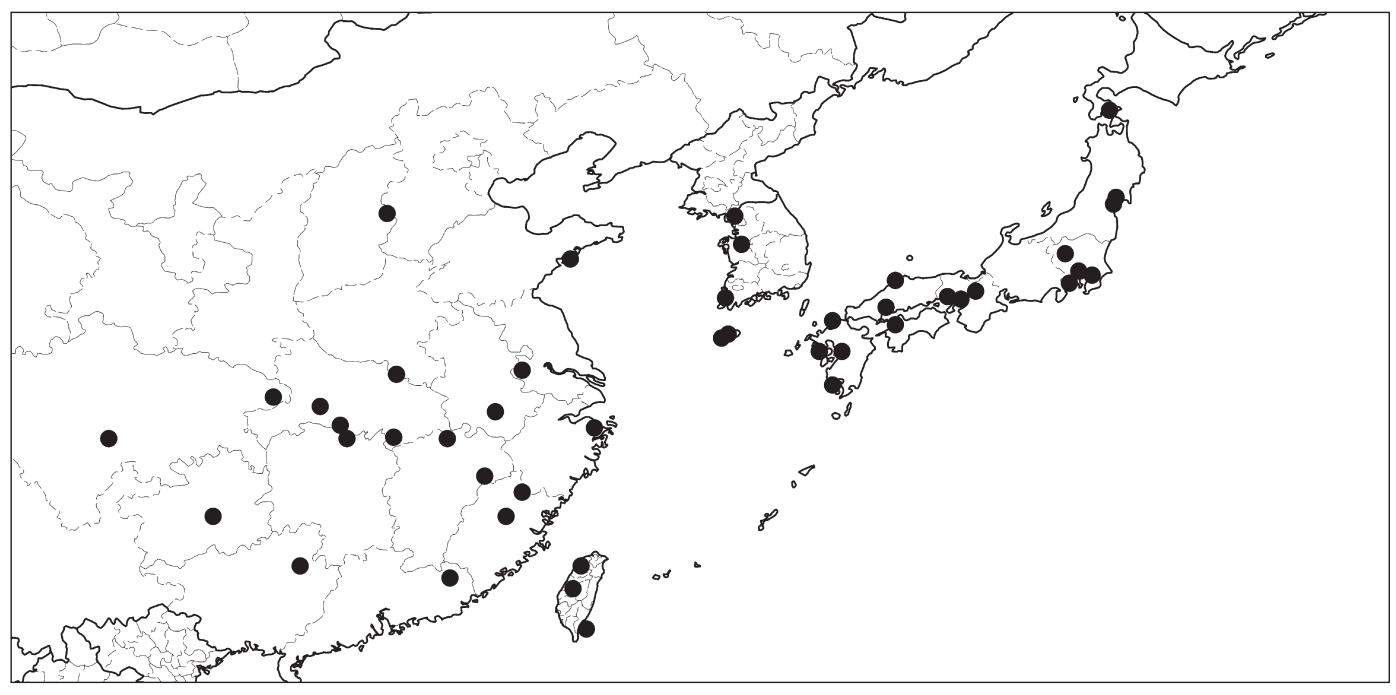




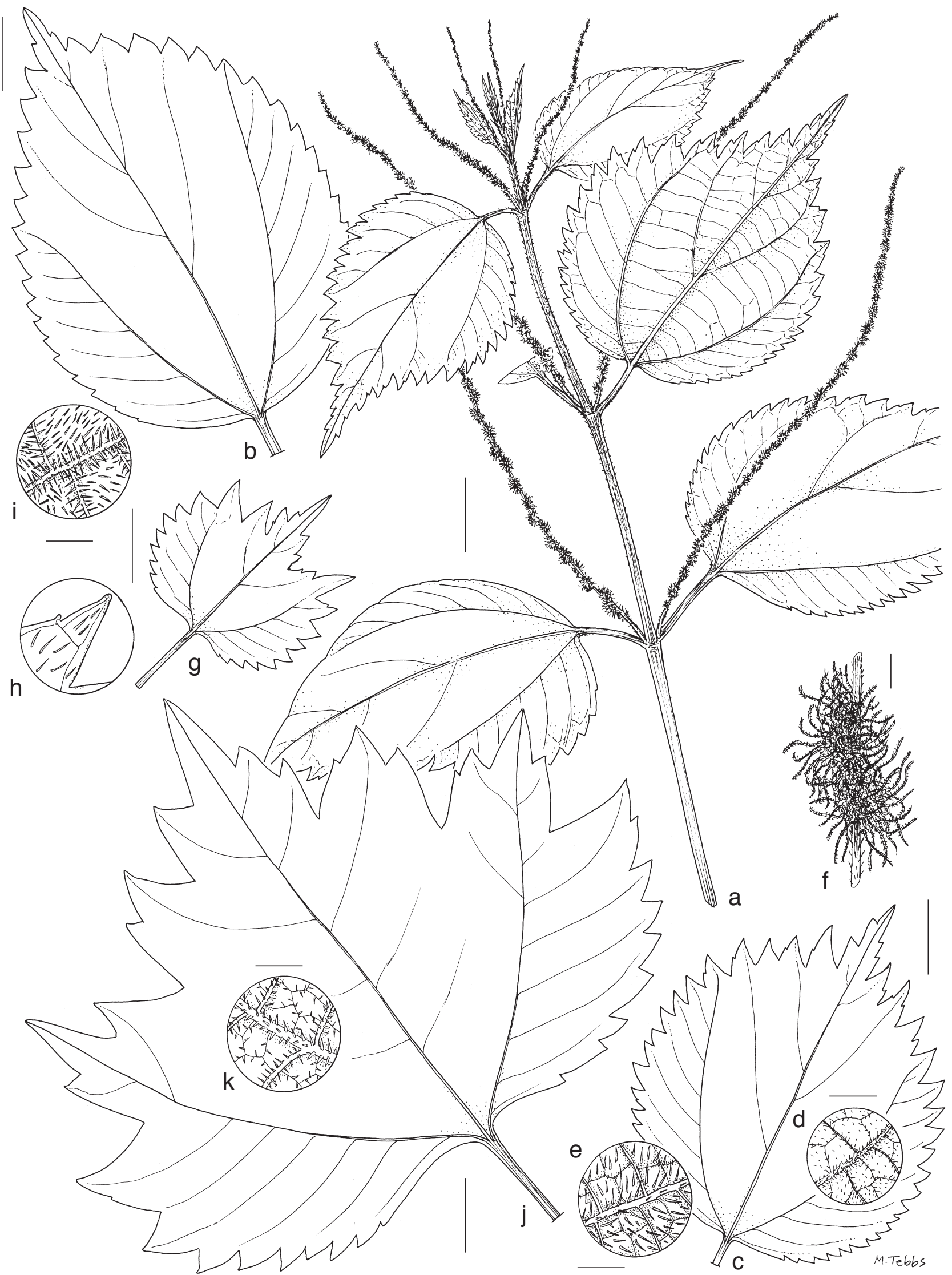

Fig. 34 a-f: Boehmeria japonica (L.f.) Miq. var. japonica. a. Habit of stem with female inflorescence-bearing axes; b, c. leaves from different plants; d. leaf, detail of adaxial surface; e. leaf, detail of abaxial surface; f. detail of female inflorescence-bearing axis with crowded flower-clusters (inflorescences). $-\mathrm{g}-\mathrm{i}$ : Boehmeria japonica var. silvestrii (Pamp.) Friis \& Wilmot-Dear. g. Leaf; h. leaf, detail of adaxial surface and large tooth near apex; i. leaf, detail of abaxial surface. — j, k: Intermediate between var. japonica and var. silvestrii. j. Leaf; k. leaf, detail of abaxial surface (a, f: Hicken s.n.; b: Suzuki s.n.; c-e: Fortune s.n.; g-i: Liou 4571; j, k: Furuse 21652; all K). — Scale bars: a-c, g, j= 2 cm; d-f, h, i, k = 2 mm. 
forms) or 10-15(-17) (ovate acuminate forms), large, even those at extreme base at least 1-2.5 mm long, often much broader than long, usually larger rather than more numerous on larger leaves and the most distal teeth with length 3-10x that of proximal ones; leaf apex varying from acuminate with a single long tooth several times longer than most marginal teeth, to rounded-truncate in outline but 3-5-toothed or 3-lobed, with 1-2 subapical teeth either side of terminal tooth, these long incurved or broad outward-pointing (often secondarily toothed); texture usually fairly thick-chartaceous; hairs on adaxial surface adpressed or \pm spreading, often bulbous-based giving rough feel; hairs on abaxial surface spreading, denser but softer (not bulbous-based). Inflorescence-bearing axes (5-)10-25 cm long, hairy like the stem; fruiting clusters large, 4-6 mm diam, well-spaced or often a continuous densely congested mass along axis; male flowers rarely present, tepals with or without dorsal appendage. Fruiting perianth very variable in shape, ovoid, ellipsoid or obovoid abruptly or gradually tapering to base and with or without beak, $1-2$ by $0.5-1 \mathrm{~mm}$ long, with a distinct marginal rim or (especially Japanese material) markedly flattened into a wing around achene.

Distribution - Throughout the range of the species (excl. northern China), South Korea, Japan, China (including Taiwan).

Habitat \& Ecology - Very varied; swamps in sandy soil; open or shady damp ravines; thin evergreen forest; scrub in valleys; barren dry hillsides; walls and roadsides; 70-1500 m altitude.

Notes -1 . The lectotypes of both var. appendiculata and var. longispica fall well within the range of variation of var. japonica as here defined (as discussed above under the species, see Note 4). It is not known why Yahara (1984b: 320) made his new combination $B$. japonica var. longispica when he had earlier (1984a: 135) published the combination B. japonica var. appendiculata, citing the epithet longispica in synonymy.

2. Ohba (2006: 107) considers $B$. minor as the correct name for a natural hybrid involving $B$. splitgerbera and $B$. tenera.

3. Ohba (2006: 107) considers B. tikusiensis as the correct name for a natural hybrid involving $B$. sieboldiana and $B$. japonica.

4. Var. japonica is characterised by hairs (except on adaxial surface of leaf) always spreading often abundant and leaves medium or large with an extremely wide range of size, shape and proportions. Okabe and Yahara showed this entity to be polyploid and apomictic, only occasionally producing fertile male flowers.
5. Relationships with other varieties and species, apomixis and possible hybridisation are discussed in detail under the species as a whole.

6. Material intermediate with var. silvestrii includes the following types:

Boehmeria platanifolia Franch. \& Sav. (1875 '1873') 440, nom. nud., however with Savatier 1117 cited. - Boehmeria japonica (L.f.) Miq. var. platanifolia Maxim. (1876) 643. - Boehmeria longispica var. platanifolia (Maxim.) Franch \& Sav. (1878 '1879') 497. - Boehmeria platanifolia (Maxim.) C.H.Wright (1899) 486. - Type: Savatier 1117 (holo P, on two sheets), Japan, Hakone Pass, August: year unknown.

Yahara (1984a: 141) considers this entity to be a hybrid between var. japonica and var. silvestrii.

Boehmeria maximowiczii Nakai \& Satake (in Satake 1936: 522), nom. illeg. superfl.

Although Nakai \& Satake (in Satake 1936: 522) indicate Nakai 2970 (TI), collected in Japan at Honsyu, Nagato as the type of this name, they also cite $B$. japonica var. platanifolia Maxim.

7. Material intermediate (possibly hybrid) with $B$. sieboldiana includes the following types and names based on them:

Boehmeria kiusiana Satake (1936: 508). - Type: Hatusima s.n. (holo TI), Japan, Kyusyu, Tikuzen, 26 Sept. 1932.

Boehmeria sieboldiana Blume var. ovata Satake (1938b) 263. - Type: Suzuki s.n. (holo TI), Japan, Honshu, Uzen, Mt Tide-san, 8 Aug. 1937.

8. Material intermediate (possibly hybrid) with $B$. holosericea includes the types of $B$. nakashimae, B. praestabilis, B. quelpartensis, $B$. villigera. See discussion and citations under $B$. holosericea (Note 7 ).

b. var. silvestrii (Pamp.) Friis \& Wilmot-Dear, comb. nov. Fig. 34g-i; Map 36

Basionym: Boehmeria platanifolia (Maxim.) C.H.Wright var. silvestrii Pamp. (1915) 278. - Boehmeria silvestrii (Pamp.) W.T.Wang (1982) 204. — Syntypes: Silvestri 4070 (FI), 4070a (FI), China, Hubei, 1912.

Usually a herb, often much-branched from the base, (rarely a subshrub), to $1.5 \mathrm{~m}$. Stems glabrous or soon glabrescent; hairs sparse, short, fine, adpressed. Leaves broadly rhombic-ovate or ovate-truncate, $4.5-12$ by $3-8 \mathrm{~cm}$, length $(0.4-) 1-1.5 \times$ width; marginal teeth only $8-12$ either side; leaf apex deeply laciniate usually to $0.3-0.5 \times$ total lamina length consisting of $1-2$ very long subapical teeth either side of terminal tooth and nearly equalling it in length; terminal tooth linear-oblong with 1-several small teeth on each margin and often markedly constricted at its base, subapical teeth often also secondarily toothed; base

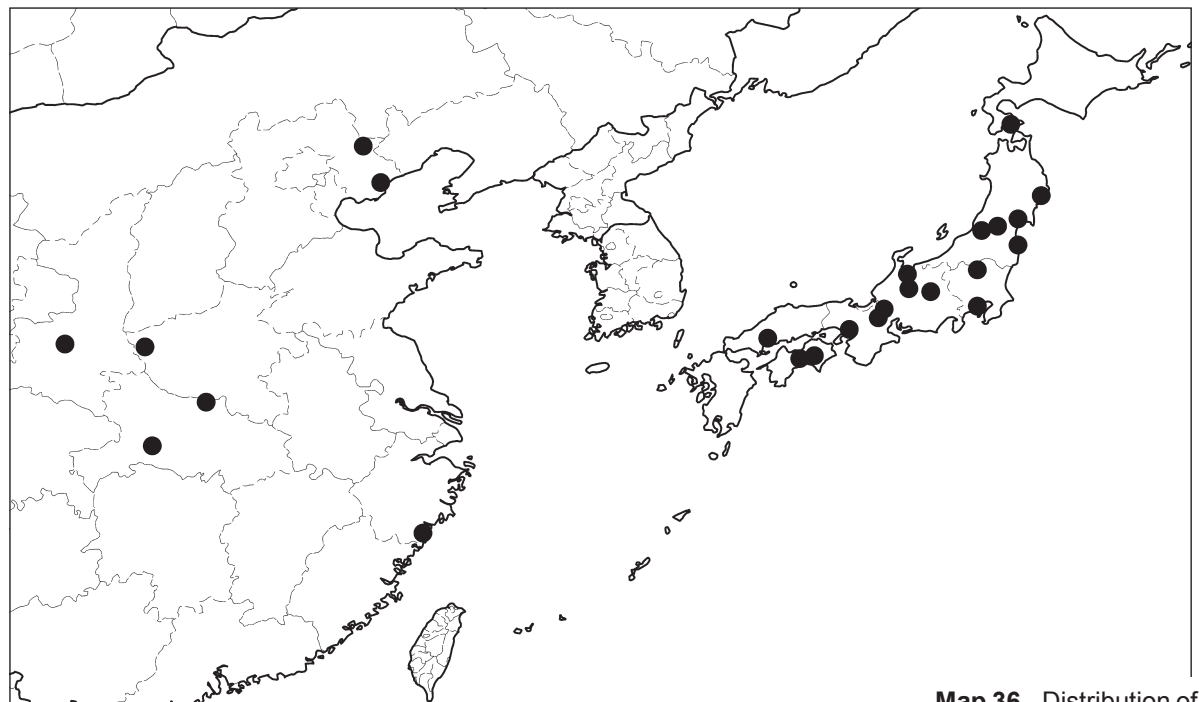

Map 36 Distribution of Boehmeria japonica (L.f.) Miq. var. silvestrii (Pamp.) Friis \& Wilmot-Dear. 

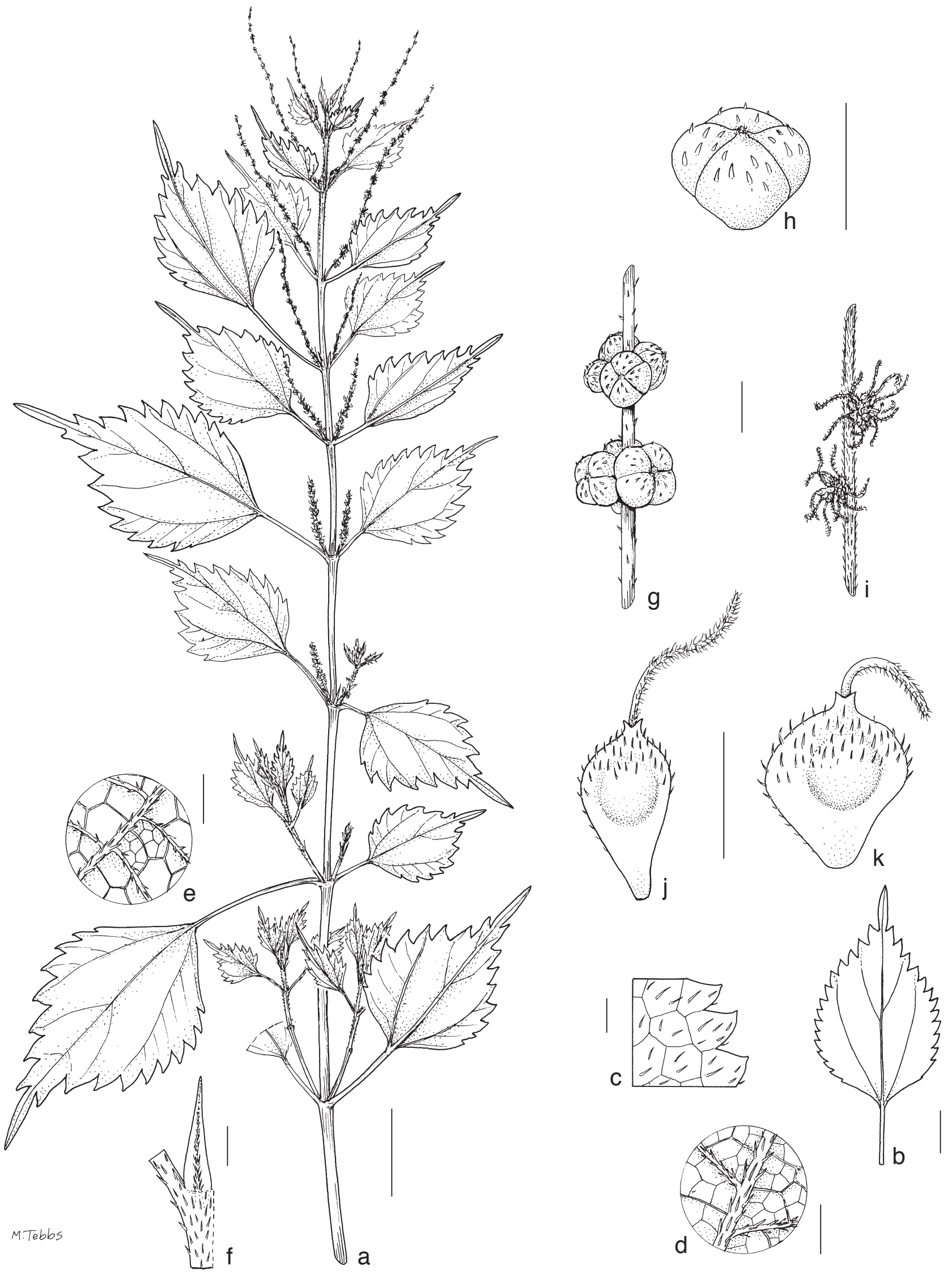

Fig. 35 Boehmeria japonica var. tenera (Blume) Friis \& Wilmot-Dear. a. Habit of stem with unbranched inflorescence-bearing axes; b. leaf; c. leaf, detail of adaxial surface and margin; d, e. leaf, detail of abaxial surface from different plants; $f$. detail of stem and stipule; g. detail of male inflorescence-bearing axis with two flower-clusters (inflorescences); h. male bud; i. detail of female inflorescence-bearing axis with two flower-clusters (inflorescences); j, k. fruiting perianths from different plants (a, e, f, i: Farges 608; b-d: Henry 4728; g, h: Furuse 42315; j: Silvestri 400; k: Cheng 201; all K). - Scale bars: $a=2 \mathrm{~cm} ; \mathrm{b}=1 \mathrm{~cm}$; $\mathrm{c}-\mathrm{e}=2 \mathrm{~mm} ; \mathrm{f}-\mathrm{k}=1 \mathrm{~mm}$. 
broadly cuneate or \pm truncate; texture membranous or very thin-chartaceous, hairs like the stem or lamina and petiole glabrous. Inflorescence-bearing axes 5-20 cm long, with hairs like the stem, sparse to abundant; fruiting clusters well-spaced or contiguous but not densely congested, individual clusters distinct, 1-4 mm diam. Male tepals without dorsal appendage. Fruiting perianth $1-1.5$ by $0.8-1 \mathrm{~mm}$ (smallest in small-leaved plants), winged or not.

Distribution - Northern and central China, South Korea, Japan (Hokkaido, Honshu, Shikoku).

Habitat \& Ecology - Forest margins, streams and moist slopes in deciduous forest; thickets; $100-1400$ m altitude (-2600 according to Chen et al. 2003: 173).

Notes -1 . This variety, like var. tenera, occurs further north in China than var. japonica and is the only variety recorded from Hokkaido. It extends less far into south-eastern China than the other two varieties. Leaves are similar in range of shape to broad and laciniate forms of var. japonica but thin-textured and glabrous or hairs adpressed, leaves also often smaller. Okabe (1956) showed var. silvestrii as sexually reproducing rather than apomictic.

2. The relationships with other varieties and intermediate forms are discussed in detail under the species (see Notes 5-8), and type material here considered as intermediate between the two is cited under var. japonica (see Note 6). A leaf form intermediate with var. japonica is illustrated in Fig. 34j, $\mathrm{k}$.

3. Boehmeria japonica var. tricuspidata Maxim. is a name not validly published based on a misreading of the account by Maximowicz (1876). It has frequently been used in annotating Japanese material.

c. var. tenera (Blume) Friis \& Wilmot-Dear, comb. nov. - Fig. 35; Map 37

Basionym: Boehmeria spicata (Thunb.) Thunb. var. tenera Blume (1857) 220. - Type: Unknown collector s.n. L 908.186-164 (holo L, according to Yahara 1984a: 130), Japan.

Urtica spicata Thunb. (1784) 69. - Boehmeria spicata (Thunb.) Thunb. (1794b) 330, nom. illeg. superfl. (see Note 1 under species as a whole). - Type: Herb. Thunb. 22115 (lecto UPS-THUNB, selected by Yahara 1984a: 130), Japan.

Boehmeria spicata (Thunb.) Thunb. var. akari Blume (1857) 220. - Type: Unknown collector s.n. (holo L, 908.186-156; iso K), Japan.

Boehmeria gracilis C.H.Wright (1899) 485. - Syntypes: Henry 4692 (K; isosyn A), 4728 (syn K), China, Hubei, Patung; Henry 6258 (K), China, Changlo. - See Note 6 under the species as a whole.
Boehmeria spicata (Thunb.) Thunb. var. microphylla Nakai ex Satake (1936) 483. - Type: Nakai s.n. (holo TI), Japan, Honsyu, 26 June 1931. - See Note 3.

Boehmeria paraspicata Nakai ex Satake (1936) 483. - Type: G. Koidzumi s.n. (holo TI), Japan, Hokkaido, Isikari Prov., Aug. 1916. - See Note 7.

Boehmeria paraspicata Nakai ex Satake forma viridis Satake (1936) 485. - Type: Hisauchi s.n. (holo TI), Japan, Honshu, Sagami, 19 July 1931. - See Note 7.

Boehmeria tricuspis (Hance) Makino var. unicuspis Makino (1948) 641, nom. nud. - See Note 6.

Boehmeria hwaliensis Y.C.Liu \& F.Y.Lu in Lu (1978) 100. — Type: Liu \& Ou 1741 (holo TCF, digital image seen), Taiwan, Hualien, Luan Shan.

Boehmeria densiflora sensu Chen, non Hook. \& Arn. (Chen et al. 2003: 175). - See Note 4.

Usually a herb, sometimes a subshrub, to $1 \mathrm{~m}$. Stems with fine adpressed hairs, soon glabrescent. Leaves ovate or rhombicovate, small or medium, $2-9(-14)$ by $1-4(-8) \mathrm{cm}$, length (1.6-)1.8-2.7x width; marginal teeth only $6-10(-12)$ either side, those near apex sometimes only $1.5-2 \times$ length of those near base but then all teeth markedly up-curved and relatively long relative to size of leaf (tooth depth often a quarter of total distance to midrib); outline of apex gradually narrowing towards a single long \pm linear terminal tooth which often (especially in largest leaves) comprises a third to half of lamina length; base cuneate to truncate; texture membranous or very thinchartaceous, adaxial surface with hairs like stem, often soon glabrescent, abaxial surface often \pm glabrous. Inflorescencebearing axes $5-10(-15) \mathrm{cm}$ long, glabrous or hairs sparse, adpressed or spreading; fruiting clusters usually well-spaced, 2-4 $\mathrm{mm}$ diam. Male tepals with or without dorsal appendage. Fruiting perianth $1-2$ by $0.6-1.2 \mathrm{~mm}$, winged or not.

Distribution - China (including Taiwan, but excluding the southernmost part of the mainland), South Korea, Japan (Honshu, Shikoku, Kyusyu).

Habitat \& Ecology — Forest margins, thickets, streams, grassland; $100-2050 \mathrm{~m}$ altitude.

Notes -1 . Var. tenera is distinctive in being glabrous or sparsely adpressed-hairy with thin-textured leaves, as in var. silvestrii but leaves small ovate, acuminate, with marginal teeth few and relatively long. Var. tenera appears to be more common than var. silvestrii (many more collections seen) and to extend to drier habitat. It is absent from northern Japan (Hokkaido) but recorded further southeast in China than var. silvestrii. Like var. silvestrii it occurs further north in China than does var. japonica.

2. The interpretation of the variation within this variety is discussed fully under the species as a whole (see Note 6). As

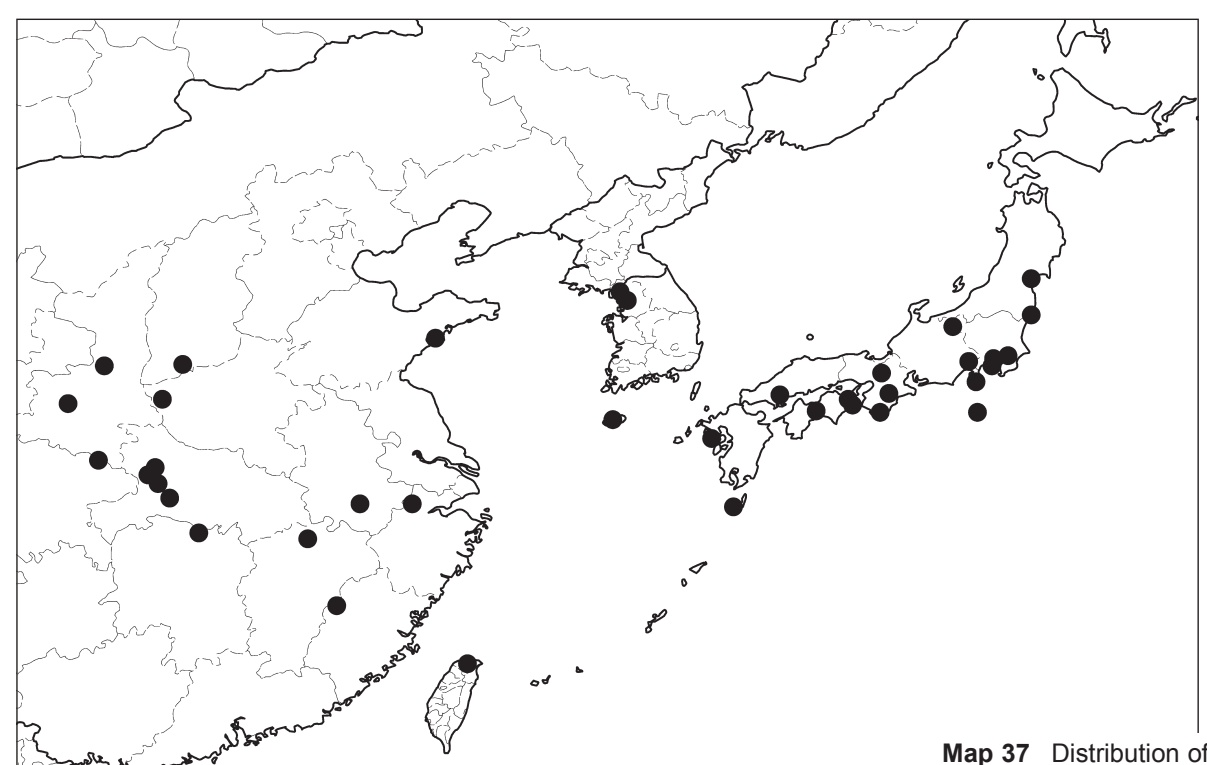

Map 37 Distribution of Boehmeria japonica (L.f.) Miq. var. tenera (Blume) Friis \& Wilmot-Dear. 

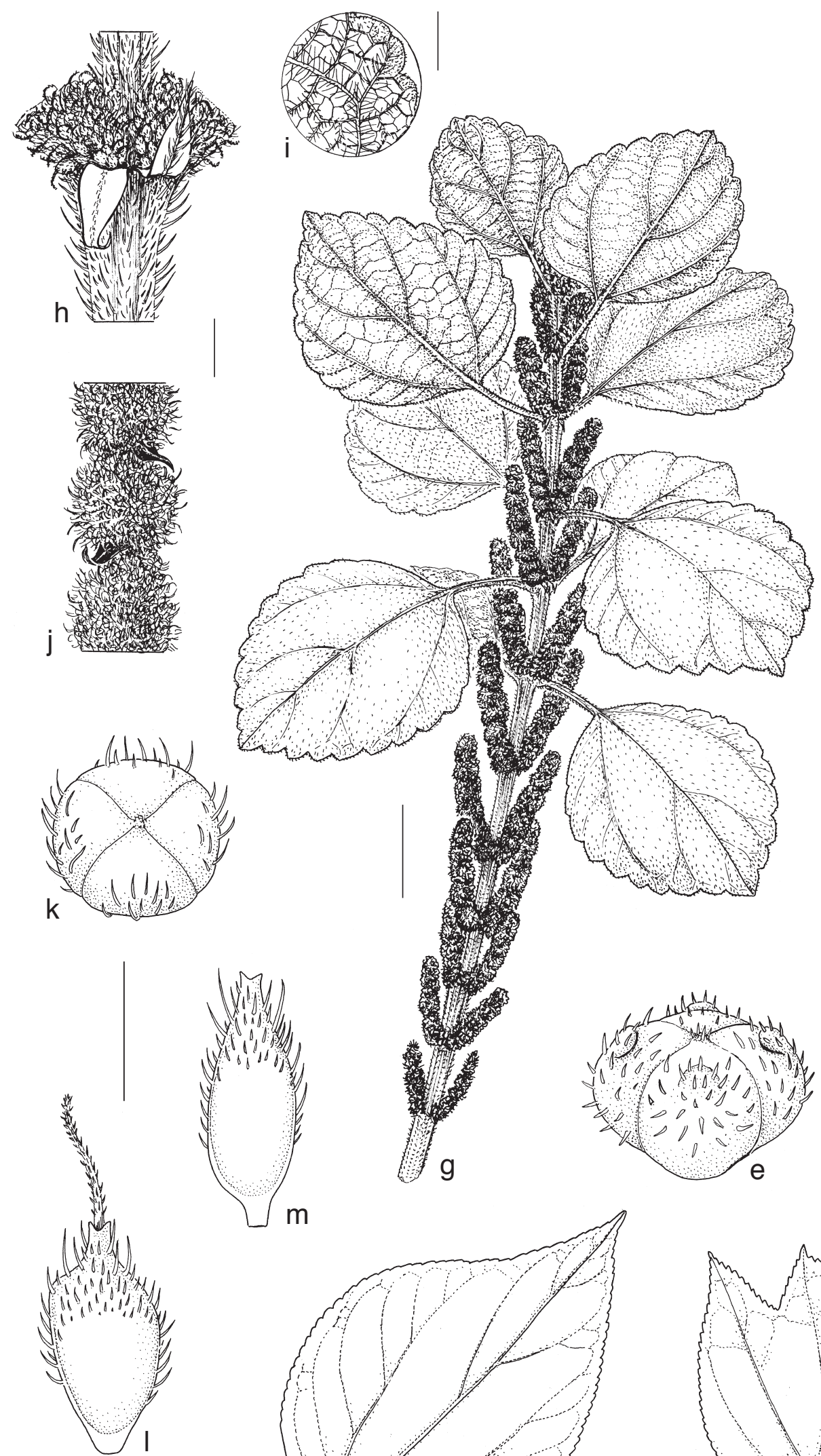

M.Tebbs
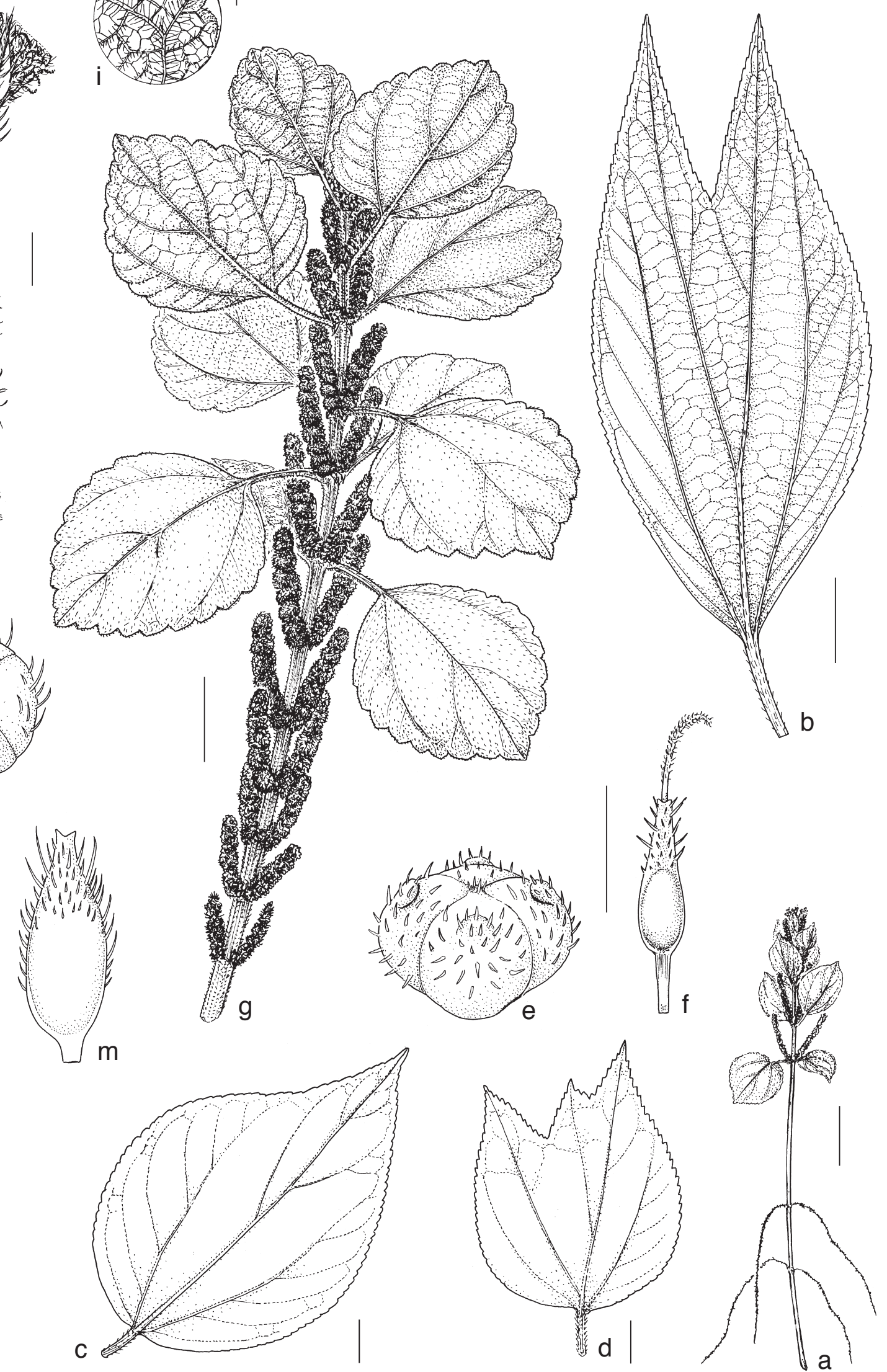

Fig. 36 a-f: Boehmeria splitgerbera Koidz. a. Habit of stem with inflorescence-bearing axes, in lowermost part of plant pendulous male axes, above erect, congested female axes; $b-d$. leaves from different plants; e. male bud; f. fruiting perianth. - g-m: Boehmeria yaeyamensis Hatus. g. Upper part of stem showing congested erect inflorescence-bearing axes; h. detail of stem showing stipules and base of paired axillary inflorescence-bearing axes concealing petiole base; i. leaf, detail of abaxial surface; j. portion of inflorescence-bearing axis showing congested female flower-clusters (inflorescences) and bracts; k. male bud; I, m. fruits of different form from same plant (a, f: Furuse 26669; b, e: Hort Kew s.n.; c: Furuse 28436; d: Koyama 268; g-j: Furuse 4213; k: Furuse 3199; I, m: Furuse 4148; all K). - Scale bars: $a=5 \mathrm{~cm} ; \mathrm{b}, \mathrm{g}=2 \mathrm{~cm} ; \mathrm{c}, \mathrm{d}=1 \mathrm{~cm} ; \mathrm{e}, \mathrm{f}, \mathrm{k}-\mathrm{m}=1 \mathrm{~mm} ; \mathrm{h}-\mathrm{j}=2 \mathrm{~mm}$. 
discussed above under the species as a whole (see Note 7, 8 ), few intermediates with either var. silvestrii or var. japonica have been seen compared to the large number of collections clearly referable to this taxon.

3. Yahara (1984a: 130, 132) tentatively maintained var. microphylla differing apparently (Okabe 1956) in its chromosome number $(2 n=28)$ from typical var. spicata $(2 n=42)$, but stated that its "separation ... as a distinct variety of diploid remains an assumption because the correlation between ploidy level and phenetic features is not fully understood yet". We here consider it as representing one extreme of a continuous range of variation in leaf-size shown by var. tenera.

4. The photo under B. hwaliensis in Yang et al. (1996: 202, 785 photo 79 ) does not conform to the type material but to that of $B$. minor (small-leaved var. japonica).

5. Confusion with $B$. virgata subsp. macrophylla var. densiglomerata and $B$. sieboldiana is discussed under the species as a whole (see Notes 12 \& 15).

6. According to Yahara (1983a: 261) the name B. tricuspis var. unicuspis was widely used in Japanese floristic literature but never validly published.

7. Boehmeria paraspicata and B. paraspicata forma viridis, and names based on these, represent forms closest to this taxon although their leaves are rather broad; they possibly represent forms intermediate with var. silvestrii.

\section{Boehmeria splitgerbera Koidz. — Fig. 36a-f; Map 38}

Boehmeria splitgerbera Koidz. (1926) 345. - Splitgerbera japonica Miq. (1840) 134, t. 14, f. A-K, non B. japonica (L.f.) Miq. (1867). - Type: Unknown collector, cultivated from Japan s.n. (iso K, WU), "Japan, E, cult in horto prope Tjpannas".

Boehmeria biloba Miq. in Zollinger ([June] 1854) 100, nom. illeg. superfl., based on Splitgerbera japonica Miq. (1840: 134, t. 14). - See Note 1. Boehmeria bifida Blume (1857) 222, nom. illeg. superfl., based on Splitgerbera japonica Miq.

Robust herb, 0.5-1 m tall, with 1-several stems arising from woody rootstock, each stem partly prostrate in lower part and unbranched or little-branched; ultimate stems robust, 2-2.5 $\mathrm{mm}$ diam, with hairs of 2 kinds, abundant stiff long curved hairs mixed with sparse short soft spreading ones. Stipules narrowly triangular, c. 10 by $2 \mathrm{~mm}$ long. Leaves opposite, not or slightly dimorphic in size only, very variable in shape and often misshapen, elliptic, broadly ovate to obovate or even orbicular or more or less spathulate but markedly asymmetrical with width of one half up to $1.5 \times$ other half, medium or large, $8-14$ by $5-9$ $\mathrm{cm}$, length (1-)1.2-2x width; margin shallowly dentate, teeth 30-40 either side, outward-pointing, indistinct or up to 1.5 by 2-6 $\mathrm{mm}$ long; leaf apex very variable, broadly acute to rounded, abruptly short-acuminate or asymmetrically bilobedbi-acuminate; base narrowly long-cuneate to broad shortcuneate, rounded or even truncate; basal veins rather straight, usually extending well into distal third of lamina or almost to tip especially in non-lobed leaves; upper lateral veins $2(-3)$ on one side, 4-5 on other and often arising in lower half of lamina, these and tertiary reticulation finely prominent abaxially; texture thickly chartaceous to thinly coriaceous, leaves often bullate; adaxial surface with scattered hairs like those on stem; abaxial surface with abundant hairs like stem; petiole short but variable, 2-4 cm long, 0.15-0.3x lamina length. Flower-clusters borne on leafless axes, unbranched, 1 per axil, male axes 10-16 $\mathrm{cm}$, female 4-8 cm long, some axes with both sexes; bracts narrowly triangular 3 by $1.5 \mathrm{~mm}$ with long-acute or acuminate apex; male clusters usually well-spaced, 2-3 mm diam, with 5-10 loosely-arranged flowers; female clusters often crowded or contiguous, 4-5 mm diam, with 50-100 densely crowded flowers; bracteoles inconspicuous, narrowly triangular or linear, c. 1/3 of flower length, $0.5 \mathrm{~mm}$ long. Male flowers 4-merous, sessile or subsessile, mature buds globose, c. $1 \mathrm{~mm}$ diam, dorsal appendage prominent up to $0.2 \mathrm{~mm}$ long, hairs dense, long. Female flowers narrowly oblong-ovoid, up to 1.5 by 0.3 $\mathrm{mm}$; stigma $1-1.5 \mathrm{~mm}$ long. Fruiting perianth up to 1.8 by $1 \mathrm{~mm}$, very variable in shape, ovoid or obovoid-oblong usually tapering into long-pedicellate basal portion, often rather inflated at apex and usually markedly laterally flattened except for small central part containing achene, densely hairy. Achene ellipsoid, c. 0.5 by $0.4 \mathrm{~mm}$.

Distribution - Japan (Hokkaido, Honshu, Kyushyu, Izu Islands, Bonin Islands), South Korea.

Habitat \& Ecology - A pioneer species on volcanic rocky cliff faces along seashore, roadsides; sea level-1000(-2000) m altitude.

Conservation status - Data deficient (DD). Its particular habitats are not currently threatened, and it is known from over 50 collections but the scarcity of recent collections is puzzling.

Notes - 1. Boehmeria biloba Miq. in Zollinger ([June] 1854: 100), nom. superfl. illeg., based on Splitgerbera japonica Miq. (1840) 134, t. 14, the epithet of which should have been adopted, as the combination $B$. japonica (L.f.) Miq. had not yet been proposed in 1854 . The combination $B$. biloba had already been suggested by Weddell (in a preprint from March 1854, p. 27 (preprint of Weddell 1854: 199), similarly based indirectly on the above-mentioned S. japonica Miq. (1840), which Weddell erroneously, but unambiguously, referred to as S. biloba Miq. (with full reference to page and illustration of S. japonica, but with the wrong name, S. biloba), possibly confused by the presence of the nomen nudum Urtica biloba Siebold on some early collections of this plant. Hence the name $B$. biloba cannot be used.

2. Boehmeria splitgerbera is easily distinguished especially in its leaves, which are thick-textured (especially on sea-shores), \pm bullate, fairly broad, but often rather abruptly cuneate at the base, shallowly and finely dentate, leaf shape often very varied even on a single plant but usually at least some leaves bilobed, others often misshapen and/or obovate; veins are robust and rather straight, basal lateral veins running nearly to tip of lamina, often bifurcated near apex and with many rather robust tertiary veins running towards the margin. Its indumentum of mixed long coarse and short spreading hairs is also distinctive. Spreading stems and height only up to $1 \mathrm{~m}$ tall are features retained in cultivation (Yahara 1983a: 236 and appears to be adaptation to its habitat).

3. Boehmeria yaeyamensis (allopatric, Ryukyu Islands) is somewhat similar in habit, indumentum, leaf texture and densely crowded female inflorescence-bearing axes but does not have misshapen or bilobed leaves, bifurcate veins or winged or \pm pedicellate fruiting perianths; both are maritime species of very restricted distributions.

4. A range of entities of obscure identity exists in Japan and South Korea (Jeju 'Quelpart' Island) having some or all of the following characters distinctive to $B$. splitgerbera (2 kinds of hairs; leaves misshapen or slightly bilobed at apex; lateral veins bifurcated near apex; reticulation prominent), but leaf margin with fewer, larger, teeth, leaf texture also sometimes thin. As discussed in the introduction section, Yahara (1983a) showed populations of this nature in Izu (Honshu) to be polyploid, apomictic and morphologically distinct from one another. He suggested that they originated through hybridisation of $B$. splitgerbera with either an unknown parent (the thickerleaved forms) or the $B$. japonica complex (the thinner-leaved forms). Some of the thin-leaved material is, however, so similar in leaf shape to $B$. holosericea that this is a more likely parent (see further under $B$. holosericea, Note 8). The types of the names in the following Note, some of which were mentioned by Yahara (1983a, 1984a), fall within this range of variation. 
5. Material intermediate between B. splitgerbera and other taxa.

Boehmeria arenicola Satake (1936) 499. - Type: Satake 3557 (holo TI; iso TI), Japan, Honsyu, Sagami, 16 Oct. 1935.

Boehmeria arenicola Satake var. awana Satake (1936) 500. Type: Satake 3566 (holo TI), Japan, Honshu, Awa Prov.

Boehmeria dura Satake (1936) 529. - Type: Satake 3587 (holo TI; iso TI), Japan, Honsyu, Izu, 5 Sept. 1935.

Ohba (2006: 107) accepts $B$. dura as the correct name for a natural hybrid involving $B$. splitgerbera and $B$. japonica.

Boehmeria izuosimensis Satake (1936) 532. — Type: Y. Jotani s.n. (holo TI), Japan, Honsyu, Izu Islands, Osima Island, 9 Sept. 1931.

Ohba (2006: 107) accepts B. izuosimensis as the correct name for a natural hybrid involving $B$. splitgerbera and $B$. japonica. Boehmeria kiyozumensis Satake (1936) 497. - Type: H. Hara s.n. (holo TI), Japan, Honsyu, Awa, 5 Nov. 1934.

Boehmeria tenuifolia Satake (1936) 501. - Type: Y. Momiyama 529 (holo TI), Japan, Honsyu, Sagami, 3 Nov. 1934.

Boehmeria tenuifolia Satake forma conferta Satake (1936) 501. - Type: Momiyama s.n. (holo TI), Japan, Honsyu, Sagami, 10 Nov. 1935.

Boehmeria tenuifolia Satake var. nigricans Satake (1936) 501. - Type: Satake 3572 (holo TI), Japan, Honsyu, Izu province, 4 Sept. 1935.

Boehmeria pannosa Nakai \& Satake in Satake (1936) 510; Nakai (1936) 150. - Type: Nakai \& Maekwa s.n. (holo TI, n.v.; photo in Satake 1936), Japan, Honsyu, Suo, 22 July 1935.

\section{Boehmeria yaeyamensis Hatus. - Fig. $36 \mathrm{~g}-\mathrm{m}$; Map 38}

Boehmeria yaeyamensis Hatus. (1979) 34. - Syntypes: Hatusima 24563 (KAG), 24564 (KAG), Japan, Ryukyu Islands, Yonakuni Island.

Robust erect woody-based herb or subshrub, 0.3-0.8 m tall; ultimate branchlets robust, $1.5-3 \mathrm{~mm}$ diam; hairs of two kinds, dense, short $(\leq 0.1 \mathrm{~mm})$, spreading hairs mixed with sparser coarser longer $(0.2-0.3 \mathrm{~mm})$ ones, some bulbous-based, soon glabrescent. Stipules $3-5$ by $1.5-2.5 \mathrm{~mm}$, thick-textured. Leaves opposite, moderately dimorphic in size only, 'larger' leaf with length of lamina only $1.2-1.5 x$, but length of petiole $2-3 x$ that of 'smaller' ones; very broadly ovate, rhombic-ovate or deltate, $4-10$ by $3-9 \mathrm{~cm}$, length $1.1-1.3 \times$ width; margin crenate, teeth few, 7-10 either side, often of irregular width but always broad and shallow, $1.5-4$ by $4-7 \mathrm{~mm}$, width $2-3 \times$ length; leaf apex obtuse or broadly acute and rounded or mucronate at extreme tip; base broadly rounded, truncate or slightly cordate, rarely broad-cuneate; basal veins extending into distal half, upper lateral veins similarly arranged on both sides of leaf, 1-2 arising in distal half, main veins and reticulation thinly prominent abaxially; texture thick-(rarely thin-)chartaceous to coriaceous; adaxial surface drying dark green, rough with bulbous-based hairs like the longer ones on the stem, sparse to abundant; abaxial surface drying much paler, with hairs abundant but soft, shorter, finer, often half-adpressed, often so dense that abaxial surface appears velvety; petiole relatively long often $0.25-0.75 \times$ lamina length. Inflorescence-bearing axes only 1-6 cm long, unbranched, 1 per axil, all axes seen with mostly female flowers, male flowers 1-few in occasional clusters on some axes and mostly near the apex, clusters so densely crowded as to give whole axis a cylindrical appearance 5-6 cm diam with individual clusters more or less indistinguishable; each cluster with usually more than 50 densely congested female flowers; bracteoles $0.5-1 \mathrm{~mm}$ long but inconspicuous in densely congested clusters. Male flowers 4-merous, sessile, mature buds c. $1 \mathrm{~mm}$ diam, globose, tepals without dorsal appendage, hairs abundant, mostly bulbous-based like on stem. Female flowers ellipsoid to obovoid, c. 0.8 by 0.25 $\mathrm{mm}$, with finer hairs than on male flowers; stigma c. $1 \mathrm{~mm}$ long. Fruiting perianth slightly asymmetrically ellipsoid to obovoid or oblong with \pm truncate apex, often 3-angled, 1.5-2 by $0.6-1 \mathrm{~mm}$, without beak, slightly laterally flattened in lower part containing achene and with inflated wing-like distal part, densely hairy near apex. Achene subspherical, $0.5 \mathrm{~mm}$ diam.

Distribution - Endemic to Japan (south-western Ryukyu Islands, Yaeyama Island: Yonakuni, Ishigaki).

Habitat \& Ecology - Roadsides and dry sunny open coral limestone cliffs near seashore; at or near sea level.

Conservation status - We are uncertain whether to assess it as Near Threatened (NT) or Endangered (EN). It is known from only seven collections from two localities but the level of risk to its particular habitat, some of which is protected on these islands, is uncertain. Tentatively it is given the status of Endangered (EN) on the criteria EN B2ab(iii).

Notes - 1. A species endemic to the Ryukyu Islands, distinctive in leaves small, broad, often thick-textured, few-toothed large-crenate, short thick unbranched inflorescence-bearing

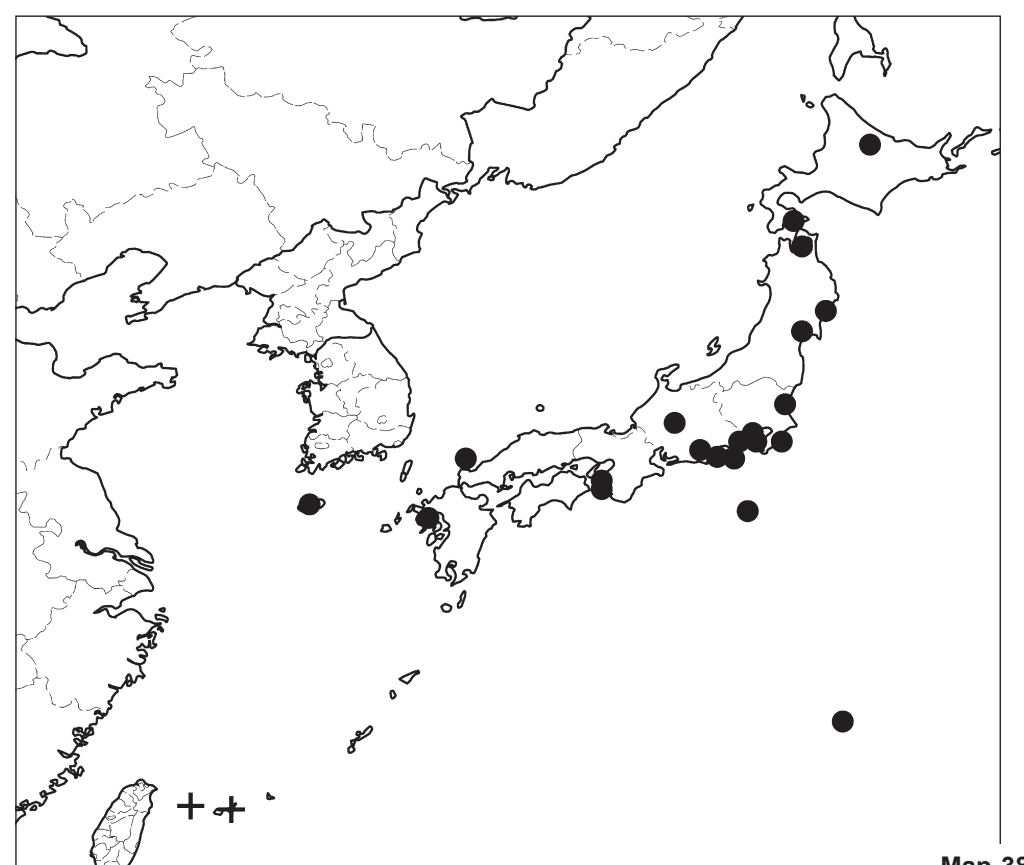

Map 38 Distribution of Boehmeria splitgerbera Koidz. (๑) and B. yaeyamensis Hatus. $(+)$ 
axes with densely congested mainly female clusters, few scattered male flowers and apparently no separate male axes, male tepals without dorsal appendage and two kinds of hairs on the stem.

Similar in habit, indumentum, leaf texture and crowded female clusters to $B$. splitgerbera, which is often of similar habitat but allopatric (eastern and north-eastern Japan) and differing in \pm isomorphic somewhat misshapen leaves often bilobed at apex and numerous (30-40) much smaller teeth.

2. It also bears some resemblance to certain individuals of a range of coastal entities found in eastern and north-eastern Japan and South Korea. These are allied to $B$. splitgerbera but have mostly been identified as ' $B$. gigantea' (= $B$. holosericea). They are similar to $B$. yaeyamensis in having two kinds of hairs on the stem and thick-textured leaves, but differ in much larger isomorphic leaves with more numerous teeth (usually over 20 each side) and acuminate apex. A group of such entities was studied by Yahara (1983a: 234-243) in Honshu who suggested them to be hybrids of $B$. splitgerbera with the other parent uncertain (see further discussion and list of types falling within this variation under $B$. splitgerbera in Note 4,5 ).

\section{Boehmeria rugosissima (Blume) Miq. - Fig. 37; Map 39}

Boehmeria rugosissima (Blume) Miq. (1851) 32. - Urtica rugosissima Blume (1825) 490. - Boehmeria platyphylla D.Don var. rugosissima (Blume) Wedd. (1856) 366. - Boehmeria caudata (Burm.f.) J.J.Sm. var. rugosissima (Blume) J.J.Sm. (1910) 711. — Type: Herb Reinwardt 1691 (lecto L, selected here); Herb Reinwardt s.n. (possible isolecto L), Jawa [Java], "in fruticetes montosis". - See Note 1.

Shrub, 1.5-3 m tall; ultimate branches 1.5-2.5 mm diam, hairs sparse or abundant, usually spreading, fine, short or long $(\leq 0.5 \mathrm{~m})$ or of mixed length. Stipules narrowly triangular free to base, often very large and conspicuous, $10-25$ by (2-)3-5 $\mathrm{mm}$, thin- or thick-textured, soon caducous from second or third node. Leaves opposite, scarcely dimorphic or 'larger' ones up to $2.5 \times$ length of 'smaller' ones, not or slightly asymmetrical, broadly ovate, somewhat variable in size and relative proportions, usually at least some on plant large, $13-25$ by (6-)8-20 $\mathrm{cm}$ (rarely none over 9 by $5 \mathrm{~cm}$ ), length 1.3-2.3x width; margin up-curved-serrate or crenate-serrate, teeth 35-70 either side, very shallow even on large leaves, $1-2$ by $2.5-4 \mathrm{~mm}$, often becoming indistinct towards base; leaf apex attenuate-acuminate, short and broad; base narrowly rounded to slightly cuneate but usually slightly cordate at extreme base; basal veins extending into distal third, upper lateral veins on one side 3-5, lowermost arising near middle of lamina, 2-4 on other side, all arising in distal half of lamina, impressed but often rather inconspicuous adaxially, usually prominent abaxially, coarser lateral venation often similarly prominent; texture usually thickly chartaceous (some large-leaved forms thin-chartaceous) and leaves always bullate, but bullation in large leaves sometimes reduced to small projections on adaxial surface in the centre of each areole (with corresponding depression in abaxial surface), drying markedly brownish; adaxial surface with single \pm spreading hair in centre of each bullation, later glabrescent with slight bulbous base of hair remaining, abaxial surface with hairs sparse to abundant, short, fine and spreading, and/or with coarse longer hairs on veins only; petiole very variable relative to lamina length, 1.3-16 $\mathrm{cm}, 0.1-0.5 \times$ (rarely almost equalling) lamina length. Flowerclusters partly axillary but mostly borne on leafless axes c. 6-15 $\mathrm{cm}$ long and arising one from each axil but almost always with a few long branches from basal half, some of these often so close to base as to appear several axes per axil, unisexual, the male axes sometimes with 2nd-order branching; axes often drooping near apex; bracts $2-3$ by $1-1.5 \mathrm{~mm}$, short and broad but with long-acute apex; clusters spaced (1-)2-4 mm apart, up to $3(-4) \mathrm{mm}$ diam, male clusters with 2-10 flowers; female clusters with 15-20(-30) quite densely crowded flowers; bracteoles inconspicuous. Male flowers 4-merous, subsessile or with pedicel up to $0.5(-1) \mathrm{mm}$ long, mature buds depressedglobose, c. $1.3 \mathrm{~mm}$ diam, dorsal appendages distinct, hairs abundant, spreading, relatively coarse. Female flowers $0.6-1$ by $0.3-0.5 \mathrm{~mm}$, ovoid or ellipsoid, abruptly slightly tapering at apex but \pm without beak (apical teeth sometimes conspicuous) and not truncate, hairy as male; stigma (0.5-)1-2 mm long, straight or hooked. Fruiting perianth $0.8-1.2$ by $0.5(-1) \mathrm{mm}$, ovoid, ellipsoid or obovoid, slightly dorsiventrally flattened with slight marginal ridge or more markedly with slight winged shoulders, apex acute, hairs sparse or abundant, conspicuous, robust, spreading. Achene almost filling fruiting perianth, yellowish brown.

Distribution - Indonesia (Sumatera, Jawa, northern Sulawesi), Philippines (Mindoro, Mindanao).

Habitat \& Ecology - Evergreen forest, disturbed or cultivated areas; $450-1600 \mathrm{~m}$ altitude.

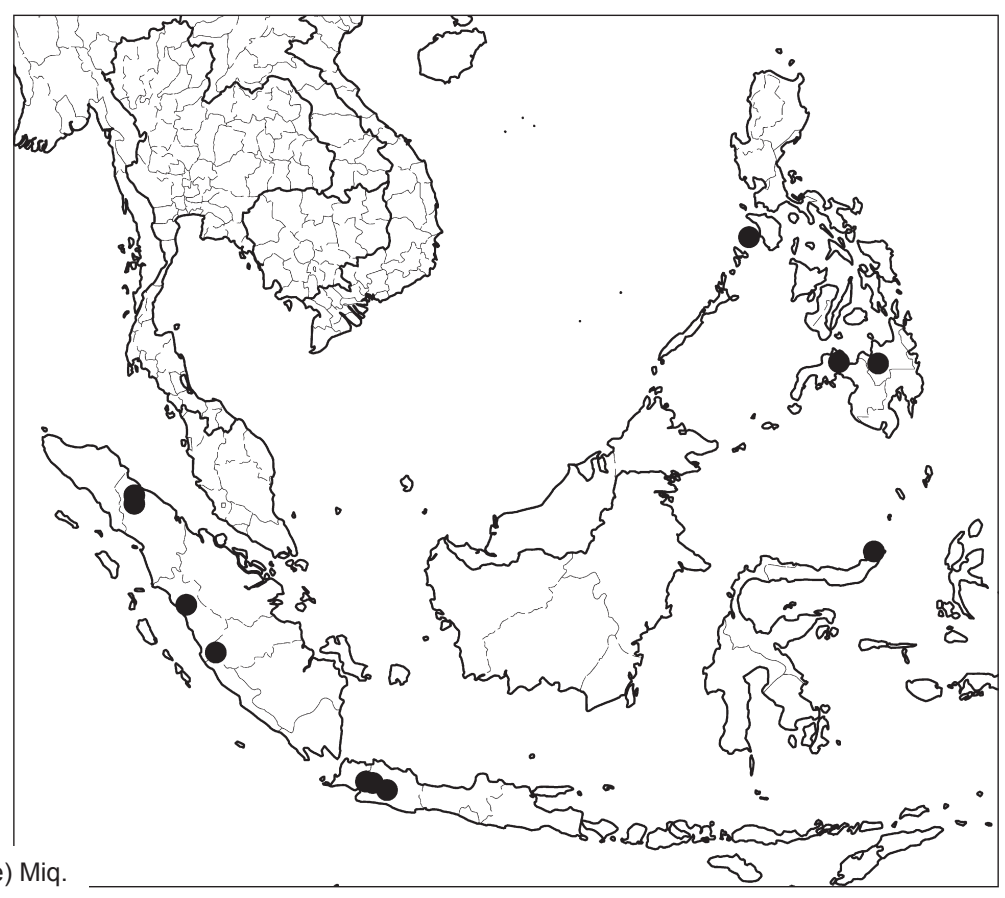




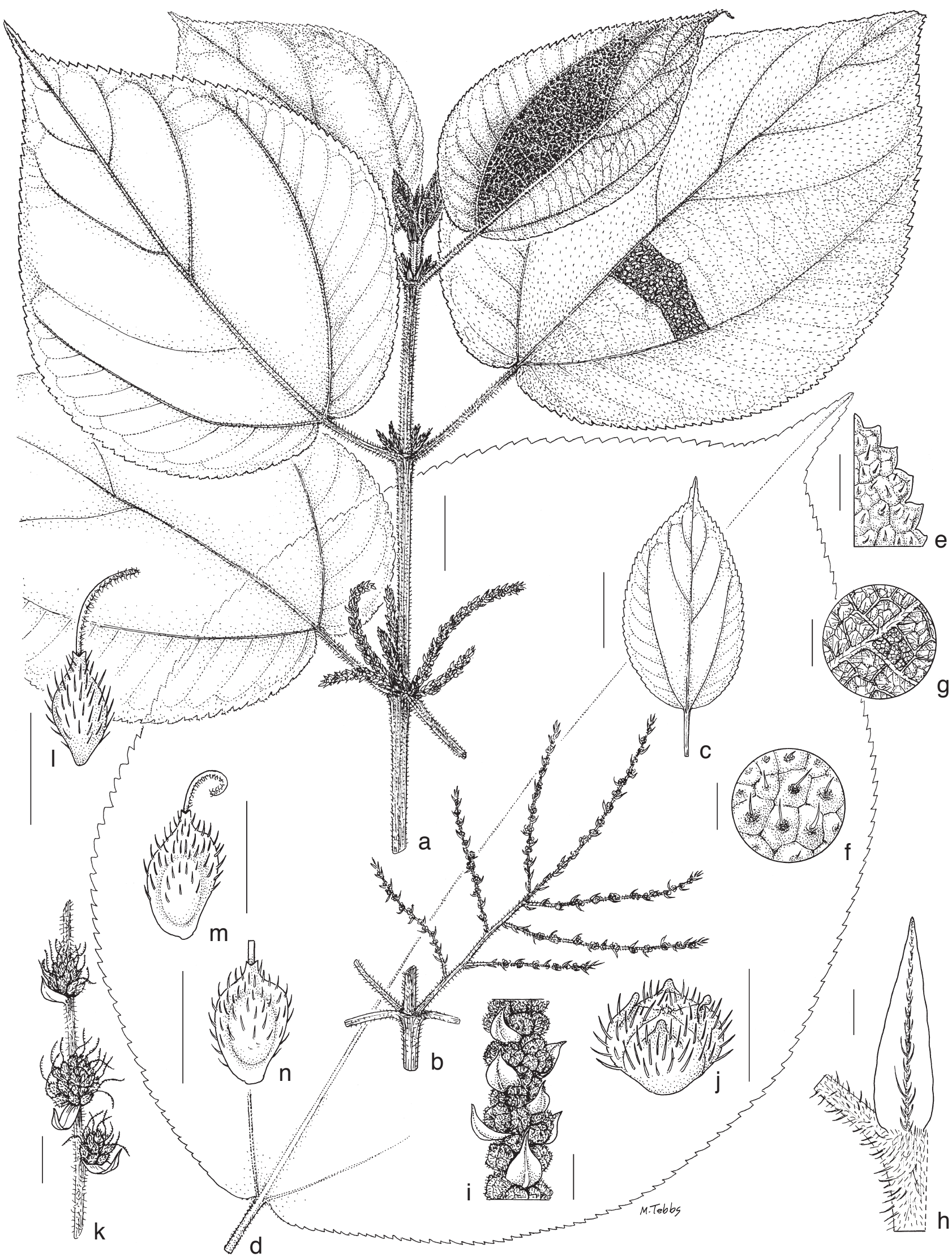

Fig. 37 Boehmeria rugosissima (Blume) Miq. a. Habit of stem with young inflorescence-bearing axes, branched at base; b. detail of stem with pair of mature inflorescence-bearing axes; c, d. leaves from different plants; e, f. leaf, detail of margin and adaxial surface; g. leaf, detail of abaxial surface; h. detail of stem and stipule; i. portion of young male inflorescence-bearing axis with densely congested flower-clusters (inflorescences) and bracts; j. male bud; $k$. portion of female inflorescence-bearing axis with flower-clusters (inflorescences) and bracts; I. female flower; $\mathrm{m}, \mathrm{n}$. fruiting perianths from same plant (a, e-g, i: Lanjouw 103; b, j: Beccari 281; c, h: Morley 21; d, k, l: Koorders 31831B; m, n: Bunnemeijer 8122; all K). — Scale bars: a-d $=2 \mathrm{~cm} ; \mathrm{e}=5 \mathrm{~mm} ; \mathrm{f}-\mathrm{i}, \mathrm{k}=2 \mathrm{~mm}$; j, I-n = $1 \mathrm{~mm}$. 
Conservation status - It is uncertain whether this species should be assessed as Near Threatened (NT) or Vulnerable (VU). It is known from over 80 collections but rather few are recent and it appears to occur in only ten widely scattered localities. In the Philippines and some areas near Manado (Menado) habitat is severely degraded but in the mountain ridges in Indonesia it may be less at risk. Tentatively it is given the status of Vulnerable (VU) on the criteria B2ab(iii).

Notes - 1. Our choice of lectotype of B. rugosissima: Although no collection number is cited in the original description, one collection has been traced which bears the handwritten annotation "Urtica rugosa R." This collection is selected as lectotype as being one of only two specimens from Herb. Reinwardt; it is an adequate specimen for typification and it seems reasonable to assume that this was part of the material Blume saw. He would not have been able to use Reinwardt's preliminary label name, since the name Urtica rugosa was already occupied by Urtica rugosa Sw. (1787: 60). The other sheet from Herb. Reinwardt lacks the epithet on the label but is otherwise so similar that it may well be a duplicate collection from a different part of the same large plant.

2. This is a species of narrow geographical distribution, mainly Sumatera and Jawa and just reaching the southern Philippines, from which only two collections of certain identity have been seen. It is distinctive in its leaves bullate, usually large, broad and thick-textured, drying dark brownish adaxially but often much paler chestnut-brown abaxially, and its large conspicuous stipules.

3. It can be confused with thick-leaved forms of $B$. virgata var. virgata (sympatric but widespread) which differs in stipules almost always smaller, female inflorescence-bearing axes often $>30$ (rather than $\leq 15$ ) $\mathrm{cm}$ long, achene small relative to fruiting perianth and leaves mostly relatively narrower with apex usually attenuate. Of the very few collections of the two taxa seen from the Philippines, two collections from Mindanao (Ramos et al. 38857, 39190) are intermediate and impossible to assign to either taxon.

4. Forms of $B$. pilosiuscula (partly sympatric) with large thick leaves can be very difficult to distinguish from small-leaved forms of B. rugosissima. Differences are as follows: In B. pilosiuscula flowers and fruiting perianth are always truncate at apex (and at least fruiting perianth often with an abrupt distinct beak, distinctly flattened and winged in apical part), and female inflorescence-bearing axes (especially in Jawa) usually have a few male clusters at the apex. There is slight overlap in other characters: leaf length $3-15 \mathrm{~cm}$ (in B. rugosissima is (9-)13-25 $\mathrm{cm}$ ); stipules $4-12$ by $1-2.5 \mathrm{~mm}$ (even in small-leaved forms of $B$. rugosissima usually broader and longer, $10-25$ by (2-)3-5 $\mathrm{mm}$ ); leaves of $B$. rugosissima dry rather blackish adaxially and at least small-leaved forms are thick-textured and strongly rugose with the adaxial surface consisting entirely of narrow conical bullations with no space between (all these characters are rare in B. pilosiuscula). Large leaves of $B$. rugosissima may be thin-textured and shallowly bullate, but such leaves are very much larger than any seen in B. pilosiuscula. In B. pilosiuscula at least female axes are always short $1-6(-10) \mathrm{cm}$, clearly single and unbranched whereas axes in B. rugosissima are $6-15 \mathrm{~cm}$ and usually branched, whereas in B. pilosiuscula upper veins are scarcely distinct from coarser tertiary veins and lamina is often elliptic or elliptic-obovate and at least some leaves often markedly asymmetrical due to the different outline of the two sides, whereas in B. rugosissima lateral veins are clear and prominent and lamina is clearly ovate and almost symmetrical.

The two taxa are apparently sometimes found growing together as mixed collections also exist (Jawa: Korthals s.n. (L); Reinwardt s.n. $1855(\mathrm{P})$; Zollinger $1795(\mathrm{U}))$. A few somewhat intermediate collections of possible hybrid origin have also been seen and found impossible to assign satisfactorily to either species, with leaves like $B$. pilosiuscula (slightly bullate) but inflorescence-bearing axes looser (unbranched) with wellspaced flower-clusters.

5. Boehmeria rugosissima is rather similar to some forms of the Hawaiian endemic B. grandis, the leaves of which are also large, thick-textured with prominent veins and drying brownish, but which differs in many $(6-10)$ veins in the distal half of the lamina and several almost equally prominent coarse tertiary veins arising lower on midrib and in its fruiting perianth usually clearly winged with relatively small achene; stipules are also mostly much larger and broader. It can also be confused with the partly sympatric (but more widespread) B. virgata subsp. macrophylla var. scabrella which can have bullate leaves but has smaller stipules ( $7 \mathrm{~mm}$ long or less), leaves with more numerous hairs, usually drying greenish, often thin-textured.

6 . The conspicuous stipules are very like those of Cypholophus anisoneurus (Solomon Islands and Vanuatu), a taxon hitherto included in this genus, which also has large leaves, but these are thin-textured drying light greenish brown, usually strongly asymmetrical and with vein arrangement very different in the two sides; it also has female clusters in leaf axils rather than on long axes.

\section{Boehmeria pilosiuscula (Blume) Hassk. - Fig. 38; Map} 40, 41

Boehmeria pilosiuscula (Blume) Hassk. (1844) 79. - Urtica pilosiuscula Blume (1825) 491. - Boehmeria platyphylla D.Don var. pilosiuscula (Blume) Hand.-Mazz. (1929) 151. - Type: Kollmann s.n. (holo G; iso NY), Indonesia, Jawa [Java], "montosis". - See Note 1.

Woody-based herb or subshrub, erect, up to $1.5 \mathrm{~m}$ tall, or decumbent, trailing or scrambling and often rooting at nodes, stems 0.3-5 m long; ultimate stems slender, c. $0.8 \mathrm{~mm}$ diam, with soft spreading hairs of two kinds, dense minute $(<0.1 \mathrm{~mm})$ and straight mixed with sparse long $(0.2-0.4 \mathrm{~mm})$ and curved. Stipules triangular and often small, $4-7(-10)$ by $1-1.5(-2) \mathrm{mm}$, chartaceous. Leaves opposite, moderately dimorphic with 'larger' $1.3-2 \times$ length of 'smaller' ones and relatively narrower, broadly elliptic to elliptic-ovate or elliptic-obovate, lamina varying in shape often even on one plant, some leaves almost symmetrical, others distinctly asymmetrical with two sides of lamina of similar width but different outlines; small or medium, 3-12(-15) by $1.5-6(-8) \mathrm{cm}$, length $(1.7-) 1.8-2(-2.25) \times$ width; margin serrate, teeth $25-40(-45)$ either side, $1-2$ by $2-3(-4) \mathrm{mm}$, broader rather than more numerous in larger leaves and usually slightly up-curved; leaf apex with abrupt short or relatively long acumen toothed to tip, base distinctly oblique with one side rounded, the other side cuneate; basal veins rather straight, fine but distinct, extending into distal third, upper lateral veins similarly arranged on both sides of lamina, 1-2 arising near middle of lamina or in distal half but not very distinct from reticulation which is also visible adaxially and finely prominent abaxially; texture usually rather thin-chartaceous, but leaves often slightly bullate; hairs on adaxial surface all of same kind, sparse or abundant, adpressed or \pm spreading, on abaxial surface those on veins fairly long $(0.2-0.7 \mathrm{~mm})$ spreading, sparse or abundant, elsewhere minute, inconspicuous and sparse; petiole relatively long relative to lamina, often just over half of lamina length, up to $4 \mathrm{~cm}$, with two kinds of hairs like the stem. Flower-clusters borne on leafless inflorescence-bearing axes, 1 per axil; erect and short; bisexual or unisexual; entirely or predominantly male axes rarely seen, 4-6 cm long, with several shorter lateral branches in lower half which are up to $2 \mathrm{~cm}$ and progressively shorter towards axis apex, with female clusters (where present) restricted to a few along main axis; entirely female or predominantly female axes much more 
common, unbranched, only $1-6(-10) \mathrm{cm}$ long with groups of female clusters so closely contiguous and densely congested that the axis appears to be \pm cylindrical, a dense mass of tightly congested flowers, sometimes with well-marked sterile basal portion or gaps between groups of clusters; if bisexual then also with a few small few-flowered male clusters near tip of axis only, these congested or spaced 2-3 mm apart; male clusters $1.5-2(-3) \mathrm{mm}$ diam, with few-10 flowers, female clusters large, (3-)4-7 mm diam, with (30-)usually well over 50 densely crowded flowers; bracts subtending male clusters abruptly fine-acuminate, c. 1-2 mm long, bracts subtending female clusters inconspicuous; bracteoles narrowly oblong, fairly conspicuous (in crowded female clusters only when fruit fallen), $0.5 \mathrm{~mm}$ long. Male flowers 4-merous, on pedicels 0.5-1.5 mm long, mature buds globose, c. $1.5 \mathrm{~mm}$ diam, dorsal appendage of tepals distinct, hairs of two kinds, sparse, short, adpressed and longer hooked. Female flowers $0.7-0.8$ by $0.2-0.5 \mathrm{~mm}$, narrowly obconical to broadly obovoid-truncate, often with abrupt beak to half of perianth length or often conspicuously 2-toothed, hairs abundant, spreading, long, white, hooked; stigma c. $1 \mathrm{~mm}$ long. Fruiting perianth $1-1.2$ by $0.8-1$ $\mathrm{mm}$, broadly obconical-flattened (i.e., obtriangular in outline) with or without minute abrupt beak, dorsiventrally flattened near apex forming winged 'shoulders' in distal half, abundantly hairy in distal part. Achene rather asymmetrically ellipsoid or obconical-3-angled, relatively flattened, shiny yellow-brown almost as long as fruiting perianth, \pm rugose.

Distribution - India (Tamil Nadu, Arunachal Pradesh), Sri Lanka, Burma, southern China (incl. Hainan and Taiwan), Thailand, Indonesia (Sumatera, Jawa, Borneo, Nusa Tenggara [Lesser Sunda Islands]), Philippines (Luzon).

Habitat \& Ecology - Moist areas in evergreen forest, often by streams; or in clearings in disturbed areas or on roadside banks; sea level-1650 m altitude.

Conservation status - Near Threatened (NT) or possibly Vulnerable (VU). The species is known from c. 150 collections, some of which are recent, but appears to occur in only c. 25 rather scattered locations in India, Indochina, Indonesia and the Philippines. Thus the EOO of over $8000000 \mathrm{~km}^{2}$ is extremely misleading. Its $\mathrm{AOO}$ is less than $500 \mathrm{~km}^{2}$ and it occurs in fairly restricted forest habitat. The record from southern India may well represent a population now extinct as the region is extensively cultivated, and habitats in Taiwan, the Philippines and Jawa are increasingly degraded; those in China and Indochina are not currently so but may become so in the future with increasing agriculture. Those in the mountain ridge in West Sumatera are not currently threatened. Tentatively it is given the status of Vulnerable (VU) on the criteria VU B2ab(iii).

Separate formal assessments are not given for the two, intergrading, varieties.

Notes -1 . The collector of the type of B. pilosiuscula, Kollmann, is not cited in Blume's protologue but the label on the specimen in $\mathrm{G}$ has the basionym written in Blume's handwriting, which strongly indicates this collection is the holotype.

2. The illustrations in Yang et al. (1996: photo no. 80 on p. 785) and Ying (1998: 62, photo 561) are labelled as B. formosana but are almost certainly of this taxon.

3. Boehmeria pilosiuscula is distinctive in its female and bisexual inflorescence-bearing axes short and interruptedcongested with large often densely congested clusters of tightly congested female flowers, its male flowers mainly found in a few small male clusters only at the apex of these axes, its fruiting perianth broad obconical-truncate, its mixed stem indumentum of sparse relatively long curved hairs and dense minute pubescence spreading at right angles to the stem and its leaves small and thin-textured, often markedly asymmetrical. It is probably under-collected, only one collection have been seen from each of North and South India, Sumatera and Borneo, so the material seen may not represent its complete distribution.

4. Two almost allopatric regional varieties are recognised. Var. pilosiuscula (north-eastern and south-eastern India, Sri Lanka, Burma, Philippines, Indonesia) and var. suffruticosa (Burma, Thailand. China). The typical variety at its extreme presents a rather different appearance to that of var. suffruticosa but is rather variable. Var. suffruticosa shows little range of variation but forms intermediate between the two occur in Taiwan, Hainan, Thailand and Jawa. See detailed discussion under var. pilosiuscula (Note 3).

5. Boehmeria listeri (sympatric, Himalayas and Burma) also has mixed indumentum (but the minute hairs are smaller and denser giving the whole plant a grey tinge), leaves asymmetrical (but relatively narrower and usually longer) and fruiting perianth obconical (but not apically flattened); it differs also in inflorescence-bearing axes usually longer, the bisexual (and female) ones mostly with several long branches at the base (rather than unbranched) and male flowers mainly in the lower part of the axis or abundant throughout its length.

6. Only B. ourantha (partly sympatric in Himalayas and Burma) and $B$. yaeyamensis (allopatric, maritime, Ryukyu Islands) also have male flowers similarly arranged in the upper parts of mainly female axes rather than below the female (on lateral male branches or in entirely male axes in lower leaf axils). Boehmeria yaeyamensis also has mixed stem hairs, small leaves and rather short thick axes with densely congested female clusters but is not otherwise similar, easily distinguished by its leaves \pm symmetrical, truncate to cordate, thick-textured and even broader with few rounded teeth. Boehmeria ourantha has stem hairs uniform, dense long conspicuous and golden, leaves larger, symmetrical, truncate or cordate, marginal teeth larger and inflorescence-bearing axes long.

7. Without male flowers, forms of $B$. pilosiuscula with large thick-textured leaves can be confused with the partly sympatric $B$. rugosissima and the two are apparently sometimes found growing together (see detailed discussion in Note 4 under B. rugosissima).

8. When male flowers are not present, B. virgata subsp. macrophylla var. scabrella and forms of $B$. pilosiuscula with less markedly asymmetrical leaves can readily be confused due to the similar leaf shape and short erect inflorescenceaxes with crowded clusters. The two are partly sympatric (in northern India, Southern China and Jawa). However, the mixed stem indumentum gives a distinctive appearance discernible by the naked eye; var. scabrella has \pm uniform usually stiff straight closely-adpressed or half-adpressed hairs and even forms with some hairs softer and slightly curved clearly lack the minute indumentum. Female flowers in var. scabrella are obovoid, tapering towards their apex such that not even large crowded female clusters appear like a solid mass, rather than obconical-truncate with a broad apex. In var. scabrella female clusters are also mostly smaller, up to c. $4 \mathrm{~mm}$ diam (rather than 4-7 $\mathrm{mm}$ ) and male clusters are always on separate branched axes or short branches at the base (rather than a few clusters along the apical part) of an otherwise female axis. Fruiting perianth in $B$. virgata subsp. macrophylla var. scabrella is very varied including ovoid \pm unwinged forms and flattened spindleshaped with a wing more or less surrounding the achene, rather than consistently obtriangular with a flattened apex. Leaves in $B$. virgata subsp. macrophylla var. scabrella are also often broader (length often only 1.3-1.5x width). Boehmeria virgata subsp. macrophylla var. scabrella differs from var. suffruticosa additionally in longer and broader marginal teeth, $1.5-2$ by $3-6 \mathrm{~mm}$ (rather than $\leq 1.5$ by $2 \mathrm{~mm}$ ), and much longer female axes (at least $5 \mathrm{~cm}$ long). It is less easy to distinguish from var. 


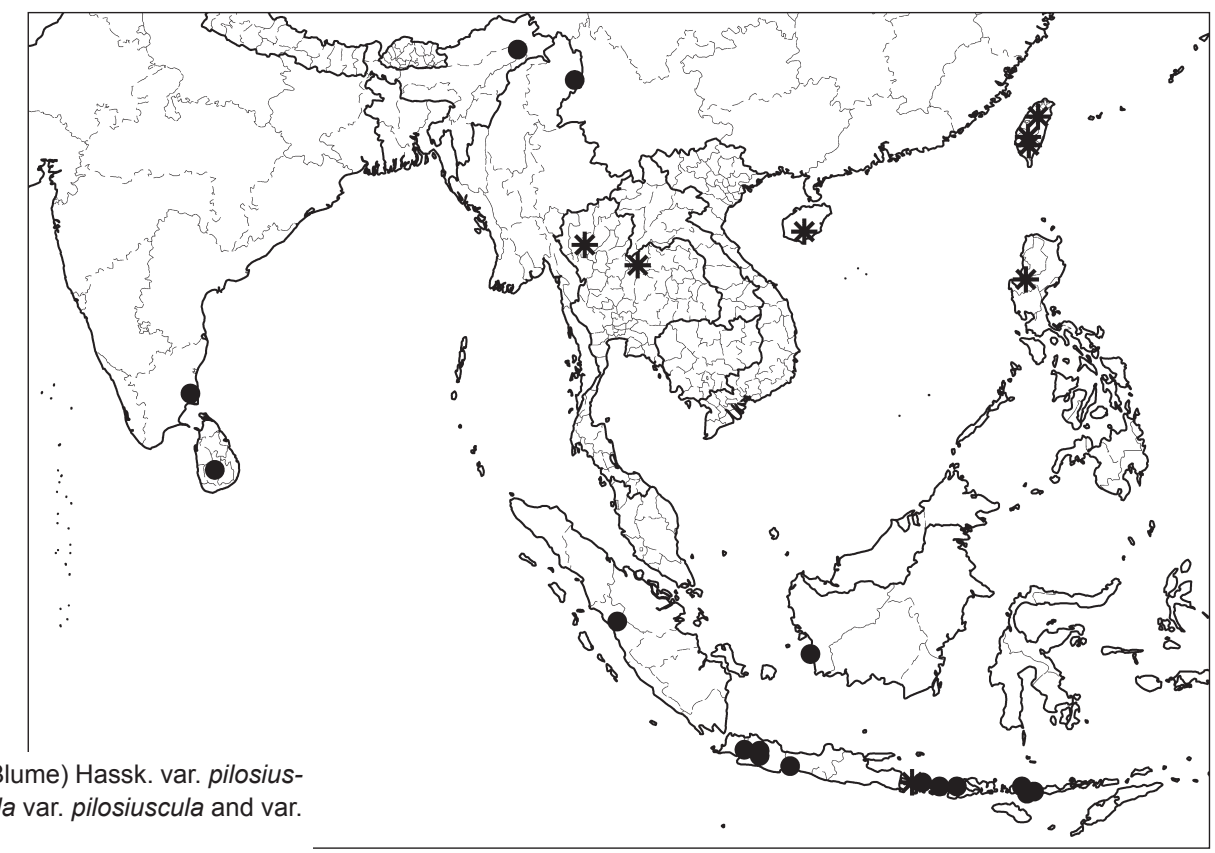

Map 40 Distribution of Boehmeria pilosiuscula (Blume) Hassk. var. pilosiuscula (๑) and intermediates between B. pilosiuscula var. pilosiuscula and var. suffruticosa (*).

pilosiuscula but its mainly male axes are many-branched and frequent and male flowers are subsessile rather than usually clearly pedicellate.

\section{Key to varieties}

1. Female and bisexual axes with clusters congested into continuous mass $\leq 2 \mathrm{~mm}$ long and lower $0.5-1 \mathrm{~mm}$ part of axis often naked (whole axis 1-2(-3) mm long), flower-bearing part $\leq 2 \mathrm{~cm}$; leaves never bullate, always thin-textured, marginal teeth $1(-1.5) \mathrm{mm}$ long, usually up to 30 either side; entirely male branched axes absent. - Burma; Thailand; China . . . . . . . . . . . . . . . . b. var. suffruticosa

1. Female and bisexual axes, at least some on plant, with flower-bearing part 3-10 cm long; clusters contiguous along part of length but usually distinct; leaves mostly bullate, often relatively thick, marginal teeth either more than 35 either side or $\geq 2 \mathrm{~mm}$ long; branched (entirely male axes present or not). — India; Sri Lanka; Burma; Indonesia; Philippines a. var. pilosiuscula

\section{a. var. pilosiuscula - Fig. 38a-i; Map 40}

Boehmeria platyphylla D.Don var. zeylanica Wedd. (1869) 211. — Boehmeria macrophylla Hornem. var. zeylanica (Wedd.) Wadhwa (1999) 265. - Type: Thwaites 2197 (lecto K; isolecto CAL, G, P), Sri Lanka. - See Note 1.

Boehmeria humilis Miq. (1851) 33. - Boehmeria pilosiuscula (Blume) Hassk. var. humilis (Miq.) Blume (1857) 223. - Boehmeria platyphylla D.Don var. humilis (Miq.) Wedd. (1869) 212. - Boehmeria caudata (Burm.f.) J.J.Sm. var. humilis (Miq.) J.J.Sm. (1910) 717. - Type: Junghuhn s.n. (holo L), Indonesia, Jawa [Java], Mt Medin, Ungaran.

Boehmeria pilosiuscula (Blume) Hassk. var. procera Blume (1857) 223. Type: Not indicated or traced.

Shrub. Leaves (3-)5-12(-15) cm long, marginal teeth (25-)3545 , either broader or more numerous in larger leaves, $1-2$ by 2-4 mm; thin- or thick-textured, but leaves \pm bullate with conspicuous reticulation, hairs adaxially \pm spreading, often with conspicuous bulbous base giving rough texture. Female or bisexual inflorescence-bearing axes (2-)3-6(-10) cm long, the longest ones sometimes drooping in upper part, often with intermittent gaps between groups of clusters; entirely or predominantly male axes occasionally also present, 4-6 mm long, branched in basal quarter, clusters contiguous or spaced up to $1 \mathrm{~mm}$ apart, 2-3 $\mathrm{mm}$ diam, with 2-5(-10) flowers.
Distribution - India, Sri Lanka, Burma, Indonesia (Sumatera, Jawa, Borneo, Nusa Tenggara [Lesser Sunda Islands]), Philippines (Luzon).

Habitat \& Ecology - Clearings in disturbed areas of evergreen primary forest; sea level-1650 m altitude.

Notes - 1. Hooker (1888: 578 ) states about the collection Thwaites 2197 that it is "mixed with var. scabrella" and Wadhwa writes the same on the Peradenya (PDA) sheet of this collection. Wadhwa's determination on the duplicate of this collection at $\mathrm{K}$ indicates that parts of the collection represents $B$. rugosissima, but in our opinion all the material in the duplicates we have seen represents $B$. pilosiuscula. In order to avoid further doubt, we designate the $\mathrm{K}$ duplicate as lectotype.

2. Few collections (sometimes only one) have been seen from most localities, suggesting that it is under-collected.

3. It differs from var. suffruticosa in leaves with teeth either more numerous or larger, mostly bullate, often larger or thicker-textured, inflorescence-bearing axes usually longer with clusters often less crowded together along the axis, the flowerbearing part of at least some axes 3-10 cm (rather than $\leq 2 \mathrm{~cm}$ ) and the occasional presence of branched mainly male axes.

4. Var. pilosiuscula is often less easy than is var. suffruticosa to distinguish from $B$. virgata subsp. macrophylla var. scabrella. As discussed above in Note 8 under the species as a whole the only absolutely distinguishing features from $B$. virgata subsp. macrophylla var. scabrella are the mixed stem indumentum, 'solid' female clusters, female flowers with a truncate apex and the presence of male clusters at tips of mainly female-axes.

5. Specimens with somewhat bullate leaves can be confused with small-leaved forms of the sympatric $B$. rugosissima. Fertile material is easily distinguished, with inflorescence-bearing axes always unisexual and both sexes are usually several-branched near their base with well-spaced clusters and the fruiting perianth of $B$. rugosissima is not truncate at its apex. Sterile material can be distinguished by leaves \pm symmetrical and either much larger or thick-textured and deeply and closely rugose-bullate, or both; stipules are also often much larger. Two clearly mixed collections exist, suggesting that the two species can be found growing together; intermediate material of possible hybrid origin has also been seen. See under B. rugosissima (Note 4) for more detailed discussion. 


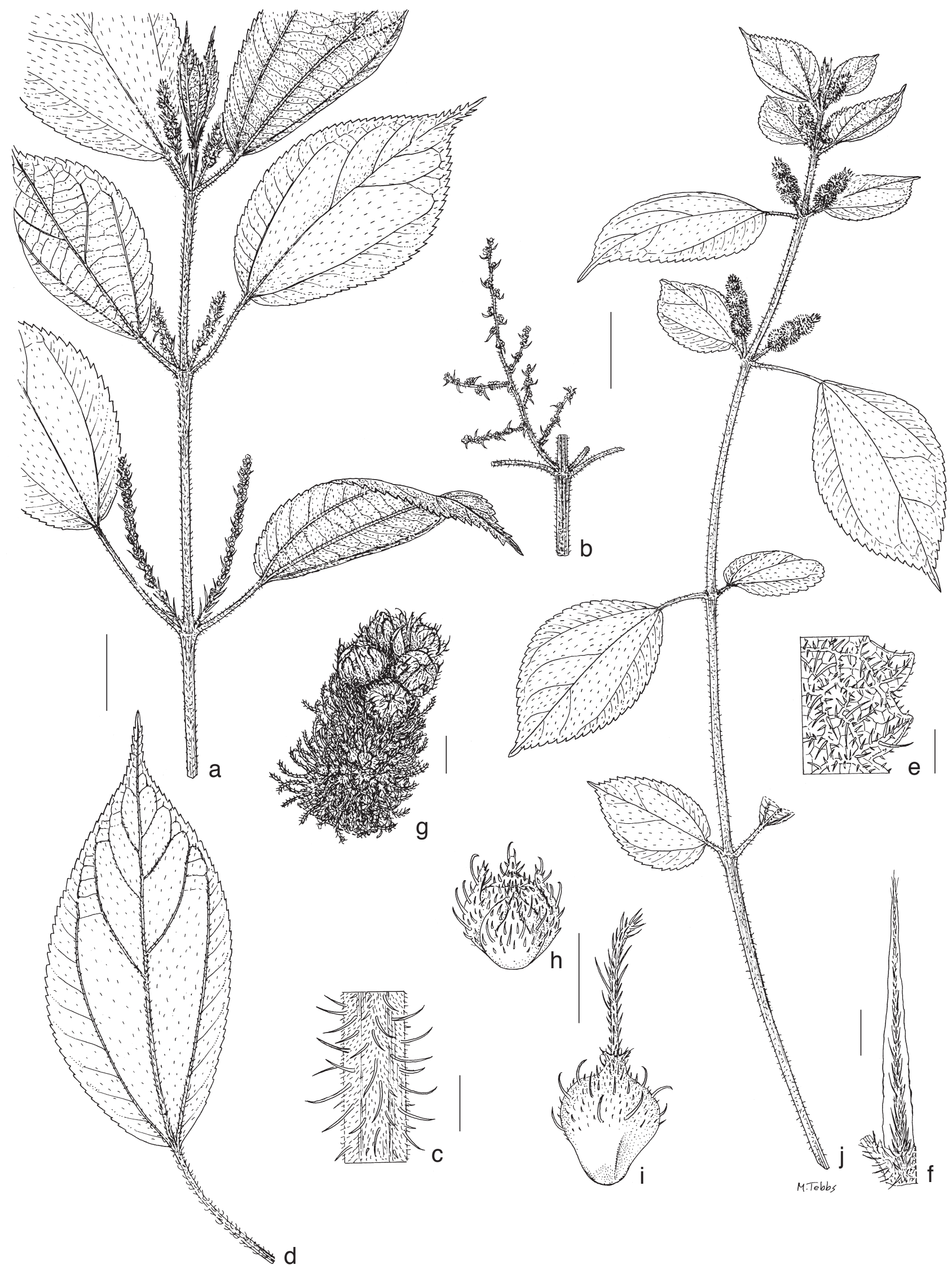

Fig. 38 a-i: Boehmeria pilosiuscula (Blume) Hassk. var. pilosiuscula. a. Habit of stem with bisexual and female inflorescence-bearing axes; b. lower node of stem with branched male inflorescence-bearing axis; c. detail of stem showing two kinds of spreading hairs; d. leaf; e. leaf, detail of abaxial surface; f. detail of stem and stipule; g. upper part of bisexual inflorescence-bearing axis with congested female flower-clusters (inflorescences) below and few-flowered male clusters (inflorescences) at apex; h. male bud; i. fruiting perianth. — j: Boehmeria pilosiuscula var. suffruticosa Acharya, Friis \& Wilmot-Dear. Habit of stem with bisexual and female inflorescence-bearing axes (a, e, f, h: Sinclair 10053, K; b: de Vriese s.n., L; c, d: Kostermans 18171, K; g: Henry 12370, K; i: Gammie 190, K; j: Henry 12696, K). — Scale bars: a, b, d, j= $2 \mathrm{~cm} ; \mathrm{c}, \mathrm{g}-\mathrm{i}=1 \mathrm{~mm} ; \mathrm{e}, \mathrm{f}=2 \mathrm{~mm}$. 


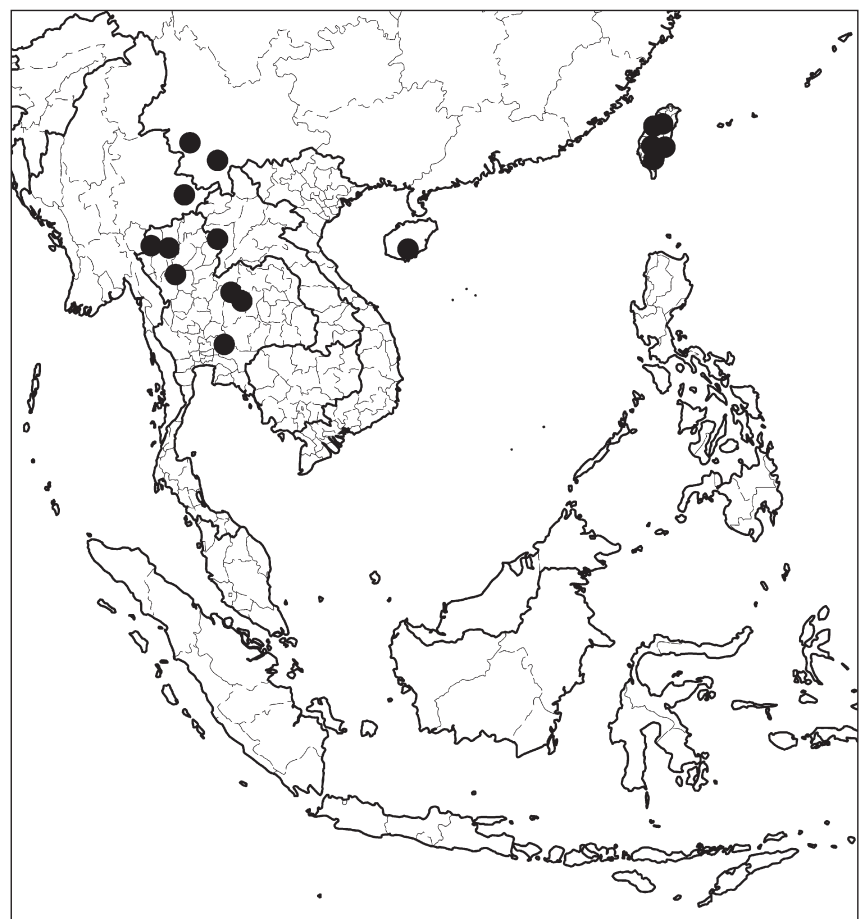

Map 41 Distribution of Boehmeria pilosiuscula (Blume) Hassk. var. suffruticosa Acharya, Friis \& Wilmot-Dear.

\section{b. var. suffruticosa Acharya, Friis \& Wilmot-Dear, var. nov. -}

Fig. 38j; Map 41

A var. typica atque a multis ceteris speciebus generis axe florali brevissima atque glomerulos femineos contiguos crebrissimos ferenti structura dura interrupte subcylindrica formanti differt; a var. typica etiam parte florifera axis $1-2 \mathrm{~cm}$ tantum (nec $3-10 \mathrm{~cm}$ ) longa, foliis numquam bullatis neque crasse chartaceis atque ad marginem dentes $\leq 30$ tantum numero, 1(-1.5) $\mathrm{mm}$ tantum altos (nec usque $2 \mathrm{~mm}$ altos) ferentibus distinguenda. - Typus: Larsen et al. 44502 (holo K; iso AAU), Thailand, Nan prov., Sapan falls, 600 m.

Subshrub or herb. Leaves 3-9(-11) cm long; marginal teeth consistently only $25-30(-35)$, broader rather than more numerous in larger leaves, $1(-1.5)$ by $2-3(-4) \mathrm{mm}$; texture very thinchartaceous; hairs adaxially soft, adpressed or half-adpressed. No entirely male axes seen; female and bisexual axes $1-3 \mathrm{~cm}$ long but lower $0.5-1 \mathrm{~cm}$ of axis often naked; female clusters contiguous, providing a thick (c. $0.5 \mathrm{~cm}$ diam) cylindrical appearance of the inflorescence-architecture which seems to be made up of one inflorescence-bearing axis only.

Distribution - Burma, Thailand, southern China (including Hainan and Taiwan).

Habitat \& Ecology - Moist areas in evergreen forest, often by streams; roadside banks and barren stony areas; 500-1200 $(-1500) \mathrm{m}$ altitude.

Notes -1 . This variety is distinctive in its female inflorescence-bearing axes which are extremely short (at most $2 \mathrm{~cm}$ long) and almost 'cylindrical' due to congested masses of clusters, and leaves small, often markedly dimorphic in both size and shape and/or markedly asymmetrical, thin-textured, shallowly serrate soft-hairy, veins slender.

2. This variety is the easier of the two to distinguish from $B$. virgata subsp. macrophylla var. scabrella. See detailed discussion in Note 8 under the species.

3. The joint publication of this new taxon was accepted by Acharya and is partly based on his earlier unpublished findings.

\section{Boehmeria listeri Friis \& Wilmot-Dear - Fig. 39; Map 42}

Boehmeria listeri Friis \& Wilmot-Dear in Wilmot-Dear et al. (2010) 432. Type: Lister 99 (holo CAL; iso K), India, Duphla Hills, Harpili [Hapoli], 19 Dec. 1874.
Tree or shrub, 2-3 m tall, or rarely subshrub, < $1 \mathrm{~m}$ tall; young stems up to $2 \mathrm{~mm}$ diam with hairs of usually two kinds, some abundant and relatively long $(0.2-0.3 \mathrm{~mm})$, curved \pm adpressed) usually mixed with sparse minute ( $<0.1 \mathrm{~mm}$ long) spreading hairs; later glabrescent. Stipules narrowly triangular, conspicuous $9-11$ by c. $2.5 \mathrm{~mm}$, with long hairs (c. $0.5 \mathrm{~mm}$ long) on midrib and minute but abundant pubescence elsewhere. Leaves opposite, slightly or more often markedly dimorphic with length of 'larger' 1.25-2.5x length of 'smaller' ones and relatively broader with more distinctly acuminate apex; slightly asymmetrical (outline of two sides slightly dissimilar), narrowly elliptic-ovate to elliptic, $10-21$ by $3.5-7.5 \mathrm{~cm}$, length (2.3-)2.8-3.1× width; margin finely-serrate, teeth (40-)45-65 either side, up-curved, acute, minute $0.5-1(-1.5)$ by $1-3(-4)$ $\mathrm{mm}$ with width $1-2(-3) \times$ length; leaf apex attenuate-acuminate often slightly sideways-curved, base asymmetrically rounded or slightly cuneate; basal veins extending into distal third on one side, just in distal half on other side, upper lateral veins usually dissimilar, on narrow side only 3 , all arising in distal half, on other side usually an additional (1-)2 arising near or below middle of lamina, all veins inconspicuous adaxially, finely prominent abaxially, coarser tertiary veins also finely prominent; texture very thin-chartaceous, leaves drying grey-green or blackish; adaxial surface with a minute bullation in centre of each areole, with single hair arising from it, otherwise glabrous, abaxial surface with two kinds of hairs like the stem, the minute ones throughout leaf surface, often giving a pale sheen, the long ones longer than on the stem $(0.5-1 \mathrm{~mm})$, sparse and restricted to the venation; petiole variable, $0.2-0.3 \times$ lamina length, $2-5 \mathrm{~cm}$, with two kinds of hairs like the abaxial leaf surface. Flower-clusters arranged along leafless inflorescencebearing axes, these \pm pendulous, 1-2 per axil, unbranched or with 1-2 long lateral branches very close to base, appearing as if several from each axil, $5-13 \mathrm{~cm}$ long, with long hairs and often also minute ones like the stem; both sexes often on same axes, mostly in unisexual clusters with male clusters in lower part, female distally, but sometimes clusters mostly bisexual and rarely also a few male flowers present in mainly female clusters at extreme apex distal to entirely female clusters; bracts broadly triangular, often conspicuous (especially when clusters are few-flowered), up to 1 by $1 \mathrm{~mm}$; clusters spaced $1-10 \mathrm{~cm}$ apart or sometimes \pm contiguous; male clusters $2-4 \mathrm{~mm}$ diam, with few-10(-15) flowers, female clusters $2-3 \mathrm{~mm}$ diam, with

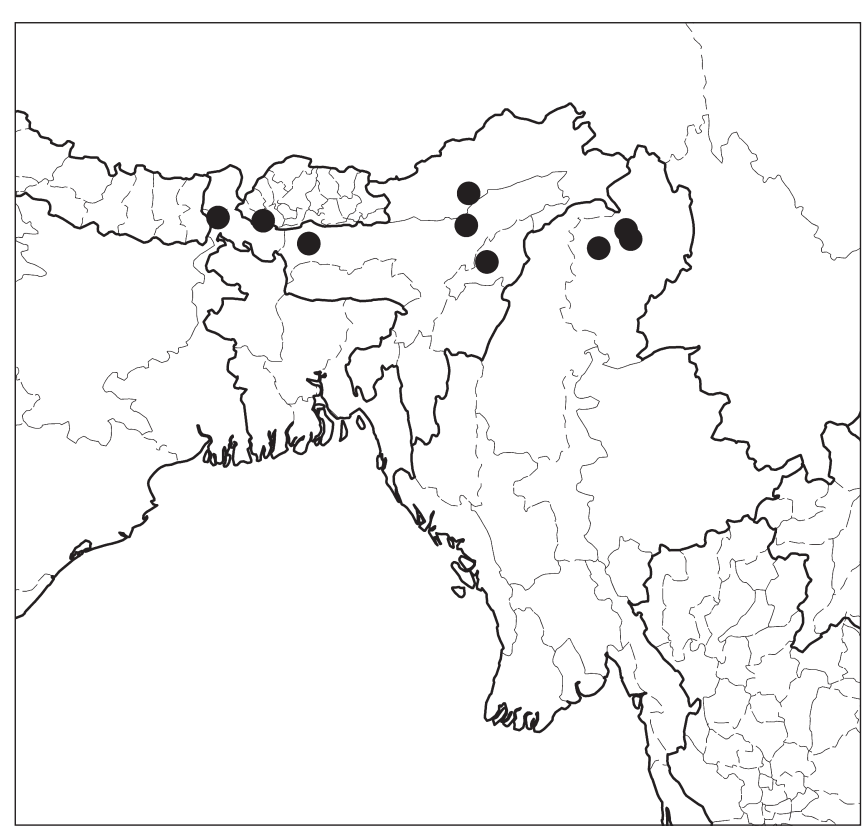

Map 42 Distribution of Boehmeria listeri Friis \& Wilmot-Dear. 


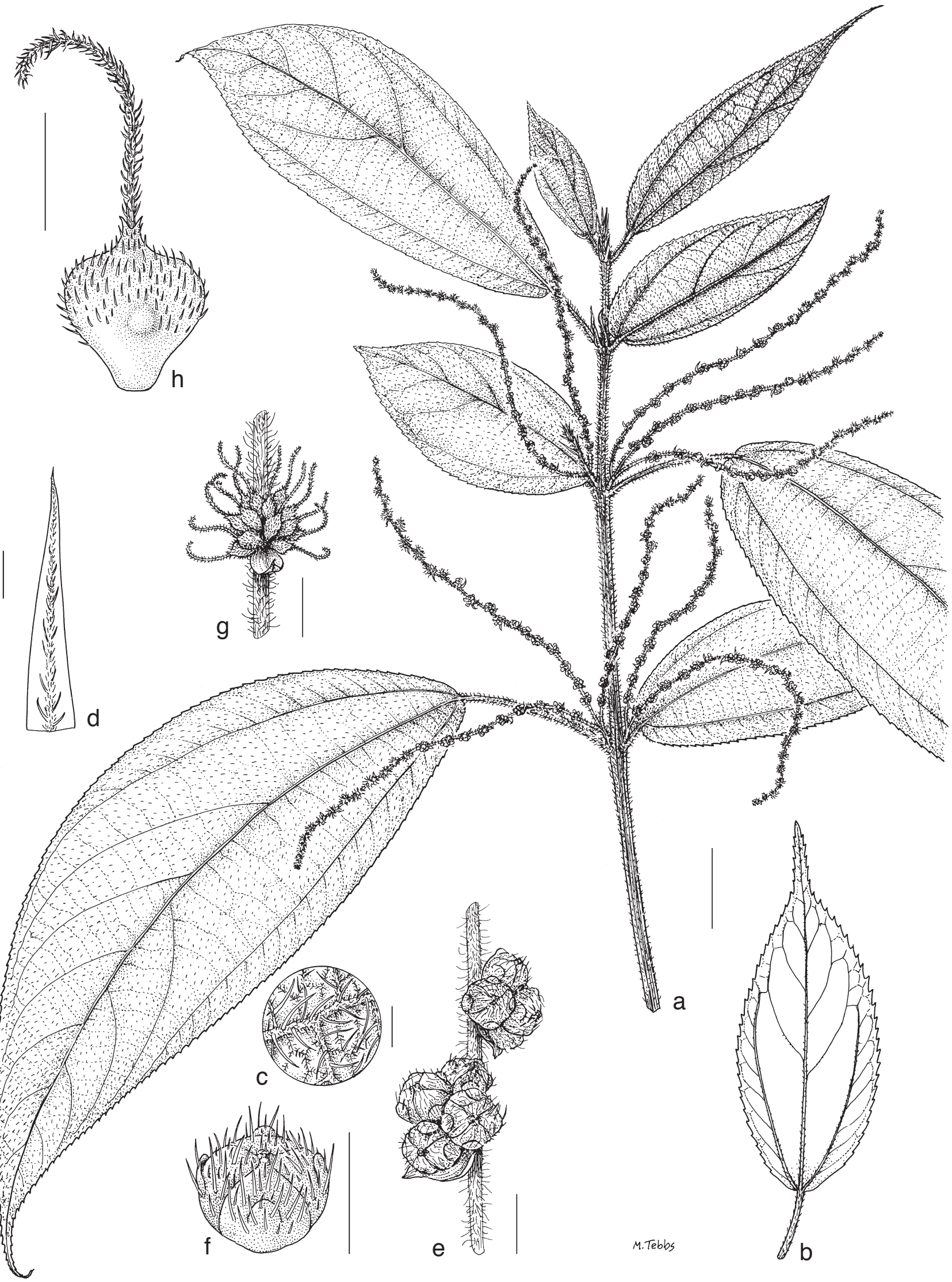

Fig. 39 Boehmeria listeri Friis \& Wilmot-Dear. a. Habit of stem with several bisexual inflorescence-bearing axes at each node; b. leaf; c. detail of lower surface of lamina, showing two types of hair; d. stipule; e. detail of male part of inflorescence-bearing axis with two flower-clusters (inflorescences) and bracts, showing two types of hair; $f$. male bud; $g$. detail of female part of inflorescence-bearing axis with one flower-cluster (inflorescence) and bract; $h$. fruiting perianth (a, $c-g$ : Stainton 6723; b, h: Dec. 1890, King s.n.; all K). - Scale bars: a, b = $2 \mathrm{~cm} ; \mathrm{c}, \mathrm{e}-\mathrm{h}=1 \mathrm{~mm} ; \mathrm{d}=2 \mathrm{~mm}$. 
(10-)20-more than 40 crowded flowers; bracteoles triangular, inconspicuous, less than $0.3 \mathrm{~mm}$ long. Male flowers 4-merous, sessile, mature buds globose, c. $1.5 \mathrm{~mm}$ diam, tepals with apiculus and prominent dorsal appendages and abundant long hairs like the stem. Female flowers obovoid (rarely ovoid) with indistinct beak, with dense long hairs like the stem; stigma variable 1-2(-2.5) mm long. Fruiting perianth obovoid to broadly obconical often broadly truncate at apex or sometimes with minute beak, $1-1.3$ by $0.5-1 \mathrm{~mm}$, slightly laterally flattened or indistinctly several-angled but without marginal rim or wing, abundantly long-hairy. Achene almost filling fruiting perianth.

Distribution - Eastern Himalaya: India, Bhutan, Bangladesh, Burma.

Habitat \& Ecology - Forest understory in partial shade; slopes of subtropical forest, river margins, on limestone; 150$1000 \mathrm{~m}$ altitude.

Conservation status - Near Threatened (NT). The conservation status was estimated by Wilmot-Dear et al. (2010: 435), with an EOO of $97408 \mathrm{~km}^{2}$. The species occurs in areas of low habitat disturbance, while a few localities were close to areas of intensive agriculture. However, due to the relatively wide geographical and ecological range of the species it was decided not to place the species in a threat category.

Notes - 1. Boehmeria listeri is rather nondescript in appearance, resembling various different species in various characters, such that its best placing in the genus is unclear. Its diagnostic characters are its leaves long narrow and grey-green (drying greyish brown), often elliptic (rather than ovate which is much more common in the genus) with teeth numerous and small, venation rather asymmetrically arranged, its indumentum of mixed long and minute fine hairs usually present on most parts of the plant, the minute ones giving a slightly greyish appearance and its fruiting perianth unwinged, short, broad, usually obconical. It is provisionally placed here since $B$. pilosiuscula (sympatric in India and Burma) has a similarly obconical fruiting perianth (although usually \pm flattened at its apex), asymmetrical leaves (but shorter relatively broader with fewer longer teeth) and two clearly different kinds of indumentum on many parts, differing in the fine pubescence being less minute and more sparse on leaves, petioles and stipules, which are not distinctly greyish. Flowers are also differently arranged on the bisexual axes in $B$. pilosiuscula, male clusters being few, restricted to the apex (rather than numerous, mostly in the lower half of the axis) and bisexual clusters are few with only a few male flowers; in $B$. pilosiuscula female and bisexual inflorescence-bearing axes are always single and unbranched, usually shorter, \pm erect and often very congested. However, molecular work is needed to clarify its position.

2. On his original label King apparently considered $B$. listeri to be a variety of the sympatric but more widespread $B$. penduliflora (B. macrophylla D.Don). That species has leaves somewhat similar-textured with hairs of two lengths on the abaxial surface but leaves are much narrower and often much longer (length 5-7× width), glabrous adaxially (except the young leaves at the extreme apex of the stem), its stem hairs are uniform and its fruiting perianth has a distinct broad wing. We have seen one specimen, one of two K duplicates of Griffith 4555 somewhat intermediate between the two, species with stem indumentum uniform and perianth flattened-obovoid fruiting with a distinct marginal rim as in $B$. penduliflora but with leaf shape and proportions as in $B$. listeri. This specimen appears to be part of a mixed collection since the second $\mathrm{K}$ sheet and several other duplicates are of a clearly different plant conforming in all respects to $B$. penduliflora and it seems very likely that the two entities were found growing together. No other intermediate collections have been seen; the two species overlap in altitudinal range and possibly this aberrant collection might be a hybrid.
3. The allopatric (Philippine) B. multiflora is somewhat similar to $B$. listeri in the proportions and densely grey-hairy underside of its leaves, but it lacks the mixed indumentum and differs in abundant indumentum on leaf adaxial surface, prominent dorsal appendages on male flowers, thicker female inflorescencebearing axes due to larger clusters and fruiting perianth usually with distinct wing.

4. Some variants of the sympatric (widespread) B. virgata subsp. macrophylla are superficially rather similar, especially those forms intermediate between var. macrostachya and var. scabrella which have inflorescence-bearing axes branched at the base and leaves relatively long and narrow with many small teeth; however, these forms do not have stem and petiole indumentum of mixed hairs of two different kinds and their leaves are clearly ovate rather than elliptic-ovate and drying greenish rather than greyish brown abaxially. Some variants of the allopatric (widespread) B. virgata subsp. virgata var. virgata are more similar in indumentum and leaf morphology but differ in marginal teeth relatively broader, fruiting perianth winged, female axes much longer $(20-70 \mathrm{~cm})$ and male axes also usually longer and branched throughout length.

5. The allopatric (Indonesian) B. rugosissima can have mixed stem indumentum and minutely bullate leaves almost glabrous adaxially, but leaves dry brownish rather than greyish and are usually much broader and stipules often very large.

6. A species of Cypholophus, C. decipiens Winkl., (allopatric, Papua New Guinea and the Pacific) has strikingly similar leaves with markedly asymmetrical venation on the two sides (differing from $B$. listeri only in upper veins $0-2$ rather than usually 3 on narrow side) and many minute teeth, sometimes also mixed stem indumentum, such that sterile material of $B$. listeri could be misidentified as this common and widespread species; however, on fertile material the sessile axillary female flower-clusters of $C$. decipiens are diagnostic.

7. Two collections of uncertain identity have been seen with relatively much broader leaves with length only $\mathrm{c}$. $1.5 \times$ width but otherwise conforming to B. listeri: Forest 24801 (UC), north-eastern Upper Burma (leaves obovate, only 6.5-9 cm long with abrupt short acumen); and Hooker et al. s.n. (NY), India, Sikkim (leaves elliptic 11-12 cm long).

\section{NAMES OF UNCERTAIN IDENTITY IN OLD WORLD BOEHMERIA}

Authorities of species only mentioned in this list are not included in the list of References. References to their works can be found in Index Kewensis or IPNI.

Boehmeria caudata (Burm.f.) J.J.Sm. var. pendula J.J.Sm. (1910) 708. - Type: Koorders s.n. (holo BO, not traced), Indonesia, Jawa [Java], "Res. Besoeki". - Judged from the description this is probably a synonym of $B$. virgata, but further identification is not possible without original material.

Boehmeria diffusa Wedd. var. canescens Wedd. (1856) 357. Type not indicated or traced. - Identification is not possible without original material.

Boehmeria diffusa Wedd. var. hirta Wedd. (1856) 356. - Type: not indicated or traced. - Identification is not possible without original material.

Boehmeria diffusa Wedd. var. strigosa Wedd. (1856) 357. Type not indicated or traced. - Identification is not possible without original material.

Boehmeria greviaefolia C.Presl (1845) 540. - Type: Hilsenberg s.n. (not traced), Mauritius. - The name was proposed for a plant originally named $B$. caudata Sieber, presumably an 
unpublished manuscript name. Boehmeria greviaefolia would appear to be identifiable with $B$. virgata subsp. macrophylla var. macrostachya, but certain identification is not possible without original material. Weddell (1869: 215) renders the name $B$. grewiaefolia.

Boehmeria jacquiniana Blume (1857) 219. - Type: Jacquin s.n. (holo W). - Specimen bearing the ms name Urtica interrupta Jacq., material only allows a very tentative identification as $B$. japonica var. tenera.

Boehmeria rubrinervia Hassk. (1844) 79. - Type: Unknown collector [Blume] s.n. (n.v.), Indonesia, Jawa [Java], Salak. - From description probably = Nothocnide repanda, but certain identification is not possible without original material.

Boehmeria rupestris C.B.Rob. (1911) 5. - Type: Ramos B.S. 5542 (not traced), Philippines, Luzon, Benguet, R. Trinidad. - From description probably $=B$. pilosiuscula, but certain identification is not possible without original material.

Boehmeria scabra (Blume) Hassk. (1844) 79. - Urtica scabra Blume (1825) 504. - Type: Unknown collector (not traced), Indonesia, Jawa [Java], "circa Batavia, in ruderatis." Identification is not possible without original material.

Boehmeria scabrella Gaudich. ex Miq. (1859) 252, nom. illeg. superfl. - Type not traced. - Miquel cites in synonymy a range of earlier published names relating to either $B$. virgata subsp. macrophylla var. scabrella or B. ourantha, as follows: Urtica caudata Burm.f., Boehmeria ourantha Miq., Urtica scabrella Roxb., Urtica uragera Steud.

Boehmeria spiciflora Blume (1857) 217. - Type: Herb. Jacquin f. s.n. (holo $\mathrm{W}$; iso L), eastern India. - Probably B. virgata var. macrostachya, but specimen too fragmentary for certain identification.

\section{EXCLUDED NAMES}

Names already excluded in the extensive lists of Weddell (1856: 386; 1869: 216-218) are not repeated here, except for a few cases, where we have reached a conclusion different from that of Weddell. Authorities of species only mentioned in this list are not included in the list of References. Their works can be found in Index Kewensis or IPNI.

Boehmeria amarantus H.Lév. (1913) 550. Type not traced; from the description almost certainly not Boehmeria.

Boehmeria anisoneura Guill. (1932) = Cypholophus anisoneurus (Guill.) Friis \& Wilmot-Dear (see Wilmot-Dear \& Friis 2010: 287).

Boehmeria arachnoidea Walp. (1843) = Pouzolzia arachnoidea (Walp.) Wedd. (see Wilmot-Dear \& Friis 2006: 65).

Boehmeria australis Endl. (1833) = Pouzolzia australis (Endl.) Friis \& Wilmot-Dear (see Wilmot-Dear \& Friis 2006: 15).

Boehmeria australis Endl. subsp. dealbata (Cheeseman) Sykes $(2005)=$ Pouzolzia australis (Endl.) Friis \& Wilmot-Dear (see Wilmot-Dear \& Friis 2006: 15).

Boehmeria bodinieri H.Lév. (1913) 550 = Laportea bulbifera (Siebold \& Zucc.) Wedd. (1856) (see Chen et al. 2003: 86).

Boehmeria calophleba C.Moore \& F.Muell. in Mueller (1872) = Pouzolzia australis (Endl.) Friis \& Wilmot-Dear (see WilmotDear \& Friis 2006: 15).
Boehmeria capensis (Thunb.) Spreng. (1826) 844; Parietaria capensis Thunb. (1794) 31 = Droguetia iners (Forssk.) Schweinf. subsp. iners (see Friis \& Wilmot-Dear 1988: 39).

Boehmeria cavaleriei H.Lév. (1913: 550). Types not seen; from the description almost certainly not Boehmeria.

Boehmeria cinerascens Blume (1857) = Pouzolzia sanguinea (Blume) Merr. var. cinerascens (Blume) Friis \& Wilmot-Dear (see Wilmot-Dear \& Friis 2006: 30).

Boehmeria dealbata Cheeseman (1892) = Pouzolzia australis (Endl.) Friis \& Wilmot-Dear (see Wilmot-Dear \& Friis 2006: 15).

Boehmeria delavayi Gagnep. (1928) 126. = Pouzolzia sanguinea var. formosana (Li) Friis \& Wilmot-Dear (see WilmotDear \& Friis 2006: 26).

Boehmeria delavayi Gagnep. var. Iongifolia Gagnep. (1928: 127). = Pouzolzia sanguinea var. formosana (Li) Friis \& Wilmot-Dear (see Wilmot-Dear \& Friis 2006: 26).

Boehmeria elongata Blume (1857) 218, nom. illeg., non Fisch. ex Hornem. (1815). Type not traced; from the description probably B. cylindrica (see Wilmot-Dear \& Friis 1996: 59).

Boehmeria esquirolii H.Lév. \& Blin. in Léveillé (1912: 372) = Maoutia puya (Hook.) Wedd. (see Chen et al. 2003: 188).

Boehmeria irritans Ridl. (1926) = Pipturus argenteus (Forst.) Wedd.

Boehmeria martini H.Lév. (1913) 551 = Pilea martinii (H.Lév.) Hand.-Mazz. (see Chen et al. 2003: 104).

Boehmeria nepalensis Wedd. = Pouzolzia sanguinea (Blume) Merr. var. sanguinea (see Wilmot-Dear \& Friis 2006: 24).

Boehmeria procridioides (Wedd.) Blume (1857) = Pouzolzia parasitica (Forssk.) Schweinf. (see Wilmot-Dear \& Friis 2006: 38).

Boehmeria propinqua Decne. = Pipturus argenteus (Forst.) Wedd.

Boehmeria rigida Benth. in Hook. = Urera obovata Benth.

Boehmeria rugulosa Wedd. = Pouzolzia rugulosa (Wedd.) Friis \& Wilmot-Dear (see Wilmot-Dear et al. 2009: 60).

Boehmeria sanguinea (Blume) Hassk. = Pouzolzia sanguinea (Blume) Merr. var. sanguinea (see Wilmot-Dear \& Friis 2006: 21).

Boehmeria sanguinea (Blume) Hassk. var. glabrata (Blume) Blume = Pouzolzia sanguinea (Blume) Merr. var. sanguinea (see Wilmot-Dear \& Friis 2006: 23).

Boehmeria sanguinea (Blume) Hassk. var. minor Blume = Pouzolzia sanguinea (Blume) Merr. var. sanguinea (overlooked by Wilmot-Dear \& Friis 2006).

Boehmeria sanguinea (Blume) Hassk. var. montana (Miq.) Blume = Pouzolzia sanguinea (Blume) Merr. var. sanguinea (see Wilmot-Dear \& Friis 2006: 23).

Boehmeria sanguinea (Blume) Hassk. var. rubra Blume = Pouzolzia sanguinea (Blume) Merr. var. sanguinea (see Wilmot-Dear \& Friis 2006: 23).

Boehmeria tirapensis Deb \& R.M.Dutta $(1964)=$ Pouzolzia sanguinea (Blume) Merr. var. fulgens (Wedd.) Hara (see Wilmot-Dear \& Friis 2006: 37). 


\section{Boehmeria vanioti H.Lév. = Pilea notata C.H.Wright. \\ Boehmeriopsis pallida Kom. = Fatoua villosa (Thunb.) Nakai (Moraceae) (see Kitagawa 1979: 222).}

Acknowledgements We thank the keepers and curators of the herbaria listed in Materials and Methods. The drawings have been excellently prepared by Margaret Tebbs, Kew. We also wish to thank the Keepers of the Herbarium, Royal Botanic Gardens, Kew, Professor S. Owens, and subsequently Professor D. Mabberley, and the Head of Asian section, Dr. Rogier de Kok, who have all shown interest in and patiently supported this long-running project.

\section{REFERENCES}

Acharya N, Yonekura K, Suzuki M. 2002. A new species and a new variety of Boehmeria from the Himalayas with special reference to the status of B. penduliflora. Acta Phytotaxonomica et Geobotanica, Kyoto 53, 1: 1-9. Acharya N, Yonekura K, Suzuki M. 2003. Cytological studies of the genus Boehmeria in Nepal. Journal of Japanese Botany 78: 95-102.

Bailey FM. 1888. A synopsis of the Queensland flora: containing the Phanerogamous \& Cryptogamous plants. Second Supplement. Government printer, Brisbane.

Beddome RH. 1873. Flora silvatica for Southern India. Part 27: 183-234. The Forester's manual of botany for Southern India. Gantz Brothers, Madras. Blume C. 1825. Bijdragen tot de flora van Nederlandsch Indië. 10de Stuk: 485-528. Lands Drukkerij, Batavia.

Blume C. 1853. The authors have been unable to trace such a publication: see Note 4 on p. 101

Blume C. 1857 (publ. 19 Feb.). Museum Botanicum Lugduno Batavum. Vol. 2 (fasc. 13-16): 193-256. Brill, Leiden.

Brown FBH. 1935. Flora of southeastern Polynesia Vol. 3. Dicotyledons. Bernice P. Bishop Museum, Honolulu.

Burman NL. 1768. Flora Indica necnon Prodromus Flora Capensis. Haek Leiden \& Schreuder, Amsterdam.

Chen CJ, Lin Q, Friis I, Wilmot-Dear CM, Monro AK. 2003. Urticaceae. In: Wu Z, Raven P (eds), Flora of China. Vol. 5: 76-189. Science Press, Beijing \& Missouri Botanical Garden Press, St Louis.

Chen CJ, Wilmot-Dear CM, Friis I. 2005. Notes on Chinese Boehmeria. Kew Bulletin 60: 449-453.

Chew WL. 1989. Urticaceae. In: AS George (ed), Flora of Australia, Vol. 3, Hamamelidales to Casuarinales: 68-93. Australian Government Publishing Service, Canberra.

Chun WY, et al. 1963. Materials for the Flora of Hainan (II). Acta Phytotaxonomica Sinica 8, 4: 342-357.

Craib WG. 1916. Contributions to the Flora of Siam, Additamentum. Kew Bulletin 9: 259-269.

Cronk QCB. 1998. The ochlospecies concept. In: Huxley CR, Lock JM, Cutler DF (eds), Chorology, taxonomy and ecology of the Floras of Africa and Madagascar - from the Frank White Memorial Symposium, held in Plant Sciences Department, Oxford University, on Sept. 26-27th, 1996, by the Linnaean Society of London, the Royal Botanic Gardens, Kew, and Wollfson College, Oxford: 155-170. Royal Botanic Gardens, Kew.

Deb DB, Dutta RM. 1964. A new species of Boehmeria from northeast India. Indian Forester 90: 782-784.

Degener O. 1947. Flora Hawaiiensis: The new illustrated Flora of Hawaii. Family 97 . Urticaceae. Boehmeria. Published by the author, Honolulu.

Domin K. 1921. Beiträge zur Flora und Pfanzengeographie Australiens: Dicotyledoneae. Bibliotheca Botanica 22, 89: 1-1317.

Don D. 1825. Prodromus Florae Nepalensis. Gale, London.

Elmer ADE. 1910. Urticaceae in the vicinity of Mount Apo. Leaflets of Philippine Botany, Manila 3: 875-901.

Forster JGA. 1786. Florulae Insularum Australium Prodromus. Dieterich, Göttingen.

Franchet AR, Savatier PAL. 1875 '1873'. Enumeratio Plantarum in Japonia sponte crescentium. Vol. 1, part 2. Savy, Paris.

Franchet AR, Savatier PAL. 1878 '1879'. Enumeratio Plantarum in Japonia sponte crescentium. Vol. 2, part 2. Savy, Paris.

Friis I. 1981. A synopsis of Girardinia (Urticaceae). Kew Bulletin 36: 143-157. Friis I. 1993. Urticaceae. In: Kubitzki K, Rohwewr JG, Bittrich V (eds), The families and genera of vascular plants, Vol. 2, Flowering plants, Dicotyledones, Magnoliid, Hamamelid and Caryophillid families: 612-630. Springer Verlag, Berlin, etc.

Friis I, Marais W. 1982. Name changes in well-known species of Boehmeria (Urticaceae). Kew Bulletin 37: 163-164.

Friis I, Wilmot-Dear CM. 1988. A revision of the tribe Forsskaoleae (Urticaceae). Nordic Journal of Botany 8: 25-59.
Friis I, Wilmot-Dear CM. 1999. Boehmeria balslevii Friis \& Wilmot-Dear. In: Jørgenson PM, León-Yánez S (eds), Catalogue of the vascular plants of Ecuador. Missouri Botanic Garden Press, St. Louis, etc.

Gagnepain F. 1928. Quelques Boehmeria nouveaux d'Asie Orientale. Notulae systematicae, Herbie du Muséum de Paris 4, 4-5: 126-128.

Gagnepain F. 1929. Urticaceae (sensu stricto). In: Lecomte MH (ed), Flore générale de l'Indo-Chine. Vol. 5: 828-916. Masson \& Cie, Paris.

Gagnepain F. 1950. Genres nouveaux, especes nouvelles d'Indochine Part 2. Notulae systematicae, Herbie du Muséum de Paris (ed. Humbert) 14: 22-43.

Gaudichaud-Baupré C. 1830 '1828’. Botanique. In: De Freycinet ML, Voyage Autour du monde, entrepris par ordre du roi, ... exécuté sur les corvettes de S. M. I'Uranie et la Physicienne ... Pillet-ainé, Paris.

Ghafoor A. 1977. Urticaceae. In: Jafri SMH, El-Gadi A (eds), Flora of Libya. Vol. 47: 1-19. Al Fateh University, Tripoli, Libya.

Grierson AJC, Long DG. 1983. Flora of Bhutan, including a record of plants from Sikkim. Vol. 1, part 1. Royal Botanic Gardens, Edinburgh.

Guillaumin A. 1932. Contributions to the Flora of the New Hebrides (continued). Journal of the Arnold Arboretum 13: 81-126.

Guillemin JBA. 1837. Zephyritis Taitensis. Énumeration des plantes découverts par les voyageurs dans les lles de la Société, principalement dans celle de Tahiti (suite). Annales des sciences naturelles. Botanique. Sér. 2, 8: 81-126.

Hance HF. 1874. On a small collection of plants from Kiukiang. Journal of Botany, British and Foreign 12 [n.s. 3]: 258-262.

Hance HF. 1885. Spicilegia florae sinensis: Diagnoses of new and habitats of rare or hitherto unrecorded Chinese plants. Journal of Botany, British and Foreign 23 [n.s. 14]: 321-330.

Handel-Mazzetti HRE. 1929. Symbolae Sinicae, Vol. 7, Anthophyta. Springer, Wien.

Hasskarl JC. 1844. Catologus plantarum in horto Bogoriense cultum alter. Typis Officinae, Batavia.

Hatusima S. 1971. Flora of the Ryukyus: (including Amami Islands, Okinawa Islands \& Sakishima Archipelago [Title in Japanese: "Ryukyu Shokobutso Shi". Text in Japanese]. Shokobutsu chiri bunrui kenkyu [i. e. Study Group of Biological Education of Okinawa]. Naha, Okinawa.

Hatusima S. 1979. A new species of Boehmeria from the Ryukyus. Journal of Phytogeography and Taxonomy 27, 1: 34.

Hayata B. 1911. Materials for a Flora of Formosa. Journal of the College of Science, Imperial University of Tokyo 30, 1: 1-482.

Heller AA. 1897. Observations on the ferns and flowering plants of the Hawaii islands. Minnesota Botanical Studies 1: 760-922.

Hillebrand W. 1888. Flora of the Hawaiian Islands. Williams \& Norgate, London; Westermans \& Co., New York.

Hochreutiner BPG. 1925. Plantae Hochreutineranae, 2. Candollea 2: 317-513.

Honda H. 1931. Nuntia ad Florem japoniae XIV. Botanical Magazine, Tokyo 45: 469-471.

Hooker JD. 1888. Urticaceae. In: Hooker JD (ed), Flora of British India. Vol. 5. Part 15: 477-594. Reeve \& Co., London.

Hooker WJ. 1849. Niger Flora. Berliere, London.

Hooker WJ, Arnott GW. 1837. The botany of Captain Beechey's voyage Part 2. Bohn, London.

Hooker WJ, Arnott GW. 1838. The botany of Captain Beechey's voyage, Part 6. Bohn, London.

Hornemann JW. 1815. Hortus Regius Botanicus Hafniensis. Vol. 2. Møller Hauniae [Copenhagen].

IUCN 2001. IUCN Red List Categories and Criteria, Version 3,1. IUCN Species Survival Commission, Gland, Switzerland, and Cambridge, IUCN.

Jacquin JF. 1760. Enumeratio systematica plantarum, quas in insulis Caribaeis vicinaque Americes continente detexit novas, ......., Leiden.

Kitagawa M. 1979. Neo-Lineamenta florae manshuricae, or enumeration of the spontaneous vascular plants hitherto known from Manchuria (northeastern China) together with their synonymy and distribution. Flora et Vegetatio Mundi, herausgegeben von Reihold Tüxen 4: 1-715. Cramer, Vaduz.

Kitamura S, Murata G. 1961. Coloured illustrations of herbaceous plants of Japan. Hoikusya, Osaka.

Kitamura S, Murata G. 1962. New names and new conceptions adopted in our coloured Illustrations of herbaceous plants of Japan, II. Choripetalae. Acta Phytotaxonomica et Geobotanica, Kyoto 20: 195-208.

Koidzumi G. 1926. Contributiones ad Cognitionem Florae Asiae Orientalis. Botanical Magazine, Tokyo 40: 330-348.

Koidzumi G. 1941. Boehmeria nipponivea Koidz., nov. spec. Acta Phytotaxonomica et Geobotanica, Kyoto 10: 223.

Kravtsova TI. 2001. Pericarp structure in representatives of tribe Boehmerieae (Urtcaceae). Botanicheskii zhurnal, St. Petersburg 86, 6: 18-39.

Kravtsova TI. 2009. Comparative carpology of the Urticaceae Juss. KMK Scientific Press, Moscow. 
Kravtsova TI, Friis I, Wilmot-Dear CM. 2000. Morphology and anatomy of fruits in New World Boehmeria in relation to taxonomy. Kew Bulletin 55: 43-62.

Kravtsova T, Friis I, Wilmot-Dear CM. 2003. Morphology and anatomy of fruits in Pouzolzia (Urticaceae) in relation to taxonomy. Kew Bulletin 58: 297-327. Kuntze O. 1891. Revisio Generum Plantarum, Pars 1-2. Felix, etc., Leipzig. Leandri JD. 1950. Les Urticacées de Madagascar. Annales du Musée CoIoniale de Marseille, Sér. 6, 7-8: 1-93.

Leandri JD. 1965. 56e Famille. Urticaceae. In: Humbert H (ed), Flore du Madagascar et des Comores. Museum National d'Histoire Naturelle, Laboratoire de Phanérogamie, Paris.

Léveillé H. 1912. Decades Plantarum Novarum, LXXV-LXXIX. Feddes

Repertorium specierum novarum regni vegetabilis 10: 369-378.

Léveillé H. 1913. Decades Plantarum Novarum, CIV-CV. Feddes Reperto-

rium specierum novarum regni vegetabilis 11: 548-552.

Linnaeus C. 1753. Species Plantarum. Vol. 2. Laurentius Salvius, Holmiae [Stockholm].

Linnaeus C. 1781. Supplementum Plantarum. Impensis Orphanotrophei, Brunsvigae [Braunsweig]

Long DG. 1982. Notes relating to the Flora of Bhutan 5. Notes from the Royal Botanic Garden, Edinburgh 40, 1: 115-138.

Lu FY. 1978. Contributions to the Dicotyledenous plants of Taiwan 4. Quarterly Journal of Chinese Forestry, Taipei 11, 3: 95-114.

Makino T. 1909. Observations on the Flora of Japan (continued). Botanical Magazine, Tokyo 23: 244-252.

Makino T. 1912. Observations on the Flora of Japan (continued). Botanical Magazine, Tokyo 26: 384-394.

Makino T. 1925. Illustrated Flora of Japan. Hokuryukan Co., Tokyo.

Makino T. 1948. Illustrated Flora of Japan (revised ed.). Hokuryukan Co., Tokyo.

Makino T, Nemoto K. 1931. Flora of Japan. Ed. 2. Shunyodo Shoten, Tokyo. Matsumura J. 1912. Index plantarum japonicarum, sive Enumeratio plantarum omnium ex insulis Kurile, Yezo, Nippon, Sikoku, Kiushu, Luikui et Formosa hucusque cognitarum. Vol. 2, Phanerogamae. Maruzen, Tokyo.

Maximowicz CJ. 1876. Diagnoses plantarum novarum Japoniae \& Mandshuriae Decas 20. Mélanges biologique tirés du Bulletin (physico-mathématique) de l'Académie Impériale des Sciences de St-Pétersbourg 9: 581-660.

Maximowicz CJ. 1877. Diagnoses plantarum novarum Japoniae \& Mandshuriae Decas 20. Bulletin de l'Académie Impériale des Sciences de StPétersbourg, Sér. 3, 22: 209-264. (Verbatim reprint of 1876 publication).

Merrill ED. 1913. Plantae Wenzelianae. Philippine Journal of Science, Section C, Botany 8: 363-390.

Miquel FAW. 1840. Commentarii Phytographichi. Fasc. 3: 93-146, pl. 12-14. Luchtmans, Lugduni-Batavorum [Leiden].

Miquel FAW. 1851 [March]. Plantae Junghuhnianae. Pars 1: 1-106. Sythoff, Lugduni-Batavorum [Leiden] \& Baillière, Paris.

Miquel FAW. 1859. Urticaceae. Flora Nederlandsch Indie (Flora Indiae Batavae). Vol. 1, 2 \& 2, 1: 224-275. Van der Post, Amsterdam \& Utrecht; Fried. Fleischer, Leipzig.

Miquel FAW. 1867. Urticaceae. In: Miquel FAW (ed), Prolusio Florae Japonicae. Part 5: 130-132. Ex Annales Musei Botanici Lugduno Batavi. Vol. 3. Van der Post, etc., Amsterdam.

Miyazaki T, Ohba H. 2003. A new species of Boehmeria (Urticaceae) from Kochi prefecture, Shikoku, Japan. Journal of Japanese Botany 78, 2: 61-65.

Moat J. 2007. Conservation assessment tools extension for ArcView 3.x,

v. 1. 2. GIS-Unit, Royal Botanic Gardens, Kew. http://www.kew.org/gis/ projects/cats/index.html

Nakai T. 1914. Plantae novae Coreanae et Japonicae II. Feddes Repertorium specierum novarum regni vegetabilis 13: 267-278.

Nakai T. 1918. Notulae ad plantas Japoniae et Koreae XVIII. Botanical Magazine, Tokyo, 32: 215-232.

Nakai T. 1927. Report on the vegetation of Shikajima. 'Iyonokani Sikazima n Shokubuti Chosa Gaikyo Hokoku'. No publisher, Tokyo.

Nakai T. 1936. Flora Sylvatica Koreana. Vol. 21. Forest experimental Station, Chosen, Keijyo.

Nguyên TH. 2003. Danh luc cac loai thuc vat viet nam. Vol. 2. NXB Nong nghiep, Hanoi.

Ohba H. 2006. Boehmeria. In: Iwatsuki K, Bufford DE, Ohba H (eds), Flora of Japan. Vol. 2A. Angiospermae, Dicotyledonae, Archichlamydeae (a): 101-108. Kodansha, Tokyo.

Ohwi J. 1953. Flora of Japan. (Japanese ed.; title: Nippon shokubutsu shi; text in Japanese). Shibundo, Tokyo.

Ohwi J. 1965. Flora of Japan. (Meyer FG \& Walker EH, rev. ed.; text in English). Shibundo, Tokyo \& Smithsonian Institution Publications, Washington DC.

Okabe S. 1956. Chromosome numbers and apomixis in Boehmeria. Japanese Journal of Genetics, Tokyo 31: 308.
Okabe S. 1963. Apomixis in the genus Boehmeria. Science Reports of the Tohoku University, Ser. 4 (Biology) 29: 207-214.

Pampanini R. 1915. Le Piante vascolari raccolte dal Rev. P.C. Silvestri. Nuovo giornale botanico Italiano, n.s. 22: 249-296.

Panigrahi G, Murti SK. 1999. Flora of Bilaspur District, Madhya Pradesh. Vol. 2. Botanical Survey of India, Calcutta.

Poiret JLM. 1798. Ortie, Urtica. In: Lamarck JBAPM (ed), Encyclopédie méthodique, Botanique. Vol. 4, 2: 636-646. Panckoucke etc., Paris \& Plomteux, Liège.

Presl KB. 1845. Botanische Bemerkungen. Abhandlungen der Könichlichen Böhmischen Gesselschaft der Wissenschaften, Prague, Ser. 5, 3: 431-584 [Reprint issued 1846, but said to be published in '1844']

Ramachandran VS, Nair VJ. 1988. Flora of Cannanore. Botanical Survey of India, Calcutta.

Rendle AB. 1917. Tropical African Urticaceae. Journal of Botany, British and Foreign 55: 201-203.

Ridley HN. 1911 ' 1910'. A scientific expedition to Temengoh, Upper Perak. Journal of the Straits Branch of the Royal Asiatic Society, Singapore 57: $5-122$.

Ridley HN. 1920. On a collection of plants from peninsular Siam. Journal of the Federated Malay States Museum, Kuala Lumpur 10, 2: 65-126.

Ridley HN. 1926. Additions to the Flora of Malaya. Kew Bulletin 1926: 469 479.

Robinson CB. 1908. Alabastra Philippinensia. Philippine Journal of Science, Section C, Botany 3: 175-218.

Robinson CB. 1911. Philippine Urticaceae 1 \& 2. Philippine Journal of Science, Section C, Botany 6, 3: 1-31, 299-314.

Roxburgh W. 1814. Hortus bengalensis, or a catalogue of the plants growing in the honourable East India Company's Botanic Garden at Calcutta. Mission Press, Serampore.

Roxburgh W. 1832. Flora Indica. Vol. 3 (ed. J. Roxburgh). Serampore, for Thacker \& Co., Calcutta \& Parbury and Allen \& Co., London.

Satake Y. 1936. Boehmeria japonica. Journal of the Faculty of Science, University of Tokyo, Section 3, Botany 4, 6: 467-542.

Satake Y. 1938a. Trivial notes on Japanese plants 3. Journal of Japanese botany 14: 196-204.

Satake Y. 1938b. Trivial notes on Japanese plants 4. Journal of Japanese botany 14: 255-264.

Satake Y. 1938c. Boehmeria species of Kyushu. Journal of Japanese botany 14: $508-514$

Shih BL, Yang YP. 1998. New names and record of Urticaceae in Taiwan. Taiwania 43, 2: 150-153.

Siebold PF, Zuccarini JG. 1846. Florae japonicae familiae naturales pars secunda. Abhandlungen der Matematisch-Physikalischen Classe der Königlich Bayerischen Akademie der Wissenschaften, München 4, 3: 123-240.

Skottsberg CJF. 1926. Vascular plants from the Hawaiian Islands, 1. Acta Horti Gothoburgensis 2: 185-328.

Skottsberg CJF. 1944. Vascular plants from the Hawaiian Islands, 15. Acta Horti Gothoburgensis 15: 275-551.

Smith JJ. 1910. Urticaceae. In: Bijdrage No. 12 tot de Kennis der Boomsoorten op Java. Mededeelingen, uitgaande van het Departement van Landbouw in Nederlandsch-Indië, Batavia 10: 672-753.

Sprengel K. 1826. Boehmeria. In: Sprengel K (ed), Caroli Linnaei . . Systema Vegetabilium. Ed. 16, Vol. 3: 844-846. Dieterich, Göttingen.

Steudel EG. 1850. Urticeae nondum descriptae. Flora, Regensburg 33: 257-261.

Suzuki T. 1936. Urticaceae. In: Masamune G (ed), Short Flora of Formosa. Kudoa, Taihoku.

Swartz O. 1787. Tolf Nya Slag af Urticae Slägte, från Vest-Indien, uptäckte och beskrifne. Konglig Vetenskaps Academiens nya Handlingar, Stockholm 8: $58-72$.

Swartz O. 1788. Nova genera et species plantarum, seu Prodromus decriptionum vegetabilium ... in Indiam occidentalem. Swederi, Stockholm.

Tanaka T. 1925. On certain Thunbergian plants from Japan. Bulteno science de la Fakultato Tarkultura, Kjusu Imperia Universitato 1: 188-209.

Thunberg CP. 1784. Flora Japonica. Müller, Leipzig.

Thunberg CP. 1794a. Prodromus Plantarum Capensium Part 1. Edman, Uppsala.

Thunberg CP. 1794b. Botanical observations on the Flora japonica. Transactions of the Linnean Society, London 2: 326-342.

Vidal S. 1886. Revision des plantes vasculaires filipinas. Perez, Manila.

Wadhwa BM. 1999. Urticaceae. In: Dassanayake MD, Clayton WD (eds), Revised handbook to the Flora of Ceylon. Vol. 13: 232-284. Oxford \& IBH Publishing Co., New Delhi \& Calcutta.

Wagner WC, Herbst DL, Sohmer SH. 1999. A manual of the flowering plants of Hawaii. Revised Edition. Bishop Museum Press, Honolulu.

Walker EH. 1976. Flora of Okinawa and the Southern Ryukyus. Smithsonian Institute Publications, Washington DC. 
Wallich N. 1831. A numerical list of dried plants in the East India Company's Museum collected under the superintendence of Dr Wallich of the Company's botanic garden at Calcutta. Fascicle containing entries no. 2604-4827. East India Company, London.

Wang WT. 1981a. Revisio Boehmeriae Sinicae. Acta Bototanica Yunnanica 3, 3: 307-328.

Wang WT. 1981b. Revisio Boehmeriae Sinicae (cont'd). Acta Botanica Yunnanica 3, 4: 401-416.

Wang WT. 1982. A new rank of Boehmeria (Urticaceae). Acta Phytotaxonomica Sinica 20, 2: 204.

Wang WT. 1983. Species Nova Boehmeria e Sina australe. Guihaia 3, 2: 77-80.

Wang WT. 1996. New taxa of Urticaceae from China. Bulletin of Botanical Research of the North-Eastern Forestry University, Harbin 16, 3: 247-249.

Wang WT, Chen CJ. 1979. Urticaceae novae e Flora Tibetica. Acta Phytotaxonomica Sinica 17, 1: 105-109.

Wang WT, Chen CJ. 1995. Urticaceae. In: Wang WT, Chen CJ (eds), Flora Republicae Popularis Sinicae. Vol. 23, 2: 1-448. Science Press, Beijing. Weddell HA. 1854. Revue de la famille des Urticacées. Annales des Sciences Sér. 4, Botanique 1: 173-212.

Weddell HA. 1856. Monographie de la famille des Urticacées. Archives du Muséum d'Histoire Naturelle, Paris 9: 1-400, pl. I-XII.

Weddell HA. 1869. Urticaceae. In: De Candolle A (ed), Prodromus systematis naturalis regni vegetabilis, vol. $16,1: 32-235^{64}$. Masson \& fils, Paris.

Wight R. 1843. Icones Plantarum Indiae Orientalis. Vol. 2, Part 4. Pharoa for the author, Madras.

Wilmot-Dear CM. 2009. Urticaceae for the non-specialist: identification in the Flora Malesiana region, Indochina and Thailand. Blumea 54: 233-241. Wilmot-Dear CM, Acharya N, Kravtsova TI, Friis I. 2009. Pouzolzia rugulosa transferred from Boehmeria, and the distinction between Boehmeria and Pouzolzia (Urticaceae). Edinburgh Journal of Botany 66: 51-64.

Wilmot-Dear CM, Friis I. 1996. The New World species of Boehmeria and Pouzolzia (Urticaceae, tribus Boehmerieae). A taxonomic revision. Opera Botanica 129: 1-103.

Wilmot-Dear CM, Friis I. 1998. Cypholophus decipiens (Urticaceae): Taxonomy and range of a species often misplaced in Boehmeria. Kew Bulletin 53, 4: 919-927.

Wilmot-Dear CM, Friis I. 2006. The Old World species of Pouzolzia (Urticaceae, tribus Boehmerieae). A taxonomic revision. Nordic Journal of Botany 24, 1: 5-115.

Wilmot-Dear CM, Friis I. 2010. Cypholophus anisoneurus comb. nov. - an endemic species of Urticaceae from Vanuatu and Solomon Islands hitherto misplaced in Boehmeria. Nordic Journal of Botany 28: 285-287.
Wilmot-Dear CM, Friis I. 2011. New World Pouzolzia and Boehmeria (Urticaceae): A new species, Pouzolzia amambaiensis, and additional observations on already described species of both genera. Nordic Journal of Botany 29, 6: 691-695.

Wilmot-Dear CM, Friis I, Kravtsova TI. 2003. A new species of Boehmeria (Urticaceae), B. burgeriana Wilmot-Dear, Friis \& Kravtsova, endemic to Costa Rica. Kew Bulletin 58: 213-218.

Wilmot-Dear CM, Friis I, Thomas Z. 2010. New species in Old-World Boehmeria (Urticaceae). Edinburgh Journal of Botany 67, 3: 431-450.

Wright CH. 1899. Urticaceae: Urticeae. In: Forbes FB, Hemsley WB (eds), An enumeration of all the plants known from China \& Hong Kong (continued). Journal of the Linnean Society 26: 471-492.

Yahara T. 1981. Taxonomic studies of the Urticaceae, 1. The genus Boehmeria in Thailand. Acta Phytotaxonomica et geobotanica, Kyoto 32: 1-21.

Yahara T. 1983a. A biosystematic study of the local populations of some species of the genus Boehmeria with special reference to apomixis. Journal of the Faculty of Science, University of Tokyo, Sect. 3. Botany 13, 3: 217-261.

Yahara T. 1983b. A recognition of Boehmeria nakashimae, sp. nov. Journal of Japanese Botany 58, 3: 82-89.

Yahara T. 1984a. Notes on the nomenclature and infraspecific classification of Boehmeria japonica (L.f.) Miq. and B. spicata (Thunb.) Thunb. (Urticaceae). Journal of Japanese Botany 59, 5: 129-142.

Yahara T. 1984b. A correction for a combination in Boehmeria. Journal of Japanese Botany 59, 10: 320.

Yahara T. 1986. Distribution of sexual and agamous populations of Boehmeria silvestrii and its three relatives (Urticaceae). Journal of Japanese Botany 59: 121-132.

Yahara T. 1990. Evolution of agamospermous varieties in Boehmeria \& Eupatorium. Plant Species Biology, Kyoto 5: 183-196.

Yamamoto Y. 1932. Observationes ad Floram Formosanum, II. Journal of the Society of Tropical Agriculture, Taihoku [Taipei] 4: 49-55.

Yang YP, Shih BL, Liu HY. 1996. Urticaceae. Flora of Taiwan ed. 2, Vol. 2: 197-257 and photographs on p. 785-790. National Science Council of the Republic of China, Taipei.

Ying SS. 1988. Coloured illustrated Flora of Taiwan [Chinese title: Taiwan gao deng zhi wu cai se tu zhi : han yin jin zhong; text in Chinese, except for Latin scientific names]. Vol. 3, Hamamelidales to Tamaricales. Zhong wen ban, Taipei.

Zollinger H. 1854. Systematisches Verzeichniss der im indischen Archipel in den Jahren 1842-1848 gesammelten sowie der aus Japan empfangenen Pflanzen. Kiesling, Zürich.

\section{IDENTIFICATION LIST}

Only c. 4200 collections are included in this list. Old collections without reasonably clear indication of collector and/or number have been left out, except where a collection is clearly identified by number alone or when a collector has apparently only made one unnumbered collection of Boehmeria. Where a taxon was very well represented from a given locality, not all collections were recorded, but all identified material was provided with 'determinavit' labels. In the case of a mixed collection or where duplicates with reasonably complete material of the same collection were identified to different taxa, this is clearly indicated below. The abbreviations behind the collectors' numbers refer to the following names in Boehmeria:

bey $\quad=B$. beyeri

cli-cli $\quad=$ B. clidemioides var. clidemioides

cli-dif $=B$. clidemioides var. diffusa

cli-int-cd $=B$. clidemioides - intermediates between var. clidemioides and var. diffusa

cli-int-cu $=$ B. clidemioides - intermediates between var. clidemioides and var. umbrosa

cli-umb $=$ B. clidemioides var. umbrosa

con $=B$. conica

den-bon $=B$. densiflora var. boninensis

den-den $=B$. densiflora var. densiflora

dep $=$ B. depauperata

did $=$ B. didymogyne

gra $=$ B. grandis

ham $=B$. hamiltoniana

hel $\quad=B$. helferi

het-blu $=B$. heterophylla var. blumei

het-het $=B$. heterophylla var. heterophylla

het-int-hb $=B$. heterophylla - intermediates between var. heterophylla and var. blumei

hol

$=$ B. holosericea holx

jap-int-js with other taxa

jap-int-js $=B$. japonica - intermediates between var. japonica and var. silvestrii

jap-int-jst $=B$. japonica - intermediates between var. japonica, var. silvestrii and var. tenera

jap-int-jt $=$ B. japonica - intermediates between var. japonica and var. tenera

jap-int-st $=$ B. japonica - intermediates between var. silvestrii and var. tenera

jap-jap $=B$. japonica var. japonica

jap-sil $\quad=\quad B$. japonica var. silvestrii

jap-ten $=B$. japonica var. tenera

japx $\quad=\quad B$. japonica - presumed hybrids between $B$. japonica and unknown species

japxsib = B. japonica and B. sieboldiana - presumed hybrids between these two species

kur $\quad=$ B. kurzii

lan $=B$. lanceolata

lep $=B$. leptostachya lis $=B$. listeri

mul $=$ B. multiflora

our $=B$. ourantha

pen $\quad=B$. penduliflora

pil-int-ps $=B$. pilosiuscula - intermediates between var. pilosiuscula and var. suffruticosa

pil-pil $\quad=$ B. pilosiuscula var. pilosiuscula

pil-suf $\quad=\quad$ B . pilosiuscula var. suffruticosa

ply $\quad=\quad B$. polystachya

rug $=$ B. rugosissima

rug-vir $=$ intermediate between $B$. rugosissima and $B$. virgata var. virgata (see Note 3 under B. rugosissima)

sia $=$ B. siamensis

sib-fuz $=$ B. sieboldiana var. fuzhouensis

sib-int-sf $=B$. sieboldiana - intermediates between var. sieboldiana and var. fuzhouensis

sib-sib $=B$. sieboldiana var. sieboldiana

sp.indet. = unidentified material from the island of New Guinea, possibly representing new taxa of Boehmeria

spg 
$\operatorname{spg} x$

sub

ter-int-tk

B. splitgerbera - presumed hybrids with other species

$=$ B. subintegra

tween var. ternifolia and var. kamley

ter-kam = B. ternifolia var. kamley

ter-ter $=$ B. ternifolia var. ternifolia

tsa $=$ B. tsaratananensis

vir-aus $=B$. virgata var. austroqueenslandica

vir-can $=B$. virgata var. canescens

vir-int-dgst $=B$. virgata - intermediates between var. densiglomerata and var. strigosa

vir-int-m $=$ B. virgata - intermediates closest to var. macrostachya vir-int-mm $=B$. virgata - intermediates between var. macrostachya and var. miniticymosa

vir-int-msc $=B$. virgata - intermediates between var. macrostachya and var. scabrella

vir-int-r $=B$. virgata - intermediates between var. rotundifolia and other varieties

vir-int-st $=$ B. virgata - intermediates closest to var. strigosa

vir-int-vm $=B$. virgata - intermediates between var. virgata and var. maxima

vir-int-vv $=B$. virgata - intermediates between var. virgata and var. velutina

vir-lon $=B$. virgata var. longissima

vir-mac $=$ B. virgata var. macrostachya
vir-max
vir-min
vir-mol
vir-rot
vir-sca
vir-str
vir-sum
vir-tom
vir-vel
vir-vir

\section{$=$ B. virgata var. maxima}
= B. virgata var. minuticymosa
$=$ B. virgata var. molliuscula
$=$ B. virgata var. rotundifolia
= B. virgata var. scabrella
= B. virgata var. strigosa
= B. virgata var. sumatrana
$=$ B. virgata var. tomentosa
= B. virgata var. velutina
$=\quad B$. virgata var. virgata

zol-int-zp

$\begin{aligned} & \text { podocarpa } \\ \text { zol-pod }= & \text { B. zollingeriana var. podocarpa } \\ \text { zol-zol }= & B . \text { zollingeriana var. zollingeriana }\end{aligned}$
1984 Sino-American Expedition 691: vir-int-r - 1996 Gaoligong Shan Expedition 46: cli-cli - 1997 Gaoligong Shan Expedition 8249: cli-cli.

Abbe et al. 9317: zol-zol - Abeba 41421: vir-sca - Adam 26271: vir-mol - Ahmad \& Scolek 568: niv - Akayama et al. 2010093: ter-ter - Akogo 19: vir-mol - Alcasid \& Edano 5279: het-het - Alcasid et al. PNH5279: het-het - Alsterund 29: sia - Alston 13624: cli-int-cd; 14489: dep; 15662: vir-vir - Amano T 7337: yae - Amoroso 2085: rug - Anderson 869: ham; 901: vir-sca; 4636: dep - Ando 605: den-den - Andrianantoanima 343: tsa - Antilahimena 379: vir-mol - Aressitt 1120: lan -Ariyanti NSW604045: dep; NSW604046: dep - Arnott 959: vir-mac - Arsin 19493: rug - Asano K 22315: jap-ten - Atho et al. NY-HN41: vir-int-dgst - Attie 25: vir-mol Averyanoi 39: cli-int-cd.

Backer 3650: cli-int-cd; 5729: our; 25313: cli-int-cd; 36917: zol-zol; 37322: zol-zol; 37323: cli-int-cd; 37686: cli-int-cd - Baker 985: het-int-hb - Balakrishnan 10952: dep - Balansa 592: niv; 594: pen; 595: vir-str; 2491: niv; 2492: niv; 2495: niv; 2496: niv; 2497: niv; 2498: niv; 2499: niv; 2500: niv; 2502: cli-int-cd; 2503: cli-int-cd; 2506: niv; 2507: zol-int-zp; 2514: dep; 2520: pen; 2521: pen; 2523: vir-int-r; 2524: vir-int-r - Baldwin 9618: virmol - Bamps 4183: vir-mol - Banlugan 72522: niv - Barber 3064: vir-lon - Barbon PPI12896: mul; PPI12931: mul; PPI22681: den-den - Barchet 606: jap-int-js - Barclay et al. 2242: ter-ter - Barnett 319: vir-mol - Baron 779: vir-mol; 1933: vir-mol; 3197: vir-mol; 3684: vir-mol; 3740: vir-mol Bartlett 357: niv; 6095: jap-int-jst; 7560: dep; 7566: dep; 7908: rug; 14275: het-int-hb; 14278: het-int-hb; 14819: het-het - Bartlett et al. 357: niv; 1155: vir-mol - Bathie 9972: tsa - Beauchamp 1173: den-den - Beccari 281: rug - Beddome 87: dep; 7592: vir-int-msc-Bedi R 680: ply - Belcher 573: cli-dif; 598: vir-rot; 599: vir-int-r; 657: cli-dif - Bernardi 14950: gra; 15019: gra; 15182: gra - Betche 37237: vir-aus - Beumee 846: rug - Beyer 266: jap-ten; 13540: bey - Bhatt 193: vir-int-msc - Bhuttacharya 21283: ter-ter - Bidgood 2832: vir-mol - Billiet 588: gra - Bis Ram 359: ter-ter; 110359: ter-ter - Biswas K 3846: ham - Blackburn 146: vir-mol - Blake 15817: viraus - Bloembergen 4333: vir-vir; 4394: vir-vir; 4690: vir-vir - Blume 12798: spg - Bodinier 530: den-den; 560: den-den; 919: niv; 1452: den-den; 1649: jap-jap; 1715: cli-int-cd - Bodner 145: den-den; 228: niv; 253: niv - Boeea 6484: niv - Boivin 1103: vir-mol; 1104: gra; 3115: vir-mol - Bon 1761: virint-mm; 2777: vir-str; 4012: niv; 4227: niv - Bor 249: ter-ter; 20875: ham; 20882: vir-mac; 20983: cli-int-cd - Borhidi 85235: vir-mol; 86183: vir-mol; 87032: vir-mol - Bosser 7362: pen; 18912: vir-mol; 20839: vir-mol; 20880: gra; 21456: gra - Boufford 25235: den-den - Bourbon et al. PPI1546: het-blu - Bourdy 108: vir-vir - Bowes Lyon 96: ter-ter; 9126: ter-kam Boyce 842: pen - Brass 16057: vir-mol; 23704: sub; 23806: sub; 27469: sp.indet. - Bretschneider 77/654: jap-ten - Brinkman 612: cli-int-cd; 745: vir-vir - Brooks 375: jap-sil; 377: jap-sil - Brown-Henry 585: vir-vir - Bruggeman 153: rug - Brummitt 9377: vir-mol - Bryan 170: vir-vir - BSI 25147: cli-int-cd - Bullock 608: vir-int-mm; 779: vir-int-mm; 891: pen - Bunchuai 1203: niv - Bunnemeyer 4828: vir-sum; 7947: cli-int-cd; 8122: rug; 11132: vir-vir; 11248: vir-vir; 11307: vir-vir; 11813: vir-vir; 12356: vir-vir; 12487 : vir-vir - Burkill 171: our; 34065: pen - Burley 35: mul; 3894: vir-vir; 3991: vir-vir - Buwalda 3689: vir-vir; 3755 : vir-vir.

Cabalion 2521: vir-vir - Caille 14861: vir-mol - Calder et al. 1601: dep - Canton Ch. Coll. 12386: vir-dgl - Carles 159: jap-ten - Carlquist 1888: gra - Carr 13931: sub; 15046: sub; 15315: sub; 15443: sub; 16100: sub - Carvalhu 4453: vir-mol - Cavalerie 4381: vir-int-r - Celestino PNH7833: den-den; PNH7951: mul - Chan FRI19929: dep - Chan KY 1281: niv - Chand TR 512: ham; 2165: ham; 2347: vir-sca; 2574: ham; 2620: dep; 2774: pen; 3354: cli-int-cd; 3752: vir-mac; 4598: dep; 4752: pen; 4893: vir-mac; 5582: dep; 5754: our; 7508: ter-ter; 8015: vir-mac; 8145: cli-dif-Chang CE 14633: den-den - Chantaranathai 90,452: vir-min; 90,462: zol-zol - Chapman 2833: vir-mol - Charette 1373: jap-ten - Charoenphol 512: ham; 4571: niv - Chase 424: vir-mol; 7135: vir-mol; 8226: vir-mol; 19217: vir-mol - Chaud 2611: vir-int-msc; 3320: vir-int-msc; 8037: vir-int-msc - Chautaranothai 1344: dep - Cheatham 167: niv - Cheek 5402: vir-mol; 5848: vir-mol;
7607: vir-mol - Chen KY 1281: niv - Chen LH 92386: zol-zol - Chen S 451: jap-jap; 603: niv; 719: niv; 786: niv; 805: jap-jap; 1632: jap-jap; 1696: jap-jap; 1865: jap-jap; 1913: niv; 1996: niv; 2096: cli-int-cd; 2101: jap-jap; 2236: sib-fuz; 2276: niv; 2450: jap-jap; 3611: jap-int-js; 3637: jap-jap; 3803 jap-jap; 3820: jap-ten; 3920: jap-ten; 3972: niv; 3973: niv; 4019: niv; 4048 : niv; 4234: niv; 4343: sib-int-sf; 4363: sib-int-sf; 4383: niv; 4425: niv - Chen SH 13260: vir-str; 15988: sib-sib - Chen SQ 14808: vir-dgl - Chen YF 1900: den-den; 3530: sib-sib; 4466: den-den; 4932: den-den; 4936: zol-pod; 7773 niv; 15123: jap-ten - Chen YJ 15123: jap-ten - Cheng WC 201: jap-ten; 222: niv; 5035: niv; 5827: niv - Cheo \& Wilson 12737: jap-jap - Cheo HC 296: niv; 18264: niv; 18427: niv - Cherian 106140: vir-int-msc - Chevalier 15043: vir-mol - Chew RSNH234: vir-vir - Chew HF 110560: jap-jap - Chew WL 1279: cli-int-cd - Chiao 2921: jap-jap - Chiao CY 2737: jap-ten; 2921 : jap-jap; 14250: jap-jap; 14329: jap-ten - Chien 6050: cli-umb - Chin SC 3447: vir-vir - Chin SH 13260: vir-str - China-Germany Joint Exp. 1766 niv - Ching RC 1627: jap-jap; 2028: jap-jap; 2235: cli-dif; 2388: niv; 3184: niv; 4888: jap-jap; 5035: niv; 5478: vir-str; 6385: vir-str; 7066: pen; 8469: jap-jap; 8472: jap-ten; 8600: jap-int-jt; 8606: jap-int-jt; 25410: sib-sib Chinghai-Tibet Exp. 2775: ply - Chock 9A: gra; 935: gra; 971: gra - Choi HH 71: jap-ten - Chong K 110: pil-suf-Chou ZL 150: jap-ten-Chow 80305: niv - Chow \& Wan 79056: vir-str; 79124: jap-jap; 79126: vir-str - Chow HC 1407: jap-ten - Chow HF 109645: jap-jap; 110560: jap-jap; 110948 : jap-sil - Chow KS 88: jap-jap; 78100: niv; 78251: niv; 80305: niv - Chow KS et al. 78100: niv; 78251: niv - Christophersen 63: rug; 741: vir-vir; 987 : vir-vir; 1425: gra; 2018: vir-vir; 2022: vir-vir; 2683: vir-vir; 3070: vir-vir; 3702: gra-Chu KL 3135: cli-umb; 3346: cli-umb - Chui ZQ 8111,025: niv - Chun SH 12927: pen; 15988: sib-sib - Chun WY 6181: den-den; 6779: den-den; 8232: jap-int-jt - Chun WY \& Chien SS 8170: jap-int-jt - Chunet 787: japsil; 1246: jap-ten - Chung HH 1044: niv; 2448: niv; 2798: sib-fuz; 2842 : jap-jap; 3672: jap-jap - Chung IC 4256: niv - Clarke 46: our; 101: den-den; 5207: pen; 7264: our; 7368: our; 8925B: vir-int-msc; 8925C: vir-int-msc; 8998C: cli-dif; 9072B: vir-int-msc; 9072D: vir-int-msc; 9080A: pen; 9307B: vir-int-m; 12349B: cli-cli; 12555B: ter-ter; 12565F: ter-ter; 12589D: pen; 13029: ter-kam; 13126A: dep; 13176B: vir-int-mm; 13222: ham; 13318A: cli-cli; 16226A: ham; 16634: our; 18899A: cli-cli; 19262: our; 21896B: ply; 21917: pen; 23528A: vir-int-mm; 23803: vir-int-mm; 24947B: ham; 26242: ply; 26242B: ply; 26467B: ply; 26467C: ply; 26736B: ply; 26736C: ply; 26748A: ter-int-tk; 26930B: cli-cli; 27174B: cli-cli; 27246B: ham; 31713B: pen; 33684: vir-int-msc; 34129: vir-mac; 35022B: ter-ter; 35022E: ter-ter; 35184E: ter-ter; 36256E: vir-int-msc; 36583B: ham; 36661: pen; 38730: ter-ter; 41409: ter-ter; 41530: pen; 43084: cli-dif; 44228F: our; 44994B: pen; 45471A: vir-int-r - Clason-Laarman 35: zol-pod; 48: cli-int-cd; 84: zol-pod; 192: cli-int-cd - Class of 1958 2437: lep - Class of 1960 634: dep - Cleghorn 1856: zol-zol - Clemens 4238: den-den; 5811: bey; 6595: het-int-hb; 7262: mul; 16282: mul; 17642: het-blu; 26400: cli-int-cd; 26400A: cli-int-cd; 27344: dep; 29612: dep; 42937: vir-aus; 51879: bey - Clutton-Brock 367: vir-mol - Coert 38,39: dep - Collett 308: ter-ter; 565: ter-ter; 658: vir-mac; 922: zol-pod - Collins 1425: niv - Colville Barclay 1196: gra - Commerson 675: vir-mol - Conklin PNH16773: het-het; PNH19213: het-het - Conklin \& Buwaya 78688: den-den; 78718: niv - Conklin et al. 2553: mul - Conn \& Solomon 4118: den-den - Coode 4167: gra; 4348: vir-mol - Cooke 136: niv - Cooper 1205: ter-kam; 1564: ply; 2786: ply; 3281: vir-rot; 5976: our; 5976A: our - Corbisier 1567: vir-mol - Cours 3621: tsa - Coveney 10556: vir-aus; 10570: vir-aus; NSW152202: vir-aus; NSW152203: vir-aus - Cowan 18: gra; 679: gra; 200D: vir-int-msc - Cox 197: vir-vir - Cox et al. 551: ter-ter - Cramer 103: dep - Cribb 11294: vir-tom - Croat 32227: vir-mol Crosby 2034: gra - Crosby et al. 1835: gra - Cuming 1561: het-het; 2311 : niv - Cuong NM 150: vir-dgl.

Da Yao Shan Team 10068: cli-dif; 13815: cli-cli - Danser 5911: rug; 6606: vir-vir; 6702: cli-int-cd - Dao DD 842: con - Daramola et al. FRI67450: vir-tom - David 861: jap-jap - Davis NGF596: vir-vel - Davis A \& I 596: virvel - Dawe 423: vir-mol - Dayaoshan Team 10068: cli-dif; 10504: jap-jap; 
11648: niv - De Haas 2344: vir-rot; 2886: sia - De Konig 7384: vir-mol - De la Batlue 9972: tsa - De Nere 157: vir-mol - De Vogel 2500: vir-vir; 2784: dep; 6920: vir-vir; 6922: vir-vir - De Voogd 2466: pil-pil; 2609: vir-vir; 2840: vir-vir - De Vriese 1: vir-vir; 12: our; 42: pil-pil; 49: cli-cli; 2097: our - De Wilde 3443: vir-tom - Degener 8695: gra; 8696: gra; 11819: gra; 13536: vir-vir; 14327: vir-vir; 15008: vir-vir; 15337: vir-vir; 19729: gra; 20805: gra; 21588: gra; 27462: gra; 31521: gra; 31522: gra - Deighton 4540: vir-mol Deka 5233: pen - Deki 18322: ter-ter - Delavay 3070: pen; 4010: sib-sib; 4230: niv; 4542: cli-int-cd; 5182: cli-int-cd - den Hoed 3189: rug - Denker 103: cli-int-cd - Descoings 12520: vir-mol - Deyener 14327: vir-vir; 15008: vir-vir - Dickason 6597: zol-zol - Dickins 1378: spg - Dilmy 1049: zol-zol; 1116: vir-vir - Djamhari 21: rug - Dobremez 53: ter-ter; 244: ter-ter; 565 : vir-rot; 661: vir-int-msc; 673: pen; 801: vir-rot; 895: ter-ter; 2170: ter-ter; 2263: ter-ter; 2364: vir-int-msc - Doi Yoshio 14: sib-sib - Dolis Tadong 250: dep - Dolmis Soibeh 227: dep - Dorr 2775: vir-mol - Dorzeli 130: vir-vir; 255: vir-vir; 305: vir-vir - Doumenge 499: vir-mol - Du \& Kao 9387: zol-pod - Du et al. HNK2800: lan - Ducloux 687: cli-umb; 755: cli-int-cd; 788: niv - Dummer 797: vir-tom; 3102: vir-mol; 3191: vir-tom; 5594: virmol - Dunn 4368: jap-ten - Duthie 3377: ply; 4406: vir-int-msc; 10570 : vir-int-mm; 24955: ter-ter.

Eberhardt 3244: niv; 3289: vir-str - Edaño PNH6621: het-blu; PNH11493: het-het; PNH11524: het-int-hb; PNH11842: dep; PNH17838: het-blu; PNH17884: het-blu; PNH17906: mul; PNH17920: het-blu; PNH17955: het-het; PNH18039: het-het; PNH19876: het-het; PNH41753: het-het; PNH48666: het-het - Edaño et al. 38545: het-int-hb - Edgeworth 167: terter; 174: vir-int-msc; 175: ter-ter - Eggeling 375G: vir-mol; E2264: vir-mol - Elbert 305: vir-vir; 839: cli-int-cd; 841: pil-pil; 1032: vir-vir; 1386: cli-int-cd; 1473: cli-int-cd; 2649: vir-vir; 2726: vir-vir; 2800: vir-vir; 2847: vir-vir; 3024: vir-vir - Elliott 1191: den-den - Elmer 4275: mul; 6656: het-blu; 10520: dep; 11306: vir-vir; 13326: het-int-hb; 14275: mul; 14804: het-het; 15627 : het-het; 21130: dep; 21976: mul; 22252: mul - English 13: sia - Enoh 250: rug - Escarre 460: vir-mol - Esquirol 3734: vir-str; 6751: pen - Eyma 170: cli-int-cd; 1540: vir-vir; 1948: vir-vir; 2335: dep; 3322: vir-vir.

Faber 427: vir-dgl; 431: cli-int-cd; 383187: sib-sib - Falconer 988: cli-dif Fan \& Li 67: jap-jap; 217: jap-ten; 461: niv - Fang 2641: cli-umb - Fang WP 5776: cli-dif - Fanshawe 4014: vir-mol; 4404: vir-tom; 5631: vir-mol Farges 56: jap-int-jt; 608: jap-ten - Faure 906: sib-sib; 908: sib-sib; 2044: sib-sib - Faurie 395: den-den; 397: den-den; 398: den-den; 473: den-den; 474: den-den; 501: gra; 763: jap-sil; 910: niv; 911: hol; 1052: zol-pod; 1117: spg; 1195: niv; 2021: niv; 2344: jap-int-jt; 2345: jap-jap; 2346: jap-sil; 2347: jap-jap; 2348: jap-jap; 2349: spg; 2350: jap-jap; 2616: hol; 4178: jap-intst; 6499: niv; 8109: den-den; 8157: zol-pod; 8205: sib-sib; 8413: zol-pod; 11484: niv; 12057: niv - Fay 7040: vir-mol - Fei LF S813-42: jap-ten - Fenix BS3574: het-int-hb; BS12731: het-het; BS15789: vir-vir; BS26086: het-inthb; BS28029: het-het; BS28030: sib-sib; BS28042: het-int-hb - Fernandez 134: dep - Fields 46: our - Fischer 1667: dep; 1826: niv - Florence 2222: vir-vir; 2910: vir-vir; 2923: vir-vir; 3374: vir-vir; 3669: vir-vir; 3854: vir-vir; 4804: vir-vir; 5047: vir-vir; 6751: vir-vir; 8181: vir-vir; 10660: vir-vir - Flores et al. 74: tsa - Floret 815: vir-mol - Flynn 2311: gra - Flynn \& Flynn 318: vir-vir - Forbes 50: gra; 50K: gra; 134: gra; 252: gra; 297: gra; 403: gra; 557: gra; 557K: gra; 702: our; 867: gra; 892: our; 1114: rug; 2400: gra; 2526: gra; 3911: cli-int-cd - Ford 33: zol-pod; 34: den-den; 107: sib-sib; 173: vir-sca; 177: vir-str; 1892: vir-sca - Forrest 7681: pen; 7991: our; 8311: cli-cli; 8506: our; 8539: cli-cli; 8803: niv; 8834: pen; 10971: niv; 11986: pen; 12255: sia; 15885: cli-dif; 18457: cli-cli; 22105: cli-int-cd; 24801: pil-pil; 24851: vir-rot; 27996: pen - Forster PIF30504: vir-aus - Forsyth 255: niv - Fortune 85: jap-jap - Fosberg 3833: niv; 8950: gra; 9563: gra; 9613: gra; 9755: gra; 10261: gra; 11486: vir-vir; 37229: niv; 37538: sib-sib; 37714: niv; 37912: sib-sib; 53220: pil-pil; 60988: vir-vir - Frake PNH37958: het-blu - Franck C.W. 617: cli-dif - Friedmann 445: pen; 454: vir-mol; 563: gra; 673: gra; 983: vir-mol; 1032: vir-mol - Friedmann in Bernardi 14951: vir-mol - Friis 2599: vir-mol; 4062: vir-mol; 7134: vir-mol - Fu GY 2201: pil-suf - Fuertes PPI37442: vir-int-vv; PPI38636: het-blu - Fukuoka L-65178: niv - Fukuyama 62: zol-pod; 1548: den-den - Furuse 763: niv; 1263: yae; 1291: niv; 1325: niv; 1536: niv; 1633: niv; 2592: niv; 2682: niv; 3194: yae; 3199: yae; 3231: niv; 3258: niv; 3433: sib-sib; 3790: sib-sib; 4148: yae; 4213: yae; 4334: sib-sib; 4743: den-den; 5404: den-den; 5537: den-den; 5628: den-den; 6714: jap-sil; 9843: jap-jap; 9844: jap-jap; 10013: jap-jap; 10054 : jap-jap; 11165: den-bon; 11655: jap-jap; 11844: jap-int-jst; 11936: sib-sib; 12034: sib-sib; 18781: niv; 18782: niv; 18783: jap-ten; 19562: jap-int-jt; 21652: jap-jap; 21688: jap-ten; 26631: sib-sib; 26669: spg; 26859: jap-int-jt; 26873: sib-sib; 28436: spg; 34818: jap-jap; 39444: sib-sib; 42615: jap-sil; 42693: niv; 42694: niv; 42889: hol; 42917: jap-jap; 43371: sib-sib; 43404: sib-sib; 45315: sib-sib; 45347: sib-sib; 45892: sib-sib; 45905: sib-sib; 45994: sib-sib; 46102: niv; 46103: spgx; 46104: spgx; 46138: spg; 46161: jap-jap; 47060: japxsib; 47153: spg; 47171: jap-jap; 47295: spgx; 47322: jap-jap; 47976: jap-ten; 47977: jap-ten; 48008: jap-sil; 48122: jap-sil; 48327: sib-sib; 48328: jap-jap; 48433: sib-sib.
Gaerlan PPI2587: rug; PPI2690: vir-int-vm; PPI3234: rug; PPI9903: zol-pod; PPI13234: mul; PPI26686: mul - Gaerlan et al. PPI23226: vir-vir - Gagne 1134: vir-vir; 1341: vir-vir; 1366: vir-vir - Gamble 190: pil-pil; 906B: ply; 1080: ply; 1192A: vir-sca; 1194A: vir-min; 1194B: vir-min; 1196A: ter-kam; 1199B: pen; 1200B: dep; 1201E: dep; 4826A: vir-mac; 6746A: dep; 7006: ter-ter; 7103: ply; 7379: vir-int-mm; 7575: pen; 7921: ham; 9034: vir-mac; 9777: ham; 12056: vir-lon; 12403: vir-lon; 15482: dep; 15934: vir-int-mm; 16981: niv; 18543: vir-mac; 24628: vir-mac; 26635: ter-ter-Gao XP 50914: vir-str - Garber 484: gra - Garcia PNH35020: mul - Gardner 819: pil-pil; 5869: niv; 9484: vir-int-vv - Garrett 238: zol-int-zp; 684: our; 1091: cli-int-cd; 1316: dep - Gaudichaud 447: vir-sca; 448: vir-mac; 449: vir-sca - Geesink 6203: our - Geesink et al. 7428: lep; 8042: sia - Gereau 4146: vir-mol; 4277: vir-mol - Gibbs 7657: niv - Gilbert Rogers 361: ham; 715: vir-mol - Gill 121: vir-int-msc - Gillespie 2753: vir-vir; 2833: vir-vir; 2916: vir-vir; 3945: vir-vir; 4036: vir-vir; 4696: vir-vir - Gillett 1916: gra - Goaligong Shan Expedition 1997 8548: pen - Goldsmith 45/62: vir-mol - Grant 3672: vir-vir; 3871: vir-vir; 4119: vir-vir; 4224: vir-vir; 5447: niv; 7468: gra - Greatrex 220,38: sib-sib - Gressitt 261: den-den; 276: sib-sib; 299: zol-pod; 372: niv; 1120: lan; 1476: jap-jap; 2276: sib-sib - Gressitt et al. 276: sib-sib - Grey-Wilson 4379: ply - Grey-Wilson et al. 271: ter-ter - Grierson \& Long 1456: dep; 1524: dep; 1682: vir-can; 1699: dep; 3306: dep; 3428: pen; 3493: ham; 3782: dep; 3930: dep; 4508: pen - Grierson et al. 453: ter-kam; 1078: terter; 2682: ter-kam; 3360: vir-int-msc - Griffith 141: vir-int-msc; 142: cli-dif; 1303: pen; 2582: ham; 4555: pen; 4555A: con; 4556: ham; 4557: ter-ter; 4558: vir-int-msc; 4560: ham; 4561: dep; 4562: cli-cli; 4564: niv; 4590B: ham - Grimble 7575: pen - Guang KJ 1636: niv - Guizhou Team 1641: vir-str - Guo YH 376: jap-sil - Gustafson 1758: gra - Gutiemez PNH78071: het-int-hb; PNH78034: het-het.

Haines 6: sia; 408: pen; 499: vir-int-mm; 597: ply; 797: ter-kam; 929: cli-dif; 987: ham; 995: vir-int-mm; 1066: dep; 2309: vir-int-mm; 2503: sia; 2831: virmac; 3558: vir-mac; 4420: vir-int-msc; 4422: vir-mac; 5068: vir-mac; 5138 : vir-int-mm; 5139: pen - Hall 254: vir-mol - Halle 2037: vir-vir; 5875: vir-mol; 7433: vir-vir - Hallier 252: rug; 401: rug; 609: rug; 2935: dep - Hance 393: den-den - Hancock 22: niv; 375: cli-cli; 462: con - Handel-Mazzetti 4882: cli-int-cd; 5238: pen; 5619: our; 9340: cli-umb; 11187: niv; 12329: cli-int-cu; 12332: jap-jap; 12540: sib-fuz - Hansen et al. 12982: dep - Hara et al 69107: ter-ter; 6307103: ham; 6307104: pen; 6307111: pen; 6307113: virmac; 6307119: vir-int- msc; 6307121: vir-mac; 6307122: vir-mac; 6307124: vir-mac; 6307132: vir-int-mm - Harder 5879: zol-zol; 5943: niv; 5944: niv - Harley 1540: vir-mol - Harrison 220a: gra - Hashimoto G 74: sib-sib Hatusima 7: sib-sib; 7a: sib-sib; 19C: jap-jap; 21: hol; 25: hol; 16466: hol; 17337: den-den; 17818: sib-sib; 19879: sib-sib; 24563: yae; 25535: jap-jap; 82235: hol - Hatusima et al. 25493: sib-sib; 27833: sib-sib - Hayakawa's coll. 1144: jap-ten - HB 5326: vir-vir - Hedren 325: vir-tom - Helfer 125: hel; 4561: dep; 4584: hel; 4585: hel - Heller 2436: gra; 2906: gra - Henan Team 949: jap-ten; 34208: jap-sil - Henderson 22313: dep-Heng Li 11619: pen - Hennipman 3035: cli-dif - Henry 15: niv; 33: pil-suf; 184: den-den; 187: sib-sib; 390: zol-pod; 468: zol-pod; 468E: zol-pod; 483: niv; 1293: sibsib; 1692: cli-dif; 1808: jap-sil; 2049: jap-jap; 2159: niv; 2924: cli-dif; 3215: cli-dif; 4274: cli-dif; 4622: sib-sib; 4692: jap-ten; 4778: jap-ten; 4878: niv; 6150: jap-jap; 6258: jap-ten; 7033: jap-jap; 9063: pen; 9063A: pen; 9063D: pen; 9792A: cli-cli; 9792B: cli-cli; 9792C: cli-cli; 10736: cli-int-cd; 11247: niv; 11611: sia; 12070: con; 12262: cli-dif; 12262A: cli-int-cd; 12262B: cli-int-cd; 12303: our; 12353: ham; 12370: pil-suf; 12371: vir-int-r; 12540: pen; 12541 zol-zol; 12542: niv; 12795: cli-cli; 12896: dep; 13189: zol-zol - Henry BC 51: pil-suf - Hepper 5373: vir-tom - Herat et al. 500: gra - Herb. Madras 5705: dep - Herb. Soc. Host 1839: vir-mac - Herb. Univ. Imp. Tokyo 3523 sib-sib - Herbst 1168: gra; 1876: gra; 2103: gra; 6033: gra - Hiep 643K: dep; 3552: niv; 3863: niv - Hiep NT et al. 130: lan; 134: lan; 431: vir-intdgst; 638: lan; NY-HN431: vir-str - Higashiro 10379: gra - Hildebrandt 1664: vir-mol - Hillebrand 8: gra; 164: gra - Hiroe 164,13: jap-sil; 1100: jap-ten; 5853: sib-sib; 6236: jap-sil; 6448: jap-jap; 6459: niv; 7265: jap-ten; 7331: holx; 7337: holx; 7721: jap-ten; 12027: jap-jap; 12662: jap-sil; 12992: jap-ten; 13301: spg; 14229: jap-jap; 14286: niv; 14288: jap-sil; 14650: japsil; 14813: holx; 16391: niv; 16420: jap-ten; 18234: jap-ten - Hisauti K 4 sib-sib; 45811: spg - Ho YY 325: niv; 642: sib-int-sf; 647: niv; 1322: niv; 1381: jap-jap; 1577: niv - Hochreutiner 1295: our; 1427: cli-int-cd; 2097 our; 1448: pil-pil - Holmes H. 1429: vir-mol - Holstvoogd 133: vir-sca; 177: pil-pil - Homsombath \& Newman 1445: zol-zol - Homsombath et al 1384: pen - Honan Team 949: jap-ten - Hoogland et al. 3988: sub; 4467: sp.indet. - Hooker JD 530: dep; 583: vir-min - Hooker JD \& Thomson 500 dep; 530: dep; 1378: vir-sca - Hooper et al. 914: vir-mol - Horlyck et al. TZ367: vir-mol - Hosaka et al. 664: gra; 1191: gra; 2372: gra - Hosokawa 1639: den-den; 1640: zol-pod - Hosseus 445: sia - Hotta \& Inamasu 60: jap-sil - Hou XX 1193: jap-int-st - How FC 71558: niv; 71562: niv; 72249: sib-sib; 72365: pil-int-ps; 73998: niv - Hsia WY 1929: jap-sil - Hsieh \& Wu 1438B: jap-int-st - Hsiung, Chang \& Tsiang 31023: cli-umb - Hu HH 1696: 
jap-ten - Hu SY 5444: den-den; 6169: niv; 7221: den-den; 8113: niv; 9595: niv; 9832: niv; 11643: den-den; 12382: niv - Hu YY 642: sib-int-sf - Hu ZX 3502: cli-dif - Huang 4260: sib-sib - Huang C 595: con - Huang MX 112278: niv - Huang TC 2380: den-den; 5179: den-den; 8278: den-den; 8777: zol-pod; 9178: den-den; 13104: pil-int-ps - Huang TC \& SF 13104: pil-int-ps - Huang TC et al. 5179: den-den; 9178: den-den - Hugel 49: vir-mac; 322: vir-int-msc - Humber 24500: tsa - Humblot 1521: vir-mol - Hume 412: gra - Hutchinson et al. 72: vir-mol - Huter 171: vir-int-mm; 277: pen; 408: pen.

Iboet 202: dep; 389: niv - In-Cho Chung 9789: jap-ten - Inokuma 55: japten - Inone 1580: den-den; 82235: hol - Ip NK 122: niv; 4790: jap-ten; 7706: niv - Ishidayo 136: holx - Ishikawa 177: gra - Iwami 440: den-den - Iwatsuki 378: jap-ten; 461: rug; 464: rug; 1566: dep; 10950: vir-min; P933: het-het; T-9728: pil-suf - Iwatsuki et al. 378: jap-int-jt; 399: hol; 859: niv; 933: het-het; 1566: dep.

Jackson 890: vir-mol - Jacobi et al. 1569: gra - Jacqemont 617: vir-int-m; 782: ter-ter; 2449: vir-int-m - Jagarmani 490: dep - Janardhanan 76326: vir-int-m - Jeffrey 19: vir-mol - Jeng YC 344: zol-pod - Jesimin Duaneh 408: dep - Ji Ai Team 431/87: vir-dgl - Jiang L \& Zhao CF 252: ply - Jiang Y 10518: niv - Johansson 156: vir-vir - Johns NGF 7956: vir-vel - Jones 1173: vir-vir; 1587: vir-vir - Joseph 11297: vir-int-m - Juan 187: cli-dif; 521: vir-mac - Julien 15058: vir-mol - Junghuhn 2: vir-sum; 6: cli-int-cd; 507: our - Jungthapa(?) 99: vir-int-mm.

Kajewski 1644: vir-vir - Kanai 1082: jap-sil - Kanai \& Ono 764196: den-bon - Kanai et al. 1082: jap-sil; 764146: den-bon; 6307118: vir-rot; 6307120: vir-sca - Kanchai 430: sia - Kanehira et al. 13819: vir-vir - Kanjilal U 1047: pen - Kano, Murata et al. 6307148: vir-can - Kao MT 7136: denden; 7257: zol-pod; 9759: zol-pod; 10336: pil-int-ps - Kapoor 71740: virsca - Kaudern W 7: vir-vir; 293: vir-vir - Kautchai 186: our - Kawakami J 242: den-den - Keenan 3461: dep; 3637A: ply; 3675: dep - Keenan et al. 3461: dep; 3711: dep - Keng YL 549: jap-jap; 1575: jap-jap - Kerr 17: gra; 412-0: gra; 415-1: gra; 538: sia; 865: pen; 1738: dep; 2098L: sia; 2393: vir-int-msc; 2668: pen; 2703: vir-min; 2762: zol-zol; 3050: zol-zol; 3431: niv; 4120: gra; 4760: pil-suf; 6344: our; 10186: zol-zol; 18299: dep - Kessler 312001: dep - Kew-Edinburgh Kathmandu Exp. KEKE897: ply; KEKE1051: ply - King's Collector 205: dep; 356: niv - Kingdom-Ward 3463: cli-dif; 13235: cli-cli; 17403: ter-ter; 17888: cli-cli; 17949: vir-int-msc; 20531: dep; 21251: vir-int-r; 21251A: cli-int-cd - Kinsun Bakia 465: dep Kitagawa et al. 379: sib-sib - Kiuk et al. 23990: niv - Kloss 49: rug; 135: rug - Knig 205: niv - Kobayashi 243: sib-sib; 1795: spgx - Koelz 4018: vir-int-msc; 23268: vir-mac; 25225: con; 25575: vir-int-msc; 25952: vir-mac; 27360: dep; 31113A: vir-mac; 31296: vir-min; 32782: dep - Koense 324: cli-int-cd - Kojewski 1644: vir-vir - Kondo 2: den-bon - Konta 4090: pen; 18332: jap-sil; 18355: sib-sib; T29661: zol-int-zp - Koorders 29439: dep; 14783B: dep; 15394B: dep; 21333B: dep; 23222B: cli-int-cd; 27127B: pil-pil; 29439B: dep; 29444B: vir-vir; 31831B: rug; 31929B: rug; 32371A: dep; 32371B: dep; 39439B: dep; 40615B: cli-int-cd; 42998B: cli-int-cd - Kornassi 723: vir-vir - Kostermans 2048: vir-vir; 6362: vir-vir; 6362A: vir-vir; 18171: pil-pil; 19120: vir-vir; 22220: zol-zol - Kostermans et al. 4: pil-pil; 412: vir-vel - Kouta 18353: niv - Koyama 15354: sia; 15370: sia; 32048: sia; T-31424: pil-suf; T-31703: pil-suf; T-39078: vir-min; T-39119: vir-min; T-40104: vir-min; T-61608: vir-min; T-61609: pil-suf - Koyama et al. 3547: spg; 14270: den-den; 30456: zol-int-zp; 32048: sia - Krug 205: niv; 573: jap-ten; 574: jap-jap - Kuntze 1862: did; 4792: pil-pil; 5048: pilpil; 6274: did; 6624: vir-can; 6628: ham - Kuo CM 3821: zol-pod; 5599: zol-pod; 7405: pil-int-ps; 11036: zol-pod - Kurosaki 2188: jap-sil; 15354: holx; 15491: holx - Kurz 117: our; 560: pil-pil; 3115: kur.

Labat 3794: vir-mol - Lace 1812: vir-sca; 4136: cli-dif; 5087: sia; 5470: pen; 5915: zol-zol - Lae YS 144: niv; 1050: niv - Lakshnahayia 569: niv - Lam \& Meeuse 5198: pen; 5232: gra - Lanjouw 103: rug - Lao \& Kuo 1623: zol-pod - Larsen 1629: pil-suf; 4890: pil-suf; 6833: pen; 34318: zol-int-zp; 41464: zol-int-zp; 41991: zol-int-zp; 44274: zol-zol; 44388: cli-cli; 44389: cli-int-cd; 44430: cli-int-cd; 44456: pen; 44502: pil-suf; 44535: niv; 44545: zol-int-zp; 44557: cli-dif; 44698: ham; 44706: pen; 44791: vir-min; 44804: pil-suf; 44858: zol-zol; 44859: dep; 44866: cli-cli; 44900: cli-cli; 44990: sia; 45069: niv; 46154: sia; 46157: sia; 46340: pen; 46367: ham - Lau SK 2015: vir-dgl; 3537: niv; 4031: vir-dgl; 4388: niv; 4619: vir-dgl; 4631: sib-sib - Lau WP 603: niv; 1615: niv; 3973: niv; 4019: niv - Lau YS 144: niv; 1050: niv - Law YW 849: jap-ten - Leano 5449: niv - Leclancher 76A: niv - Lecomte \& Finet 246: vir-str; 524: cli-int-cd - Leeuwenberg 6985: vir-mol; 9701: vir-mol; 9898: vir-mol; 10310: vir-mol - Lei Cl 248: niv - Leiberg 6078: het-blu - Lejoly 3698: vir-mol; 86/986: vir-mol - Leland et al. 29B: vir-vir - Leonard 2543: vir-mol - Lepine 103B: vir-vir - Letestu 2719: vir-mol - Letouzey 3544: vir-mol; 6868: vir-tom; 7533: vir-mol; 8807: vir-tom - Leu WP 1624: pil-suf - Levine 84: cli-cli; 1171: vir-sca - Levine et al. 107: niv - Lewis et al. 758: vir-mol - Li BS \& Cheng SZ 4145: con; 4543: con; 4545: con - Li CT 1440: cli-dif; 2825: cli-dif; 600047: cli-dif - Li Heng 11451: con - Li MS 478: jap-jap - Li PG 111: jap-int-jt - Li PY 4570: jap-ten - Li XG 202635: sib-sib - Li YK 1591: our; 8526: niv; 400248: virdgl; 400526: jap-jap - Li ZH 1532: cli-dif - Li ZY 552: jap-jap - Li ZY et al. 209: niv - Li ZZ 1411: dep - Liang BH 83277: vir-str - Liang HY 61307: cli-int-cd - Liang QF \& Wu DL 32013: sia - Liang XR 66060: niv - Liao FC 1480: zol-pod - Licent 2290: jap-sil; 2480: jap-ten; 7712: jap-jap - Lin 769: zol-pod - Lin \& Chen 502: den-den - Lin CH 555: pil-suf - Lin et al. 352: den-den - Lin LY et al. 4: pil-suf - Lin Pi 6484: niv - Lin Rong 3009: vir-dgl - Lin SH 769: zol-pod - Lin XQ 26393: lan - Lin YT 11132: sib-fuz - Ling Y 13517: jap-jap - Liou KM 643: jap-ten; 4571: jap-sil; 4809: japten - Liou TN L1594: jap-ten - Lisowski 54227: vir-mol - Lister 99: lis - Liu 704: zol-pod - Liu \& Keng K2784: zol-pod - Liu WX 679: vir-sca - Liu XX 475: sib-sib; 28199: sib-sib - Loher 4948: den-den; 4951: den-den; 4960: het-blu; 4962: het-blu; 12487: het-blu - Long 3644: gra - Long et al. 789 : pen; 944E: ter-kam; 969: vir-int-r - Loogen 2: cli-int-cd - Lorence 92: virmol; 1170: pen - Lorzing 425: cli-int-cd; 4770: rug; 5193: rug; 5526: dep; 8230: cli-cli; 11300: cli-int-cd - Louis et al. 1257: vir-mol - Lovett 11294: vir-tom - Lowe 3081: vir-mol - Lowry et al. 4084: tsa - Luchun Bot. Exp. 574: con; 754: con - Ludlow et al. 6435: ply; 6498: ply; 7285: ham; 18509: con - Luke et al. 8175: vir-mol - Luo LB 132: vir-dgl; 191: jap-jap; 256: niv - Lurbeck 28: rug - Lyon 1226: gra.

Maas Geesteranus 6260: vir-mol - MacDaniels 65: gra; 840: gra; 1302: virvir; 1306: vir-vir; 1563: vir-vir; 1628: vir-vir; 1691: vir-vir; 1727: vir-vir; 1729: niv - MacGregor 648: our; 906: pen; 907: vir-min; 911: zol-int-zp; 1132: sia; 1US: sia - Madias Herb. 16547: vir-Ion - Madulid 7146: het-het; PPI25120: den-den; PPI25172: den-den; PPI26686: mul - Madulid et al. PPI108658: niv - Magofuku T 282: sib-sib - Maheshwari 5044: vir-int-m - Mahyar 436 : vir-max - Maire 746: cli-umb; 913: niv; 2343: cli-cli; 3508: niv - Maitland 602: vir-mol; 1273: vir-mol; 1362: vir-tom - Majumdar 150: pen; 308: terter - Makino 116030: jap-jap; 116032: jap-jap; 116038: jap-int-jt; 116042 jap-jap; 116061: jap-ten; 117357: jap-int-st; 117358: jap-int-st; 117361: jap-jap; 119001: hol; 124664: spg; 124671: spg; 124674: spg; 124677 : spg; 124695: niv; 124698: niv; 124699: niv; 124701: niv; 124704: niv; 124705: niv; 124708: niv; 124713: niv; 124725: niv; 124729: niv; 124759 : niv; 124761: niv; 124762: niv; 124764: niv; 124777: jap-int-js; 124802: japten; 124809: jap-ten; 124817: jap-ten; 124833: jap-ten; 124837: jap-ten; 124868: jap-ten; 124869: jap-ten; 124870: jap-ten; 124871: jap-ten; 124872 jap-ten; 124877: sib-sib; 124882: jap-sil - Malcomber 1482: vir-mol - Malla 6568: ter-ter - Mann 209: vir-mol - Mann \& Brigham 397: gra - Manner \& Street 272: het-int-hb - Manning 2007: vir-mol; 2175: vir-mol - Mao PY 3046: vir-sca; 3210: con; 3337: con; 3410: con; 4210: con - Marriot 124: vir-int-msc - Martelino \& Edano BS35288: het-het - Martin ex Bodineier 1715: cli-int-cu - Matsumoto FOK57597: jap-ten; FOK57603: jap-sil Matthew 264: jap-ten; 46489: vir-Ion; 46880: dep - Matuda E 240: sib-sib; 247: jap-jap - Maximowicz 14828: jap-jap - Maxwell 13940: sia; 69-1370: vir-min; 75-1022: dep; 76-683: dep; 87-613: our; 87-1043: pen; 88-1105: pil-int-ps; 89-37: dep; 89-117: vir-min; 89-148: sia; 89-516: sia; 91-209: sia; 91-1079: vir-min; 93-1008: vir-min; 93-1119: vir-min; 94-1122: niv; 94-1308: niv; 95-776: vir-min; 95-871: vir-min; 95-1008: niv; 96-37: vir-min; 96-502: sia; 97-250: dep; 97-918: pen; 97-962: pil-suf; 98-819: lan; 02-335: virmin - Mayebara K 318: sib-sib; 2457: jap-jap; 2459: sib-sib; 2461: sib-sib; 2472: sib-sib; 2476: sib-sib; 2499: sib-sib; 3548: sib-sib - McClintock 147: vir-tom - McClure 1787: niv; 3381: niv; 4068: niv; 7260: niv; 8001: niv; 8433: pil-suf; 8537: pil-int-ps; 9143: lan; 9146: lan; 9614: lan; 15994: hethet; 16052: mul - McCosh 128: ter-ter - McDaniels 1729: niv - McGregor 10185: niv; BS43524: het-het; BS43841: het-het - McLaren (Aberconway) 70A: cli-cli - McMillen 48: lis - Meebold 6253: man; 6546: cli-dif; 7092: vir-mac; 7715: vir-aus; 8586: dep; 12157: dep; 13468: vir-lon - Mei Hua Shan team 62: cli-dif - Meijer 32: rug; 9952: vir-vir; 10038: vir-vir - Meliden Giking 247: dep - Mell 516: niv; 681: jap-jap; 928: niv - Melville 3628: vir-aus - Mendoza PNH20347: het-het; PNH81871: den-den; PNH92451: niv; PNH97459: mul; PNH97565: den-den - Mendoza et al. PNH10440: het-het; PNH10626: het-int-hb; PNH10675: het-het - Merrill 42: niv; 803: mul; 7482: vir-vir; 7628: mul; 7630: bey; 8278: het-blu; 10774: niv; 11350: jap-jap - Meurillon CNAD823: vir-mol - Mg Kyaw 62: pen - Miao BM 9856: niv - Middleton 142: cli-int-cd; 1574: niv; 2179: dep; 2220: niv; 2255: dep; 2380: dep - Miehe 7: vir-sca; 00-455-15: vir-int-r; 00-457-07: vir-int-r; 00472-12: vir-int-r - Mikage 9485540: ply - Mikage et al. 9455376: vir-int-msc - Mildbraed 9759: vir-tom - Mills 191: jap-ten - Milne Redhead 3528: vir-mol - Mitsuta et al. T-46451: pen - Miyagi 8487: den-den - Mizushima U 939: sib-sib - Mogea et al. 5248: vir-vir - Mokino 124837: jap-ten - Momiyama 529: spgx; 8242: jap-jap; 8363: jap-jap; 8364: hol - Monro \& Wei 6409: virstr-Mooney 255: vir-int-mm; 1537: vir-mac; 1874: vir-int-msc-Moore 275 vir-vir; 511: vir-vir; 666: niv - Moran 4963: den-den; 5106: den-den; 5524: jap-jap - Morley 21: rug - Morse 142: niv; 722: niv - Morton et al. SL517: vir-mol - Motley 198: niv; 273: vir-sca - Mukerji 6212: niv - Muller 1070: vir-mol - Muller \& Pope 2027: vir-mol - Mumford 466: vir-vir - Mumford et al. 147: vir-vir - Munro 44: gra; 73: gra; 145: gra - Murata T-496: niv; T-2620: jap-ten; T-4299: jap-ten; T-5910: jap-ten; T-6956: jap-ten; T-7036: 
jap-ten; T-7777: jap-sil; T-8388: sib-sib; T-8422: jap-ten; T-10019: sib-sib; T-10454: den-den; T-11656: jap-jap; T-14896: cli-int-cd; T-15751: holx; T-16110: jap-sil; T-20465: niv; T-21122: jap-sil; T-36142: hol; T-38573: niv; T-38656: niv; T-41617: pil-suf; T-41850: cli-int-cd; T-41851: dep; T-42675: our; T-42875: our; T-44804: jap-ten; T-50248: vir-min; T-51483: niv - Murti 12995: pen - Musya-Santinozyo 2370: jap-int-jt.

Nadeaud 311: vir-vir - Nagamasu 50076: vir-min - Nagata 1197: gra - Nai SS 3351: niv - Nakai 4999: hol - Nakashima K 7: sib-sib; 13: sib-sib; 19: hol - Nakohara 68: sib-sib - Namba 151: den-den; 362: den-den - Narayanaswami 582: vir-mac - Naruhashi 1823: jap-ten - Native collectors 588: pen - Nedi 558: vir-vir - Nedi \& Idjan 168: vir-sca - New Jersey State University 161: het-het - Nguyen VD 1688: niv; HNK67: cli-int-cd; HNK938: pen; HNK1280: dep; HNK1349: dep; HNK1442: dep; HNK1790: niv; HNK1844: niv; HNK1848: niv; HNK1879: niv - Nicholson 3353: ter-ter - Nicolson 2359: vir-rot; 2949: ham - Nie MX 92260: niv; 92266: jap-jap; 92323: jap-jap - Nielsen 172: vir-vir - Noerkas 132: vir-vir - Nooteboom 791: sia - Noshiro 9760172: ply - Nukai G 4796: sib-sib - Nur 7353: dep; 7375: vir-vir - Nusbaumer L.N.1673: tsa.

Odashima 13610: niv - Ohashi 8384: spg - Ohashi et al. 8497: jap-ten; 708131: jap-sil - Ohba 518: jap-sil; 987: jap-ten; 1965: jap-sil; 2417: holx; 69747: spg; 826067: den-bon; 826087: spg; 8571831: ply - Ohushi 70813: jap-sil - Ohwi 9083: jap-int-js - Ohwi et al. 280: jap-sil - Okahara 131: niv - Oldham 215: jap-jap; 247: niv; 519: den-den; 520: zol-pod; 521: sib-sib; 522: niv; 744: jap-jap; 767: jap-ten; 768: jap-jap; 769 : jap-int-jt; 770 : niv Ono \& Kobayashi 127496: den-bon; 127518: den-bon - Ooststroom 12671: vir-sca; 13727: vir-sca - Orsom 2625: vir-mol - Ou \& Kao 9387: zol-pod. Paie 28048: dep - Pancho PNH134651: den-den - Pang B 46627: cli-umb - Pani G 1189: vir-mac - Panigrahi 3222: cli-int-cd; 4598: pen; 6163: con; 6960: vir-int-m; 14670: ham; 15168: con; 16994: vir-int-msc; 22437: ham - Parham 7077: vir-vir; 10378: vir-vir; 11516: niv - Parker RN 3247: terter - Parkinson 3470: ham - Parks 20079: vir-vir - Parry 947: pen; 1280: niv - Pawek 1996: vir-mol; 5467: vir-mol - Pei C 10117: cli-dif; 10151: clidif - Pei NX 2140: jap-jap - Pendry et al. DNEPZ, A69: vir-min; DNEPZ, B173: vir-min - Peng DY 46840: cli-dif - Perrotet 1044: vir-lon - Petelot 722: vir-int-dgst; 723: lan; 724: vir-int-dgst; 1647: cli-int-cd; 5263: pen; 6027: cli-int-cd - Petraitr 103: vir-min - Phan Ke Lok 531: vir-int-dgst; NY-HN531: vir-int-dgst - Phengklai 308: zol-int-zp; 7184: our - Pheug Klae 4437: niv - Phillipson 1614: vir-mol - Phillyps 1765: vir-mol - Phousena et al. 3942: sia - Phusomsaeng 33: pil-int-ps; 40: vir-min - Pierre 743: niv; 4653: niv; 4806: vir-min; 4808: zol-zol - Playfair 243: den-den; 451: zol-pod - Pleyte 255: cli-int-cd; 420: dep - Pobeguin 1872: vir-mol - Poilane 1191: lan; 1921 pen; 2406: niv; 4259: cli-cli; 10474: lan - Polunin 456: vir-rot; 590: vir-rot; 1286: vir-mac; 1358 : ply; 1501: con; 1789: ply; 2612: ply; 5401: ply; 5746 : vir-mac - Polunin et al. 5576: vir-int-msc; 5600 : ter-ter - Popta SM 750,122: pil-pil; 1297: our - Posthumus 2377: rug; 2479: vir-vir; 3500: vir-vir - Powell 224: vir-vir; 225: vir-vir - Praet 64: vir-sum - Price 40: den-den; 247: niv; 447: zol-pod - Procter 600: vir-tom - Pulle 3141: our - Pullen R 1124: virvel - Purseglove 2282: vir-mol; P2061: vir-mol - Put 3273: pil-suf; 3276: vir-min; 3280: cli-int-cd; 3283: dep; 3879: our; 4415: vir-min.

Qinghai-Tibet Exp. 1974 2775: ply - Quayle 4: vir-vir.

Raap 137: rug; 614: rug; 647: rug - Rahman 4390: dep; 4731: dep - Rahman et al. 3641: pen; 3687: vir-min; 4390: dep - Ramachandran 54080: dep; 58714: vir-int-m - Ramamoorthy et al. 2654: dep - Ramaut 17: niv - Ramos BS8197: mul; BS11035: het-het; BS12531: het-blu; BS13710: het-int-hb; BS24133: het-het; BS26320: het-blu; BS26321: mul; BS27478: zol-pod; BS33015: mul; BS33129: zol-int-zp; BS39749: het-het; BS42148: het-blu; BS42729: het-int-hb; BS43060: vir-vir; BS76769: den-den; BS76837: het-blu; BS80368: niv; BS80395: den-den; BS84934: dep; PPI15662: hetblu - Ramos et al. BS28707: het-int-hb; BS34411: het-int-hb; BS38084: den-den; BS38857: rug-vir; BS39190: rug-vir; BS45032: pil-pil; BS48938: dep; BS49225: het-het; BS49516: dep; BS75548: het-int-hb - Rao 20005: pen - Rao AS 39091: dep; 85694: dep - Rao GVS 22811: vir-int-m Rao RS 10240: dep; 10307: ham; 10389: dep - Rao TA 4105: vir-sca - Rappard 190: zol-int-zp - Reafforestation Team 848: our - Ream 550: den-den - Reekmans 466: vir-mol; 7540: vir-mol; 10021: vir-mol; 10960: vir-mol - Reep 152: pil-pil - Regalado 824: vir-vir - Reinecke 429: vir-vir - Remy 195: gra - Reporter on Economic Products 11615: our; 12359: vir-can - Reynoso PPI11815: het-blu - Rhusomsaeng 121: niv - Rich A 239: vir-int-mm; 903: vir-mac - Richard 78: vir-tom; 220: vir-mol; 291: virmol; 689: vir-tom - Richards 17613: vir-mol - Ridley 14645: lan - Ritchie 1366: vir-mac - Roberty 15862: vir-mol - Robinson BS49: rug; BS135: rug; BS1593: niv; BS6539: vir-vir; BS9546: het-blu; BS14122: mul - Robinson \& Kloss 7: vir-sum; 64: vir-sum - Robson 1660: vir-mol - Roby 2758 : gra - Rock 1915: sia; 1944: dep; 2080: pen; 2126: pil-suf; 2349: zol-zol; 2502: vir-min; 2519: pen; 2579: dep; 4566: gra; 4570: gra; 6986: pen; 7819: pen - Rong Jiang, Ba Kai \& Ji Ai exp. 74,743: vir-dgl - Rong Jiang Team 74-743: vir-dgl - Rong Lin 3009: vir-dgl - Runnak 527: cli-int-cd - Russell 51: gra - Rutten 1765: vir-vir.
Sako 2150: hol; 7294: hol - Sampson 634: vir-int-r - Samsuri Ahmad et al. 586: niv - Sands 1999: vir-vel - Sangkhachaud 1055: vir-min - Sanliere 136: vir-lon - Santisuk 1421: zol-int-zp - Santos 27: mul; 5469: mul; 5625A: den-den - Sarasen 528: vir-vir - Sasaki 244: niv; 21394: sib-sib; 21507: den-den; 420090: pil-int-ps - Satake 3527: sib-sib; 3533: holx; 3541: holx; 3544: hol - Sauliere 136: vir-lon - Sauveur 3407: sp.indet. - Savatier 1117: jap-jap; 1118: holx; 1119: hol - Saw Leng Guan FRI 34474: dep - Saw On Pe 16430: sia - Sawada T 474: sib-sib; 479: jap-ten - Sayers NGF24253: vir-vel - Schafer 5434: vir-vir; 5453: vir-vir - Schatz 2402: tsa; 3174: vir-mol; 3176: vir-mol - Scheffer 66: pil-pil - Schiam 6128: vir-vir - Schiffner 1900: vir-sca - Schlechter 12906: vir-mol; 13868: dep - Schlieben 8089: vir-mol; 10910: gra; 11101: vir-mol; 11109: vir-mol; 11123: vir-tom - Schmid 3654: vir-vir - Schmitz 148: vir-vir; 3300: vir-vir; 5097: pil-pil; 6130: vir-vir - Schneider 2568: niv - Schodde 3137: dep - Schram BW6128: vir-vir - Scientific Survey Team 1602: vir-int-msc - Scott-Elliot 2267: tsa - Seem et al. 2124: mul - Seemann 432: vir-vir; 433: vir-vir - Selling 3098: gra - Semsei 3564: vir-mol; 3878: vir-mol - Serre 533: jap-ten - Setchell et al. 213: vir-vir; 250: vir-vir; 490: vir-vir; 531: vir-vir - Sharland 1228: vir-mol - Shemmermann 6807: gra - Shen 375: den-den - Shimizu 79-25: den-bon; 11152: den-den; 18700: niv; T-8805: vir-min; T-9058: vir-min; T-20006: sia; T-20038: sia; T-20040: vir-min; T-20973: our - Sieber 48: vir-mol; 330: vir-vir - Sikdar 4472: dep - Sillitoe 362: vir-mol - Silvestri 391: jap-jap; 396: jap-jap; 397 jap-jap; 399: jap-ten; 3319: jap-ten - Simada 245: pil-suf; 246: pil-suf; 248 : zol-pod - Simada-Hidetaro 977: zol-pod - Simeda 2458: pil-suf - Simons 633: vir-int-msc - Sin GS 420: our - Sin SS 536: vir-dgl - Sinclair 9894 niv; 10053: pil-pil - Sinclair \& Long 5024: ply; 5750: vir-rot - Sinclair et al. 9722: mul - Singh J 90: vir-mac - Sino-Amer. Bot. Exp. 1980 482: cli-dif; 793: jap-ten - Sino-British Exp. 1981 27: our - Sino-Russian Exp. 1358: con-Skottsberg 1772: gra-Smith 148: vir-vir; 197: vir-vir; 209: vir-vir; 262 : pen; 278: vir-vir; 284: vir-vir; 393: vir-vir; 944: vir-vir; 994: vir-vir; 4017: vir-vir; 4759: vir-vir; 4854: vir-vir; 7362: vir-vir; 8289: vir-vir; 8761: vir-vir - Smith H 6373: jap-ten - Smith HC 16277: zol-zol - Smith JJ 794: our - Smith WW 29: vir-int-msc - Smitinand 7600: sia; 10245: sia - Soegandirdja 211 cli-int-cd - Soejarto 10451: dep - Soejarto et al. 10452: vir-dgl - Soewarta 118: rug - Sohmer 6554: gra - Sorensen 4764: vir-min; S134: pen - Soulie 1216: cli-int-cd - Spire 1546: sia - Srithong 196: dep - St John 10934: gra; 11596: gra; 12119: gra; 12139: gra; 13417: gra; 13915: gra; 13974: gra; 14128: vir-vir; 15359: vir-vir; 17103: vir-vir; 17115: vir-vir; 17307 : vir-vir; 17401: vir-vir; 18176: vir-vir; 18189: vir-vir; 20189: gra; 23115: gra; 23150 gra; 23175: gra; 23285: gra; 24859: gra; 24964: gra; 26504: vir-mol; 26698: gra-Stainton 53: ter-ter; 275 : ter-ter; 289: ter-ter; 616: vir-sca; 1377 : pen; 1569: ply; 1622: vir-rot; 1688: vir-rot; 2575: ter-ter; 3504: ply; 3546: vir-rot; 3719: ter-ter; 4262: ter-ter; 4281: vir-rot; 5030: ter-ter; 5636: pen; 6441: vir-rot; 6600: ply; 6648: pen; 6712: ply; 6716: dep; 6957: ter-ter; 6995 ter-ter; 7273: ply; 7496: vir-rot; 7505: ply; 7559: vir-sca; 7671: pen; 8779: pen - Stainton et al. 7670: vir-mac - Stauffer 457: vir-mol - Stevens 58169 : sub - Stevens et al. LAE54956: het-het - Steward 987: niv; 1013: jap-ten; 1303: jap-ten; 1331: niv; 1585: jap-jap; 1586: jap-jap; 2339: jap-jap; 2635 jap-ten; 2681: jap-jap; 9714: jap-jap; IP4790: jap-ten - Stewart 1233: virint-mm - Stokes 315: vir-vir - Stolz 479: vir-tom; 500: vir-tom; 588: vir-tom; 600: vir-mol - Stone 1134: gra; 1489: gra; 3181: gra - Strachey et al. 4: ter-ter; 5: vir-min; 6: vir-int-msc; 7: pen - Streimann NGF34087: vir-vir Streimann et al. NGF30765: vir-vel - Subba Rap 47328: our - Subramanian KN 1169: dep - Subramanyam 5608: dep - Suddee 918: vir-min; 1086: sia; 1089: cli-int-cd - Sulit \& Conklin 16775: het-int-hb - Sun BX 2444: lan - Sun HF 2331: vir-int-msc - Suzuki 4315: zol-pod; 4678: den-den; 4679: den-den; 5856: sib-sib; 5961: jap-jap; 6114: sib-sib; 40075: ter-kam; 399002: japxsib; 459004: jap-int-js; 464017: spg; 489020: jap-int-js; 489031: jap-sil; 508008: jap-int-st; 509002: jap-jap; 8860110: ter-kam; 9170806 : ply; 9240184: ter-kam; 9455151: ter-ter - Suzuki-Tokio 4001B: den-den; 4159: den-den; 4306: zol-pod; 4362: sib-sib; 4436: sib-sib; 5005: zol-pod; 7149: jap-ten; 7617: sib-sib.

Taam YW 85: sib-sib; 95: vir-str; 1326: den-den - Tabata 3370: ply - Tabata et al. 10981: ter-kam - Tagawa 655: jap-sil; 4073: cli-int-cd; 10961: jap-ten - Tagawa-Motozi 2164: jap-int-js - Tai TL 104340: jap-int-jt - Takahashi FOK58223: jap-sil - Takamatsu 677: vir-vir - Takeda 137: jap-jap - Takenouchi 9370: jap-jap - Takeuchi 270: gra; 277: gra; 278A: gra; 957: gra; 2285: gra; 2701: gra; 2713: gra - Talbot 686: vir-mol; 1629: dep - Tam PC 59352: jap-jap - Tamree 5,75862: dep - Tamune 3442: spg - Tan CM 95853: niv; 951264: cli-dif; 9610245: cli-dif - Tanaka 84: den-den; 194 niv; 5042: niv; 100284: jap-jap - Tanaka et al. 11015: zol-pod; 11110: denden; 11125: sib-sib - Tanaku 11015: zol-pod - Tang HC 37: den-den; 416 : den-den; 443: den-den; 644: niv; 646: vir-int-msc; 776: den-den; 1447: niv; 1877: niv; 2058: niv; 2180: niv; 2323: den-den - Tang L 6114: jap-jap; 7347: cli-dif; 7348: cli-dif - Tang T 153: den-den - Tang WS 1326: denden; 1471: zol-pod - Tannowa \& Yoshida 3: den-bon - Tao DD 842: con - Taquet 1403: niv; 1404: hol; 1405: spgx; 1407: niv; 1409: sib-sib; 1415 jap-ten; 1416: jap-ten; 1433: sib-sib; 4429: jap-ten; 4430: jap-ten; 4431: 
sib-sib; 5965: sib-sib; 5966: sib-sib - Tateishi 1406: holx; 4527: jap-ten; 4631: holx - Tem 304: our - Teng SW 90779: zol-pod - Teraoka 368: gra - Teysmann 30: vir-vir; 5326: vir-vir; 12250: vir-vir - Thomson T 530: dep; 1789: vir-int-msc - Thorel 1129: niv; 2379: cli-dif; 9178: pen - Thorenaar 80: dep - Thulin 2743: vir-mol - Thwaites 2196: G sheet: vir-lon; K sheet: pil-pil; 2197: pil-pil; 2198: dep; 2460: pil-pil - Tiang L \& Zhao 252: ply - Tibet Scientific Survey 1602: vir-int-msc - Tixier 218: dep - To K \& Tang WT \& Tsang UK 387: vir-dgl - Togasi 1253: niv - Toppin 6066: con - Toquet 341: jap-jap; 1406: jap-jap - Torii K 4286: jap-sil - Treutler 602: ply; 602A: ply; 701: ham; 1082: pen - Troth 785: pen - Tsai HT 5537: con; 51930: con; 52451: con; 53199: pen; 53582: niv; 55181: cli-cli; 55184: con; 55357; con; 55393: lan; 56684: pen; 56724: con; 56781: con; 56873: con; 60110: cli-dif; 61993: pen; 62024: cli-int-cd - Tsang 20747: sp.ident. - Tsang WT 799: Ian; 956: niv; 20734: jap-jap; 20747: cli-int-cd; 20787: niv; 20853: niv; 21528: jap-jap; 21672: niv; 22946: vir-int-msc; 23046: niv; 23054: niv; 23289: niv; 23295: niv; 26844: pen; 27890: jap-jap; 28099: vir-dgl; 28128 : vir-str; 28345: niv; 29655: den-den; 30455: lan - Tsang WT et al. 130: lan; 139: lan; 14206: niv; 14859: niv - Tsau 51930: con - Tschonoski 14826: jap-jap - Tsiang Y 253: den-den; 1202: vir-min; 1262: jap-jap; 4920: niv; 5477: jap-jap; 7026: cli-int-cd; 7279: zol-pod; 9498: cli-dif; 10070: jap-jap; 10462: jap-jap; 10667: niv; 12119: pen; 13400: con - Tsoong KK D-2100: sib-int-sf - Tsugaru T61762: sia - Tsui TM 648: niv; 830: vir-int-st - Tuyama 10399: niv - Tweedie 3623: vir-mol.

Umrao Singh 421: vir-mac - Unknown Chinese collector 1641: vir-str - Unknown collector 232: jap-ten; 436: jap-ten; 550: vir-int-msc; 1194,3: vir-int-m; 1526: vir-vir; 1883: vir-min; 4619: vir-dgl; 7450: ply; 10475: dep - Unwin 3005: sia - Upadhyay 1667: pen.

Vajruvelu 44081: dep - Van Balgooy 246: vir-vir; 3096: vir-vir; 4616: vir-vir Van Beusekom 160: cli-int-cd; 1316: our; 3524: cli-dif; 3751: zol-zol; 4279: vir-min; 4638: cli-dif; 4658: cli-int-cd; 4665: niv; 4730: cli-dif-Van den Brink 1390: vir-sca; 1739: rug; 1803: cli-int-cd; 2183: pil-pil; 2246: dep; 2399: vir-sca; 2810: pil-pil; 2899: pil-pil; 2915: niv; 3189: rug; 6738: niv - Van der Veken 9693: vir-mol - Van Leeuwen 452: vir-vir; 791: pil-pil - Van Royen 3953: vir-max; 7542: vir-max - Van Steenis 1266: dep; 2116: cli-int-cd; 3909: rug; 7224: zol-zol; 7782: pil-int-ps; 7926: cli-int-cd; 10325: vir-vir; 10333: hetblu; 21353: rug - Vanoverberg 269: den-den; 3454: den-den - Vansteeuis 7926: cli-int-cd - Varadarajan et al. 1566: het-het - Veillon RSNH4526: vir-vir - Vera 36: vir-vir - Verheijen 361: pil-pil; 392: vir-vir; 2328: pil-pil; 2561: pil-pil; 4416: vir-vir - Vernandt \& Villeuyn 653: vir-vir - Versteegh 12583: vir-vel - Vidal 605: het-blu; 1784: den-den; 3773: niv; 3864: hetint-hb; 5369: sia - Vogy GB 414: cli-int-cd - Von Backer 5729: our; 13437: pil-pil - Von Hareveld 1990: ham; 6665: ham - Vraish 35: vir-vir - Vu Xuan Phuong HNK302: vir-min; HNK336: pen; HNK339: pen; HNK719: pen. Wadhwa et al. 585: dep; 586: vir-lon - Wagner 5075: gra - Walker 959: vir-lon; 1251: pil-pil; 1777: pil-pil; 5843: niv; 6897: den-den; 7621: sib-sib;
8511: holx - Walker et al. 7294: sib-sib - Walker in herb. Graham 1846 vir-int-msc - Wallich 520: ter-ter; 1953: ter-ter; 4581A: vir-sca; 4581B: vir-intmsc; 4581B(K-WALL, M): vir-sca; 4581D: vir-int-mm; 4582: vir-can; 4582A: vir-mac; 4582B: vir-mac; 4582C: vir-mac; 4582D: vir-can; 4584: ply; 4585: ter-ter; 4590: ham; 4590B: ham; 4595: pen; 4595A: pen; 4606B: niv; 4610: dep - Walsh 374: cli-int-cd; 467: cli-int-cd - Wang CW 35670: pil-suf; 36186: pil-suf; 41867: vir-sca; 44218: niv; 64209: cli-int-cu; 72908: con; 76094: con; 76496: con; 76977: dep; 78295: con; 78885: vir-sca; 79247: vir-intmsc; 79628: pen; 79925: zol-zol; 80020: zol-zol; 80671: dep; 83021: con; 85419: cli-umb - Wang S 163790: niv - Wang ZT 87083: cli-int-cd; 870188 : cli-int-cd-Warburg 1318: niv; 5889: vir-dgl; 5893: niv; 7039: jap-ten; 8083: jap-ten; 9917: den-den; 9922: niv; 10478: den-den - Warshauer et al. 3145: gra - Watanabe R FOK59347: jap-sil; FOK657409: jap-ten - Watt 193: niv; 10752: pen - Watts 1011: vir-mol - Weber 1122: het-het - Weiner 69,662: vir-vir - Wenzel 35: dep; 1904: het-het; 3349: het-het - Wheatley 660: vir-vir; 853: vir-vir - Whistler W1913: vir-vir; W2475: vir-vir; W4259: vir-vir; W4833: vir-vir; W11483: vir-vir; W111558: vir-vir - White 10,21: viraus; 8741: vir-aus; 10369 : vir-aus; 12574 : vir-aus; 12721 : vir-aus - White Team 1804: sia - Whitmore 3372: vir-vir - Whitney exp. 597: vir-vir - Wight 1108: pil-pil; 2694: dep; 2707: vir-lon; 2959: vir-lon - Wilford 515: den-den; 516: zol-pod; 547: sib-sib - Wilkes 2: vir-vir; 10: vir-vir; 11: vir-vir - Williams 1026: cli-int-cd; 1088: mul - Wilsch 1140: jap-ten - Wilson 224: gra; 961: vir-vir; 1364: jap-sil; 3759: niv; 5757: cli-umb; 8237: den-bon; 9882: den-den; 10068: den-den - Winckel 1388B: pil-pil - Winit 1442: zol-zol Witeng 90779: zol-pod - Wong Yun Siew 5221: niv - Woo JP \& TK 723 : den-den - Woo TK 13744: den-den - Wraber 3665: vir-rot - Wright 299: den-den; 303: den-bon; 2707: vir-int-m - Wu CC 1070: niv - Wu DL 32013: sia - Wulluh 4585: ter-ter - Wuyi Exped. 816: niv; 2567: jap-jap - Wuyi Shan Survey Team 80-0019: jap-ten - Wuyi Survey Team (1970) 816: niv. Xiamin Expedition (1981) 34: niv - Xiao BZ 3607: jap-ten - Xiong JH 18028: niv - Xiong JH \& Zhou ZL 92057: jap-int-jt; 93916: niv.

Yahara et al. 7939: jap-ten - Yamamotu 544: zol-pod - Yamashita FOK58177: jap-sil - Yamazaki 35: den-den; 7039: sib-sib - Yamazaki et al. 200: den-bon - Yang HN 2668: zol-pod - Yang TY 1338: den-den; 2122: zol-pod - Yang XX 428: jap-ten - Yao K 8650: jap-ten - Yatabe 447: jap-ten; 478: jap-ten - Yates 530: cli-int-cd; 736: cli-int-cd; 1421: rug; 1643: dep - Ying YS et al. 575: cli-umb - Yinger et al. 3548: niv - Yongsot 6398: jap-ten - Yu PH 450: cli-dif; 733: cli-int-cd - Yu TT 80: den-den; 19478: cli-umb - Yunger 2331: jap-jap; 2523: jap-jap; 3087: jap-jap.

Zainudin 5517: dep - Zhang GC 91: jap-jap; 283: vir-dgl - Zhang ZS \& Zhang YT 3660: sia - Zhang ZY 18028: niv - Zhou HC 6201: sib-sib - Zhou HF 109645: jap-jap; 111104: niv - Zhou JL 21673: den-den - Zhou Lang Shan Team 781457: sib-sib - Zhu[Chu] TP 524: pil-suf; 614: sia - Zimmermann 431/1738: jap-jap - Zollinger 534: vir-vir; 758: niv; 856: our; 1795: A, G and K sheets: rug; $U$ sheet: mixed pil-pil and rug; 2012: vir-vir; 2765: zolzol; 3119: spg - Zschokke \& Laraya 29411: niv - Zwickey 1065: het-het.

\section{INDEX}

Accepted names (also accepted names of other genera than Boehmeria) are in roman type. New names are in bold type; synonyms and superfluous names are in italics. The number after each name is the number of the species as used in this revision; (unc.) refers to taxa of uncertain identity and (excl.) to excluded from Boehmeria. References to names of taxa discussed in notes under other taxa are given in square brackets.

Boehmeria Jacq. [p. 90] allophylla W.T.Wang $28 a$ amarantus H.Lév. (excl.) amplissima Blume 20 anisoneura Guill. (excl.) arachnoidea Walp. (excl.) arenicola Satake 29 var. awana Satake 29 australis Endl. (excl.) subsp. dealbata (Cheeseman) Sykes (excl.) beyeri C.B.Rob. $4[5,18,19]$

bicuspis C.J.Chen $8 \mathrm{C}$

bifida Blume, nom. illeg. superfl. 29 biloba Miq., nom. illeg. superfl. 29 blinii H.Lév. 9b

var. podocarpa W.T.Wang 9b

blumei Wedd. 5b

bodinieri H.Lév. (excl.)

boninensis Nakai $18 \mathrm{~b}$

burgeriana Wilmot-Dear, Friis \& Kravtsova [3] calophleba C.Moore \& F.Muell. (excl.) candicans (Burm.f.) Hassk. 1 canescens Wedd., nom. inval. 23ii-i canescens (Wedd.) Blume 23ii-i
Boehmeria (cont.) capensis (Thunb.) Spreng. (excl.) caudata (Burm.f.) J.J.Sm., nom. illeg., non Sw. 23ii-I

var. celebica (Blume) J.J.Sm. 23i-a var. humilis (Miq.) J.J.Sm. 32a var. ourantha (Miq.) J.J.Sm. 25 var. pendula J.J.Sm. (unc.)

var. rugosissima (Blume) J.J.Sm. 31

caudata Sieber., nom. inval. (under B. greviaefolia (unc.))

caudata Sw. 23ii-I [23ii]

caudigera Wedd., nom. inval. 24a

cavaleriei H.Lév. (excl.)

celebica (Blume) Blume 23i-a

chiangmaiensis Yahara 16

chingshuishaniana S.S.Ying 28a

cinerascens Blume (excl.)

clidemioides Miq. 8 [5, 6, 7, 8, 23ii, 23ii-g, 23ii-j,

23ii-k, 23ii-l]

var. clidemioides $8 \mathrm{a}$

var. diffusa (Wedd.) Hand.-Mazz. 8b

var. platyphylloides Yahara 8a

var. umbrosa Hand.-Mazz. 8c
Boehmeria (cont.)

comosa Wedd., nom. illeg. 8b

var. neglecta (Blume) Wedd. 2

compacta Blume 1

conica C.J.Chen, Wilmot-Dear \& Friis 14 [13, 23ii, 23ii-g]

cumingiana Blume $5 a$

cuspidata Blume nom. illeg., non Wedd. 23ii

cylindrica (L.) Sw. [8]

cypholophoides Merr. 2

dealbata Cheeseman (excl.)

delavayi Gagnep. (excl.)

var. longifolia Gagnep. (excl.)

densiflora Hook. \& Arn. 18 [11, 12, 17, 19, 22 ,

23i-a, 28c]

var. boninensis (Nakai) Friis \& Wilmot-Dear $18 \mathrm{~b}$ [23i-a]

var. densiflora 18a [17, 19, 23i-a]

var. intermedia Acharya \& Yonek. 17

var. penduliflora (Wedd. ex D.G.Long)

Acharya \& Yonek. 17

densiflora sensu Chen, non Hook. \& Arn. 28c

densiglomerata W.T.Wang 23ii-n

depauperata Wedd. 2 [22] 
Boehmeria (cont.)

didymogyne Wedd. 3 [21]

diffusa Wedd. $8 \mathrm{~b}$

var. canescens Wedd. (unc.) [8b]

var. hirta Wedd. (unc.) [8b]

var. strigosa Wedd. (unc.) [8b]

diversiflora Miq. 9

dolichostachya W.T.Wang 23ii-o

var. mollis (W.T.Wang) W.T.Wang \&

J.C.Chen 23ii-o

dura Satake 29

egregia Satake 27

elliptica Wedd. 23ii-e

elongata Blume, nom. illeg. (excl.)

erythropoda Miq. 23i-a

erythropoda sensu Yahara 10

esquirolii H.Lév. \& Blin. (excl.)

formosana Hayata 27a [32]

var. fuzhouensis W.T.Wang 27b

var. stricta (C.H.Wright) C.J.Chen $27 a$

frutescens (Thunb.) Thunb.

var. concolor (Makino) Nakai 1

var. viridula (Yamam.) T.Suzuki 1

gigantea Satake 26

glomerulifera Miq. 2

var. leioclada W.T.Wang 2

gracilis C.H.Wright 28c

grandifolia Wedd., nom. illeg. 28a

grandis (Hook. \& Arn.) A.Heller 20 [23i-a, 31]

var. cuneata Skottsb. 20

var. kauaiensis Skottsb. 20

grandissima Nakai 26

var. serrulata Satake 26

greviaefolia C.Presl (unc.)

hamiltoniana Wedd. 12 [9, 10, 11, 18]

hatusimae Satake $28 \mathrm{a}$

helferi Blume 7

heteroidea Blume 9a

var. latifolia Gagnep. 9a

heterophylla Wedd. 5 [4, 6, 8, 18, 19, 22, 23ii-k]

var. blumei (Wedd.) Friis \& Wilmot-Dear $5 \mathrm{~b}$ [4]

var. heterophylla $5 a$

heterophylla (Wedd.) Blume, nom. illeg. 5, 5b

hirtella Satake 27a

hispidula Blume 26

holosericea Blume 26 [8, 23ii, 23ii-g, 24, 25, 27,

27a, 28, 28a, 29, 30]

var. strigosa W.T.Wang 23ii-o

huegeliana Blume 23ii

humilis Miq. 32a

hwaliensis Y.C.Liu \& F.Y.Lu 28c

ingjiangensis W.T.Wang 12

irritans Ridl. (excl.)

izuosimensis Satake 29

jacquiniana Blume (unc.)

japonica (L.f.) Miq. 28 [7, 8, 8c, 23, 23ii-g, 23ii-n, 23ii-o, 24, 26, 27, 27a, 29]

var. appendiculata (Blume) Yahara 28a

var. japonica 28a [26]

var. Iongispica (Steud.) Yahara 28a

var. platanifolia Maxim. 28a

var. silvestrii (Pamp.) Friis \& Wilmot-Dear $28 \mathrm{~b}$

var. tenera (Blume) Friis \& Wilmot-Dear 28c var. tricuspidata auct. [28b]

var. tricuspis (Hance) Maxim. 28a

kamley Acharya \& Yonek. 24b

kiusiana Satake 28a [27]

kiyozumensis Satake 29

klossii Ridl. 2

kurzii Hook.f. 15 [16, 22]

lanceolata Ridl. 11 [12]

leiophylla W.T.Wang 2

leptostachya Friis \& Wilmot-Dear $10[9,12]$

listeri Friis \& Wilmot-Dear 33 [17, 32]

Iohuiensis S.S.Chien 11
Boehmeria (cont.)

longifolia Gand. [26]

longispica Steud. 28a

var. appendiculata Blume 28a

var. heterodonta Blume 28a

var. platanifolia (Maxim.) Franch \& Sav. 28a

var. tricuspis (Hance) Franch. \& Sav. 28a

macrophylla (Thunb.) Siebold \& Zucc., nom. illeg. $28 a$

macrophylla D.Don, nom. illeg. 17 [33]

macrophylla Hornem. 23ii [23ii-e]

subsp. canescens (Wedd.) Panigrahi \& Murti

23ii-i

var. canescens (Wedd.) D.G.Long 23ii-i

var. dongtouensis W.T.Wang 23ii-g

var. longissima (Hook.f.) V.S.Ramach. \&

V.J.Nair 23ii-h

var. rotundifolia (D.Don) W.T.Wang 23ii-j

var. scabrella (Roxb.) D.G.Long 23ii-I

var. tomentosa (Wedd.) D.G.Long 23ii-f [25]

var. zeylanica (Wedd.) Wadhwa 32a

macrostachya (Wight) F.M.Bailey 23ii-g

malabarica Wedd., nom. illeg. 2

var. depauperata (Wedd.) Wedd. 2

var. leioclada (W.T.Wang) W.T.Wang 2

manipurensis Friis \& Wilmot-Dear 6

martini H.Lév. (excl.)

massuriensis Blume 23ii [23]

maugereti H.Lév. \& Vaniot 8b

mauritiana Wedd. 23ii-e

var. Iuxurians Blume 23ii-e

var. molliuscula Blume 23ii-e

maximowiczii Nakai \& Satake 28a

microcarpa Wedd. 23i-a

minor Satake 28a

miqueliana Tanaka 28a

mollicoma Miq. 1

monticola Blume 2

multiflora C.B.Rob. 19 [17, 18, 22, 23i-a, 23i-b, 33]

nakaiana Satake 27 a

nakashimae Yahara 26 [28a]

neglecta Blume 2

nepalensis Wedd. (excl.)

nipononivea Koidz. 1

var. concolor (Makino) Ohwi 1

nivea (L.) Gaudich. 1 [23i-d, 23ii-i]

forma concolor (Makino) Kitam. 1

forma nipononivea (Koidz.) Hatus. 1

forma viridula (Yamam.) Hatus. 1

subsp. nipononivea (Koidz.) Kitam. 1

var. candicans (Burm.f.) Wedd. 1

var. concolor Makino

var. nipononivea (Koidz.) W.T.Wang 1

var. reticulata Blume 1

var. tenacissima (Roxb.) Miq. 1

var. viridula Yamam. 1

oblongifolia W.T.Wang 2

ourantha Miq. 25 [23ii, 23ii-f, 23ii-k, 24, 26, 32]

pachystachya Satake 28a

pannosa Nakai \& Satake 29

paraspicata Nakai ex Satake 28c

forma viridis Satake $28 \mathrm{c}$

penduliflora Wedd. ex D.G.Long 17 [18, 20, 22 , 33]

var. loochooensis (Wedd.) W.T.Wang 18a

pilosiuscula (Blume) Hassk. 32 [8, 23ii, 23ii-I,

25, 27a, 31]

var. humilis (Miq.) Blume $32 \mathrm{a}$

var. pilosiuscula $32 \mathrm{a}$

var. procera Blume $32 \mathrm{a}$

var. suffruticosa Acharya, Friis \&

Wilmot-Dear 32b [23ii]

pilushanensis Y.C.Liu \& F.Y.Lu 28a

platanifolia (Maxim.) C.H.Wright 28a

var. silvestrii Pamp. 28b

var. tricuspis (Hance) Matsum. 28a
Boehmeria (cont.)

platanifolia Franch. \& Sav., nom. inval. 28a

platyphylla D.Don $23 \mathrm{ii}-\mathrm{g}$

var. angolensis Rendle 23ii-e

var. austroqueenslandica Domin 23i-d

var. canescens (Wedd.) Wedd. 23i-i

var. celebica (Blume) Wedd. 23i-a

var. cinerascens Hook.f. 8

var. clidemioides (Miq.) Wedd. 8

var. cuspidata (Blume) Wedd. [23ii]

subvar. canescens Wedd. 23ii-i

var. cuspidata Wedd. 24a

var. hamiltoniana (Wedd.) Wedd. 12

var. holosericea (Blume) Wedd. 26

var. humilis (Miq.) Wedd. 32a

var. japonica Wedd. (1856) 28a [28]

var. japonica Wedd. (1859), nom. illeg. 28

var. longissima Hook.f. 23ii-h

var. loochooensis Wedd. 18a

var. macrophylla (Thunb.) Wedd. 28a

var. macrostachya (Wight) Wedd. 23ii-g

subvar. elliptica (Wedd.) Wedd. 23ii-e

subvar. phyllostachya Wedd. 23ii-e

var. marquesensis F.Br. 23ia

var. masoalensis Leandri 21

var. microcarpa (Wedd.) Wedd. 23i-a

var. moluccana (Blume) Wedd. [23i-a]

var. nigeriana Wedd. 23ii-e

var. ourantha (Miq.) Hochr. 25

var. pilosiuscula (Blume) Hand.-Mazz. 32

var. rugosissima (Blume) Wedd. 31

var. scabrella (Roxb.) Wedd. 23ii-I

var. sieboldiana (Blume) Wedd. 27

var. stricta C.H.Wright 27a [27b]

var. sumatrana (Miq.) Wedd. 23ii-m

var. tomentosa (Wedd.) Wedd. 23ii-f

var. tricuspis Hance 28 a

var. ugandensis Rendle 23ii-e

var. virgata (G.Forst.) Wedd. 23

subvar. sumatrana (Miq.) Wedd. 23ii-m

var. zeylanica Wedd. 32

polystachya Wedd. 13 [1, 14, 16, 20, 23ii, 23ii-j, 23ii-I]

praestabilis Satake 26 [28a]

procridioides (Wedd.) Blume (excl.)

propinqua Decne. (excl.)

pseudo-sieboldiana Honda 27a

pseudotomentosa Yahara 25

pseudotricuspis W.T.Wang $8 \mathrm{c}$

quelpaertensis Satake 26 [28a]

forma glabra Satake 26

ramiflora Bedd., nom. inval. 2

ramiflora Jacq. [p. 90], 2

rigida Benth. (excl.)

robusta Nakai \& Satake 28 a

rotundifolia D.Don 23ii-j [25]

rubrinervia Hassk. (unc.)

rugosissima (Blume) Miq. 31 [19, 20, 23i-a, 32,

32a, 33]

rugulosa Wedd. (excl.) [13]

rupestris C.B.Rob. (unc.)

sanguinea (Blume) Hassk. (excl.)

var. glabrata (Blume) Blume (excl.)

var. minor Blume (excl.)

var. montana (Miq.) Blume (excl.)

var. rubra Blume (excl.)

scabra (Blume) Hassk. (unc.)

scabrella Gaudich. ex Miq., nom. illeg. superfl.

(unc.)

siamensis Craib $16[13,15]$

sidaefolia Wedd. 8 a

sieboldiana Blume 27 [23ii, 26, 28, 28a, 28c]

var. fuzhouensis (W.T.Wang) Friis \& Wilmot-

Dear 27b

var. ovata Satake $28 a$

var. sieboldiana $27 a$

var. sikokiana Satake $27 \mathrm{a}$ 
Boehmeria (cont.)

silvestrii (Pamp.) W.T.Wang 28b

spicata (Thunb.) Thunb.

var. akari Blume $28 \mathrm{c}$

var. duploserrata C.H.Wright 28a

var. microphylla Nakai ex Satake $28 c$

var. tenera Blume $28 \mathrm{c}$

spicata (Thunb.) Thunb., nom. illeg. superfl. 28, $28 \mathrm{c}$

spiciflora Blume (unc.)

spirei Gagnep. 16

splitgerbera Koidz. 29 [26, 28, 28a, 30]

stenostachya Satake 27 a

stipularis Wedd. 20

strigosifolia W.T.Wang 23ii-o

var. mollis W.T.Wang 23ii-o

subintegra Friis \& Wilmot-Dear 22

subperforata Wedd. 2

sumatrana Miq. 23ii-m

taitensis Wedd., nom. illeg. superfl. 23

taiwaniana Nakai \& Satake 28a

var. pilushanensis (Y.C.Liu \& F.Y.Lu) S.S.Ying $28 \mathrm{a}$

taquetii Nakai 27 a

tenacissima (Roxb.) Blume 1

tenuifolia Satake 29

forma conferta Satake 29

var. nigricans Satake 29

ternifolia D.Don 24 [23ii, 23ii-g, 23ii-o, 25, 28]

var. kamley (Acharya \& Yonek.) Friis \&

Wilmot-Dear 24b [28]

var. ternifolia 24a [23ii]

thailandica Yahara 1

thorelii Gagnep. 8b

tibetica C.J.Chen 13

tikusiensis Satake 28a

tiliifolia Satake 28a

tirapensis Deb \& R.M.Dutta (excl.)

tomentosa Wedd. 23ii-f

tonkinensis Gagnep. 11

tosaensis Miyazaki \& H.Ohba 26

travancorica Bedd. 2

tricuspis (Hance) Makino 28a

forma viridipes Satake 28a

var. unicuspis Makino 28c

tsaratananensis Leandri 21

umbrosa (Hand.-Mazz.) W.T.Wang $8 c$

utilis Blume, nom. inval.? [1]

vanioti H.Lév. (excl.)

villigera Satake 26 [28a]

villosa C.B.Rob. 5

virgata (G.Forst.) Guill. 23

subsp. macrophylla (Hornem.) Friis \& Wilmot-Dear 23ii $[8,9,13,14,21,23$, 33]

var. canescens (Wedd.) Friis \& WilmotDear 23ii-i [23, 23ii-k]

var. densiglomerata (W.T.Wang) Friis \& Wilmot-Dear 23ii-n [23, 23ii-m, 23ii-o, 28c]

var. longissima (Hook.f.) Friis \& WilmotDear 23ii-h [23, 23ii]

var. macrostachya (Wight) Friis \& WilmotDear 23ii-g [1, 23, 23ii, 23ii-e, 23ii-j, 23ii-k, 23ii-I, 24, 25, 26, 33]
Boehmeria virgata subsp. macrophylla (cont.) var. minuticymosa Acharya, Friis \& Wilmot-Dear 23ii-k [23, 23ii, 23ii-i] var. molliuscula (Blume) Friis \& WilmotDear 23ii-e [23, 23ii, 23ii-f]

var. rotundifolia (D.Don) Friis \& WilmotDear 23ii-j [13, 23, 23ii, 23ii-i, 23ii-I, 24 , $25,28]$

var. scabrella (Roxb.) Friis \& Wilmot-Dear 23ii- [ $[8,13,23$, 23ii, 23ii-j, 25, 31, 32, 32a, 32b]

var. strigosa (W.T.Wang) Friis \& WilmotDear 23ii-o [23, 23ii, 23ii-m, 23ii-n, 24, $26,28]$

var. sumatrana (Miq.) Friis \& Wilmot-Dear 23ii-m [23, 23ii, 23ii-I, 23ii-m, 23ii-n, 23ii-o]

var. tomentosa (Wedd.) Friis \& WilmotDear 23ii-f $[23,25]$

subsp. virgata 23i [23]

var. austroqueenslandica (Domin) Friis \& Wilmot-Dear 23i-d [23]

var. maxima Friis \& Wilmot-Dear 23i-c [23]

var. velutina Friis \& Wilmot-Dear 23i-b [23, 23i-a]

var. virgata 23 i-a $[9,10,18,19,20,23$

23ii-I, 28, 31, 33]

wattersii (Hance) B.L.Shih \& Yuen P.Yang 9b

var. blinii (H.Lév.) B.L.Shih \& Yuen P.Yang 9b weddelliana S.Vidal 18a

wightiana Blume, nom. superfl. illeg. 23ii-g

yaeyamensis Hatus. 30 [25, 29, 32]

zollingeriana Wedd. $9[1,2,10,23 i-a, 23 i i, 23 i i-g]$

var. blinii (H.Lév.) C.J.Chen 9b [12]

var. latifolia (Gagnep.) T.H.Nguyên 9a

var. podocarpa (W.T.Wang) W.T.Wang \&

C.J.Chen $9 b$ [18]

var. zollingeriana $9 a$ [23ii]

Boehmeriopsis pallida Kom. (excl.)

Cypholophus anisoneurus (Guill.) Friis \&

Wilmot-Dear (under B. anisoneura Guill. (excl.))

[31]

decipiens H.J.P.Winkl. [23i-a, 33]

Debregeasia australis Friis, Wilmot-Dear \&

C.J.Chen [1]

Droguetia iners (Forssk.) Schweinf.

subsp. iners (under $B$. capensis (Thunb.) Spreng (excl.))

Fatoua villosa (Thunb.) Nakai (under Boehmeriopsis pallida Kom. (excl.))

Laportea bulbifera (Siebold \& Zucc.) Wedd. (under B. bodinieri H.Lév. (excl.))

Leucosyke puya (Hook.) den Baaker \& Mabb. [1]

Maoutia puya (Hook.) Wedd. (under $B$. esquirolii

H.Lév. \& Blin. (excl.)) [1]

Margarocarpus heterophyllus Wedd. $5 a$

Nothocnide repanda (Blume) Blume (under B. rubinervia (unc.))

Oreocnide frutescens (Thunb.) Miq. [1]

Parietaria capensis Thunb. (under $B$. capensis

(Thunb.) Spreng. (excl.))

Pilea martinii (H.Lév.) Hand.-Mazz. (under B. martini H.Lév. (excl.))

notata C.H.Wright (under B. vanioti H.Lév. (excl.))

wattersii Hance 9b
Pipturus argenteus (Forst.) Wedd. (under B. irritans Ridl. (excl.) and B. propinqua Decne. (excl.)) mindanaensis Elmer 2

Pouzolzia arachnoidea (Walp.) Wedd. (under B. arachnoidea Walp. (excl.))

australis (Endl.) Friis \& Wilmot-Dear (under B. australis Endl. (excl.), B. australis Endl. subsp. dealbata (Cheesm.) Sykes (excl.),

B. calophleba C.Moore \& F.Muell. (excl.) and B. dealbata Cheesemann (excl.))

parasitica (Forssk.) Schweinf. (under B. procridioides (Wedd.) Blume (excl.))

rugulosa (Wedd.) Friis \& Wilmot-Dear (under B. rugulosa Wedd. (excl.))

sanguinea (Blume) Merr. [5]

var. cinerascens (Blume) Friis \& Wilmot-Dear (under B. cinerascens Blume (excl.))

var. formosana ( $\mathrm{Li})$ Friis \& Wilmot-Dear (under B. delavayi Gagnep. (excl.) and

B. delawayi Gagnep. var. Iongifolia Gagnep. (excl.))

var. fulgens (Wedd.) Hara (under $B$. tirapensis

Deb \& R.M.Dutta (excl.)) [6]

var. sanguinea (under $B$. nepalensis Wedd. (excl.), B. sanguinea (Blume) Hassk.

(excl.), B. s. var. glabrata (Blume) Blume (excl.), B. s. var. minor Blume (excl.),

B. s. var. montana (Miq.) Blume (excl.) and

B. s. var. rubra Blume (excl.)) $[8,9]$

Ramium niveum (L.) Kuntze 1

Splitgerbera japonica Miq. 29

macrostachya Wight 23ii-g

Urera obovata Benth. (under B. rigida Benth. (excl.))

Urtica blanda Wall., nom. inval. [24a]

candicans Burm.f. 1

caudata Blume, nom. illeg. 23ii-I

caudata Burm.f. 23ii-I

caudata Poir., nom. illeg. 23ii-e

caudigera Wall., nom. inval. [24a]

celebica Blume 23i-a

grandis Hook. \& Arn. 20

interrupta Jacq., nom. inval. (under $B$. jacquiniana Blume (unc.))

japonica L.f. 28

macrophylla Thunb. 28a

macrostachya Wall., nom. inval. [23ii-g]

nivea L. 1

pilosiuscula Blume 32

rugosa Reinw., nom. inval. [31]

rugosa Sw. [31]

rugosissima Blume 31

scabra Blume (under B. scabra Blume Hassk. (unc.))

scabrella Roxb. 23ii-I [23ii-g]

spicata Thunb. $28,28 \mathrm{c}$

tenacissima Roxb. 1

venosa Wall., nom. inval. 13

virgata G.Forst. 23 